\title{
Mildly reduced kidney function and albuminuria
}

Citation for published version (APA):

Martens, R. J. H. (2017). Mildly reduced kidney function and albuminuria: looking beyond the kidney - the Maastricht Study -. [Doctoral Thesis, Maastricht University]. Maastricht University. https://doi.org/10.26481/dis.20170323rm

Document status and date:

Published: 01/01/2017

DOI:

10.26481/dis.20170323rm

Document Version:

Publisher's PDF, also known as Version of record

\section{Please check the document version of this publication:}

- A submitted manuscript is the version of the article upon submission and before peer-review. There can be important differences between the submitted version and the official published version of record.

People interested in the research are advised to contact the author for the final version of the publication, or visit the DOI to the publisher's website.

- The final author version and the galley proof are versions of the publication after peer review.

- The final published version features the final layout of the paper including the volume, issue and page numbers.

Link to publication

\footnotetext{
General rights rights.

- You may freely distribute the URL identifying the publication in the public portal. please follow below link for the End User Agreement:

www.umlib.nl/taverne-license

Take down policy

If you believe that this document breaches copyright please contact us at:

repository@maastrichtuniversity.nl

providing details and we will investigate your claim.
}

Copyright and moral rights for the publications made accessible in the public portal are retained by the authors and/or other copyright owners and it is a condition of accessing publications that users recognise and abide by the legal requirements associated with these

- Users may download and print one copy of any publication from the public portal for the purpose of private study or research.

- You may not further distribute the material or use it for any profit-making activity or commercial gain

If the publication is distributed under the terms of Article $25 \mathrm{fa}$ of the Dutch Copyright Act, indicated by the "Taverne" license above, 


\section{Mildly reduced kidney function and albuminuria: looking beyond the kidney - The Maastricht Study -}


(C) Remigius (Remy) Johannes Hendrikus Martens, Maastricht, 2017

No part of this book may be reproduced or transmitted in any form or by any means, without prior permission in writing by the author or, when appropriate, by the publishers of the publications.

Graphic Design and layout: Maryam Mafi Rad \& Mahboobeh Mafi Rad

Cover: Jean Scheijen | www.vierdrie.nl

Production: Ipskamp Printing

ISBN: 978-94-028-0534-5

The research presented in this dissertation was conducted at the Department of Internal Medicine, Division of Nephrology, Maastricht University Medical Center+, Maastricht, the Netherlands; and NUTRIM School of Nutrition and Translational Research in Metabolism, Maastricht University, Maastricht, the Netherlands; and financially supported by an unrestricted grant from Fresenius Medical Care, Bad Homburg, Germany.

Financial support for the publication of this dissertation by an unrestricted grant from Fresenius Medical Care is gratefully acknowledged. 


\title{
Mildly reduced kidney \\ function and albuminuria: \\ looking beyond the kidney
}

- The Maastricht Study -

\author{
PROEFSCHRIFT \\ ter verkrijging van de graad van doctor aan de Universiteit Maastricht, \\ op gezag van de Rector Magnificus, Prof. dr. Rianne M. Letschert, \\ volgens het besluit van het College van Decanen, \\ in het openbaar te verdedigen \\ op donderdag 23 maart 2017 om 12.00 uur \\ door
}

Remigius Johannes Hendrikus Martens 


\section{Promotores:}

Prof. dr. Jeroen P. Kooman

Prof. dr. Coen D.A. Stehouwer

\section{Copromotor:}

Dr. Ronald M.A. Henry

\section{Beoordelingscommissie:}

Prof. dr. Peter W. de Leeuw, voorzitter

Prof. dr. Ron T. Gansevoort (Universitair Medisch Centrum Groningen, Groningen)

Prof. dr. Matthijs K.C. Hesselink

Prof. dr. Kitty J. Jager (Academisch Medisch Centrum, Amsterdam)

Prof. dr. Frans J.R. Verhey 
"Croire que l'on a trouvé un fait scientifique important, avoir la fierté de l'annoncer et se contraindre des journées, des semaines, parfois des années, à se combattre soi-même, à s'efforcer de ruiner ses propres expériences et ne proclamer sa découverte que lorsqu'on a épuisé toutes les hypothèses contraires, oui, c'est une tâche ardue. Mais quand, après tant d'efforts, on croit enfin arriver à la certitude, on éprouve une des plus grandes joies que puisse ressentir l'âme humaine, et la pensée que l'on contribuera à l'honneur de son pays rend cette joie plus profonde encore."

(Louis Pasteur, 1822-1895) 


\section{Contents}

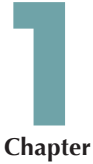

General introduction

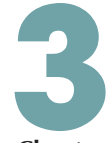

Chapter

Microvascular endothelial dysfunction is associated with albuminuria: The Maastricht Study

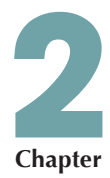

Capillary rarefaction associates with albuminuria:

The Maastricht Study
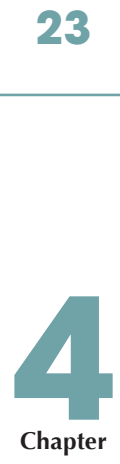

Estimated glomerular filtration rate and albuminuria are associated with biomarkers of cardiac injury in a population-based cohort study: The Maastricht Study

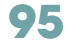




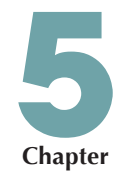

Estimated GFR, albuminuria, and cognitive performance:

The Maastricht Study

127

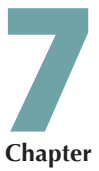

Daily activity is associated with estimated GFR and albuminuria:

The Maastricht Study

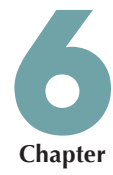

Albuminuria is associated with a higher prevalence of depression in a population-based cohort study:

The Maastricht Study

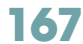

Summary and general discussion

\section{Appendix 235}

Nederlandstalige samenvatting 237

Valorization addendum 245

\section{Dankwoord 249}

Curriculum vitae 253 


\section{Chapter 1}


General introduction 

Chronic kidney disease (CKD) is a major public health concern. ${ }^{1}$ The increase in type 2 diabetes (T2DM), hypertension and obesity has contributed to a rise in the prevalence of $\mathrm{CKD}^{2}$ and nowadays it affects $8-16 \%$ of the population worldwide. ${ }^{3}$ In older individuals as well as in individuals with T2DM, hypertension and/or obesity, CKD is even more prevalent., ${ }^{2,-6}$

CKD is defined as the presence of kidney damage and/or a reduced kidney function, for at least three months, and irrespective of its cause. ${ }^{7,8}$ In clinical practice and in epidemiological studies, kidney function, on the one hand, is usually assessed by estimating the glomerular filtration rate (eGFR) from the serum concentration(s) of one or more endogenous filtration markers. ${ }^{7-9}$ Examples of these include creatinine and, more recently, cystatin $C .^{8,9}$ On the other hand, the excretion of albumin in urine (i.e., albuminuria) is mostly used to identify kidney damage. ${ }^{7,8}$ Currently, albuminuria $\geq 30 \mathrm{mg} / 24 \mathrm{~h}$ and/or an eGFR $<60 \mathrm{ml} / \mathrm{min} / 1.73 \mathrm{~m}^{2}$ are used as cut-off values to diagnose CKD. CKD has traditionally been further divided into five stages on the basis of the eGFR level. ${ }^{7}$ However, the most recent classification scheme also includes albuminuria level and cause (Figure 1.1). ${ }^{8}$

CKD is mostly asymptomatic until its more advanced stages. ${ }^{1}$ In those who ultimately reach the stage of kidney failure or end-stage renal disease, renal replacement therapy (i.e., kidney transplantation or dialysis treatment) is necessary for survival and to alleviate symptoms. ${ }^{8}$

The public health impact of CKD, however, resides for a large part in its earlier stages (i.e., CKD stages 1-3). Early-stage CKD constitutes $80-90 \%$ of all CKD cases ${ }^{3}$ and is strongly associated with cardiovascular disease (CVD) risk. ${ }^{10}$ Indeed, most individuals in CKD stages 1-3 will not reach the stage of end-stage renal disease but instead face the morbidity and mortality related to CVD..$^{11,12}$ In addition, there is evidence for associations of CKD with other health problems that may be related to $\mathrm{CVD}^{13-16}$ and negatively impact on quality of life, such as lower cognitive performance ${ }^{17-38}$ and depression. ${ }^{39}$ Further, some studies have suggested that eGFR and albuminuria may already be associated with adverse health conditions at levels which do not fulfill the current CKD criteria, ${ }_{10,40-43}$ although conflicting results exist, in particular for eGFR. ${ }^{44-47}$ Thus, insight into the risk factors, pathophysiology and manifestations of reduced eGFR and albuminuria in the general population is necessary.

This dissertation addresses three important issues that currently remain unanswered in the literature. First, reduced eGFR and albuminuria together define $\mathrm{CKD}^{7,8}$ but likely represent different pathophysiological mechanisms as both are, independently of each other, associated with CVD..$^{10}$ However, the mechanisms that link albuminuria to CVD and other adverse health conditions are still incompletely understood. Second, whereas eGFR and albuminuria are strongly associated with the classic acute manifestations of CVD, their associations with cognitive performance and, in particular, depression are less clear. In addition, it is not clear whether levels of eGFR and albuminuria which do not fulfill the CKD criteria are already associated with CVD, cognitive performance and depression. Third, the rise in CKD prevalence warrants a search for risk factors for reduced eGFR and albuminuria, which are common in the general population and amenable to intervention.

\section{Current concepts in the pathophysiology of reduced eGFR and albuminuria}

The GFR indicates the total volume of ultrafiltrate that is produced by the kidneys per unit of time and is usually expressed in $\mathrm{ml} / \mathrm{min} / 1.73 \mathrm{~m}^{2} .^{9,48}$ It is the sum of single nephron GFRs, which are themselves determined by the hydrostatic and colloid osmotic pressure differences across the glomerular capillary wall, the permeability of the glomerular capillary wall, and the surface area available for filtration. ${ }^{9,48}$ A reduction in GFR may, thus, be a biomarker of systemic vascular damage. ${ }^{49}$ However, a reduced GFR may also have detrimental effects itself 


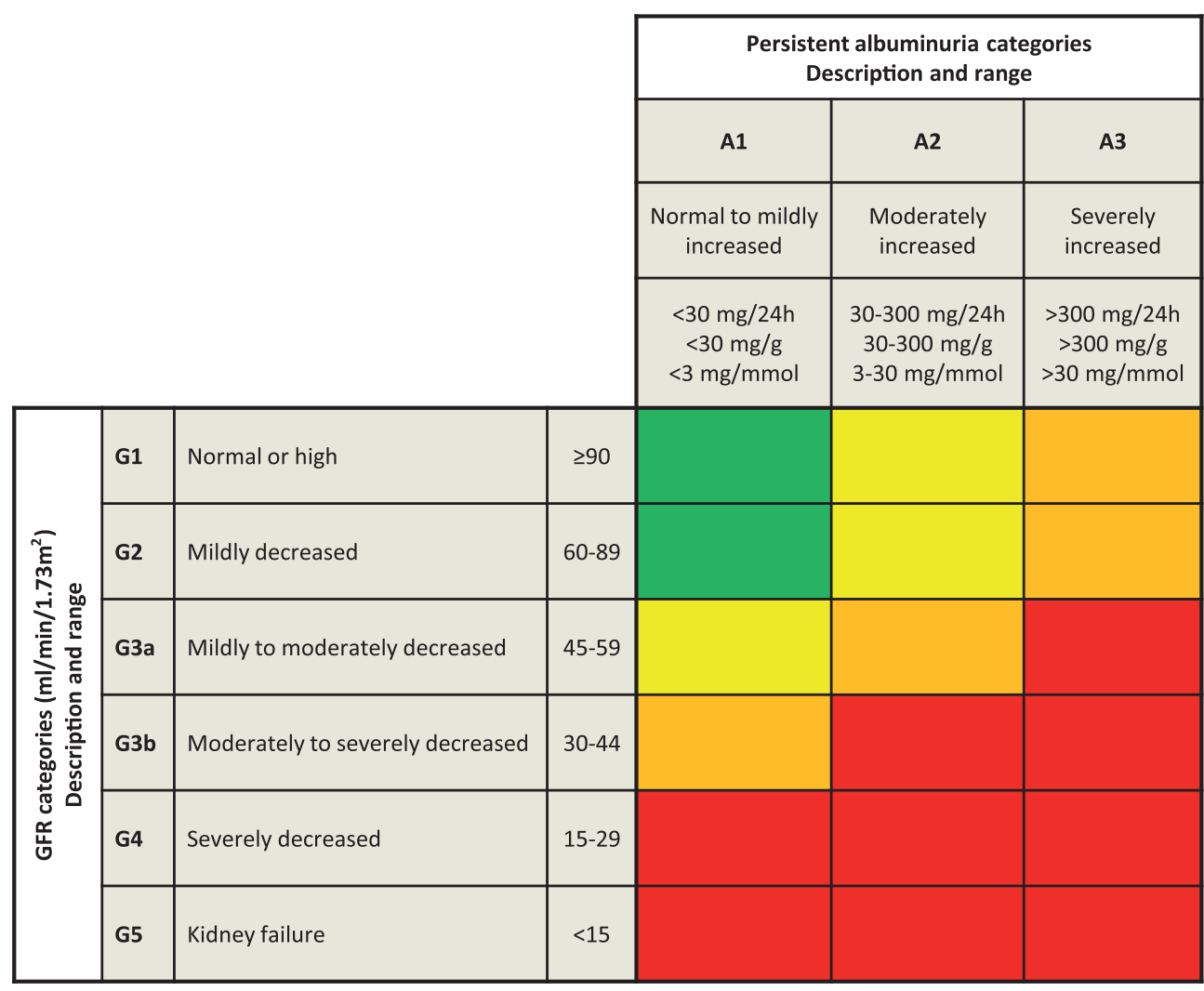

Figure 1.1. Chronic kidney disease (CKD) staging. CKD is diagnosed in individuals with albuminuria $\geq 30 \mathrm{mg} / 24 \mathrm{~h}$ and/or an $\mathrm{eGFR}<60 \mathrm{ml} / \mathrm{min} / 1.73 \mathrm{~m}^{2}$, and further staged according to eGFR and albuminuria categories. The colors indicate the risk of concurrent complications and future outcomes: green, low risk; yellow, moderately increased risk; orange, high risk; red, very high risk. Adapted from "Kidney International Supplements, Vol 3, KDIGO 2012 Clinical practice guideline for the evaluation and management of chronic kidney disease. Chapter 1: Definition and classification of CKD, pages 19-62, Copyright 2013" and "Kidney International, Vol 80, Levey AS, de Jong PE, Coresh J, Nahas ME, Astor BC, Matsushita K, Gansevoort RT, Kakiske BL, Eckardt KU, The definition, classification, and prognosis of chronic kidney disease: a KDIGO controversies conference report, pages 17-28, Copyright 2011", with permission from Elsevier.

as it may lead to, for example, hypertension, accumulation of toxic solutes (i.e., uremic toxins), chronic low-grade inflammation and endothelial dysfunction..$^{49,50}$ In addition, a reduced GFR is accompanied by a decline in metabolic and endocrine functions of the kidney. ${ }^{1}$

Albuminuria denotes the excretion of albumin in urine. Several mechanisms ensure that in healthy individuals only small amounts of albumin $\left(<15 \mathrm{mg} / 24 \mathrm{~h}^{51}\right)$ are excreted. These are illustrated in Figures 1.2 and 1.3. 


\section{Renal Corpuscle and Juxtaglomerular Apparatus}
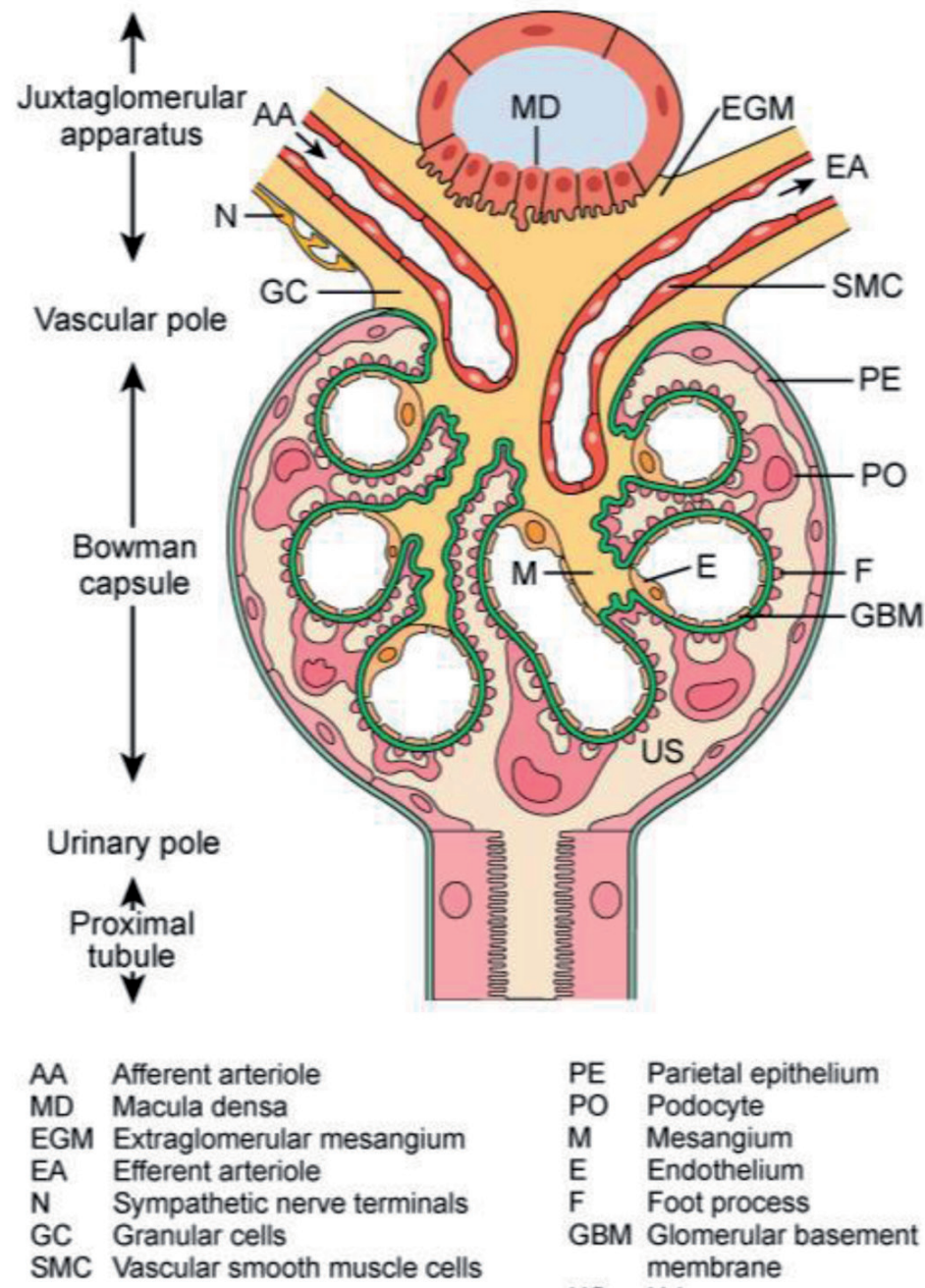

$\begin{array}{ll}\text { PE } & \text { Parietal epithelium } \\ \text { PO } & \text { Podocyte } \\ \text { M } & \text { Mesangium } \\ \text { E } & \text { Endothelium } \\ \text { F } & \text { Foot process } \\ \text { GBM } & \text { Glomerular basement } \\ & \text { membrane } \\ \text { US } & \text { Urinary space }\end{array}$

Figure 1.2. Renal corpuscle and juxtaglomerular apparatus. Reprinted from "Seldin D, Giebisch G, The Kidney, $3^{\text {rd }}$ ed., Kriz W, Kaissling B, Structural organization of the mammalian kidney, pages 587-654, Copyright 2000" and "Johnson RJ, Feehally J, Floege J, Comprehensive clinical nephrology, $5^{\text {th }}$ ed., Kriz W, Elger M, Chapter 1: Renal anatomy, pages 2-13, Copyright 2015", with permission from the authors (Kriz W and Kaissling B) and with permission from Elsevier. 


\section{Peripheral Portion of a Glomerular Lobule}

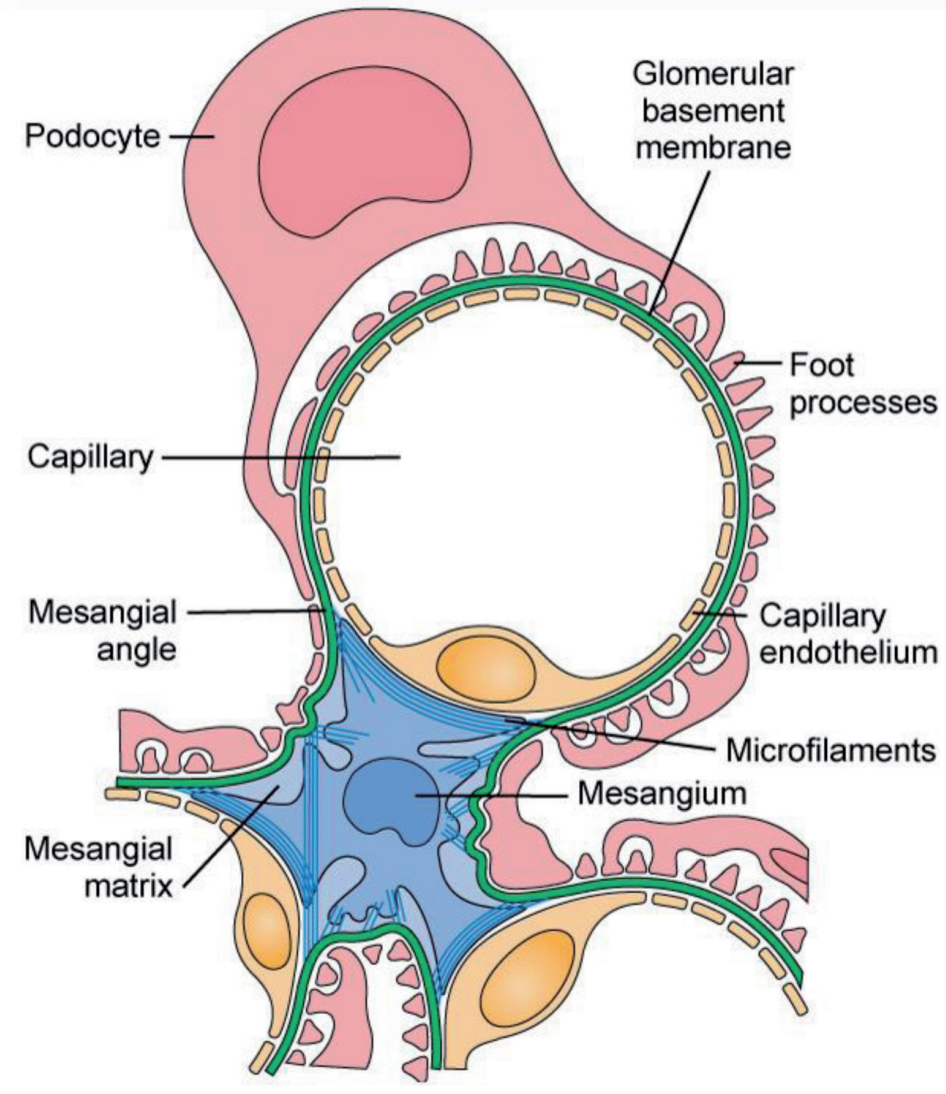

Figure 1.3. Peripheral portion of a glomerular lobule. Reprinted from "Seldin D, Giebisch G, The Kidney, $3^{\text {rd }}$ ed., Kriz W, Kaissling B, Structural organization of the mammalian kidney, pages 587-654, Copyright 2000" and "Johnson RJ, Feehally J, Floege J, Comprehensive clinical nephrology, $5^{\text {th }}$ ed., Kriz W, Elger M, Chapter 1: Renal anatomy, pages 2-13, Copyright 2015", with permission from the authors (Kriz W and Kaissling B) and with permission from Elsevier.

The intraglomerular pressure, the surface area available for filtration, and the permeability of the glomerular capillary wall determine the amount of albumin that permeates the glomerular capillary wall and enters Bowman's space. ${ }^{48}$ From the vessel lumen to Bowman's space, the glomerular capillary wall consists of a fenestrated endothelial cell layer and its glycocalyx, the glomerular basement membrane, and a podocyte layer. ${ }^{48}$ In addition, mesangial cells are in close contact with both cell layers and influence their structure and function. ${ }^{52}$ Both the size and charge selectivity of the glomerular capillary wall limit the permeation of the relatively large (molecular weight approximately $66 \mathrm{kDa}$ ) and negatively charged albumin molecules. ${ }^{48}$ In addition, albumin that is filtered into Bowman's space is for the most part reabsorbed in the proximal tubule. ${ }^{48}$ 
Alterations in any of the above mechanisms may, theoretically, increase the excretion of albumin in urine and be involved in different disease states. ${ }^{52}$ In addition, there is emerging evidence for an extensive interplay between these mechanisms, for example cross-talk between endothelial cells and podocytes. ${ }^{53}$

To explain its association with CVD and other adverse health conditions, albuminuria has been hypothesized to be a biomarker of generalized endothelial dysfunction. ${ }^{54,55}$ According to this concept, endothelial dysfunction of renal arterioles and capillaries (i.e., the renal microcirculation) causes albuminuria by increasing intraglomerular pressure and by increasing glomerular capillary wall permeability, ${ }^{55}$ the former eventually leading to glomerular capillary dropout (i.e., capillary rarefaction) and further increases in intraglomerular pressure. ${ }^{56}$ Concomitantly, endothelial dysfunction of the extrarenal microcirculation contributes to, for example, retinopathy, ${ }^{57,58}$ cognitive decline, ${ }^{59}$ depression $^{60}$ and heart failure with preserved ejection fraction, ${ }^{61}$ whereas endothelial dysfunction in coronary and carotid arteries (i.e., the macrocirculation) causes atherothrombotic CVD. ${ }^{62}$ Besides endothelial dysfunction, genetic influences and impaired (intrauterine) growth and development could also simultaneously affect glomerular and systemic capillary density, ${ }^{63,64}$ and may, therefore, link albuminuria to systemic microvascular disease as well.

Indeed, there is ample direct evidence for macrovascular endothelial dysfunction in individuals with albuminuria. ${ }^{65-71}$ However, the evidence for an association of microvascular endothelial dysfunction with albuminuria is primarily indirect, ${ }^{72-84}$ and the available direct evidence is restricted to individuals with diabetes. ${ }^{82-84}$ The latter may be important because the presence of diabetes may augment any association of microvascular endothelial dysfunction with albuminuria. ${ }^{85,86}$ In addition, evidence for an association of capillary rarefaction with albuminuria is limited. ${ }^{87}$

\section{Adverse health conditions related to reduced eGFR and albuminuria}

Based on their (hypothesized) pathophysiology, reduced eGFR and albuminuria may be associated with extrarenal adverse health conditions as both may be biomarkers of any pathophysiological mechanisms involved. In addition, reduced eGFR may play a causal role. This dissertation focuses on cardiac injury, lower cognitive performance and depression.

There is compelling evidence for an association of CKD with higher CVD mortality risk. ${ }^{10}$ However, it is less clear at what point in the course from normal kidney function to CKD the association with CVD appears. ${ }^{10,43}$ This is particularly true for the association of eGFR with CVD. Indeed, a large-scale meta-analysis of general population cohorts has shown a progressive association of lower eGFR with higher CVD mortality risk below a threshold of $75 \mathrm{ml} /$ $\min / 1.73 \mathrm{~m}^{2} .^{10}$ In contrast, a continuous association without a threshold has also been suggested. ${ }^{43}$ In this regard, the lower precision of eGFR equations at higher GFR levels ${ }^{88}$ and the relatively low incidence of hard clinical outcomes, such as CVD events and CVD mortality, in the general population, may hamper the evaluation of the association of eGFR at levels $\geq 60 \mathrm{ml} / \mathrm{min} / 1.73 \mathrm{~m}^{2}$ with CVD and other adverse health conditions.

As cardiac injury may start insidiously, biomarkers such as the high-sensitivity cardiac troponins $\mathrm{T}$ (hs-cTnT) and I (hs-cTnl) ${ }^{89}$ as well as $\mathrm{N}$-terminal pro-brain natriuretic peptide (NT-proBNP), ${ }^{90}$ may identify subclinical cardiac injury in individuals with levels of eGFR and albuminuria which do not fulfill the CKD criteria. However, few population-based studies have used this approach to study whether the association of kidney function with CVD is continuous. ${ }^{91,92}$ 
Vascular disease in individuals with reduced eGFR and albuminuria may also manifest as lower cognitive performance and depression. ${ }^{13-16}$ Indeed, microvascular dysfunction may manifest in the brain as cerebral small vessel disease. ${ }^{93,94}$ The latter may be visible on magnetic resonance imaging as, for example, white matter lesions, lacunar infarcts and microbleeds..$^{93}$ Clinically, these lesions have been associated with lower cognitive performance, dementia and depression, depending on the brain region(s) affected..$^{95-97}$ Both a reduced eGFR and albuminuria have been suggested to be biomarkers of cerebral small vessel disease. ${ }^{98}$ In addition, reduced eGFR may lead to accumulation of neurotoxins, which may further contribute to brain damage. ${ }^{13}$

Reduced eGFR and albuminuria have indeed been associated with lower cognitive performance. ${ }^{17-38}$ However, most studies on this topic have been performed in older individuals and it is less clear whether these associations may be extended to the middle-aged (i.e., 40to 65-year-old) population. ${ }^{34-38}$ In addition, incomplete adjustment for CVD risk factors, for example adjustment for office blood pressure instead of 24h average ambulatory blood pressure, may have led to residual confounding in some studies.

In contrast, no population-based studies have examined whether eGFR and albuminuria are, independently of each other, associated with depression. In this regard, the discrepancies between studies on the prevalence of depression in CKD populations argue that assessment of a diagnosis of minor or major depressive episode instead of depressive symptoms is preferred to avoid misclassification of the somatic symptoms of (comorbid) disease as depressive symptoms. ${ }^{39}$ This allows evaluating whether any associations of eGFR and albuminuria with depression are explained by the presence of comorbidities (related to their risk factors) or are independent of potential confounders.

\section{Search for new risk factors for reduced eGFR and albuminuria}

The high prevalence of CKD warrants a search for risk factors for reduced eGFR and albuminuria, which are common in the general population and may be modifiable. Studies with self-reported measures of daily activity have suggested that these may include the amount of physical activity and sedentary behavior. ${ }^{6,99-109}$ Nowadays the complete daily activity spectrum can be measured objectively with an accelerometer. This approach is not hampered by recall and reporting bias as opposed to self-reported measures. ${ }^{110}$ However, data on the associations of objectively measured daily activity with eGFR and albuminuria are limited. ${ }^{111,112}$ In addition, no studies have reported on the pattern of sedentary behavior (i.e., the manner in which sedentary time was accumulated). This may be important as patterns of sedentary behavior have been associated with other CVD risk factors, independently of the amount of sedentary time. ${ }^{113-117}$

\section{Cohort used in this dissertation}

The results presented in this dissertation are based on data of the Maastricht Study. ${ }^{118}$ The Maastricht Study is an ongoing observational prospective population-based cohort study conducted in the southern part of the Netherlands. It started in November 2010 and focuses on the etiology, complications and comorbidities of T2DM and other chronic diseases. To that extent, a large sample of individuals aged 40-75 years is recruited from the MaastrichtHeuvelland region with an oversampling of individuals with T2DM. Importantly, the Maastricht Study is characterized by an extensive phenotyping approach. This provides a unique opportunity to study the pathophysiology of reduced eGFR and albuminuria as well as their risk factors and manifestations in a population-based setting. In addition, the detailed characterization of the 
study population allows for the adjustment for an extensive series of potential confounders in the analyses, which limits residual confounding. This dissertation includes cross-sectional data of the first (841 participants) and the second (3451 participants) dataset of the Maastricht Study.

\section{OUTLINE OF THIS DISSERTATION}

In summary, this dissertation had three aims: first, to gain more insight into the mechanisms that link albuminuria with CVD and other adverse health conditions; second, to study the associations of eGFR and albuminuria with CVD, cognitive performance and depression, and, in particular, to study at what point in the course from normal kidney function to CKD these associations appear; and third, to evaluate the associations of physical activity and sedentary behavior with eGFR and albuminuria. In detail:

In chapters 2 and 3, we aimed to gain more insight into the mechanisms that explain the strong link of albuminuria with CVD and other adverse health conditions. The hypothesis that albuminuria is a biomarker of generalized (i.e., micro- and macrovascular) endothelial dysfunction formed the basis of both chapters. In addition, the particular focus was on the microvascular bed given the scarcity of data on this topic. Thus, in chapter 2, we examined whether capillary rarefaction was associated with albuminuria. In addition, in chapter 3, we examined whether measures of microvascular endothelial dysfunction (i.e., flicker-light induced retinal arteriolar dilation and heat-induced skin hyperemia) were associated with albuminuria. Because it has been suggested that the presence of diabetes may amplify an association of microvascular endothelial dysfunction with albuminuria, we further explored in chapter 3 whether any association of microvascular endothelial dysfunction with albuminuria was stronger in individuals with T2DM.

In chapters 4-6, we aimed to gain more insight into the associations of eGFR and albuminuria with extrarenal adverse health conditions. As described above, lower eGFR and higher albuminuria may be associated in particular with extrarenal adverse health conditions which involve micro- and/or macrovascular disease. Apart from cardiac injury, these may include lower cognitive performance and depression. In addition, any associations of eGFR and albuminuria may be mutually independent, and may already be present at levels of eGFR and albuminuria which do not fulfill the current CKD criteria. Studying the latter may require the use of intermediate or surrogate outcomes. Thus, in chapter 4, we examined whether eGFR and albuminuria were, independently of each other, associated with three biomarkers of (subclinical) cardiac injury (i.e., hs-cTnT, hs-cTnl and NT-proBNP). In addition, in chapter 5, we examined whether eGFR and albuminuria were, independently of each other, associated with cognitive performance. Further, in chapter 6, we examined whether eGFR and albuminuria were, independently of each other, associated with both self-reported depressive symptoms and an interview-based diagnosis of a minor or major depressive episode.

In chapter 7 , we aimed to gain more insight into the roles of the lifestyle factors physical activity and sedentary behavior as potentially modifiable risk factors for reduced eGFR and albuminuria. For this purpose, we used accelerometry data to examine whether total amounts and patterns of physical activity and sedentary behavior were associated with eGFR and albuminuria.

Finally, in chapter 8 , the main findings of this dissertation are summarized, and discussed in light of the current scientific literature and methodological considerations. In addition, their scientific, clinical and public health implications are addressed. 


\section{REFERENCES}

1. Levey AS, Coresh J. Chronic kidney disease. Lancet. 2012 Jan 14;379(9811):165-80.

2. Coresh J, Selvin E, Stevens LA, Manzi J, Kusek JW, Eggers P, et al. Prevalence of chronic kidney disease in the United States. Jama. 2007 Nov 7;298(17):2038-47.

3. Jha V, Garcia-Garcia G, Iseki K, Li Z, Naicker S, Plattner B, et al. Chronic kidney disease: global dimension and perspectives. Lancet. 2013 Jul 20;382(9888):260-72.

4. Plantinga LC, Crews DC, Coresh J, Miller ER, 3rd, Saran R, Yee J, et al. Prevalence of chronic kidney disease in US adults with undiagnosed diabetes or prediabetes. Clin J Am Soc Nephrol. 2010 Apr;5(4):673-82.

5. Crews DC, Plantinga LC, Miller ER, 3rd, Saran R, Hedgeman E, Saydah SH, et al. Prevalence of chronic kidney disease in persons with undiagnosed or prehypertension in the United States. Hypertension. 2010 May;55(5):1102-9.

6. Hallan S, de Mutsert R, Carlsen S, Dekker FW, Aasarod K, Holmen J. Obesity, smoking, and physical inactivity as risk factors for CKD: are men more vulnerable? Am J Kidney Dis. 2006 Mar;47(3):396-405.

7. National Kidney Foundation. K/DOQI clinical practice guidelines for chronic kidney disease: evaluation, classification, and stratification. Am J Kidney Dis. 2002 Feb;39(2 Suppl 1):S1-266.

8. Kidney Disease: Improving Global Outcomes (KDIGO). KDIGO 2012 Clinical practice guideline for the evaluation and management of chronic kidney disease. Kidney Int Suppl. 2013;3(1):1-150.

9. Levey AS, Inker LA, Coresh J. GFR estimation: from physiology to public health. Am J Kidney Dis. 2014 May;63(5):820-34.

10. Chronic Kidney Disease Prognosis Consortium, Matsushita K, van der Velde M, Astor BC, Woodward M, Levey AS, et al. Association of estimated glomerular filtration rate and albuminuria with all-cause and cardiovascular mortality in general population cohorts: a collaborative meta-analysis. Lancet. 2010 Jun 12;375(9731):2073-81.

11. Keith DS, Nichols GA, Gullion CM, Brown JB, Smith DH. Longitudinal follow-up and outcomes among a population with chronic kidney disease in a large managed care organization. Arch Intern Med. 2004 Mar 22;164(6):659-63.

12. Dalrymple LS, Katz R, Kestenbaum B, Shlipak MG, Sarnak MJ, Stehman-Breen C, et al. Chronic kidney disease and the risk of end-stage renal disease versus death. J Gen Intern Med. 2011 Apr;26(4):379-85.

13. Bugnicourt JM, Godefroy O, Chillon JM, Choukroun G, Massy ZA. Cognitive disorders and dementia in CKD: the neglected kidney-brain axis. J Am Soc Nephrol. 2013 Feb;24(3):353-63.

14. Knopman DS. Invited commentary: Albuminuria and microvascular disease of the brain--a shared pathophysiology. Am J Epidemiol. 2010 Feb 1;171(3):287-9; author reply 90-1.

15. Alexopoulos GS, Meyers BS, Young RC, Campbell S, Silbersweig D, Charlson M. 'Vascular depression' hypothesis. Arch Gen Psychiatry. 1997 Oct;54(10):915-22.

16. Krishnan KR, Hays JC, Blazer DG. MRI-defined vascular depression. Am J Psychiatry. 1997 Apr;154(4):497-501.

17. Kurella M, Yaffe K, Shlipak MG, Wenger NK, Chertow GM. Chronic kidney disease and cognitive impairment in menopausal women. Am J Kidney Dis. 2005 Jan;45(1):66-76.

18. Kurella M, Chertow GM, Fried LF, Cummings SR, Harris T, Simonsick E, et al. Chronic kidney disease and cognitive impairment in the elderly: the health, aging, and body composition study. J Am Soc Nephrol. 2005 Jul;16(7):2127-33.

19. Kurella Tamura M, Wadley V, Yaffe K, McClure LA, Howard G, Go R, et al. Kidney function and cognitive impairment in US adults: the Reasons for Geographic and Racial Differences in Stroke (REGARDS) Study. Am J Kidney Dis. 2008 Aug; 52(2):227-34.

20. Slinin Y, Paudel ML, Ishani A, Taylor BC, Yaffe K, Murray AM, et al. Kidney function and cognitive performance and decline in older men. J Am Geriatr Soc. 2008 Nov;56(11):2082-8.

21. Buchman AS, Tanne D, Boyle PA, Shah RC, Leurgans SE, Bennett DA. Kidney function is associated with the rate of cognitive decline in the elderly. Neurology. 2009 Sep 22;73(12):920-7.

22. Elias MF, Elias PK, Seliger SL, Narsipur SS, Dore GA, Robbins MA. Chronic kidney disease, creatinine and cognitive functioning. Nephrol Dial Transplant. 2009 Aug;24(8):2446-52.

23. Khatri M, Nickolas T, Moon YP, Paik MC, Rundek T, Elkind MS, et al. CKD associates with cognitive decline. J Am Soc Nephrol. 2009 Nov;20(11):2427-32.

24. Yaffe K, Ackerson L, Kurella Tamura M, Le Blanc P, Kusek JW, Sehgal AR, et al. Chronic kidney disease and cognitive function in older adults: findings from the chronic renal insufficiency cohort cognitive study. J Am Geriatr Soc. 2010 Feb;58(2):338-45.

25. Feng L, Yap KB, Yeoh LY, Ng TP. Kidney function and cognitive and functional decline in elderly adults: findings from the Singapore longitudinal aging study. J Am Geriatr Soc. 2012 Jul;60(7):1208-14.

26. Darsie B, Shlipak MG, Sarnak MJ, Katz R, Fitzpatrick AL, Odden MC. Kidney function and cognitive health in older adults: the Cardiovascular Health Study. Am J Epidemiol. 2014 Jul 1;180(1):68-75.

27. Slinin Y, Peters KW, Ishani A, Yaffe K, Fink HA, Stone KL, et al. Cystatin C and cognitive impairment 10 years later in older women. J Gerontol A Biol Sci Med Sci. 2015 Jun;70(6):771-8.

28. Abbatecola AM, Barbieri M, Rizzo MR, Grella R, Laieta MT, Quaranta E, et al. Arterial stiffness and cognition in elderly persons with impaired glucose tolerance and microalbuminuria. J Gerontol A Biol Sci Med Sci. 2008 Sep;63(9):991-6.

29. Weiner DE, Bartolomei K, Scott T, Price LL, Griffith JL, Rosenberg I, et al. Albuminuria, cognitive functioning, and white matter hyperintensities in homebound elders. Am J Kidney Dis. 2009 Mar;53(3):438-47.

30. Jassal SK, Kritz-Silverstein D, Barrett-Connor E. A prospective study of albuminuria and cognitive function in older adults: the Rancho Bernardo study. Am J Epidemiol. 2010 Feb 1;171(3):277-86.

31. Barzilay JI, Gao P, O’Donnell M, Mann JF, Anderson C, Fagard R, et al. Albuminuria and decline in cognitive function: The ONTARGET/TRANSCEND studies. Arch Intern Med. 2011 Jan 24;171(2):142-50.

32. Helmer C, Stengel B, Metzger M, Froissart M, Massy ZA, Tzourio C, et al. Chronic kidney disease, cognitive decline, and incident dementia: the 3C Study. Neurology. 2011 Dec 6;77(23):2043-51. 
33. Heringa SM, van den Berg E, Dekker JM, Nijpels G, Kessels RP, Kappelle LJ, et al. Albuminuria and cognitive functioning in an older population: the Hoorn study. Dement Geriatr Cogn Dis. 2011;32(3):182-7.

34. Hailpern SM, Melamed ML, Cohen HW, Hostetter TH. Moderate chronic kidney disease and cognitive function in adults 20 to 59 years of age: Third National Health and Nutrition Examination Survey (NHANES III). J Am Soc Nephrol. 2007 Jul;18(7):2205-13.

35. Joosten H, Izaks GJ, Slaets JP, de Jong PE, Visser ST, Bilo HJ, et al. Association of cognitive function with albuminuria and eGFR in the general population. Clin J Am Soc Nephrol. 2011 Jun;6(6):1400-9.

36. Kurella Tamura M, Xie D, Yaffe K, Cohen DL, Teal V, Kasner SE, et al. Vascular risk factors and cognitive impairment in chronic kidney disease: the Chronic Renal Insufficiency Cohort (CRIC) study. Clin J Am Soc Nephrol. 2011 Feb;6(2):248-56.

37. Tsai CF, Wang SJ, Fuh JL. Moderate chronic kidney disease is associated with reduced cognitive performance in midlife women. Kidney Int. 2010 Sep;78(6):605-10.

38. Barzilay JI, Lovato JF, Murray AM, Williamson J, Ismail-Beigi F, Karl D, et al. Albuminuria and cognitive decline in people with diabetes and normal renal function. Clin J Am Soc Nephrol. 2013 Nov;8(11):1907-14.

39. Palmer S, Vecchio M, Craig JC, Tonelli M, Johnson DW, Nicolucci A, et al. Prevalence of depression in chronic kidney disease: systematic review and meta-analysis of observational studies. Kidney Int. 2013 Jul;84(1):179-91.

40. Nag S, Bilous R, Kelly W, Jones S, Roper N, Connolly V. All-cause and cardiovascular mortality in diabetic subjects increases significantly with reduced estimated glomerular filtration rate (eGFR): 10 years' data from the South Tees Diabetes Mortality study. Diabet Med. 2007 Jan;24(1):10-7.

41. Berhane AM, Weil EJ, Knowler WC, Nelson RG, Hanson RL. Albuminuria and estimated glomerular filtration rate as predictors of diabetic end-stage renal disease and death. Clin J Am Soc Nephrol. 2011 Oct;6(10):2444-51.

42. Zhang R, Zheng L, Sun Z, Zhang X, Li J, Hu D, et al. Decreased glomerular filtration rate is associated with mortality and cardiovascular events in patients with hypertension: a prospective study. PloS one. 2011;6(11):e27359.

43. Stam F, van Guldener C, Becker A, Dekker JM, Heine RJ, Bouter LM, et al. Endothelial dysfunction contributes to renal function-associated cardiovascular mortality in a population with mild renal insufficiency: the Hoorn study. J Am Soc Nephrol. 2006 Feb;17(2):537-45.

44. Smink PA, Lambers Heerspink HJ, Gansevoort RT, de Jong PE, Hillege HL, Bakker SJ, et al. Albuminuria, estimated GFR, traditional risk factors, and incident cardiovascular disease: the PREVEND (Prevention of Renal and Vascular Endstage Disease) study. Am J Kidney Dis. 2012 Nov;60(5):804-11.

45. Brantsma AH, Bakker SJ, Hillege HL, de Zeeuw D, de Jong PE, Gansevoort RT, et al. Cardiovascular and renal outcome in subjects with K/DOQI stage 1-3 chronic kidney disease: the importance of urinary albumin excretion. Nephrol Dial Transplant. 2008 Dec;23(12):3851-8.

46. So WY, Kong AP, Ma RC, Ozaki R, Szeto CC, Chan NN, et al. Glomerular filtration rate, cardiorenal end points, and all-cause mortality in type 2 diabetic patients. Diabetes Care. 2006 Sep;29(9):2046-52.

47. Tonelli M, Klarenbach SW, Lloyd AM, James MT, Bello AK, Manns BJ, et al. Higher estimated glomerular filtration rates may be associated with increased risk of adverse outcomes, especially with concomitant proteinuria. Kidney Int. 2011 Dec;80(12):1306-14.

48. Eaton DC, Pooler JP. Vander's renal physiology. 8th ed: McGraw-Hill Education; 2013.

49. Tonelli M, Pfeffer MA. Kidney disease and cardiovascular risk. Annual review of medicine. 2007;58:123-39.

50. Schiffrin EL, Lipman ML, Mann JF. Chronic kidney disease: effects on the cardiovascular system. Circulation. 2007 Jul 3;116(1):85-97.

51. Ward KM. Renal function (microalbuminuria). Anal Chem. 1995 Jun 15;67(12):383R-91R.

52. Schlondorff D, Banas B. The mesangial cell revisited: no cell is an island. J Am Soc Nephrol. 2009 Jun;20(6):1179-87.

53. Siddiqi FS, Advani A. Endothelial-podocyte crosstalk: the missing link between endothelial dysfunction and albuminuria in diabetes. Diabetes. 2013 Nov;62(11):3647-55.

54. Deckert T, Feldt-Rasmussen B, Borch-Johnsen K, Jensen T, Kofoed-Enevoldsen A. Albuminuria reflects widespread vascular damage. The Steno hypothesis. Diabetologia. 1989 Apr;32(4):219-26.

55. Stehouwer CD, Smulders YM. Microalbuminuria and risk for cardiovascular disease: Analysis of potential mechanisms. J Am Soc Nephrol. 2006 Aug;17(8):2106-11.

56. Brenner BM, Meyer TW, Hostetter TH. Dietary protein intake and the progressive nature of kidney disease: the role of hemodynamically mediated glomerular injury in the pathogenesis of progressive glomerular sclerosis in aging, renal ablation, and intrinsic renal disease. N Engl J Med. 1982 Sep 9;307(11):652-9.

57. Van Hecke MV, Dekker JM, Nijpels G, Moll AC, Heine RJ, Bouter LM, et al. Inflammation and endothelial dysfunction are associated with retinopathy: the Hoorn Study. Diabetologia. 2005 Jul;48(7):1300-6.

58. Spijkerman AM, Gall MA, Tarnow L, Twisk JW, Lauritzen E, Lund-Andersen H, et al. Endothelial dysfunction and lowgrade inflammation and the progression of retinopathy in Type 2 diabetes. Diabet Med. 2007 Sep;24(9):969-76.

59. Heringa SM, van den Berg E, Reijmer YD, Nijpels G, Stehouwer CD, Schalkwijk CG, et al. Markers of low-grade inflammation and endothelial dysfunction are related to reduced information processing speed and executive functioning in an older population - the Hoorn Study. Psychoneuroendocrinology. 2014 Feb;40:108-18.

60. Van Sloten TT, Schram MT, Adriaanse MC, Dekker JM, Nijpels G, Teerlink T, et al. Endothelial dysfunction is associated with a greater depressive symptom score in a general elderly population: the Hoorn Study. Psychol Med. 2014 May;44(7):1403-16.

61. Ter Maaten JM, Damman K, Verhaar MC, Paulus WJ, Duncker DJ, Cheng C, et al. Connecting heart failure with preserved ejection fraction and renal dysfunction: the role of endothelial dysfunction and inflammation. Eur J Heart Fail. 2016 Jun;18(6):588-98.

62. Hansson GK. Inflammation, atherosclerosis, and coronary artery disease. N Engl J Med. 2005 Apr 21;352(16):1685-95. 
63. Luyckx VA, Brenner BM. The clinical importance of nephron mass. J Am Soc Nephrol. 2010 Jun;21(6):898-910.

64. Clough GF, Norman M. The microcirculation: a target for developmental priming. Microcirculation. 2011 May;18(4):286-97.

65. Stehouwer CD, Henry RM, Dekker JM, Nijpels G, Heine RJ, Bouter LM. Microalbuminuria is associated with impaired brachial artery, flow-mediated vasodilation in elderly individuals without and with diabetes: further evidence for a link between microalbuminuria and endothelial dysfunction--the Hoorn Study. Kidney Int Suppl. 2004 Nov(92):S42-4.

66. Dogra G, Rich L, Stanton K, Watts GF. Endothelium-dependent and independent vasodilation studies at normoglycaemia in type I diabetes mellitus with and without microalbuminuria. Diabetologia. 2001 May;44(5):593-601.

67. Poredos $\mathrm{P}, \mathrm{Kek}$ A. Relation of blunted dilation of the brachial artery in insulin-dependent diabetes mellitus to microalbuminuria. Am J Cardiol. 2000 Aug 1;86(3):364-7.

68. Clausen P, Jensen JS, Jensen G, Borch-Johnsen K, Feldt-Rasmussen B. Elevated urinary albumin excretion is associated with impaired arterial dilatory capacity in clinically healthy subjects. Circulation. 2001 Apr 10;103(14):1869-74.

69. Papaioannou GI, Seip RL, Grey NJ, Katten D, Taylor A, Inzucchi SE, et al. Brachial artery reactivity in asymptomatic patients with type 2 diabetes mellitus and microalbuminuria (from the Detection of Ischemia in Asymptomatic Diabetics-brachial artery reactivity study). Am J Cardiol. 2004 Aug 1;94(3):294-9.

70. Zenere BM, Arcaro G, Saggiani F, Rossi L, Muggeo M, Lechi A. Noninvasive detection of functional alterations of the arterial wall in IDDM patients with and without microalbuminuria. Diabetes Care. 1995 Jul;18(7):975-82.

71. Cosson E, Pham I, Valensi P, Paries J, Attali JR, Nitenberg A. Impaired coronary endothelium-dependent vasodilation is associated with microalbuminuria in patients with type 2 diabetes and angiographically normal coronary arteries. Diabetes Care. 2006 Jan;29(1):107-12.

72. Stehouwer CD, Nauta JJ, Zeldenrust GC, Hackeng WH, Donker AJ, den Ottolander GJ. Urinary albumin excretion, cardiovascular disease, and endothelial dysfunction in non-insulin-dependent diabetes mellitus. Lancet. 1992 Aug 8;340(8815):319-23.

73. Stehouwer CD, Gall MA, Twisk JW, Knudsen E, Emeis JJ, Parving HH. Increased urinary albumin excretion, endothelial dysfunction, and chronic low-grade inflammation in type 2 diabetes: progressive, interrelated, and independently associated with risk of death. Diabetes. 2002 Apr;51(4):1157-65.

74. Stehouwer CD, Fischer HR, van Kuijk AW, Polak BC, Donker AJ. Endothelial dysfunction precedes development of microalbuminuria in IDDM. Diabetes. 1995 May;44(5):561-4.

75. Jager A, van Hinsbergh VW, Kostense PJ, Emeis JJ, Nijpels G, Dekker JM, et al. C-reactive protein and soluble vascular cell adhesion molecule- 1 are associated with elevated urinary albumin excretion but do not explain its link with cardiovascular risk. Arterioscler Thromb Vasc Biol. 2002 Apr 1;22(4):593-8.

76. Clausen P, Feldt-Rasmussen B, Jensen G, Jensen JS. Endothelial haemostatic factors are associated with progression of urinary albumin excretion in clinically healthy subjects: a 4-year prospective study. Clin Sci (Lond). 1999 Jul;97(1):37-43.

77. Persson F, Rossing P, Hovind P, Stehouwer CD, Schalkwijk CG, Tarnow L, et al. Endothelial dysfunction and inflammation predict development of diabetic nephropathy in the Irbesartan in Patients with Type 2 Diabetes and Microalbuminuria (IRMA 2) study. Scand J Clin Lab Invest. 2008;68(8):731-8.

78. Feldt-Rasmussen B. Increased transcapillary escape rate of albumin in type 1 (insulin-dependent) diabetic patients with microalbuminuria. Diabetologia. 1986 May;29(5):282-6.

79. Nannipieri M, Rizzo L, Rapuano A, Pilo A, Penno G, Navalesi R. Increased transcapillary escape rate of albumin in microalbuminuric type II diabetic patients. Diabetes Care. 1995 Jan;18(1):1-9.

80. Nannipieri M, Penno G, Rizzo L, Pucci L, Bandinelli S, Mattei P, et al. Transcapillary escape rate of albumin in type II diabetic patients. The relationship with microalbuminuria and hypertension. Diabetes Care. 1997 Jun;20(6):1019-26.

81. Jensen EW, Espersen K, Knudsen JH, Nielsen SL. Increased transcapillary escape rate of albumin in elderly subjects due to long-term smoking habits. Clin Physiol. 1995 Mar;15(2):159-67.

82. Guglielmi MD, Pierdomenico SD, Salvatore L, Romano F, Tascione E, Pupillo M, et al. Impaired left ventricular diastolic function and vascular postischemic vasodilation associated with microalbuminuria in IDDM patients. Diabetes Care. 1995 Mar;18(3):353-60.

83. Schmiedel O, Schroeter ML, Harvey JN. Microalbuminuria in Type 2 diabetes indicates impaired microvascular vasomotion and perfusion. Am J Physiol Heart Circ Physiol. 2007 Dec;293(6):H3424-31.

84. Houben AJ, Schaper NC, Slaaf DW, Tangelder GJ, Nieuwenhuijzen Kruseman AC. Skin blood cell flux in insulindependent diabetic subjects in relation to retinopathy or incipient nephropathy. Eur J Clin Invest. 1992 Jan;22(1):67-72.

85. Zhao HJ, Wang S, Cheng H, Zhang MZ, Takahashi T, Fogo AB, et al. Endothelial nitric oxide synthase deficiency produces accelerated nephropathy in diabetic mice. J Am Soc Nephrol. 2006 Oct;17(10):2664-9.

86. Nakagawa T, Sato W, Glushakova O, Heinig M, Clarke T, Campbell-Thompson M, et al. Diabetic endothelial nitric oxide synthase knockout mice develop advanced diabetic nephropathy. J Am Soc Nephrol. 2007 Feb;18(2):539-50.

87. Triantafyllou A, Anyfanti P, Zabulis X, Gavriilaki E, Karamaounas P, Gkaliagkousi E, et al. Accumulation of microvascular target organ damage in newly diagnosed hypertensive patients. J Am Soc Hypertens. 2014 Aug;8(8):542-9.

88. Inker LA, Schmid CH, Tighiouart H, Eckfeldt JH, Feldman HI, Greene T, et al. Estimating glomerular filtration rate from serum creatinine and cystatin C. N Engl J Med. 2012 Jul 5;367(1):20-9.

89. Giannitsis E, Katus HA. Cardiac troponin level elevations not related to acute coronary syndromes. Nat Rev Cardiol. 2013 Nov;10(11):623-34.

90. Struthers A, Lang C. The potential to improve primary prevention in the future by using BNP/N-BNP as an indicator of silent 'pancardiac' target organ damage: BNP/N-BNP could become for the heart what microalbuminuria is for the kidney. Eur Heart J. 2007 Jul;28(14):1678-82.

91. Scheven L, de Jong PE, Hillege HL, Lambers Heerspink HJ, van Pelt LJ, Kootstra JE, et al. High-sensitive troponin T and 
$\mathrm{N}$-terminal pro-B type natriuretic peptide are associated with cardiovascular events despite the cross-sectional association with albuminuria and glomerular filtration rate. Eur Heart J. 2012 Sep;33(18):2272-81.

92. Xiao W, Ye P, Cao R, Yang X, Bai Y, Wu H. Urine Albumin Excretion Is Associated with Cardiac Troponin T Detected with a Highly Sensitive Assay in a Community-Based Population. PloS one. 2015;10(8):e0135747.

93. Pantoni L. Cerebral small vessel disease: from pathogenesis and clinical characteristics to therapeutic challenges. Lancet Neurol. 2010 Jul;9(7):689-701.

94. Wardlaw JM, Sandercock PA, Dennis MS, Starr J. Is breakdown of the blood-brain barrier responsible for lacunar stroke, leukoaraiosis, and dementia? Stroke. 2003 Mar;34(3):806-12.

95. Godin O, Dufouil C, Maillard P, Delcroix N, Mazoyer B, Crivello F, et al. White matter lesions as a predictor of depression in the elderly: the 3C-Dijon study. Biol Psychiatry. 2008 Apr 1;63(7):663-9.

96. Van Sloten TT, Sigurdsson S, van Buchem MA, Phillips CL, Jonsson PV, Ding J, et al. Cerebral Small Vessel Disease and Association With Higher Incidence of Depressive Symptoms in a General Elderly Population: The AGES-Reykjavik Study. Am J Psychiatry. 2015 Jun;172(6):570-8.

97. Debette S, Markus HS. The clinical importance of white matter hyperintensities on brain magnetic resonance imaging: systematic review and meta-analysis. BMJ. 2010;341:c3666.

98. Akoudad S, Sedaghat S, Hofman A, Koudstaal PJ, van der Lugt A, Ikram MA, et al. Kidney function and cerebral small vessel disease in the general population. Int J Stroke. 2015 Jun;10(4):603-8.

99. Finkelstein J, Joshi A, Hise MK. Association of physical activity and renal function in subjects with and without metabolic syndrome: a review of the Third National Health and Nutrition Examination Survey (NHANES III). Am J Kidney Dis. 2006 Sep;48(3):372-82.

100. Solbu MD, Kronborg J, Eriksen BO, Jenssen TG, Toft I. Cardiovascular risk-factors predict progression of urinary albuminexcretion in a general, non-diabetic population: a gender-specific follow-up study. Atherosclerosis. 2008 Dec;201(2):398-406.

101. Robinson ES, Fisher ND, Forman JP, Curhan GC. Physical activity and albuminuria. Am J Epidemiol. 2010 Mar 1;171(5):515-21.

102. Bharakhada N, Yates T, Davies MJ, Wilmot EG, Edwardson C, Henson J, et al. Association of sitting time and physical activity with CKD: a cross-sectional study in family practices. Am J Kidney Dis. 2012 Oct;60(4):583-90.

103. Chang A, Van Horn L, Jacobs DR, Jr., Liu K, Muntner P, Newsome B, et al. Lifestyle-related factors, obesity, and incident microalbuminuria: the CARDIA (Coronary Artery Risk Development in Young Adults) study. Am J Kidney Dis. 2013 Aug;62(2):267-75.

104. Gutierrez-Repiso C, Rojo-Martinez G, Soriguer F, Garcia-Fuentes E, Vendrell J, Vazquez JA, et al. Factors affecting levels of urinary albumin excretion in the general population of Spain: the Di@bet.es study. Clin Sci (Lond). 2013 Feb;124(4):269-77.

105. Robinson-Cohen C, Littman AJ, Duncan GE, Weiss NS, Sachs MC, Ruzinski J, et al. Physical activity and change in estimated GFR among persons with CKD. J Am Soc Nephrol. 2014 Feb;25(2):399-406.

106. Herber-Gast GC, Hulsegge G, Hartman L, Verschuren WM, Stehouwer CD, Gansevoort RT, et al. Physical Activity Is not Associated with Estimated Glomerular Filtration Rate among Young and Middle-Aged Adults: Results from the Population-Based Longitudinal Doetinchem Study. PloS one. 2015;10(10):e0133864.

107. Lynch BM, White SL, Owen N, Healy GN, Chadban SJ, Atkins RC, et al. Television viewing time and risk of chronic kidney disease in adults: the AusDiab Study. Ann Behav Med. 2010 Dec;40(3):265-74.

108. Stengel B, Tarver-Carr ME, Powe NR, Eberhardt MS, Brancati FL. Lifestyle factors, obesity and the risk of chronic kidney disease. Epidemiology. 2003 Jul;14(4):479-87.

109. White SL, Dunstan DW, Polkinghorne KR, Atkins RC, Cass A, Chadban SJ. Physical inactivity and chronic kidney disease in Australian adults: the AusDiab study. Nutr Metab Cardiovasc Dis. 2011 Feb;21(2):104-12.

110. Atkin AJ, Gorely T, Clemes SA, Yates T, Edwardson C, Brage S, et al. Methods of Measurement in epidemiology: sedentary Behaviour. Int J Epidemiol. 2012 Oct;41(5):1460-71.

111. Hawkins MS, Sevick MA, Richardson CR, Fried LF, Arena VC, Kriska AM. Association between physical activity and kidney function: National Health and Nutrition Examination Survey. Med Sci Sports Exerc. 2011 Aug;43(8):1457-64.

112. Guo VY, Brage S, Ekelund U, Griffin SJ, Simmons RK. Objectively measured sedentary time, physical activity and kidney function in people with recently diagnosed Type 2 diabetes: a prospective cohort analysis. Diabet Med. 2015 Aug 18.

113. Healy GN, Dunstan DW, Salmon J, Cerin E, Shaw JE, Zimmet PZ, et al. Breaks in sedentary time: beneficial associations with metabolic risk. Diabetes Care. 2008 Apr;31(4):661-6.

114. Healy GN, Winkler EA, Brakenridge CL, Reeves MM, Eakin EG. Accelerometer-derived sedentary and physical activity time in overweight/obese adults with type 2 diabetes: cross-sectional associations with cardiometabolic biomarkers. PloS one. 2015;10(3):e0119140.

115. Bankoski A, Harris TB, McClain JJ, Brychta RJ, Caserotti P, Chen KY, et al. Sedentary activity associated with metabolic syndrome independent of physical activity. Diabetes Care. 2011 Feb;34(2):497-503.

116. Benatti FB, Ried-Larsen M. The Effects of Breaking up Prolonged Sitting Time: A Review of Experimental Studies. Med Sci Sports Exerc. 2015 Oct;47(10):2053-61.

117. Van der Berg JD, Stehouwer CD, Bosma H, van der Velde JH, Willems PJ, Savelberg HH, et al. Associations of total amount and patterns of sedentary behaviour with type 2 diabetes and the metabolic syndrome: The Maastricht Study. Diabetologia. 2016 Apr;59(4):709-18.

118. Schram MT, Sep SJ, van der Kallen CJ, Dagnelie PC, Koster A, Schaper N, et al. The Maastricht Study: an extensive phenotyping study on determinants of type 2 diabetes, its complications and its comorbidities. Eur J Epidemiol. 2014 Jun;29(6):439-51. 


\section{Chapter 2}

Remy J.H. Martens

Ronald M.A. Henry

Alfons J.H.M. Houben

Carla J.H. van der Kallen

Abraham A. Kroon

Casper G. Schalkwijk

Miranda T. Schram

Simone J.S. Sep

Nicolaas C. Schaper

Pieter C. Dagnelie

Dennis M.J. Muris

Ed H.B.M. Gronenschild

Frank M. van der Sande

Karel M.L. Leunissen

Jeroen P. Kooman

Coen D.A. Stehouwer

J Am Soc Nephrol. 2016 Dec;27(12):3748-3757

(doi: 10.1681/ASN.2015111219) 


\section{Capillary rarefaction}

associates with allouminuria:

The Maastricht Study 


\begin{abstract}
Albuminuria may be a biomarker of generalized (i.e., microvascular and macrovascular) endothelial dysfunction. According to this concept, endothelial dysfunction of the renal microcirculation causes albuminuria by increasing glomerular capillary wall permeability and intraglomerular pressure, the latter eventually leading to glomerular capillary dropout (rarefaction) and further increases in intraglomerular pressure. However, direct evidence for an association between capillary rarefaction and albuminuria is lacking. Therefore, we examined the cross-sectional association between the recruitment of capillaries after arterial occlusion (capillary density during postocclusive peak reactive hyperemia) and during venous occlusion (venous congestion), as assessed with skin capillaroscopy, and albuminuria in 741 participants of the Maastricht Study, including 211 participants with type 2 diabetes. Overall, 57 participants had albuminuria, which was defined as a urinary albumin excretion $\geq 30 \mathrm{mg} / 24 \mathrm{~h}$. After adjustment for potential confounders, participants in the lowest tertile of skin capillary recruitment during postocclusive peak reactive hyperemia had an odds ratio for albuminuria of 2.27 (95\% confidence interval, 1.07 to 4.80 ) compared with those in the highest tertile. Similarly, a comparison between the lowest and the highest tertiles of capillary recruitment during venous congestion yielded an odds ratio of 2.89 (95\% confidence interval, 1.27 to 6.61$)$ for participants in the lowest tertile. In conclusion, lower capillary density of the skin microcirculation independently associated with albuminuria, providing direct support for a role of capillary rarefaction in the pathogenesis of albuminuria.
\end{abstract}




\section{INTRODUCTION}

Albuminuria is strongly associated with cardiovascular disease (CVD) risk. ${ }^{1}$ A leading hypothesis to explain this link is that albuminuria is a biomarker of generalized (i.e., micro- and macrovascular) endothelial dysfunction. ${ }^{2,3}$ According to this concept, endothelial dysfunction of renal arterioles and capillaries (i.e., the renal microcirculation) causes albuminuria by increasing glomerular capillary wall permeability and by increasing intraglomerular pressure, $^{3}$ the latter eventually leading to glomerular capillary drop-out (rarefaction) and further increases in intraglomerular pressure. ${ }^{4}$ Concomitantly, endothelial dysfunction in coronary and carotid arteries (i.e., the macrocirculation) leads to atherothrombotic CVD. ${ }^{2,3}$

Indeed, studies using flow-mediated dilation of the brachial, ${ }^{5-9}$ femoral, ${ }^{10}$ and left anterior descending coronary artery ${ }^{11}$ have provided strong direct evidence for the presence of endothelial dysfunction in the macrocirculation of individuals with albuminuria.

In contrast, evidence for endothelial dysfunction in the microcirculation of individuals with albuminuria is primarily indirect, as it derives from studies using plasma biomarkers, ${ }^{12-17}$ the transcapillary escape rate of albumin, ${ }^{18-21}$ strain-gauge plethysmography following forearm ischemia, ${ }^{22}$ and laser Doppler flowmetry following either iontophoresis of acetylcholine and sodium nitroprusside ${ }^{23}$ or arterial occlusion. ${ }^{24}$ In addition, evidence for an association between capillary rarefaction and albuminuria is confined to a relatively small study which showed the frequent co-occurrence of both in individuals with hypertension. ${ }^{25}$

In view of these considerations, we examined, in a population-based cohort study, the hypothesis that capillary rarefaction is associated with albuminuria. To do this, we used skin capillaroscopy, because capillary rarefaction in the kidney cannot be studied noninvasively in humans. Skin capillaroscopy is a noninvasive technique that allows direct visualization of capillary density in skin by measuring the recruitment of capillaries in response to arterial and venous occlusion, which are thought to be measures of functional and structural capillary density. ${ }^{26}$

\section{METHODS}

\section{The Maastricht Study population and design}

In this study, we used data from The Maastricht Study, an observational prospective population-based cohort study. The rationale and methodology have been described previously. ${ }^{27}$ In brief, the study focuses on the etiology, pathophysiology, complications, and comorbidities of type 2 diabetes mellitus (T2DM), and is characterized by an extensive phenotyping approach. Eligible for participation were all individuals with ages between 40 and 75 years living in the southern part of the Netherlands. Participants were recruited through mass media campaigns and from the municipal registries and the regional Diabetes Patient Registry via mailings. Recruitment was stratified according to known T2DM status for reasons of efficiency. The present report includes cross-sectional data from the first 866 participants, who completed the baseline survey between November of 2010 and March of 2012. The examinations of each participant were performed within a time window of three months. The study has been approved by the institutional medical ethical committee (NL31329.068.10) and the Minister of Health, Welfare and Sports of the Netherlands, on the basis of the Health Council's opinion (Permit 131088-105234-PG), and was conducted in accordance with the Declaration of Helsinki. All participants gave written informed consent. 


\section{Skin capillaroscopy}

All participants were asked to refrain from smoking and drinking coffee or tea $\geq 3 \mathrm{~h}$ before the measurements. A light meal (breakfast and/or lunch) low in fat content, was allowed prior to the start of the measurements. Skin capillaroscopy measurements were performed in a quiet, temperature-controlled room $\left(T=24^{\circ} \mathrm{C}\right)$ with participants in the supine position as previously described. ${ }^{28}$

Briefly, capillaries were visualized in the dorsal skin of the distal phalanges of the third and fourth finger of the right hand by use of a digital video microscope (Capiscope ${ }^{\circledR}, \mathrm{KK}$ Technology, Honiton, United Kingdom) with a system magnification of $\times 100 .{ }^{28}$ Capillaries were visualized $4.5 \mathrm{~mm}$ proximal to the terminal row of capillaries in the middle of the nailfold. The investigator selected a region of interest of $1-\mathrm{mm}^{2}$ skin area. Capillary density (mean of two fields) was measured under three conditions. First, baseline capillary density was measured. Baseline capillary density was defined as the number of continuously erythrocyte-perfused capillaries per $1 \mathrm{~mm}^{2}$ skin and was counted for 15 seconds. Second, capillary recruitment during postocclusive peak reactive hyperemia was assessed after 4 minutes of arterial occlusion. Arterial occlusion was applied using a miniature cuff at the base of the investigated finger inflated to suprasystolic pressure $(260 \mathrm{mmHg})$ for 4 minutes. Directly after release of the cuff, all (continuously and intermittently) perfused capillaries were counted for 15 seconds. Third, venous congestion was applied, with the cuff inflated to $60 \mathrm{mmHg}$ for 2 minutes, and all (continuously and intermittently) perfused capillaries were counted for 15 seconds. The number of perfused capillaries was counted in the recorded digital raw data with use of a semiautomatic procedure (CapiAna) ${ }^{28}$ by two investigators who were blinded to participants' clinical status. The intra- and interobserver coefficients of variation for the counting procedure were $2.5 \%$ and $5.6 \%$, respectively, as described previously. ${ }^{28}$

For the primary analyses, we used recruitment during postocclusive peak reactive hyperemia as well as during venous congestion (expressed as the percentage change in capillary density from baseline) and the absolute number of capillaries during postocclusive peak reactive hyperemia as well as during venous congestion (expressed as capillaries per $1 \mathrm{~mm}^{2}$ ).

\section{Kidney function}

The glomerular filtration rate (GFR) was estimated using the Chronic Kidney Disease Epidemiology Collaboration (CKD-EPI) equation on the basis of both serum creatinine and serum cystatin C (Supplemental Methods). ${ }^{29}$ To assess urinary albumin excretion, participants were requested to collect two 24h urine collections (Supplemental Methods).

Albuminuria was defined as an albumin excretion $\geq 30 \mathrm{mg} / 24 \mathrm{~h},{ }^{30}$ which is used in clinical practice to guide CVD prevention, particularly in individuals with T2DM. ${ }^{31}$ In an additional analysis, albuminuria was defined as an albumin excretion $\geq 15 \mathrm{mg} / 24 \mathrm{~h}$ (the upper level of daily albumin excretion in healthy individuals ${ }^{32}$ ) in agreement with the fact than an association with (CVD) mortality already exists at levels of urinary albumin excretion $<30 \mathrm{mg} / 24 \mathrm{~h}^{1}$ and to explore whether misclassification of albuminuria occurred with the clinical cutoff. These definitions were preferably on the basis of the average of two (available in $89.9 \%$ of the participants) $24 \mathrm{~h}$ urine collections.

\section{Potential confounders}

We assessed glucose metabolism status, body mass index, waist circumference, hip circumference, office blood pressure, $24 \mathrm{~h}$ average ambulatory blood pressure, fasting glucose, hemoglobin A1c (HbA1c; glycated hemoglobin), total cholesterol, high-density 
lipoprotein (HDL) cholesterol, low-density lipoprotein (LDL) cholesterol, triglycerides, medication use, smoking behavior, alcohol consumption, educational level, and prevalent CVD as described previously. ${ }^{27,33}$ Definitions of these potential confounders are provided in the Supplemental Methods. In addition, we assessed the following plasma biomarkers of inflammation: high-sensitivity C-reactive protein (CRP), serum amyloid A (SAA), interleukin 6 (IL-6), interleukin 8 (IL-8), tumor necrosis factor $\alpha$ (TNF- $\alpha$ ), and soluble intercellular adhesion molecule 1 (sICAM-1). ${ }^{34}$

\section{Statistical analyses}

All analyses were performed with IBM SPSS Statistics, Version 22.0 (IBM Corp., Armonk, NY, USA) unless stated otherwise.

Participants were divided into tertiles of the percentage recruitment during postocclusive peak reactive hyperemia as well as into tertiles of the percentage recruitment during venous congestion because the association with albuminuria seemed to be nonlinear. Participants with normal glucose tolerance, impaired fasting glucose and impaired glucose tolerance were combined into one category (participants without T2DM) because of the small number of participants with impaired fasting glucose and impaired glucose tolerance.

Associations between tertiles of the percentage recruitment during postocclusive peak reactive hyperemia as well as during venous congestion and the presence of albuminuria were evaluated using multivariable logistic regression analyses. Similarly, associations between tertiles of the absolute number of capillaries during postocclusive peak reactive hyperemia as well as during venous congestion and the presence of albuminuria were evaluated. The tertile with the highest recruitment or the highest absolute number of capillaries (tertile 1) was used as reference category. Next, we adjusted for potential confounders as follows: model 1, unadjusted model; model 2, adjusted for age, sex, and T2DM; model 3a, model 2 adjusted for waist circumference, total cholesterol-to-HDL cholesterol ratio, triglycerides, use of lipid-modifying medication, office systolic blood pressure, use of antihypertensive medication, eGFR, prevalent CVD, smoking behavior, alcohol consumption, and educational level; and model 3b, model 3a with replacement of office systolic blood pressure by $24 \mathrm{~h}$ average ambulatory systolic blood pressure.

We used interaction terms to examine whether the associations were modified by the presence or absence of T2DM. A $P$ value of the interaction term $\left(P_{\text {interaction }}\right)<0.10$ in model 3a was considered to indicate a statistically significant interaction.

Adjusted percentages of participants with albuminuria per tertile of recruitment were derived from the logistic regression models (model 2) with adjustment for age, sex, and T2DM by marginal standardization ${ }^{35}$ (calculated with Stata Statistical Software, Release 11.2SE; StataCorp LP, College Station, TX, USA).

Several additional analyses were performed, each starting from the models described above. First, we used the absolute change in capillary density from baseline (expressed as capillaries per $1 \mathrm{~mm}^{2}$ ) during postocclusive peak reactive hyperemia and during venous congestion to categorize participants. Second, we excluded participants with an albumin excretion $>300 \mathrm{mg} / 24 \mathrm{~h}(\mathrm{n}=8)$. Third, we replaced office systolic blood pressure with office diastolic blood pressure, office pulse pressure, office mean arterial pressure, presence of hypertension, $24 \mathrm{~h}$ average ambulatory diastolic blood pressure, $24 \mathrm{~h}$ average ambulatory pulse pressure or $24 \mathrm{~h}$ average ambulatory mean arterial pressure in model $3 \mathrm{a}$, and we replaced the use of antihypertensive medication with the use of a renin-angiotensin system inhibitor, the use of a diuretic, or their combined use. Fourth, we replaced waist circumference 
with waist-to-hip-ratio or body mass index, replaced the total cholesterol-to-HDL cholesterol ratio with $\mathrm{LDL}$ and $\mathrm{HDL}$, and additionally adjusted for $\mathrm{HbA1c}$ and a z-score of the inflammation biomarkers ${ }^{34}$ in model 3a. Fifth, we repeated the analyses in participants with two urine collections and after exclusion of $24 \mathrm{~h}$ urine collections with a measured $24 \mathrm{~h}$ urine creatinine excretion not within $30 \%$ of expected values ${ }^{36}$ to explore whether biological variation and inaccurate collection, respectively, led to non-differential misclassification with bias towards zero. Sixth, we repeated the analyses with quintiles and deciles of the respective capillaroscopy measures as independent variables. Seventh, we repeated the analyses with albuminuria defined as an albumin excretion $\geq 15 \mathrm{mg} / 24 \mathrm{~h}$. Eight, we performed multivariable linear regression analyses to examine whether the capillaroscopy measures were associated with urinary albumin excretion on a continuous scale. Urinary albumin excretion had to be transformed by taking the inverse square root of urinary albumin excretion to fulfill the normality assumption, because it was highly positively skewed and could not be transformed adequately using common ${ }^{37}$ transformations.

\section{RESULTS}

\section{Characteristics of the study population}

For this study on the basis of the first dataset of The Maastricht Study ( $\mathrm{n}=866)$, four participants with type 1 diabetes were excluded. In the remaining 862 participants, qualitatively satisfactory data on skin capillaroscopy were available in 818 participants. In another 12 participants, the $24 \mathrm{~h}$ urine collections were either collected erroneously $(<20 \mathrm{~h}$ or $>28 \mathrm{~h})$ or were not handed in at all. Of the remaining 806 participants, we additionally excluded participants with missing data on waist circumference $(n=3)$, smoking behavior $(n=14)$, alcohol consumption $(n=17)$, total cholesterol-to-HDL cholesterol ratio $(n=8)$, triglycerides $(n=7)$, eGFR $(n=15)$, office blood pressure $(n=2)$ and/or prior CVD status $(n=32)$. These missings were not mutually exclusive. The study population, therefore, consisted of 741 participants.

Table 2.1 shows the clinical characteristics of the study population stratified according to tertiles of the percentage recruitment during postocclusive peak reactive hyperemia. Tertile one indicates the tertile with the highest level of capillary recruitment.

In general, participants with the lowest recruitment were more often men, were less educated, suffered more often from hypertension and T2DM, and were more often treated with lipid-modifying or antihypertensive medication. Clinical characteristics according to tertiles of the percentage recruitment during venous congestion are shown in Supplemental Table 2.1.

\section{Recruitment of skin capillaries and the presence of albuminuria}

Overall, participants with the lowest recruitment more often had albuminuria (Figure 2.1).

After adjustment for potential confounders and compared with participants with the highest percentage recruitment during postocclusive peak reactive hyperemia (reference category), the odds ratio (OR) and 95\% confidence interval $(95 \% \mathrm{Cl})$ for albuminuria for participants in the lowest tertile was 2.27 (1.07 to 4.80) (Table 2.2, model 3a). After adjustment for potential confounders and compared with participants with the highest percentage recruitment during venous congestion (reference category), the $\mathrm{OR}(95 \% \mathrm{Cl})$ for albuminuria for participants in the lowest tertile was 2.89 (1.27 to 6.61) (Table 2.2, model 3a). 
Table 2.1. Clinical characteristics of the study population according to tertiles of the percentage recruitment during postocclusive peak reactive hyperemia

\begin{tabular}{|c|c|c|c|}
\hline \multirow[b]{2}{*}{ Characteristic } & \multicolumn{3}{|c|}{$\begin{array}{l}\text { Tertiles of the percentage recruitment during } \\
\text { postocclusive peak reactive hyperemia }\end{array}$} \\
\hline & $\begin{array}{l}\text { Tertile } 1 \text { (high) } \\
\mathbf{n}=247\end{array}$ & $\begin{array}{l}\text { Tertile } 2 \text { (middle) } \\
\mathrm{n}=247\end{array}$ & $\begin{array}{l}\text { Tertile } 3 \text { (low) } \\
n=247\end{array}$ \\
\hline $\begin{array}{l}\text { Recruitment during postocclusive peak } \\
\text { reactive hyperemia (\%) }\end{array}$ & 73.7 [55.0-186.7] & $38.9[27.0-54.9]$ & $16.3[0.0-26.9]$ \\
\hline \multicolumn{4}{|l|}{ Demographics } \\
\hline Age (years) & $59.2 \pm 8.5$ & $60.0 \pm 8.6$ & $60.0 \pm 8.5$ \\
\hline Men & $119(48.2)$ & $143(57.9)$ & $150(60.7)$ \\
\hline $\begin{array}{l}\text { Educational level } \\
\text { Low } \\
\text { Middle } \\
\text { High }\end{array}$ & $\begin{array}{l}33(13.4) \\
95(38.5) \\
119(48.2)\end{array}$ & $\begin{array}{l}37(15.0) \\
101(40.9) \\
109(44.1)\end{array}$ & $\begin{array}{l}50(20.2) \\
110(44.5) \\
87(35.2)\end{array}$ \\
\hline Prior cardiovascular disease & $50(20.2)$ & $36(14.6)$ & $48(19.4)$ \\
\hline \multicolumn{4}{|l|}{ Lifestyle variables } \\
\hline $\begin{array}{l}\text { Smoking behavior } \\
\text { Never smoker } \\
\text { Former smoker } \\
\text { Current smoker }\end{array}$ & $\begin{array}{l}80(32.4) \\
128(51.8) \\
39(15.8)\end{array}$ & $\begin{array}{l}78(31.6) \\
132(53.4) \\
37(15.0)\end{array}$ & $\begin{array}{l}72(29.1) \\
136(55.1) \\
39(15.8)\end{array}$ \\
\hline $\begin{array}{l}\text { Alcohol consumption } \\
\text { None } \\
\text { Low (women } \leq 7 \text { glasses/week; } \\
\text { men } \leq 14 \text { glasses/week) } \\
\text { High (women }>7 \text { glasses/week; } \\
\text { men }>14 \text { glasses/week) }\end{array}$ & $\begin{array}{l}34(13.8) \\
126(51.0) \\
87(35.2)\end{array}$ & $\begin{array}{l}42(17.0) \\
135(54.7) \\
70(28.3)\end{array}$ & $\begin{array}{l}47(19.0) \\
131(53.0) \\
69(27.9)\end{array}$ \\
\hline \multicolumn{4}{|l|}{ Metabolic variables } \\
\hline $\begin{array}{l}\text { BMI categories } \\
\text { Normal weight }\left(<25 \mathrm{~kg} / \mathrm{m}^{2}\right) \\
\text { Overweight }\left(25-<30 \mathrm{~kg} / \mathrm{m}^{2}\right) \\
\text { Obesity }\left(\geq 30 \mathrm{~kg} / \mathrm{m}^{2}\right)\end{array}$ & $\begin{array}{l}81(32.8) \\
117(47.4) \\
49(19.8)\end{array}$ & $\begin{array}{l}86(34.8) \\
106(42.9) \\
55(22.3)\end{array}$ & $\begin{array}{l}67(27.1) \\
122(49.4) \\
58(23.5)\end{array}$ \\
\hline $\begin{array}{l}\text { Waist circumference }(\mathrm{cm}) \\
\text { Men } \\
\text { Women }\end{array}$ & $\begin{array}{l}100.9 \pm 11.7 \\
89.5 \pm 12.1\end{array}$ & $\begin{array}{l}101.3 \pm 11.6 \\
91.5 \pm 13.7\end{array}$ & $\begin{array}{l}103.2 \pm 11.5 \\
92.4 \pm 14.3\end{array}$ \\
\hline $\begin{array}{l}\text { Waist-to-hip-ratio } \\
\text { Men } \\
\text { Women }\end{array}$ & $\begin{array}{l}1.00 \pm 0.07 \\
0.87 \pm 0.07\end{array}$ & $\begin{array}{l}1.00 \pm 0.06 \\
0.88 \pm 0.07\end{array}$ & $\begin{array}{l}1.01 \pm 0.07 \\
0.89 \pm 0.08\end{array}$ \\
\hline Office systolic blood pressure (mmHg) & $136.1 \pm 18.2$ & $135.9 \pm 18.7$ & $140.0 \pm 19.9$ \\
\hline Office diastolic blood pressure (mmHg) & $76.5 \pm 10.3$ & $76.0 \pm 10.8$ & $77.8 \pm 10.5$ \\
\hline $\begin{array}{l}24 \mathrm{~h} \text { average ambulatory systolic blood } \\
\text { pressure }(\mathrm{mmHg})^{\mathrm{a}}\end{array}$ & $118.3 \pm 11.9$ & $119.3 \pm 11.9$ & $120.9 \pm 12.6$ \\
\hline $\begin{array}{l}24 \mathrm{~h} \text { average ambulatory diastolic blood } \\
\text { pressure }(\mathrm{mmHg})^{\mathrm{a}}\end{array}$ & $73.6 \pm 7.4$ & $74.3 \pm 7.4$ & $74.6 \pm 7.1$ \\
\hline Hypertension & $136(55.1)$ & $136(55.1)$ & $158(64.0)$ \\
\hline
\end{tabular}


Table 2.1. (continued)

\begin{tabular}{|c|c|c|c|}
\hline Characteristic & $\begin{array}{l}\text { Tertile } 1 \text { (high) } \\
\mathrm{n}=\mathbf{2 4 7}\end{array}$ & $\begin{array}{l}\text { Tertile } 2 \text { (middle) } \\
\mathrm{n}=247\end{array}$ & $\begin{array}{l}\text { Tertile } 3 \text { (low) } \\
n=247\end{array}$ \\
\hline $\begin{array}{l}\text { Glucose metabolism status } \\
\text { Normal glucose metabolism } \\
\text { Impaired fasting glucose } \\
\text { Impaired glucose tolerance } \\
\text { Type } 2 \text { diabetes }\end{array}$ & $\begin{array}{l}151(61.1) \\
10(4.0) \\
43(17.4) \\
43(17.4) \\
\end{array}$ & $\begin{array}{l}139(56.3) \\
11(4.5) \\
27(10.9) \\
70(28.3)\end{array}$ & $\begin{array}{l}114(46.2) \\
19(7.7) \\
16(6.5) \\
98(39.7) \\
\end{array}$ \\
\hline $\begin{array}{l}\text { Fasting glucose }(\mathrm{mmol} / \mathrm{l}) \\
\text { Without type } 2 \text { diabetes } \\
\text { With type } 2 \text { diabetes }\end{array}$ & $\begin{array}{l}5.4 \pm 0.6 \\
7.9 \pm 1.7\end{array}$ & $\begin{array}{l}5.4 \pm 0.6 \\
7.6 \pm 1.4\end{array}$ & $\begin{array}{l}5.5 \pm 0.6 \\
7.7 \pm 1.9\end{array}$ \\
\hline $\begin{array}{l}\text { HbA1C }(\%)^{b} \\
\text { Without type } 2 \text { diabetes } \\
\text { With type } 2 \text { diabetes }\end{array}$ & $\begin{array}{l}5.7 \pm 0.4 \\
6.9 \pm 0.8\end{array}$ & $\begin{array}{l}5.6 \pm 0.4 \\
6.7 \pm 0.7\end{array}$ & $\begin{array}{l}5.6 \pm 0.3 \\
6.9 \pm 0.9 \\
\end{array}$ \\
\hline Total cholesterol (mmol/l) & $5.4 \pm 1.2$ & $5.2 \pm 1.2$ & $5.0 \pm 1.1$ \\
\hline $\begin{array}{l}\text { HDL cholesterol }(\mathrm{mmol} / \mathrm{l}) \\
\text { Men } \\
\text { Women }\end{array}$ & $\begin{array}{l}1.2 \pm 0.5 \\
1.5 \pm 0.4\end{array}$ & $\begin{array}{l}1.1 \pm 0.3 \\
1.5 \pm 0.4\end{array}$ & $\begin{array}{l}1.1 \pm 0.3 \\
1.5 \pm 0.5\end{array}$ \\
\hline LDL cholesterol (mmol/l) & $3.4 \pm 1.1$ & $3.3 \pm 1.0$ & $3.1 \pm 1.0$ \\
\hline Triglycerides (mmol/l) & $1.20[0.79-1.75]$ & $1.26[0.89-1.78]$ & $1.25[0.89-1.79]$ \\
\hline Total-to-HDL cholesterol ratio & $4.2 \pm 1.2$ & $4.3 \pm 1.3$ & $4.1 \pm 1.2$ \\
\hline \multicolumn{4}{|l|}{ Kidney function } \\
\hline $\mathrm{eGFR}\left(\mathrm{ml} / \mathrm{min} / 1.73 \mathrm{~m}^{2}\right)$ & $88.7 \pm 14.7$ & $87.6 \pm 14.5$ & $87.8 \pm 16.0$ \\
\hline Albumin excretion rate (mg/24h) & $8.2[5.4-11.6]$ & $7.8[5.5-11.5]$ & $7.8[5.5-15.7]$ \\
\hline Albumin excretion $\geq 15 \mathrm{mg} / 24 \mathrm{~h}$ & 34 (13.8) & $37(15.0)$ & $64(25.9)$ \\
\hline Albumin excretion $\geq 30 \mathrm{mg} / 24 \mathrm{~h}$ & $12(4.9)$ & $13(5.3)$ & $32(13.0)$ \\
\hline \multicolumn{4}{|l|}{ Medication } \\
\hline Antihypertensive medication & $94(38.1)$ & 89 (36.0) & $113(45.7)$ \\
\hline Renin-angiotensin system inhibitor & 75 (30.4) & $65(26.3)$ & $84(34.0)$ \\
\hline Lipid-modifying medication & $87(35.2)$ & 78 (31.6) & $106(42.9)$ \\
\hline
\end{tabular}

Data are presented as $n(\%)$, mean \pm standard deviation, median [interquartile range] or (only for the percentage recruitment during postocclusive peak reactive hyperemia) median [range].

Abbreviations: BMI, body mass index; eGFR, estimated glomerular filtration rate; HbA1c, hemoglobin A1c (glycated hemoglobin); HDL cholesterol, high-density lipoprotein cholesterol; LDL cholesterol, low-density lipoprotein cholesterol.

a $24 \mathrm{~h}$ average ambulatory blood pressure measurements were missing in $n=76$ participants $(n=27$ for tertile $1, n=23$ for tertile 2 and $n=26$ for tertile 3 ). ${ }^{b}$ To convert to HbA1c values in millimoles per mole: $(10.93 \times \mathrm{HbA1c}[\%])-23.5$.

When we replaced office systolic blood pressure with $24 \mathrm{~h}$ average ambulatory systolic blood pressure $(\mathrm{n}=665)$, the OR $(95 \% \mathrm{Cl})$ for albuminuria became 2.19 (0.96 to 5.00) for those with the lowest percentage recruitment during postocclusive peak reactive hyperemia (Table 2.2, model 3b) and 2.68 (1.10 to 6.52) for those with the lowest percentage recruitment during venous congestion (Table 2.2, model $3 \mathrm{~b}$ ). 


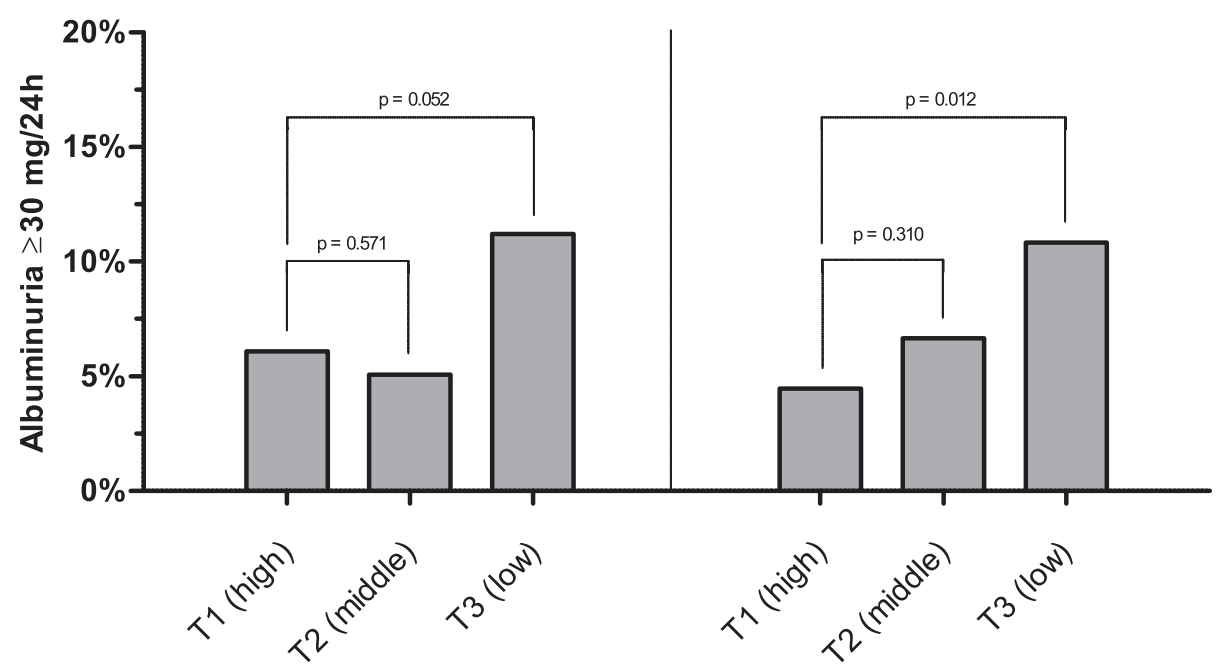

Tertiles of percentage recruitment during postocclusive peak reactive hyperemia
Tertiles of percentage recruitment during venous congestion

Figure 2.1. Capillary recruitment is associated with albuminuria. Bar charts showing the association between recruitment during postocclusive peak reactive hyperemia (left panel) as well as during venous congestion (right panel) and the presence of albuminuria $\geq 30$ $\mathrm{mg} / 24 \mathrm{~h}$. Tertiles of the percentage recruitment during postocclusive peak reactive hyperemia ranged from 55.0 to 186.7 (tertile 1 [T1]), 27.0 to 54.9 (tertile 2 [T2]) and 0.0 to 26.9 (tertile 3 [T3]). Tertiles of the percentage recruitment during venous congestion ranged from 55.8 to 253.3 (T1), 27.6 to 55.7 (T2) and -2.9 to 27.5 (T3). Percentages of participants with albuminuria $\geq 30 \mathrm{mg} / 24 \mathrm{~h}$ per tertile were adjusted for age, sex, and type 2 diabetes (model 2 ) by marginal standardization. $P$ values were derived from the same models.

When we replaced the percentage change in capillary density with the absolute numbers of capillaries during postocclusive peak reactive hyperemia as well as during venous congestion, the results were similar (Table 2.3).

When the variables of models $3 \mathrm{a}$ and $3 \mathrm{~b}$ were added separately to a model adjusted for age and sex, adjustment for T2DM led to the largest reduction of the OR when the percentage recruitment was the determinant. When the absolute number of capillaries was the determinant, adding additional variables after initial adjustment for age and sex did not materially alter our results (data not shown).

Analyses with interaction terms suggested that the associations between the percentage recruitment during postocclusive peak reactive hyperemia as well as venous congestion and albuminuria were only present in individuals without T2DM $\left(P_{\text {interaction }}<0.10\right)$ (Supplemental Table 2.2), whereas no such interaction was observed for the absolute number of capillaries under both conditions $\left(P_{\text {interaction }}>0.10\right)$ (Supplemental Table 2.3). 


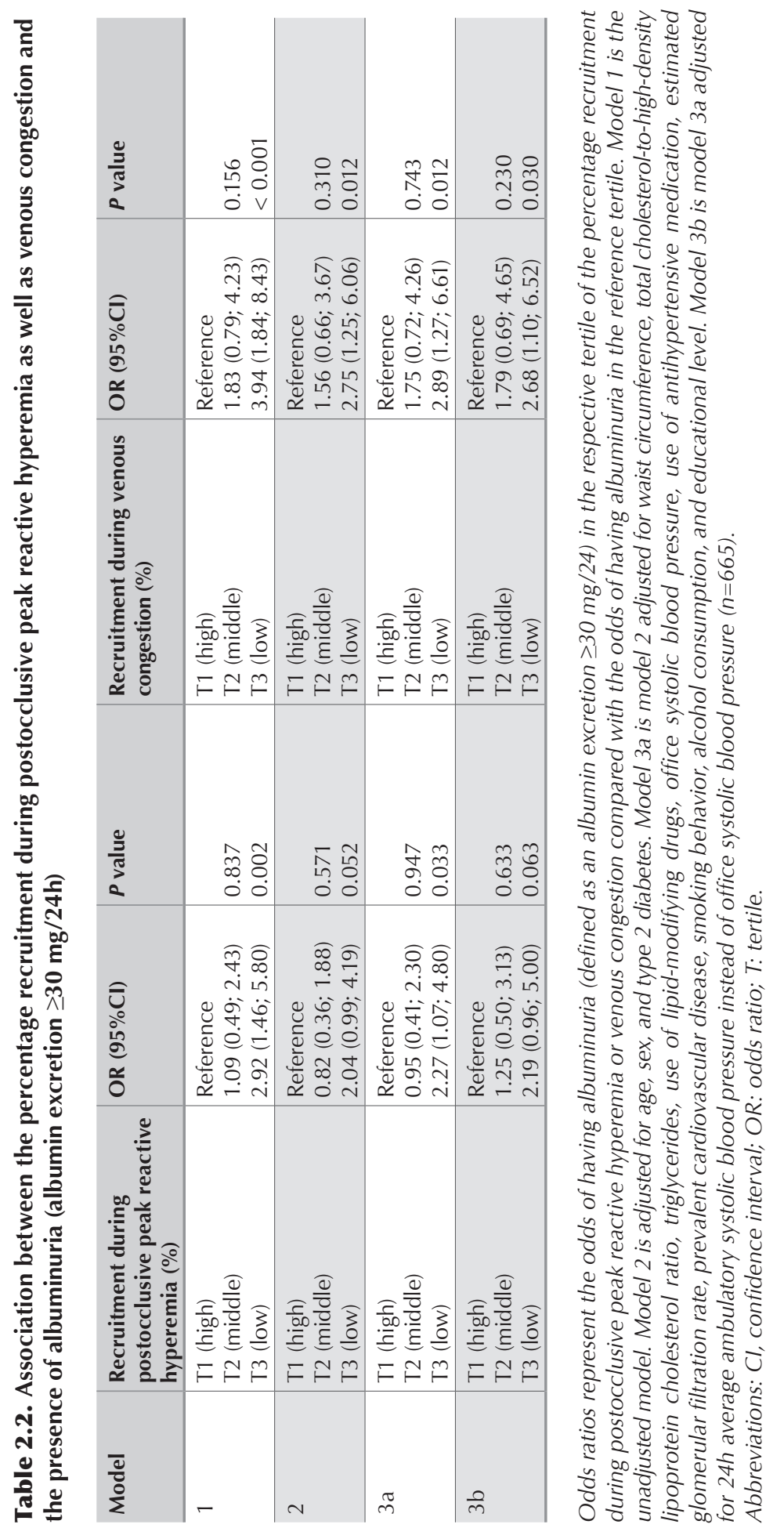




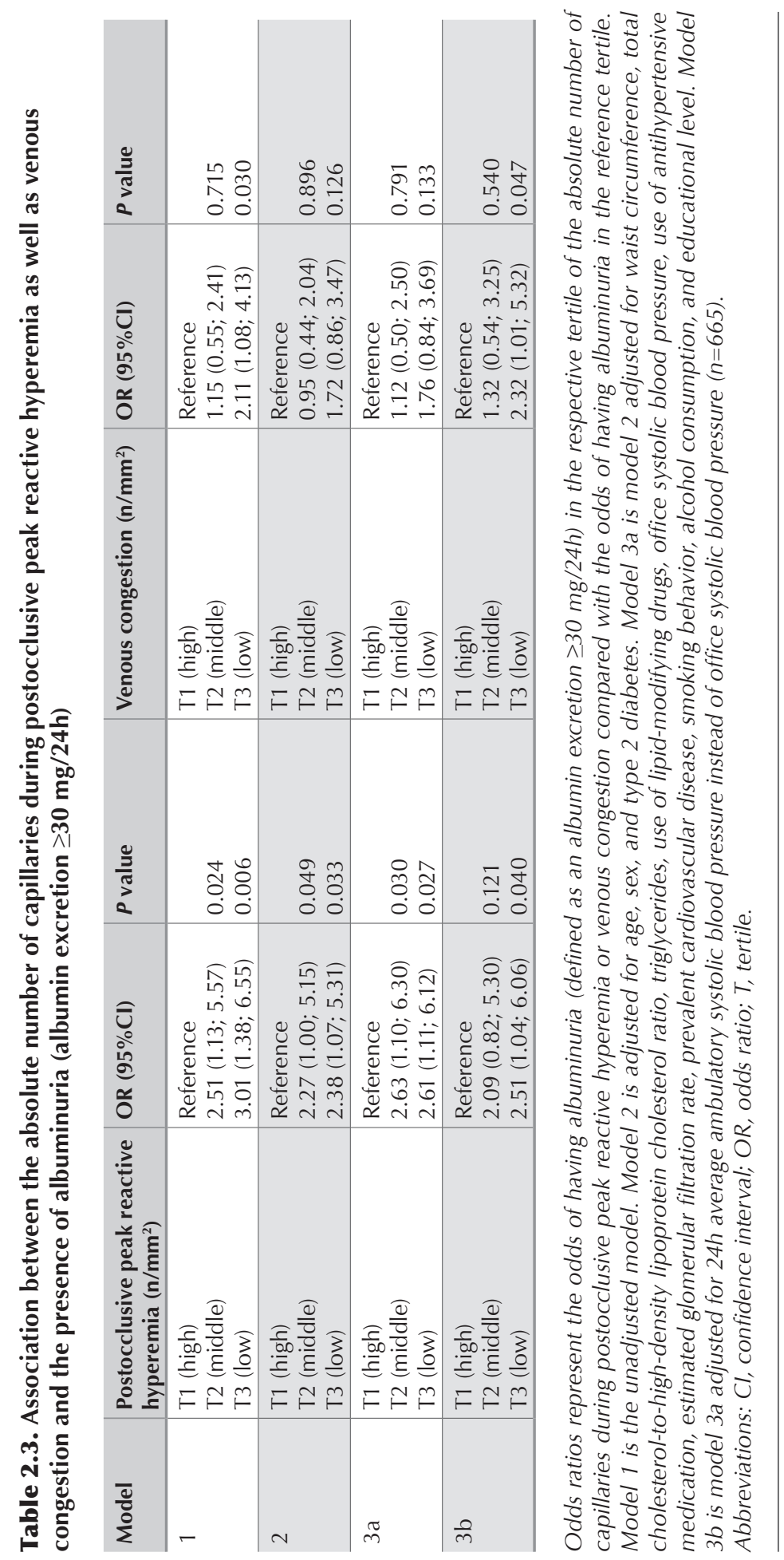




\section{Additional analyses}

First, recruitment of capillaries may be expressed as either the absolute or percentage change in capillary density (see Methods). When we replaced the percentage change with absolute change in capillary density, results were not materially altered for either postocclusive peak reactive hyperemia or venous congestion (data not shown). Second, mutual adjustment for the percentage recruitment during venous congestion or the percentage recruitment during postocclusive peak reactive hyperemia suggested multicollinearity (i.e., a strong increase in the standard error of the regression coefficient of the central determinant; data not shown). Third, results were not materially altered when we excluded participants with an albumin excretion >300 mg/24h; when we replaced office systolic blood pressure with either office diastolic blood pressure, office pulse pressure, office mean arterial pressure, presence of hypertension, 24h average ambulatory diastolic blood pressure, $24 \mathrm{~h}$ average ambulatory pulse pressure, or $24 \mathrm{~h}$ average ambulatory mean arterial pressure; when we replaced the use of antihypertensive medication with the use of a renin-angiotensin system inhibitor, the use of a diuretic or their combined use; when we replaced waist circumference with waist-tohip ratio or body mass index; when we replaced the total cholesterol-to-HDL cholesterol ratio with LDL and $\mathrm{HDL}$; and when we additionally adjusted for $\mathrm{HbA1c}$ or an inflammation $z$-score $(n=738)$. Fourth, analyses in the subpopulation with two urine collections $(n=666)$ and the subset of $24 \mathrm{~h}$ urine collections with measured $24 \mathrm{~h}$ urine creatinine excretion within $30 \%$ of expected values $(n=642)$ did not indicate non-differential misclassification caused by biological variability and inaccurate collection, respectively (data not shown). Fifth, analyses on the basis of quintiles and deciles of the respective capillaroscopy measures were also consistent with a threshold level (Supplemental Tables 2.4-2.6). However, these analyses were hampered by a loss of power. Sixth, we defined albuminuria as an albumin excretion $\geq 15 \mathrm{mg} / 24 \mathrm{~h}$, in agreement with the fact that an association with (CVD) mortality already exists at levels of urinary albumin excretion $<30 \mathrm{mg} / 24 \mathrm{~h}^{1}$ and to explore whether misclassification of albuminuria status occurred with the clinical cutoff value. With this definition, the associations for the entire study population became somewhat weaker (Supplemental Table $2.7)$ and there was no statistical interaction with T2DM $\left(P_{\text {interaction }}>0.10\right)$. Seventh, multivariable linear regression analyses showed no associations between tertiles of the respective capillaroscopy measures and (inverse square root-transformed) continuous urinary albumin excretion (data not shown).

\section{DISCUSSION}

The main finding of this population-based study is that lower capillary density was associated with the presence of albuminuria, regardless of whether T2DM was present. This association was independent of CVD risk factors, including 24h average ambulatory blood pressure and biomarkers of low-grade inflammation. To the best of our knowledge, this is the first population-based study that provides direct support for a role of capillary rarefaction in the pathogenesis of albuminuria.

An association between capillary rarefaction and albuminuria is in agreement with the Brenner hypothesis ${ }^{4}$ (i.e., an increase in intraglomerular pressure will lead to glomerular capillary drop-out [rarefaction] and further increases in intraglomerular pressure on the one hand and greater permeation of albumin through the glomerular capillary wall on the other). Indeed, in individuals with T2DM, estimated intraglomerular pressure was higher in the 
presence of albuminuria. ${ }^{38}$ Additionally, in individuals who underwent a large reduction in renal mass, remaining kidney mass was inversely associated with urinary albumin excretion. ${ }^{39}$ Furthermore, in a smaller study, capillary rarefaction in the skin microcirculation and albuminuria frequently co-occurred in individuals with hypertension. ${ }^{25}$ This study extends this knowledge, because it is the first to examine a direct measure of capillary rarefaction in a large populationbased sample with adjustment for potential confounders.

A key assumption underlying this study is that skin capillary rarefaction reflects capillary rarefaction of the kidney. Although the skin microcirculation has not been compared directly with that of the kidney, several observations support the view that it is representative for the systemic microcirculation, including the kidney's. First, age-related changes in the skin microcirculation parallel those in the systemic vasculature. ${ }^{40}$ Second, the microcirculation of the skin and kidney share associations with salt-sensitive hypertension ${ }^{41}$ and low birth weight. ${ }^{42-45}$

Both capillary density during venous occlusion and capillary density after arterial occlusion were used as reproducible ${ }^{26,46}$ estimates of maximal skin capillary density. ${ }^{47}$ In this study, we could not determine to what extent differences in capillary density were due to structural (i.e., anatomical) or functional (i.e., non-perfusion) rarefaction. However, the occurrence of multicollinearity after mutual adjustment suggests that both measures assessed the same or at least overlapping construct(s) in this study.

Importantly, misclassification of albuminuria status because of the use of renin-angiotensin system inhibitors may explain why capillary rarefaction in individuals with T2DM was associated with albuminuria when defined as an albumin excretion $\geq 15 \mathrm{mg} / 24 \mathrm{~h}$ but not when defined as an albumin excretion $\geq 30 \mathrm{mg} / 24 \mathrm{~h}$. Renin-angiotensin system inhibitors reduce urinary albumin excretion by lowering intraglomerular pressure, ${ }^{48,49}$ an effect that is enhanced by diuretics, ${ }^{50}$ and an albumin excretion $\geq 30 \mathrm{mg} / 24 \mathrm{~h}$ is used as an indication for their use, particularly in individuals with T2DM. ${ }^{31}$ Hence, individuals previously having had an albumin excretion $\geq 30 \mathrm{mg} / 24 \mathrm{~h}$ could be classified erroneously as having no albuminuria with this definition, thus obscuring an association with capillary rarefaction. Indeed, the frequent use of renin-angiotensin system inhibitors in individuals with T2DM and a urinary albumin excretion $15-<30 \mathrm{mg} / 24 \mathrm{~h}(64.9 \%$ versus $19.5 \%$ in individuals with a similar urinary albumin excretion but without T2DM) supports this explanation. Alternatively, the statistically significant interaction between T2DM and the percentage recruitment during postocclusive peak reactive hyperemia as well as venous congestion may be attributable to the play of chance given the low number of cases.

A lack of power because of the small variation in urinary albumin excretion with only few individuals with an albumin excretion $\geq 30 \mathrm{mg} / 24 \mathrm{~h}$ may explain why the results of this study suggest a threshold level for capillary density and why capillary rarefaction was not associated with continuous urinary albumin excretion. In addition, we measured urinary albumin excretion instead of the permeation of albumin through the glomerular capillary wall, and small increases in permeation may be compensated for by tubular reabsorption. ${ }^{51}$

A strength of this study is that participants of the Maastricht Study were well-characterized, allowing adjustment for an extensive series of potential confounders, including $24 \mathrm{~h}$ average ambulatory blood pressure and low-grade inflammation. In this regard, the use of office blood pressure only could have underestimated any effect of blood pressure on albuminuria and, thereby, overestimated the association between capillary rarefaction and albuminuria. However, some of the variables in our models may also be intermediates in the association between capillary rarefaction and albuminuria, possibly leading to overadjustment 
bias (i.e., the associations reported are conservative). ${ }^{52}$ For instance, capillary rarefaction may be involved in the pathogenesis of T2DM, which may subsequently lead to albuminuria via a hyperglycemia-induced increase in glomerular capillary wall permeability. ${ }^{3}$ Similarly, higher blood pressure may be both a cause and a consequence of capillary rarefaction. ${ }^{53}$

From a clinical perspective, both capillary rarefaction itself and the resulting increase in intraglomerular pressure may be a target in the management of albuminuria. Indeed, renin-angiotensin system inhibitors, which reduce intraglomerular pressure ${ }^{48,49}$ form the mainstay of the current management of albuminuria. ${ }^{31}$ However, current management is not specifically aimed at regenerating glomeruli. Nonetheless, in a recent study treatment with a renin-angiotensin system inhibitor led to an increase in kidney vasculature in a rat model of progressive glomerular injury, ${ }^{54}$ suggesting that capillary rarefaction itself could be a future therapeutic target.

This study had some limitations. First, no direct measure of capillary rarefaction of the kidney was used. However, at present, capillary rarefaction of the kidney, in contrast to capillary rarefaction of skin, cannot be studied noninvasively in humans. Second, because of the logistics of this large-scale population-based study, participants were not asked to come in fasting. However, to minimize the effects of dietary intake on the microcirculation, ${ }^{55-57}$ participants were asked to have a standardized low-fat breakfast (or lunch) and to refrain from caffeine-containing beverages and smoking. In addition, results were not materially altered after adjustment for non-adherence to the dietary and smoking restrictions. Third, the cross-sectional design does not allow us to make strong causal inferences. In addition, a longitudinal design with frequent assessment of urinary albumin excretion and medication use would have avoided misclassification of albuminuria status. Fourth, the study population primarily consisted of white individuals of European descent (99.2\%), limiting generalizability to other populations.

In conclusion, lower capillary density of the skin microcirculation was independently associated with the presence of albuminuria, regardless of the presence of T2DM. Thereby, this is the first population-based study that provides direct support for a role of capillary rarefaction in the pathogenesis of albuminuria. 


\section{REFERENCES}

1. Chronic Kidney Disease Prognosis Consortium, Matsushita K, van der Velde M, Astor BC, Woodward M, Levey AS, et al. Association of estimated glomerular filtration rate and albuminuria with all-cause and cardiovascular mortality in general population cohorts: a collaborative meta-analysis. Lancet. 2010 Jun 12;375(9731):2073-81.

2. Deckert T, Feldt-Rasmussen B, Borch-Johnsen K, Jensen T, Kofoed-Enevoldsen A. Albuminuria reflects widespread vascular damage. The Steno hypothesis. Diabetologia. 1989 Apr;32(4):219-26.

3. Stehouwer CD, Smulders YM. Microalbuminuria and risk for cardiovascular disease: Analysis of potential mechanisms. J Am Soc Nephrol. 2006 Aug;17(8):2106-11.

4. Brenner BM, Meyer TW, Hostetter TH. Dietary protein intake and the progressive nature of kidney disease: the role of hemodynamically mediated glomerular injury in the pathogenesis of progressive glomerular sclerosis in aging, renal ablation, and intrinsic renal disease. N Engl J Med. 1982 Sep 9;307(11):652-9.

5. Stehouwer CD, Henry RM, Dekker JM, Nijpels G, Heine RJ, Bouter LM. Microalbuminuria is associated with impaired brachial artery, flow-mediated vasodilation in elderly individuals without and with diabetes: further evidence for a link between microalbuminuria and endothelial dysfunction--the Hoorn Study. Kidney Int Suppl. 2004 Nov(92):S42-4.

6. Dogra G, Rich L, Stanton K, Watts GF. Endothelium-dependent and independent vasodilation studies at normoglycaemia in type I diabetes mellitus with and without microalbuminuria. Diabetologia. 2001 May;44(5):593-601.

7. Poredos P, Kek A. Relation of blunted dilation of the brachial artery in insulin-dependent diabetes mellitus to microalbuminuria. Am J Cardiol. 2000 Aug 1;86(3):364-7.

8. Clausen P, Jensen JS, Jensen G, Borch-Johnsen K, Feldt-Rasmussen B. Elevated urinary albumin excretion is associated with impaired arterial dilatory capacity in clinically healthy subjects. Circulation. 2001 Apr 10;103(14):1869-74.

9. Papaioannou GI, Seip RL, Grey NJ, Katten D, Taylor A, Inzucchi SE, et al. Brachial artery reactivity in asymptomatic patients with type 2 diabetes mellitus and microalbuminuria (from the Detection of Ischemia in Asymptomatic Diabetics-brachial artery reactivity study). Am J Cardiol. 2004 Aug 1;94(3):294-9.

10. Zenere BM, Arcaro G, Saggiani F, Rossi L, Muggeo M, Lechi A. Noninvasive detection of functional alterations of the arterial wall in IDDM patients with and without microalbuminuria. Diabetes Care. 1995 Jul;18(7):975-82.

11. Cosson E, Pham I, Valensi P, Paries J, Attali JR, Nitenberg A. Impaired coronary endothelium-dependent vasodilation is associated with microalbuminuria in patients with type 2 diabetes and angiographically normal coronary arteries. Diabetes Care. 2006 Jan;29(1):107-12.

12. Stehouwer CD, Nauta JJ, Zeldenrust GC, Hackeng WH, Donker AJ, den Ottolander GJ. Urinary albumin excretion, cardiovascular disease, and endothelial dysfunction in non-insulin-dependent diabetes mellitus. Lancet. 1992 Aug 8;340(8815):319-23.

13. Stehouwer CD, Gall MA, Twisk JW, Knudsen E, Emeis JJ, Parving HH. Increased urinary albumin excretion, endothelial dysfunction, and chronic low-grade inflammation in type 2 diabetes: progressive, interrelated, and independently associated with risk of death. Diabetes. 2002 Apr;51(4):1157-65.

14. Stehouwer CD, Fischer HR, van Kuijk AW, Polak BC, Donker AJ. Endothelial dysfunction precedes development of microalbuminuria in IDDM. Diabetes. 1995 May;44(5):561-4.

15. Jager A, van Hinsbergh VW, Kostense PJ, Emeis JJ, Nijpels G, Dekker JM, et al. C-reactive protein and soluble vascular cell adhesion molecule-1 are associated with elevated urinary albumin excretion but do not explain its link with cardiovascular risk. Arterioscler Thromb Vasc Biol. 2002 Apr 1;22(4):593-8.

16. Clausen P, Feldt-Rasmussen B, Jensen G, Jensen JS. Endothelial haemostatic factors are associated with progression of urinary albumin excretion in clinically healthy subjects: a 4-year prospective study. Clin Sci (Lond). 1999 Jul;97(1):37-43.

17. Persson F, Rossing P, Hovind P, Stehouwer CD, Schalkwijk CG, Tarnow L, et al. Endothelial dysfunction and inflammation predict development of diabetic nephropathy in the Irbesartan in Patients with Type 2 Diabetes and Microalbuminuria (IRMA 2) study. Scand J Clin Lab Invest. 2008;68(8):731-8.

18. Feldt-Rasmussen B. Increased transcapillary escape rate of albumin in type 1 (insulin-dependent) diabetic patients with microalbuminuria. Diabetologia. 1986 May;29(5):282-6.

19. Nannipieri M, Rizzo L, Rapuano A, Pilo A, Penno G, Navalesi R. Increased transcapillary escape rate of albumin in microalbuminuric type II diabetic patients. Diabetes Care. 1995 Jan;18(1):1-9.

20. Nannipieri M, Penno G, Rizzo L, Pucci L, Bandinelli S, Mattei P, et al. Transcapillary escape rate of albumin in type II diabetic patients. The relationship with microalbuminuria and hypertension. Diabetes Care. 1997 Jun;20(6):1019-26.

21. Jensen EW, Espersen K, Knudsen JH, Nielsen SL. Increased transcapillary escape rate of albumin in elderly subjects due to long-term smoking habits. Clin Physiol. 1995 Mar;15(2):159-67.

22. Guglielmi MD, Pierdomenico SD, Salvatore L, Romano F, Tascione E, Pupillo M, et al. Impaired left ventricular diastolic function and vascular postischemic vasodilation associated with microalbuminuria in IDDM patients. Diabetes Care. 1995 Mar;18(3):353-60.

23. Schmiedel O, Schroeter ML, Harvey JN. Microalbuminuria in Type 2 diabetes indicates impaired microvascular vasomotion and perfusion. Am J Physiol Heart Circ Physiol. 2007 Dec;293(6):H3424-31.

24. Houben AJ, Schaper NC, Slaaf DW, Tangelder GJ, Nieuwenhuijzen Kruseman AC. Skin blood cell flux in insulin-dependent diabetic subjects in relation to retinopathy or incipient nephropathy. Eur J Clin Invest. 1992 Jan;22(1):67-72.

25. Triantafyllou A, Anyfanti P, Zabulis X, Gavriilaki E, Karamaounas P, Gkaliagkousi E, et al. Accumulation of microvascular target organ damage in newly diagnosed hypertensive patients. J Am Soc Hypertens. 2014 Aug;8(8):542-9.

26. Serne EH, Gans RO, ter Maaten JC, Tangelder GJ, Donker AJ, Stehouwer CD. Impaired skin capillary recruitment in essential hypertension is caused by both functional and structural capillary rarefaction. Hypertension. 2001 Aug;38(2):238-42. 
27. Schram MT, Sep SJ, van der Kallen CJ, Dagnelie PC, Koster A, Schaper N, et al. The Maastricht Study: an extensive phenotyping study on determinants of type 2 diabetes, its complications and its comorbidities. Eur J Epidemiol. 2014 Jun;29(6):439-51.

28. Gronenschild EH, Muris DM, Schram MT, Karaca U, Stehouwer CD, Houben AJ. Semi-automatic assessment of skin capillary density: proof of principle and validation. Microvasc Res. 2013 Nov;90:192-8.

29. Inker LA, Schmid CH, Tighiouart H, Eckfeldt JH, Feldman HI, Greene T, et al. Estimating glomerular filtration rate from serum creatinine and cystatin C. N Engl J Med. 2012 Jul 5;367(1):20-9.

30. National Kidney Foundation. K/DOQI clinical practice guidelines for chronic kidney disease: evaluation, classification, and stratification. Am J Kidney Dis. 2002 Feb;39(2 Suppl 1):S1-266.

31. Kidney Disease: Improving Global Outcomes (KDIGO) Blood Pressure Work Group. KDIGO Clinical Practice Guideline for the Management of Blood Pressure in Chronic Kidney Disease. Kidney Int Suppl. 2012;2:337-414.

32. Ward KM. Renal function (microalbuminuria). Anal Chem. 1995 Jun 15;67(12):383R-91R.

33. Spauwen PJ, van Boxtel MP, Verhey FR, Kohler S, Sep SJ, Koster A, et al. Both Low and High 24-Hour Diastolic Blood Pressure Are Associated With Worse Cognitive Performance in Type 2 Diabetes: The Maastricht Study. Diabetes Care. 2015 Aug;38(8):1473-80.

34. Van Dooren FE, Verhey FR, Pouwer F, Schalkwijk CG, Sep SJ, Stehouwer CD, et al. Association of Type D personality with increased vulnerability to depression: Is there a role for inflammation or endothelial dysfunction? - The Maastricht Study. J Affect Disord. 2016 Jan 1;189:118-25.

35. Muller CJ, MacLehose RF. Estimating predicted probabilities from logistic regression: different methods correspond to different target populations. Int J Epidemiol. 2014 Jun;43(3):962-70.

36. Ix JH, Wassel CL, Stevens LA, Beck GJ, Froissart M, Navis G, et al. Equations to estimate creatinine excretion rate: the CKD epidemiology collaboration. Clin J Am Soc Nephrol. 2011 Jan;6(1):184-91.

37. Altman DG. Practical statistics for medical research. London: Chapman and Hall/CRC; 1990. p. 143-5.

38. Imanishi M, Yoshioka K, Konishi Y, Okumura M, Okada N, Sato T, et al. Glomerular hypertension as one cause of albuminuria in type II diabetic patients. Diabetologia. 1999 Aug;42(8):999-1005.

39. Novick AC, Gephardt G, Guz B, Steinmuller D, Tubbs RR. Long-term follow-up after partial removal of a solitary kidney. N Engl J Med. 1991 Oct 10;325(15):1058-62.

40. Holowatz LA, Thompson-Torgerson CS, Kenney WL. The human cutaneous circulation as a model of generalized microvascular function. J Appl Physiol (1985). 2008 Jul;105(1):370-2.

41. De Jongh RT, Serne EH, RG IJ, Stehouwer CD. Microvascular function: a potential link between salt sensitivity, insulin resistance and hypertension. J Hypertens. 2007 Sep;25(9):1887-93.

42. Serne EH, Stehouwer CD, ter Maaten JC, ter Wee PM, Donker AJ, Gans RO. Birth weight relates to blood pressure and microvascular function in normal subjects. J Hypertens. 2000 Oct;18(10):1421-7.

43. IJzerman RG, van Weissenbruch MM, Voordouw JJ, Yudkin JS, Serne EH, Delemarre-van de Waal HA, et al. The association between birth weight and capillary recruitment is independent of blood pressure and insulin sensitivity: a study in prepubertal children. J Hypertens. 2002 Oct;20(10):1957-63.

44. Manalich R, Reyes L, Herrera M, Melendi C, Fundora I. Relationship between weight at birth and the number and size of renal glomeruli in humans: a histomorphometric study. Kidney Int. 2000 Aug;58(2):770-3.

45. Hughson M, Farris AB, 3rd, Douglas-Denton R, Hoy WE, Bertram JF. Glomerular number and size in autopsy kidneys: the relationship to birth weight. Kidney Int. 2003 Jun;63(6):2113-22.

46. Jonk AM, Houben AJ, Schaper NC, de Leeuw PW, Serne EH, Smulders YM, et al. Angiotensin II enhances insulinstimulated whole-body glucose disposal but impairs insulin-induced capillary recruitment in healthy volunteers. J Clin Endocrinol Metab. 2010 Aug;95(8):3901-8.

47. Antonios TF, Rattray FE, Singer DR, Markandu ND, Mortimer PS, MacGregor GA. Maximization of skin capillaries during intravital video-microscopy in essential hypertension: comparison between venous congestion, reactive hyperaemia and core heat load tests. Clin Sci (Lond). 1999 Oct;97(4):523-8.

48. Anderson S, Rennke HG, Garcia DL, Brenner BM. Short and long term effects of antihypertensive therapy in the diabetic rat. Kidney Int. 1989 Oct;36(4):526-36.

49. Pelayo JC, Quan AH, Shanley PF. Angiotensin II control of the renal microcirculation in rats with reduced renal mass. Am J Physiol. 1990 Feb;258(2 Pt 2):F414-22.

50. Morales E, Caro J, Gutierrez E, Sevillano A, Aunon P, Fernandez C, et al. Diverse diuretics regimens differentially enhance the antialbuminuric effect of renin-angiotensin blockers in patients with chronic kidney disease. Kidney Int. 2015 Dec;88(6):1434-41.

51. Birn H, Christensen El. Renal albumin absorption in physiology and pathology. Kidney Int. 2006 Feb;69(3):440-9.

52. Schisterman EF, Cole SR, Platt RW. Overadjustment bias and unnecessary adjustment in epidemiologic studies. Epidemiology. 2009 Jul;20(4):488-95.

53. Levy BI, Ambrosio G, Pries AR, Struijker-Boudier HA. Microcirculation in hypertension: a new target for treatment? Circulation. 2001 Aug 7;104(6):735-40.

54. Remuzzi A, Sangalli F, Macconi D, Tomasoni S, Cattaneo I, Rizzo P, et al. Regression of Renal Disease by Angiotensin II Antagonism Is Caused by Regeneration of Kidney Vasculature. J Am Soc Nephrol. 2016 Mar;27(3):699-705.

55. Jonk AM, Houben AJ, Schaper NC, de Leeuw PW, Serne EH, Smulders YM, et al. Meal-related increases in microvascular vasomotion are impaired in obese individuals: a potential mechanism in the pathogenesis of obesity-related insulin resistance. Diabetes Care. 2011 May;34 Suppl 2:S342-8.

56. Keske MA, Clerk LH, Price WJ, Jahn LA, Barrett EJ. Obesity blunts microvascular recruitment in human forearm muscle after a mixed meal. Diabetes Care. 2009 Sep;32(9):1672-7.

57. Clerk LH, Vincent MA, Jahn LA, Liu Z, Lindner JR, Barrett EJ. Obesity blunts insulin-mediated microvascular recruitment in human forearm muscle. Diabetes. 2006 May;55(5):1436-42. 
Supplemental Material 


\section{SUPPLEMENTAL METHODS}

\section{Kidney function}

The glomerular filtration rate (GFR) was estimated using the Chronic Kidney Disease Epidemiology Collaboration (CKD-EPI) equation based on both serum creatinine and serum cystatin $\mathrm{C}^{1}$ Serum creatinine was measured with a Jaffé method traceable to isotope dilution mass spectrometry (Beckman Synchron LX20, Beckman Coulter Inc., Brea, USA). Serum cystatin $\mathrm{C}$ was measured with a particle enhanced immunoturbidimetric assay standardized against ERM-DA471/IFCC reference material (Roche Cobas 8000, F. Hoffman-La Roche Ltd, Basel, Switzerland).

To assess urinary albumin excretion, participants were requested to collect two $24 \mathrm{~h}$ urine collections. Urinary albumin concentration was measured with a standard immunoturbidimetric assay by an automatic analyzer (Beckman Synchron LX20, Beckman Coulter Inc., Brea, USA) and multiplied by collection volume to obtain the $24 \mathrm{~h}$ urinary albumin excretion. A urinary albumin concentration below the detection limit of the assay $(2 \mathrm{mg} / \mathrm{l})$ was set at $1.5 \mathrm{mg} / \mathrm{l}$ before multiplying by collection volume. Only urine collections with a collection time between $20 \mathrm{~h}$ and $28 \mathrm{~h}$ were considered valid. If needed, urinary albumin excretion was extrapolated to a $24 \mathrm{~h}$ excretion.

Albuminuria was defined as an albumin excretion $\geq 30 \mathrm{mg} / 24 \mathrm{~h},{ }^{2}$ which is used in clinical practice to guide cardiovascular disease (CVD) prevention, particularly in individuals with type 2 diabetes (T2DM). ${ }^{3}$ In an additional analysis, albuminuria was defined as an albumin excretion $\geq 15 \mathrm{mg} / 24 \mathrm{~h}$ (the upper level of daily albumin excretion in healthy individuals ${ }^{4}$ in agreement with the fact that an association with (CVD) mortality already exists below the clinical cutoff value of $30 \mathrm{mg} / 24 \mathrm{~h} .{ }^{5}$ These definitions were preferably based on the average of two (available in $89.9 \%$ of the participants) $24 \mathrm{~h}$ urine collections.

\section{Potential confounders}

We assessed glucose metabolism status, body mass index, waist circumference, hip circumference, office blood pressure, $24 \mathrm{~h}$ average ambulatory blood pressure, fasting glucose, hemoglobin A1c (HbA1c; glycated hemoglobin), total cholesterol, high-density lipoprotein (HDL) cholesterol, low-density lipoprotein (LDL) cholesterol, triglycerides, medication use, smoking behavior, alcohol consumption, educational level and prevalent CVD as described previously. ${ }^{6,7}$ Glucose metabolism status was classified according to the World Health Organization 2006 criteria $^{8}$ into normal glucose metabolism, impaired fasting glucose, impaired glucose tolerance, and diabetes mellitus. Participants with diabetes mellitus and participants using glucose-lowering medication were considered as having T2DM if they had no (self-reported) type 1 or other specific type of diabetes. Prevalent CVD was defined as a self-reported history of myocardial infarction, and/or cerebrovascular infarction or hemorrhage, and/or percutaneous artery angioplasty of, or vascular surgery on, the coronary, abdominal, peripheral or carotid arteries. Alcohol consumption was classified into three categories: non-consumption, low-consumption $(<7$ glasses per week for women and $\leq 14$ glasses per week for men) and high-consumption ( $>7$ glasses per week for women and $>14$ glasses per week for men). Waist-to-hip ratio was calculated by dividing waist circumference by hip circumference. Total cholesterol-to-HDL cholesterol ratio was calculated by dividing total cholesterol by HDL cholesterol. Hypertension was defined as an office systolic blood pressure $\geq 140 \mathrm{mmHg}$, an office diastolic blood pressure $\geq 90 \mathrm{mmHg}$ and/or the use of antihypertensive medication. Office pulse pressure was defined as office systolic blood 
pressure minus office diastolic blood pressure and office mean arterial pressure as office diastolic blood pressure plus 0.412 times office pulse pressure. ${ }^{9}$ Similar equations were used to calculate $24 \mathrm{~h}$ average ambulatory pulse pressure and $24 \mathrm{~h}$ average ambulatory mean arterial pressure, respectively. Educational level was assessed during the cognitive assessment and was classified into three groups: low (none, primary, or lower vocational education only), intermediate (intermediate general secondary, intermediate vocational or higher general secondary education) and high (higher vocational education or university level of education).,10 


\section{REFERENCES}

1. Inker LA, Schmid CH, Tighiouart H, Eckfeldt JH, Feldman HI, Greene T, et al. Estimating glomerular filtration rate from serum creatinine and cystatin C. N Engl J Med. 2012 Jul 5;367(1):20-9.

2. National Kidney Foundation. K/DOQI clinical practice guidelines for chronic kidney disease: evaluation, classification, and stratification. Am J Kidney Dis. 2002 Feb;39(2 Suppl 1):S1-266.

3. Kidney Disease: Improving Global Outcomes (KDIGO) Blood Pressure Work Group. KDIGO Clinical Practice Guideline for the Management of Blood Pressure in Chronic Kidney Disease. Kidney Int Suppl. 2012;2:337-414.

4. Ward KM. Renal function (microalbuminuria). Anal Chem. 1995 Jun 15;67(12):383R-91R.

5. Chronic Kidney Disease Prognosis Consortium, Matsushita K, van der Velde M, Astor BC, Woodward M, Levey AS, et al. Association of estimated glomerular filtration rate and albuminuria with all-cause and cardiovascular mortality in general population cohorts: a collaborative meta-analysis. Lancet. 2010 Jun 12;375(9731):2073-81.

6. Schram MT, Sep SJ, van der Kallen CJ, Dagnelie PC, Koster A, Schaper N, et al. The Maastricht Study: an extensive phenotyping study on determinants of type 2 diabetes, its complications and its comorbidities. Eur J Epidemiol. 2014 Jun;29(6):439-51.

7. Spauwen PJ, van Boxtel MP, Verhey FR, Kohler S, Sep SJ, Koster A, et al. Both Low and High 24-Hour Diastolic Blood Pressure Are Associated With Worse Cognitive Performance in Type 2 Diabetes: The Maastricht Study. Diabetes Care. 2015 Aug;38(8):1473-80.

8. World Health Organization. Definition and diagnosis of diabetes mellitus and intermediate hyperglycemia: report of a WHO/IDF consultation2006: Available from: http://www.who.int/diabetes/publications/Definition $\% 20$ and $\% 20$ diagnosis\%20of\%20diabetes_new.pdf.

9. Meaney E, Alva F, Moguel R, Meaney A, Alva J, Webel R. Formula and nomogram for the sphygmomanometric calculation of the mean arterial pressure. Heart. 2000 Jul;84(1):64.

10. De Bie SE. Standaardvragen 1987: Voorstellen voor uniformering van vraagstellingen naar achtergrondkenmerken en interviews [Standard questions 1987: Proposal for uniformization of questions regarding background variables and interviews]. Leiden, The Netherlands: Leiden University Press.; 1987. 
Supplemental Table 2.1. Clinical characteristics of the study population according to tertiles of the percentage recruitment during venous congestion

\begin{tabular}{|c|c|c|c|}
\hline & \multicolumn{3}{|c|}{$\begin{array}{l}\text { Tertiles of the percentage recruitment during } \\
\text { venous congestion }\end{array}$} \\
\hline & $\begin{array}{l}\text { Tertile } 1 \text { (high) } \\
\mathrm{n}=247\end{array}$ & $\begin{array}{l}\text { Tertile } 2 \text { (middle) } \\
\mathrm{n}=247\end{array}$ & $\begin{array}{l}\text { Tertile } 3 \text { (low) } \\
\mathrm{n}=247\end{array}$ \\
\hline Recruitment during venous congestion (\%) & $75.6[55.8-253.3]$ & $39.0[27.6-55.7]$ & $16.2[-2.9-27.5]$ \\
\hline \multicolumn{4}{|l|}{ Demographics } \\
\hline Age (years) & $59.4 \pm 8.5$ & $59.9 \pm 8.6$ & $59.9 \pm 8.5$ \\
\hline Men & $122(49.4)$ & $131(53.0)$ & $159(64.4)$ \\
\hline $\begin{array}{l}\text { Educational level } \\
\text { Low } \\
\text { Middle } \\
\text { High }\end{array}$ & $\begin{array}{l}32(13.0) \\
96(38.9) \\
119(48.2) \\
\end{array}$ & $\begin{array}{l}29(11.7) \\
101(40.9) \\
117(47.4) \\
\end{array}$ & $\begin{array}{l}59(23.9) \\
109(44.1) \\
79(32.0) \\
\end{array}$ \\
\hline Prior cardiovascular disease & $43(17.4)$ & $41(16.6)$ & $50(20.2)$ \\
\hline \multicolumn{4}{|l|}{ Lifestyle variables } \\
\hline $\begin{array}{l}\text { Smoking behavior } \\
\text { Never smoker } \\
\text { Former smoker } \\
\text { Current smoker }\end{array}$ & $\begin{array}{l}80(32.4) \\
130(52.6) \\
37(15.0)\end{array}$ & $\begin{array}{l}78(31.6) \\
132(53.4) \\
37(15.0) \\
\end{array}$ & $\begin{array}{l}72(29.1) \\
134(54.3) \\
41(16.6) \\
\end{array}$ \\
\hline $\begin{array}{l}\text { Alcohol consumption } \\
\text { None } \\
\text { Low (women } \leq 7 \text { glasses/week; } \\
\text { men } \leq 14 \text { glasses/week) } \\
\text { High (women }>7 \text { glasses/week; } \\
\text { men }>14 \text { glasses/week) }\end{array}$ & $\begin{array}{l}30(12.1) \\
127(51.4) \\
90(36.4)\end{array}$ & $\begin{array}{l}44(17.8) \\
127(51.4) \\
76(30.8)\end{array}$ & $\begin{array}{l}49(19.8) \\
138(55.9) \\
60(24.3)\end{array}$ \\
\hline \multicolumn{4}{|l|}{ Metabolic variables } \\
\hline $\begin{array}{l}\text { BMI categories } \\
\text { Normal weight }\left(<25 \mathrm{~kg} / \mathrm{m}^{2}\right) \\
\text { Overweight }\left(25-<30 \mathrm{~kg} / \mathrm{m}^{2}\right) \\
\text { Obesity }\left(\geq 30 \mathrm{~kg} / \mathrm{m}^{2}\right)\end{array}$ & $\begin{array}{l}86(34.8) \\
115(46.6) \\
46(18.6)\end{array}$ & $\begin{array}{l}86(34.8) \\
112(45.3) \\
49(19.8)\end{array}$ & $\begin{array}{l}62(25.1) \\
118(47.8) \\
67(27.1)\end{array}$ \\
\hline $\begin{array}{l}\text { Waist circumference }(\mathrm{cm}) \\
\text { Men } \\
\text { Women }\end{array}$ & $\begin{array}{l}100.0 \pm 11.9 \\
89.4 \pm 11.6\end{array}$ & $\begin{array}{l}101.3 \pm 11.4 \\
90.1 \pm 12.8\end{array}$ & $\begin{array}{l}103.6 \pm 11.4 \\
94.5 \pm 15.6\end{array}$ \\
\hline $\begin{array}{l}\text { Waist-to-hip-ratio } \\
\text { Men } \\
\text { Women }\end{array}$ & $\begin{array}{l}0.99 \pm 0.07 \\
0.87 \pm 0.07\end{array}$ & $\begin{array}{l}1.00 \pm 0.06 \\
0.88 \pm 0.07\end{array}$ & $\begin{array}{l}1.01 \pm 0.07 \\
0.90 \pm 0.08\end{array}$ \\
\hline Office systolic blood pressure (mmHg) & $136.4 \pm 18.3$ & $136.0 \pm 18.6$ & $139.6 \pm 20.0$ \\
\hline Office diastolic blood pressure (mmHg) & $76.7 \pm 10.4$ & $75.7 \pm 10.4$ & $78.1 \pm 10.7$ \\
\hline $\begin{array}{l}\text { 24h average ambulatory systolic blood } \\
\text { pressure }(\mathrm{mmHg})^{\mathrm{a}}\end{array}$ & $118.6 \pm 11.7$ & $119.1 \pm 12.4$ & $120.8 \pm 12.3$ \\
\hline $\begin{array}{l}\text { 24h average ambulatory diastolic blood } \\
\text { pressure }(\mathrm{mmHg})^{\mathrm{a}}\end{array}$ & $73.9 \pm 7.3$ & $74.1 \pm 7.4$ & $74.6 \pm 7.2$ \\
\hline Hypertension & $135(54.7)$ & $137(55.5)$ & $158(64.0)$ \\
\hline
\end{tabular}


Supplemental Table 2.1. (continued)

\begin{tabular}{|c|c|c|c|}
\hline & $\begin{array}{l}\text { Tertile } 1 \text { (high) } \\
\mathrm{n}=247\end{array}$ & \begin{tabular}{|l|} 
Tertile 2 (middle) \\
$\mathrm{n}=\mathbf{2 4 7}$
\end{tabular} & $\begin{array}{l}\text { Tertile } 3 \text { (low) } \\
\mathrm{n}=247\end{array}$ \\
\hline $\begin{array}{l}\text { Glucose metabolism status } \\
\text { Normal glucose metabolism } \\
\text { Impaired fasting glucose } \\
\text { Impaired glucose tolerance } \\
\text { Type } 2 \text { diabetes }\end{array}$ & $\begin{array}{l}153(61.9) \\
7(2.8) \\
44(17.8) \\
43(17.4) \\
\end{array}$ & $\begin{array}{l}144(58.3) \\
12(4.9) \\
26(10.5) \\
65(26.3)\end{array}$ & $\begin{array}{l}107(43.3) \\
21(8.5) \\
16(6.5) \\
103(41.7)\end{array}$ \\
\hline $\begin{array}{l}\text { Fasting glucose }(\mathrm{mmol} / \mathrm{l}) \\
\text { Without type } 2 \text { diabetes } \\
\text { With type } 2 \text { diabetes }\end{array}$ & $\begin{array}{l}5.4 \pm 0.5 \\
7.9 \pm 1.6\end{array}$ & $\begin{array}{l}5.3 \pm 0.6 \\
7.7 \pm 1.5\end{array}$ & $\begin{array}{l}5.5 \pm 0.6 \\
7.6 \pm 1.9\end{array}$ \\
\hline $\begin{array}{l}\text { HbA1C }(\%)^{b} \\
\text { Without type } 2 \text { diabetes } \\
\text { With type } 2 \text { diabetes }\end{array}$ & $\begin{array}{l}5.7 \pm 0.4 \\
6.9 \pm 0.8\end{array}$ & $\begin{array}{l}5.6 \pm 0.4 \\
6.8 \pm 0.7\end{array}$ & $\begin{array}{l}5.6 \pm 0.4 \\
6.8 \pm 0.9\end{array}$ \\
\hline Total cholesterol (mmol/l) & $5.5 \pm 1.2$ & $5.2 \pm 1.1$ & $5.0 \pm 1.1$ \\
\hline $\begin{array}{l}\text { HDL cholesterol }(\mathrm{mmol} / \mathrm{l}) \\
\text { Men } \\
\text { Women }\end{array}$ & $\begin{array}{l}1.2 \pm 0.5 \\
1.5 \pm 0.4\end{array}$ & $\begin{array}{l}1.2 \pm 0.3 \\
1.5 \pm 0.4\end{array}$ & $\begin{array}{l}1.1 \pm 0.3 \\
1.5 \pm 0.5\end{array}$ \\
\hline LDL cholesterol (mmol/l) & $3.5 \pm 1.1$ & $3.3 \pm 1.0$ & $3.1 \pm 1.0$ \\
\hline Triglycerides (mmol/l) & $1.20[0.79-1.76]$ & $1.19[0.86-1.66]$ & 1.31 [0.90-1.92] \\
\hline Total-to-HDL cholesterol ratio & $4.2 \pm 1.2$ & $4.2 \pm 1.3$ & $4.3 \pm 1.2$ \\
\hline \multicolumn{4}{|l|}{ Kidney function } \\
\hline $\mathrm{eGFR}\left(\mathrm{ml} / \mathrm{min} / 1.73 \mathrm{~m}^{2}\right)$ & $89.1 \pm 14.1$ & $87.3 \pm 15.4$ & $87.8 \pm 15.7$ \\
\hline Albumin excretion rate (mg/24h) & $8.2[5.4-11.1]$ & $7.4[5.4-11.4]$ & $7.9[5.5-16.6]$ \\
\hline Albumin excretion $\geq 15 \mathrm{mg} / 24 \mathrm{~h}$ & 31 (12.6) & $38(15.4)$ & $66(26.7)$ \\
\hline Albumin excretion $\geq 30 \mathrm{mg} / 24 \mathrm{~h}$ & $9(3.6)$ & $16(6.5)$ & $32(13.0)$ \\
\hline \multicolumn{4}{|l|}{ Medication } \\
\hline Antihypertensive medication & $91(36.8)$ & 88 (35.6) & $117(47.4)$ \\
\hline Renin-angiotensin system inhibitor & 73 (29.6) & 59 (23.9) & $92(37.2)$ \\
\hline Lipid-modifying medication & $85(34.4)$ & $75(30.4)$ & $111(44.9)$ \\
\hline
\end{tabular}

Data are presented as $n(\%)$, mean \pm standard deviation, median [interquartile range] or (only for the percentage recruitment during venous congestion) median [range].

Abbreviations: BMI, body mass index; eGFR, estimated glomerular filtration rate; HbA1c, hemoglobin A1c (glycated hemoglobin); HDL cholesterol, high-density lipoprotein cholesterol; LDL cholesterol, low-density lipoprotein cholesterol.

a $24 \mathrm{~h}$ average ambulatory blood pressure measurements were missing in $n=76$ participants $(n=23$ for tertile $1, n=28$ for tertile 2 and $n=25$ for tertile 3$).{ }^{b}$ To convert to HbA1c values in $\mathrm{mmol} / \mathrm{mol}:(10.93 \times$ HbA1c [\%] - 23.5. 


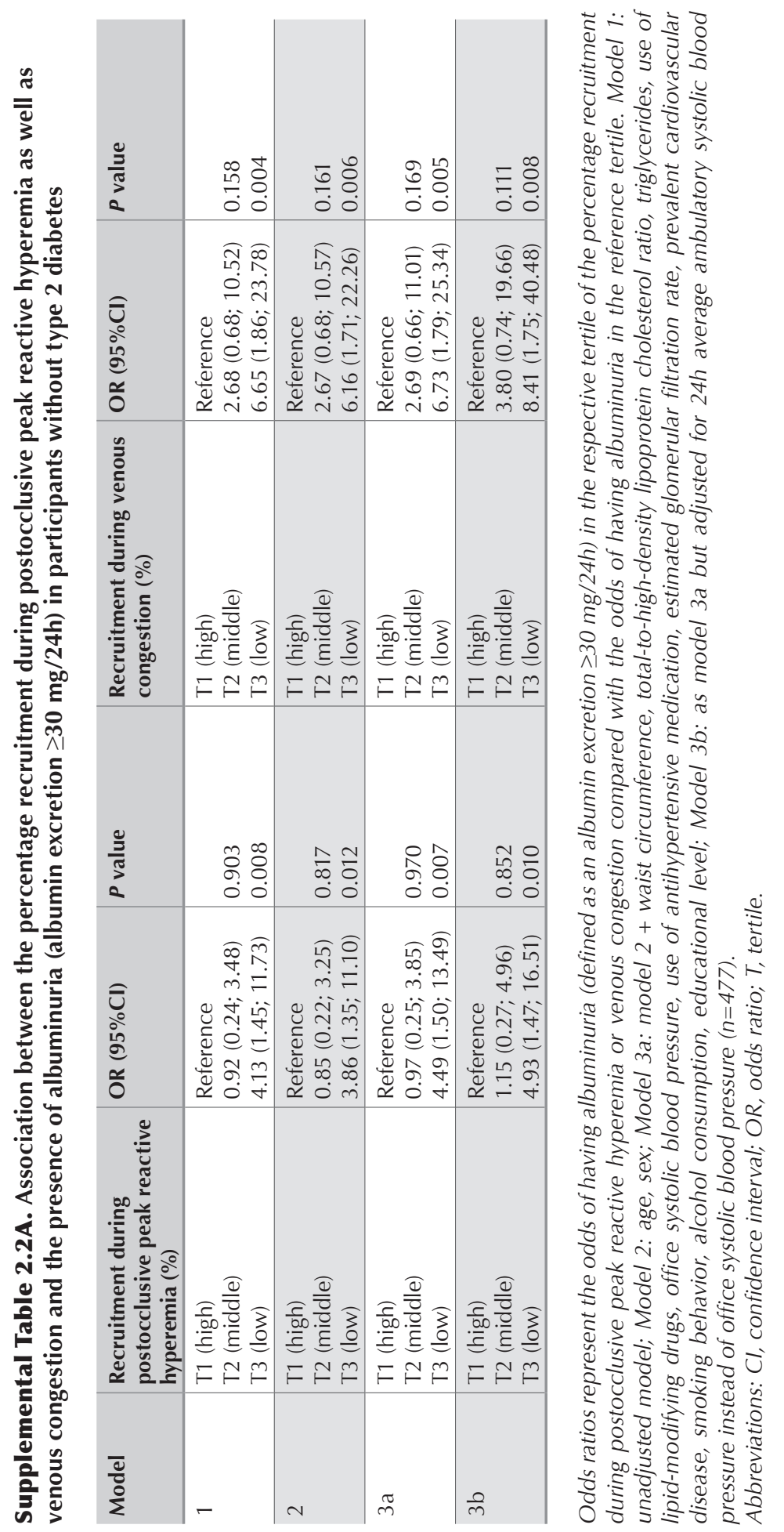




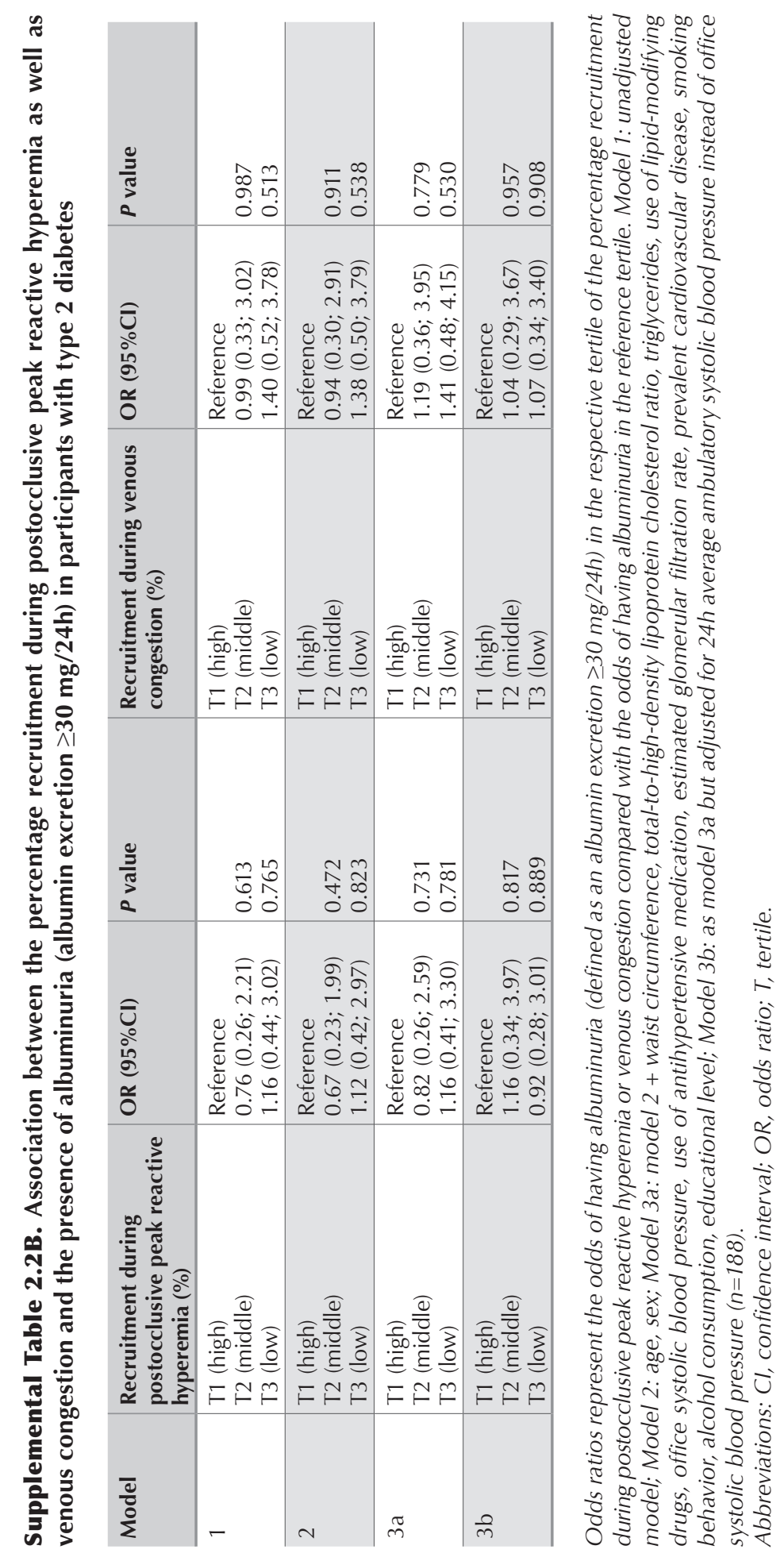




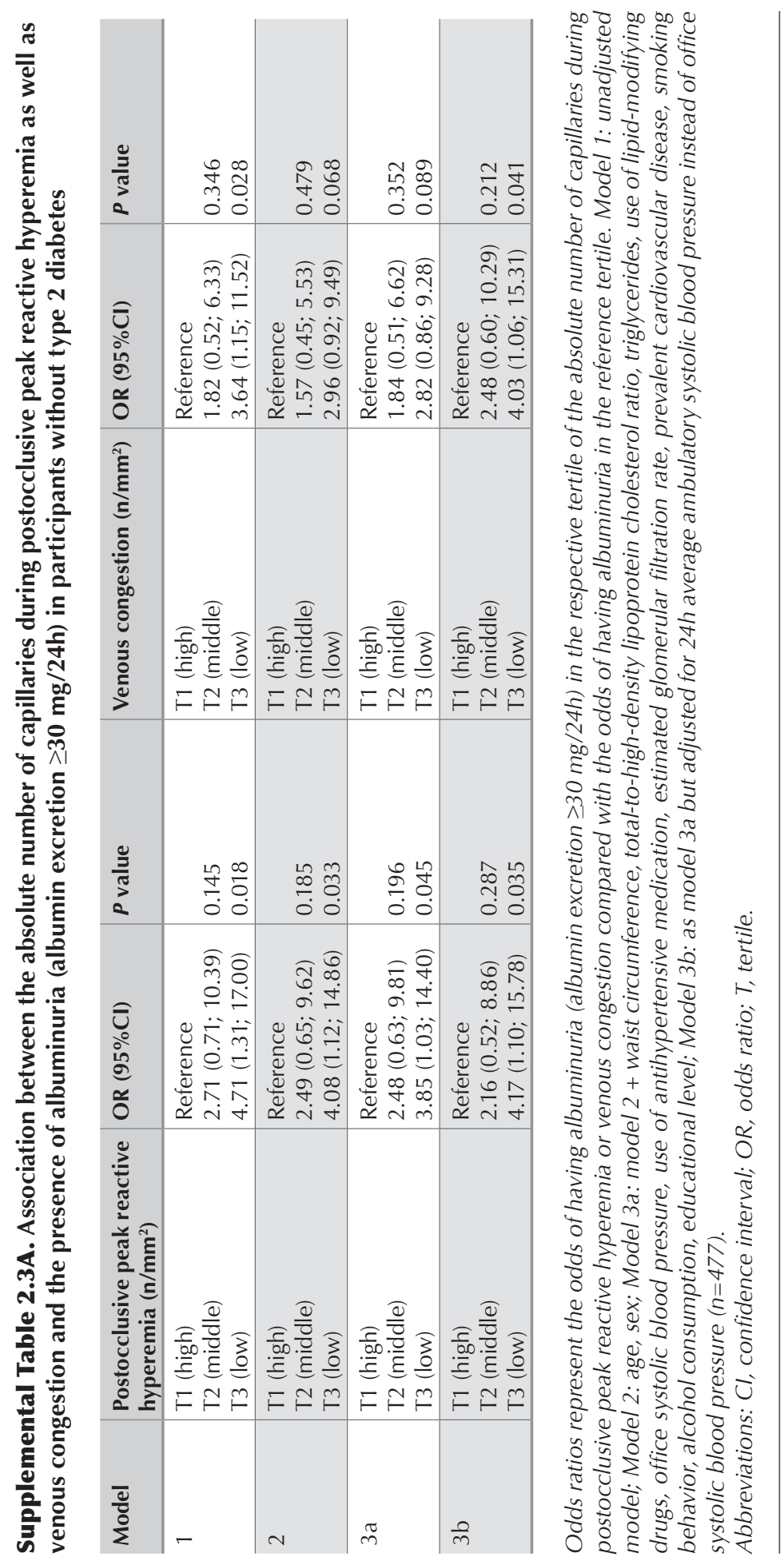




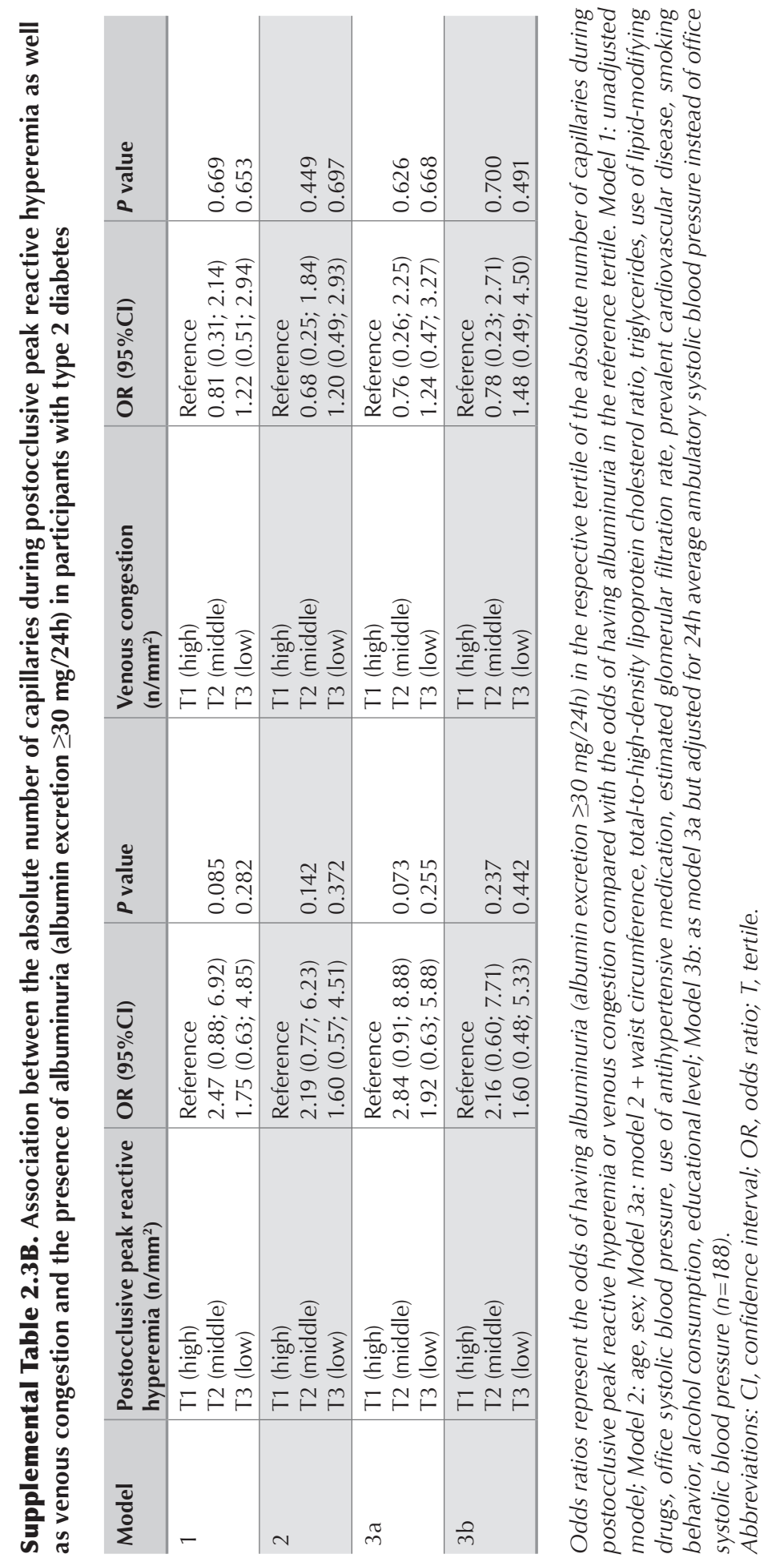



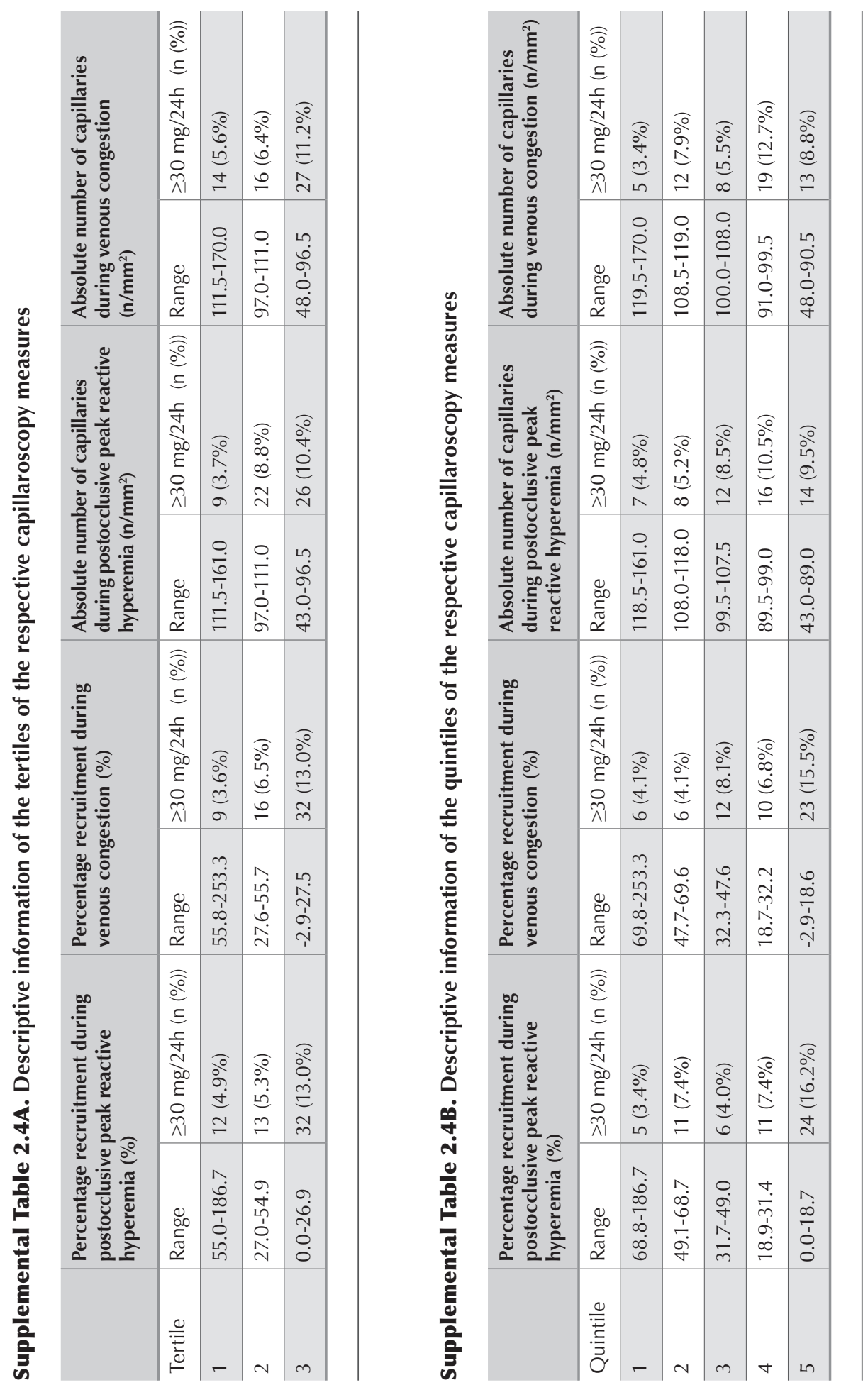


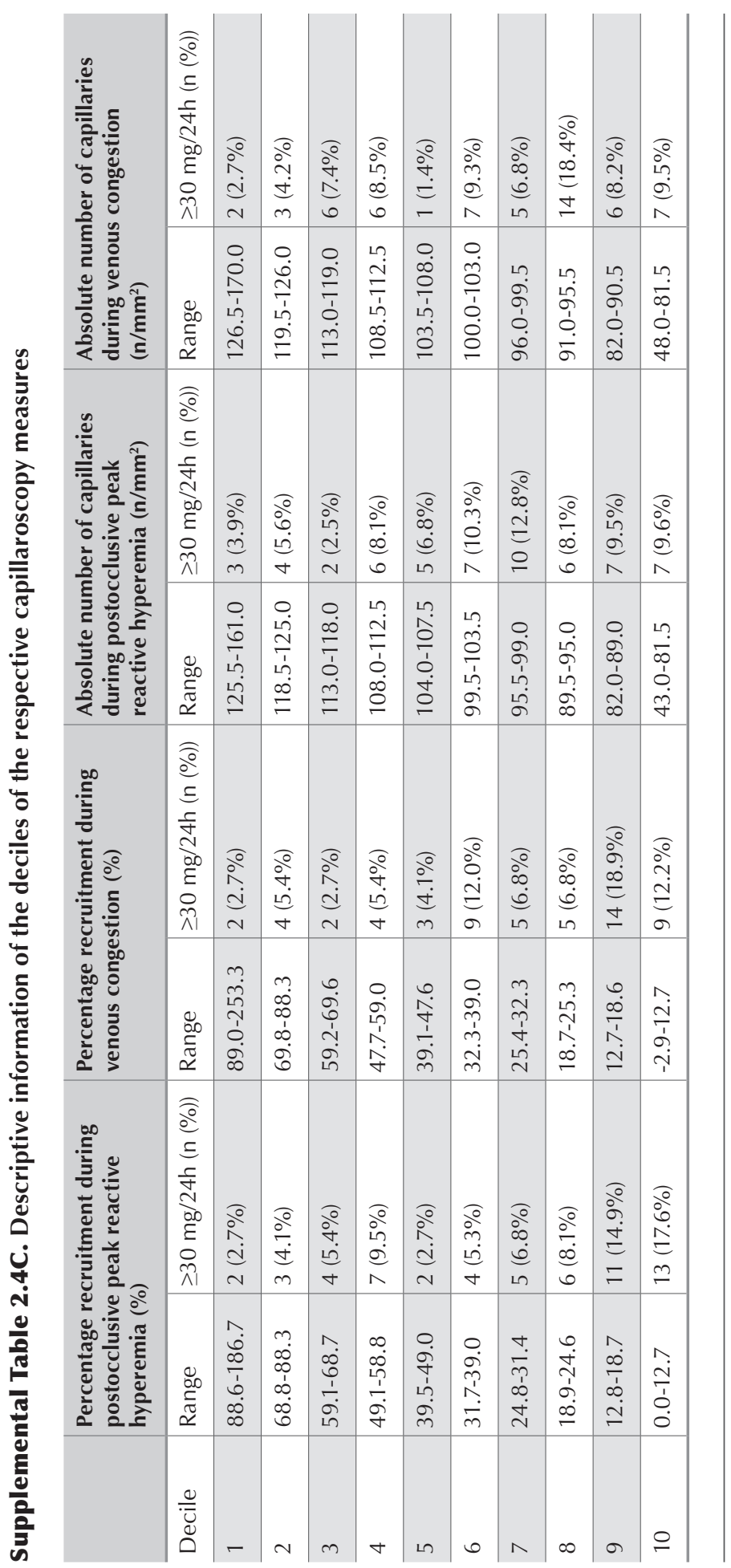



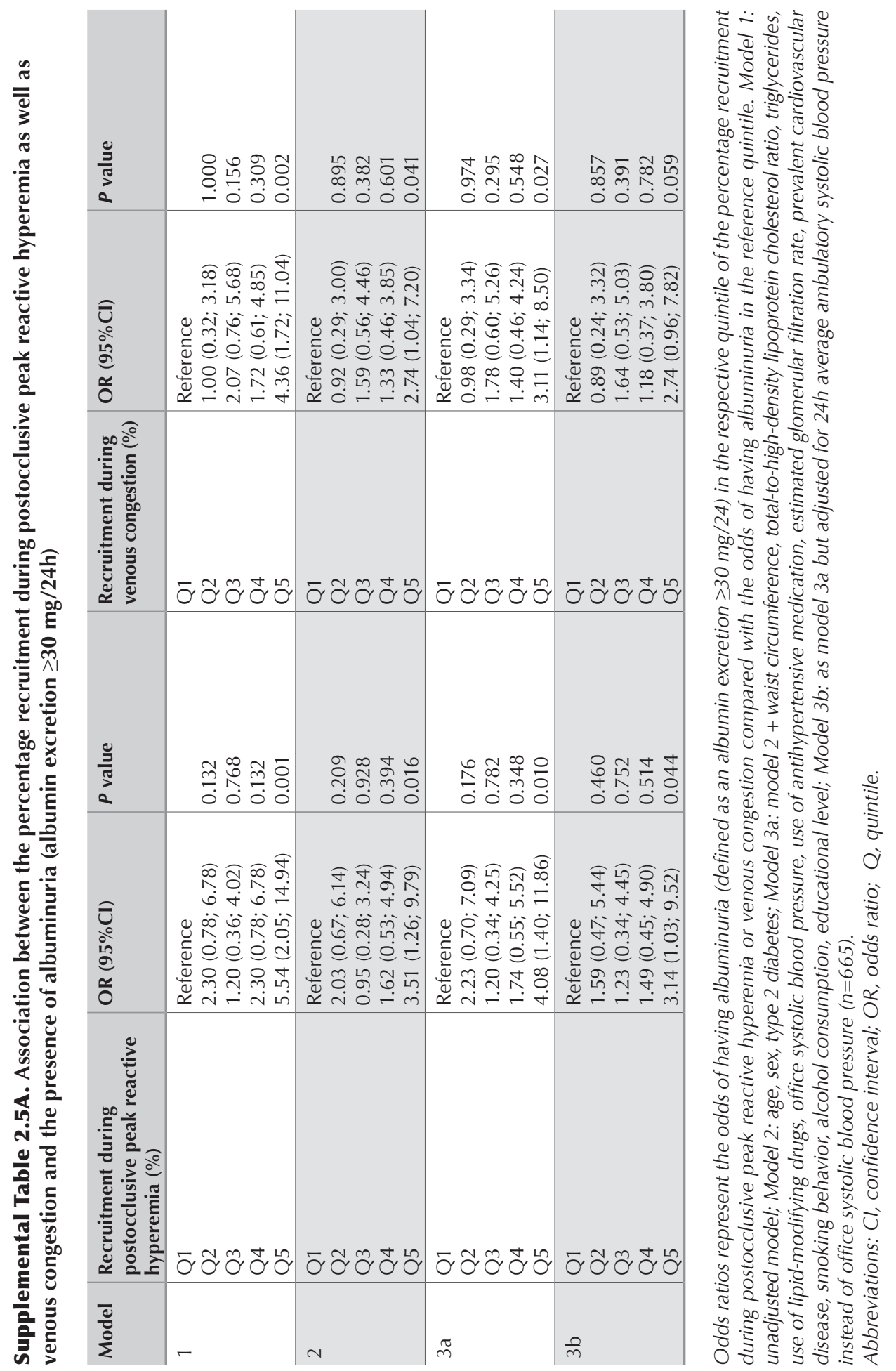


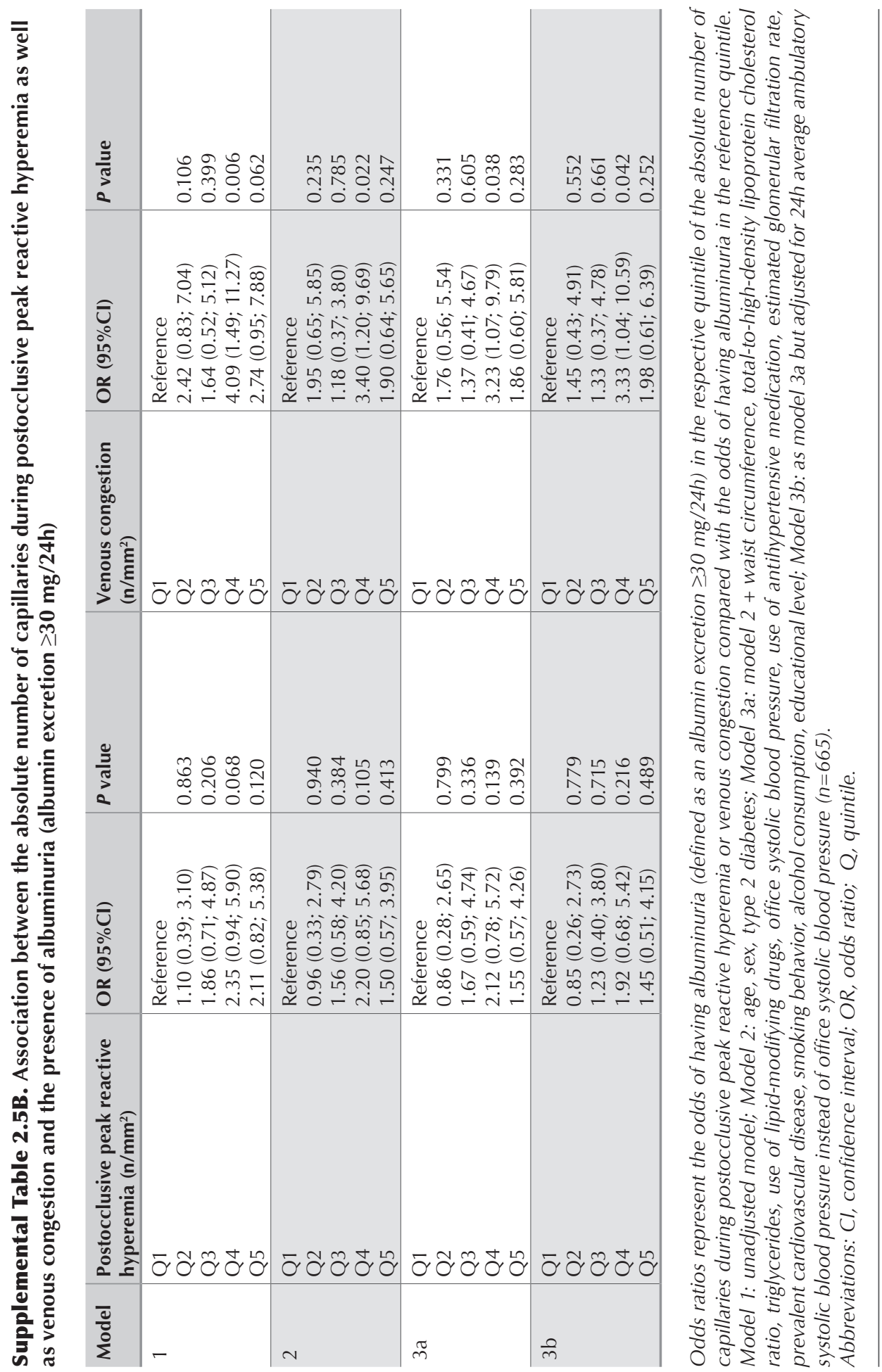




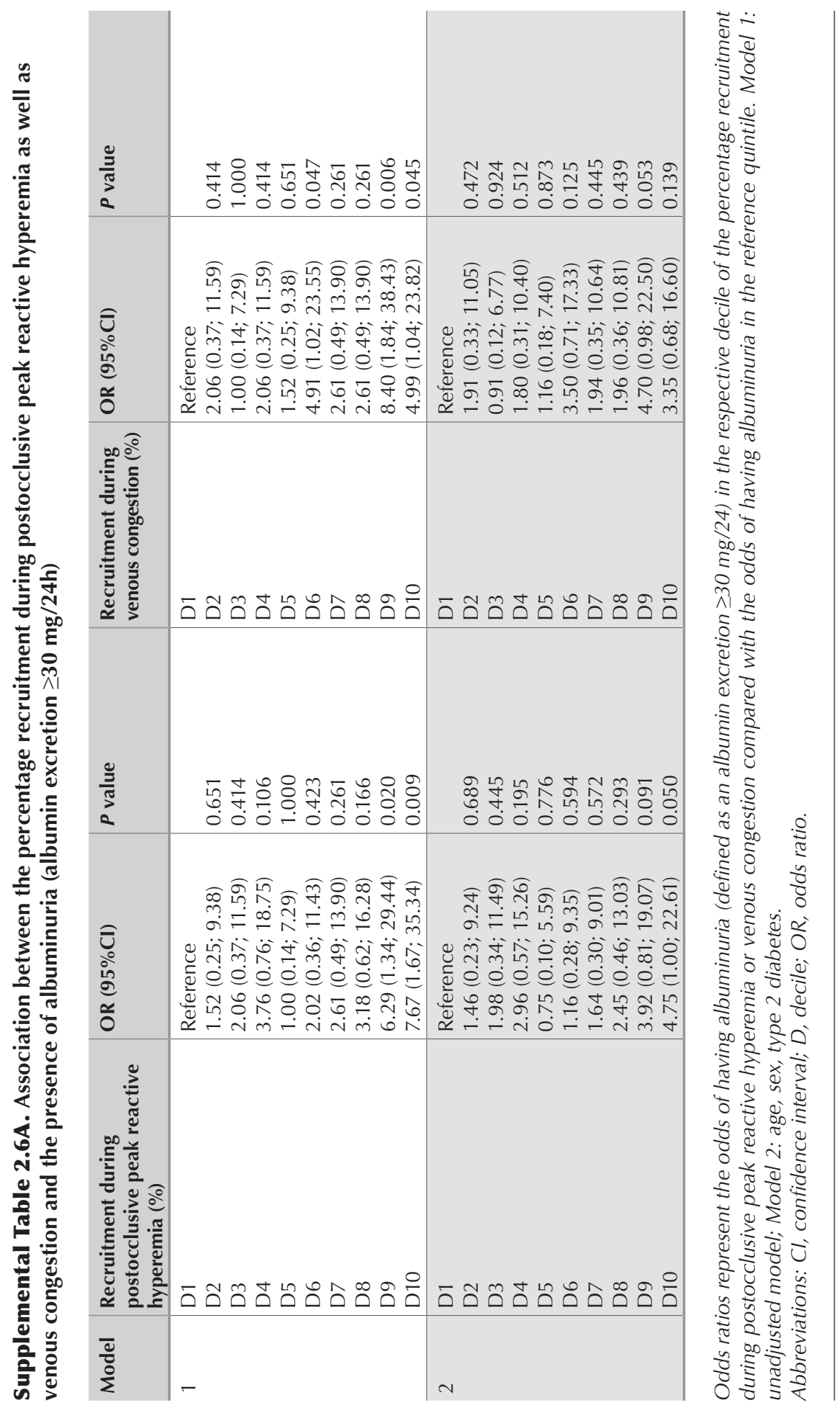




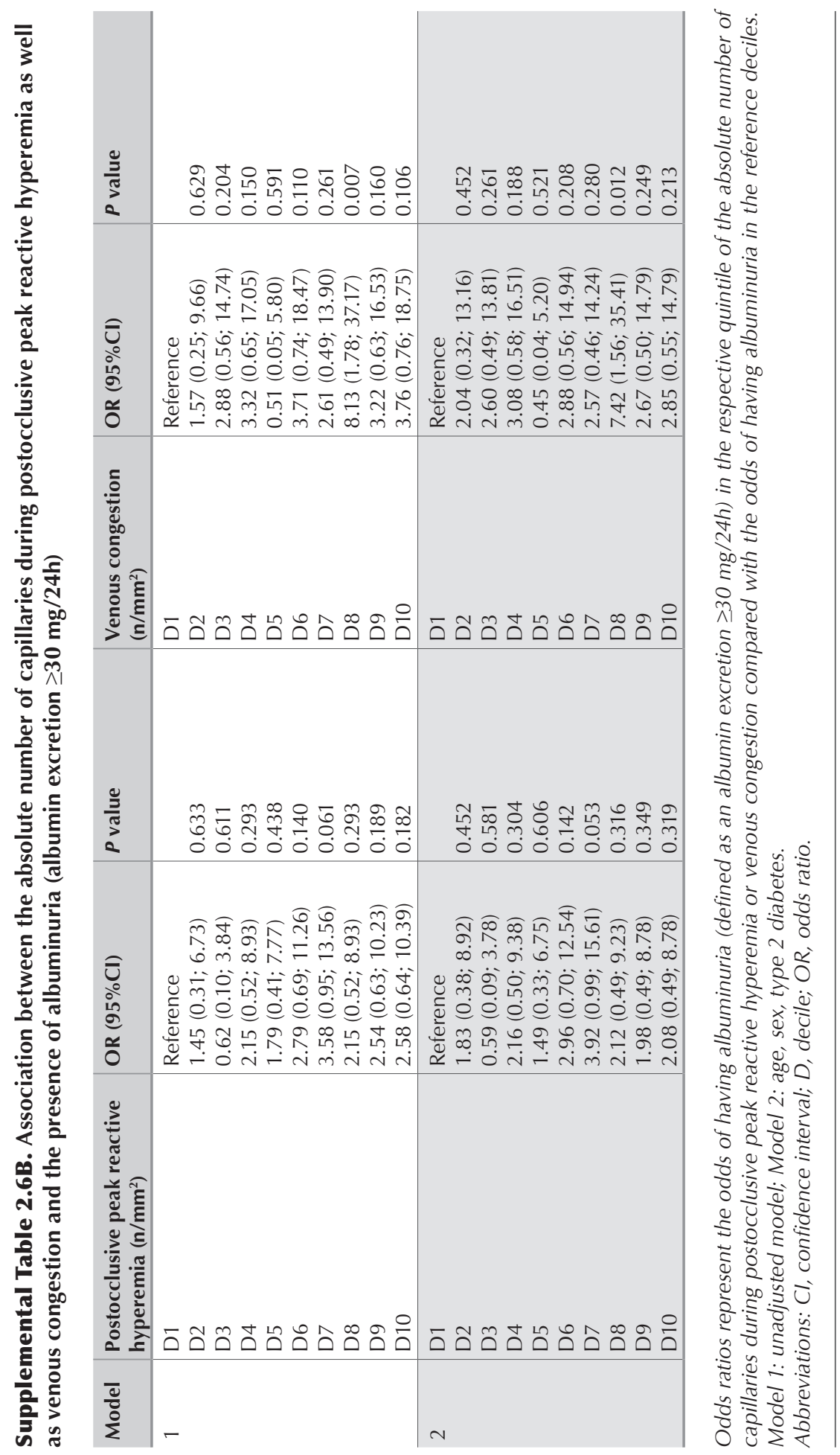




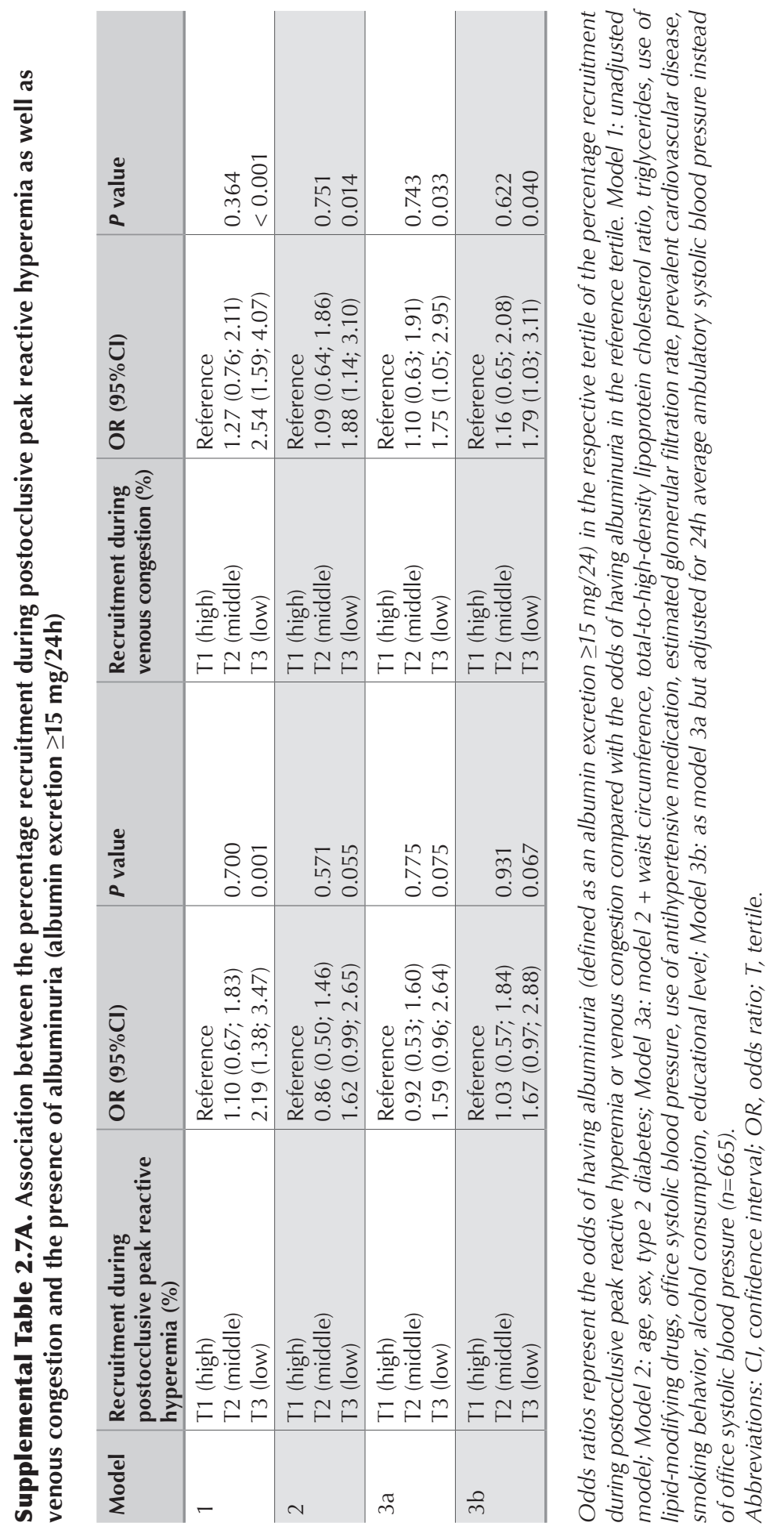




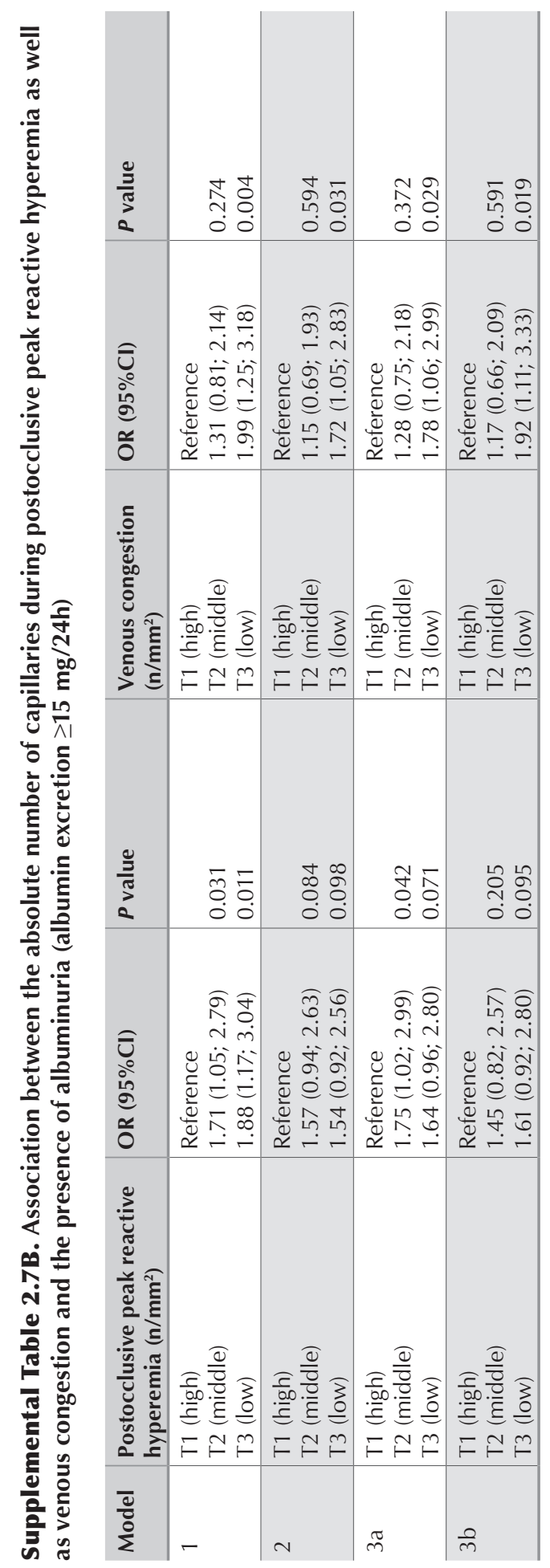

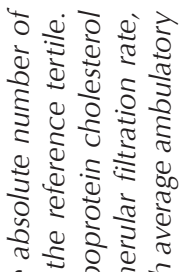
亲.

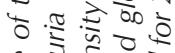

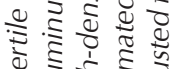
ब2

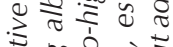
苟. 范 ๘

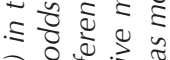

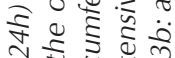
है

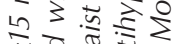

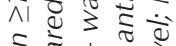

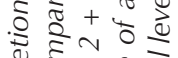
ปั

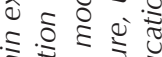

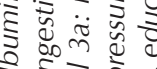
สิ สิ นิ क व $<$ 응 है

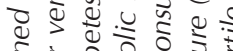
โร

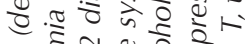

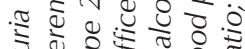

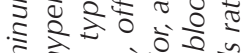
한

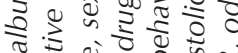
000 范

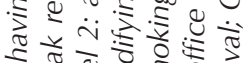

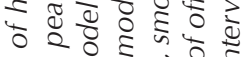

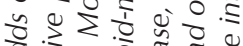

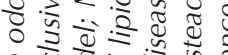
可

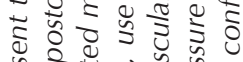

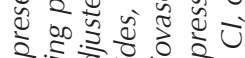

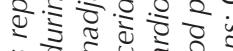
م.

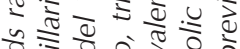

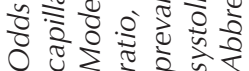




\section{Chapter 3}

Remy J.H. Martens

Alfons J.H.M. Houben

Jeroen P. Kooman

Tos T.J.M. Berendschot

Pieter C. Dagnelie

Carla J.H. van der Kallen

Abraham A. Kroon

Karel M.L. Leunissen

Frank M. van der Sande

Nicolaas C. Schaper

Jan S.A.G. Schouten

Miranda T. Schram

Simone J.S. Sep

Ben M. Sörensen

Ronald M.A. Henry

Coen D.A. Stehouwer

Submitted for publication 
Microvascular endothelial dysfunction is associated with albuminuria:

The Maastricht Study 


\begin{abstract}
Albuminuria is thought to be a biomarker of micro- and macrovascular endothelial dysfunction. However, direct evidence for an association of microvascular endothelial dysfunction with albuminuria is limited. In addition, experimental data suggest a stronger association of microvascular endothelial dysfunction with albuminuria in individuals with than in those without diabetes. Therefore, we examined associations of flicker light-induced retinal arteriolar dilation and heat-induced skin hyperemia with albuminuria in 2095 and 1508 participants, respectively, of the population-based, diabetes-enriched Maastricht Study. Median [interquartile range] albuminuria was $6.5[3.9-11.6] \mathrm{mg} / 24 \mathrm{~h}$ and $8.2 \%$ had albuminuria $\geq 30$ $\mathrm{mg} / 24 \mathrm{~h}$. After adjustment, albuminuria was 1.168 (95\% confidence interval, 1.046 to 1.303) times greater in participants in the quartile with the smallest flicker lightinduced retinal arteriolar dilation relative to those with the greatest dilation, and this association was stronger in participants with type 2 diabetes $\left(P_{\text {interaction }}<0.10\right)$. Further, each 100 percentage points lower heat-induced skin hyperemia was associated with a 1.022 (1.010 to 1.035) times greater albuminuria in participants with type 2 diabetes, whereas it was not associated with albuminuria in non-diabetic participants $\left(P_{\text {interaction }}<0.10\right)$. In conclusion, lower flicker light-induced retinal arteriolar dilation was independently associated with albuminuria and this association was stronger in individuals with type 2 diabetes. Further, lower heat-induced skin hyperemia was independently associated with albuminuria in individuals with type 2 diabetes. Thus, this is the first population-based study that provides direct evidence that microvascular endothelial dysfunction is associated with albuminuria, and that this association is stronger in individuals with than in those without type 2 diabetes.
\end{abstract}




\section{INTRODUCTION}

Albuminuria is a marker of risk of not only renal failure and cardiovascular disease (CVD), ${ }_{1}$ but also of retinopathy, ${ }^{2-4}$ heart failure, ${ }^{5,6}$ impaired cognitive performance, ${ }^{7-9}$ and depression. ${ }^{10}$ A leading hypothesis to explain these associations is that albuminuria is a biomarker of generalized (i.e., micro- and macrovascular) endothelial dysfunction. ${ }^{2,3,11-14}$

This concept posits that endothelial dysfunction of renal arterioles and capillaries (i.e., the renal microcirculation) increases intraglomerular pressure and glomerular capillary wall permeability, and thereby causes albuminuria. ${ }^{12,15}$ Concomitantly, endothelial dysfunction of the extrarenal microcirculation contributes to retinopathy, ${ }^{2,3}$ cognitive decline, ${ }^{16}$ depression, ${ }^{17}$ and heart failure with preserved ejection fraction, ${ }^{14}$ whilst endothelial dysfunction in coronary and carotid arteries (i.e., the macrocirculation) leads to atherothrombotic CVD. ${ }^{18}$

Indeed, there is strong evidence for the presence of endothelial dysfunction in the macrocirculation of individuals with albuminuria. ${ }^{19-25}$ In addition, we have shown that capillary rarefaction of the skin microcirculation was associated with albuminuria. ${ }^{26}$

In contrast, evidence for endothelial dysfunction in the microcirculation of individuals with albuminuria is primarily indirect, as it derives mainly from studies using plasma biomarkers ${ }^{27-32}$ and the transcapillary escape rate of albumin, ${ }^{33-36}$ in addition to studies, in individuals with diabetes only, using strain-gauge plethysmography following forearm ischemia, ${ }^{37}$ and laser Doppler flowmetry following either iontophoresis of acetylcholine and sodium nitroprusside, ${ }^{38}$ or arterial occlusion. ${ }^{39}$

Importantly, experimental data suggest that the association of microvascular endothelial dysfunction with albuminuria may be stronger in individuals with diabetes than in non-diabetic individuals, because hyperglycemia may lead to dysregulation of the vascular endothelial growth factor (VEGF)-nitric oxide (NO) axis, which may exacerbate vascular injury. ${ }^{40}$ Alternatively or additionally, (hyperglycemia-induced) glomerular hyperfiltration ${ }^{41-44}$ may increase permeation of albumin through an injured glomerular capillary wall.

In view of the above, we examined, in a population-based cohort study of individuals without and with type 2 diabetes (T2DM), whether direct measures of microvascular endothelial dysfunction are associated with albuminuria. For this purpose, we assessed flicker light-induced retinal arteriolar dilation and heat-induced skin hyperemia. These responses are thought to involve the endothelial release of $\mathrm{NO}$ as well as other vasodilators, ${ }^{45,46}$ and can be assessed noninvasively ${ }^{45,46}$ and reproducibly ${ }^{47,48}$ with the Dynamic Vessel Analyzer $(\mathrm{DVA})^{45}$ and laser Doppler flowmetry, ${ }^{46}$ respectively. In addition, we examined whether any association of microvascular endothelial dysfunction with albuminuria is stronger in individuals with T2DM than in those without.

\section{METHODS}

\section{The Maastricht Study population and design}

We used data from The Maastricht Study, an observational prospective population-based cohort study. The rationale and methodology have been described previously. ${ }^{49}$ In brief, the study focuses on the etiology, pathophysiology, complications and comorbidities of T2DM and is characterized by an extensive phenotyping approach. Eligible for participation were all individuals aged between 40 and 75 years and living in the southern part of the Netherlands. Participants were recruited through mass media campaigns and from the municipal registries and the regional Diabetes Patient Registry via mailings. Recruitment was stratified according 
to known T2DM status, with an oversampling of individuals with T2DM, for reasons of efficiency. The present report includes cross-sectional data from the first 3451 participants, who completed the baseline survey between November 2010 and September 2013. The examinations of each participant were performed within a time window of three months. The study has been approved by the institutional medical ethical committee (NL31329.068.10) and the Minister of Health, Welfare and Sports of the Netherlands (Permit 131088-105234-PG), and was conducted in accordance with the Declaration of Helsinki. All participants gave written informed consent.

\section{Assessment of microvascular endothelial function}

All participants were requested to refrain from smoking and drinking caffeine-containing beverages three hours before the measurements. A light meal (breakfast and/or lunch) low in fat content was allowed at last 90 minutes before the start of the measurements. ${ }^{50}$

\section{Flicker light-induced retinal arteriolar dilation}

The retinal arteriolar response to flicker light was assessed with the DVA (Imedos, Jena, Germany) as described previously. ${ }^{50}$ Briefly, pupils were dilated with $0.5 \%$ tropicamide and $2.5 \%$ phenylephrine at least 15 minutes prior to the start of the examination. For safety reasons, participants with an intraocular pressure $>30 \mathrm{mmHg}$ were excluded from the measurements. Per participant, either the left or right eye was selected depending on the time of day the measurement was performed and without reference to participant characteristics. A straight arteriolar segment of approximately $1.5 \mathrm{~mm}$ in length located 0.5 to 2.0 disc diameter from the margin of the optic disc in the temporal section was examined. Vessel diameter was automatically and continuously measured for 150 seconds. A baseline recording of 50 seconds was followed by a 40 -second flicker light exposure period (flicker frequency $12.5 \mathrm{~Hz}$, bright-todark contrast ratio 25:1), followed by a 60-second recovery period. Baseline retinal arteriolar diameter and flicker light-induced retinal arteriolar dilation were automatically calculated with the integrated DVA software (version 4.51; Imedos, Jena, Germany). Baseline retinal arteriolar diameter was calculated as the average diameter of the 20-50 seconds recording and was expressed in measurement units $(\mathrm{MU})$, where $1 \mathrm{MU}$ is equal to $1 \mu \mathrm{m}$ of the Gullstrand eye. ${ }^{51}$ Flicker light-induced retinal arteriolar dilation was expressed as the percentage retinal arteriolar dilation over baseline and based on the average dilation achieved at time-points 10 and 40 seconds during the flicker stimulation period.

\section{Heat-induced skin hyperemia}

Heat-induced skin hyperemia was assessed with a laser Doppler system (Periflux 5000; Perimed, Stockholm, Sweden), equipped with a thermostatic laser Doppler probe (PF457; Perimed, Stockholm, Sweden) at the dorsal side of the wrist of the left hand, as described previously. ${ }^{50}$ Briefly, skin blood flow measurements were performed in a climate-controlled room at $24^{\circ} \mathrm{C}$. The laser Doppler output was recorded for 25 minutes with a sample rate of $32 \mathrm{~Hz}$, which gives a semi-quantitative assessment of skin blood flow expressed in arbitrary perfusion units (PU). Skin blood flow was first recorded unheated for 2 minutes to serve as a baseline. Thereafter, the temperature of the probe was rapidly and locally increased to $44^{\circ} \mathrm{C}$, and then kept constant until the end of the registration. In 596 individuals, heat-induced skin hyperemia measurements were recorded between 20-25 minutes. These data were extrapolated to 25 minutes by adding the product of the average PU during the last completely recorded 1 minute interval and a correction factor of 1.017 , to the average $\mathrm{PU}$ 
during the recorded time, and taking the recording time into account. The correction factor of 1.017 was the ratio of the average PU in the 20-25 minutes interval (based on all available data) relative to the 19-20 minutes interval. The heat-induced skin hyperemic response was expressed as the percentage increase in average PU during the 23 minutes heating phase over the average baseline PU.

\section{Albuminuria}

To assess urinary albumin excretion (UAE), participants were requested to collect two $24 \mathrm{~h}$ urine collections (Supplemental Methods). ${ }^{26} \mathrm{UAE}$ was expressed both as a continuous and as a categorical variable ( $<15 \mathrm{mg} / 24 \mathrm{~h}, 15-<30 \mathrm{mg} / 24 \mathrm{~h}$, and $\geq 30 \mathrm{mg} / 24 \mathrm{~h})$, in agreement with the fact that an association with (cardiovascular) disease already exists below the clinical cut-off value of $30 \mathrm{mg} / 24 \mathrm{~h}$. $^{1}$ These definitions were preferably based on the average of two (available in $91.5 \%$ of the participants) $24 \mathrm{~h}$ urine collections.

\section{Potential confounders}

We assessed fasting glucose, hemoglobin A1c (HbA1c; glycated hemoglobin), glucose metabolism status, total cholesterol, high-density lipoprotein (HDL) cholesterol, low-density lipoprotein (LDL) cholesterol, triglycerides, body mass index, waist circumference, office blood pressure, $24 \mathrm{~h}$ average ambulatory blood pressure, medication use, smoking behavior, alcohol consumption, educational level, prevalent CVD, and (subjective) physical activity, as described previously. ${ }^{49,52}$ The glomerular filtration rate (GFR) was estimated with the Chronic Kidney Disease Epidemiology Collaboration (CKD-EPI) equation based on both serum creatinine and serum cystatin $\mathrm{C}(\mathrm{eGFR}$ crcys $) .{ }^{53}$ Further details on the definitions of the above potential confounders are provided in the Supplemental Methods. In addition, we assessed the retinopathy status as described in the Supplemental Methods.

\section{Statistical analyses}

All analyses were performed with IBM SPSS Statistics Version 22.0 (IBM Corp., Armonk, NY, USA). Characteristics of the entire study population and according to albuminuria categories were summarized as means with standard deviations (SD), medians with interquartile ranges, and numbers with percentages, as appropriate. Baseline retinal arteriolar diameter and flicker light-induced retinal arteriolar dilation were categorized into quartiles as the associations of flicker light-induced retinal arteriolar dilation with albuminuria seemed to be non-linear. The quartile with the largest baseline retinal arteriolar diameter and the quartile with the greatest flicker light-induced retinal arteriolar dilation served as reference categories. Baseline skin perfusion and heat-induced skin hyperemia were analyzed as continuous variables and expressed per $1 \mathrm{PU}$ lower baseline skin perfusion and per 100 percentage points lower heatinduced skin hyperemia, respectively.

Associations of baseline retinal arteriolar diameter, flicker light-induced retinal arteriolar dilation, baseline skin perfusion and heat-induced skin hyperemia with UAE, expressed as a continuous variable, were examined with multivariable linear regression analyses. UAE was highly positively skewed and had to be transformed by taking the inverse square root to fulfill the normality assumption of linear regression. However, as the results obtained with natural logarithm transformed UAE were qualitatively similar and are more easily interpretable, these results are presented. The regression coefficients were exponentiated to obtain the ratio of UAE per one unit increase in the independent variable. In addition, we performed multinomial logistic regression analyses to examine the associations with UAE as a categorical 
dependent variable ( $<15 \mathrm{mg} / 24 \mathrm{~h}$ served as the reference category). All analyses were adjusted for potential confounders as follows: model 1) unadjusted model; model 2) age, sex, glucose metabolism status; model 3a) model 2 + waist circumference, total-to-HDL cholesterol ratio, triglycerides, use of lipid-modifying medication, office systolic blood pressure, use of antihypertensive medication (including renin-angiotensin system inhibitors), eGFR $_{\text {crcys' }}$ prevalent CVD, smoking behavior, alcohol consumption, educational level; model 3b) as model 3a but adjusted for $24 \mathrm{~h}$ average ambulatory systolic blood pressure instead of office systolic blood pressure.

In addition, we tested for statistical interaction with T2DM (a $P$ value of the interaction term $\left(P_{\text {interaction }}\right)<0.10$ was considered statistically significant). In these analyses, participants with normal glucose metabolism and prediabetes (Supplemental Methods) were combined into one category, because of the small number of participants with prediabetes and the even smaller number of participants in the respective albuminuria categories in this group.

We performed several additional analyses, each starting from model 3a. First, we tested for statistical interaction with HbA1c and eGFR to explore whether hyperglycemia and glomerular hyperfiltration, ${ }^{41-44}$ respectively, modified our results. Second, to assess the robustness of our results, we replaced office systolic blood pressure with office diastolic blood pressure, office pulse pressure, office mean arterial pressure, their $24 \mathrm{~h}$ average ambulatory equivalents or the presence of hypertension; the use of antihypertensive medication with the use of a renin-angiotensin system inhibitor, the use of a diuretic or their combined use; waist circumference with body mass index; the total-to-HDL cholesterol ratio with LDL and HDL cholesterol levels; and we additionally adjusted for total or moderate to vigorous physical activity, and the presence of retinopathy. Third, we repeated the analyses in the subpopulation with two $24 \mathrm{~h}$ urine collections and in the subpopulation with a measured $24 \mathrm{~h}$ creatinine excretion within $30 \%$ of expected values, ${ }^{54}$ to explore whether biological variation and inaccurate collection, respectively, had led to non-differential misclassification with bias towards the null, and in the subpopulation with a UAE $\leq 300 \mathrm{mg} / 24 \mathrm{~h}$. Fourth, we repeated the analyses with flicker light-induced retinal arteriolar dilation and heat-induced skin hyperemia expressed as the absolute difference in retinal arteriolar diameter and skin perfusion, respectively, from baseline. Fifth, we repeated the analyses with quintiles and deciles of baseline retinal arteriolar diameter and flicker light-induced retinal arteriolar dilation.

\section{RESULTS}

\section{Characteristics of the study population}

Figure 3.1 is a flow diagram delineating the derivation of the final study populations. In total, 2095 participants were included in the analyses on flicker light-induced retinal arteriolar dilation (retina study population) and 1508 in the analyses on heat-induced skin hyperemia (skin study population). None of the participants was on dialysis. The characteristics shown in Table 3.1 of included versus excluded participants due to missing data were largely comparable (data not shown). 


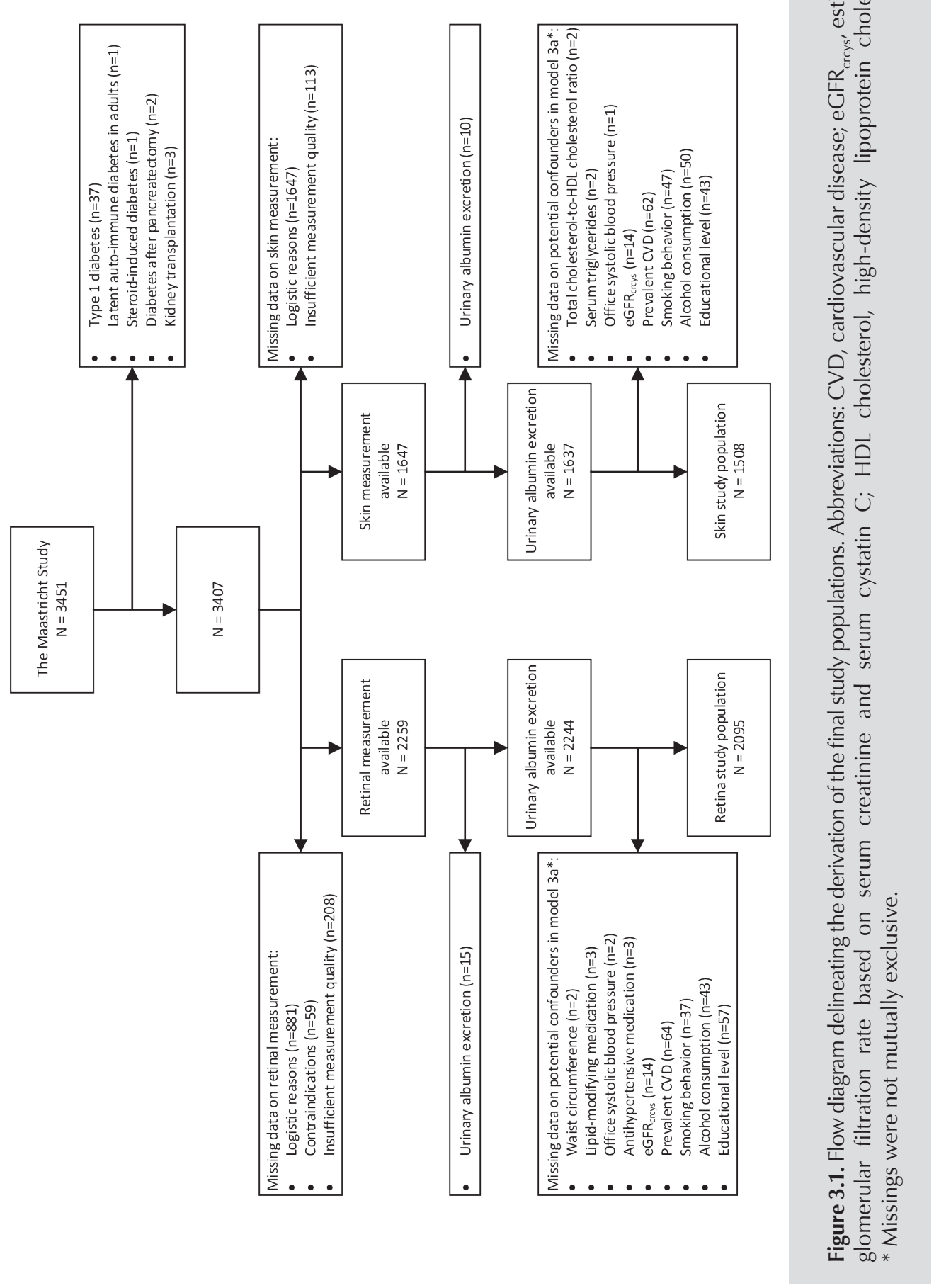


Table 3.1 and Supplemental Table 3.1 present the characteristics of the retina and skin study populations, respectively, according to albuminuria categories. The characteristics of both study populations were similar. In general, participants with higher UAE were older and more often men; more often had T2DM, hypertension and retinopathy; had lower eGFR crcys $_{\text {s }}$ and a worse CVD risk profile; and more often used antihypertensive and lipid-modifying medication.

\section{Flicker light-induced retinal arteriolar dilation and albuminuria}

Flicker light-induced retinal arteriolar dilation was categorized into quartiles as its association with albuminuria seemed to be non-linear. Quartile (Q) 1 consisted of the participants with the greatest flicker light-induced retinal arteriolar dilation and served as the reference category. In the entire retina study population and with UAE expressed as a continuous variable, UAE was higher in Q2 (albeit not statistically significantly), was statistically significantly higher in Q3 and then showed no further increase in Q4, after adjustment for potential confounders (Table 3.2, model 3a). For example, UAE was (Ratio (95\% confidence interval $(95 \% \mathrm{CI})$ )) 1.099 (0.987 to 1.224) times higher in Q2, 1.189 (1.067 to 1.326) times higher in Q3, and 1.168 (1.046 to 1.303) times higher in Q4. Results were similar when we replaced office systolic blood pressure with $24 \mathrm{~h}$ average ambulatory systolic blood pressure $(\mathrm{n}=1856$; Table 3.2, model 3b) and when UAE was expressed as a categorical variable (Table 3.3).

Analyses with interaction terms suggested that the association of flicker light-induced retinal arteriolar dilation with albuminuria was stronger in participants with T2DM than without T2DM $\left(P_{\text {interaction }}<0.10\right.$ for the associations of Q3 and Q4 with UAE expressed as a continuous variable, and for the association of Q3 with UAE $\geq 30 \mathrm{mg} / 24 \mathrm{~h}$; Tables 3.2 and 3.3, model 3a; also illustrated in Figure 3.2, panel A). However, the stratified analyses were hampered by a loss of statistical power.

Baseline retinal arteriolar diameter was not associated with continuous or categorical UAE (Supplemental Tables 3.2 and 3.3, models 1-3), regardless of T2DM $\left(P_{\text {interaction }}>0.10\right)$.

\section{Heat-induced skin hyperemia and albuminuria}

In the entire skin study population, heat-induced skin hyperemia was not associated with UAE, expressed as either a continuous or a categorical variable, after adjustment for potential confounders (Tables 3.4 and 3.5, model 3a). However, analyses with interaction terms suggested statistical interaction with T2DM $\left(P_{\text {interaction }}<0.10\right)$, to such an extent that lower heat-induced skin hyperemia was associated with higher UAE, expressed as a continuous variable, in participants with T2DM but not in those without T2DM (Table 3.4, models 1-3; also illustrated in Figure 3.2, panel B). For example, after adjustment for potential confounders and in participants with T2DM, each 100 percentage points lower heat-induced skin hyperemia was associated with a (Ratio $(95 \% \mathrm{Cl})) 1.022$ (1.010 to 1.035) times higher UAE (Table 3.4, model 3a). Results were similar when we replaced office systolic blood pressure with $24 \mathrm{~h}$ average ambulatory systolic blood pressure $(n=1324$; Table 3.4, model $3 \mathrm{~b})$ and when UAE was expressed as a categorical variable (Table 3.5).

In the entire skin study population, baseline skin perfusion was associated with UAE expressed as a categorical variable, but not with UAE expressed as a continuous variable (Supplemental Tables 3.4 and 3.5, models 1-3). Analyses with interaction terms suggested that the association with UAE expressed as a continuous variable was stronger in participants with T2DM $\left(P_{\text {interaction }}=0.10\right)$, although this was not clear for UAE expressed as a categorical variable (Supplemental Tables 3.4 and 3.5). 


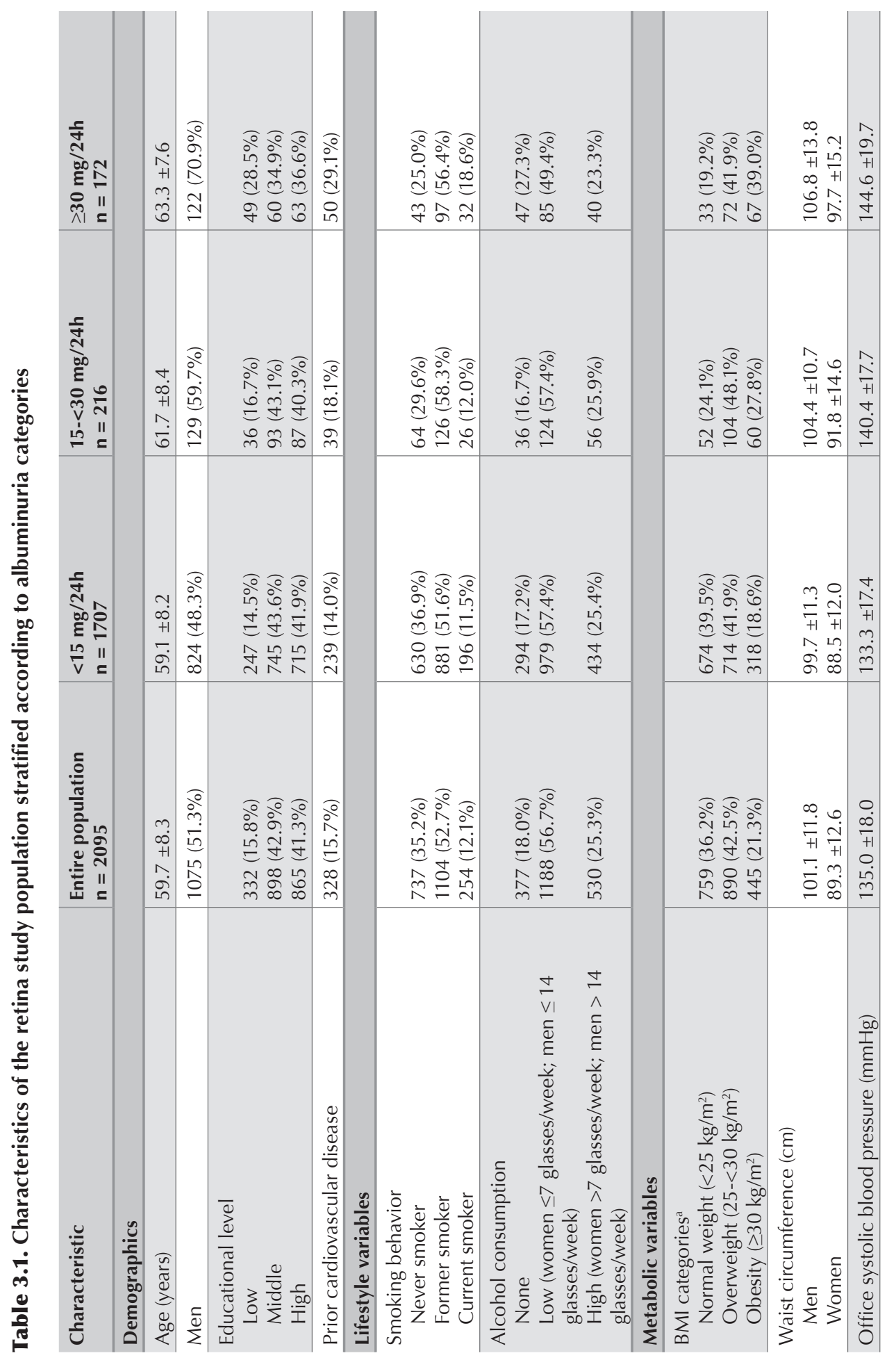




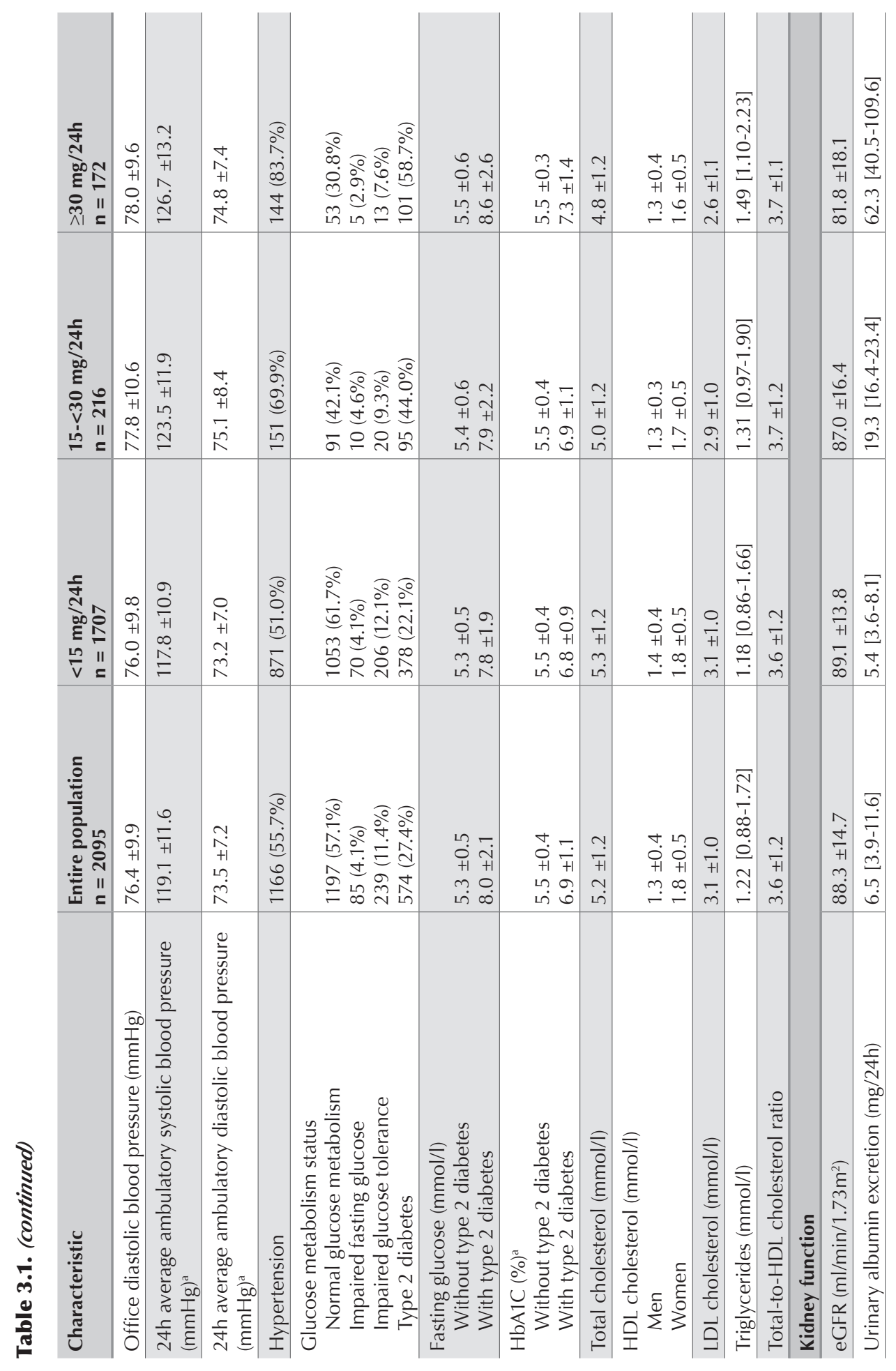




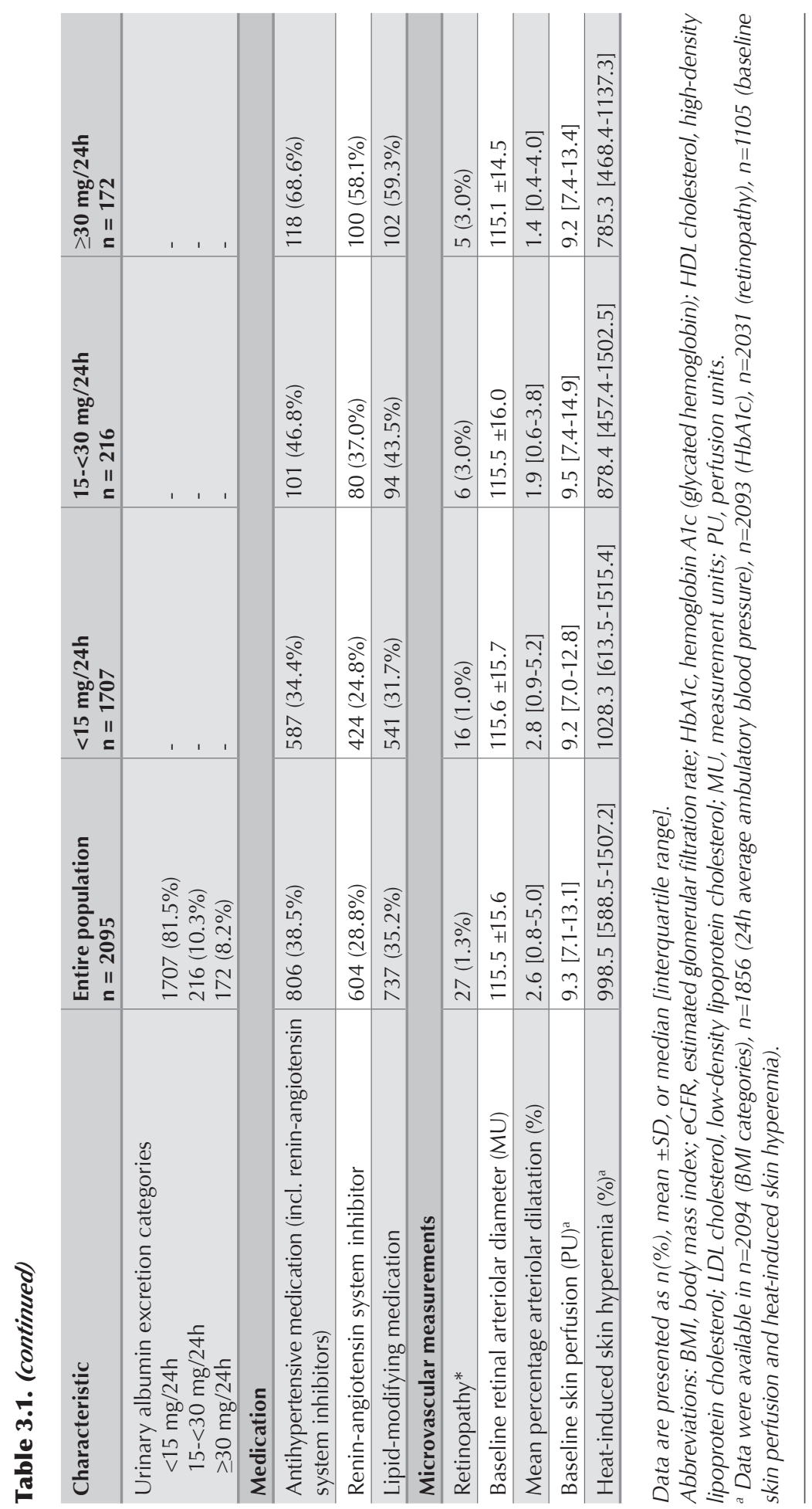




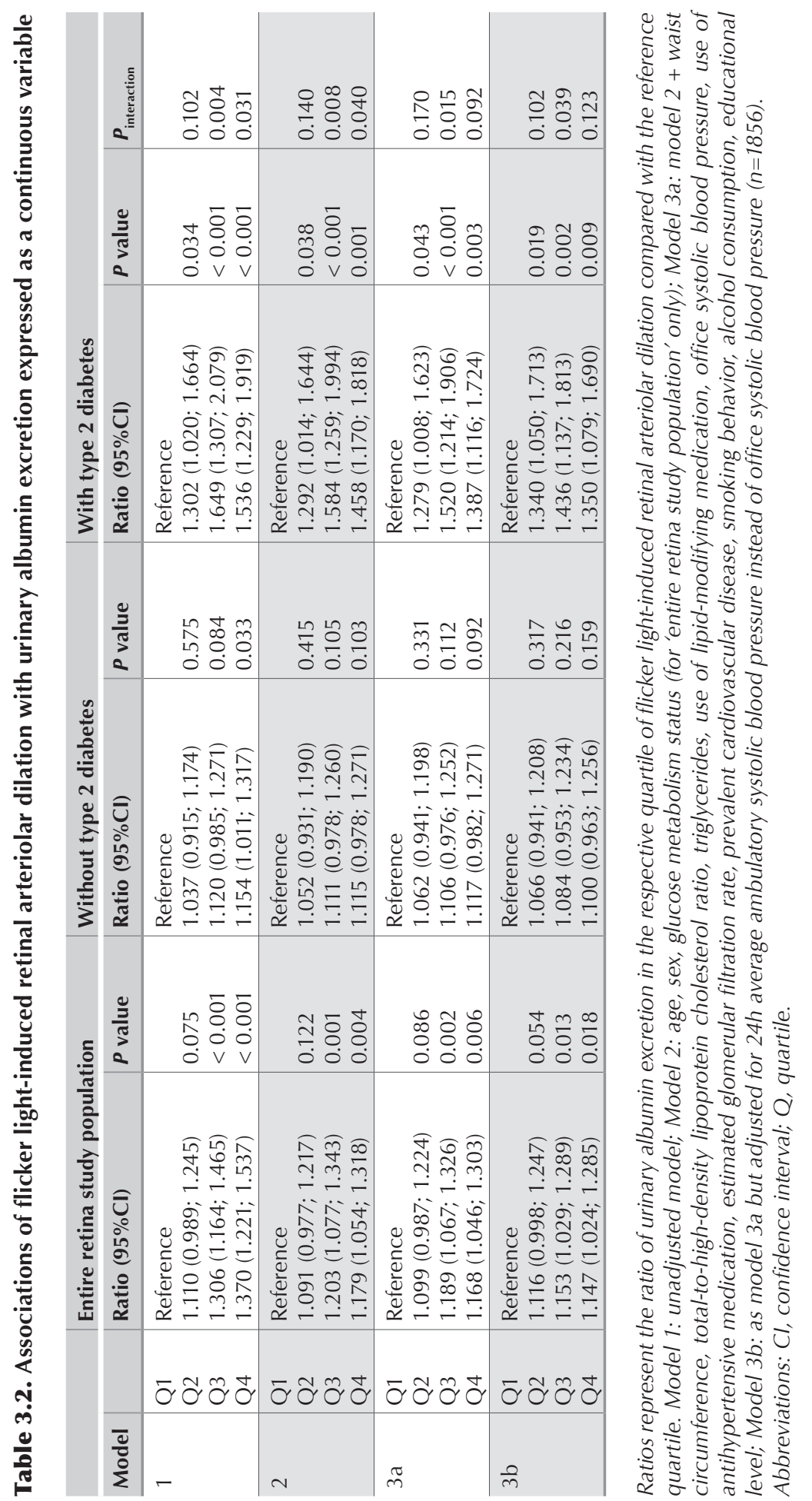




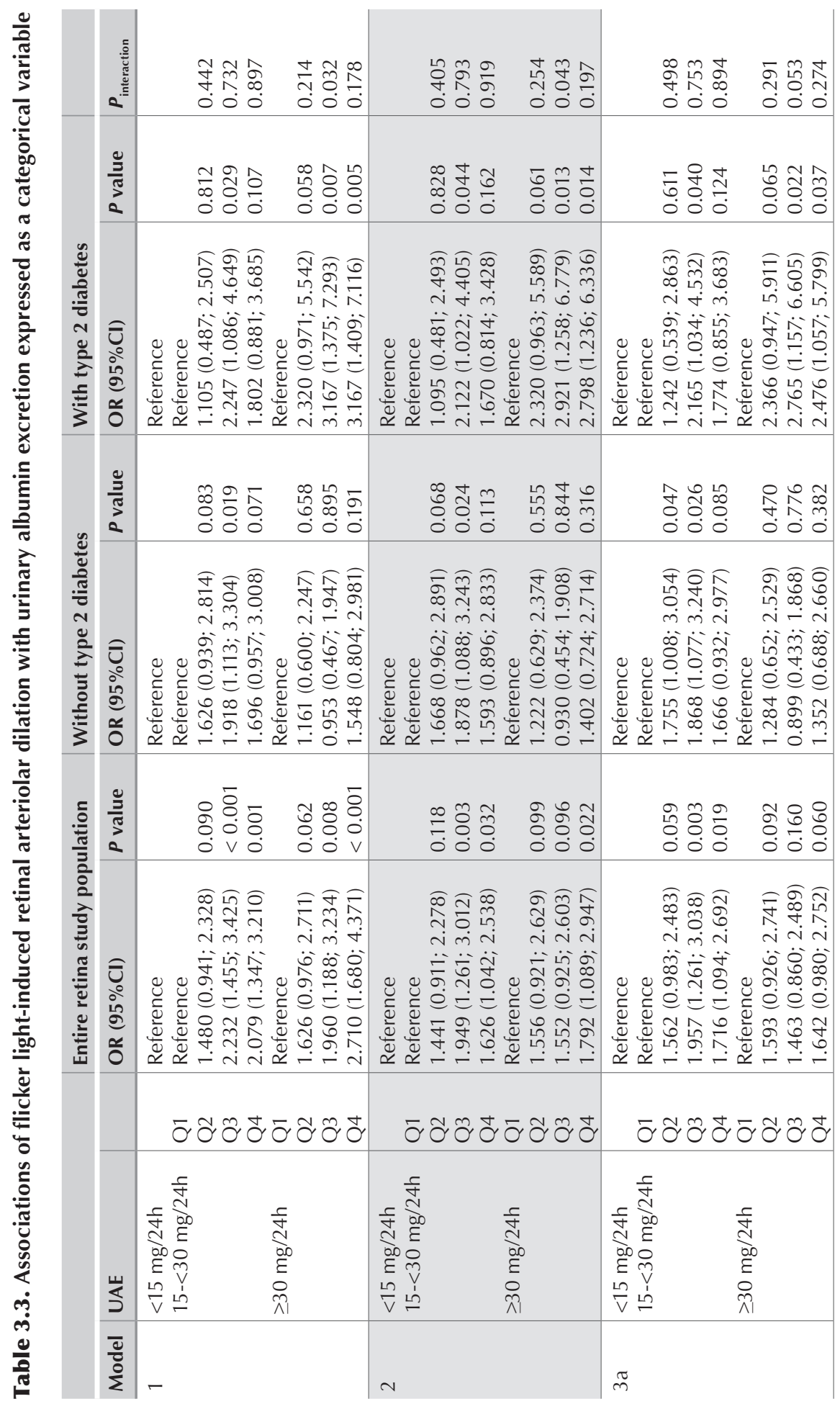




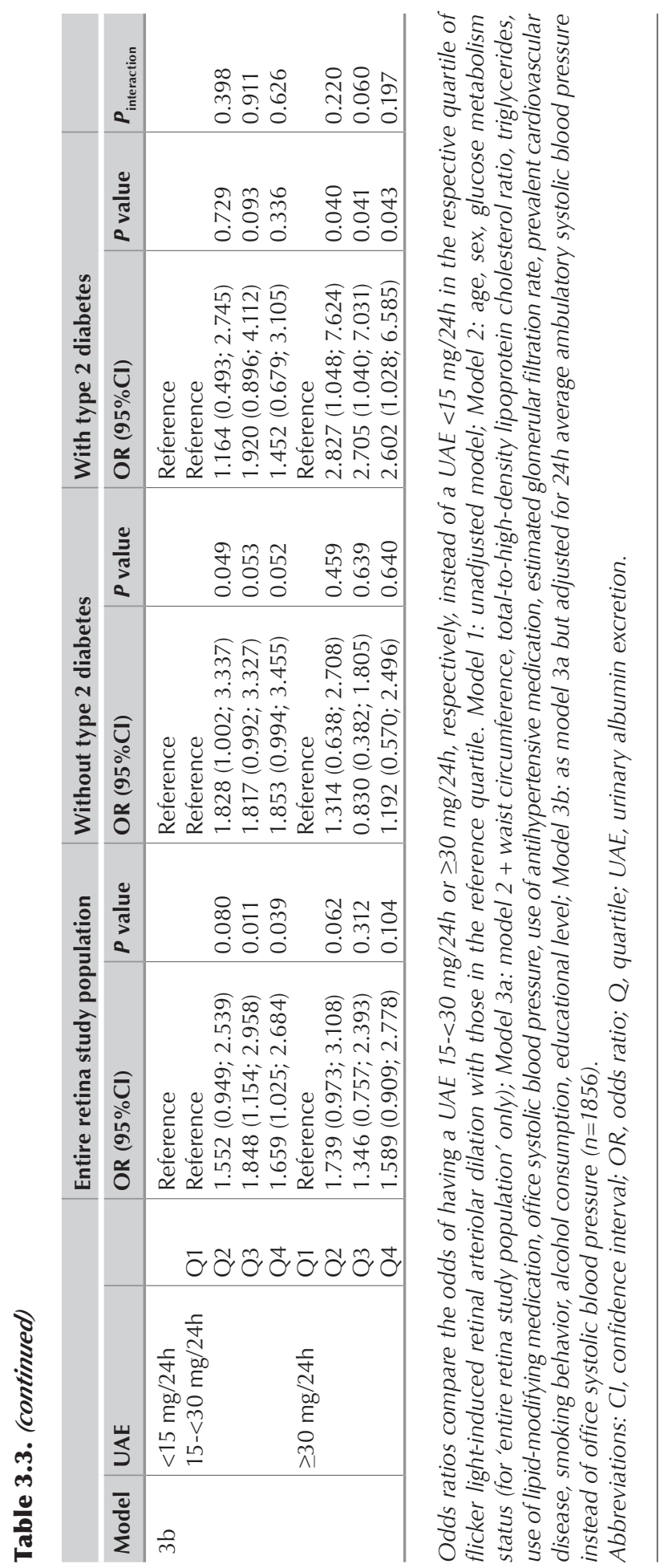




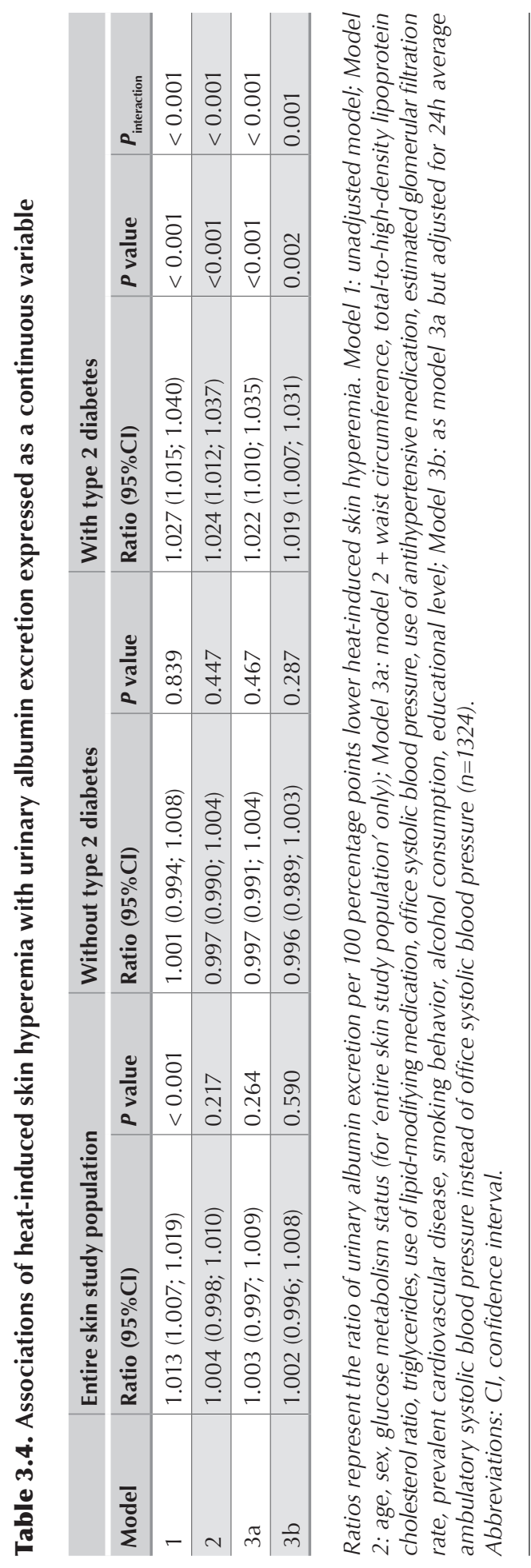




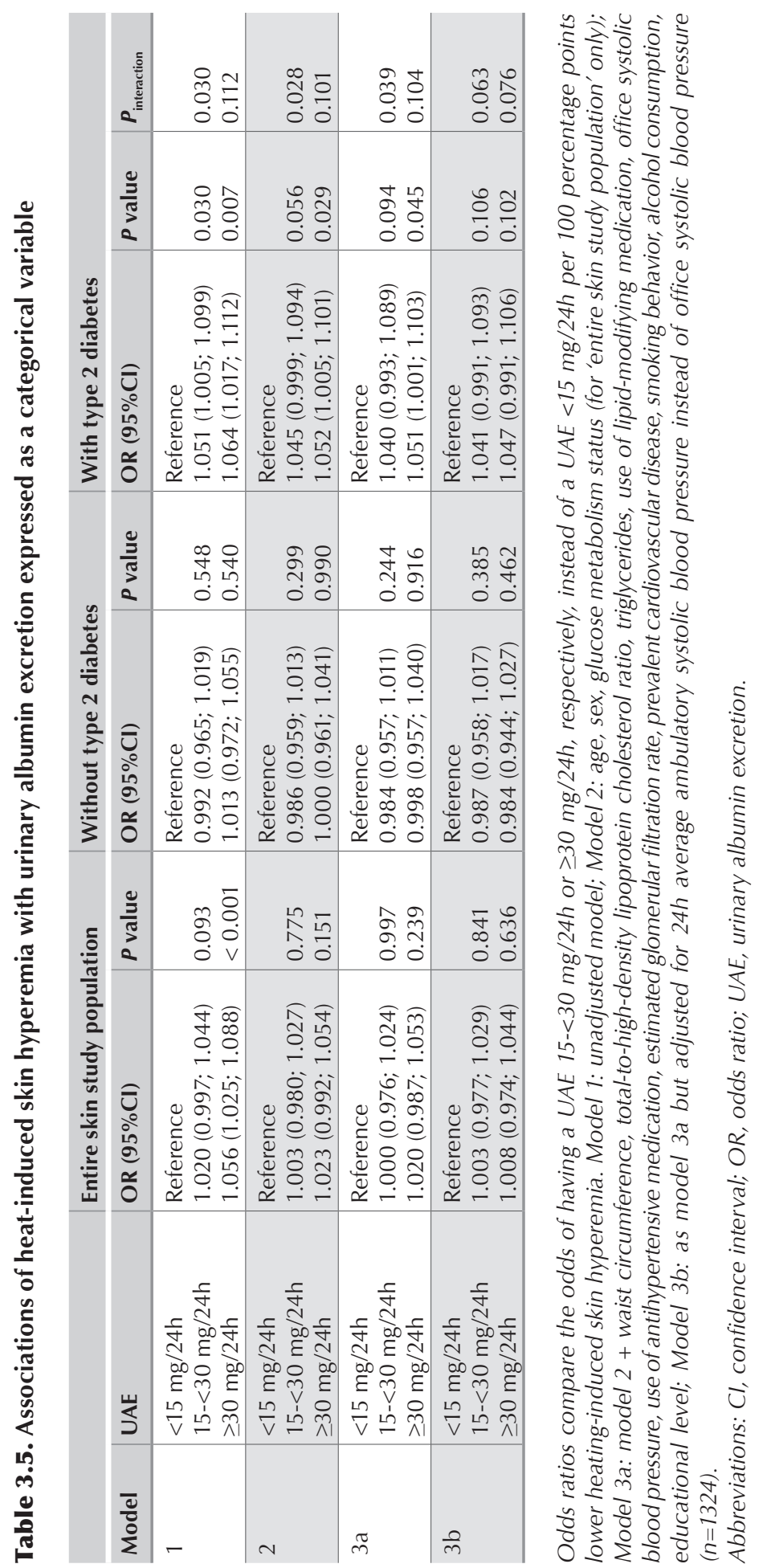


A

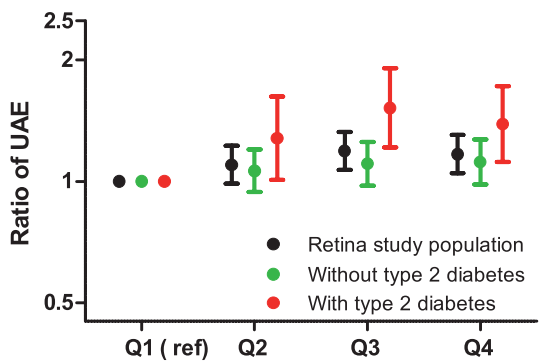

Flicker light-induced retinal arteriolar dilation (\%)
B

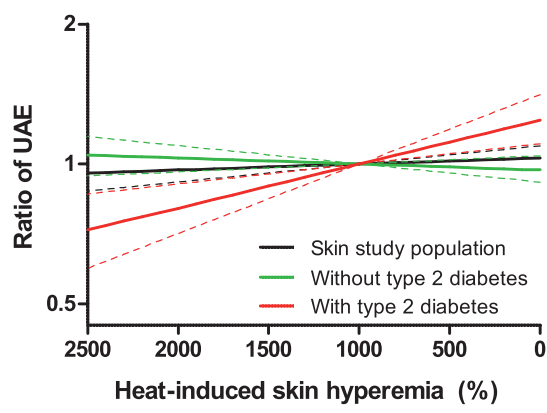

D

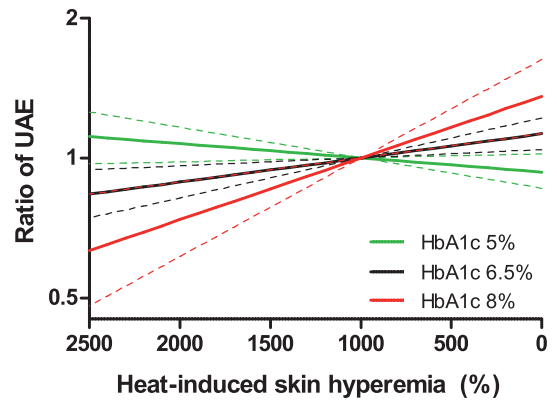

Figure 3.2. Flicker light-induced retinal arteriolar dilation and heat-induced skin hyperemia are associated with albuminuria. Panels A and B present the associations of flicker light-induced retinal arteriolar dilation and heat-induced skin hyperemia, respectively, with albuminuria, and the interaction with type 2 diabetes. Panels $C$ and $D$ present the interaction of flicker light-induced retinal arteriolar dilation and heat-induced skin hyperemia, respectively, with $\mathrm{HbA1c}$. Ratios indicate the ratio of geometric mean urinary albumin excretion relative to participants in the quartile with the greatest flicker light-induced retinal arteriolar dilation and per 100 percentage points lower heat-induced skin hyperemia, respectively. For heat-induced skin hyperemia, the median heat-induced skin hyperemia (998.0\%) served as the reference. All results are adjusted for the variables of model $3 a$ (see text). Bars and dashed lines indicate 95\% confidence intervals. Abbreviations: ref, reference; HbA1c, hemoglobin A1c (glycated hemoglobin); Q, quartile; UAE, urinary albumin excretion.

\section{Additional analyses}

First, we explored whether hyperglycemia and glomerular hyperfiltration ${ }^{41-44}$ could explain why the associations of flicker light-induced retinal arteriolar dilation and heat-induced skin hyperemia with albuminuria were more evident in participants with T2DM. Therefore, we additionally tested for statistical interaction between both measures of microvascular endothelial dysfunction and $\mathrm{HbA1c}$ as well as eGFR in model 3a. These analyses indicated that flicker light-induced retinal arteriolar dilation and heat-induced skin hyperemia were more strongly 
associated with albuminuria at higher $\mathrm{HbA1c}$ levels $\left(P_{\text {interaction }}<0.10\right.$; illustrated in Figure 3.2, panels C and D), but not at higher eGFR (data not shown). Thus, for Q2, Q3 and Q4 of flicker light-induced retinal arteriolar dilation, the ratio of UAE relative to Q1 was $1.106(p=0.186)$, $1.162(p=0.035)$ and $1.147(p=0.052)$ times higher, respectively, per one percentage point higher HbA1c. In addition, the ratio of UAE per 100 percentage points lower heat-induced skin hyperemia was 1.013 ( $p=0.002)$ times higher per one percentage point higher HbA1c. Second, for both flicker light-induced retinal arteriolar dilation and heat-induced skin hyperemia results were not materially altered when we replaced office systolic blood pressure with office diastolic blood pressure, office pulse pressure, office mean arterial pressure, their $24 \mathrm{~h}$ average ambulatory equivalents or the presence of hypertension; when we replaced the use of antihypertensive medication with the use of a renin-angiotensin system inhibitor, the use of a diuretic or their combined use; when we replaced waist circumference with body mass index; when we replaced the total-to-HDL cholesterol ratio with LDL and HDL cholesterol levels; and when we additionally adjusted for total ( $n=1867$ and $n=1330$ ) or moderate to vigorous $(n=1866$ and $n=1329)$ physical activity, or the presence of retinopathy $(n=2031$ and $n=1360$; data not shown). Third, for flicker light-induced retinal arteriolar dilation, analyses in the subpopulations with two $24 \mathrm{~h}$ urine collections $(\mathrm{n}=1939)$ and with a measured $24 \mathrm{~h}$ creatinine excretion within $30 \%$ of expected values $(n=1873)$ did not indicate non-differential misclassification due to biological variation and inaccurate collection, respectively (data not shown). In contrast, the association of heat-induced skin hyperemia with albuminuria was slightly stronger in the subpopulations with two 24h urine collections $(n=1389)$ and with a measured $24 \mathrm{~h}$ creatinine excretion within $30 \%$ of expected values $(n=1337)$. This suggests some non-differential misclassification of UAE due to biological variation and inaccurate collection, respectively (data not shown). Results were qualitatively similar when participants with a UAE $>300 \mathrm{mg} / 24 \mathrm{~h}(\mathrm{n}=13$ and $\mathrm{n}=8$ ) were excluded. Fourth, when flicker light-induced retinal arteriolar dilation was expressed as the absolute difference in retinal arteriolar diameter from baseline, the association with UAE expressed as a continuous variable was similar, whereas the association with UAE $\geq 30 \mathrm{mg} / 24 \mathrm{~h}$ was attenuated and no longer statistically significant (odds ratios (95\%Cls) in Q3 and Q4, 1.316 (0.785 to 2.207) and 1.381 (0.837 to 2.279), respectively; model 3a). When heat-induced skin hyperemia was expressed as the absolute change in skin perfusion from baseline, the association with UAE expressed as a continuous variable was similar. In contrast, lower heat-induced skin hyperemia became associated with a lower odds for a UAE $15-<30 \mathrm{mg} / 24 \mathrm{~h}$ in participants without T2DM (odds ratio (95\%Cl) 0.950 (0.917 to 0.984); model 3a), whereas the association with UAE $15-<30 \mathrm{mg} / 24 \mathrm{~h}$ in participants with T2DM was attenuated and no longer statistically significant (odds ratio (95\%Cl) 1.016 (0.961 to 1.074); model 3a). Fifth, analyses with quintiles and deciles of flicker light-induced retinal arteriolar dilation also showed that its association with albuminuria leveled off at lower values. However, these analyses were hampered by a loss of statistical power (data not shown).

\section{DISCUSSION}

This population-based study, in individuals without and with T2DM, on the association of microvascular endothelial dysfunction with albuminuria showed that lower flicker light-induced retinal arteriolar dilation was associated with albuminuria and that this association was stronger in individuals with T2DM. In addition, lower heat-induced skin hyperemia was associated with albuminuria in participants with T2DM but not in non-diabetic participants. 
These associations were independent of CVD risk factors, including $24 \mathrm{~h}$ average ambulatory blood pressure. To our knowledge, this is the first population-based study that provides direct support for the concept that microvascular endothelial dysfunction related to albuminuria is extensive, if not generalized, and that this association is stronger in individuals with than in those without T2DM.

These results agree with those of studies in individuals with type 1 or type 2 diabetes, which have shown associations of direct measures of microvascular endothelial dysfunction in skin with albuminuria. ${ }^{37-39}$ The present study expands this knowledge, as it is the first to examine microvascular endothelial dysfunction in two vascular beds in a large, wellcharacterized population-based sample of individuals with and without T2DM, and with extensive adjustment for potential confounders.

The association of microvascular endothelial dysfunction with albuminuria fits the hypothesis that albuminuria is a biomarker of generalized endothelial dysfunction. ${ }^{11,12}$ Endothelial dysfunction of the renal microcirculation may cause albuminuria by increasing glomerular capillary wall permeability and intraglomerular pressure. ${ }^{2}$ The former may involve alterations in the barrier properties of the glomerular endothelium itself ${ }^{12}$ and altered endothelial-podocyte cross-talk leading to podocyte injury. ${ }^{55}$

The molecular mechanisms involved in both flicker light-induced retinal arteriolar dilation and heat-induced skin hyperemia include the endothelial release of NO. ${ }^{45,46}$ Reduced NO availability may reflect microvascular endothelial dysfunction in general, but may also play a direct role. Indeed, NO has been shown to preserve glomerular capillary wall permeability, ${ }^{56,57}$ and endothelial NO synthase inhibition induced podocyte injury and albuminuria in an animal model of diabetes. ${ }^{58}$ In contrast, NO's role in the regulation of renal hemodynamics is unlikely to explain our results, because reduced $\mathrm{NO}$ availability is expected to reduce rather than increase intraglomerular pressure. ${ }^{59}$

The results of this study suggest that hyperglycemia amplifies the association of microvascular endothelial dysfunction with albuminuria. This observation is in agreement with animal studies which have shown higher UAE in NO synthase knock-out models in the presence of diabetes. ${ }^{60,61}$ In this regard, it has been suggested that hyperglycemia leads to dysregulation of the vascular endothelial growth factor (VEGF)-NO axis. ${ }^{40}$ That is, high glucose levels may reduce $\mathrm{NO}$ availability and increase VEGF expression..$^{40}$ In the face of reduced $\mathrm{NO}$ availability, VEGF may exacerbate vascular injury through abnormal angiogenesis ${ }^{40}$ and alteration of the endothelial glycocalyx. ${ }^{62}$ Alternatively, (hyperglycemia-induced) glomerular hyperfiltration ${ }^{41-44}$ may increase permeation of albumin through the injured glomerular capillary wall. Although this hypothesis was not supported by a positive interaction of microvascular endothelial dysfunction with eGFR, the low precision of the eGFR equations at higher GFR ${ }^{53}$ may have masked this interaction.

Impaired neural activity is an additional mechanism that can reduce both flicker lightinduced retinal arteriolar dilation and heat-induced skin hyperemia. ${ }^{45,46}$ However, it is not clear how impaired neural activity would increase albuminuria.

The association of flicker light-induced retinal arteriolar dilation with albuminuria leveled off at lower levels. This may be explained by selective non-participation of individuals with higher UAE and the lowest flicker light-induced retinal arteriolar dilation, who may suffer from the greatest burden of comorbid disease, including impaired cognitive performance and depression (i.e., incidence-prevalence bias ${ }^{63}$ ). In addition, the $95 \% \mathrm{Cls}$ are too wide to exclude the possibility that the true association is linear. 
Baseline retinal arteriolar diameter was not associated with albuminuria, whereas lower baseline skin perfusion was associated with lower albuminuria. However, the pattern of associations of baseline skin perfusion was not consistent and not biologically plausible. Therefore, we attribute these findings to the play of chance.

From a clinical perspective, microvascular endothelial dysfunction may explain, at least in part, associations of albuminuria with retinopathy, heart failure, impaired cognitive performance, and depression. , $3,13,14$ In this regard, the endothelial dysfunction observed in the retinal microcirculation of individuals with albuminuria may be particularly relevant to its associations with impaired cognitive performance and depression as well as retinopathy, as the retinal and cerebral microcirculation show embryological, anatomical and physiological similarities. ${ }^{64}$ In addition, the skin microcirculation has been suggested to mirror the systemic microcirculation. ${ }^{65,66}$

The results of this study also suggest that albuminuria may be a better biomarker of microvascular endothelial dysfunction in individuals with than in those without T2DM. Therefore, associations of albuminuria with microvascular disease may be stronger in T2DM. To the best of our knowledge, there are no published data on this issue.

An important strength of this study is the detailed characterization of its population, which allowed for adjustment for an extensive series of potential confounders. In particular, $24 \mathrm{~h}$ average ambulatory blood pressure may better capture the effects of blood pressure on albuminuria than office blood pressure, which reduces residual confounding. In addition, an extensive series of additional analyses verified the robustness of our results.

This study also had some limitations. First, the cross-sectional design limited causal inferences. Second, despite adjustment for an extensive series of potential confounders, we cannot fully exclude residual confounding. Conversely, the inclusion of variables which could also be intermediates in the association of microvascular endothelial dysfunction with albuminuria in our models may have introduced overadjustment bias. ${ }^{67}$ For example, higher blood pressure may be both a cause and a consequence of endothelial dysfunction. ${ }^{68}$ In addition, adjustment for CVD and retinopathy might be considered unnecessary ${ }^{67}$ as both may be manifestations of microvascular endothelial dysfunction. Nevertheless, the regression coefficients were relatively robust to adjustment for the variables in model $3 \mathrm{a}$ and the variables in the additional analyses, which suggests that both residual confounding and overadjustment bias are limited. Third, data on flicker light-induced retinal arteriolar dilation and heatinduced skin hyperemia were not available in all participants. However, the characteristics of included participants and participants who were excluded due to missing data were largely comparable, as were the characteristics of the participants in the retina and skin study populations. Fourth, the study population primarily consisted of Caucasian individuals from European descent $(98.9 \%)$, which potentially limits its generalizability to other populations.

In conclusion, lower flicker light-induced retinal arteriolar dilation was independently associated with albuminuria and this association was stronger in individuals with T2DM. In addition, lower heat-induced skin hyperemia was independently associated with albuminuria in individuals with T2DM. Thus, this is the first population-based study that provides direct support for the concept that microvascular endothelial dysfunction related to albuminuria is extensive, if not generalized, and that this association is stronger in individuals with than in those without T2DM. This suggests that individuals with albuminuria may not only benefit from improving renal endothelial function and reducing albuminuria, but from improving systemic endothelial function as well. 


\section{REFERENCES}

1. Fox CS, Matsushita K, Woodward M, Bilo HJ, Chalmers J, Heerspink HJ, et al. Associations of kidney disease measures with mortality and end-stage renal disease in individuals with and without diabetes: a meta-analysis. Lancet. 2012 Nov 10;380(9854):1662-73.

2. Van Hecke MV, Dekker JM, Nijpels G, Moll AC, Heine RJ, Bouter LM, et al. Inflammation and endothelial dysfunction are associated with retinopathy: the Hoorn Study. Diabetologia. 2005 Jul;48(7):1300-6.

3. Spijkerman AM, Gall MA, Tarnow L, Twisk JW, Lauritzen E, Lund-Andersen H, et al. Endothelial dysfunction and low-grade inflammation and the progression of retinopathy in Type 2 diabetes. Diabet Med. 2007 Sep;24(9):969-76.

4. Chen YH, Chen HS, Tarng DC. More impact of microalbuminuria on retinopathy than moderately reduced GFR among type 2 diabetic patients. Diabetes Care. 2012 Apr;35(4):803-8.

5. Gerstein HC, Mann JF, Yi Q, Zinman B, Dinneen SF, Hoogwerf B, et al. Albuminuria and risk of cardiovascular events, death, and heart failure in diabetic and nondiabetic individuals. Jama. 2001 Jul 25;286(4):421-6.

6. Ingelsson E, Sundstrom J, Lind L, Riserus U, Larsson A, Basu S, et al. Low-grade albuminuria and the incidence of heart failure in a community-based cohort of elderly men. Eur Heart J. 2007 Jul;28(14):1739-45.

7. Martens RJ, Kooman JP, Stehouwer CD, Dagnelie PC, van der Kallen CJ, Koster A, et al. Estimated GFR, Albuminuria, and Cognitive Performance: The Maastricht Study. Am J Kidney Dis. 2016 Jun 10.

8. Jassal SK, Kritz-Silverstein D, Barrett-Connor E. A prospective study of albuminuria and cognitive function in older adults: the Rancho Bernardo study. Am J Epidemiol. 2010 Feb 1;171(3):277-86.

9. Barzilay JI, Gao P, O'Donnell M, Mann JF, Anderson C, Fagard R, et al. Albuminuria and decline in cognitive function: The ONTARGET/TRANSCEND studies. Arch Intern Med. 2011 Jan 24;171(2):142-50.

10. Katon WJ, Lin EH, Russo J, Von Korff M, Ciechanowski P, Simon G, et al. Cardiac risk factors in patients with diabetes mellitus and major depression. J Gen Intern Med. 2004 Dec;19(12):1192-9.

11. Deckert T, Feldt-Rasmussen B, Borch-Johnsen K, Jensen T, Kofoed-Enevoldsen A. Albuminuria reflects widespread vascular damage. The Steno hypothesis. Diabetologia. 1989 Apr;32(4):219-26.

12. Stehouwer CD, Smulders YM. Microalbuminuria and risk for cardiovascular disease: Analysis of potential mechanisms. J Am Soc Nephrol. 2006 Aug;17(8):2106-11.

13. Knopman DS. Invited commentary: Albuminuria and microvascular disease of the brain--a shared pathophysiology. Am J Epidemiol. 2010 Feb 1;171(3):287-9; author reply 90-1.

14. Ter Maaten JM, Damman K, Verhaar MC, Paulus WJ, Duncker DJ, Cheng C, et al. Connecting heart failure with preserved ejection fraction and renal dysfunction: the role of endothelial dysfunction and inflammation. Eur J Heart Fail. 2016 Jun;18(6):588-98.

15. Brenner BM, Meyer TW, Hostetter TH. Dietary protein intake and the progressive nature of kidney disease: the role of hemodynamically mediated glomerular injury in the pathogenesis of progressive glomerular sclerosis in aging, renal ablation, and intrinsic renal disease. N Engl J Med. 1982 Sep 9;307(11):652-9.

16. Heringa SM, van den Berg E, Reijmer YD, Nijpels G, Stehouwer CD, Schalkwijk CG, et al. Markers of low-grade inflammation and endothelial dysfunction are related to reduced information processing speed and executive functioning in an older population - the Hoorn Study. Psychoneuroendocrinology. 2014 Feb;40:108-18.

17. Van Sloten TT, Schram MT, Adriaanse MC, Dekker JM, Nijpels G, Teerlink T, et al. Endothelial dysfunction is associated with a greater depressive symptom score in a general elderly population: the Hoorn Study. Psychol Med. 2014 May;44(7):1403-16.

18. Hansson GK. Inflammation, atherosclerosis, and coronary artery disease. N Engl J Med. 2005 Apr 21;352(16):1685-95.

19. Stehouwer CD, Henry RM, Dekker JM, Nijpels G, Heine RJ, Bouter LM. Microalbuminuria is associated with impaired brachial artery, flow-mediated vasodilation in elderly individuals without and with diabetes: further evidence for a link between microalbuminuria and endothelial dysfunction--the Hoorn Study. Kidney Int Suppl. 2004 Nov(92):S42-4.

20. Dogra G, Rich L, Stanton K, Watts GF. Endothelium-dependent and independent vasodilation studies at normoglycaemia in type I diabetes mellitus with and without microalbuminuria. Diabetologia. 2001 May;44(5):593-601.

21. Poredos P, Kek A. Relation of blunted dilation of the brachial artery in insulin-dependent diabetes mellitus to microalbuminuria. Am J Cardiol. 2000 Aug 1;86(3):364-7.

22. Clausen P, Jensen JS, Jensen G, Borch-Johnsen K, Feldt-Rasmussen B. Elevated urinary albumin excretion is associated with impaired arterial dilatory capacity in clinically healthy subjects. Circulation. 2001 Apr 10;103(14):1869-74.

23. Papaioannou GI, Seip RL, Grey NJ, Katten D, Taylor A, Inzucchi SE, et al. Brachial artery reactivity in asymptomatic patients with type 2 diabetes mellitus and microalbuminuria (from the Detection of Ischemia in Asymptomatic Diabetics-brachial artery reactivity study). Am J Cardiol. 2004 Aug 1;94(3):294-9.

24. Zenere BM, Arcaro G, Saggiani F, Rossi L, Muggeo M, Lechi A. Noninvasive detection of functional alterations of the arterial wall in IDDM patients with and without microalbuminuria. Diabetes Care. 1995 Jul;18(7):975-82.

25. Cosson E, Pham I, Valensi P, Paries J, Attali JR, Nitenberg A. Impaired coronary endothelium-dependent vasodilation is associated with microalbuminuria in patients with type 2 diabetes and angiographically normal coronary arteries. Diabetes Care. 2006 Jan;29(1):107-12.

26. Martens RJ, Henry RM, Houben AJ, van der Kallen CJ, Kroon AA, Schalkwijk CG, et al. Capillary Rarefaction Associates with Albuminuria: The Maastricht Study. J Am Soc Nephrol. 2016 May 9.

27. Stehouwer CD, Nauta JJ, Zeldenrust GC, Hackeng WH, Donker AJ, den Ottolander GJ. Urinary albumin excretion, cardiovascular disease, and endothelial dysfunction in non-insulin-dependent diabetes mellitus. Lancet. 1992 Aug $8 ; 340(8815): 319-23$. 
28. Stehouwer CD, Gall MA, Twisk JW, Knudsen E, Emeis JJ, Parving HH. Increased urinary albumin excretion, endothelial dysfunction, and chronic low-grade inflammation in type 2 diabetes: progressive, interrelated, and independently associated with risk of death. Diabetes. 2002 Apr;51(4):1157-65.

29. Stehouwer CD, Fischer HR, van Kuijk AW, Polak BC, Donker AJ. Endothelial dysfunction precedes development of microalbuminuria in IDDM. Diabetes. 1995 May;44(5):561-4.

30. Jager A, van Hinsbergh VW, Kostense PJ, Emeis JJ, Nijpels G, Dekker JM, et al. C-reactive protein and soluble vascular cell adhesion molecule- 1 are associated with elevated urinary albumin excretion but do not explain its link with cardiovascular risk. Arterioscler Thromb Vasc Biol. 2002 Apr 1;22(4):593-8.

31. Clausen P, Feldt-Rasmussen B, Jensen G, Jensen JS. Endothelial haemostatic factors are associated with progression of urinary albumin excretion in clinically healthy subjects: a 4-year prospective study. Clin Sci (Lond). 1999 Jul;97(1):37-43.

32. Persson F, Rossing P, Hovind P, Stehouwer CD, Schalkwijk CG, Tarnow L, et al. Endothelial dysfunction and inflammation predict development of diabetic nephropathy in the Irbesartan in Patients with Type 2 Diabetes and Microalbuminuria (IRMA 2) study. Scand J Clin Lab Invest. 2008;68(8):731-8.

33. Feldt-Rasmussen B. Increased transcapillary escape rate of albumin in type 1 (insulin-dependent) diabetic patients with microalbuminuria. Diabetologia. 1986 May;29(5):282-6.

34. Nannipieri M, Rizzo L, Rapuano A, Pilo A, Penno G, Navalesi R. Increased transcapillary escape rate of albumin in microalbuminuric type II diabetic patients. Diabetes Care. 1995 Jan;18(1):1-9.

35. Nannipieri M, Penno G, Rizzo L, Pucci L, Bandinelli S, Mattei P, et al. Transcapillary escape rate of albumin in type II diabetic patients. The relationship with microalbuminuria and hypertension. Diabetes Care. 1997 Jun;20(6):1019-26.

36. Jensen EW, Espersen K, Knudsen JH, Nielsen SL. Increased transcapillary escape rate of albumin in elderly subjects due to long-term smoking habits. Clin Physiol. 1995 Mar;15(2):159-67.

37. Guglielmi MD, Pierdomenico SD, Salvatore L, Romano F, Tascione E, Pupillo M, et al. Impaired left ventricular diastolic function and vascular postischemic vasodilation associated with microalbuminuria in IDDM patients. Diabetes Care. 1995 Mar;18(3):353-60.

38. Schmiedel O, Schroeter ML, Harvey JN. Microalbuminuria in Type 2 diabetes indicates impaired microvascular vasomotion and perfusion. Am J Physiol Heart Circ Physiol. 2007 Dec;293(6):H3424-31.

39. Houben AJ, Schaper NC, Slaaf DW, Tangelder GJ, Nieuwenhuijzen Kruseman AC. Skin blood cell flux in insulin-dependent diabetic subjects in relation to retinopathy or incipient nephropathy. Eur J Clin Invest. 1992 Jan;22(1):67-72.

40. Nakagawa T. Uncoupling of the VEGF-endothelial nitric oxide axis in diabetic nephropathy: an explanation for the paradoxical effects of VEGF in renal disease. Am J Physiol Renal Physiol. 2007 Jun;292(6):F1665-72.

41. Vora JP, Dolben J, Dean JD, Thomas D, Williams JD, Owens DR, et al. Renal hemodynamics in newly presenting non-insulin dependent diabetes mellitus. Kidney Int. 1992 Apr;41(4):829-35.

42. Nelson RG, Bennett PH, Beck GJ, Tan M, Knowler WC, Mitch WE, et al. Development and progression of renal disease in Pima Indians with non-insulin-dependent diabetes mellitus. Diabetic Renal Disease Study Group. N Engl J Med. 1996 Nov 28;335(22):1636-42.

43. Vedel P, Obel J, Nielsen FS, Bang LE, Svendsen TL, Pedersen OB, et al. Glomerular hyperfiltration in microalbuminuric NIDDM patients. Diabetologia. 1996 Dec;39(12):1584-9.

44. Melsom T, Mathisen UD, Ingebretsen OC, Jenssen TG, Njolstad I, Solbu MD, et al. Impaired fasting glucose is associated with renal hyperfiltration in the general population. Diabetes Care. 2011 Jul;34(7):1546-51.

45. Lim M, Sasongko MB, Ikram MK, Lamoureux E, Wang JJ, Wong TY, et al. Systemic associations of dynamic retinal vessel analysis: a review of current literature. Microcirculation. 2013 Apr;20(3):257-68.

46. Roustit M, Cracowski JL. Assessment of endothelial and neurovascular function in human skin microcirculation. Trends Pharmacol Sci. 2013 Jul;34(7):373-84.

47. Nguyen TT, Kreis AJ, Kawasaki R, Wang JJ, Seifert BU, Vilser W, et al. Reproducibility of the retinal vascular response to flicker light in Asians. Curr Eye Res. 2009 Dec;34(12):1082-8.

48. Agarwal SC, Allen J, Murray A, Purcell IF. Comparative reproducibility of dermal microvascular blood flow changes in response to acetylcholine iontophoresis, hyperthermia and reactive hyperaemia. Physiological measurement. 2010 Jan;31(1):1-11.

49. Schram MT, Sep SJ, van der Kallen CJ, Dagnelie PC, Koster A, Schaper N, et al. The Maastricht Study: an extensive phenotyping study on determinants of type 2 diabetes, its complications and its comorbidities. Eur J Epidemiol. 2014 Jun;29(6):439-51.

50. Sorensen BM, Houben AJ, Berendschot TT, Schouten JS, Kroon AA, van der Kallen CJ, et al. Prediabetes and Type 2 Diabetes are Associated with Generalized Microvascular Dysfunction: The Maastricht Study. Circulation. 2016 Sep 27.

51. Nagel E, Vilser W, Fink A, Riemer T. [Variance of retinal vessel diameter response to flicker light. A methodical clinical study]. Ophthalmologe. 2006 Feb;103(2):114-9.

52. Spauwen PJ, van Boxtel MP, Verhey FR, Kohler S, Sep SJ, Koster A, et al. Both Low and High 24-Hour Diastolic Blood Pressure Are Associated With Worse Cognitive Performance in Type 2 Diabetes: The Maastricht Study. Diabetes Care. 2015 Aug;38(8):1473-80.

53. Inker LA, Schmid CH, Tighiouart H, Eckfeldt JH, Feldman HI, Greene T, et al. Estimating glomerular filtration rate from serum creatinine and cystatin C. N Engl J Med. 2012 Jul 5;367(1):20-9.

54. Ix JH, Wassel CL, Stevens LA, Beck GJ, Froissart M, Navis G, et al. Equations to estimate creatinine excretion rate: the CKD epidemiology collaboration. Clin J Am Soc Nephrol. 2011 Jan;6(1):184-91.

55. Siddiqi FS, Advani A. Endothelial-podocyte crosstalk: the missing link between endothelial dysfunction and albuminuria in diabetes. Diabetes. 2013 Nov;62(11):3647-55.

56. Arcos MI, Fujihara CK, Sesso A, de Almeida Prado EB, de Almeida Prado MJ, de Nucci G, et al. Mechanisms of albuminuria in the chronic nitric oxide inhibition model. Am J Physiol Renal Physiol. 2000 Dec;279(6):F1060-6. 
57. Sharma M, McCarthy ET, Savin VJ, Lianos EA. Nitric oxide preserves the glomerular protein permeability barrier by antagonizing superoxide. Kidney Int. 2005 Dec;68(6):2735-44.

58. Yuen DA, Stead BE, Zhang Y, White KE, Kabir MG, Thai K, et al. eNOS deficiency predisposes podocytes to injury in diabetes. J Am Soc Nephrol. 2012 Nov;23(11):1810-23.

59. Carlstrom M, Wilcox CS, Arendshorst WJ. Renal autoregulation in health and disease. Physiol Rev. 2015 Apr;95(2):405-511.

60. Zhao HJ, Wang S, Cheng H, Zhang MZ, Takahashi T, Fogo AB, et al. Endothelial nitric oxide synthase deficiency produces accelerated nephropathy in diabetic mice. J Am Soc Nephrol. 2006 Oct;17(10):2664-9.

61. Nakagawa T, Sato W, Glushakova O, Heinig M, Clarke T, Campbell-Thompson M, et al. Diabetic endothelial nitric oxide synthase knockout mice develop advanced diabetic nephropathy. J Am Soc Nephrol. 2007 Feb;18(2):539-50.

62. Foster RR, Armstrong L, Baker S, Wong DW, Wylie EC, Ramnath R, et al. Glycosaminoglycan regulation by VEGFA and VEGFC of the glomerular microvascular endothelial cell glycocalyx in vitro. Am J Pathol. 2013 Aug;183(2):604-16.

63. Delgado-Rodriguez M, Llorca J. Bias. J Epidemiol Community Health. 2004 Aug;58(8):635-41.

64. Patton N, Aslam T, Macgillivray T, Pattie A, Deary IJ, Dhillon B. Retinal vascular image analysis as a potential screening tool for cerebrovascular disease: a rationale based on homology between cerebral and retinal microvasculatures. J Anat. 2005 Apr;206(4):319-48.

65. Holowatz LA, Thompson-Torgerson CS, Kenney WL. The human cutaneous circulation as a model of generalized microvascular function. J Appl Physiol (1985). 2008 Jul;105(1):370-2.

66. IJzerman RG, de Jongh RT, Serne EH. Commentary on viewpoint: the human cutaneous circulation as a model of generalized microvascular function. J Appl Physiol (1985). 2008 Jul;105(1):378; author reply 89.

67. Schisterman EF, Cole SR, Platt RW. Overadjustment bias and unnecessary adjustment in epidemiologic studies. Epidemiology. 2009 Jul;20(4):488-95.

68. Quyyumi AA, Patel RS. Endothelial dysfunction and hypertension: cause or effect? Hypertension. 2010 May;55(5):1092-4. 
Supplemental Material 


\section{SUPPLEMENTAL METHODS}

\section{Albuminuria}

To assess urinary albumin excretion (UAE), participants were requested to collect two $24 \mathrm{~h}$ urine collections. Urinary albumin concentration was measured with a standard immunoturbidimetric assay by an automatic analyzer (due to a change of supplier by the Beckman Synchron LX20, Beckman Coulter Inc., Brea, USA; and the Roche Cobas 6000, F. Hoffmann-La Roche, Basel, Switzerland) and multiplied by collection volume to obtain the $24 \mathrm{~h}$ UAE. A urinary albumin concentration below the detection limit of the assay $(2 \mathrm{mg} / \mathrm{l}$ for the Beckman Synchron LX20 and $3 \mathrm{mg} / \mathrm{l}$ for the Roche Cobas 6000) was set at $1.5 \mathrm{mg} / \mathrm{l}$ before multiplying by collection volume. Only urine collections with a collection time between $20 \mathrm{~h}$ and $28 \mathrm{~h}$ were considered valid. If needed, UAE was extrapolated to a $24 \mathrm{~h}$ excretion. UAE was expressed both as a continuous and as a categorical variable $(<15 \mathrm{mg} / 24 \mathrm{~h}, 15-<30 \mathrm{mg} / 24 \mathrm{~h}$, and $\geq 30 \mathrm{mg} / 24 \mathrm{~h})$, in agreement with the fact that an association with (cardiovascular) disease already exists below

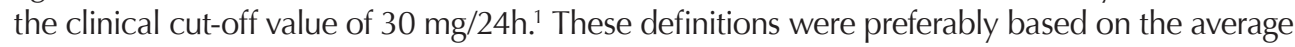
of two (available in $91.5 \%$ of the participants) $24 \mathrm{~h}$ urine collections.

\section{Retinopathy}

Once the pupils were dilated with tropicamide $0.5 \%$ and phenylephrine $2.5 \%$, fundus photography of both eyes was performed. All fundus photographs were made with an auto fundus camera (Model AFC-230, Nidek, Gamagori, Japan) in 45 degrees of at least three fields: one field centered on the optic disc, one field centered on the macula and one temporal field positioned one disc-diameter from the center of the macula. These fundus photographs were evaluated by a trained and experienced grader in a masked fashion and in case of any doubt or an abnormal finding, the fundus photograph was discussed with a medical retina specialist (JS). Based on these fundus photographs, the presence of diabetic retinopathy was graded according to the Diabetic Retinopathy Disease Severity Scale and the International Clinical Diabetic Retinopathy Disease Severity Scale (no diabetic retinopathy (DRP) = no abnormalities; mild non-proliferative DRP = micro-aneurysms only; moderate non-proliferative $\mathrm{DRP}=$ more than just micro-aneurysms but less than severe non-proliferative DRP; severe non-proliferative DRP: severe intraretinal hemorrhages and microaneurysms in each of four quadrants or definite venous beading in two or more quadrants or moderate intraretinal microvascular abnormalities in one or more quadrants and no signs of proliferative retinopathy; proliferative DRP: neovascularisation and/or vitreous/preretinal hemorrhage). ${ }^{2}$ Fundus photography was not implemented at the start of The Maastricht Study, but some months later on. In 107 participants with type 2 diabetes who had no fundus photograph at our research center, data could be supplemented with general practitioner data on retinopathy. In this study, the highest grade of the left or right eye was counted to dichotomize the presence of retinopathy.

\section{Definitions of other potential confounders}

Glucose metabolism was classified according to the World Health Organization 2006 criteria $^{3}$ into normal glucose metabolism, impaired fasting glucose, impaired glucose tolerance, and diabetes mellitus. Participants with diabetes mellitus and participants using glucoselowering medication were considered as having type 2 diabetes if they had no (self-reported) type 1 or other specific type of diabetes mellitus. For the present study, impaired fasting glucose and impaired glucose tolerance were combined into prediabetes. Total-to-high-density 
lipoprotein (HDL) cholesterol ratio was calculated by dividing total cholesterol by HDL cholesterol. Body mass index was categorized into normal weight $\left(<25 \mathrm{~kg} / \mathrm{m}^{2}\right)$, overweight $(25$ $\left.<30 \mathrm{~kg} / \mathrm{m}^{2}\right)$, and obesity $\left(\geq 30 \mathrm{~kg} / \mathrm{m}^{2}\right)$. Hypertension was defined as an office systolic pressure $\geq 140 \mathrm{mmHg}$, an office diastolic pressure $\geq 90 \mathrm{mmHg}$ and/or the use of antihypertensive medication. Office pulse pressure was defined as office systolic pressure minus office diastolic pressure and office mean arterial pressure as office diastolic pressure plus 0.412 times office pulse pressure. ${ }^{4}$ Similar equations were used to calculate $24 \mathrm{~h}$ average ambulatory pulse pressure and $24 \mathrm{~h}$ average ambulatory mean arterial pressure, respectively. Smoking behavior was categorized into never, former, and current. Alcohol consumption was classified into no consumption, low consumption $(\leq 7$ glasses per week for women and $\leq 14$ glasses per week for men) and high consumption ( $>7$ glasses per week for women and $>14$ glasses per week for men). Educational level was classified into low (none, primary, or lower vocational education only), intermediate (intermediate general secondary, intermediate vocational or higher general secondary education) and high (higher vocational education or university level of education). ${ }^{5,6}$ Questionnaire based prevalent cardiovascular disease (CVD) was defined as a self-reported history of myocardial infarction, cerebrovascular infarction or hemorrhage, or percutaneous artery angioplasty of, or vascular surgery on, the coronary, abdominal, peripheral or carotid arteries. 


\section{REFERENCES}

1. Fox CS, Matsushita K, Woodward M, Bilo HJ, Chalmers J, Heerspink HJ, et al. Associations of kidney disease measures with mortality and end-stage renal disease in individuals with and without diabetes: a meta-analysis. Lancet. 2012 Nov 10;380(9854):1662-73.

2. American Academy of Ophtalmology Retina/Vitreous Panel. Preferred practice pattern® guidelines. Diabetic retinopathy. San Francisco, CA: American Academy of Opthalmology; 2014. Availabe from: http://www.aao.org/ppp

3. World Health Organization. Definition and diagnosis of diabetes mellitus and intermediate hyperglycemia: report of a WHO/IDF consultation2006: Available from: http://www.who.int/diabetes/publications/Definition\%20and\%20 diagnosis\%20of\%20diabetes_new.pdf.

4. Meaney E, Alva F, Moguel R, Meaney A, Alva J, Webel R. Formula and nomogram for the sphygmomanometric calculation of the mean arterial pressure. Heart. 2000 Jul;84(1):64.

5. De Bie SE. Standaardvragen 1987: Voorstellen voor uniformering van vraagstellingen naar achtergrondkenmerken en interviews [Standard questions 1987: Proposal for uniformisation of questions regarding background variables and interviews]. Leiden, The Netherlands: Leiden University Press; 1987.

6. Spauwen PJ, van Boxtel MP, Verhey FR, Kohler S, Sep SJ, Koster A, et al. Both Low and High 24-Hour Diastolic Blood Pressure Are Associated With Worse Cognitive Performance in Type 2 Diabetes: The Maastricht Study. Diabetes Care. 2015 Aug;38(8):1473-80. 


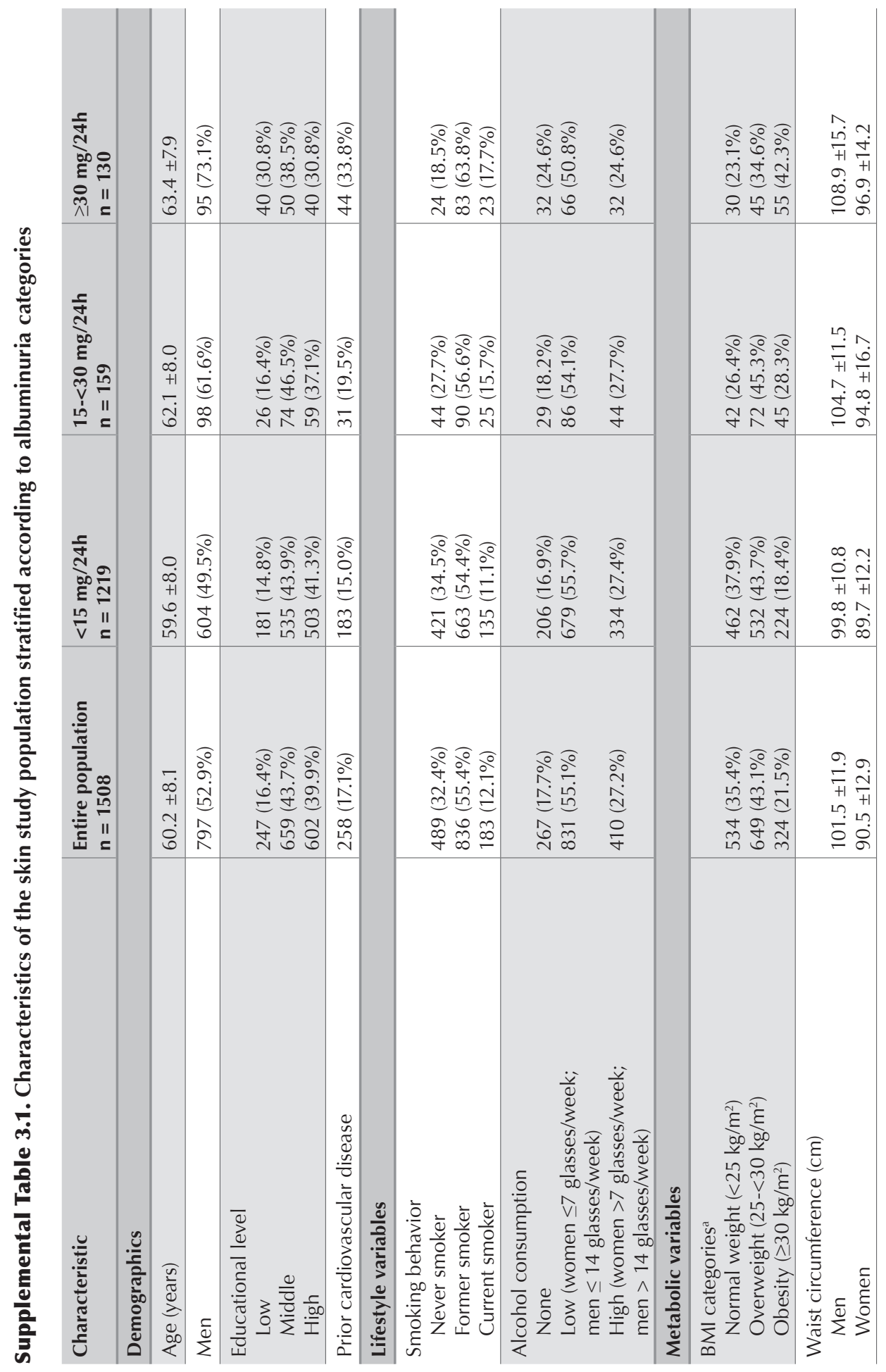




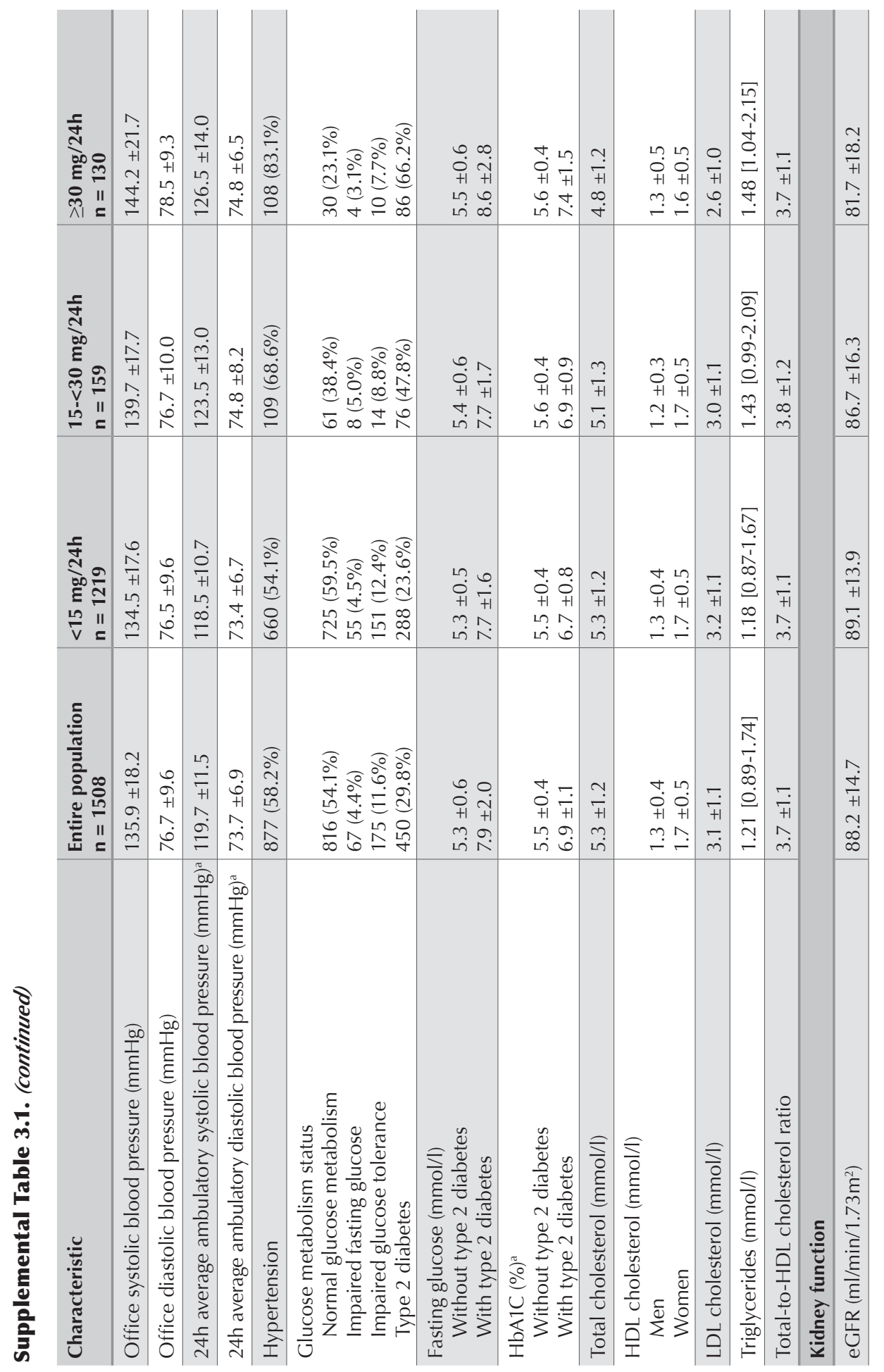




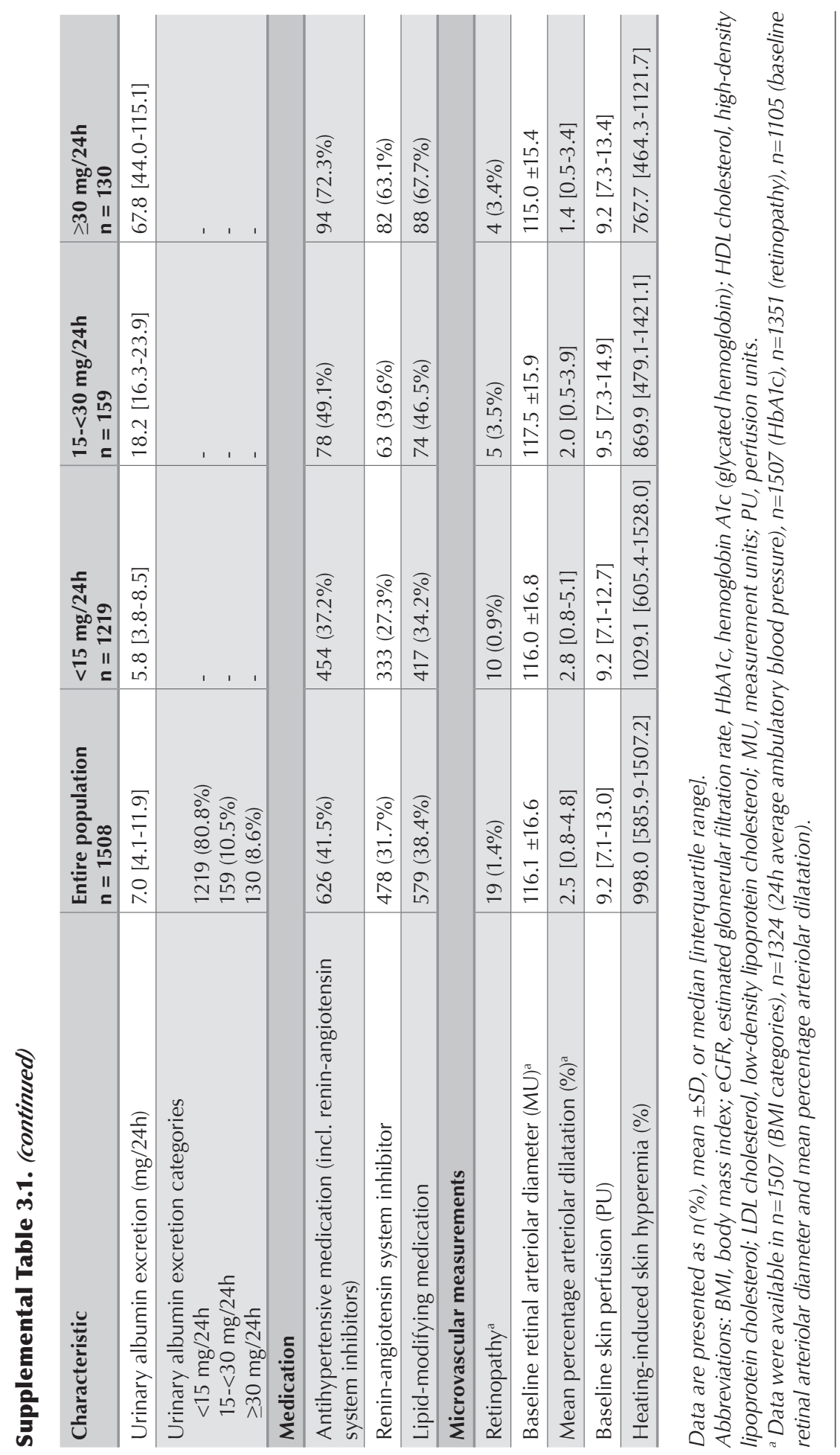




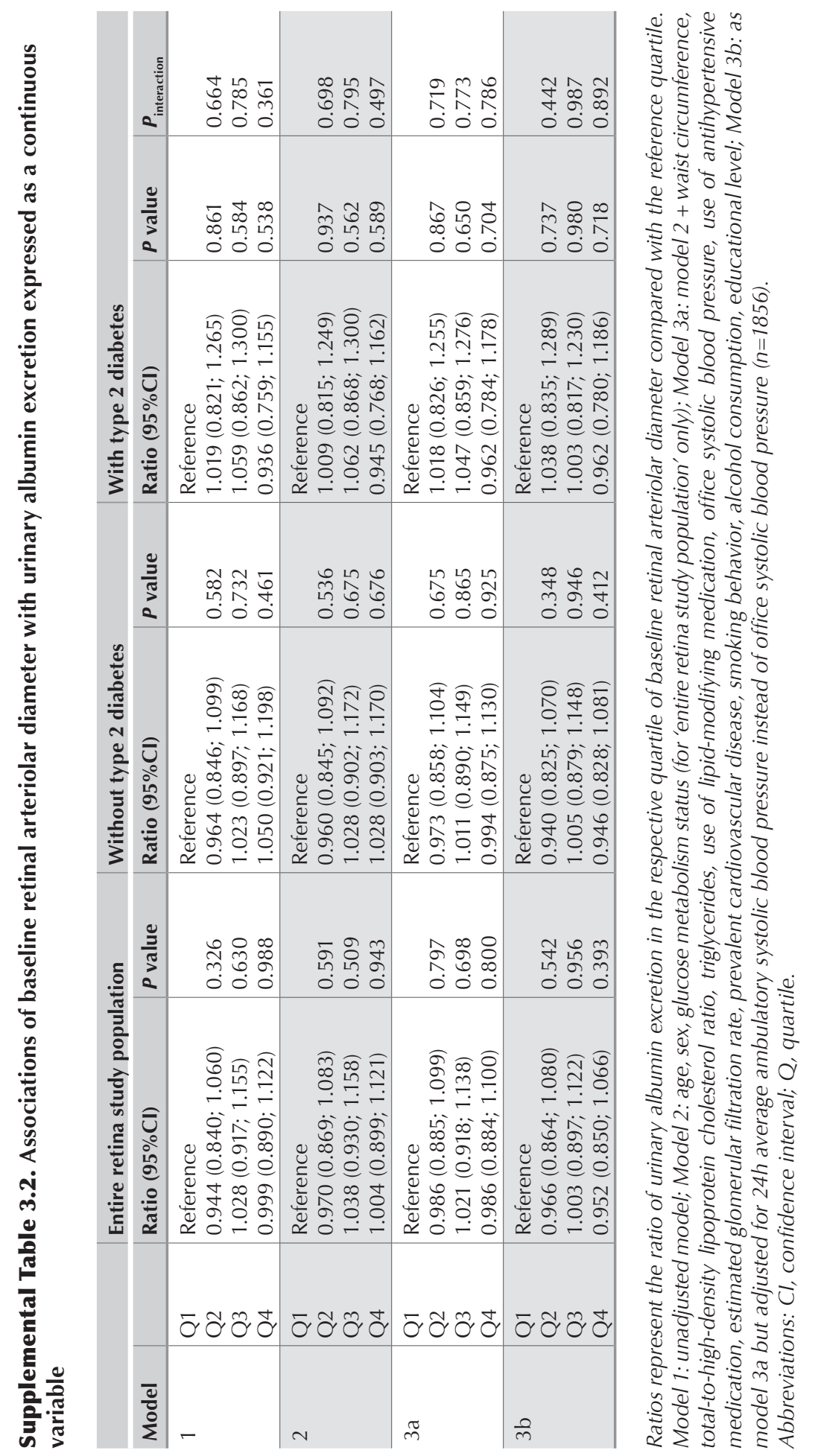




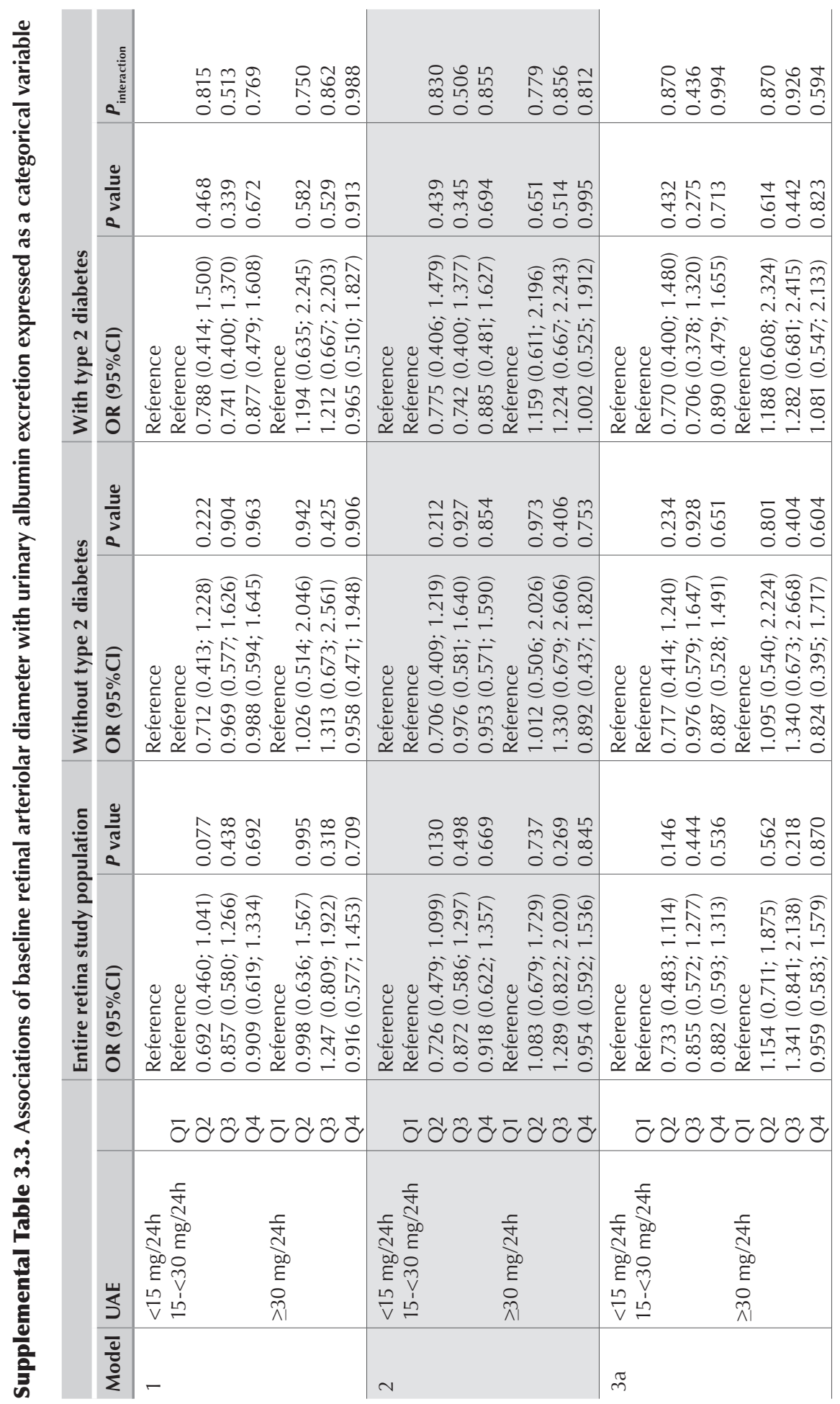




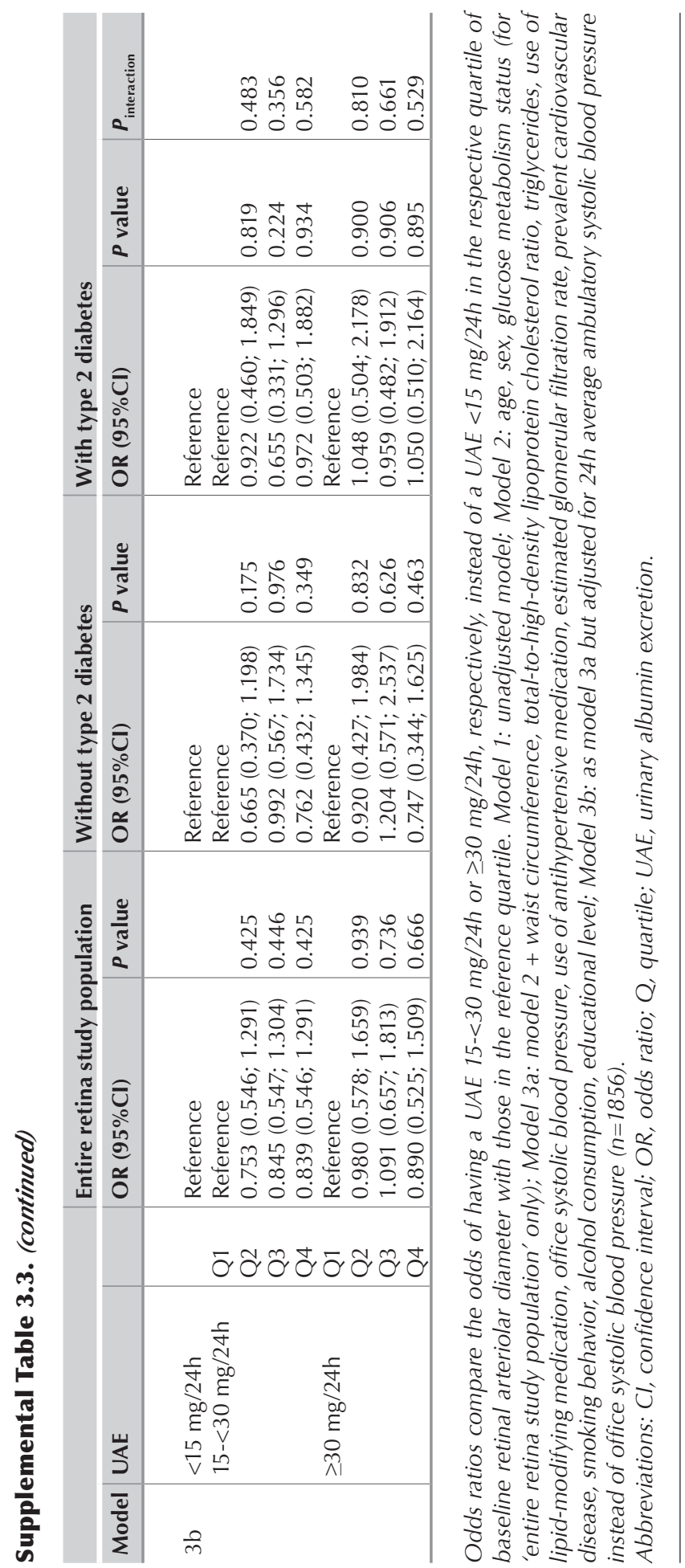




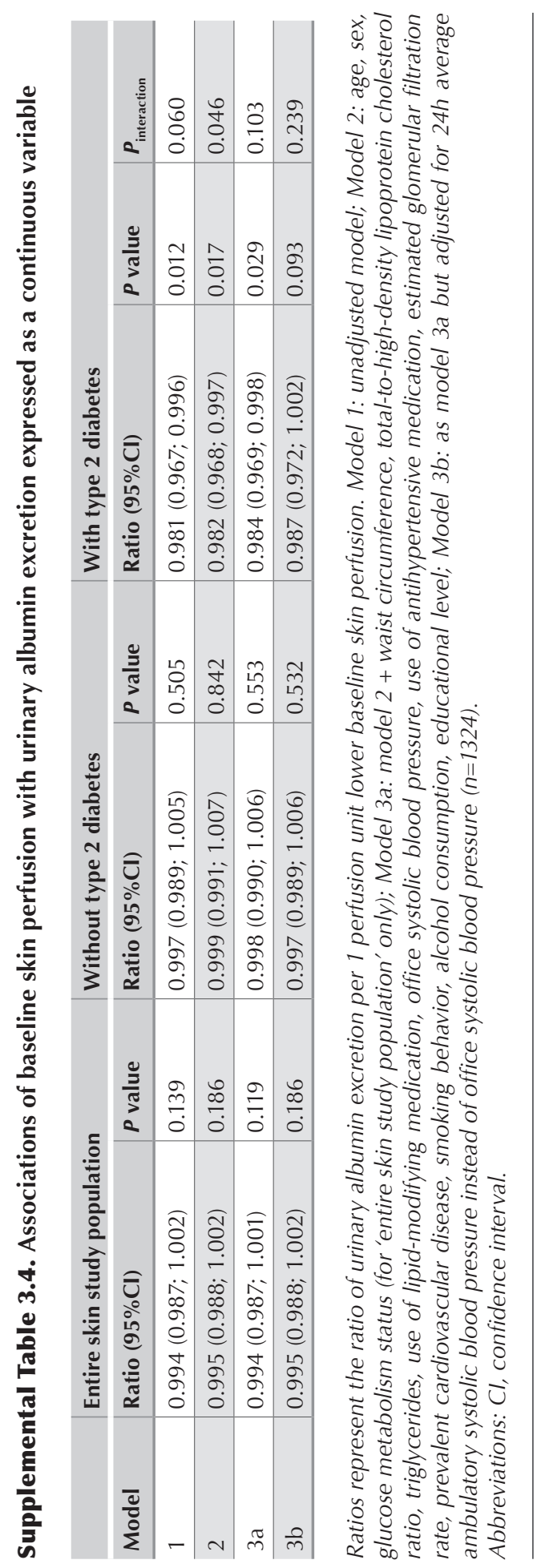




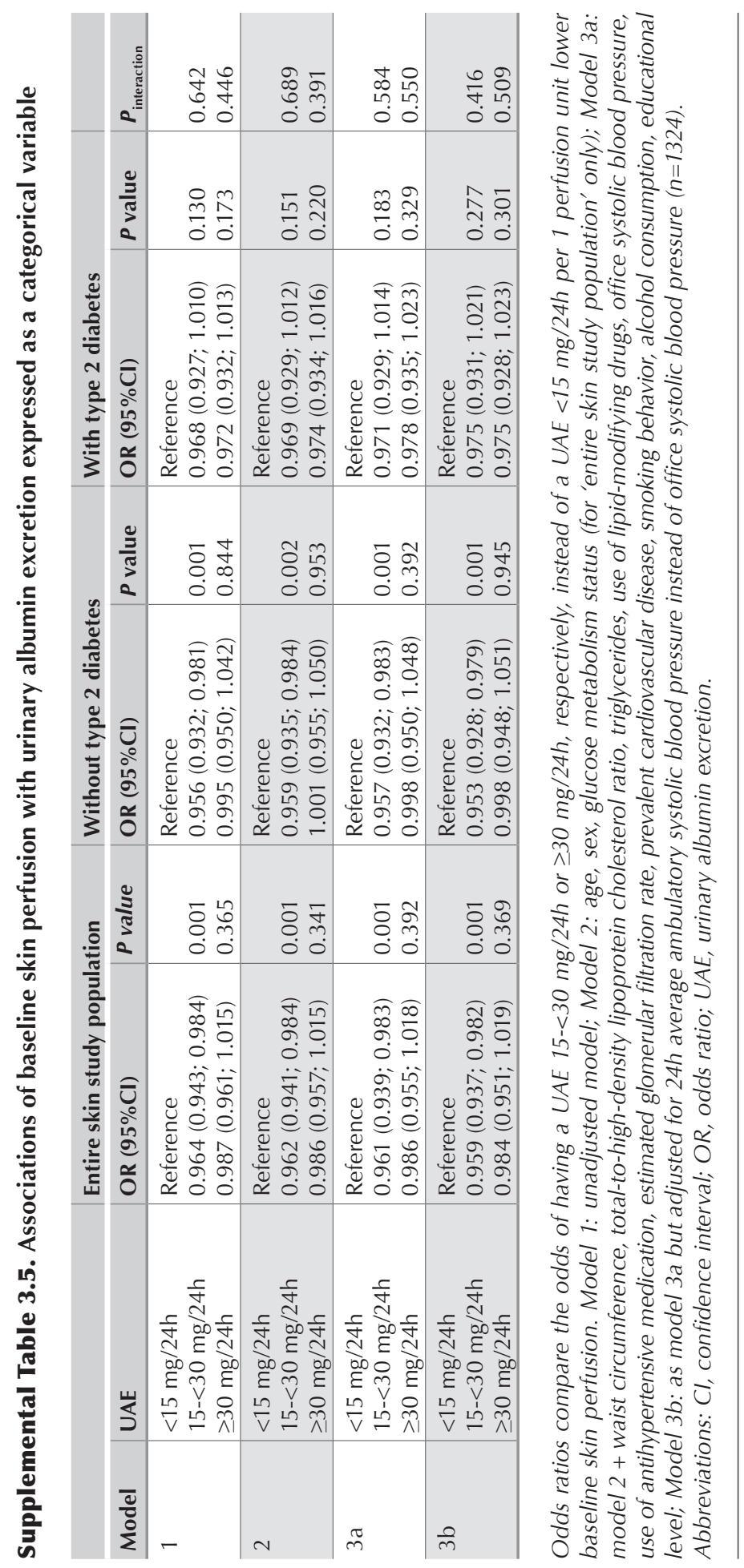




\section{Chapter 4}

Remy J.H. Martens

Dorien M. Kimenai

Jeroen P. Kooman

Coen D.A. Stehouwer

Frans E.S. Tan

Otto Bekers

Pieter C. Dagnelie

Carla J.H. van der Kallen

Abraham A. Kroon

Karel M.L. Leunissen

Frank M. van der Sande

Nicolaas C. Schaper

Simone J.S. Sep

Miranda T. Schram

Jeroen D. van Suijlen

Marja P. van Dieijen-Visser

Steven J.R. Meex

Ronald M.A. Henry

Clin Chem - accepted for publication 


\section{Estimated glomerular}

filtration rate and

albuminuria are associated

with biomarkers of cardiac

injury in a population-based

cohort study:

The Maastricht Study 


\begin{abstract}
Background: Chronic kidney disease (CKD) associates with an increased cardiovascular disease mortality risk. It is, however, less clear at what point in the course from normal kidney function to CKD the association with cardiovascular disease appears. Studying the associations of estimated glomerular filtration rate (eGFR) and albuminuria with biomarkers of (subclinical) cardiac injury in a population without substantial CKD may clarify this issue.
\end{abstract}

Methods: We examined the cross-sectional associations of eGFR and urinary albumin excretion (UAE) with high-sensitivity cardiac troponin (hs-cTn) T, hs-cTnl, and N-terminal pro-brain natriuretic peptide (NT-proBNP) in 3103 individuals from a population-based diabetes-enriched cohort study.

Results: After adjustment for potential confounders, eGFR and UAE were associated with these biomarkers of cardiac injury, even at levels which do not fulfill the CKD criteria. For example, eGFR $60-<90 \mathrm{ml} / \mathrm{min} / 1.73 \mathrm{~m}^{2}\left(\mathrm{vs} . \geq 90 \mathrm{ml} / \mathrm{min} / 1.73 \mathrm{~m}^{2}\right)$ was associated with a (Ratio $(95 \%$ confidence interval $(95 \% \mathrm{Cl}))$ ) 1.21 (1.17 to 1.26$)$, 1.14 (1.07 to 1.20$)$ and 1.19 (1.12 to 1.27) times higher hs-cTnT, hs-cTnl and NT-proBNP, respectively. The association of eGFR with hs-cTnT was statistically significantly stronger than that with hs-cTnl. In addition, UAE $15-<30 \mathrm{mg} / 24 \mathrm{~h}$ (vs. $<15 \mathrm{mg} / 24 \mathrm{~h}$ ) was associated with a 1.04 (0.98 to 1.10$), 1.08$ (1.00 to 1.18) and 1.07 (0.96 to 1.18) times higher hs-cTnT, hs-cTnl and NT-proBNP, respectively.

Conclusions: eGFR and albuminuria were already associated with biomarkers of (subclinical) cardiac injury at levels which do not fulfill the CKD criteria. Although reduced renal elimination may partly underlie the associations of eGFR, these findings support the concept that eGFR and albuminuria are, over their entire range, associated with cardiac injury. 


\section{INTRODUCTION}

Chronic kidney disease (CKD), which is defined as an estimated glomerular filtration rate (eGFR) $<60 \mathrm{ml} / \mathrm{min} / 1.73 \mathrm{~m}^{2}$ and/or a urinary albumin excretion (UAE) $\geq 30 \mathrm{mg} / 24 \mathrm{~h}$, is associated with an increased cardiovascular disease (CVD) mortality risk. ${ }^{1}$ It is, however, not entirely clear at what point in the course from normal kidney function to CKD the association with CVD risk appears. ${ }^{1,2}$ For example, GFR estimates that include cystatin $C$ have been associated with CVD mortality at levels far above the $60 \mathrm{ml} / \mathrm{min} / 1.73 \mathrm{~m}^{2}$ threshold, whereas this is less clear for eGFR based on creatinine only. ${ }^{2}$ In addition, it is important to gain insight into the mechanisms that underlie the CVD mortality risk associated with eGFR and albuminuria. Studying the associations of eGFR levels $\geq 60 \mathrm{ml} / \mathrm{min} / 1.73 \mathrm{~m}^{2}$ and UAE levels $<30 \mathrm{mg} / 24 \mathrm{~h}$ with biomarkers of (subclinical) cardiac injury, such as the cardiac troponins (cTn) $\mathrm{T}$ and I, and $\mathrm{N}$-terminal pro-brain natriuretic peptide (NT-proBNP), ${ }^{3,4}$ may help clarifying these issues. The interpretation of these biomarkers in the face of kidney disease is, nevertheless, controversial. ${ }^{5}$

In this regard, it is important to distinguish eGFR from albuminuria as both entities may be associated with biomarkers of cardiac injury via different mechanisms. For instance, reduced eGFR may cause cardiac injury via chronic low-grade inflammation and endothelial dysfunction, ${ }^{6}$ but may also reduce the renal elimination of cTn and NT-proBNP. ${ }^{5,7}$ In contrast, albuminuria has been hypothesized to be a biomarker of generalized endothelial dysfunction ${ }^{8}$ and capillary rarefaction, ${ }^{9}$ which in turn may cause (subclinical) cardiac ischemia, ${ }_{10}^{10}$ resulting in higher cTn and NT-proBNP levels. ${ }^{3,4}$ Indeed, the limited available data ${ }^{5,11-13}$ suggest that eGFR and albuminuria are mutually independently associated with $\mathrm{CTn}^{5,11,13}$ and NT-proBNP. ${ }^{11}$ However, only two of these studies have examined a population without substantial CKD. ${ }^{11,13}$

In addition, only two studies have examined whether cTnT and cTnl behave similarly with regard to their associations with eGFR at levels $\geq 60 \mathrm{ml} / \mathrm{min} / 1.73 \mathrm{~m}^{2},{ }^{14}$ and with albuminuria. ${ }^{5}$ This may be important as both cTn are used interchangeably in clinical practice, whereas cTnT has been suggested to be more strongly dependent on renal elimination than $\mathrm{cTnl}^{15}$ The latter is supported by stronger associations of eGFR ${ }^{5,15-18}$ and measured GFR ${ }^{19}$ with cTnT than with cTnl at levels $<60 \mathrm{ml} / \mathrm{min} / 1.73 \mathrm{~m}^{2}$, even when both $\mathrm{cTn}$ were measured with high-sensitivity (hs) assays. ${ }^{5,15,17,19}$

In view of the above, we examined whether eGFR and albuminuria were, independently of each other, associated with hs-cTnT, hs-cTnl and NT-proBNP in a population-based cohort, and whether these associations already appeared at levels of eGFR and albuminuria which do not fulfill the CKD criteria. In addition, we compared the strength of any associations of eGFR and albuminuria with hs-cTnT and hs-cTnl.

\section{METHODS}

\section{The Maastricht Study population and design}

We used data from The Maastricht Study, an observational prospective population-based cohort study. The rationale and methodology have been described previously. ${ }^{20}$ In brief, the study focuses on the etiology, pathophysiology, complications and comorbidities of type 2 diabetes mellitus (T2DM) and is characterized by an extensive phenotyping approach. Eligible for participation were all individuals aged between 40 and 75 years and living in the southern part of the Netherlands. Participants were recruited through mass media campaigns and from the municipal registries and the regional Diabetes Patient Registry via mailings. Recruitment 
was stratified according to known T2DM status, with an oversampling of individuals with T2DM, for reasons of efficiency. The present report includes cross-sectional data from the first 3451 participants, who completed the baseline survey between November 2010 and September 2013. The examinations of each participant were performed within a time window of three months. The study has been approved by the institutional medical ethical committee (NL31329.068.10) and the Minister of Health, Welfare and Sports of the Netherlands (Permit 131088-105234-PG). All participants gave written informed consent. For this study, participants with type 1 diabetes or other specific types of diabetes $(n=41)$ were excluded. After further successively excluding participants whose GFR $_{\text {crys }}$ was missing $(n=33)$, whose $24 \mathrm{~h}$ urine collections were collected erroneously $(<20 \mathrm{~h}$ or $>28 \mathrm{~h})$ or were not handed in at all $(\mathrm{n}=42)$, and who had missing data on other variables in our primary regression models $(n=232), 3103$ participants were included.

\section{Kidney function}

GFR was estimated with the Chronic Kidney Disease Epidemiology Collaboration (CKD-EPI) equation based on the combination of serum creatinine and serum cystatin $C\left(\mathrm{eGFR}_{\text {crcys }}\right)$ for the primary analyses (Supplemental Methods). ${ }^{21}$ For additional analyses, eGFR was calculated with the CKD-EPI equations based on serum creatinine $\left(\mathrm{eGFR}_{\mathrm{cr}}\right)^{21}$ and serum cystatin $\mathrm{C}\left(\mathrm{eGFR}_{\text {cys }}\right){ }^{21}$

To assess UAE, participants were requested to collect two 24h urine collections (Supplemental Methods). UAE was preferably based on the average of two (available in $91.9 \%$ of the participants) $24 \mathrm{~h}$ urine collections.

\section{Cardiac biomarkers}

Fasting blood samples were collected from all participants and processed according to the manufacturers' instructions. Serum samples were stored at $-80^{\circ} \mathrm{C}$ for $1-4$ years. Hs-cTnT was measured on a Roche Cobas 6000 analyzer (F. Hoffmann-La Roche, Basel, Switzerland) with the Elecsys Troponin T hs assay (F. Hoffmann-La Roche, Basel, Switzerland), which has a limit of blank (LoB) of $3 \mathrm{ng} / \mathrm{l}$, a limit of detection (LoD) of $5 \mathrm{ng} / \mathrm{l}$, and achieves a 10\% coefficient of variation (10\% CV) at $13 \mathrm{ng} / \mathrm{l}$. Hs-cTnl was measured on an ARCHITECT i2000 SR analyzer (Abbott Diagnostics, Lake Forest, IL, USA) with the ARCHITECT STAT High Sensitive Troponin-I assay (Abbott Diagnostics, Lake Forest, IL, USA), which has a LoB range of 0.7-1.3 ng/l, a LoD range of 1.1-1.9 ng/l, and achieves a 10\% CV at $4.7 \mathrm{ng} / \mathrm{l}$. NT-proBNP was assessed on a Roche Cobas 6000 analyzer (F. Hoffmann-La Roche, Basel, Switzerland) with the Elecsys proBNP II assay (F. Hoffmann-La Roche, Basel, Switzerland), which has a LoD of $5.0 \mathrm{ng} / \mathrm{l}$ (LoB not reported), and achieves a $20 \% \mathrm{CV}$ at $50.0 \mathrm{ng} / \mathrm{l}$.

\section{Covariates}

We collected data on glucose metabolism status, hemoglobin A1c (HbA1c), total cholesterol, high-density lipoprotein (HDL) cholesterol, low-density lipoprotein (LDL) cholesterol, triglycerides, waist circumference, office blood pressure, 24h average ambulatory blood pressure, medication use, smoking behavior, alcohol consumption, educational level, questionnaire based prevalent CVD, resting 12-lead electrocardiogram (ECG), and self-reported physical activity as described previously. ${ }^{20,22}$ Please see Supplemental Methods for further details and definitions. 


\section{Statistical analyses}

All analyses were performed with IBM SPSS Statistics Version 22.0 (IBM). Characteristics of the entire study population and according to eGFR ${ }_{\text {crys }}$ and albuminuria categories were summarized as means with standard deviations (SD), medians with interquartile ranges (IQR), and numbers with percentages, as appropriate. The cardiac biomarkers are described with both actual mean (with SD) and median (with IQR) levels. However, given their positively skewed distributions, the median and interquartile range most accurately capture their central tendency and variation. For the comparison of participants across eGFR crcys $_{\text {and albuminuria }}$ categories, continuous variables were analyzed with one-way ANOVA if normally distributed and with the Kruskal-Wallis test if not. Categorical variables were compared with the chi-square test.

Associations of eGFR crcys $_{\text {s }}$ and albuminuria with hs-cTnT, hs-cTnl and NT-proBNP were evaluated with multivariable linear regression analyses. eGFR $\mathrm{ercys}_{\mathrm{s}}$ and albuminuria were analyzed as categorical $\left(\geq 90,60-<90\right.$ and $<60 \mathrm{ml} / \mathrm{min} / 1.73 \mathrm{~m}^{2} ;<15,15-<30$ and $\geq 30 \mathrm{mg} / 24 \mathrm{~h}$ ) and as continuous (per minus $10 \mathrm{ml} / \mathrm{min} / 1.73 \mathrm{~m}^{2}$; per doubling of UAE) variables. To obtain similar proportions of individuals with a value above the LoB for hs-cTnT and hs-cTnl $(87.1 \%$, and $87.9 \%$, respectively), the LoB of hs-cTnl was considered to be $0.9 \mathrm{ng} / \mathrm{l}$. For both hs-cTnT and hs-cTnl, concentrations below the LoB were subsequently set at LoB/2. NT-proBNP concentrations below the LoD were set at LoD/2. Thereafter, concentrations of hs-cTnT, hs-cTnl and NT-proBNP were natural log transformed. The regression coefficients were exponentiated to obtain the ratio of (geometric mean) concentrations of the cardiac biomarkers per one unit increase in the independent variable. We adjusted for potential confounders as follows: model 1) unadjusted model; model 2) age, sex, glucose metabolism status; model 3) model 2 + waist circumference, total-to-HDL cholesterol ratio, triglycerides, use of lipid-modifying medication, smoking behavior, alcohol consumption, educational level, eGFR $_{\text {crcys }}$ /albuminuria; model 4a: model $3+$ office systolic pressure, use of antihypertensive medication, ischemic ECG abnormalities; model $4 \mathrm{~b}$ ) similar to model $4 \mathrm{a}$ but adjusted for $24 \mathrm{~h}$ average ambulatory systolic pressure instead of office systolic pressure. Systolic pressure, use of antihypertensive medication and ischemic ECG abnormalities were entered in a separate model as these may be both confounders and intermediates in the associations examined.

The distributions of hs-cTnT and hs-cTnl should be taken into account when comparing their associations with eGFR crys and albuminuria. Therefore, we subsequently calculated partial correlations of eGFR ${ }_{\text {crys }}$ and albuminuria with hs-cTnT and hs-cTnl in model 4a and compared these with a test for comparing correlations measured on the same individuals. ${ }^{23}$

Several additional analyses were performed. First, analyses were repeated: in participants with $\mathrm{UAE} \leq 300 \mathrm{mg} / 24 \mathrm{~h}$ and in participants with two valid urine collections; with additional adjustment for total and moderate to vigorous physical activity; and with alternative operationalizations of prior CVD, blood pressure and the use of antihypertensive medication. Second, eGFR crys $_{\text {s }}$ was replaced with either eGFR cr $_{\text {r }}$ eGFR cys $_{\text {. }}$ Third, we added interaction terms to model 4 a to explore interaction with glucose metabolism status because glucose metabolism status has been shown to modify associations of other CVD risk factors with CVD events ${ }^{24}\left(P_{\text {interaction }}<0.10\right.$ was considered statistically significant). Fourth, to explore whether any association of eGFR crcys $_{\text {and }}$ and albuminuria with (subclinical) cardiac injury could also be detected with an ECG, we examined their associations with ischemic ECG abnormalities. 


\section{RESULTS}

\section{Characteristics of the study population}

Table 4.1 and Supplemental Table 4.1 show the characteristics of the study population stratified according to eGFR crcys $_{\text {and }}$ albuminuria categories, respectively. Due to oversampling, $27.7 \%$ had T2DM. Average eGFR crcys was $88.2 \pm 14.8 \mathrm{ml} / \mathrm{min} / 1.73 \mathrm{~m}^{2}$. Most participants had an $\operatorname{eGFR}_{\text {crcys }} \geq 90 \mathrm{ml} / \mathrm{min} / 1.73 \mathrm{~m}^{2}(48.2 \%)$ or $60-<90 \mathrm{ml} / \mathrm{min} / 1.73 \mathrm{~m}^{2}(47.7 \%)$, whereas $4.1 \%$ had an $\mathrm{eGFR}_{\text {crcys }}<60 \mathrm{ml} / \mathrm{min} / 1.73 \mathrm{~m}^{2}$. Median UAE was 6.7 [IQR 4.1-11.9] mg/24h. In 10.4\% UAE was $15-<30 \mathrm{mg} / 24 \mathrm{~h}$, whereas it was $\geq 30 \mathrm{mg} / 24 \mathrm{~h}$ in $8.6 \%$. In general, participants with lower eGFR $_{\text {crcys }}$ and participants with higher UAE had a worse CVD risk profile. Further, lower eGFR $_{\text {crys }}$ was accompanied by higher UAE and vice versa. Supplemental Figure 4.1 shows the distribution of hs-cTnT and hs-cTnl. Hs-cTnT was above the LoD in 55.6\%. Hs-cTnl was above the LoD in $49.3 \%$ (1.9 ng/l) to $80.2 \%(1.1 \mathrm{ng} / \mathrm{l})$.

\section{eGFR and cardiac biomarkers}

Participants with lower eGFR crys $_{\text {s }}$ had higher hs-cTnT, hs-cTnl and NT-proBNP (Table 4.1). After adjustment for potential confounders, and as compared with eGFR crcys $_{2} \geq 90 \mathrm{ml} / \mathrm{min} / 1.73 \mathrm{~m}^{2}$, both $\mathrm{eGFR}_{\text {crys }} 60-<90 \mathrm{ml} / \mathrm{min} / 1.73 \mathrm{~m}^{2}$ and $\mathrm{eGFR}_{\text {crcys }}<60 \mathrm{ml} / \mathrm{min} / 1.73 \mathrm{~m}^{2}$ remained associated with higher hs-cTnT, hs-cTnl and NT-proBNP (Table 4.2, model 4a). Results were similar when we adjusted for $24 \mathrm{~h}$ average ambulatory systolic pressure (Table 4.2 , model $4 \mathrm{~b}$ ).

When eGFR crcys $_{\text {was }}$ wapressed as a continuous variable, each $10 \mathrm{ml} / \mathrm{min} / 1.73 \mathrm{~m}^{2}$ lower eGFR $_{\text {crcys }}$ was associated with a (Ratio (95\% confidence interval $\left.\left.(95 \% \mathrm{Cl})\right)\right) 1.11$ (1.09 to 1.12) times higher hs-cTnT, a 1.07 (1.05 to 1.10) times higher hs-cTnl, and a 1.10 (1.08 to 1.13) times higher NT-proBNP (model 4a). However, these models somewhat underestimated the

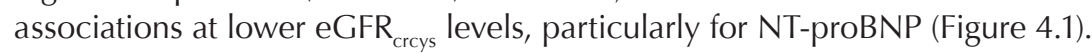

\section{eGFR and cardiac biomarkers - hs-cTnT vs. hscTnl}

The associations of categorical and continuous eGFR crcys $_{\text {with }}$ hs-cTnT were slightly stronger than those with hs-cTnl (Table 4.2, model 4a). This difference was statistically significant when we took their different distributions into account using a comparison of partial correlations in model 4a $\left(\mathrm{p}<0.001\right.$ for $\mathrm{eGFR}_{\text {crcys }} 60-<90 \mathrm{ml} / \mathrm{min} / 1.73 \mathrm{~m}^{2}, \mathrm{eGFR}_{\text {crcys }}<60 \mathrm{ml} / \mathrm{min} / 1.73 \mathrm{~m}^{2}$ and continuous eGFR crcys $_{\text {s }}$.

\section{Albuminuria and cardiac biomarkers}

Participants with higher UAE had higher hs-cTnT, hs-cTnl and NT-proBNP (Supplemental Table 4.1). After adjustment for potential confounders, and as compared with UAE $<15$ $\mathrm{mg} / 24 \mathrm{~h}$, both UAE $15-<30 \mathrm{mg} / 24 \mathrm{~h}$ and $U A E \geq 30 \mathrm{mg} / 24 \mathrm{~h}$ remained associated with higher hs-cTnl, whereas only UAE $\geq 30 \mathrm{mg} / 24 \mathrm{~h}$ was associated with higher hs-cTnT and NT-proBNP (Table 4.3, model 4a). Results were similar when we adjusted for $24 \mathrm{~h}$ average ambulatory systolic pressure (Table 4.3, model 4b).

When albuminuria was expressed as a continuous variable, each doubling of UAE was associated with a (Ratio $(95 \% \mathrm{Cl})) 1.03$ (1.02 to 1.04) times higher hs-cTnT, a 1.05 (1.03 to 1.07) times higher hs-cTnl, and a 1.07 (1.04 to 1.09) times higher NT-proBNP (model 4a). However, these models somewhat underestimated the associations at higher UAE, particularly for hs-cTnl and NT-proBNP (Figure 4.2). 


\section{Albuminuria and cardiac biomarkers - hs-cTnT vs. hs-cTnl}

The associations of categorical and continuous albuminuria with hs-cTnl seemed to be slightly stronger than those with hs-cTnT (Table 4.3, model 4a), but this difference was not statistically significant when we took the distributions of hs-cTnT and hs-cTnl into account using a comparison of partial correlations in model $4 a$ ( $p=0.57$ for UAE $15-<30 \mathrm{mg} / 24 \mathrm{~h}$; $p=0.13$ for $U A E \geq 30 \mathrm{mg} / 24 \mathrm{~h} ; \mathrm{p}=0.72$ for continuous $U A E$ ).

\section{Additional analyses}

First, results were not materially altered: when we restricted the analyses to participants with UAE $\leq 300 \mathrm{mg} / 24 \mathrm{~h}(\mathrm{n}=3081)$ or to participants with two urine collections ( $\mathrm{n}=2851)$; after additional adjustment for total $(n=2717)$ or moderate to vigorous physical activity $(n=2716)$, or questionnaire based prevalent CVD ( $n=3059)$; when we replaced office systolic pressure with either office diastolic pressure, office pulse pressure, office mean arterial pressure or their $24 \mathrm{~h}$ average ambulatory equivalents, or the presence of hypertension; and when we replaced the use of antihypertensive medication with the use of a renin-angiotensin system inhibitor (data not shown). Second, when eGFR ${ }_{\text {crcys }}$ was replaced with GGFR $_{\mathrm{cr}^{\prime}}$ associations of eGFR with hs-cTnT and NT-proBNP became numerically weaker but remained statistically significant, whereas results were similar when eGFR $_{\text {crcys }}$ was replaced with eGFR $_{\text {cys }}$ (Supplemental Table 4.2). Third, analyses with interaction terms indicated statistically significant interaction $\left(P_{\text {interaction }}<0.10\right)$ between eGFR $_{\text {crcys }}$ and T2DM, to such an extent that the associations of eGFR ${ }_{\text {crcys }}$ with the cardiac biomarkers were stronger in participants with T2DM than in participants with normal glucose metabolism (stratified analyses in Supplemental Table 4.3). In addition, the associations of albuminuria with NT-proBNP were stronger in participants with T2DM than in participants with normal glucose metabolism (stratified analyses in Supplemental Table 4.4). Fourth, UAE $\geq 30 \mathrm{mg} / 24 \mathrm{~h}$, but none of the eGFR $_{\text {crys }}$ categories, was positively associated with ischemic ECG abnormalities after adjustment for potential confounders (Supplemental Table 4.5). 


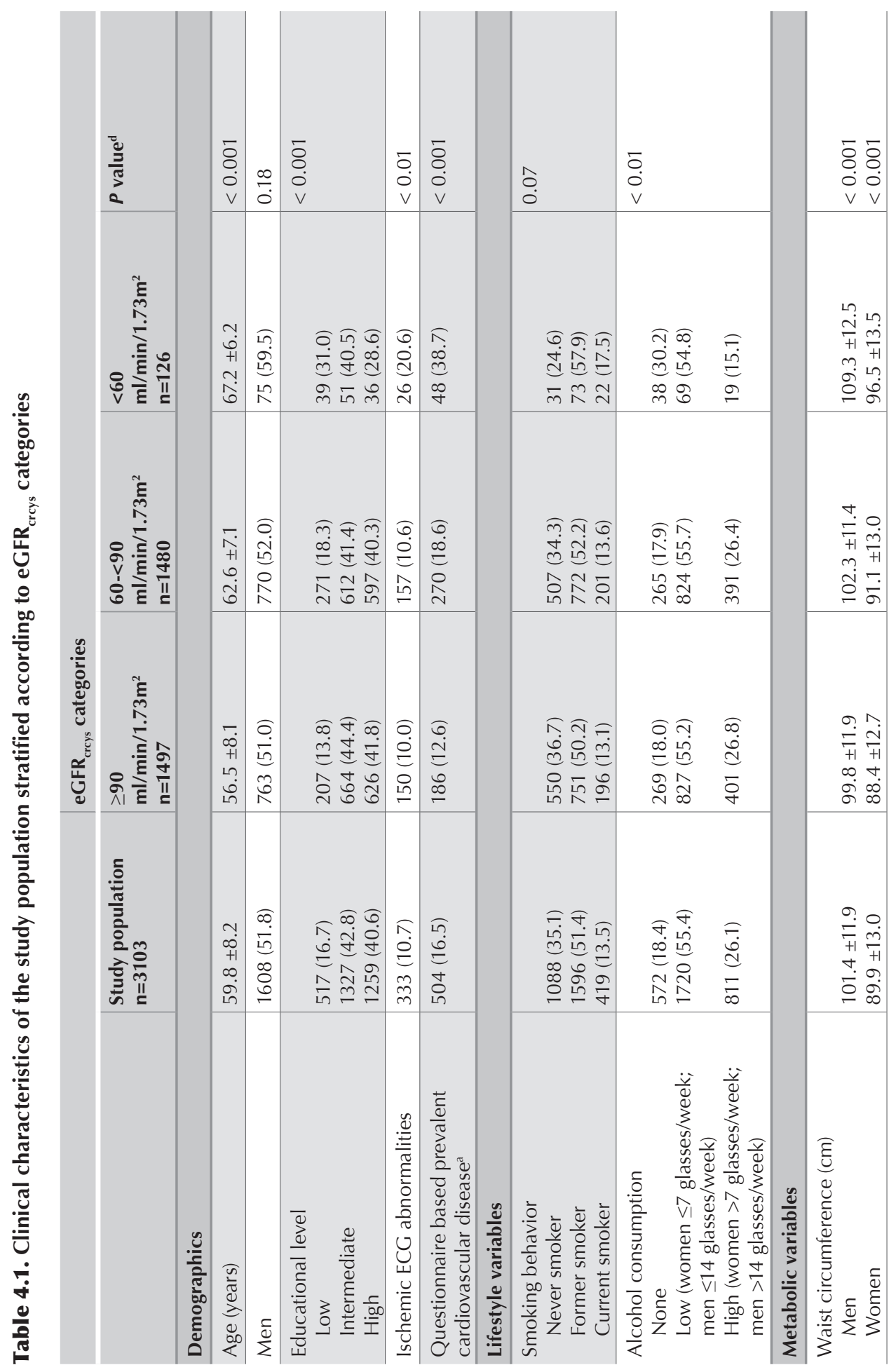




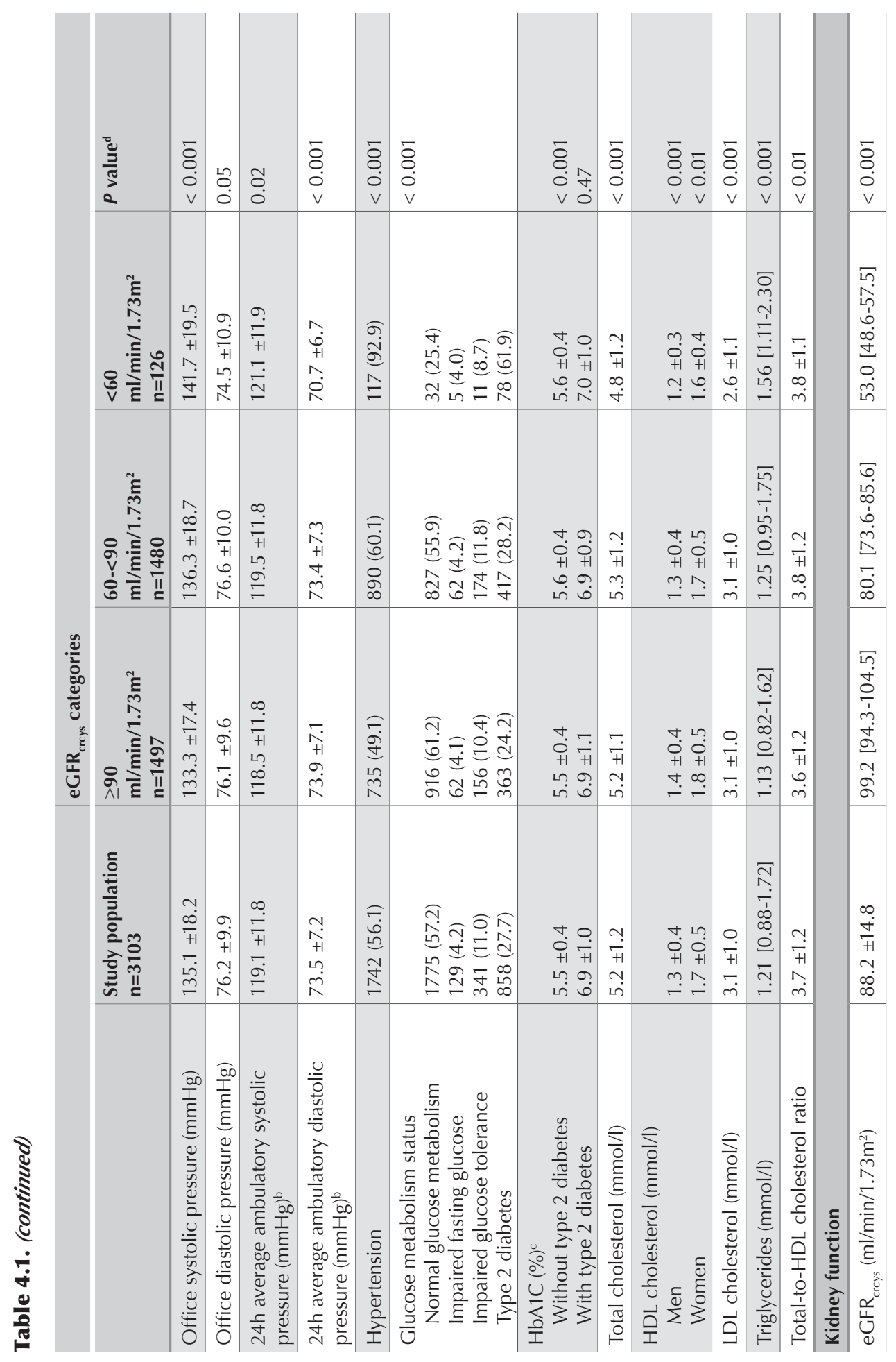




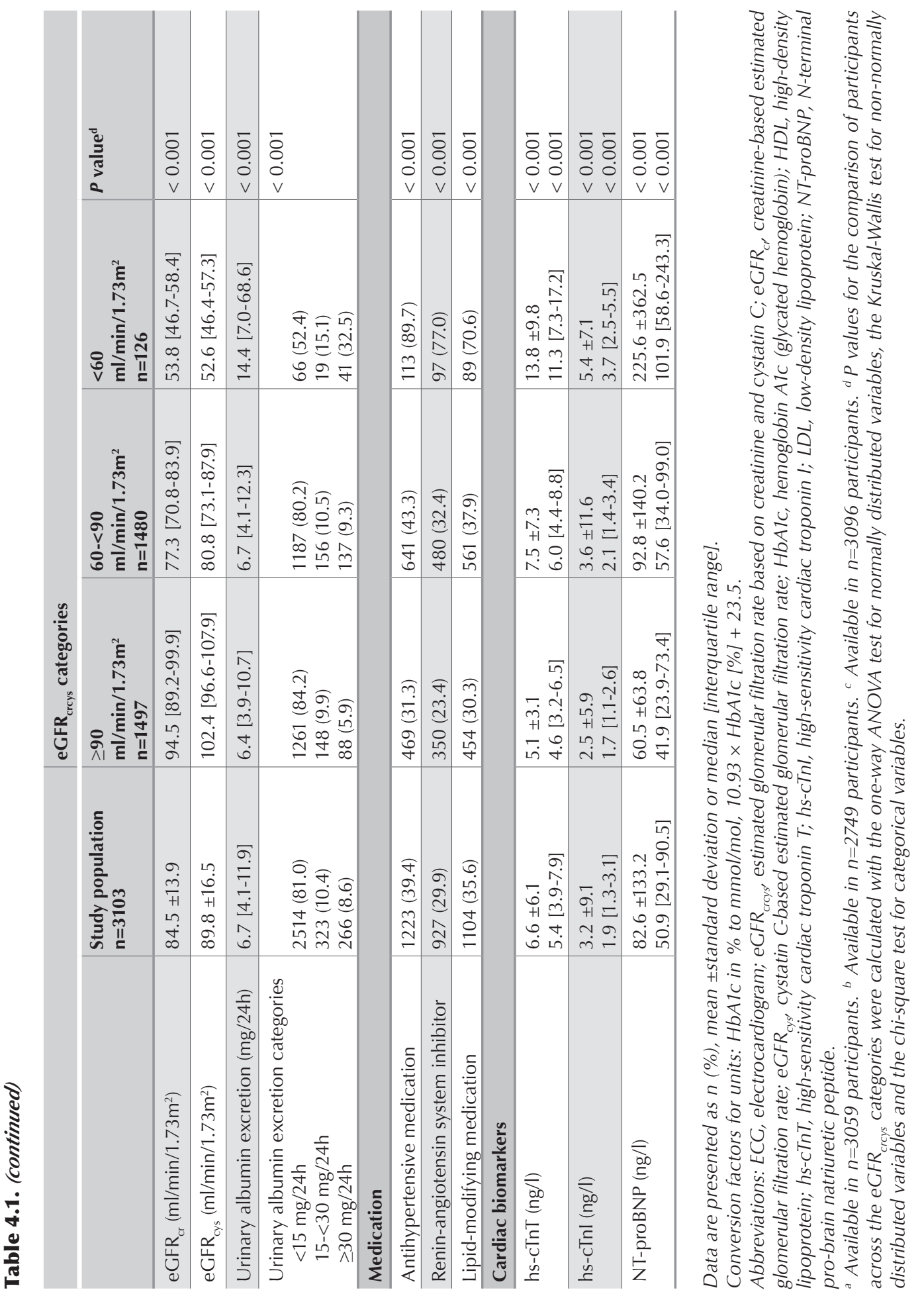




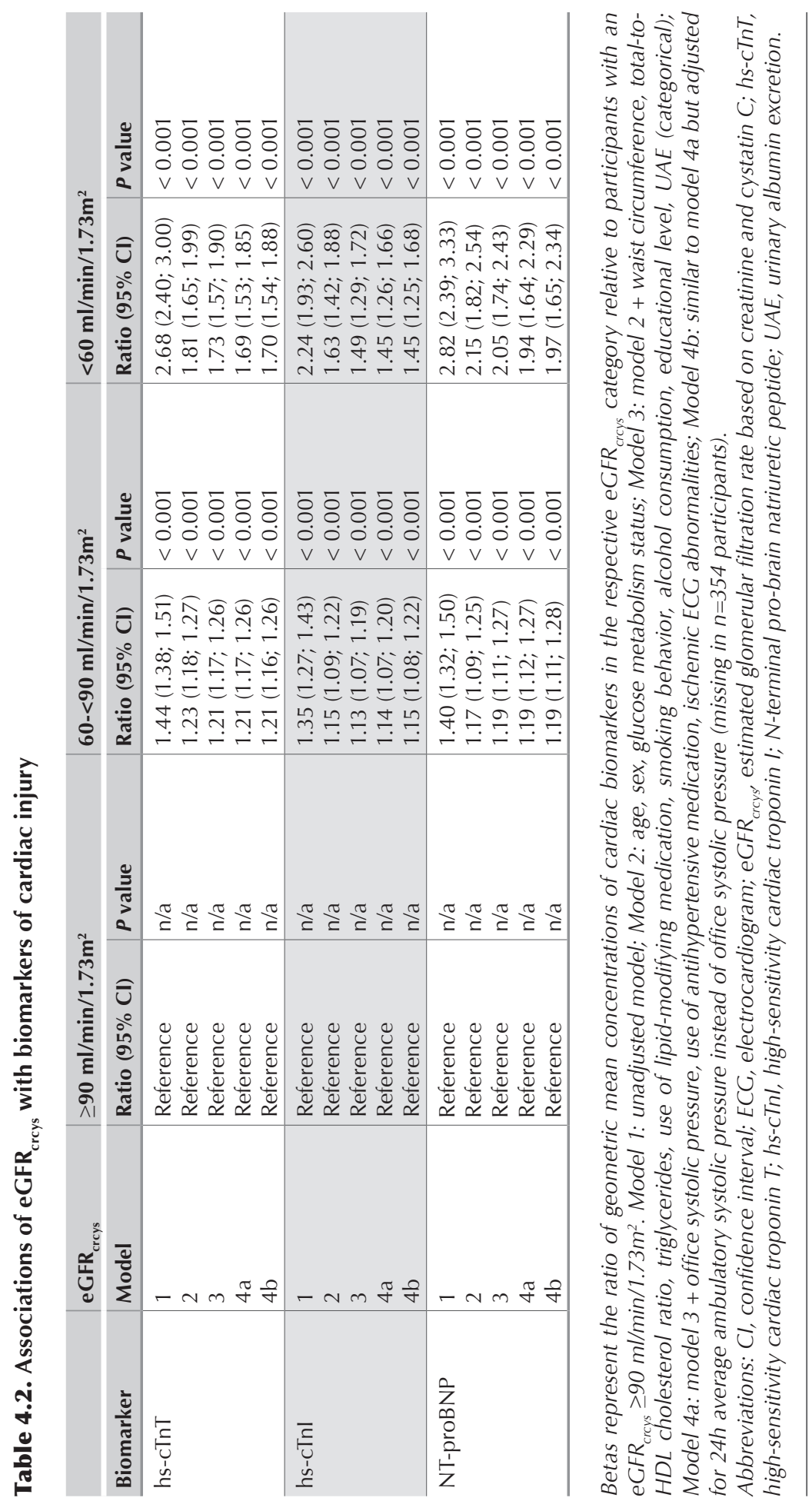



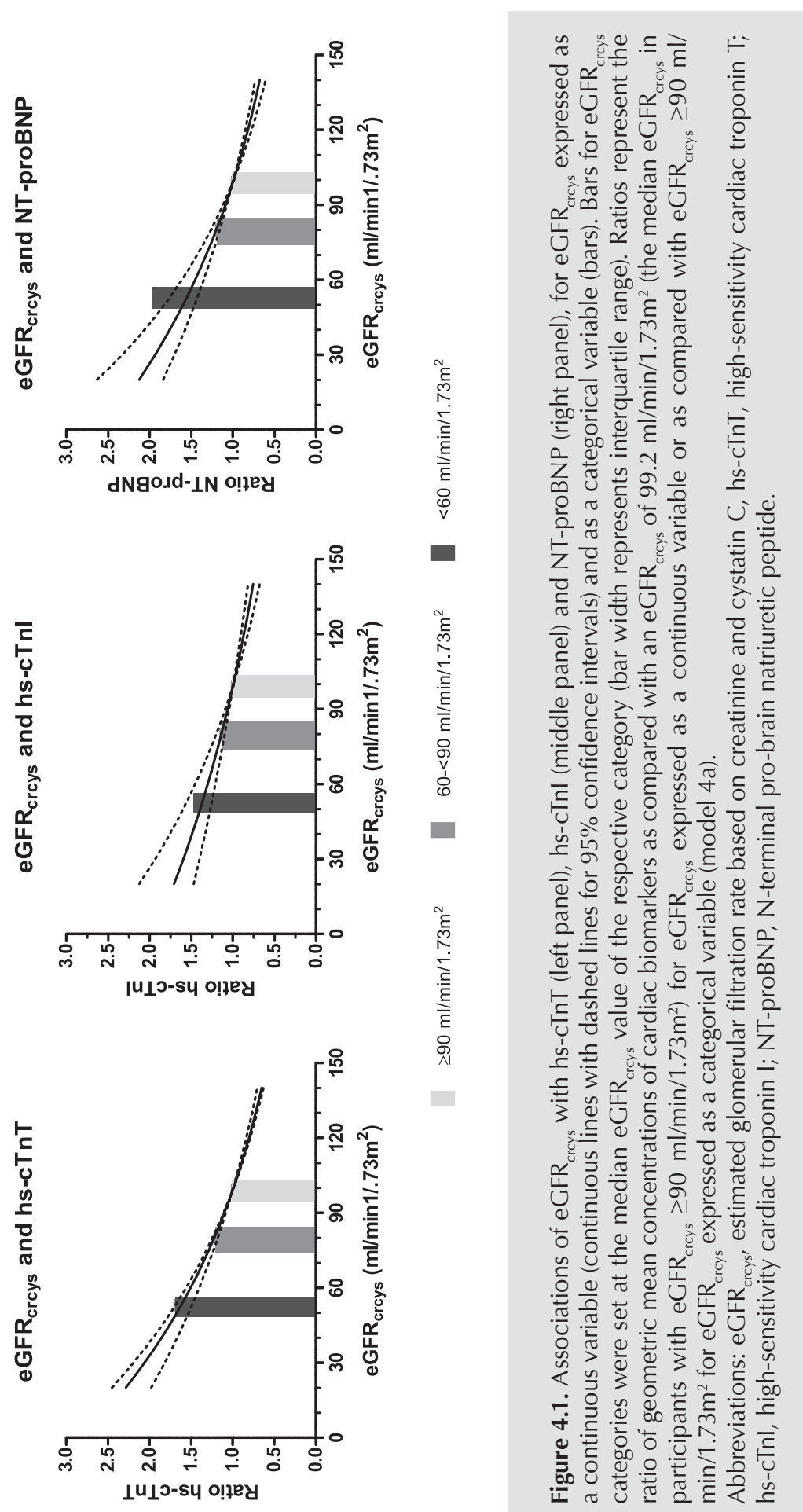


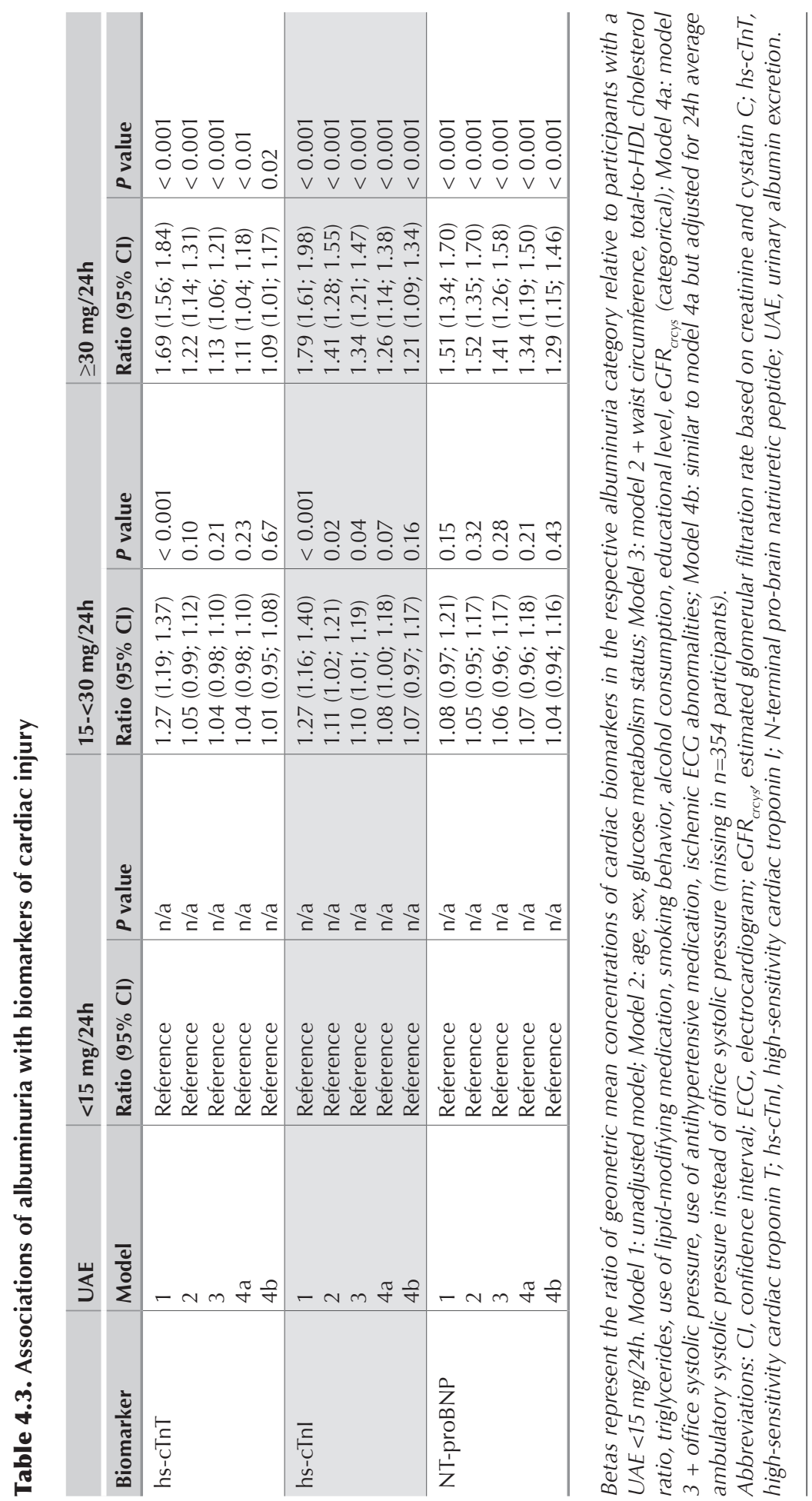



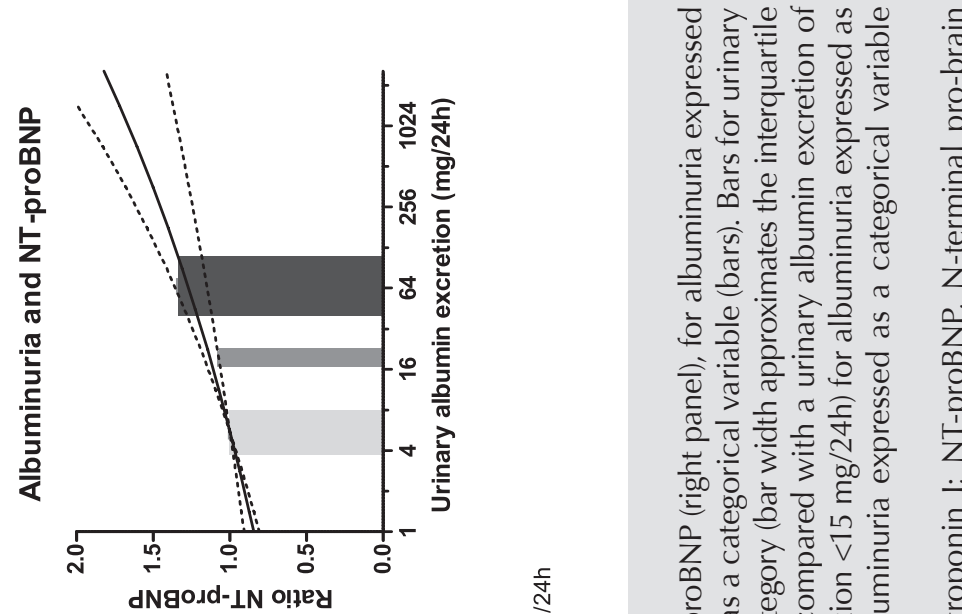

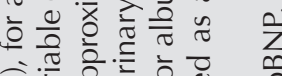

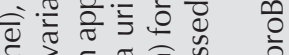

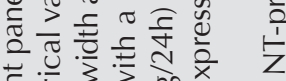

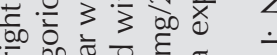

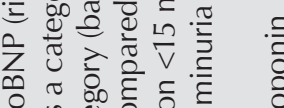

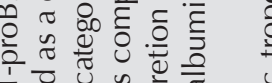

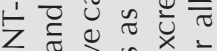

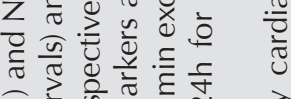

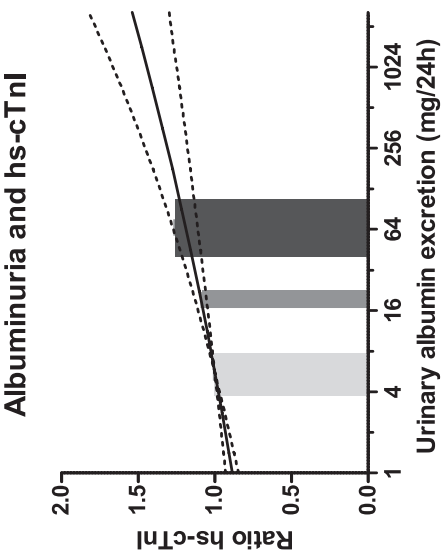

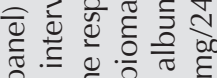

ㅇํำ

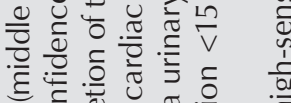

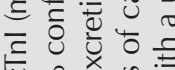

论

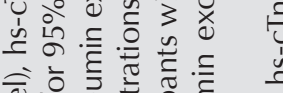

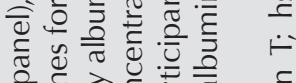

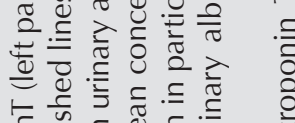

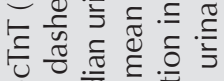

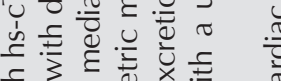

ज纯

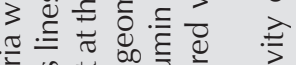

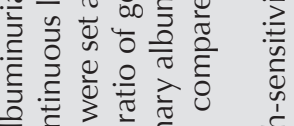

స

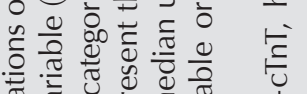

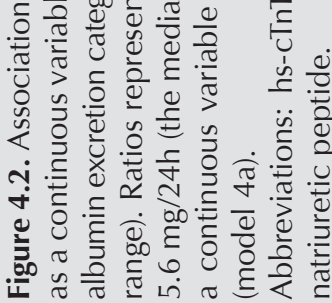




\section{DISCUSSION}

This population-based study on the associations of eGFR and albuminuria with biomarkers of cardiac injury had two main findings. First, $\mathrm{eGFR}_{\text {crcys }}$ and albuminuria were mutually independently associated with hs-cTnT, hs-cTnl and NT-proBNP after adjustment for demographics, lifestyle variables and CVD risk factors. Second, eGFR $_{\text {crcys }}$ was more strongly associated with hs-cTnT than with hs-cTnl. However, although statistically significant, this difference seemed modest in absolute terms. Of interest, for albuminuria the associations with hs-cTnT and hs-cTnl were much more similar.

Our results are in line with most ${ }^{5,11,13}$ but not all ${ }^{12}$ of the few previous studies that have conjointly evaluated eGFR and albuminuria, and have shown mutually independent associations of both with hs-cTnT, ${ }^{5,11,13}$ hs-cTnl, ${ }^{5}$ and NT-proBNP. ${ }^{11}$ The present study expands the population-based data on this topic ${ }^{11,13}$ by its direct comparison of both cTn and the detailed characterization of its population, which allowed adjustment for an extensive series of potential confounders, including $24 \mathrm{~h}$ average ambulatory blood pressure. Altogether, the available data argue that eGFR and albuminuria are, over their entire range, associated with these biomarkers of cardiac injury.

cTn are released following myocardial injury due to, for example, cardiac ischemia, and possibly also cardiac strain. ${ }^{3}$ Similarly, NT-proBNP may be a marker of "pancardiac disease", 4 being associated with left ventricular dysfunction, left ventricular hypertrophy, left atrial dilation, and cardiac ischemia. ${ }^{4}$ NT-proBNP $(8.5 \mathrm{kDa})$ is subsequently eliminated via the kidneys, ${ }^{7}$ whereas the elimination routes of $\mathrm{cTnT}^{\mathrm{T}}$ and $\mathrm{cTnl}$ are unknown. However, based on their molecular weight, free cTnT $(37 \mathrm{kDa})$, free cTnl $(24 \mathrm{kDa})$ and their fragments, may be (partly) filtered by the glomeruli and catabolized by the tubules. ${ }^{25,26}$ Indeed, after myocardial infarction, cTnT and cTnl have been observed as free cTnT and cTnl, larger cTnT-I-C (77 kDa) and cTnl-C (40 kDa) complexes, and fragments. ${ }^{27-31}$ In contrast, in renal failure, cTnT circulates primarily as fragments, ${ }^{32}$ whereas the circulating form of $\mathrm{cTnl}$ in renal failure is unknown.

In this study, we could not determine the relative contributions of lower renal elimination and cardiac injury to the association of eGFR with the cardiac biomarkers. The observation that eGFR seemed to be associated more strongly with the biomarkers than albuminuria, the absence of a positive association with ischemic ECG abnormalities and the minor attenuation of the regression coefficients after adjustment for these ECG findings may indicate a role for lower renal elimination. However, the cardiac biomarkers may identify cardiac injury that is subclinical and not visible on an ECG. Further, findings from other studies strongly argue that cardiac injury is involved. First, eGFR has been associated with CVD mortality at levels $\geq 60$ $\mathrm{ml} / \mathrm{min} / 1.73 \mathrm{~m}^{2}$, especially if the GFR estimate included cystatin $\mathrm{C}_{1}{ }^{2}$ and the evidence for an association of eGFR $<60 \mathrm{ml} / \mathrm{min} / 1.73 \mathrm{~m}^{2}$ with CVD is compelling. ${ }^{1,2}$ Second, hs-cTnT and NT-proBNP have been associated with incident overt CVD regardless of eGFR in the general population. ${ }^{11}$ Therefore, the results of this study suggest that (subclinical) cardiac injury may be a mechanism for the CVD mortality risk associated with lower eGFR in the general population.

In this study, eGFR was associated with the cardiac biomarkers regardless of the filtration marker and equation used. Nevertheless, associations of eGFR with hs-cTnT and NT-proBNP were numerically stronger with GFR estimates that included cystatin C. This observation agrees with data on the association of eGFR with CVD mortality. ${ }^{2}$ Non-GFR determinants of cystatin $\mathrm{C}$, which may include obesity, diabetes and inflammation, may have augmented the association with the cardiac biomarkers. ${ }^{2}$ Alternatively, cystatin $\mathrm{C}$ may be a more sensitive biomarker of GFR than creatinine in populations with more comorbidities. ${ }^{33}$ 
The association of albuminuria with the biomarkers of cardiac injury, which was independent of its association with ischemic ECG abnormalities, fits the strong association of albuminuria with CVD mortality. 'Generalized endothelial dysfunction and/or capillary rarefaction may explain the association of albuminuria with cardiac injury. According to this theory, endothelial dysfunction and capillary rarefaction in the microcirculation (i.e., microvascular dysfunction) of the kidneys leads to albuminuria, ${ }^{8,9}$ whereas in the heart both may cause a supply-demand mismatch with (subclinical) ischemia. ${ }^{10}$ Indeed, lower coronary flow reserve ${ }^{34}$ and lower myocardial perfusion reserve, ${ }^{35}$ which are measures of microvascular dysfunction of the heart, ${ }^{10}$ have been associated with higher $\mathrm{CTn}^{34}$ and NT-proBNP ${ }^{35}$ in individuals without overt coronary artery disease. Importantly, albuminuria has also been associated with lower coronary flow reserve. ${ }^{36}$

Explorative analyses suggested that the associations of eGFR with hs-cTnT, hs-cTnl and NT-proBNP, and the association of albuminuria with NT-proBNP, were stronger in individuals with T2DM. Although speculative, these observations may have several explanations. First, the diabetic milieu may augment the effects of reduced eGFR on CVD. Second, experimental data suggest that albuminuria could be a better biomarker of microvascular disease in individuals with diabetes than in non-diabetic individuals. ${ }^{37,38}$ This may be because hyperglycemia may disrupt the vascular endothelial growth factor (VEGF)-nitric oxide (NO) axis and, thereby, aggravates vascular injury. ${ }^{39}$ Alternatively or additionally, in individuals with T2DM, glomerular hyperfiltration ${ }^{40}$ may increase permeation of albumin through an injured glomerular capillary wall. Third, for NT-proBNP the interaction with T2DM may reflect the distributions of eGFR and UAE according to glucose metabolism status (i.e., lower eGFR and higher UAE in individuals with T2DM), combined with curvilinear associations of both with NT-proBNP (Figures 4.1 and 4.2). Nevertheless, we cannot exclude the play of chance.

Our finding that eGFR was more strongly associated with hs-cTnT than hs-cTnl expands the results of studies in selected populations ${ }^{5,14-19}$ to the range of eGFR observed in the general population. Differences in renal elimination between both cTn, for example accumulation of CTnT fragments, ${ }^{32}$ may explain their differential association with eGFR..$^{15}$ However, other explanations should also be considered. For example, differences in stability and modification after release into the circulation that interfere with detection may exist in the face of reduced eGFR. ${ }^{41}$ Hence, future mechanistic studies should compare the extent of renal elimination of cTnT and cTnl. The similar associations of albuminuria with both cTn disagree with a smaller study that also showed stronger associations of albuminuria with hs-cTnT than hs-cTnl. ${ }^{5}$ However, that study did not formally compare both cTn taking their different distributions into account.

Our study had some limitations. First, due to the cross-sectional design and the absence of data on hard clinical outcomes, such as incident CVD, we cannot make strong causal inferences and we cannot determine the direction of the associations. In fact, these may be bidirectional. ${ }^{42,43}$ In addition, data on hard clinical outcomes may clarify the clinical relevance of the differences between hs-cTnT and hs-cTnl. Second, although we measured cTnT and cTnl with high-sensitivity assays, concentrations were still below the LoB and LoD in a substantial number of participants. Third, the lack of standardization of hs-cTnl assays may hamper generalizability to other hs-cTnl assays. Fourth, participants resided in a single region in the Netherlands and the vast majority were Caucasian individuals from European descent (98.6\%), which may limit generalizability to other ethnic groups.

In conclusion, eGFR and albuminuria were, independently of each other, associated with biomarkers of (subclinical) cardiac injury, and these associations already appeared at 
levels that do not fulfill the CKD criteria. Although reduced renal elimination may partly underlie the associations of eGFR, this study supports the concept that eGFR and albuminuria are, over their entire range, associated with cardiac injury. In addition, eGFR was more strongly associated with hs-cTnT than with hs-cTnl. The mechanisms responsible for this difference need further study as this could be of clinical relevance. 


\section{REFERENCES}

1. Fox CS, Matsushita K, Woodward M, Bilo HJ, Chalmers J, Heerspink HJ, et al. Associations of kidney disease measures with mortality and end-stage renal disease in individuals with and without diabetes: a meta-analysis. Lancet. 2012 Nov 10;380(9854):1662-73.

2. Shlipak MG, Matsushita K, Arnlov J, Inker LA, Katz R, Polkinghorne KR, et al. Cystatin C versus creatinine in determining risk based on kidney function. N Engl J Med. 2013 Sep 5;369(10):932-43.

3. Giannitsis E, Katus HA. Cardiac troponin level elevations not related to acute coronary syndromes. Nat Rev Cardiol. 2013 Nov;10(11):623-34.

4. Struthers A, Lang C. The potential to improve primary prevention in the future by using BNP/N-BNP as an indicator of silent 'pancardiac' target organ damage: BNP/N-BNP could become for the heart what microalbuminuria is for the kidney. Eur Heart J. 2007 Jul;28(14):1678-82.

5. DeFilippi C, Seliger SL, Kelley W, Duh SH, Hise M, Christenson RH, et al. Interpreting cardiac troponin results from high-sensitivity assays in chronic kidney disease without acute coronary syndrome. Clin Chem. 2012 Sep;58(9):1342-51.

6. Schiffrin EL, Lipman ML, Mann JF. Chronic kidney disease: effects on the cardiovascular system. Circulation. 2007 Jul $3 ; 116(1): 85-97$.

7. Van Kimmenade RR, Januzzi JL, Jr., Bakker JA, Houben AJ, Rennenberg R, Kroon AA, et al. Renal clearance of B-type natriuretic peptide and amino terminal pro-B-type natriuretic peptide a mechanistic study in hypertensive subjects. J Am Coll Cardiol. 2009 Mar 10;53(10):884-90.

8. Stehouwer CD, Smulders YM. Microalbuminuria and risk for cardiovascular disease: Analysis of potential mechanisms. J Am Soc Nephrol. 2006 Aug;17(8):2106-11.

9. Martens RJ, Henry RM, Houben AJ, van der Kallen CJ, Kroon AA, Schalkwijk CG, et al. Capillary Rarefaction Associates with Albuminuria: The Maastricht Study. J Am Soc Nephrol. 2016 May 9.

10. Camici PG, Crea F. Coronary microvascular dysfunction. N Engl J Med. 2007 Feb 22;356(8):830-40.

11. Scheven L, de Jong PE, Hillege HL, Lambers Heerspink HJ, van Pelt LJ, Kootstra JE, et al. High-sensitive troponin T and $\mathrm{N}$-terminal pro-B type natriuretic peptide are associated with cardiovascular events despite the cross-sectional association with albuminuria and glomerular filtration rate. Eur Heart J. 2012 Sep;33(18):2272-81.

12. Dubin RF, Li Y, He J, Jaar BG, Kallem R, Lash JP, et al. Predictors of high sensitivity cardiac troponin T in chronic kidney disease patients: a cross-sectional study in the chronic renal insufficiency cohort (CRIC). BMC Nephrol. 2013;14:229.

13. Xiao W, Ye P, Cao R, Yang X, Bai Y, Wu H. Urine Albumin Excretion Is Associated with Cardiac Troponin T Detected with a Highly Sensitive Assay in a Community-Based Population. PloS one. 2015;10(8):e0135747.

14. Guclu T, Bolat S, Senes M, Yucel D. Relationship between high sensitivity troponins and estimated glomerular filtration rate. Clin Biochem. 2016 Jan 6.

15. Cardinaels EP, Daamen MA, Bekers O, Ten Kate J, Niens M, van Suijlen JD, et al. Clinical Interpretation of Elevated Concentrations of Cardiac Troponin T, but Not Troponin I, in Nursing Home Residents. J Am Med Dir Assoc. 2015 Aug 6.

16. Lamb EJ, Kenny C, Abbas NA, John RI, Webb MC, Price CP, et al. Cardiac troponin I concentration is commonly increased in nondialysis patients with CKD: experience with a sensitive assay. Am J Kidney Dis. 2007 Apr;49(4):507-16.

17. Lippi G, Cervellin G. High-sensitivity troponin T is more susceptible than high-sensitivity troponin I to impaired renal function. Am J Cardiol. 2013 Dec 15;112(12):1985.

18. Abbas NA, John RI, Webb MC, Kempson ME, Potter AN, Price CP, et al. Cardiac troponins and renal function in nondialysis patients with chronic kidney disease. Clin Chem. 2005 Nov;51(11):2059-66.

19. Bjurman C, Petzold M, Venge P, Farbemo J, Fu ML, Hammarsten O. High-sensitive cardiac troponin, NT-proBNP, hFABP and copeptin levels in relation to glomerular filtration rates and a medical record of cardiovascular disease. Clin Biochem. 2015 Mar;48(4-5):302-7.

20. Schram MT, Sep SJ, van der Kallen CJ, Dagnelie PC, Koster A, Schaper N, et al. The Maastricht Study: an extensive phenotyping study on determinants of type 2 diabetes, its complications and its comorbidities. Eur J Epidemiol. 2014 Jun;29(6):439-51.

21. Inker LA, Schmid CH, Tighiouart H, Eckfeldt JH, Feldman HI, Greene T, et al. Estimating glomerular filtration rate from serum creatinine and cystatin C. N Engl J Med. 2012 Jul 5;367(1):20-9.

22. Spauwen PJ, van Boxtel MP, Verhey FR, Kohler S, Sep SJ, Koster A, et al. Both Low and High 24-Hour Diastolic Blood Pressure Are Associated With Worse Cognitive Performance in Type 2 Diabetes: The Maastricht Study. Diabetes Care. 2015 Aug;38(8):1473-80.

23. Steiger JH. Tests for comparing elements of a correlation matrix. Psychol Bull. 1980;87(2):245-51.

24. Van Sloten TT, Henry RM, Dekker JM, Nijpels G, Unger T, Schram MT, et al. Endothelial dysfunction plays a key role in increasing cardiovascular risk in type 2 diabetes: the Hoorn study. Hypertension. 2014 Dec;64(6):1299-305.

25. Carone FA, Peterson DR, Oparil S, Pullman TN. Renal tubular transport and catabolism of proteins and peptides. Kidney Int. 1979 Sep;16(3):271-8.

26. Maack T, Johnson V, Kau ST, Figueiredo J, Sigulem D. Renal filtration, transport, and metabolism of low-molecularweight proteins: a review. Kidney Int. 1979 Sep;16(3):251-70.

27. Wu AH, Feng YJ, Moore R, Apple FS, McPherson PH, Buechler KF, et al. Characterization of cardiac troponin subunit release into serum after acute myocardial infarction and comparison of assays for troponin T and I. American Association for Clinical Chemistry Subcommittee on cTnl Standardization. Clin Chem. 1998 Jun;44(6 Pt 1):1198-208.

28. Cardinaels EP, Mingels AM, van Rooij T, Collinson PO, Prinzen FW, van Dieijen-Visser MP. Time-dependent degradation pattern of cardiac troponin T following myocardial infarction. Clin Chem. 2013 Jul;59(7):1083-90.

29. Labugger R, Organ L, Collier C, Atar D, Van Eyk JE. Extensive troponin I and T modification detected in serum from patients with acute myocardial infarction. Circulation. 2000 Sep 12;102(11):1221-6. 
30. Peronnet E, Becquart L, Poirier F, Cubizolles M, Choquet-Kastylevsky G, Jolivet-Reynaud C. SELDI-TOF MS analysis of the Cardiac Troponin I forms present in plasma from patients with myocardial infarction. Proteomics. 2006 Dec;6(23):6288-99.

31. Katrukha AG, Bereznikova AV, Esakova TV, Pettersson K, Lovgren T, Severina ME, et al. Troponin I is released in bloodstream of patients with acute myocardial infarction not in free form but as complex. Clin Chem. 1997 Aug;43(8 Pt 1):1379-85.

32. Mingels AM, Cardinaels EP, Broers NJ, Van Sleeuwen A, Streng AS, Van Dieijen-Visser MP, et al. Cardiac troponin T: smaller molecules in patients with end-stage renal disease than after onset of acute myocardial infarction. Clin Chem. Manuscript accepted for publication (CLINCHEM/2016/261644).

33. Shlipak MG, Mattes MD, Peralta CA. Update on cystatin C: incorporation into clinical practice. Am J Kidney Dis. 2013 Sep;62(3):595-603.

34. Taqueti VR, Everett BM, Murthy VL, Gaber M, Foster CR, Hainer J, et al. Interaction of impaired coronary flow reserve and cardiomyocyte injury on adverse cardiovascular outcomes in patients without overt coronary artery disease. Circulation. 2015 Feb 10;131(6):528-35.

35. Mitchell A, Misialek JR, Folsom AR, Duprez D, Alonso A, Jerosch-Herold M, et al. Usefulness of N-terminal Pro-brain Natriuretic Peptide and Myocardial Perfusion in Asymptomatic Adults (from the Multi-Ethnic Study of Atherosclerosis). Am J Cardiol. 2015 May 15;115(10):1341-5.

36. Von Scholten BJ, Hasbak P, Christensen TE, Ghotbi AA, Kjaer A, Rossing P, et al. Cardiac Rb PET/CT for fast and non-invasive assessment of microvascular function and structure in asymptomatic patients with type 2 diabetes. Diabetologia. 2015 Nov 2.

37. Zhao HJ, Wang S, Cheng H, Zhang MZ, Takahashi T, Fogo AB, et al. Endothelial nitric oxide synthase deficiency produces accelerated nephropathy in diabetic mice. J Am Soc Nephrol. 2006 Oct;17(10):2664-9.

38. Nakagawa T, Sato W, Glushakova O, Heinig M, Clarke T, Campbell-Thompson M, et al. Diabetic endothelial nitric oxide synthase knockout mice develop advanced diabetic nephropathy. J Am Soc Nephrol. 2007 Feb;18(2):539-50.

39. Nakagawa T. Uncoupling of the VEGF-endothelial nitric oxide axis in diabetic nephropathy: an explanation for the paradoxical effects of VEGF in renal disease. Am J Physiol Renal Physiol. 2007 Jun;292(6):F1665-72.

40. Vora JP, Dolben J, Dean JD, Thomas D, Williams JD, Owens DR, et al. Renal hemodynamics in newly presenting non-insulin dependent diabetes mellitus. Kidney Int. 1992 Apr;41(4):829-35.

41. Freda BJ, Tang WH, Van Lente F, Peacock WF, Francis GS. Cardiac troponins in renal insufficiency: review and clinical implications. J Am Coll Cardiol. 2002 Dec 18;40(12):2065-71.

42. Bansal N, Katz R, Dalrymple L, de Boer I, DeFilippi C, Kestenbaum B, et al. NT-proBNP and troponin T and risk of rapid kidney function decline and incident CKD in elderly adults. Clin J Am Soc Nephrol. 2015 Feb 6;10(2):205-14.

43. Ho JE, Hwang SJ, Wollert KC, Larson MG, Cheng S, Kempf T, et al. Biomarkers of cardiovascular stress and incident chronic kidney disease. Clin Chem. 2013 Nov;59(11):1613-20. 
Supplemental Material 


\section{SUPPLEMENTAL METHODS}

\section{Kidney function}

The glomerular filtration rate (GFR) was estimated with the Chronic Kidney Disease Epidemiology Collaboration (CKD-EPI) equation based on the combination of serum creatinine and serum cystatin $\mathrm{C}\left(\mathrm{eGFR}\right.$ crrys ) for the primary analyses. ${ }^{1}$ For additional analyses, eGFR was calculated with the CKD-EPI equations based on serum creatinine $\left(\mathrm{eGFR}_{\mathrm{cr}}\right)^{1}$ and serum cystatin $\mathrm{C}\left(\mathrm{eGFR}_{\mathrm{cys}}\right)^{1}{ }^{1}$ Serum creatinine was measured with a Jaffé method traceable to isotope dilution mass spectrometry (due to a change of supplier by the Beckman Synchron LX20, Beckman Coulter Inc., Brea, UAS; and the Roche Cobas 6000, F. Hoffmann-La Roche, Basel, Switzerland). Serum cystatin C was measured with a particle enhanced immunoturbidimetric assay standardized against ERM-DA471/IFCC reference material (Roche Cobas 8000, Roche, Basel, Switzerland).

To assess urinary albumin excretion (UAE), participants were requested to collect two $24 \mathrm{~h}$ urine collections. Urinary albumin concentration was measured with a standard immunoturbidimetric assay by an automatic analyzer (due to a change of supplier by the Beckman Synchron LX20, Beckman Coulter Inc., Brea, USA; and the Roche Cobas 6000, F. Hoffmann-La Roche, Basel, Switzerland) and multiplied by collection volume to obtain the 24h UAE. A urinary albumin concentration below the detection limit of the assay $(2 \mathrm{mg} / \mathrm{l}$ for the Beckman Synchron LX20 and $3 \mathrm{mg} / \mathrm{l}$ for the Roche Cobas 6000) was set at $1.5 \mathrm{mg} / \mathrm{l}$ before multiplying by collection volume. Only urine collections with a collection time between $20 \mathrm{~h}$ and $28 \mathrm{~h}$ were considered valid. If needed, UAE was extrapolated to a $24 \mathrm{~h}$ excretion. UAE was preferably based on the average of two (available in $91.9 \%$ of the participants) $24 \mathrm{~h}$ urine collections.

\section{Further details on, and definitions of, covariates}

Glucose metabolism was classified according to the World Health Organization 2006 criteria $^{2}$ into normal glucose metabolism, impaired fasting glucose, impaired glucose tolerance, and diabetes mellitus. Participants with diabetes mellitus and participants using glucose-lowering medication were considered as having type 2 diabetes (T2DM) if they had no (self-reported) type 1 or other specific type of diabetes mellitus. For the present study, impaired fasting glucose and impaired glucose tolerance were combined into prediabetes. Total-to-highdensity lipoprotein $(\mathrm{HDL})$ cholesterol ratio was calculated by dividing total cholesterol by HDL cholesterol. Hypertension was defined as an office systolic pressure $\geq 140 \mathrm{mmHg}$, an office diastolic pressure $\geq 90 \mathrm{mmHg}$ and(or) the use of antihypertensive medication. Office pulse pressure was defined as office systolic pressure minus office diastolic pressure and office mean arterial pressure as office diastolic pressure plus 0.412 times office pulse pressure. ${ }^{3}$ Similar equations were used to calculate $24 \mathrm{~h}$ average ambulatory pulse pressure and $24 \mathrm{~h}$ average ambulatory mean arterial pressure, respectively. Smoking behavior was categorized into never, former, and current. Alcohol consumption was classified into no consumption, low consumption ( $<7$ glasses per week for women and $\leq 14$ glasses per week for men) and high consumption ( $>7$ glasses per week for women and $>14$ glasses per week for men). Educational level was classified into low (none, primary, or lower vocational education only), intermediate (intermediate general secondary, intermediate vocational or higher general secondary education) and high (higher vocational education or university level of education). ${ }^{4,5}$ Questionnaire based prevalent CVD was defined as a self-reported history of myocardial infarction, cerebrovascular infarction or hemorrhage, or percutaneous artery 
angioplasty of, or vascular surgery on, the coronary, abdominal, peripheral or carotid arteries. Electrocardiogram (ECG) data were coded according to the Minnesota code classification system, ${ }^{6}$ and ischemic ECG abnormalities were defined as a Minnesota code 1.1.1-1.2.8 (major or medium Q or QS waves), 7.1.1-7.1.2 (complete left bundle branch block), 1.3.1-1.3.2 (minor Q or QS waves), or any of 4.1.1, 4.1.2, 4.2 and 4.3 if accompanied by 5.1, 5.2 or 5.3 (ST segment abnormalities accompanied by abnormal T waves). ${ }^{7}$ 


\section{REFERENCES}

1. Inker LA, Schmid CH, Tighiouart H, Eckfeldt JH, Feldman HI, Greene T, et al. Estimating glomerular filtration rate from serum creatinine and cystatin C. N Engl J Med. 2012 Jul 5;367(1):20-9.

2. World Health Organization. Definition and diagnosis of diabetes mellitus and intermediate hyperglycemia: report of a WHO/IDF consultation2006: Available from: http://www.who.int/diabetes/publications/Definition $\% 20$ and $\% 20$ diagnosis\%20of\%20diabetes_new.pdf.

3. Meaney E, Alva F, Moguel R, Meaney A, Alva J, Webel R. Formula and nomogram for the sphygmomanometric calculation of the mean arterial pressure. Heart. 2000 Jul;84(1):64.

4. De Bie SE. Standaardvragen 1987: Voorstellen voor uniformering van vraagstellingen naar achtergrondkenmerken en interviews [Standard questions 1987: Proposal for uniformisation of questions regarding background variables and interviews]. Leiden, The Netherlands: Leiden University Press; 1987.

5. Spauwen PJ, van Boxtel MP, Verhey FR, Kohler S, Sep SJ, Koster A, et al. Both Low and High 24-Hour Diastolic Blood Pressure Are Associated With Worse Cognitive Performance in Type 2 Diabetes: The Maastricht Study. Diabetes Care. 2015 Aug;38(8):1473-80.

6. Prineas R, Crow R, Zhang Z. The Minnesota code manual of electrocardiographic findings. 2nd ed. London: SpringerVerlag; 2010.

7. Keen H, Morrish N, Lee ET. An analysis of serial Minnesota ECG code changes in the London cohort of the WHO Multinational Study of Vascular Disease in Diabetes. Diabetologia. 2001 Sep;44 Suppl 2:S72-7. 

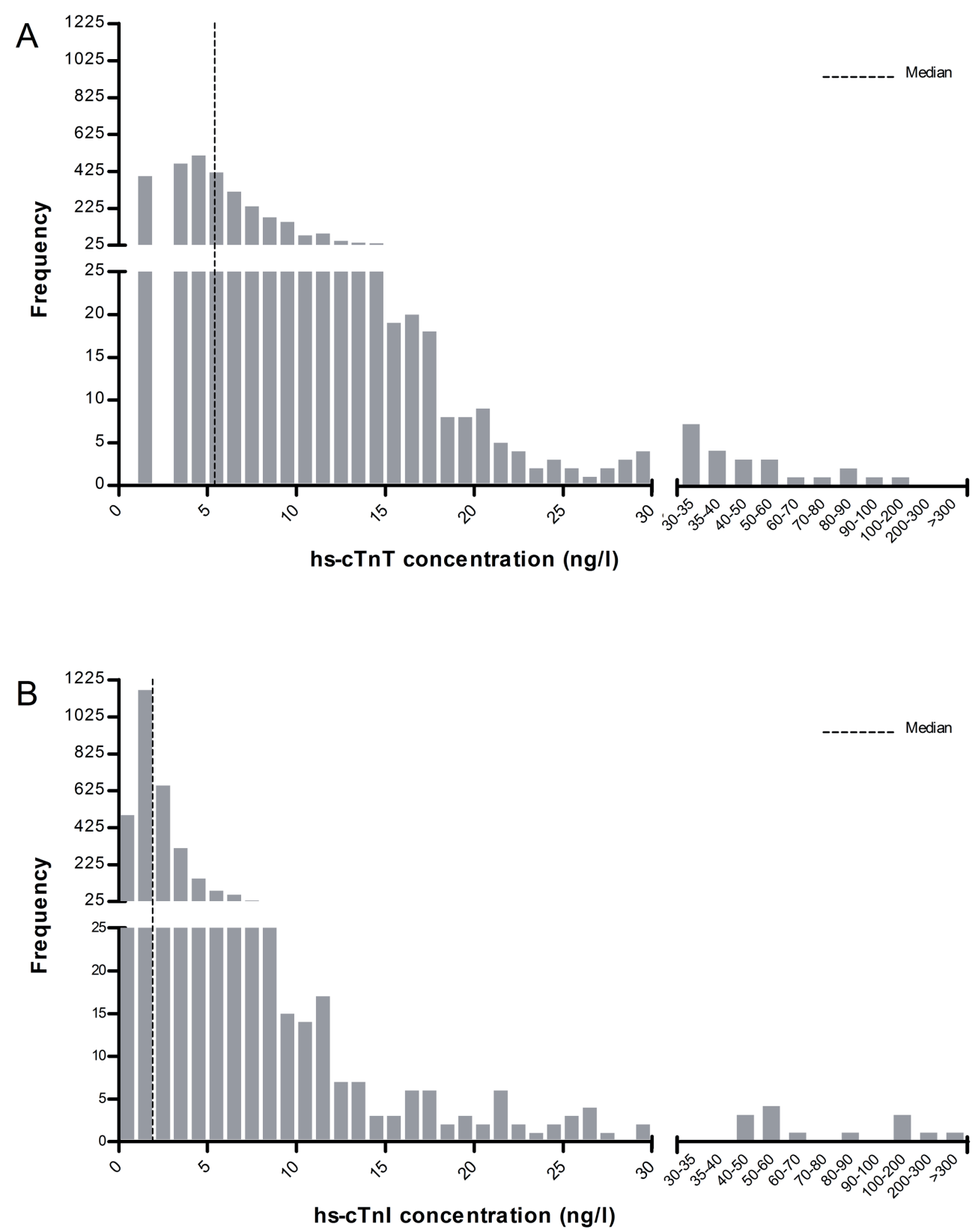

Supplemental Figure 4.1. Distribution of hs-cTnT (panel A) and hs-cTnl (panel B). Dashed lines indicate median concentrations. Abbreviations: hs-cTnT, high-sensitivity cardiac troponin $\mathrm{T}$; hs-cTnl, high-sensitivity cardiac troponin I. 


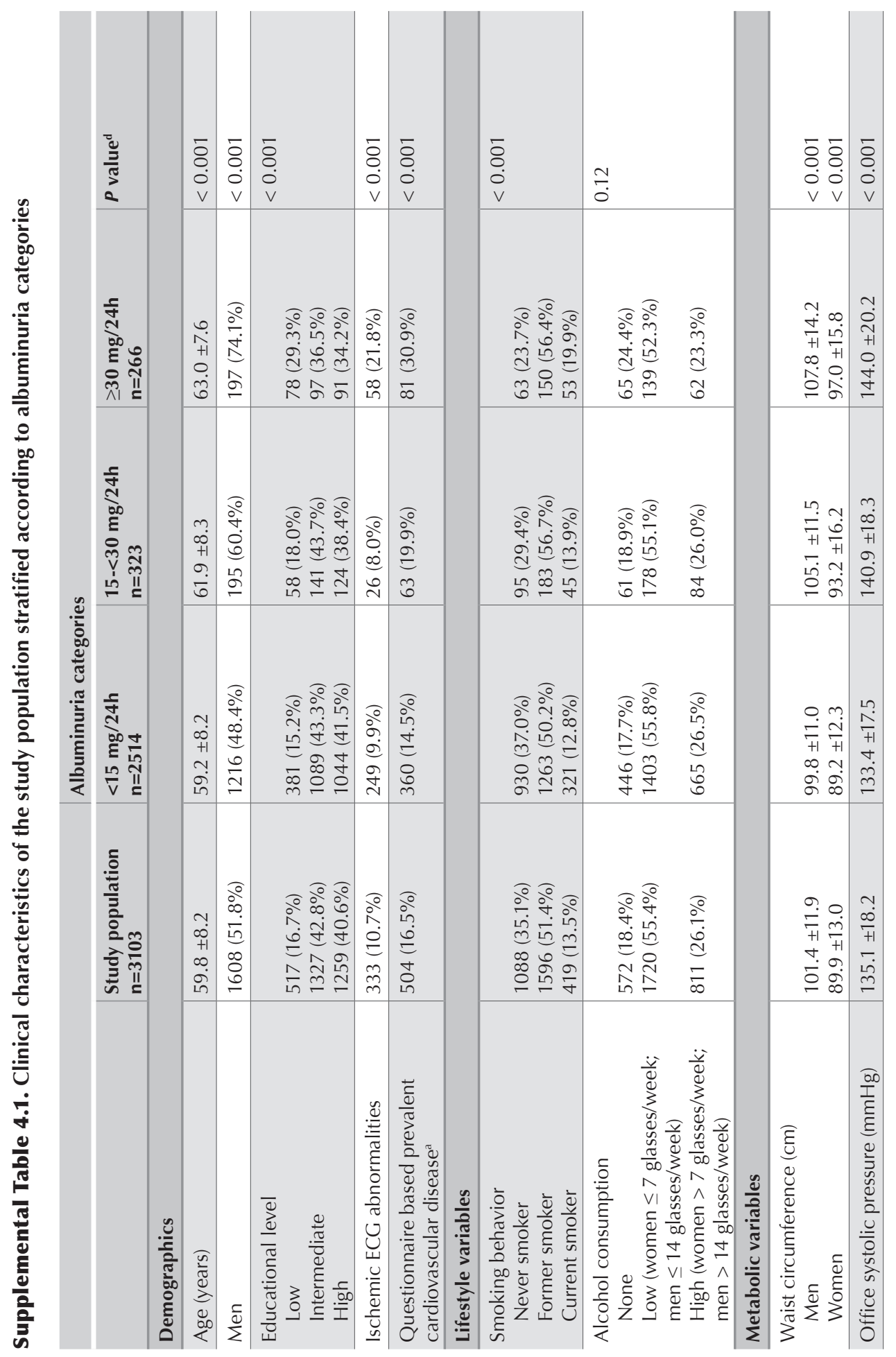




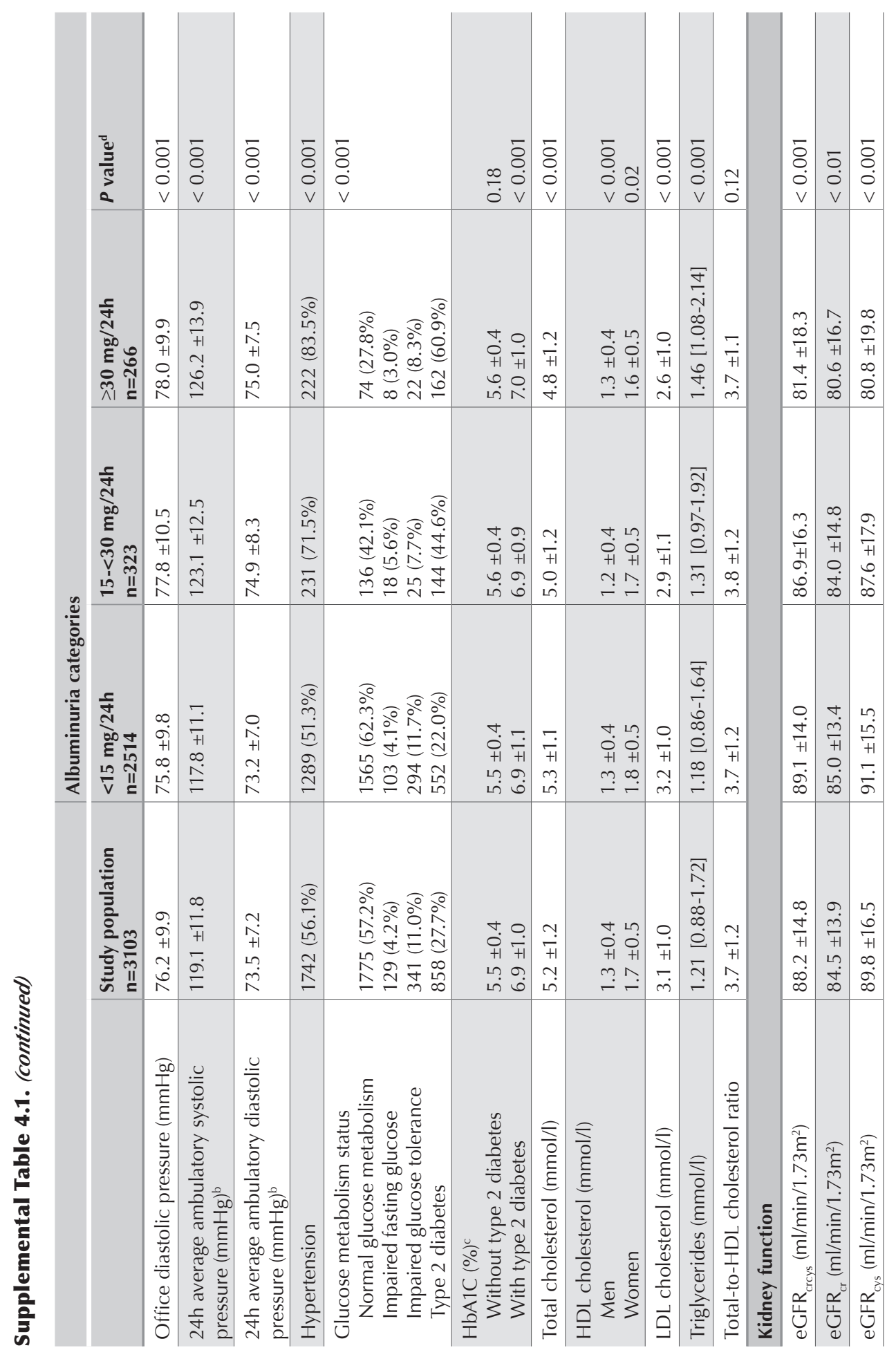




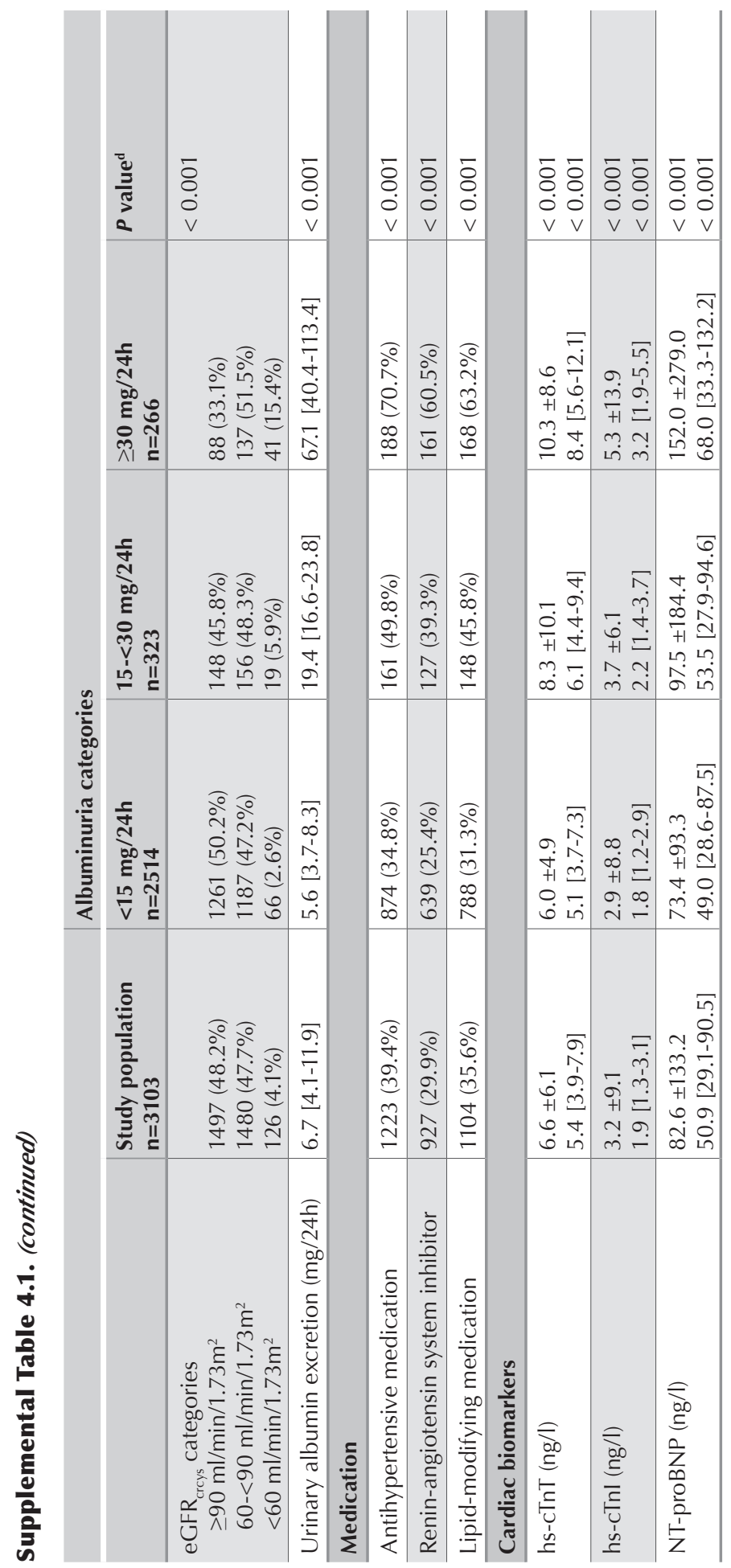

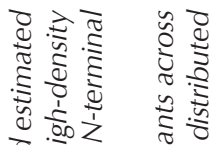
वे

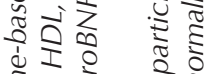
言茫 ปे

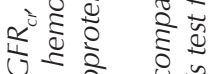
ن⿺辶 ن

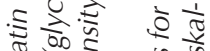
ữ

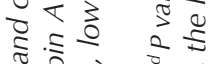

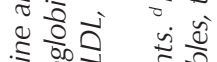
है 제 ฐำ.

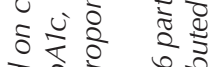
वे)

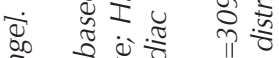

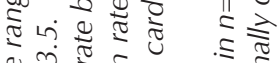

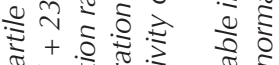

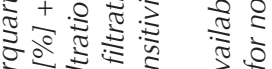

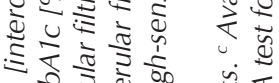

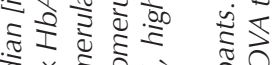

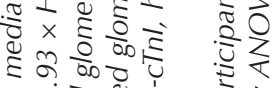

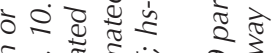

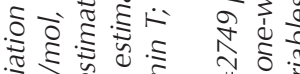

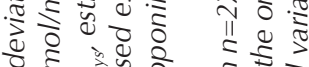

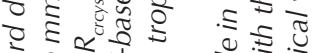

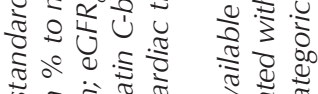

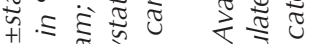
वิ $\frac{1}{2}$ के ये के

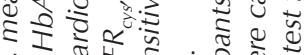
ลें

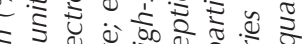

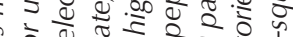

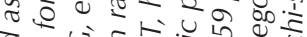

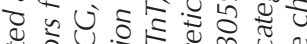
ป ป

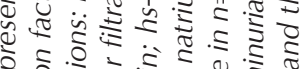

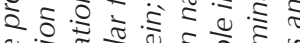

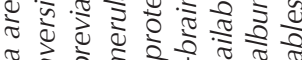

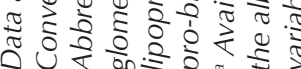




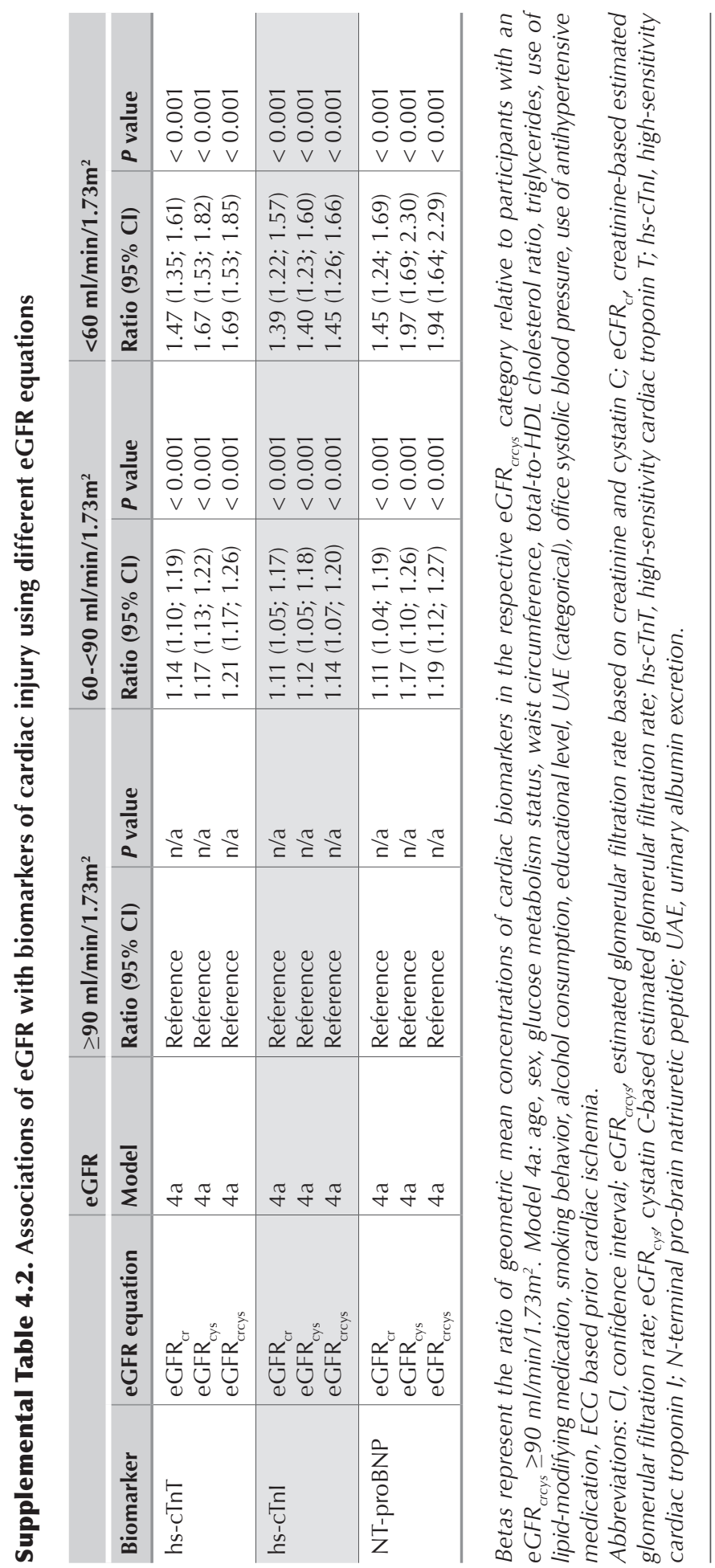




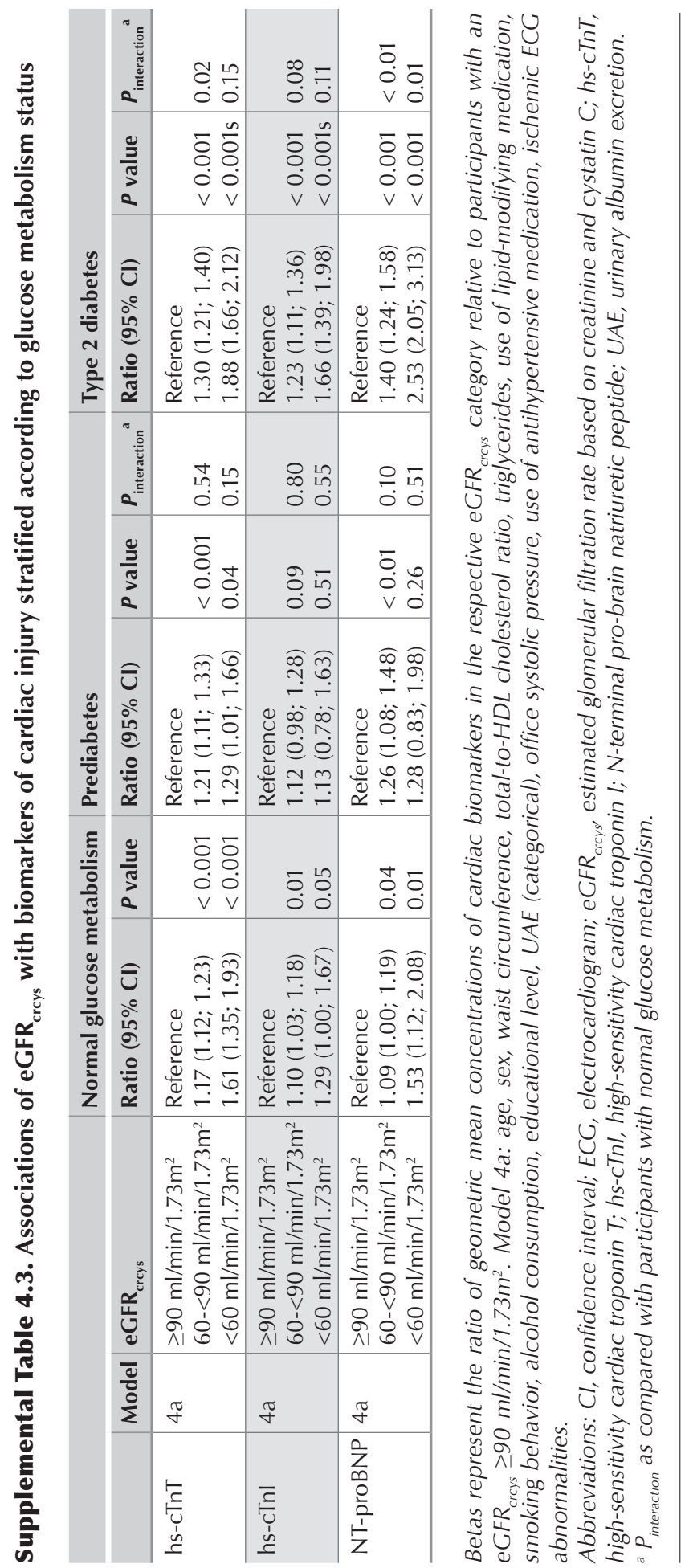




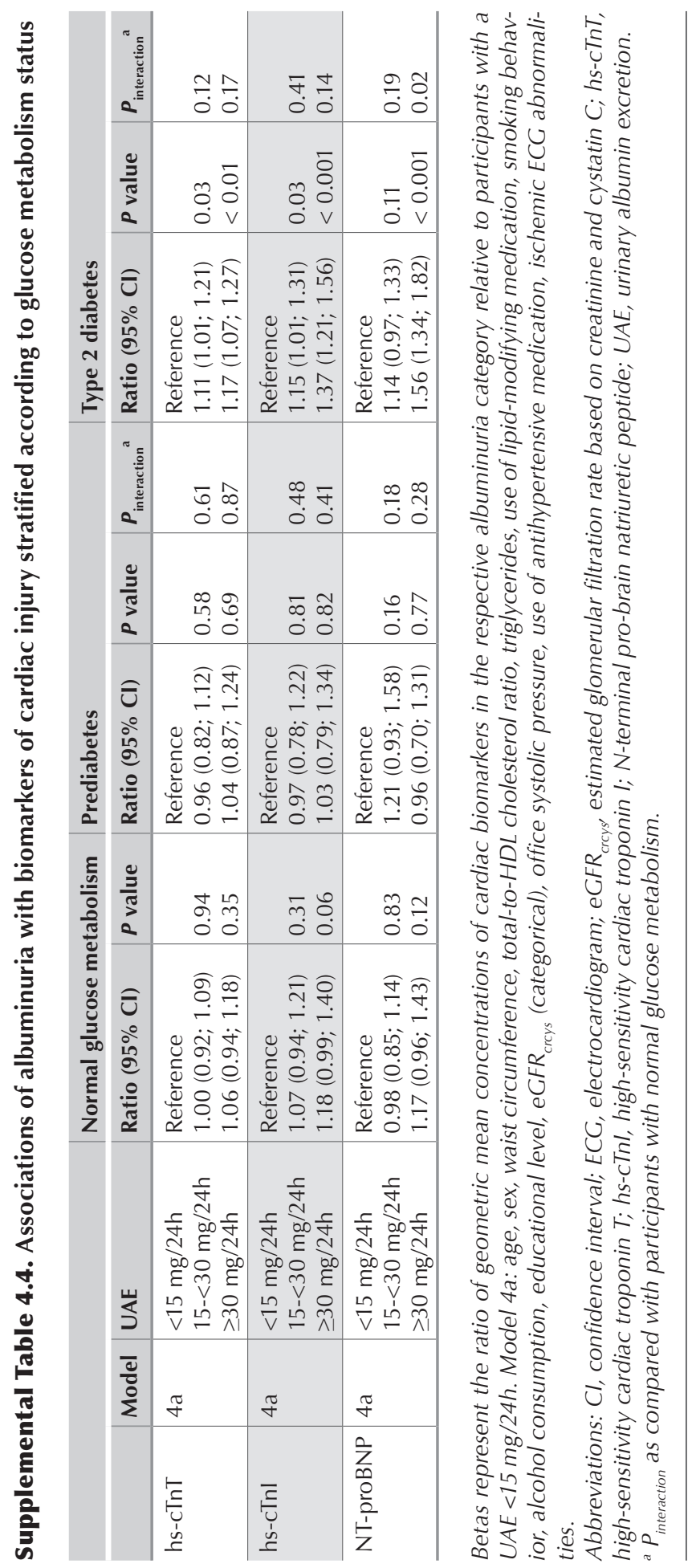




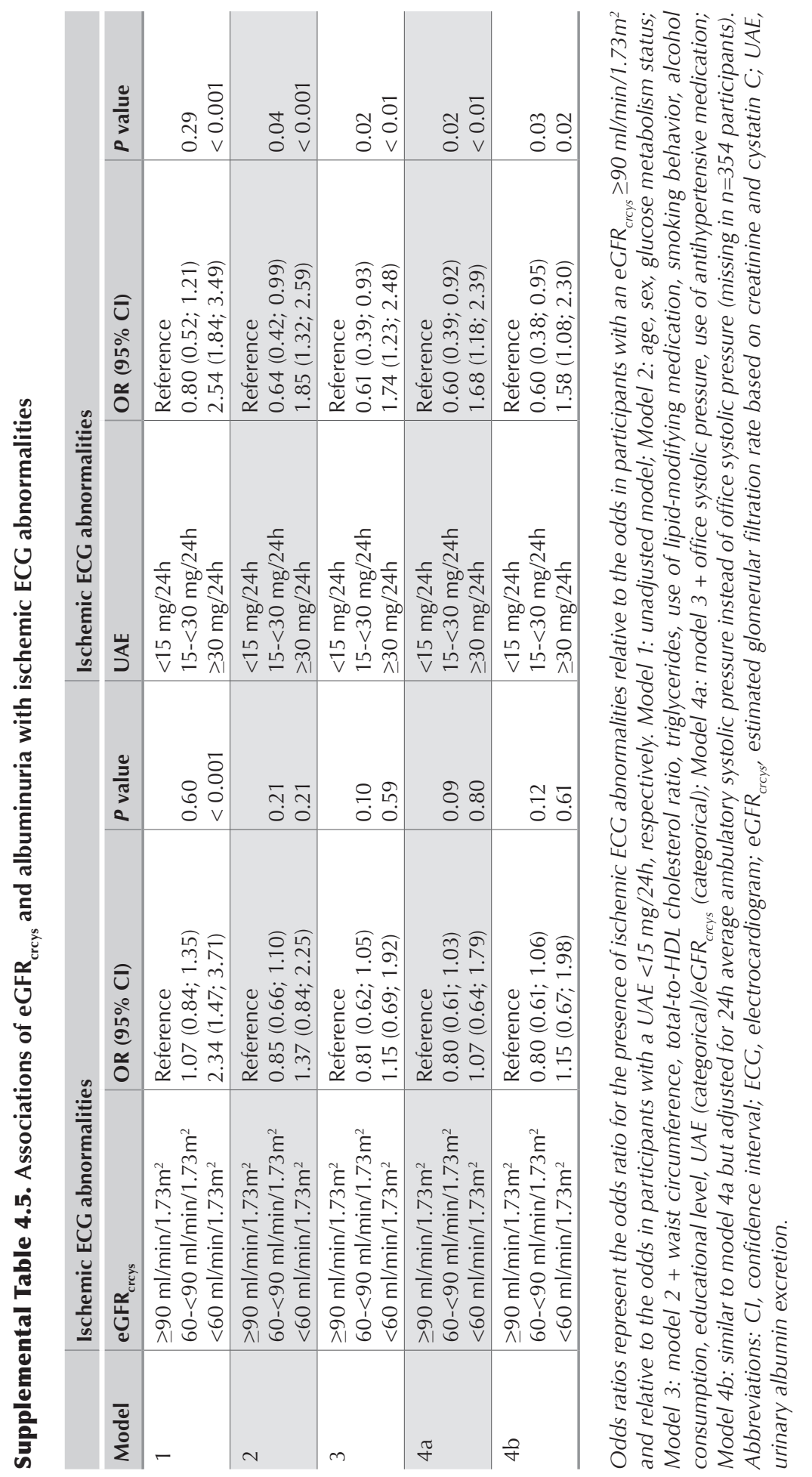




\section{Chapter 5}

Remy J.H. Martens

Jeroen P. Kooman

Coen D.A. Stehouwer

Pieter C. Dagnelie

Carla J.H. van der Kallen

Annemarie Koster

Abraham A. Kroon

Karel M.L. Leunissen

Giel Nijpels

Frank M. van der Sande

Nicolaas C. Schaper

Simone J.S. Sep

Martin P.J. van Boxtel

Miranda T. Schram

Ronald M.A. Henry

Am J Kidney Dis. 2017 Feb;69(2):179-191

(doi: 10.1053/j.ajkd.2016.04.017) 


\section{Estimated GFR, albuminuria, and cognitive performance: The Maastricht Study}




\section{ABSTRACT}

Background: Reduced estimated glomerular filtration rate (eGFR) and albuminuria have been associated with worse cognitive performance. However, few studies have examined whether these associations are confined to older individuals or may be extended to the middle-aged population.

Study design: Cross-sectional analyses of a prospective population-based cohort study.

Setting \& Participants: 2987 individuals aged 40-75 years from the general population (The Maastricht Study).

Predictor: eGFR and urinary albumin excretion (UAE).

Outcomes: Memory function, information processing speed, and executive function.

Measurements: Analyses were adjusted for demographic variables (age, sex, and educational level), lifestyle factors (smoking behavior and alcohol consumption), depression, and cardiovascular disease risk factors (glucose metabolism status, waist circumference, total-to-high-density lipoprotein cholesterol ratio, triglyceride level, use of lipid-modifying medication, systolic blood pressure, use of antihypertensive medication, and prevalent cardiovascular disease).

Results: UAE was $<15 \mathrm{mg} / 24 \mathrm{~h}$ in 2439 (81.7\%) participants, $15-<30 \mathrm{mg} / 24 \mathrm{~h}$ in $309(10.3 \%)$, and $\geq 30 \mathrm{mg} / 24 \mathrm{~h}$ in $239(8.0 \%)$. In the entire study population, UAE $\geq 30 \mathrm{mg} / 24 \mathrm{~h}$ was associated with lower information processing speed as compared to UAE $<15 \mathrm{mg} / 24 \mathrm{~h}$ (beta [standard deviation difference] = $-0.148 ; 95 \%$ confidence interval $(95 \% \mathrm{Cl}),-0.263$ to -0.033$)$ after full adjustment, whereas continuous albuminuria was not. However, significant interaction terms ( $P$ value of the interaction term $<0.05)$ suggested that albuminuria was most strongly and extensively associated with cognitive performance in older individuals. Mean ( \pm standard deviation) eGFR, estimated by the Chronic Kidney Disease Epidemiology Collaboration (CKD-EPI) creatinine-cystatin C equation $\left(\mathrm{eGFR}_{\text {crys }}\right)$, was $88.4 \pm 14.6 \mathrm{ml} / \mathrm{min} / 1.73 \mathrm{~m}^{2}$. eGFR crcys $_{\text {ch }}$ was not associated with any of the domains of cognitive performance after full adjustment. However, significant interaction terms ( $P$ value of the interaction term $<0.05)$ suggested that GFR $_{\text {crcys }}$ was associated with cognitive performance in older individuals.

Limitations: Cross-sectional design, which limited causal inferences.

Conclusions: In the entire study population, albuminuria was independently associated with lower information processing speed, whereas eGFR crcys $_{\text {sas not }}$ wan associated with cognitive performance. However, both were more strongly and extensively associated with cognitive performance in older individuals. 


\section{INTRODUCTION}

In older individuals, both reduced estimated glomerular filtration rate (eGFR) and albuminuria have been associated with lower cognitive performance, ${ }^{1-17}$ although not consistently so., ${ }^{4,14,16,18,19}$

Conceptually, reduced GFR may lead to the accumulation of neurotoxins or may represent lifetime exposure to cardiovascular disease (CVD) risk factors or CVD itself, ${ }^{20}$ whereas albuminuria may be a biomarker of generalized endothelial dysfunction. ${ }^{21,22}$ Thereby, reduced GFR may play a direct role in the pathobiology of cognitive decline, ${ }^{20}$ but may also, similar to albuminuria, act as a biomarker of any underlying mechanisms involved in cognitive decline..$^{20,22}$

However, few studies ${ }^{19,23-26}$ have examined whether the associations of eGFR ${ }^{19,23-25}$ and albuminuria ${ }^{19,26}$ with cognitive performance are confined to older individuals or may be extended to the middle-aged (i.e., 40- to 65-year-old) population. This is important because it can be hypothesized that in middle-aged individuals, brain reserve capacity (i.e., "the amount of damage that can be sustained before reaching a threshold for clinical expression" ${ }^{27}$ ) is higher, as a result of which changes in cognitive performance are subtle. ${ }^{27,28}$ In addition, some studies may have been affected by residual confounding due to incomplete adjustment for CVD risk factors.

We, therefore, first examined the associations of eGFR and albuminuria with several domains of cognitive performance (i.e., memory function, information processing speed, and executive function) in 40- to 75-year-old individuals who participated in the populationbased Maastricht Study. Second, we explored whether any such associations differed by age.

\section{METHODS}

\section{The Maastricht Study population and design}

In this study, we used data from The Maastricht Study, an observational prospective population-based cohort study. The rationale and methodology have been described previously. ${ }^{29}$ In brief, the study focuses on the etiology, pathophysiology, complications, and comorbid conditions of type 2 diabetes (T2DM) and is characterized by an extensive phenotyping approach. Eligible for participation were all individuals aged 40 to 75 years and living in the southern part of the Netherlands. Participants were recruited through mass media campaigns and from the municipal registries and the regional Diabetes Patient Registry by mailings. Recruitment was stratified according to known T2DM status, with an oversampling of individuals with T2DM, for reasons of efficiency. The present report includes cross-sectional data from the first 3451 participants, who completed the baseline survey between November 2010 and September 2013. The examinations of each participant were performed within a time window of three months. The study has been approved by the institutional medical ethical committee (NL31329.068.10) and the Minister of Health, Welfare and Sports of the Netherlands (Permit 131088-105234-PG), and was conducted in accordance with the Declaration of Helsinki. All participants gave written informed consent.

\section{Kidney function}

GFR was estimated by the Chronic Kidney Disease Epidemiology Collaboration (CKD-EPI) serum creatinine and serum cystatin $\mathrm{C}$ equation $\left(\mathrm{eGFR}_{\mathrm{crcys}}\right)^{30}$ for the primary analyses. For additional analyses, GFR was estimated by the CKD-EPI serum creatinine equation $\left(\mathrm{eGFR}_{\mathrm{cr}}\right)$, ${ }^{30}$ the CKD-EPI serum cystatin C equation (eGFR $\left.{ }_{\text {cys }}\right)^{30}$ and the isotope-dilution mass spectrometry 
(IDMS)-traceable 4-variable Modification of Diet in Renal Disease (MDRD) Study equation $(\mathrm{eGFR} \text { MDRD })^{31}$ Serum creatinine was measured with a Jaffé method traceable to IDMS (due to a change of supplier, two instruments were used in the study, the Beckman Synchron LX20, Beckman Coulter Inc., Brea, USA and the Roche Cobas 6000, F. Hoffmann-La Roche Ltd, Basel, Switzerland). Serum cystatin C was measured with aparticle-enhanced immunoturbidimetric assay standardized against ERM-DA471/IFCC (International Federation of Clinical Chemistry and Laboratory Medicine) reference material (Roche Cobas 8000, F. Hoffman-La Roche Ltd, Basel, Switzerland). To assess urinary albumin excretion (UAE), participants were requested to collect two $24 \mathrm{~h}$ urine samples. Urinary albumin concentration was measured with a standard immunoturbidimetric assay by an automatic analyzer (due to a change of supplier, by the Beckman Synchron LX20, Beckman Coulter Inc., Brea, USA and the Roche Cobas 6000, F. Hoffmann-La Roche Ltd, Basel, Switzerland) and multiplied by collection volume to obtain the $24 \mathrm{~h}$ UAE. A urinary albumin concentration below the detection limit of the assay ( $2 \mathrm{mg} / \mathrm{l}$ for the Beckman Synchron LX20 and $3 \mathrm{mg} / \mathrm{l}$ for the Roche Cobas 6000) was set at $1.5 \mathrm{mg} / \mathrm{l}$ before multiplying by collection volume. Only urine collections with a collection time between $20 \mathrm{~h}$ and $28 \mathrm{~h}$ were considered valid. If needed, UAE was extrapolated to a $24 \mathrm{~h}$ excretion. For this study, UAE was preferably based on the average of two (available in $91.3 \%$ of the participants) $24 \mathrm{~h}$ urine collections.

\section{Cognitive performance}

Cognitive performance was assessed by a concise (30-minute) neuropsychological test battery. ${ }^{29}$ For conceptual clarity, test scores were standardized and divided into three cognitive domains (i.e., memory function, information processing speed, and executive function). A detailed description of neuropsychological tests and methods used to calculate domain scores is provided in the Supplemental Methods. Briefly, memory function was evaluated using the Verbal Learning Test $^{32}$ by calculating the standardized average of total immediate and delayed recall scores. The composite score for information processing speed was derived from the Stroop Color-Word Test Part I and II, ${ }^{33}$ the Concept Shifting Test Part A and $\mathrm{B},{ }^{34}$ and the Letter-Digit Substitution Test. ${ }^{35}$ Executive function was assessed by the Stroop Color-Word Test Part III and the Concept Shifting Test Part C. If necessary, individual test scores were log-transformed to fulfill the normality assumption and/or inverted so that higher scores indicated better cognitive performance. In addition, an overall cognitive performance score was calculated as the standardized average of the three domain scores and used as a summary score.

\section{Potential confounders}

We assessed fasting glucose, hemoglobin A1c (HbA1c; glycated hemoglobin), cholesterol (total, high-density lipoprotein, and low-density lipoprotein), triglycerides, glucose metabolism status, body mass index, waist circumference, hip circumference, office blood pressure, $24 \mathrm{~h}$ average ambulatory blood pressure, medication use, smoking behavior, alcohol consumption, educational level, (subjective) physical activity, current major depressive episode, and prevalent CVD as described previously. ${ }^{29,36}$ Further details and definitions of the potential confounders are provided in the Supplemental Methods.

\section{Statistical analyses}

All analyses were performed with IBM SPSS Statistics, version 22.0 (IBM Corp., Armonk, NY, USA). Population characteristics were presented stratified by eGFR $_{\text {crcys }}$ and albuminuria categories. 
Associations of eGFR $_{\text {crcys }}$ and albuminuria with the composite scores of cognitive performance were evaluated with multivariable linear regression analyses. eGFR crcys $_{\text {was }}$ analyzed as a categorical $\left(\geq 90,60-<90\right.$, and $\left.<60 \mathrm{ml} / \mathrm{min} / 1.73 \mathrm{~m}^{2}\right)$ and a continuous (per 10$\mathrm{ml} / \mathrm{min} / 1.73 \mathrm{~m}^{2}$ lower eGFR $\left.{ }_{\text {crcys }}\right)$ variable. Similarly, UAE was analyzed as a categorical $(<15$, $15-<30$, and $\geq 30 \mathrm{mg} / 24 \mathrm{~h}$ ) and, after log base 2 transformation, a continuous (per doubling of UAE) variable. The regression coefficients (betas) represent the standard deviation (SD) difference in the cognitive domain scores as compared to eGFR crcys $_{2} \geq 90 \mathrm{ml} / \mathrm{min} / 1.73 \mathrm{~m}^{2}$, per $10-\mathrm{ml} / \mathrm{min} / 1.73 \mathrm{~m}^{2}$ lower eGFR crcys' as compared to UAE $<15 \mathrm{mg} / 24 \mathrm{~h}$, and per doubling of $\mathrm{UAE}$, respectively. For example, a beta of 0.01 is $1 \%$ of $1 \mathrm{SD}$.

We adjusted for potential confounders as follows (more details on variable handling are provided in the Supplemental Methods): model 1, unadjusted model; model 2, age, sex, educational level, and glucose metabolism status; model 3, model 2 plus waist circumference, ttotal-to-high-density lipoprotein cholesterol ratio, triglyceride level, use of lipid-modifying medication, smoking behavior, alcohol consumption; model 4, model 3 plus UAE (categorical) or eGFR ${ }_{\text {crcys }}$ (continuous); model 5a, model 4 plus office systolic blood pressure, use of antihypertensive medication, prevalent CVD, and depression; model 5b, as model 5a but with replacement of office systolic blood pressure by $24 \mathrm{~h}$ average ambulatory systolic blood pressure. Blood pressure, prevalent CVD, and depression may be confounders, but may also mediate an association between kidney function and cognitive performance (for example, hypertension and stroke, which are risk factors for cognitive decline, ${ }^{20}$ may result from kidney disease ${ }^{37-39}$ ) or be descending proxies of such intermediates (for example, depression and cognitive performance may have cerebral small vessel disease as a common cause ${ }^{40}$ ). Therefore, these variables were added in a separate model, because a model including these variables is at risk of overadjustment bias. ${ }^{41}$

We used interaction terms added to model 1 to examine whether the associations of eGFR $_{\text {crcys }}$ and albuminuria with cognitive performance were modified by age (a $P$ value of the interaction term $\left(P_{\text {interaction }}\right)<0.10$ was considered statistically significant).

Adjusted mean values of the composite score of information processing speed per albuminuria category were estimated with general linear models with adjustment for age, sex, educational level, and glucose metabolism status (model 2).

Several additional analyses were performed to assess the robustness of the results. First, eGFR $_{\text {crcys }}$ was replaced with eGFR based on the MDRD Study equation, GGFR $_{\text {cr' }}$ or eGFR ${ }_{\text {cys' }}$ because recent studies indicated that cystatin C-based estimates are more strongly associated with cognitive performance. ${ }^{10,11}$ Second, we adjusted for a quadratic association between age and cognitive performance. ${ }^{32-34}$ Third, we restricted the analyses to participants with UAE $\leq 300 \mathrm{mg} / 24 \mathrm{~h}$ and to participants with two 24h urine collections, and excluded participants with a Mini-Mental State Examination score $<24$, suggesting frank cognitive impairment. ${ }^{42}$ Fourth, the analyses were repeated with replacement of the following: office systolic blood pressure by office diastolic blood pressure, office mean arterial pressure, office pulse pressure, their $24 \mathrm{~h}$ average ambulatory equivalents, and the presence of hypertension; the use of antihypertensive medication by the use of specifically renin-angiotensin system inhibitors; and waist circumference by waist-to-hip-ratio or body mass index. Fifth, we additionally adjusted for total or moderate to vigorous physical activity. Sixth, we used interaction terms added to model 1 to examine whether associations were modified by glucose metabolism status given the design of The Maastricht Study. Seventh, we performed multiple imputation with fully conditional specification (maximal 10 iterations, 20 datasets) under the missing at random assumption. ${ }^{43,44}$ Continuous eGFR $_{\text {crcys }}$ and $U A E$, as well as the 


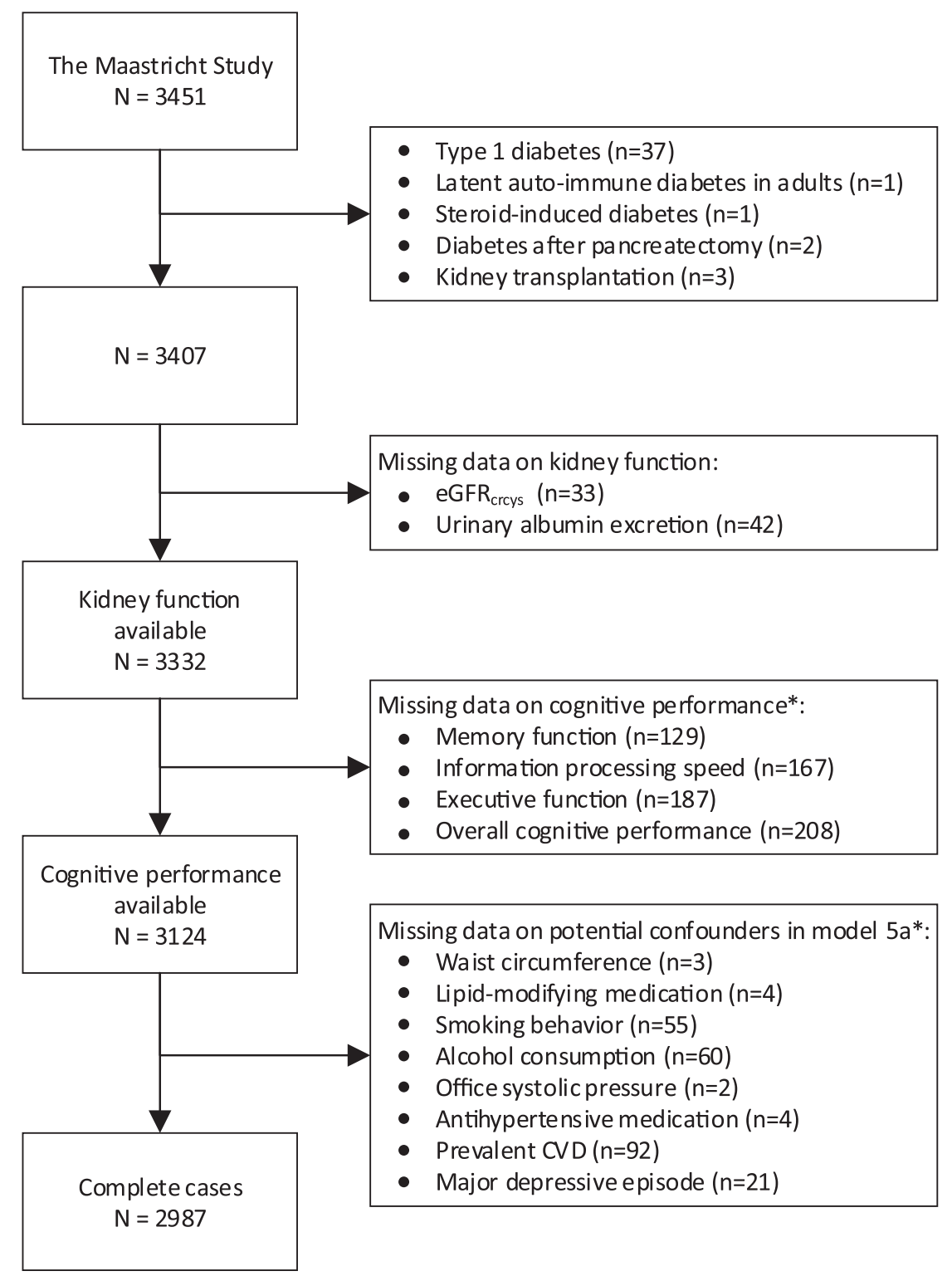

Figure 5.1. Flow diagram delineating the derivation of the final study population. Abbreviations: eGFR $_{\text {crys }}$ estimated glomerular filtration rate based on creatinine and cystatin C; CVD, cardiovascular disease. ${ }^{*}$ Missings were not mutually exclusive.

dependent and potential confounding variables of models $5 a$ and $5 b$, were included in the imputation model. Overall cognitive performance was calculated as the standardized average of the three imputed cognitive domain scores.

Variance inflation factors were $<2.5$ for all non-multiplicative variables. 


\section{RESULTS}

\section{Characteristics of the study population}

Figure 5.1 is a flow diagram delineating the derivation of the final study population. In total, 2987 participants had complete data for all variables in model 5 a and were included in the analyses. None of the participants was on dialysis treatment. Participants with missing data $(n=420)$ more often had T2DM, hypertension, prevalent CVD, and a lower educational level. In addition, they had lower eGFRs estimated by cystatin C-based equations, higher UAEs, and lower scores on all domains of cognitive performance.

Table 5.1 shows the study population characteristics overall and stratified by albuminuria categories. Supplemental Table 5.1 shows the study population characteristics stratified by eGFR $_{\text {crys }}$ categories. By design, 791 (26.5\%) participants had T2DM. The study population, which had a mean $( \pm \mathrm{SD})$ age of $59.6 \pm 8.2$ years, was well-educated $(41.2 \%$ higher vocational education or university level of education). In general, participants with higher albuminuria and participants with lower $\mathrm{GGFR}_{\text {crcys }}$ were older, more often men, were less educated, more often had T2DM and CVD, and had a worse CVD risk profile.

Table 5.1. Clinical characteristics of the study population and stratified according to albuminuria categories

\begin{tabular}{|c|c|c|c|c|}
\hline & \multirow[b]{2}{*}{$\begin{array}{l}\text { Study } \\
\text { population } \\
n=2987\end{array}$} & \multicolumn{3}{|c|}{ Albuminuria categories } \\
\hline & & $\begin{array}{l}<15 \mathrm{mg} / 24 \mathrm{~h} \\
\mathrm{n}=2439\end{array}$ & $\begin{array}{l}15-<30 \mathrm{mg} / 24 \mathrm{~h} \\
\mathrm{n}=309\end{array}$ & $\begin{array}{l}\geq 30 \mathrm{mg} / 24 \mathrm{~h} \\
\mathrm{n}=239\end{array}$ \\
\hline \multicolumn{5}{|l|}{ Demographics } \\
\hline Age (years) & $59.6 \pm 8.2$ & $59.0 \pm 8.2$ & $61.8 \pm 8.2$ & $62.4 \pm 7.7$ \\
\hline Men & $1527(51.1 \%)$ & $1166(47.8 \%)$ & $186(60.2 \%)$ & $175(73.2 \%)$ \\
\hline $\begin{array}{l}\text { Educational level } \\
\text { Low } \\
\text { Intermediate } \\
\text { High }\end{array}$ & $\begin{array}{l}468(15.7 \%) \\
1290(43.2 \%) \\
1229(41.2 \%) \\
\end{array}$ & $\begin{array}{l}348(14.3 \%) \\
1065(43.7 \%) \\
1026(42.1 \%)\end{array}$ & $\begin{array}{l}55(17.8 \%) \\
134(43.4 \%) \\
120(38.8 \%) \\
\end{array}$ & $\begin{array}{l}65(27.2 \%) \\
91(38.1 \%) \\
84(34.7 \%)\end{array}$ \\
\hline Prevalent cardiovascular disease & $481(16.1 \%)$ & $352(14.4 \%)$ & $61(19.7 \%)$ & $69(28.5 \%)$ \\
\hline \multicolumn{5}{|l|}{ Lifestyle variables } \\
\hline $\begin{array}{c}\text { Smoking behavior } \\
\text { Never smoker } \\
\text { Former smoker } \\
\text { Current smoker }\end{array}$ & $\begin{array}{l}1048(35.1 \%) \\
1549(51.9 \%) \\
390(13.1 \%) \\
\end{array}$ & $\begin{array}{l}903(37.0 \%) \\
1236(50.7 \%) \\
300(12.3 \%)\end{array}$ & $\begin{array}{l}89(28.8 \%) \\
177(57.3 \%) \\
43(13.9 \%)\end{array}$ & $\begin{array}{l}56(23.4 \%) \\
136(56.9 \%) \\
47(19.7 \%)\end{array}$ \\
\hline $\begin{array}{l}\text { Alcohol consumption } \\
\text { None } \\
\text { Low (women } \leq 7 \text { glasses/week; } \\
\text { men } \leq 14 \text { glasses/week) } \\
\text { High (women }>7 \text { glasses/week; } \\
\text { men }>14 \text { glasses/week) }\end{array}$ & $\begin{array}{l}537(18.0 \%) \\
1658(55.5 \%) \\
792(26.5 \%)\end{array}$ & $\begin{array}{l}419(17.2 \%) \\
1368(56.1 \%) \\
652(26.7 \%)\end{array}$ & $\begin{array}{l}58(18.8 \%) \\
170(55.0 \%) \\
81(26.2 \%)\end{array}$ & $\begin{array}{l}60(25.1 \%) \\
120(50.2 \%) \\
59(24.7 \%)\end{array}$ \\
\hline Total physical activity (h/week) & $13.0[8.3-18.8]$ & $13.4[8.5-18.8]$ & $12.9[7.5-18.6]$ & $11.3[6.3-18.5]$ \\
\hline $\begin{array}{l}\text { Moderate to vigorous physical } \\
\text { activity (h/week) }\end{array}$ & $4.5[2.3-8.0]$ & $4.6[2.8-8.0]$ & $4.0[1.5-8.2]$ & $3.3[1.5-7.3]$ \\
\hline
\end{tabular}


Table 5.1. (continued)

\begin{tabular}{|c|c|c|c|c|}
\hline & $\begin{array}{l}\text { Study } \\
\text { population } \\
\mathrm{n}=2987\end{array}$ & $\begin{array}{l}<15 \mathrm{mg} / 24 \mathrm{~h} \\
\mathrm{n}=2439\end{array}$ & $\begin{array}{l}15-<30 \mathrm{mg} / 24 \mathrm{~h} \\
\mathrm{n}=309\end{array}$ & $\begin{array}{l}\geq 30 \mathrm{mg} / 24 \mathrm{~h} \\
\mathrm{n}=239\end{array}$ \\
\hline \multicolumn{5}{|l|}{ Metabolic variables } \\
\hline $\begin{array}{l}\text { BMI categories } \\
\text { Normal weight }\left(<25 \mathrm{~kg} / \mathrm{m}^{2}\right) \\
\text { Overweight }\left(25-<30 \mathrm{~kg} / \mathrm{m}^{2}\right) \\
\text { Obesity }\left(\geq 30 \mathrm{~kg} / \mathrm{m}^{2}\right)\end{array}$ & $\begin{array}{l}1045(35.0 \%) \\
1286(43.1 \%) \\
655(21.9 \%) \\
\end{array}$ & $\begin{array}{l}925(37.9 \%) \\
1043(42.8 \%) \\
470(19.3 \%)\end{array}$ & $\begin{array}{l}73(23.6 \%) \\
144(46.6 \%) \\
92(29.8 \%)\end{array}$ & $\begin{array}{l}47(19.7 \%) \\
99(41.4 \%) \\
93(38.9 \%)\end{array}$ \\
\hline $\begin{array}{l}\text { Waist circumference }(\mathrm{cm}) \\
\text { Men } \\
\text { Women }\end{array}$ & $\begin{array}{l}101.3 \pm 11.8 \\
89.9 \pm 12.8\end{array}$ & $\begin{array}{l}99.7 \pm 11.1 \\
89.3 \pm 12.2\end{array}$ & $\begin{array}{l}105.3 \pm 11.6 \\
93.6 \pm 16.1\end{array}$ & $\begin{array}{l}107.7 \pm 13.7 \\
96.1 \pm 16.1\end{array}$ \\
\hline $\begin{array}{l}\text { Waist-to-hip-ratio } \\
\text { Men } \\
\text { Women }\end{array}$ & $\begin{array}{l}1.00 \pm 0.07 \\
0.88 \pm 0.07\end{array}$ & $\begin{array}{l}0.99 \pm 0.07 \\
0.87 \pm 0.07\end{array}$ & $\begin{array}{l}1.02 \pm 0.07 \\
0.89 \pm 0.08\end{array}$ & $\begin{array}{l}1.03 \pm 0.08 \\
0.92 \pm 0.09\end{array}$ \\
\hline $\begin{array}{l}\text { Office systolic blood pressure } \\
(\mathrm{mmHg})\end{array}$ & $134.8 \pm 18.1$ & $133.1 \pm 17.4$ & $141.1 \pm 18.2$ & $143.7 \pm 20.4$ \\
\hline $\begin{array}{l}\text { Office diastolic blood pressure } \\
(\mathrm{mmHg})\end{array}$ & $76.3 \pm 9.9$ & $75.9 \pm 9.8$ & $77.8 \pm 10.6$ & $78.1 \pm 9.7$ \\
\hline $\begin{array}{l}24 \mathrm{~h} \text { average ambulatory systolic } \\
\text { blood pressure }(\mathrm{mmHg})^{\mathrm{d}}\end{array}$ & $119.0 \pm 11.7$ & $117.7 \pm 11.0$ & $123.1 \pm 12.4$ & $126.4 \pm 13.9$ \\
\hline $\begin{array}{l}24 \mathrm{~h} \text { average ambulatory diastolic } \\
\text { blood pressure }(\mathrm{mmHg})^{\mathrm{d}}\end{array}$ & $73.6 \pm 7.2$ & $73.2 \pm 7.0$ & $75.0 \pm 8.3$ & $75.4 \pm 7.5$ \\
\hline Hypertension & $1659(55.5 \%)$ & $1240(50.8 \%)$ & $222(71.8 \%)$ & $197(82.4 \%)$ \\
\hline $\begin{array}{l}\text { Glucose metabolism status } \\
\text { Normal glucose metabolism } \\
\text { Impaired fasting glucose } \\
\text { Impaired glucose tolerance } \\
\text { Type } 2 \text { diabetes mellitus }\end{array}$ & $\begin{array}{l}1732(58.0 \%) \\
128(4.3 \%) \\
336(11.2 \%) \\
791(26.5 \%) \\
\end{array}$ & $\begin{array}{l}1532(62.8 \%) \\
103(4.2 \%) \\
290(11.9 \%) \\
514(21.1 \%)\end{array}$ & $\begin{array}{l}130(42.1 \%) \\
17(5.5 \%) \\
25(8.1 \%) \\
137(44.3 \%)\end{array}$ & $\begin{array}{l}70(29.3 \%) \\
8(3.3 \%) \\
21(8.8 \%) \\
140(58.6 \%)\end{array}$ \\
\hline $\begin{array}{l}\text { Fasting glucose }(\mathrm{mmol} / \mathrm{l})^{\mathrm{e}} \\
\text { Without type } 2 \text { diabetes mellitus } \\
\text { With type } 2 \text { diabetes mellitus }\end{array}$ & $\begin{array}{l}5.3 \pm 0.5 \\
7.9 \pm 2.0 \\
\end{array}$ & $\begin{array}{l}5.3 \pm 0.5 \\
7.7 \pm 1.8\end{array}$ & $\begin{array}{l}5.4 \pm 0.6 \\
8.0 \pm 2.2\end{array}$ & $\begin{array}{l}5.5 \pm 0.6 \\
8.7 \pm 2.6\end{array}$ \\
\hline $\begin{array}{l}\text { HbA1c }(\%)^{\mathrm{f}} \\
\text { Without type } 2 \text { diabetes mellitus } \\
\text { With type } 2 \text { diabetes mellitus }\end{array}$ & $\begin{array}{l}5.5 \pm 0.4 \\
6.9 \pm 1.0 \\
\end{array}$ & $\begin{array}{l}5.5 \pm 0.4 \\
6.8 \pm 0.8\end{array}$ & $\begin{array}{l}5.5 \pm 0.4 \\
7.0 \pm 1.1\end{array}$ & $\begin{array}{l}5.6 \pm 0.4 \\
7.4 \pm 1.4\end{array}$ \\
\hline Total cholesterol (mmol/l) & $5.3 \pm 1.2$ & $5.3 \pm 1.1$ & $5.0 \pm 1.2$ & $4.8 \pm 1.2$ \\
\hline $\begin{array}{l}\text { HDL cholesterol }(\mathrm{mmol} / \mathrm{l}) \\
\text { Men } \\
\text { Women }\end{array}$ & $\begin{array}{l}1.3 \pm 0.4 \\
1.7 \pm 0.5\end{array}$ & $\begin{array}{l}1.3 \pm 0.4 \\
1.7 \pm 0.5\end{array}$ & $\begin{array}{l}1.2 \pm 0.4 \\
1.7 \pm 0.5\end{array}$ & $\begin{array}{l}1.3 \pm 0.4 \\
1.6 \pm 0.5\end{array}$ \\
\hline LDL cholesterol (mmol/l) & $3.1 \pm 1.0$ & $3.2 \pm 1.0$ & $2.9 \pm 1.0$ & $2.7 \pm 1.0$ \\
\hline Triglycerides (mmol/l) & $1.20[0.88-1.72]$ & $1.17[0.86-1.65]$ & $1.31[0.98-1.91]$ & 1.46 [1.09-2.18] \\
\hline Total-to-HDL cholesterol ratio & $3.7 \pm 1.2$ & $3.7 \pm 1.2$ & $3.8 \pm 1.2$ & $3.8 \pm 1.2$ \\
\hline \multicolumn{5}{|l|}{ Kidney function } \\
\hline $\mathrm{eGFR}_{\text {crcys }}\left(\mathrm{ml} / \mathrm{min} / 1.73 \mathrm{~m}^{2}\right)$ & $88.4 \pm 14.6$ & $89.2 \pm 13.9$ & $86.9 \pm 16.1$ & $82.1 \pm 17.8$ \\
\hline $\mathrm{eGFR}_{\mathrm{cr}}\left(\mathrm{ml} / \mathrm{min} / 1.73 \mathrm{~m}^{2}\right)$ & $84.7 \pm 13.8$ & $85.1 \pm 13.3$ & $84.1 \pm 14.8$ & $81.1 \pm 16.2$ \\
\hline
\end{tabular}


Table 5.1. (continued)

\begin{tabular}{|c|c|c|c|c|}
\hline & $\begin{array}{l}\text { Study } \\
\text { population } \\
\mathbf{n}=2987\end{array}$ & $\begin{array}{l}<15 \mathrm{mg} / 24 \mathrm{~h} \\
\mathrm{n}=2439\end{array}$ & $\begin{array}{l}15-<30 \mathrm{mg} / 24 \mathrm{~h} \\
\mathrm{n}=309\end{array}$ & $\begin{array}{l}\geq 30 \mathrm{mg} / 24 \mathrm{~h} \\
\mathrm{n}=239\end{array}$ \\
\hline $\mathrm{eGFR}_{\text {cys }}\left(\mathrm{ml} / \mathrm{min} / 1.73 \mathrm{~m}^{2}\right)$ & $90.2 \pm 16.2$ & $91.3 \pm 15.4$ & $87.6 \pm 17.7$ & $81.7 \pm 19.5$ \\
\hline $\mathrm{eGFR}_{\mathrm{MDRD}}\left(\mathrm{ml} / \mathrm{min} / 1.73 \mathrm{~m}^{2}\right)$ & $80.6 \pm 15.4$ & $80.7 \pm 14.9$ & $81.5 \pm 16.6$ & $79.2 \pm 19.0$ \\
\hline $\begin{array}{l}\text { Urinary albumin excretion rate } \\
(\mathrm{mg} / 24 \mathrm{~h})\end{array}$ & $6.6[4.0-11.7]$ & $5.6[3.7-8.3]$ & $19.4[16.6-23.9]$ & $68.3[41.6-114.1]$ \\
\hline $\begin{array}{l}\text { Urinary albumin excretion } \\
\text { categories } \\
\quad<15 \mathrm{mg} / 24 \mathrm{~h} \\
15-<30 \mathrm{mg} / 24 \mathrm{~h} \\
\geq 30 \mathrm{mg} / 24 \mathrm{~h}\end{array}$ & $\begin{array}{l}2439(81.7 \%) \\
309(10.3 \%) \\
239(8.0 \%)\end{array}$ & $\begin{array}{l}- \\
- \\
-\end{array}$ & $\begin{array}{l}- \\
- \\
-\end{array}$ & $\begin{array}{l}- \\
- \\
-\end{array}$ \\
\hline \multicolumn{5}{|l|}{ Medication } \\
\hline Antihypertensive medication & $1157(38.7 \%)$ & $840(34.4 \%)$ & $153(49.5 \%)$ & $164(68.6 \%)$ \\
\hline Renin-angiotensin system inhibitor & $867(29.0 \%)$ & $605(24.8 \%)$ & $121(39.2 \%)$ & $141(59.0 \%)$ \\
\hline Lipid-modifying medication & $1033(34.6 \%)$ & $747(30.6 \%)$ & $141(45.6 \%)$ & $145(60.7 \%)$ \\
\hline \multicolumn{5}{|c|}{ Mental health and cognitive performance } \\
\hline Current major depressive episode & $109(3.6 \%)$ & $69(2.8 \%)$ & $23(7.4 \%)$ & $17(7.1 \%)$ \\
\hline Overall cognitive performance (SD) & $0.00 \pm 1.00$ & $0.08 \pm 0.98$ & $-0.23 \pm 1.05$ & $-0.51 \pm 1.00$ \\
\hline Memory function (SD) & $0.00 \pm 1.00$ & $0.06 \pm 0.98$ & $-0.19 \pm 1.03$ & $-0.42 \pm 0.99$ \\
\hline Information processing speed (SD) & $0.00 \pm 1.00$ & $0.07 \pm 0.97$ & $-0.16 \pm 1.01$ & $-0.48 \pm 1.08$ \\
\hline Executive function (SD) & $0.00 \pm 1.00$ & $0.06 \pm 0.98$ & $-0.19 \pm 1.08$ & $-0.32 \pm 1.00$ \\
\hline
\end{tabular}

Note: Data are presented as $n(\%)$, mean \pm standard deviation or median [interquartile range].

Conversion factors for units: HbA1c in \% to mmol/mol, $10.93 \times \mathrm{HbA1c}[\%]+23.5$.

Abbreviations: BMI, body mass index; $e_{F F R_{c r y s^{\prime}}}$ estimated glomerular filtration rate based on creatinine and cystatin C; $e G F R_{c^{\prime}}$ creatinine-based estimated glomerular filtration rate; eGFR ${ }_{c y y^{\prime}}$ cystatin C-based estimated glomerular filtration rate; eGFR ${ }_{M D R D}$ estimated glomerular filtration rate based on the 4-variable Modificiation in Renal Disease Study equation; HbA1c, hemoglobin A1c (glycated hemoglobin); HDL cholesterol, high-density lipoprotein cholesterol; LDL cholesterol, low-density lipoprotein cholesterol.

a Available in $n=2635$ (total physical activity) and $n=2634$ (moderate to vigorous physical activity) participants. ${ }^{b}$ Available in 2986 participants. ${ }^{c}$ Available in $n=2986$ participants. ${ }^{d}$ Available in $n=2644$ participants. ${ }^{e}$ Available in $n=2985$ participants. ${ }^{f}$ Available in $n=2980$ participants.

\section{Albuminuria and cognitive performance}

UAE was $<15 \mathrm{mg} / 24 \mathrm{~h}$ in 2439 (81.7\%) participants, $15-<30 \mathrm{mg} / 24 \mathrm{~h}$ in 309 (10.3\%), and $\geq 30$ $\mathrm{mg} / 24 \mathrm{~h}$ in 239 (8.0\%). Participants with higher UAE had lower performance on each of the cognitive domains (Table 5.1).

After adjustment for age, sex, glucose metabolism status, and educational level (Table 5.2, model 2), and with $U A E<15 \mathrm{mg} / 24 \mathrm{~h}$ as the reference category, UAE $\geq 30 \mathrm{mg} / 24 \mathrm{~h}$ was associated with lower overall cognitive performance (beta [SD difference] $=-0.149 ; 95 \%$ confidence interval $[\mathrm{Cl}],-0.256$ to -0.043 ), lower information processing speed (beta $=-0.172$; $95 \% \mathrm{Cl},-0.286$ to -0.058 ; Figure 5.2), and borderline statistically significantly lower memory function (beta $=-0.110 ; 95 \% \mathrm{Cl},-0.229$ to 0.008 ). These associations were attenuated after further adjustment for the variables of models 3 to 5, but remained statistically significant for 
overall cognitive performance (beta $=-0.110 ; 95 \% \mathrm{Cl},-0.217$ to -0.002 ; model $5 \mathrm{a}$ ) and information processing speed (beta $=-0.148,95 \% \mathrm{Cl},-0.263$ to -0.033 ; model $5 \mathrm{a}$ ).

Continuous albuminuria was not statistically significantly associated with cognitive performance after full adjustment (Table 5.3, model 5a).

Results were similar when we adjusted for $24 \mathrm{~h}$ average ambulatory systolic blood pressure instead of office systolic blood pressure (Tables 5.2 and 5.3, model 5b).

\section{Albuminuria and cognitive performance: test for interaction with age}

Analyses with interaction terms showed that the association between continuous albuminuria and cognitive performance was stronger at older age, to such an extent that the interaction terms indicated a -0.038 (executive function) to -0.030 (information processing speed) difference in the beta of albuminuria per 10 years older age (model $1, P_{\text {interaction }}<0.05$ for all cognitive domains, except memory function). The latter implied that albuminuria was not associated with cognitive performance in 50-year-old individuals, whereas in 70-year-old individuals, it was associated with lower overall cognitive performance, information processing speed, and executive function (Supplemental Table 5.2). Analyses stratified according to age tertiles showed a similar pattern (Supplemental Table 5.3).

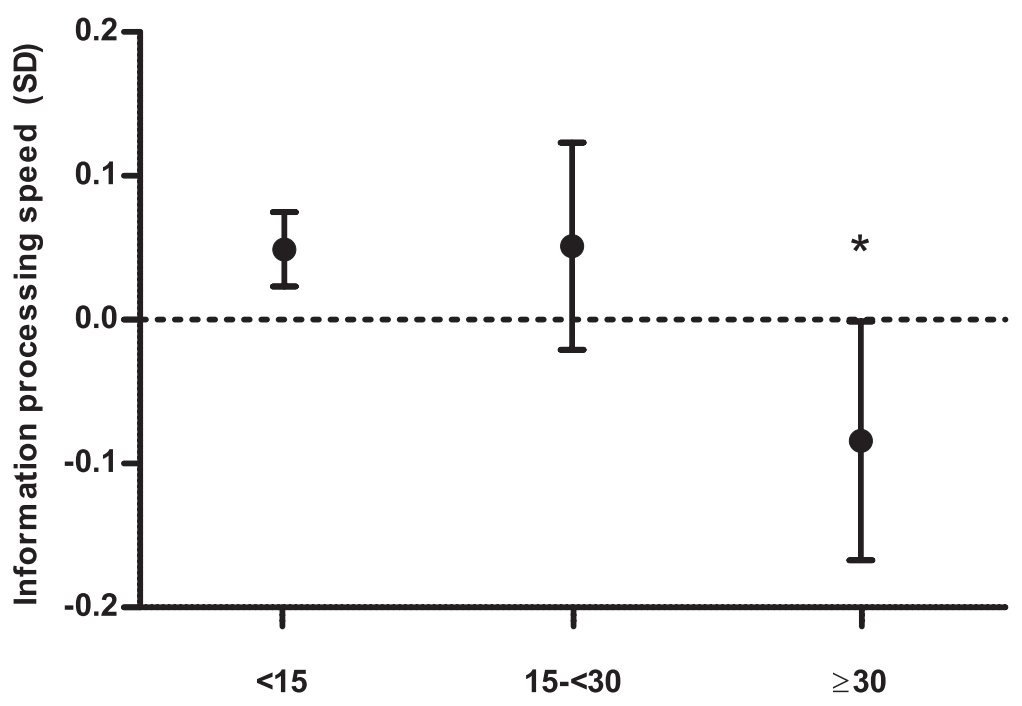

Albuminuria categories $(\mathrm{mg} / 24 \mathrm{~h})$

Figure 5.2. Association between albuminuria and information processing speed. Adjusted means of the composite score of information processing speed are expressed per albuminuria category. The means were adjusted for age, sex, educational level and glucose metabolism status (model 2). Bars indicate 95\% confidence intervals. $P$ values were derived from the same models. ${ }^{*} P<0.01$ as compared with participants with a urinary albumin excretion $<15 \mathrm{mg} / 24 \mathrm{~h}$. 

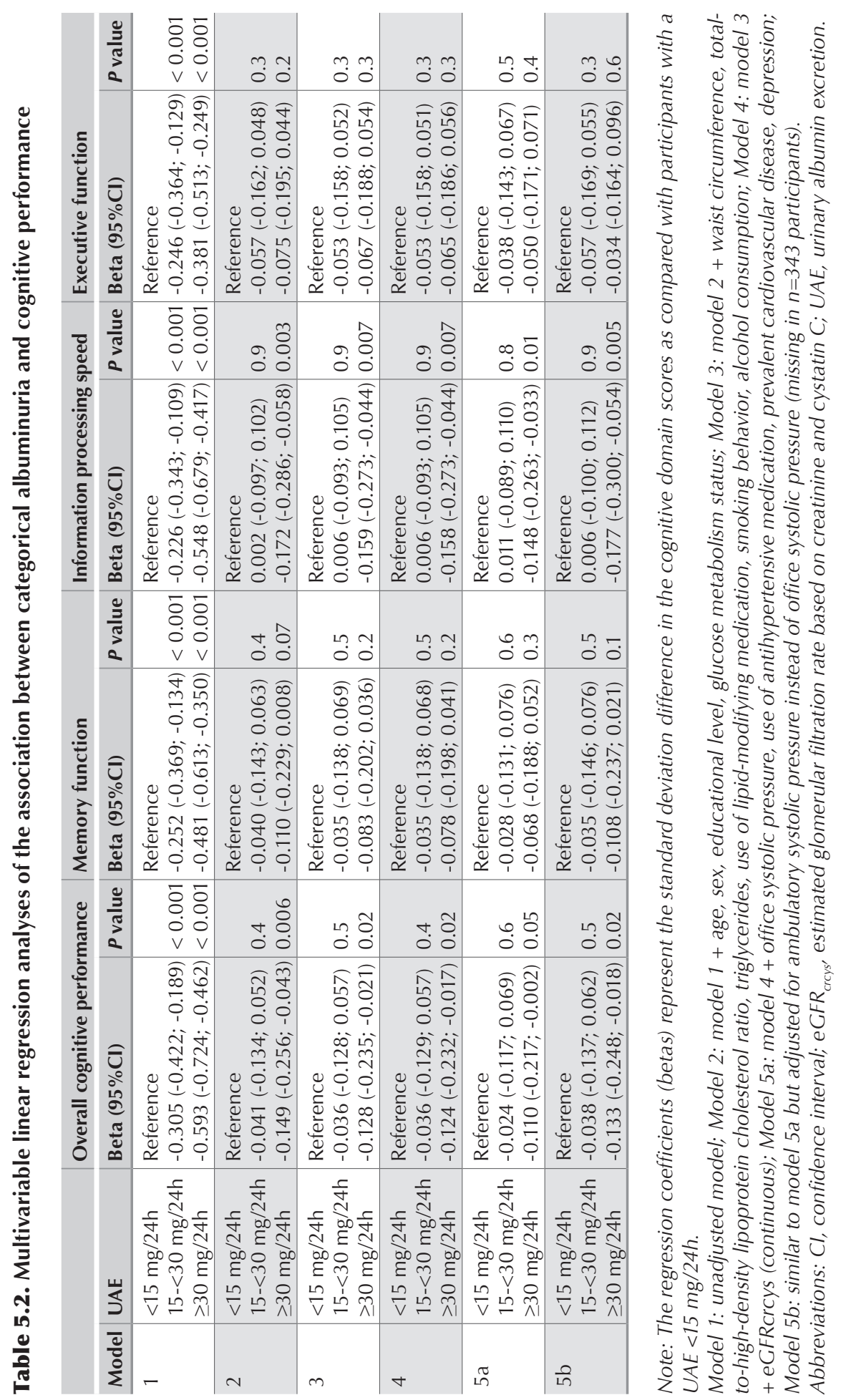


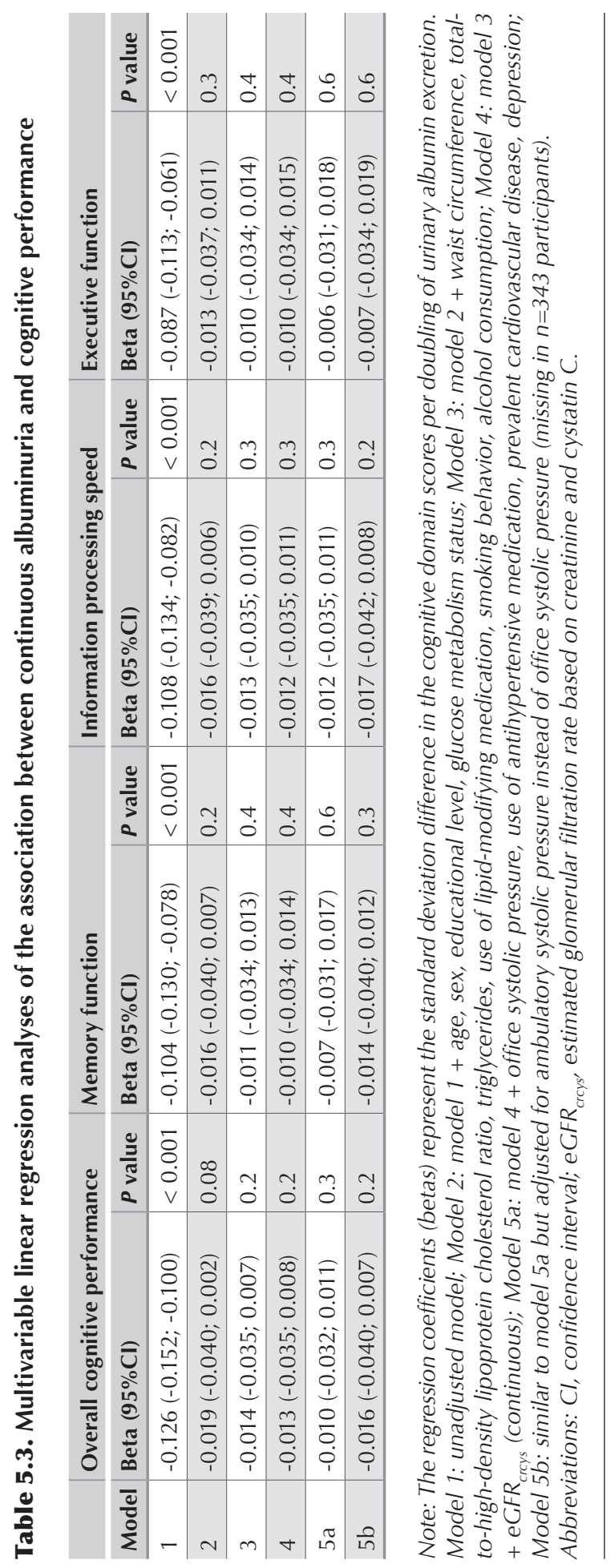




\section{eGFR and cognitive performance}

Mean $\left( \pm\right.$ SD) eGFR crys was $88.4 \pm 14.6 \mathrm{ml} / \mathrm{min} / 1.73 \mathrm{~m}^{2}$ (Table 5.1). There were $1463(49.0 \%)$ participants who had eGFR crcys $_{2} \geq 90 \mathrm{ml} / \mathrm{min} / 1.73 \mathrm{~m}^{2}, 1413(47.3 \%)$ had eGFR crcys $60-<90 \mathrm{ml} /$ $\mathrm{min} / 1.73 \mathrm{~m}^{2}$, and $111(3.7 \%)$ had eGFR $_{\text {crcys }}<60 \mathrm{ml} / \mathrm{min} / 1.73 \mathrm{~m}^{2}$. Participants with lower eGFR $_{\text {crys }}$ had lower scores on each of the cognitive domains (Supplemental Table 5.1).

After adjustment for age, sex, glucose metabolism status, and educational level (Table 5.4, model 2), eGFR crcys $<60 \mathrm{ml} / \mathrm{min} / 1.73 \mathrm{~m}^{2}$ was associated with lower overall cognitive performance (beta $=-0.191 ; 95 \% \mathrm{Cl},-0.346$ to -0.035 ), lower information processing speed (beta $=-0.215 ; 95 \% \mathrm{Cl},-0.381$ to -0.049 ), and borderline statistically significantly lower memory function (beta $=-0.151 ; 95 \% \mathrm{Cl},-0.323$ to 0.022 ). After further adjustment for the variables of models 3 to 5, these associations were attenuated and no longer statistically significant.

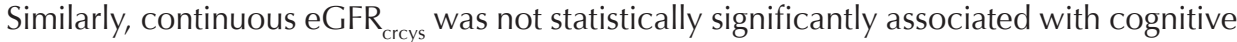
performance after full adjustment (Table 5.5, model 5a).

Results were similar when we adjusted for $24 \mathrm{~h}$ average ambulatory systolic blood pressure instead of office systolic blood pressure (Tables 5.4 and 5.5, model 5b).

\section{eGFR and cognitive performance: test for interaction with age}

Analyses with interaction terms showed that the association between continuous eGFR crcys $_{\text {s }}$ and cognitive performance was stronger at older age, to such an extent that the interaction terms indicated a -0.043 (overall cognitive performance) to - 0.031 (memory function) difference in the beta of eGFR crcys $_{\text {p }}$ per 10 years older age (model $1, P_{\text {interaction }}<0.05$ for all cognitive domains).

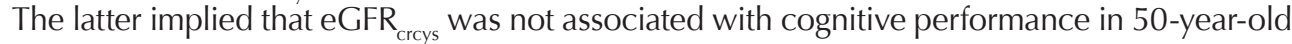
individuals, whereas in 70-year-old individuals, it was associated with lower overall cognitive performance and borderline statistically significantly lower memory function and executive function (Supplemental Table 5.4). Additional age-stratified analyses showed a similar pattern, but were hampered by a loss of statistical power (Supplemental Table 5.5).

\section{Additional analyses}

When eGFR ${ }_{\text {crcys }}$ was replaced with either eGFR based on the MDRD Study equation, eGFR $_{\mathrm{cr}}$ or eGFR ${ }_{\text {cys }}$ the results did not materially change, except for the association of eGFR crcys $_{\text {with }}$

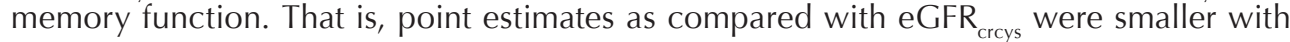
creatinine-based equations and larger with the cystatin C-based equation (Supplemental Table 5.6).

Additionally, the results were not materially altered in the following scenarios (Supplemental Tables 5.7 and 5.8): when we adjusted for a quadratic association between age and all scores of cognitive performance; when we replaced office systolic blood pressure with either office diastolic blood pressure, office mean arterial pressure, office pulse pressure, presence of hypertension, $24 \mathrm{~h}$ average ambulatory $(n=2644)$ diastolic blood pressure, mean arterial pressure, or pulse pressure; when we replaced the use of antihypertensive medication with the use of a renin-angiotensin system inhibitor, or replaced waist circumference with waist-to-hip ratio or body mass index; when the results were additionally adjusted for either total ( $n=2635$ ) or moderate to vigorous ( $n=2634)$ physical activity; 


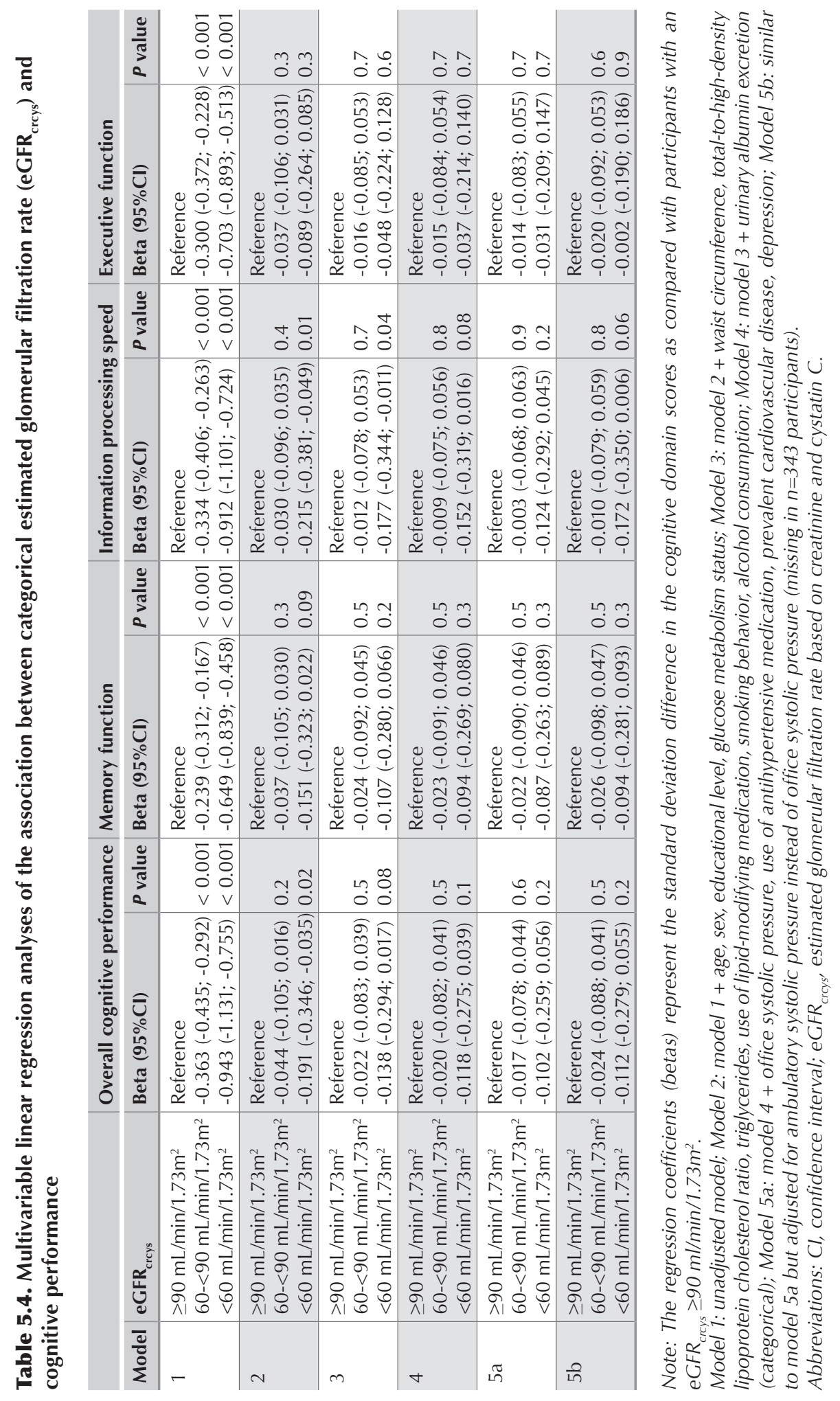




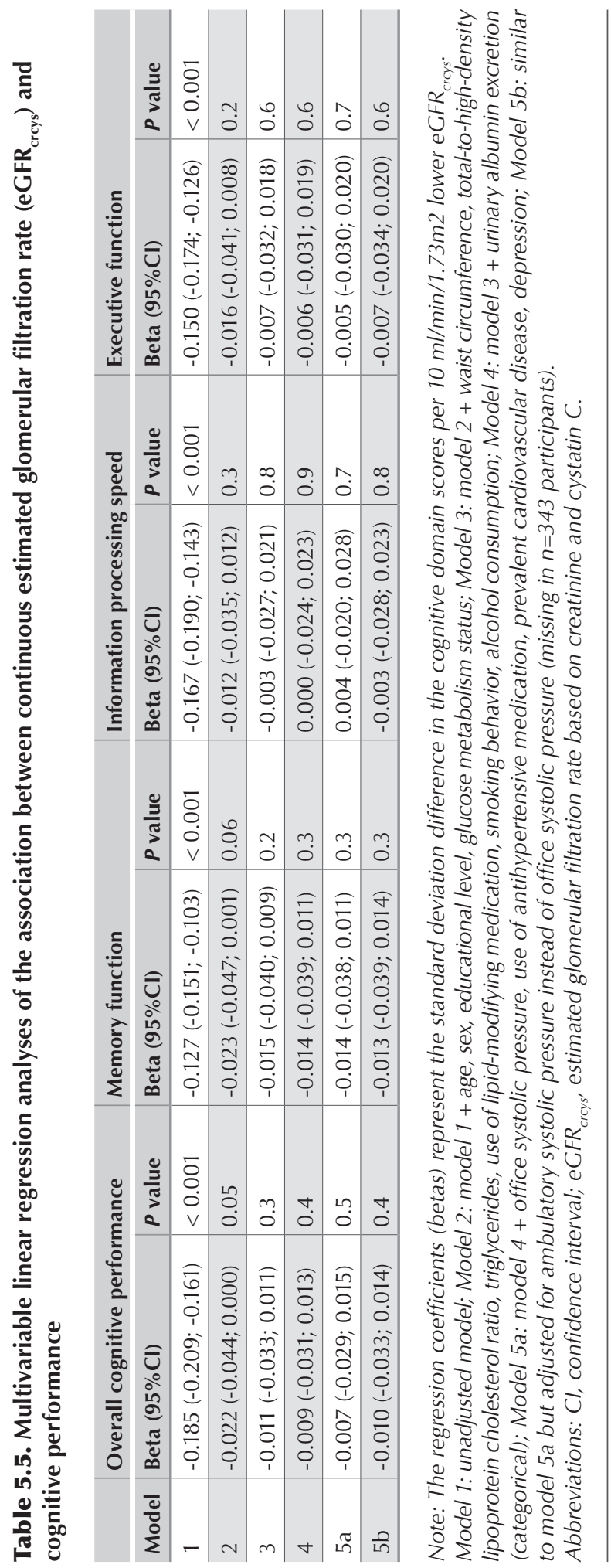


when we restricted the analyses to participants with UAE $\leq 300 \mathrm{mg} / 24 \mathrm{~h}(\mathrm{n}=2969)$ and participants with two urine collections $(n=2727)$; and when we excluded participants with a Mini-Mental State Examination score $<24(\mathrm{n}=10)$. In addition, no interactions between either

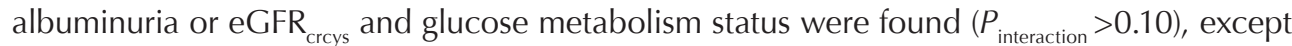
for the association of UAE $15-<30 \mathrm{mg} / 24 \mathrm{~h}$ with overall cognitive performance $\left(P_{\text {interaction }}=0.1\right)$ and executive function $\left(P_{\text {interaction }}=0.08\right)$, and the association of eGFR $_{\text {crcys }}<60 \mathrm{ml} / \mathrm{min} / 1.73 \mathrm{~m}^{2}$ with information processing speed $\left(P_{\text {interaction }}=0.04\right)$ in participants with impaired glucose metabolism only. Finally, results of multiple imputation analyses were similar to complete case analyses, with the exception that lower EFR $_{\text {crcys }}$ was borderline statistically significantly associated with lower memory function after multiple imputation (Supplemental Table 5.9).

\section{DISCUSSION}

This study on the associations of eGFR and albuminuria with cognitive performance in 40- to 75 -year-old individuals had three main findings. First, albuminuria with $U A E \geq 30 \mathrm{mg} / 24 \mathrm{~h}$ was associated with lower information processing speed, independent of educational level, CVD risk factors (including eGFR $_{\text {crcys }}$ ), and lifestyle factors. Second, eGFR crcys $_{\text {sas not }}$ associated with any of the domains of cognitive performance after adjustment for educational level, CVD risk factors (including albuminuria), and lifestyle factors. Third, associations of

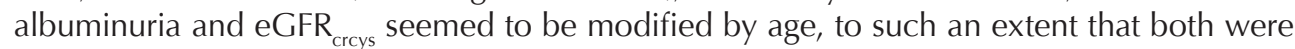
more strongly and extensively associated with cognitive performance in older individuals.

Albuminuria with $U A E \geq 30 \mathrm{mg} / 24 \mathrm{~h}$ was associated with information processing speed, while no associations were observed with memory function and executive function. As compared to continuous UAE, the categorical approach may have been less affected by the day-to-day variability in UAE and, therefore, non-differential misclassification with bias towards the null. In addition, the continuous (exponential) model, although reasonable, may not have perfectly fitted the association. However, we cannot exclude residual confounding with the categorical approach or the play of chance.

The absence of an association with executive function is in agreement with two studies in a similar age group, ${ }^{19,26}$ but contrasts with studies in older individuals, ${ }^{12-14,17}$ which have shown an association between albuminuria and executive function. One explanation for this discrepancy is that cognitive decline is more subtle in middle-aged individuals due to a higher brain reserve capacity in this age group. The statistically significant interaction between age and albuminuria, which suggested a stronger association between albuminuria and cognitive performance, including executive function, with increasing age, supports this view. In addition, the study population largely consisted of highly educated individuals who may be better able to maximize cognitive performance in the face of brain damage, ${ }^{27,28}$ and information processing speed has been shown to be the domain most affected in individuals with vascular cognitive decline. ${ }^{45}$

Generalized endothelial dysfunction may provide an explanation for the link between albuminuria and cognitive performance. ${ }^{21,22}$ According to this concept, endothelial dysfunction of the microcirculation on the one hand causes albuminuria, and, on the other hand, cerebral small vessel disease. It has been hypothesized that cerebral small vessel disease increases blood-brain barrier permeability, which leads to extravasation of blood substances and subsequent neuronal damage. ${ }^{22,46}$ Indeed, albuminuria has been associated with magnetic resonance imaging findings of cerebral small vessel disease ${ }^{47}$ and the latter predict cognitive decline. ${ }^{48}$ 
Reduced GFR may lead to neuronal damage due to the accumulation of neurotoxins and/or may reflect disease processes underlying cognitive decline, for example, exposure to CVD risk factors and CVD itself. ${ }^{20}$ The attenuation of the regression coefficients after adjustment for CVD risk factors supports the latter. However, the results of this study contrast with those of previous studies in middle-aged ${ }^{23,25}$ and older individuals, ${ }^{1,5,6,8,9}$ which have shown independent associations between lower creatinine-based estimates of GFR and the studied domains of cognitive performance. This is potentially explained by the younger mean age of the participants in the present study population. The statistically significant interaction between age and eGFR $_{\text {crys' }}$ which suggested a stronger association between eGFR $_{\text {crcys }}$ and cognitive performance with increasing age, supports this view. Additionally, the study population largely consisted of highly educated individuals and few participants had an eGFR crcys $_{<}<60 \mathrm{ml} / \mathrm{min} / 1.73 \mathrm{~m}^{2}$.

We used an equation based on both serum creatinine and serum cystatin $C$ levels to estimate GFR in our primary analyses. ${ }^{30}$ However, additional analyses showed a stronger association between eGFR and cognitive performance (i.e., memory function) when an equation based on cystatin $\mathrm{C}$ level only was used. This is in agreement with two previous studies in older individuals. ${ }^{10,11}$ A clear explanation for these results cannot be derived from this study. Cystatin C may be a more sensitive biomarker of GFR than creatinine in populations with more comorbidities, ${ }^{49}$ which allows for the detection of even a subtle association between eGFR and memory function. Alternatively, cystatin C level may be associated with other determinants of cognitive decline, such as visceral adiposity and inflammation. ${ }^{49}$

Major strengths of the present study were its extensive assessment of cognitive performance and detailed characterization of the study population, which allowed adjustment for an extensive series of potential confounders, including 24h average ambulatory blood pressure. However, this study also had some limitations. First, the cross-sectional design limited causal inferences. Second, we cannot exclude residual confounding despite adjustment for an extensive series of potential confounders. For example, inflammation markers were not available. In addition, it is important to note that, for example, blood pressure and CVD may also be intermediates in the association between kidney function and cognitive performance, possibly leading to underestimation of the evaluated associations. ${ }^{41}$ However, the relatively small attenuation of the regression coefficients after adding these variables suggests that their role as either confounder or intermediate was small. Third, individual cognitive tests often incorporate multiple cognitive domains and their classification is, therefore, somewhat arbitrary. ${ }^{42}$ Further, although extensive, the cognitive test battery used did not specifically assess, for example, working memory, semantic memory, reasoning, and visual-spatial ability. Fourth, participants with missing data differed from included participants, and the results of the complete case analyses may be conservative because the additional multiple imputation analyses also suggested an association

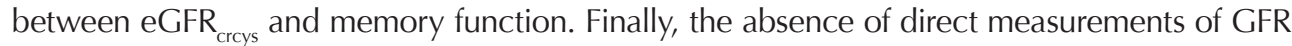
precludes any definitive conclusions on the differences between the eGFR formulas and their associations with cognitive decline.

In conclusion, in the entire study population, albuminuria was independently associated with worse cognitive performance, in particular within the domain of information processing

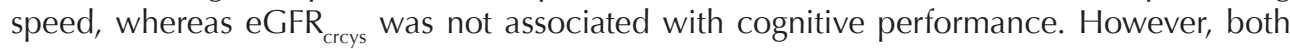
albuminuria and eGFR $_{\text {crys }}$ were more strongly and extensively associated with cognitive performance in older individuals. 


\section{REFERENCES}

1. Kurella M, Yaffe K, Shlipak MG, Wenger NK, Chertow GM. Chronic kidney disease and cognitive impairment in menopausal women. Am J Kidney Dis. 2005 Jan;45(1):66-76.

2. Kurella M, Chertow GM, Fried LF, Cummings SR, Harris T, Simonsick E, et al. Chronic kidney disease and cognitive impairment in the elderly: the health, aging, and body composition study. J Am Soc Nephrol. 2005 Jul;16(7):2127-33.

3. Kurella Tamura M, Wadley V, Yaffe K, McClure LA, Howard G, Go R, et al. Kidney function and cognitive impairment in US adults: the Reasons for Geographic and Racial Differences in Stroke (REGARDS) Study. Am J Kidney Dis. 2008 Aug;52(2):227-34.

4. Slinin Y, Paudel ML, Ishani A, Taylor BC, Yaffe K, Murray AM, et al. Kidney function and cognitive performance and decline in older men. J Am Geriatr Soc. 2008 Nov;56(11):2082-8.

5. Buchman AS, Tanne D, Boyle PA, Shah RC, Leurgans SE, Bennett DA. Kidney function is associated with the rate of cognitive decline in the elderly. Neurology. 2009 Sep 22;73(12):920-7.

6. Elias MF, Elias PK, Seliger SL, Narsipur SS, Dore GA, Robbins MA. Chronic kidney disease, creatinine and cognitive functioning. Nephrol Dial Transplant. 2009 Aug;24(8):2446-52.

7. Khatri M, Nickolas T, Moon YP, Paik MC, Rundek T, Elkind MS, et al. CKD associates with cognitive decline. J Am Soc Nephrol. 2009 Nov;20(11):2427-32.

8. Yaffe K, Ackerson L, Kurella Tamura M, Le Blanc P, Kusek JW, Sehgal AR, et al. Chronic kidney disease and cognitive function in older adults: findings from the chronic renal insufficiency cohort cognitive study. J Am Geriatr Soc. 2010 Feb;58(2):338-45.

9. Feng L, Yap KB, Yeoh LY, Ng TP. Kidney function and cognitive and functional decline in elderly adults: findings from the Singapore longitudinal aging study. J Am Geriatr Soc. 2012 Jul;60(7):1208-14.

10. Darsie B, Shlipak MG, Sarnak MJ, Katz R, Fitzpatrick AL, Odden MC. Kidney function and cognitive health in older adults: the Cardiovascular Health Study. Am J Epidemiol. 2014 Jul 1;180(1):68-75.

11. Slinin Y, Peters KW, Ishani A, Yaffe K, Fink HA, Stone KL, et al. Cystatin C and cognitive impairment 10 years later in older women. J Gerontol A Biol Sci Med Sci. 2015 Jun;70(6):771-8.

12. Abbatecola AM, Barbieri M, Rizzo MR, Grella R, Laieta MT, Quaranta E, et al. Arterial stiffness and cognition in elderly persons with impaired glucose tolerance and microalbuminuria. J Gerontol A Biol Sci Med Sci. 2008 Sep;63(9):991-6.

13. Weiner DE, Bartolomei K, Scott T, Price LL, Griffith JL, Rosenberg I, et al. Albuminuria, cognitive functioning, and white matter hyperintensities in homebound elders. Am J Kidney Dis. 2009 Mar;53(3):438-47.

14. Jassal SK, Kritz-Silverstein D, Barrett-Connor E. A prospective study of albuminuria and cognitive function in older adults: the Rancho Bernardo study. Am J Epidemiol. 2010 Feb 1;171(3):277-86.

15. Barzilay JI, Gao P, O'Donnell M, Mann JF, Anderson C, Fagard R, et al. Albuminuria and decline in cognitive function: The ONTARGET/TRANSCEND studies. Arch Intern Med. 2011 Jan 24;171(2):142-50.

16. Helmer C, Stengel B, Metzger M, Froissart M, Massy ZA, Tzourio C, et al. Chronic kidney disease, cognitive decline, and incident dementia: the 3C Study. Neurology. 2011 Dec 6;77(23):2043-51.

17. Heringa SM, van den Berg E, Dekker JM, Nijpels G, Kessels RP, Kappelle LJ, et al. Albuminuria and cognitive functioning in an older population: the Hoorn study. Dement Geriatr Cogn Dis. 2011;32(3):182-7.

18. Kurella Tamura M, Muntner P, Wadley V, Cushman M, Zakai NA, Bradbury BD, et al. Albuminuria, kidney function, and the incidence of cognitive impairment among adults in the United States. Am J Kidney Dis. 2011 Nov;58(5):756-63.

19. Joosten H, Izaks GJ, Slaets JP, de Jong PE, Visser ST, Bilo HJ, et al. Association of cognitive function with albuminuria and eGFR in the general population. Clin J Am Soc Nephrol. 2011 Jun;6(6):1400-9.

20. Bugnicourt JM, Godefroy O, Chillon JM, Choukroun G, Massy ZA. Cognitive disorders and dementia in CKD: the neglected kidney-brain axis. J Am Soc Nephrol. 2013 Feb;24(3):353-63.

21. Stehouwer CD, Smulders YM. Microalbuminuria and risk for cardiovascular disease: Analysis of potential mechanisms. J Am Soc Nephrol. 2006 Aug;17(8):2106-11.

22. Knopman DS. Invited commentary: Albuminuria and microvascular disease of the brain--a shared pathophysiology. Am J Epidemiol. 2010 Feb 1;171(3):287-9; author reply 90-1.

23. Hailpern SM, Melamed ML, Cohen HW, Hostetter TH. Moderate chronic kidney disease and cognitive function in adults 20 to 59 years of age: Third National Health and Nutrition Examination Survey (NHANES III). J Am Soc Nephrol. 2007 Jul;18(7):2205-13.

24. Kurella Tamura M, Xie D, Yaffe K, Cohen DL, Teal V, Kasner SE, et al. Vascular risk factors and cognitive impairment in chronic kidney disease: the Chronic Renal Insufficiency Cohort (CRIC) study. Clin J Am Soc Nephrol. 2011 Feb;6(2):248-56.

25. Tsai CF, Wang SJ, Fuh JL. Moderate chronic kidney disease is associated with reduced cognitive performance in midlife women. Kidney Int. 2010 Sep;78(6):605-10.

26. Barzilay JI, Lovato JF, Murray AM, Williamson J, Ismail-Beigi F, Karl D, et al. Albuminuria and cognitive decline in people with diabetes and normal renal function. Clin J Am Soc Nephrol. 2013 Nov;8(11):1907-14.

27. Stern Y. What is cognitive reserve? Theory and research application of the reserve concept. J Int Neuropsychol Soc. 2002 Mar;8(3):448-60.

28. Stern Y. Cognitive reserve in ageing and Alzheimer's disease. Lancet Neurol. 2012 Nov;11(11):1006-12.

29. Schram MT, Sep SJ, van der Kallen CJ, Dagnelie PC, Koster A, Schaper N, et al. The Maastricht Study: an extensive phenotyping study on determinants of type 2 diabetes, its complications and its comorbidities. Eur J Epidemiol. 2014 Jun;29(6):439-51.

30. Inker LA, Schmid CH, Tighiouart H, Eckfeldt JH, Feldman HI, Greene T, et al. Estimating glomerular filtration rate from serum creatinine and cystatin C. N Engl J Med. 2012 Jul 5;367(1):20-9. 
31. Levey AS, Stevens LA, Schmid CH, Zhang YL, Castro AF, 3rd, Feldman HI, et al. A new equation to estimate glomerular filtration rate. Ann Intern Med. 2009 May 5;150(9):604-12.

32. Van der Elst W, van Boxtel MP, van Breukelen GJ, Jolles J. Rey's verbal learning test: normative data for 1855 healthy participants aged 24-81 years and the influence of age, sex, education, and mode of presentation. J Int Neuropsychol Soc. 2005 May;11(3):290-302.

33. Van der Elst W, van Boxtel MP, van Breukelen GJ, Jolles J. The Stroop color-word test: influence of age, sex, and education; and normative data for a large sample across the adult age range. Assessment. 2006 Mar;13(1):62-79.

34. Van der Elst W, van Boxtel MP, van Breukelen GJ, Jolles J. The Concept Shifting Test: adult normative data. Psychol Assess. 2006 Dec;18(4):424-32.

35. Van der Elst W, van Boxtel MP, van Breukelen GJ, Jolles J. The Letter Digit Substitution Test: normative data for 1,858 healthy participants aged 24-81 from the Maastricht Aging Study (MAAS): influence of age, education, and sex. J Clin Exp Neuropsychol. 2006 Aug;28(6):998-1009.

36. Spauwen PJ, van Boxtel MP, Verhey FR, Kohler S, Sep SJ, Koster A, et al. Both Low and High 24-Hour Diastolic Blood Pressure Are Associated With Worse Cognitive Performance in Type 2 Diabetes: The Maastricht Study. Diabetes Care. 2015 Aug;38(8):1473-80.

37. Levey AS, Coresh J. Chronic kidney disease. Lancet. 2012 Jan 14;379(9811):165-80.

38. Lee M, Saver JL, Chang KH, Liao HW, Chang SC, Ovbiagele B. Low glomerular filtration rate and risk of stroke: meta-analysis. BMJ. 2010;341:c4249.

39. Lee M, Saver JL, Chang KH, Liao HW, Chang SC, Ovbiagele B. Impact of microalbuminuria on incident stroke: a meta-analysis. Stroke. 2010 Nov;41(11):2625-31.

40. Byers AL, Yaffe K. Depression and risk of developing dementia. Nat Rev Neurol. 2011 Jun;7(6):323-31.

41. Schisterman EF, Cole SR, Platt RW. Overadjustment bias and unnecessary adjustment in epidemiologic studies. Epidemiology. 2009 Jul;20(4):488-95.

42. Lezak MD, Howieson DB, Bigler ED, Tranel D. Neuropsychological assessment. $5^{\text {th }}$ ed. New York: Oxford University Press, Inc.; 2012.

43. Sterne JA, White IR, Carlin JB, Spratt M, Royston P, Kenward MG, et al. Multiple imputation for missing data in epidemiological and clinical research: potential and pitfalls. BMJ. 2009;338:b2393.

44. van Buuren S. Multiple imputation of discrete and continuous data by fully conditional specification. Stat Methods Med Res. 2007 Jun;16(3):219-42.

45. Vasquez BP, Zakzanis KK. The neuropsychological profile of vascular cognitive impairment not demented: a meta-analysis. J Neuropsychol. 2015 Mar;9(1):109-36.

46. Wardlaw JM, Sandercock PA, Dennis MS, Starr J. Is breakdown of the blood-brain barrier responsible for lacunar stroke, leukoaraiosis, and dementia? Stroke. 2003 Mar;34(3):806-12.

47. Wada M, Nagasawa H, Kurita K, Koyama S, Arawaka S, Kawanami T, et al. Microalbuminuria is a risk factor for cerebral small vessel disease in community-based elderly subjects. J Neurol Sci. 2007 Apr 15;255(1-2):27-34.

48. Debette S, Markus HS. The clinical importance of white matter hyperintensities on brain magnetic resonance imaging: systematic review and meta-analysis. BMJ. 2010;341:c3666.

49. Shlipak MG, Mattes MD, Peralta CA. Update on cystatin C: incorporation into clinical practice. Am J Kidney Dis. 2013 Sep;62(3):595-603. 
Supplemental Material 


\section{SUPPLEMENTAL METHODS}

\section{Cognitive assessment}

The composite memory score was derived from the Verbal Learning Test by weighting total immediate and delayed recall scores. The domain information processing speed included the Stroop Color-Word Test Part I and II, the Concept Shifting Test Part A and B, and the Letter-Digit Substitution Test. Executive function was assessed by the Stroop Color-Word Test Part III and the Concept Shifting Test Part C. A brief description of the individual tests is provided below.

Raw test scores were transformed into z-scores. Standardized scores of the Stroop Color-Word Test and Concept Shifting Test were inverted so that higher scores indicated better cognitive performance. Thereafter, domain-specific scores were calculated as the standardized average of the z-scores from (sub)tests within that domain (for example, memory function $=Z$ score of $\left(Z\right.$ score $_{\text {immediate recall }}+Z$ score $\left.\left._{\text {delayed recall }} / 2\right)\right)$. The standardized average of these domain scores was then considered a measure of overall cognitive performance (i.e. overall cognitive performance $=Z$ score of (memory function + information processing speed + executive function / 3)).

\section{Description of the individual cognitive tests used in the present study}

\section{Verbal Learning Test ${ }^{1}$ :}

Fifteen unrelated, monosyllabic, words were presented on a computer screen in five subsequent trials. After each trial, participants were instructed to recall as many words as possible in any order. Twenty minutes after the last trial, participants were asked again to reproduce the words. Outcomes recorded included the total number of words correctly recalled over the five trials (total immediate recall) and the number of correctly recalled words during delayed recall (delayed recall).

\section{Stroop Color-Word Test ${ }^{2}$ :}

In this test, which consisted of three parts, participants were firstly asked to read aloud color names (i.e., red, blue, yellow, and green) that were printed in black ink (Part I). Secondly, they were instructed to name solid color patches (Part II). Finally, participants had to name the ink color of color names that were printed in an incongruent color (for example participants were asked to say red when the word yellow was printed in red) (Part III). The time needed to complete Part III was adjusted for the average time needed to complete Part I and II.

\section{Concept Shifting Test ${ }^{3}$ :}

This test, a modification of the Trailing Making Test, consisted of four subtasks. During each subtask, participants were shown 16 small circles aligned along a larger imaginary circle. The small circles contained (a combination of) digits, letters, or were empty. Participants were instructed to cross-out as quickly as possible the digits in ascending order (Part A), the letters in alphabetic order (Part B), and the letters and digits in alternating order (Part C). Thereafter, participants were asked to cross-out empty circles in a clockwise fashion in two consecutive trials (Part 0). In this way, test results could be accounted for basic motor speed. The time needed to complete subtasks $A$ and $B$ was adjusted for the average time needed to complete Part 0 , the time needed to completed Part C for the average time of Part A and B. 


\section{Letter-Digit Substitution Test ${ }^{4}$ :}

Participants were requested to match digits to letters according to a given key. This key included the numbers 1 to 9, each paired with a different letter. The outcome of interest was the number of correct substitutions within 90 seconds.

\section{Potential confounders}

We assessed fasting glucose, hemoglobin A1c (HbA1c; glycated hemoglobin), total cholesterol, high-density lipoprotein (HDL) cholesterol, low-density lipoprotein (LDL) cholesterol, triglycerides, glucose metabolism status, body mass index, waist circumference, hip circumference, office blood pressure, $24 \mathrm{~h}$ average ambulatory blood pressure, medication use, smoking behavior, alcohol consumption, educational level, (subjective) physical activity, current major depressive episode and prevalent cardiovascular disease (CVD) as described previously. ${ }^{5,6}$ Glucose metabolism was classified according to the World Health Organization 2006 criteria $^{7}$ into normal glucose metabolism, impaired fasting glucose, impaired glucose tolerance, and diabetes mellitus. Participants with diabetes mellitus and participants using glucose-lowering medication were considered as having type 2 diabetes if they had no (self-reported) type 1 or other specific type of diabetes mellitus. For the present study, impaired fasting glucose and impaired glucose tolerance were combined into impaired glucose metabolism. Total-to-HDL cholesterol ratio was calculated by dividing total cholesterol by HDL cholesterol. Waist-to-hip ratio was calculated by dividing waist circumference by hip circumference. Hypertension was defined as an office systolic pressure $\geq 140 \mathrm{mmHg}$, an office diastolic pressure $\geq 90 \mathrm{mmHg}$ and/or the use of antihypertensive medication. Office pulse pressure was defined as office systolic pressure minus office diastolic pressure and office mean arterial pressure as office diastolic pressure plus 0.412 times office pulse pressure. ${ }^{8}$ Similar equations were used to calculate $24 \mathrm{~h}$ average ambulatory pulse pressure and $24 \mathrm{~h}$ average ambulatory mean arterial pressure, respectively. Smoking behavior was classified into: never, former, and current. Alcohol consumption was classified into three categories: no consumption, low consumption ( $<7$ glasses per week for women and $\leq 14$ glasses per week for men) and high consumption ( $>7$ glasses per week for women and $>14$ glasses per week for men). Educational level was classified into three groups: low (none, primary, or lower vocational education only), intermediate (intermediate general secondary, intermediate vocational or higher general secondary education) and high (higher vocational education or university level of education).6,9 Prevalent CVD was defined as a self-reported history of myocardial infarction, cerebrovascular infarction or hemorrhage, or percutaneous artery angioplasty of, or vascular surgery on, the coronary, abdominal, peripheral or carotid arteries. The presence of a current major depressive episode was assessed by the Mini-International Neuropsychiatric Interview (MINI). ${ }^{10}$ A modified version of the Community Healthy Activities Model Program for Seniors (CHAMPS) questionnaire ${ }^{11}$ was used to assess weekly total and moderate to vigorous physical activity. 


\section{Details on the metrics of the variables used in the statistical analyses}

\begin{tabular}{|c|c|}
\hline Variable & Metric \\
\hline Urinary albumin excretion (as confounder) & $<15 / 15-<30 / \geq 30$ mg/24h (dummy coded) \\
\hline $\mathrm{eGFR}_{\text {crcys }}$ (as confounder) & per $10 \mathrm{ml} / \mathrm{min} / 1.73 \mathrm{~m}^{2}$ lower eGFR ${ }_{\text {crcys }}$ \\
\hline Age & years \\
\hline Sex & man/woman \\
\hline Educational level & low/intermediate/high (dummy coded) \\
\hline Glucose metabolism status & $\begin{array}{l}\text { normal glucose metabolism/impaired glucose } \\
\text { metabolism/type } 2 \text { diabetes (dummy coded) }\end{array}$ \\
\hline Waist circumference & centimetres \\
\hline Waist-to-hip ratio & ratio \\
\hline Body mass index & $<25 / 25-<30 / \geq 30 \mathrm{~kg} / \mathrm{m}^{2}$ (dummy coded) \\
\hline Smoking behavior & never/former/current (dummy coded) \\
\hline Alcohol consumption & none/low/high (dummy coded) \\
\hline Total physical activity & h/week \\
\hline Moderate to vigorous physical activity & h/week \\
\hline Total-to-HDL cholesterol ratio & ratio \\
\hline Triglycerides & $\mathrm{mmol} / \mathrm{l}$ \\
\hline Use of lipid-modifying medication & yes/no \\
\hline Office systolic pressure & $\mathrm{mmHg}$ \\
\hline Office diastolic pressure & $\mathrm{mmHg}$ \\
\hline Office mean arterial pressure & $\mathrm{mmHg}$ \\
\hline Office pulse pressure & $\mathrm{mmHg}$ \\
\hline $24 \mathrm{~h}$ average ambulatory systolic pressure & $\mathrm{mmHg}$ \\
\hline $24 \mathrm{~h}$ average ambulatory diastolic pressure & $\mathrm{mmHg}$ \\
\hline $24 \mathrm{~h}$ average mean arterial pressure & $\mathrm{mmHg}$ \\
\hline $24 \mathrm{~h}$ average pulse pressure & $\mathrm{mmHg}$ \\
\hline Use of antihypertensive medication & yes/no \\
\hline Use of renin-angiotensin system inhibitors & yes/no \\
\hline Presence of hypertension & yes/no \\
\hline Prevalent CVD & yes/no \\
\hline Depression & yes/no \\
\hline
\end{tabular}

Abbreviations: CVD, cardiovascular disease; $e G F R_{\text {crcys' }}$ estimated glomerular filtration rate based on creatinine and cystatin C; HDL cholesterol, high-density lipoprotein cholesterol. 


\section{REFERENCES}

1. Van der Elst W, van Boxtel MP, van Breukelen GJ, Jolles J. Rey's verbal learning test: normative data for 1855 healthy participants aged 24-81 years and the influence of age, sex, education, and mode of presentation. J Int Neuropsychol Soc. 2005 May;11(3):290-302.

2. Van der Elst W, van Boxtel MP, van Breukelen GJ, Jolles J. The Stroop color-word test: influence of age, sex, and education; and normative data for a large sample across the adult age range. Assessment. 2006 Mar;13(1):62-79.

3. Van der Elst W, van Boxtel MP, van Breukelen GJ, Jolles J. The Concept Shifting Test: adult normative data. Psychol Assess. 2006 Dec;18(4):424-32.

4. Van der Elst W, van Boxtel MP, van Breukelen GJ, Jolles J. The Letter Digit Substitution Test: normative data for 1,858 healthy participants aged 24-81 from the Maastricht Aging Study (MAAS): influence of age, education, and sex. J Clin Exp Neuropsychol. 2006 Aug;28(6):998-1009.

5. Schram MT, Sep SJ, van der Kallen CJ, Dagnelie PC, Koster A, Schaper N, et al. The Maastricht Study: an extensive phenotyping study on determinants of type 2 diabetes, its complications and its comorbidities. Eur J Epidemiol. 2014 Jun;29(6):439-51.

6. Spauwen PJ, van Boxtel MP, Verhey FR, Kohler S, Sep SJ, Koster A, et al. Both Low and High 24-Hour Diastolic Blood Pressure Are Associated With Worse Cognitive Performance in Type 2 Diabetes: The Maastricht Study. Diabetes Care. 2015 Aug;38(8):1473-80.

7. World Health Organization. Definition and diagnosis of diabetes mellitus and intermediate hyperglycemia: report of a WHO/IDF consultation2006: Available from: http://www.who.int/diabetes/publications/Definition $\% 20$ and $\% 20$ diagnosis\%20of\%20diabetes_new.pdf.

8. Meaney E, Alva F, Moguel R, Meaney A, Alva J, Webel R. Formula and nomogram for the sphygmomanometric calculation of the mean arterial pressure. Heart. 2000 Jul;84(1):64.

9. De Bie SE. Standaardvragen 1987: Voorstellen voor uniformering van vraagstellingen naar achtergrondkenmerken en interviews [Standard questions 1987: Proposal for uniformization of questions regarding background variables and interviews]. Leiden, The Netherlands: Leiden University Press.; 1987.

10. Sheehan DV, Lecrubier Y, Sheehan KH, Amorim P, Janavs J, Weiller E, et al. The Mini-International Neuropsychiatric Interview (M.I.N.I.): the development and validation of a structured diagnostic psychiatric interview for DSM-IV and ICD-10. J Clin Psychiatry. 1998;59 Suppl 20:22-33; quiz 4-57.

11. Stewart AL, Mills KM, King AC, Haskell WL, Gillis D, Ritter PL. CHAMPS physical activity questionnaire for older adults: outcomes for interventions. Med Sci Sports Exerc. 2001 Jul;33(7):1126-41. 


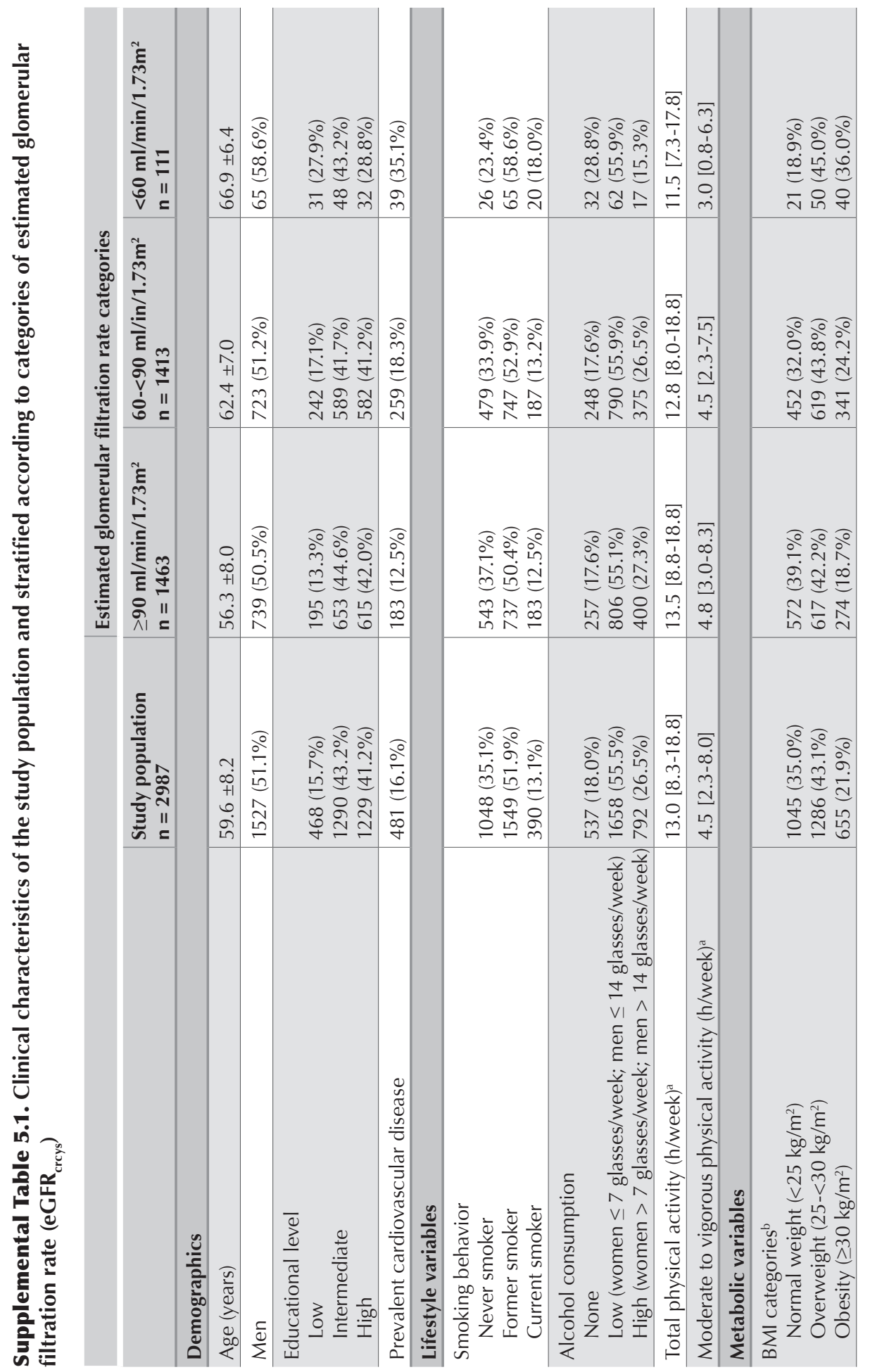




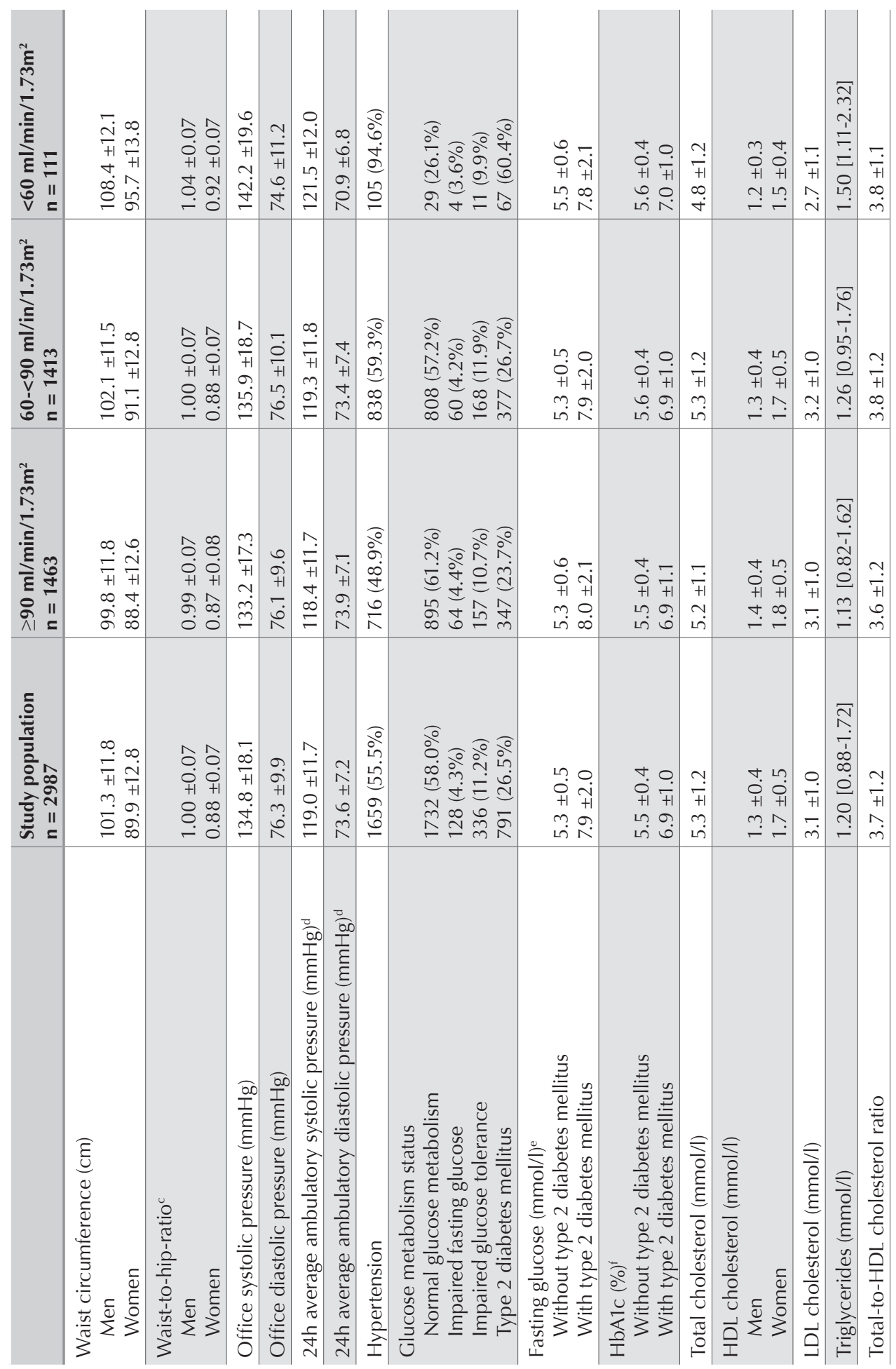




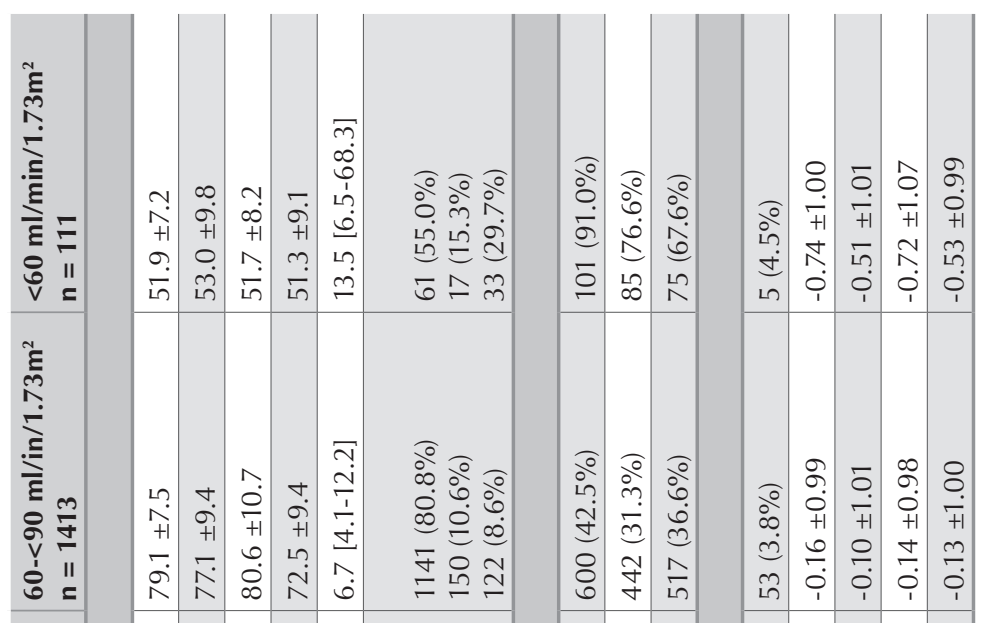

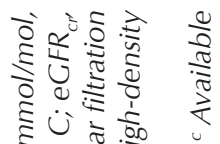
o.

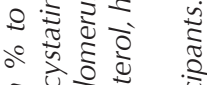

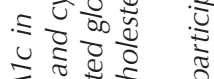

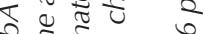

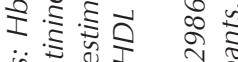

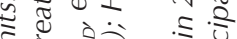
ड ปे

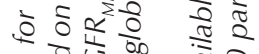
मे पू छ छ

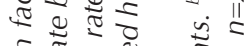

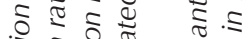
$\frac{\pi}{2} \cdot \frac{\pi}{2} \cdot \frac{\pi}{2}$ बे $: \frac{5}{50}$ के

है

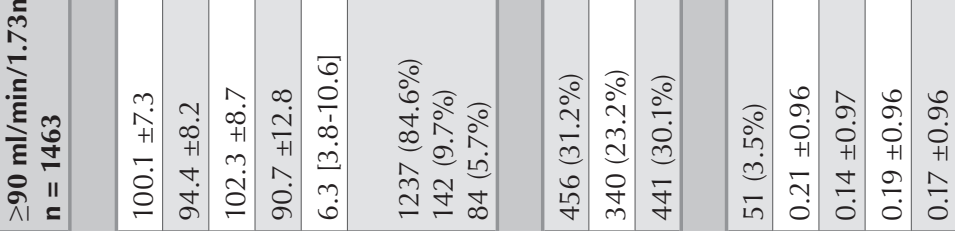

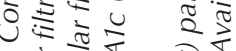

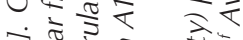

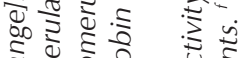

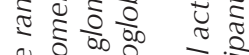
눙

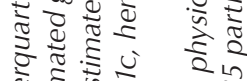
य.

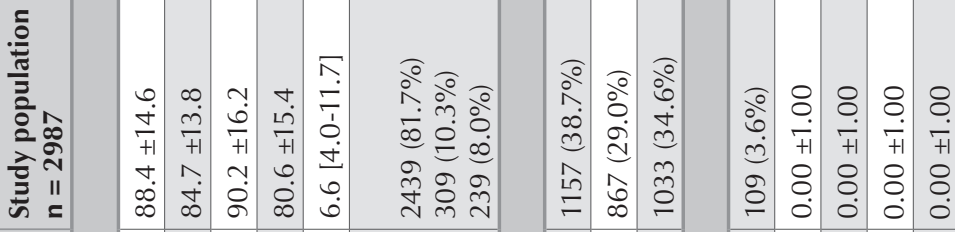

\section{곡

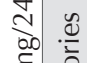 है ฮี ฮั}

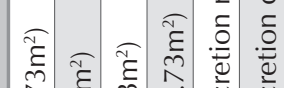
ヘ. :

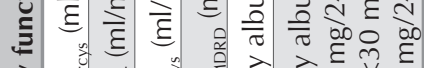

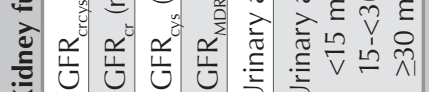

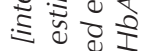

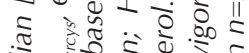
䒺 है.

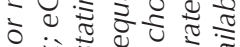
โ

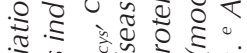

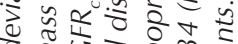

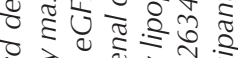
웡ㅎㅇ

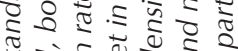

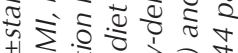

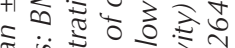

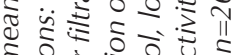
ह.․ำ 원

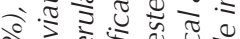

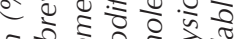

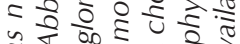

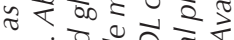

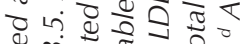
邹

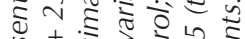

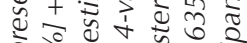
50.

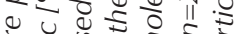
व

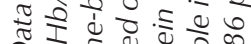
$0 x$. ํํㅇำ 


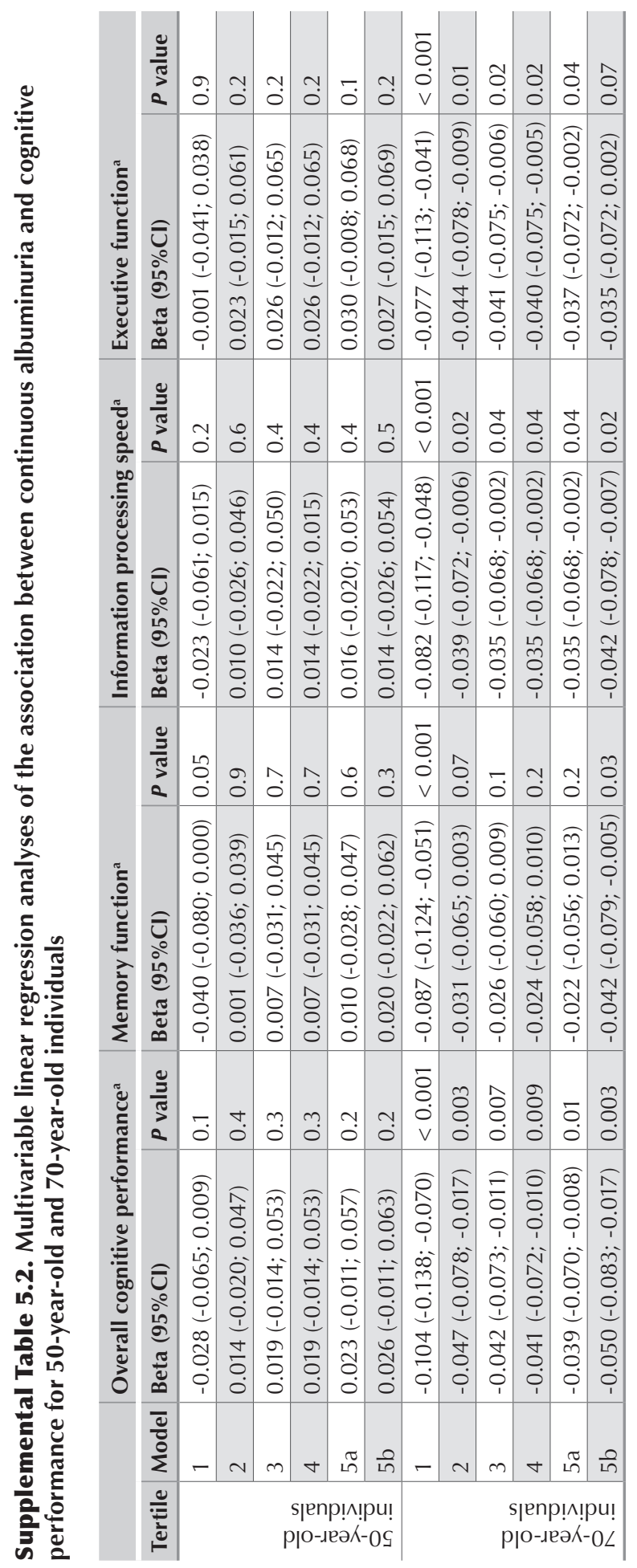

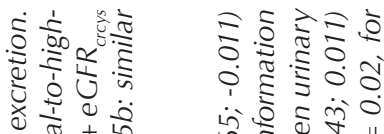

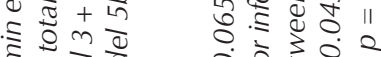

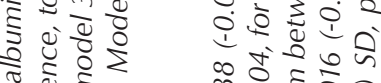
สิ है

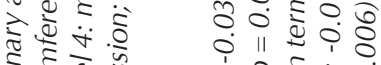

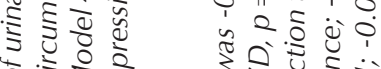
व.

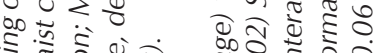

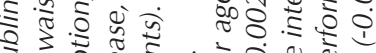
व + है

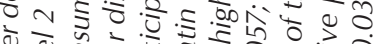

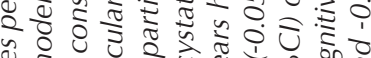

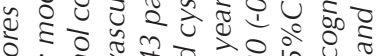

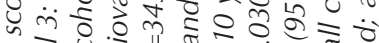

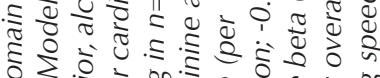

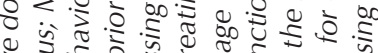

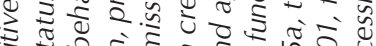
के के 8 ह ह ₹ \% के क्ष च छ ह र ป क है \& ह. ¿ 屯 ₹

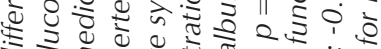

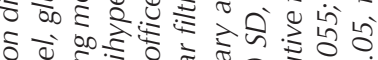

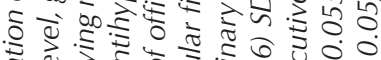
สำ क्ष क्ष ठ क है

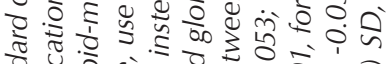
ฐิ

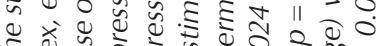

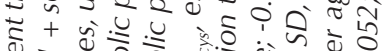
घ-

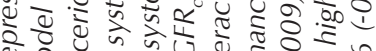
है

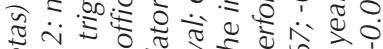

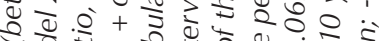
च q

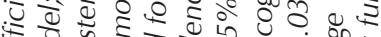

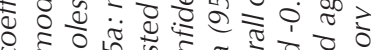

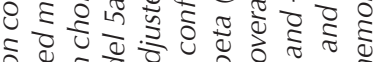
.

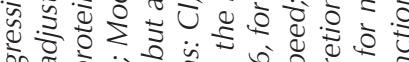

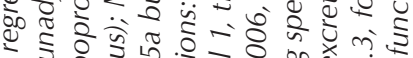

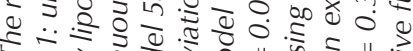

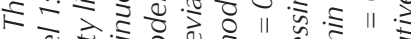
ن

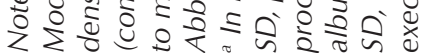




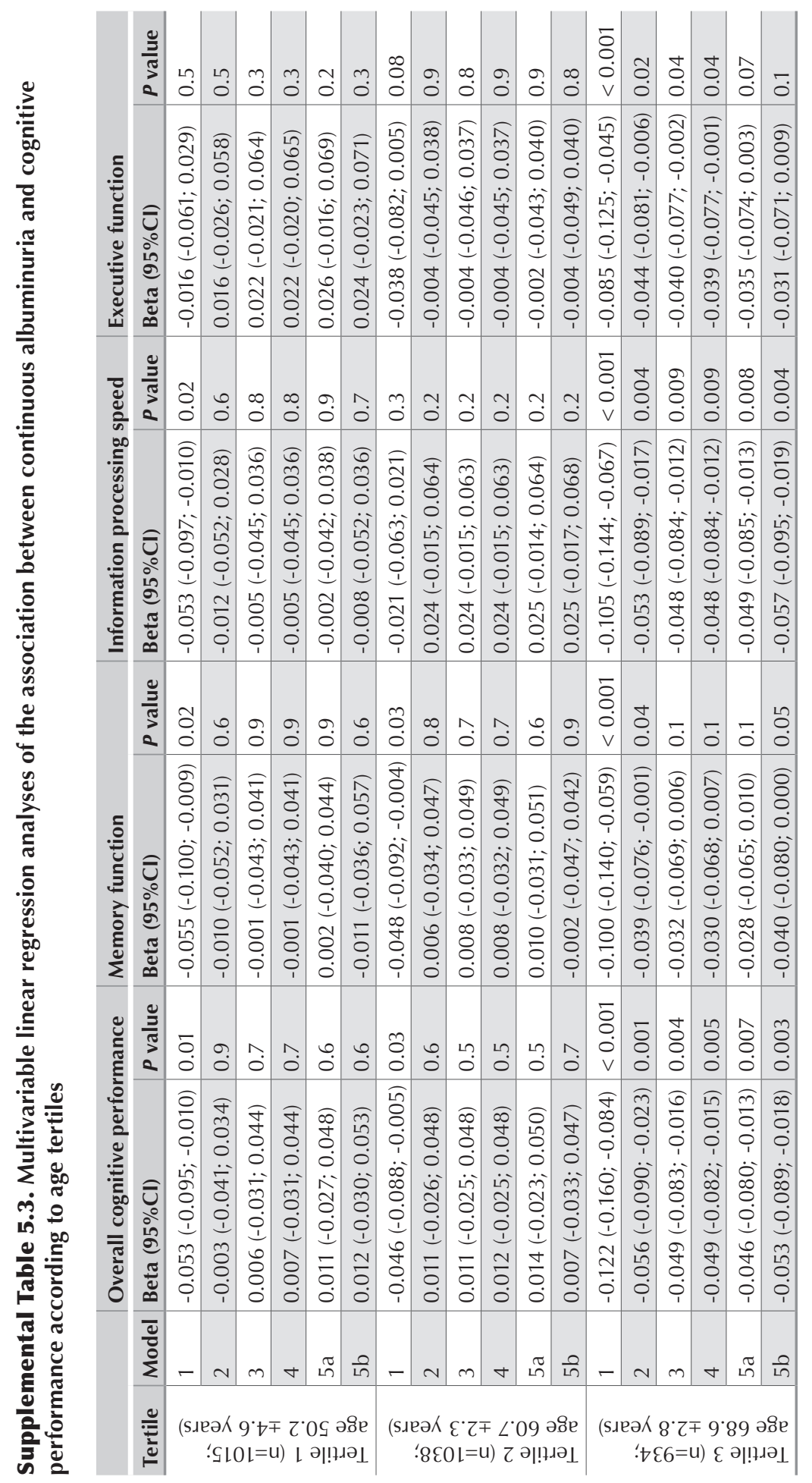

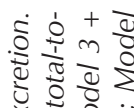

ปั

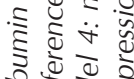

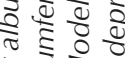

추워

เป็

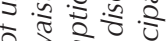

0
0

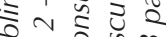

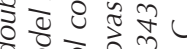

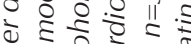

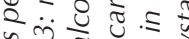

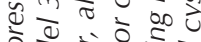

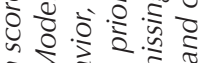

टर क्ष है

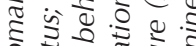

8 정 0

है ह है

ธิ宀

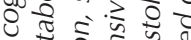

ड हैं छ के

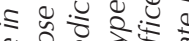

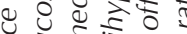

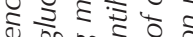

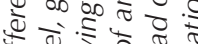

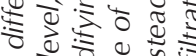

ट

क्ष

จิ

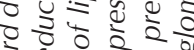

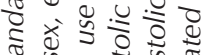

के जे के है

$\approx$ s.

$\tilde{t}+\underline{U}$

बू.

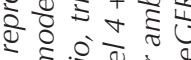

ह 웧ㅎำ

खิ

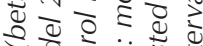

은.

눙

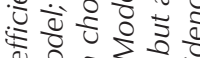

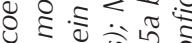

ᄃ워워ำ

के

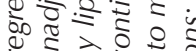

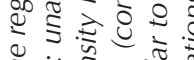

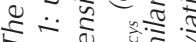

ن व

रं 


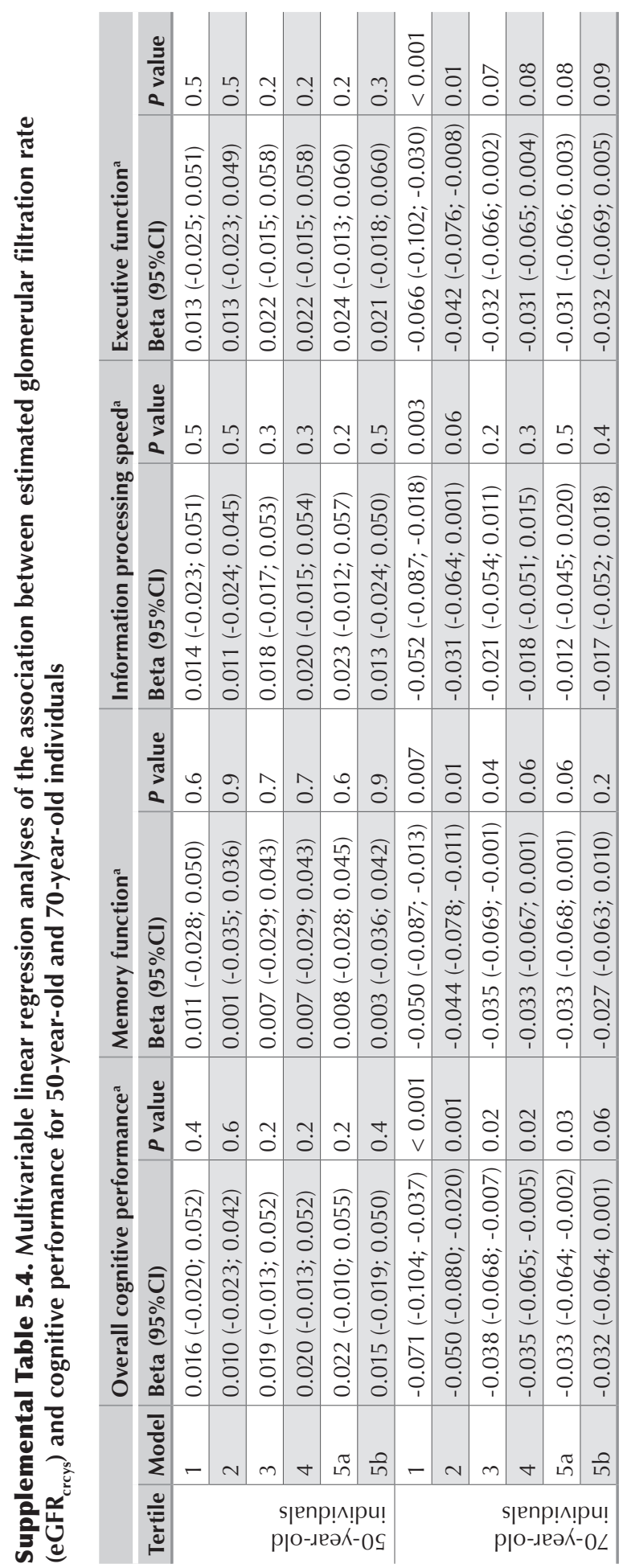

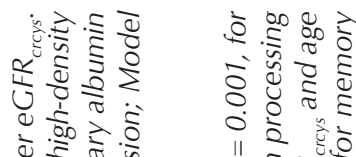

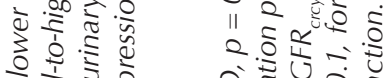

है

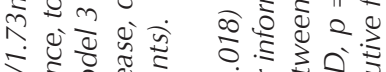

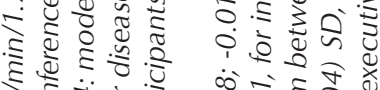

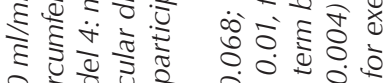

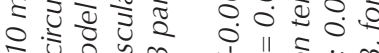

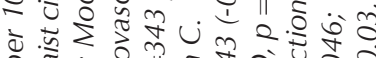

उद्या

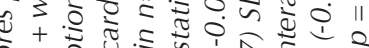

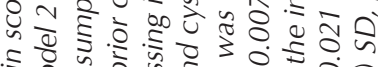

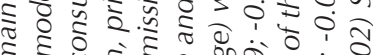

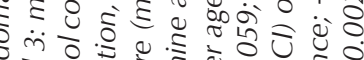

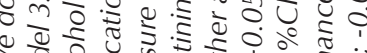

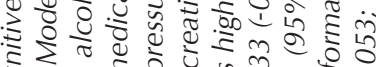

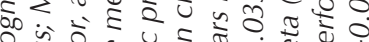

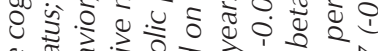

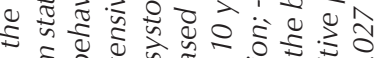

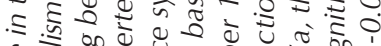
Q

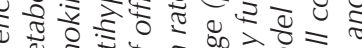

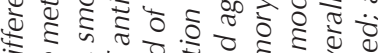

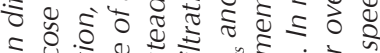

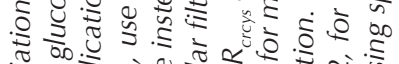

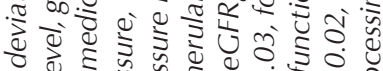

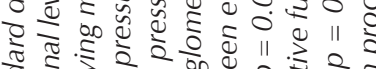
ช.

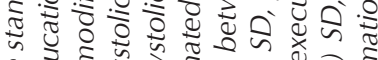
क वे के के है ह का है

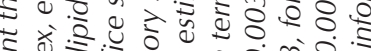
की

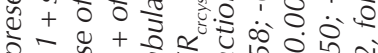

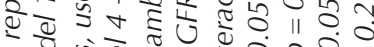

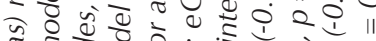

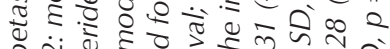

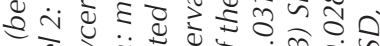
य छ

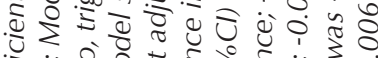

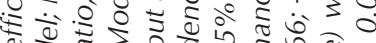

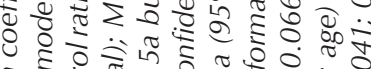
ट.

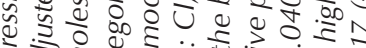

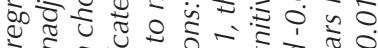

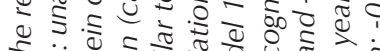

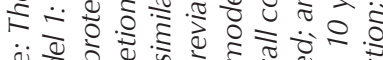
نें 


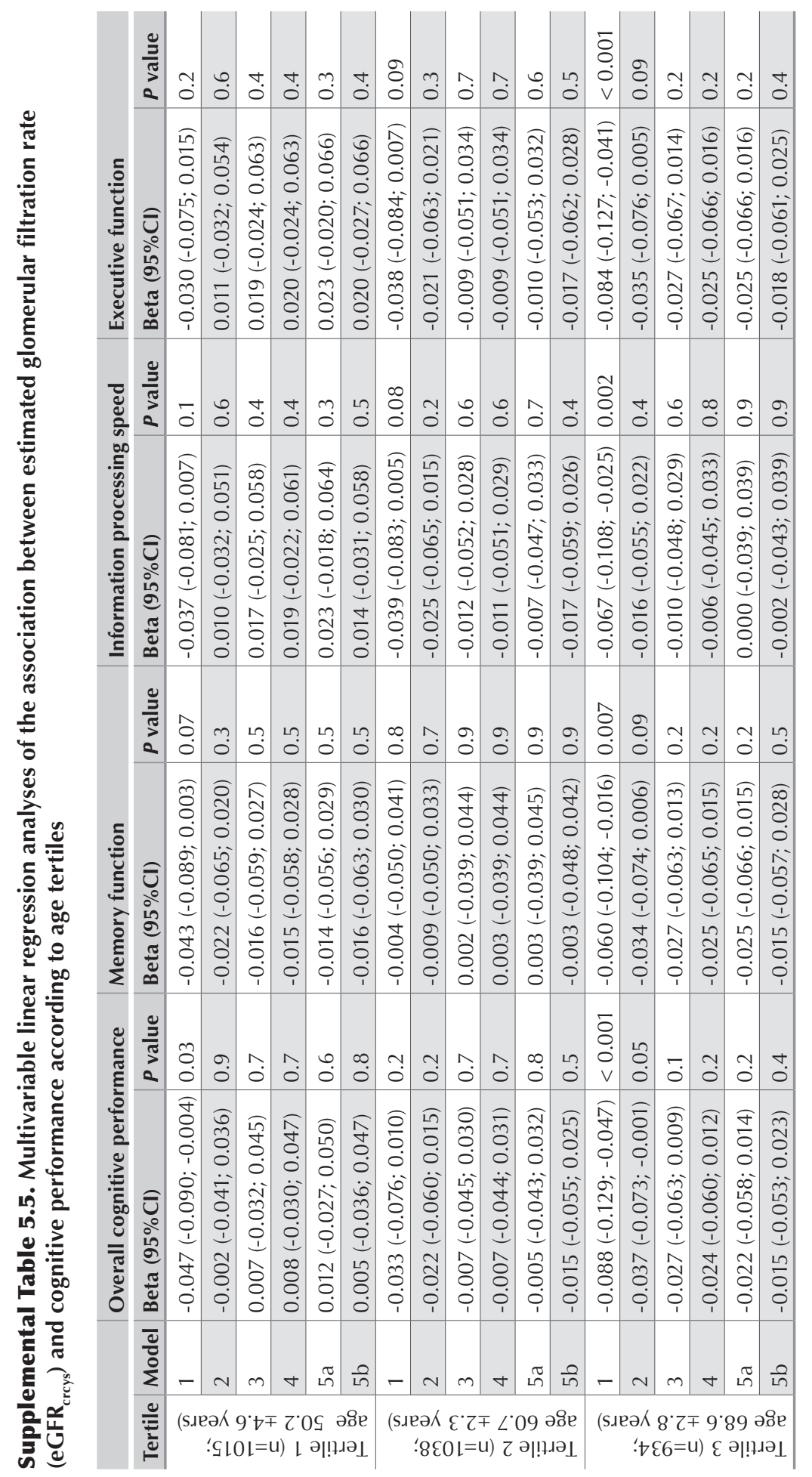

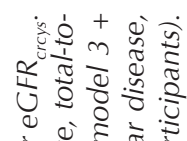
ذ)

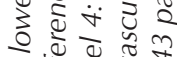
है है :

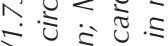

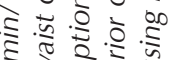
हो है है. है ㄷำ ¿ $\frac{0}{8} \div \frac{0}{0} \div$ ह ह $\overline{0} \ddot{m} \frac{\pi}{\pi}=\underline{y}$

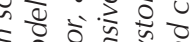

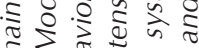

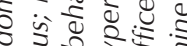

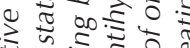
ㄷำ

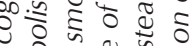

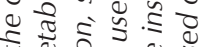

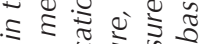

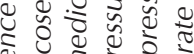

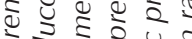
ब安

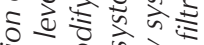

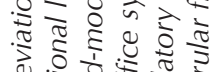

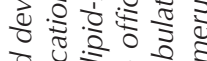

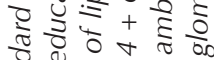

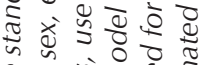
今

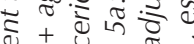

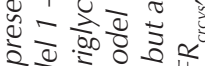

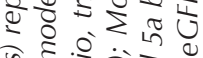

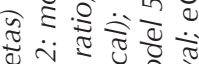
बे ఫे है

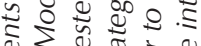

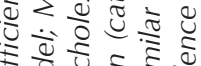
क \& 8 .

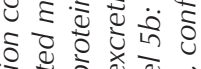

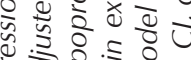

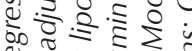

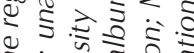
제

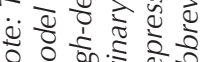
i. 


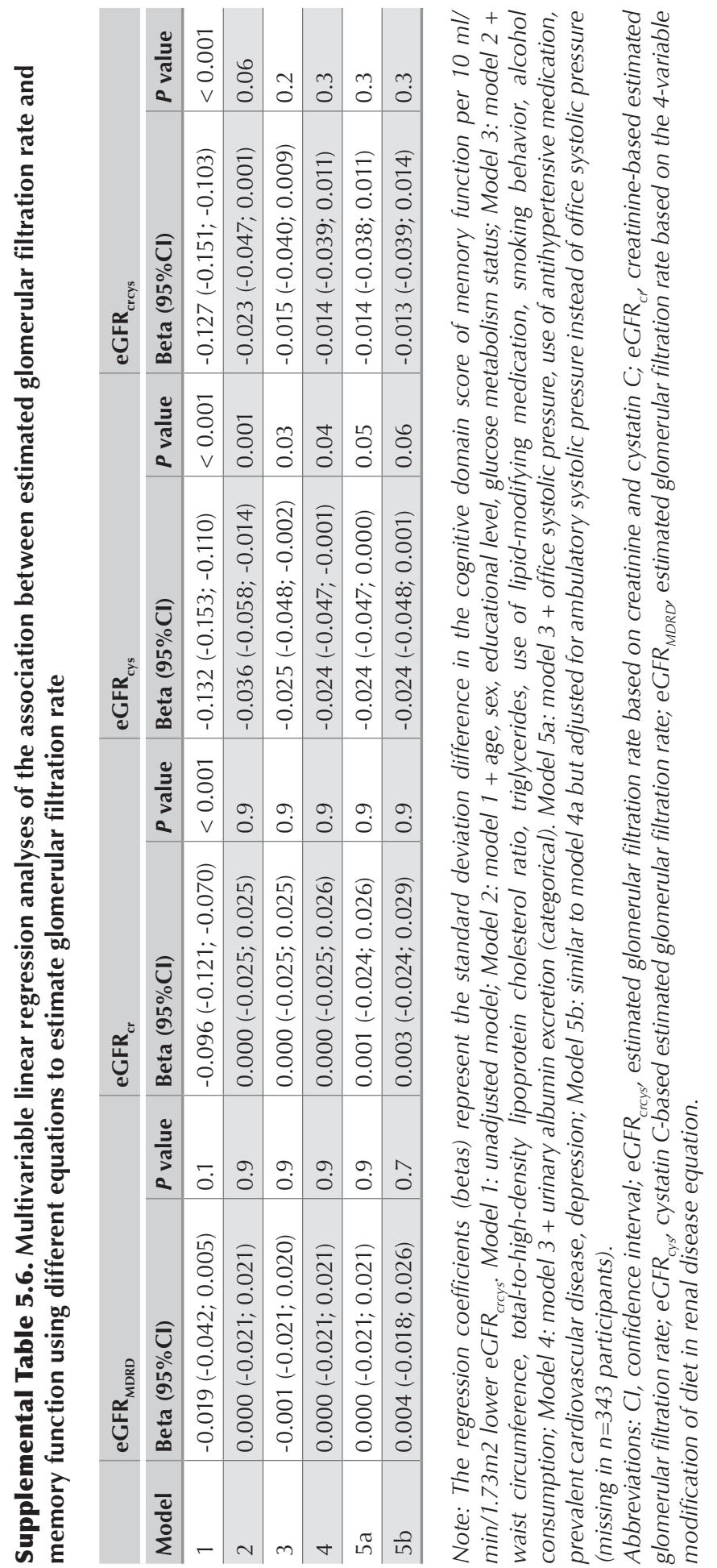




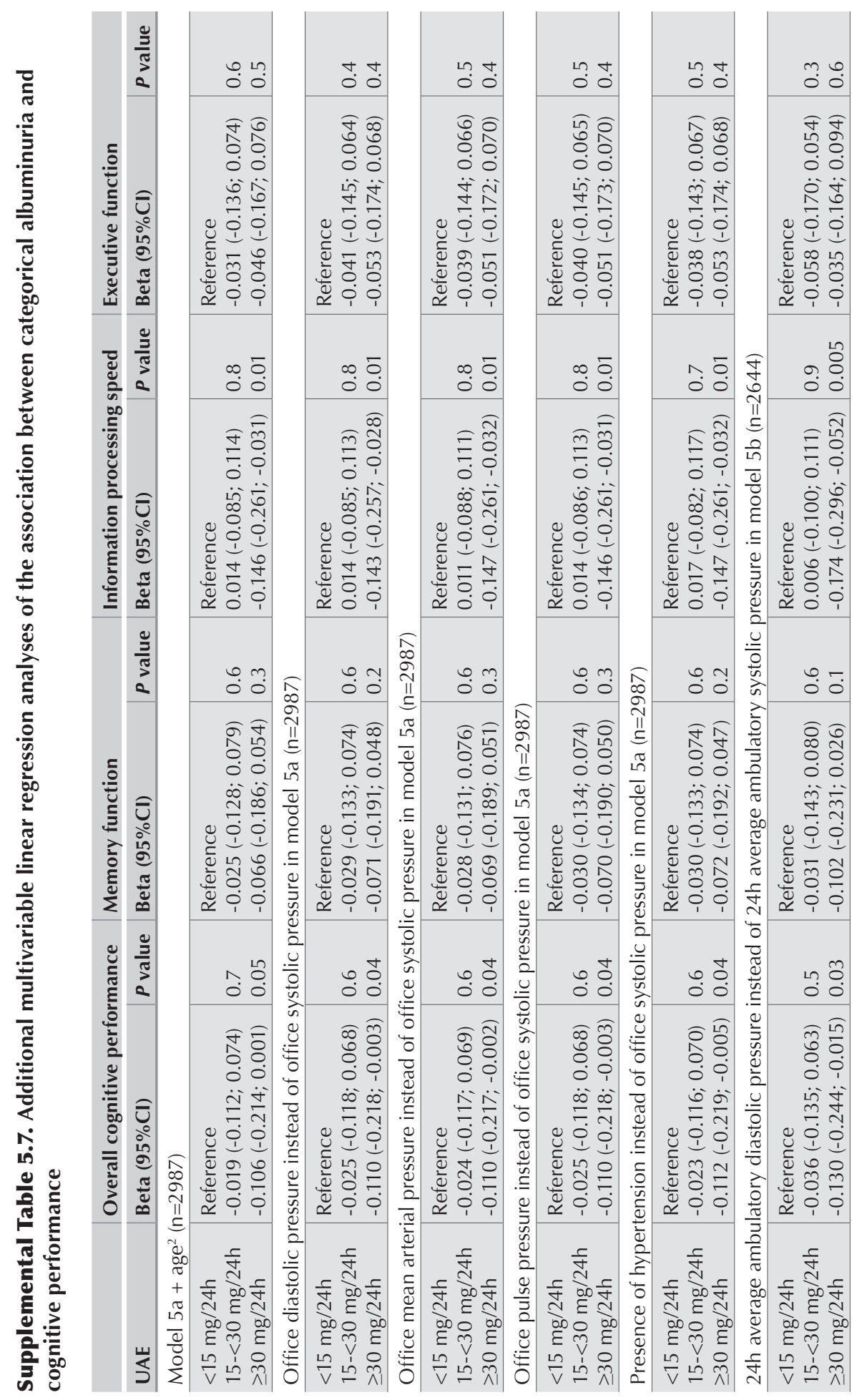




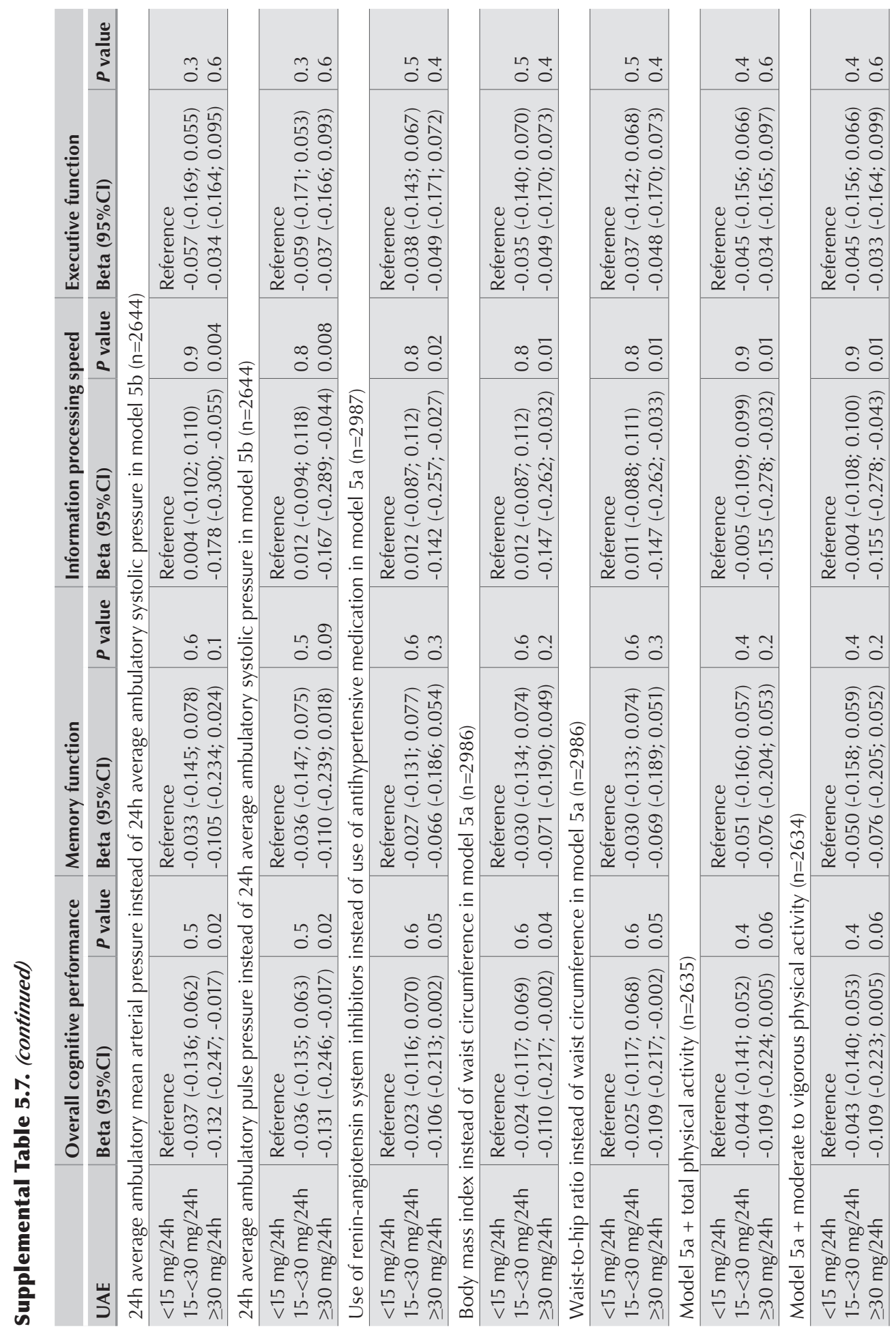



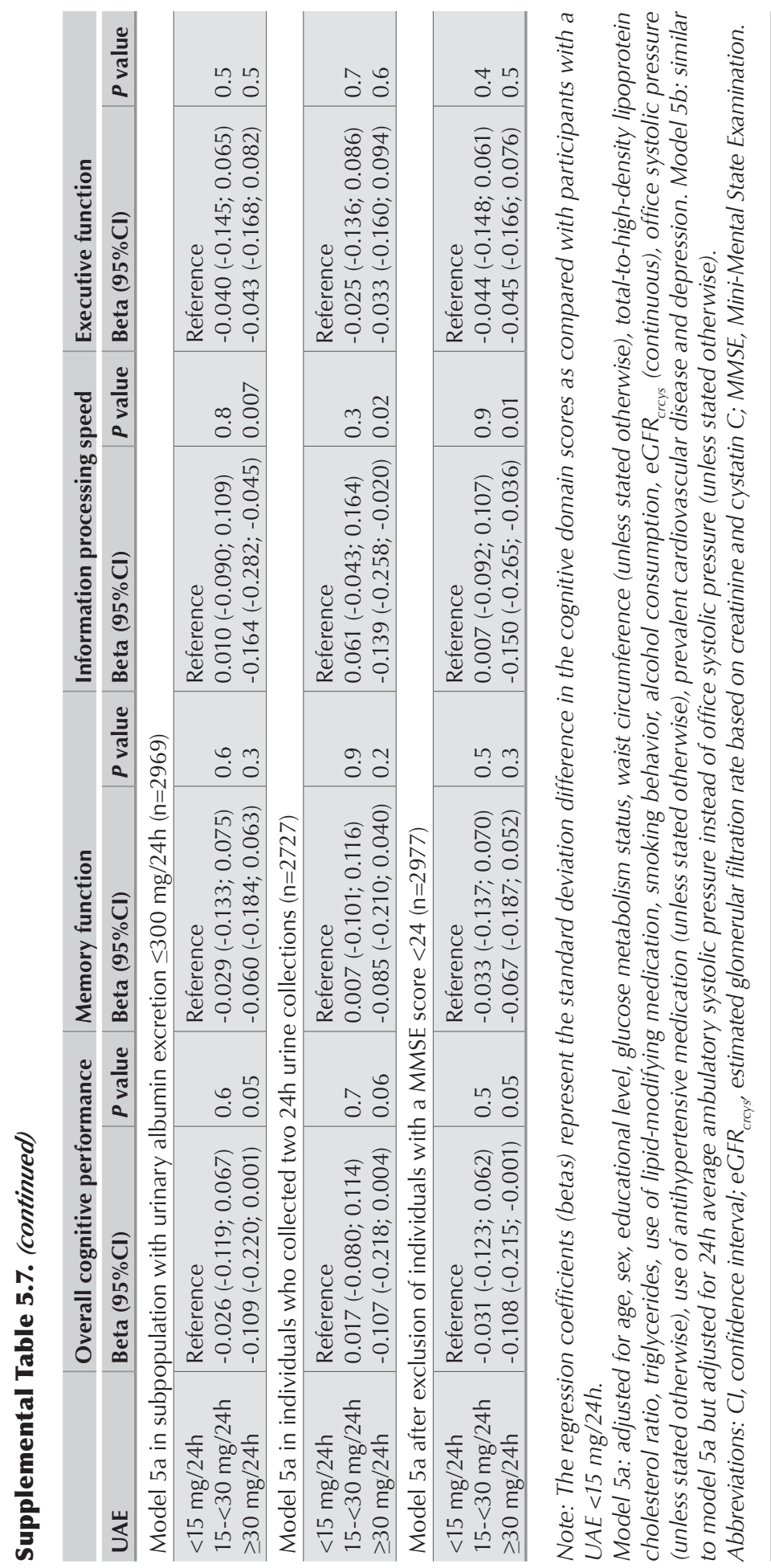


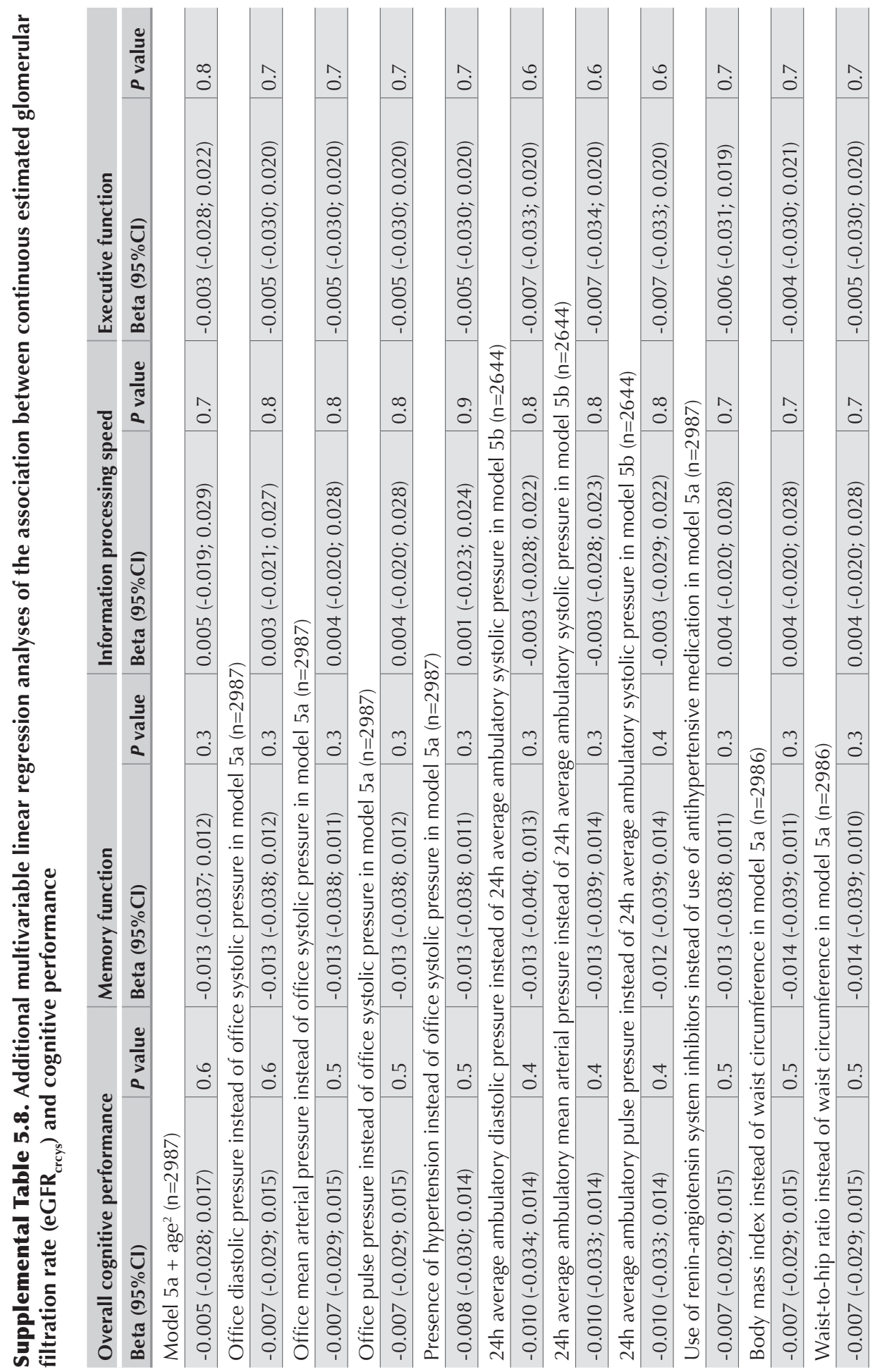




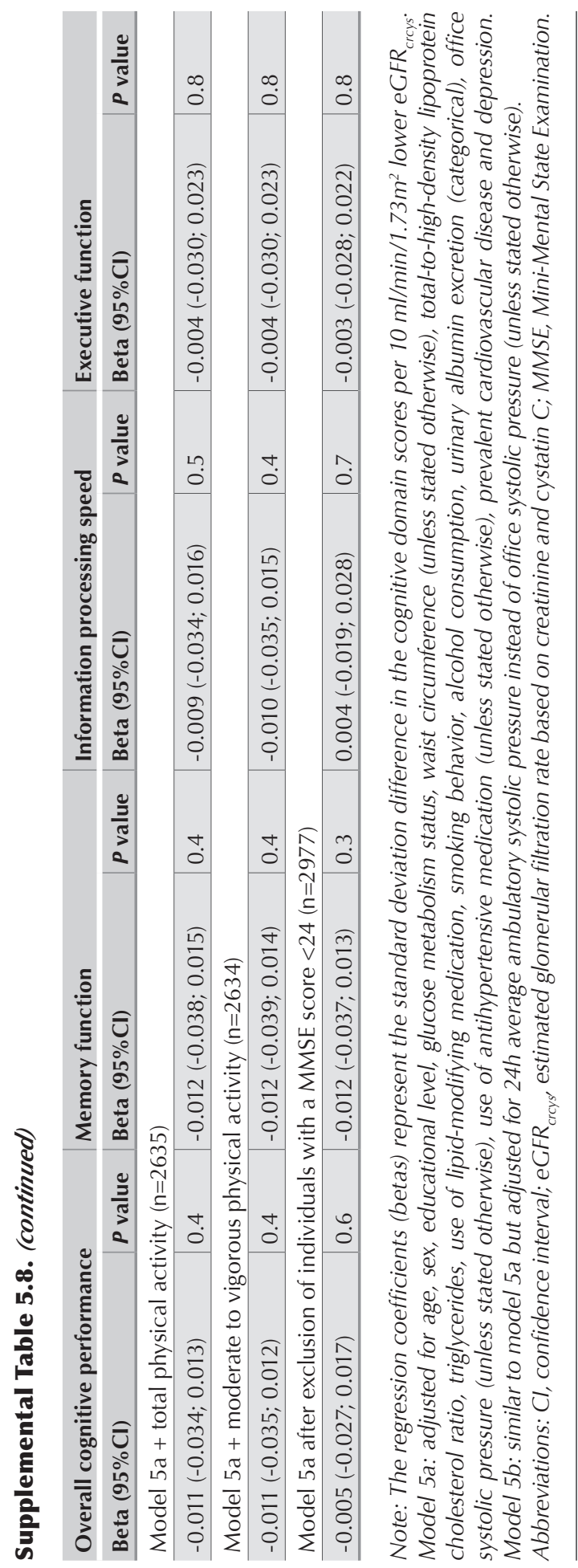




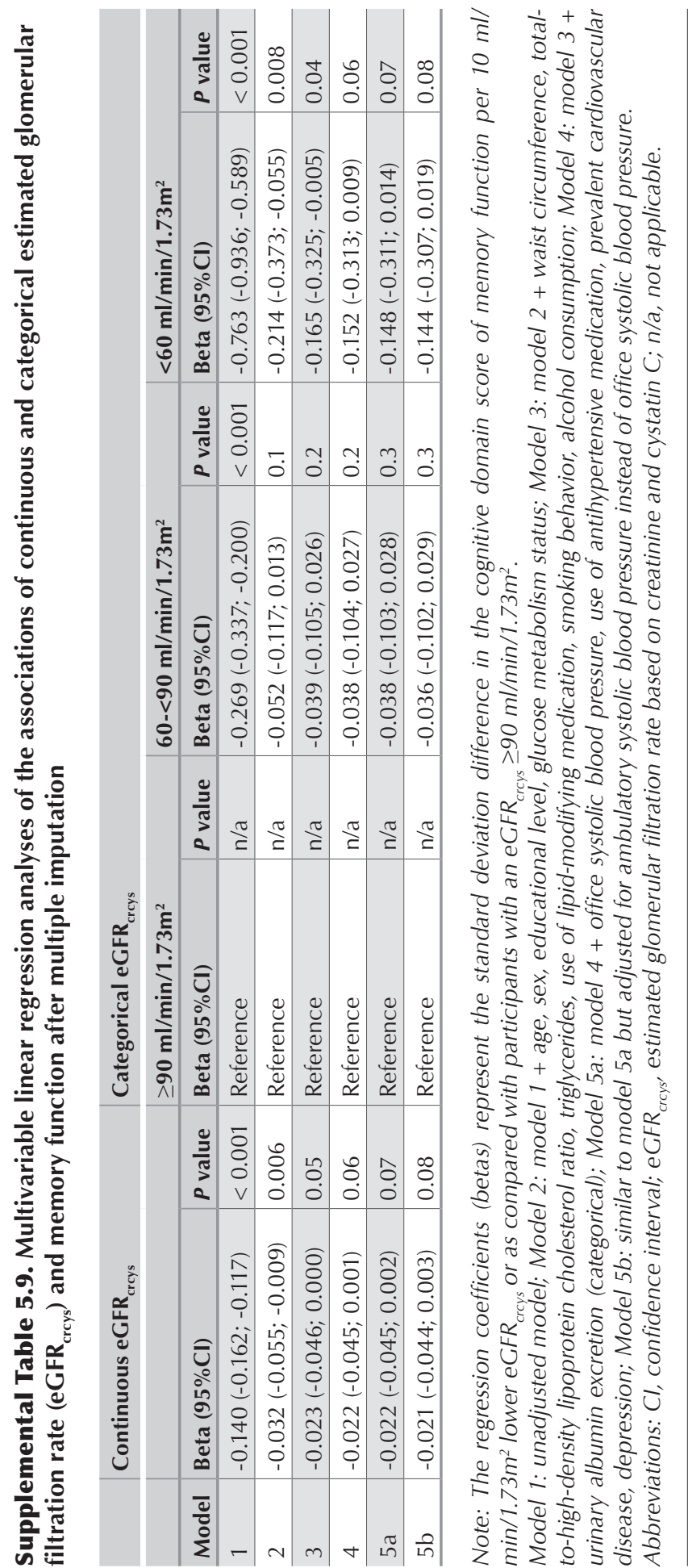




\section{Chapter 6}

Remy J.H. Martens

Jeroen P. Kooman

Coen D.A. Stehouwer

Pieter C. Dagnelie

Carla J.H. van der Kallen

Abraham A. Kroon

Karel M.L. Leunissen

Frank M. van der Sande

Nicolaas C. Schaper

Simone J.S. Sep

Sebastian Köhler

Miranda T. Schram

Ronald M.A. Henry

Nephrol Dial Transplant: 2016

(doi: 10.1093/ndt/gfw377) 
Albuminuria is associated with a higher prevalence of depression in a populationbased cohort study: The Maastricht Study 


\section{ABSTRACT}

Background: Depression is common in individuals with chronic kidney disease (CKD). However, data on the association of albuminuria, which together with reduced estimated glomerular filtration rate (eGFR) defines CKD, with depression are scarce and conflicting. In addition, it is not clear when in the course from normal kidney function to CKD the association with depression appears.

Methods: We examined the cross-sectional associations of albuminuria and eGFR with depressive symptoms and depressive episodes in 2872 and 3083 40- to 75 -year-old individuals, respectively, who completed the baseline survey of an ongoing population-based cohort study, which is conducted in the southern part of the Netherlands, between November 2010 and September 2013. Urinary albumin excretion (UAE) was the average UAE in two 24h urine collections, and eGFR was calculated with the Chronic Kidney Disease Epidemiology Collaboration (CKD-EPI) equation based on creatinine and cystatin C. Depressive symptoms were assessed with the Patient Health Questionnaire (PHQ-9), and the presence of a minor or major depressive episode with the MINI-International Neuropsychiatric Interview. Results: In total, $5.4 \%$ had a minor or major depressive episode. Urinary albumin excretion (UAE) was $<15 \mathrm{mg} / 24 \mathrm{~h}$ in $81.2 \%, 15-<30 \mathrm{mg} / 24 \mathrm{~h}$ in $10.3 \%$, and $\geq 30$ $\mathrm{mg} / 24 \mathrm{~h}$ in $8.6 \%$. In a multivariable logistic regression analysis adjusted for potential confounders, and with UAE $<15 \mathrm{mg} / 24 \mathrm{~h}$ as reference category, the odds ratio (95\% confidence interval $(95 \% \mathrm{CI})$ ) for minor or major depressive episode was 2.13 (1.36 to 3.36) for UAE $15-<30 \mathrm{mg} / 24 \mathrm{~h}$ and 1.81 (1.10 to 2.98 ) for UAE $\geq 30 \mathrm{mg} / 24 \mathrm{~h}$. Average eGFR was $88.2 \pm 14.7 \mathrm{ml} / \mathrm{min} / 1.73 \mathrm{~m}^{2}$. eGFR was not associated with the presence of a minor or major depressive episode. Results were similar when we assessed associations with depressive symptoms or clinically relevant depressive symptoms (PHQ-9 score $\geq 10$ ).

Conclusions: Albuminuria was associated with depressive symptoms and depressive episodes, even at levels of UAE that do not fulfill the CKD criteria. Future longitudinal studies should examine the direction of this association and whether albuminuria could serve as a biomarker to identify individuals at risk of depression. 


\section{INTRODUCTION}

Depression is common in individuals with chronic kidney disease (CKD) (prevalence $25 \%$ ), in whom it is associated with increased morbidity ${ }^{2}$ and mortality. ${ }^{3}$ The frequent occurrence of cerebral small vessel disease (CSVD) in CKD ${ }^{4}$ may be one explanation for the high prevalence of depression in CKD. According to the vascular depression hypothesis, ${ }^{5,6}$ CSVD may lead to depression through disruption of neuronal circuits involved in mood regulation. Further, neurotoxic effects of the uremic milieu ${ }^{7}$ and the presence of comorbidities ${ }^{8}$ as obesity, type 2 diabetes (T2DM) and hypertension may be involved.

However, data on the association of albuminuria, which together with reduced estimated glomerular filtration rate (eGFR) defines CKD, ${ }^{9}$ with depression are scarce and conflicting. ${ }^{10,11}$ Albuminuria may indicate generalized endothelial dysfunction, ${ }^{12,13}$ which in the brain may cause cSVD. ${ }^{14}$ Therefore, albuminuria may be a biomarker of vascular disease processes involved in depression. Indeed, albuminuria was borderline statistically significantly associated with depressive symptoms in individuals with diabetes without cardiovascular disease (CVD). ${ }^{10}$ In contrast, it was not in individuals with diabetes with $\mathrm{CVD}^{10}$ or in a CKD population. ${ }^{11}$ However, in both studies, assessment of depressive symptoms instead of a diagnosis of minor or major depressive episode may have led to misclassification of somatic symptoms of (comorbid) disease as depressive symptoms. ${ }^{1}$

In addition, it is not clear when in the course from normal kidney function to CKD the associations of eGFR and albuminuria with depression appear. Literature on the associations of eGFR and albuminuria with $\mathrm{CVD}^{15,16}$ suggests that both may already be associated with adverse health outcomes at levels that do not fulfill the CKD criteria. In this regard, the results of previous studies suggest that eGFR may not be associated with depression until moderately to severely reduced, ${ }^{11,17-29}$ whereas data on this topic are lacking for albuminuria.

In view of the above, we examined whether albuminuria and eGFR were, independently of each other, associated with both self-reported depressive symptoms and an interviewbased diagnosis of minor or major depressive episode in a population-based cohort without substantial CKD.

\section{METHODS}

\section{The Maastricht Study population and design}

We used data from The Maastricht Study, an observational prospective population-based cohort study..$^{30}$ Eligible for participation were all individuals aged between 40 and 75 years and living in the southern part of the Netherlands. Recruitment was stratified according to known T2DM, with an oversampling of individuals with T2DM, for reasons of efficiency. The present report includes cross-sectional data from the first 3451 participants, who completed the baseline survey between November 2010 and September 2013. The examinations of each participant were performed within a time window of three months. The study has been approved by the institutional medical ethical committee (NL31329.068.10) and the Minister of Health, Welfare and Sports of the Netherlands (Permit 131088-105234-PG), and was conducted in accordance with the Declaration of Helsinki. All participants gave written informed consent. 


\section{Kidney function}

To assess urinary albumin excretion (UAE), participants were requested to collect two $24 \mathrm{~h}$ urine collections (Supplemental Methods). UAE was preferably based on the average of two (available in $91.5 \%$ of the participants) $24 \mathrm{~h}$ urine collections. GFR was estimated with the Chronic Kidney Disease Epidemiology Collaboration (CKD-EPI) equation based on the combination of serum creatinine and serum cystatin $\mathrm{C}\left(\mathrm{eGFR}_{\text {crcys }}\right)$ (Supplemental Methods). ${ }^{31}$

\section{Depressive symptoms}

Depressive symptoms were assessed with a validated Dutch version of the 9-item Patient Health Questionnaire (PHQ-9). ${ }^{32}$ The PHQ-9 is a self-administered questionnaire based on the Diagnostic and Statistical Manual of Mental Disorders $4^{\text {th }}$ edition (DSM-IV) criteria for major depressive episode. It comprises nine items rated on a four-point scale, ranging from 0 ("not at all") to 3 ("nearly every day"). Response options are used to calculate a continuous total depressive symptom score ranging from 0 (no symptoms) to 27 (all symptoms present nearly every day). When 1-2 items were missing, the total score was calculated as $9 *$ (total points / 9 - number of missings), and rounded to the nearest integer. As a continuous variable, scores 0-9 represent no, 10-14 represent moderate, 15-19 represent moderately severe, and 20-27 represent severe depression. ${ }^{33}$ A predefined cut-off score of $\geq 10$ was considered to indicate clinically relevant depressive symptoms. ${ }^{32}$

In addition, we calculated affective (i.e., anhedonia, depressed mood, feeling of worthlessness, thoughts of death) and somatic (i.e., fatigue, appetite changes, sleep difficulties, concentration difficulties, psychomotor agitation/retardation) subscores, based on a confirmatory factor analysis conducted previously. ${ }^{34}$

\section{Minor and major depressive episode}

The Mini-International Neuropsychiatric Interview (MINI) ${ }^{35}$ was used to assess the presence of a minor or major depressive episode in de preceding 2 weeks according to the DSM-IV criteria. A major depressive episode was diagnosed if participants had at least one core symptom (i.e., depressed mood or anhedonia) and at least four other symptoms of depression (i.e., significant weight change or change in appetite, insomnia or hypersomnia, psychomotor agitation or retardation, fatigue or loss of energy, guilt or worthlessness, diminished ability to think or concentrate or indecisiveness and suicidal thoughts or plans). Persons suffering from one core symptom and one to three other symptoms were classified as having a minor depressive episode.

\section{Potential confounders}

We assessed glucose metabolism status, body mass index, waist circumference, total cholesterol, high-density lipoprotein (HDL) cholesterol, low-density lipoprotein (LDL) cholesterol, triglycerides, office blood pressure, $24 \mathrm{~h}$ average ambulatory blood pressure, medication use, smoking behavior, alcohol consumption, prevalent CVD, educational level, marital status, medical history, physical activity, and cognitive performance as described previously. ${ }^{30,36}$ Glucose metabolism was classified according to the World Health Organization 2006 criteria $^{37}$ into normal glucose metabolism, impaired fasting glucose, impaired glucose tolerance, and diabetes mellitus. Participants with diabetes mellitus and participants using glucose-lowering medication were considered as having T2DM if they had no (self-reported) type 1 or other specific type of diabetes mellitus. For this study, impaired fasting glucose and impaired glucose tolerance were combined into prediabetes. Body mass index was calculated by dividing 
weight by height ${ }^{2}$, and classified into normal weight $\left(<25 \mathrm{~kg} / \mathrm{m}^{2}\right)$, overweight $\left(25-<30 \mathrm{~kg} / \mathrm{m}^{2}\right)$ and obesity $\left(\geq 30 \mathrm{~kg} / \mathrm{m}^{2}\right)$. Total-to-HDL cholesterol ratio was calculated by dividing total cholesterol by HDL cholesterol. Hypertension was defined as an office systolic pressure $\geq 140 \mathrm{mmHg}$, an office diastolic pressure $\geq 90 \mathrm{mmHg}$ and/or the use of antihypertensive medication. Smoking behavior was classified into never, former, and current. Alcohol consumption was classified into no consumption, low consumption $(<7$ glasses per week for women; $<14$ glasses per week for men), and high consumption ( $>7$ glasses per week for women; >14 glasses per week for men). Prevalent CVD was defined as a self-reported history of myocardial infarction, cerebrovascular infarction or hemorrhage, or percutaneous artery angioplasty of, or vascular surgery on, the coronary, abdominal, peripheral or carotid arteries. Educational level was classified into low (none, primary, or lower vocational education only), intermediate (intermediate general secondary, intermediate vocational or higher general secondary education), and high (higher vocational education or university level of education). ${ }^{38,39}$ Participants who were married or in a civil partnership, or who cohabited were classified as married/living with spouse. Participants were classified as having comorbid disease other than T2DM and CVD if they reported to be diagnosed with non-skin cancer, inflammatory bowel disease, inflammatory respiratory disease and/or Parkinson's disease (28 participants with missing data were classified as having no comorbid disease). A modified version of the Community Healthy Activities Model Program for Seniors (CHAMPS) questionnaire ${ }^{40}$ was used to assess weekly total and moderate to vigorous physical activity. The Mini Mental State Examination (MMSE) was used as a measure of global cognitive performance. ${ }^{41}$ In addition, we assessed information processing speed as the standardized composite score of the Stroop Color Word Test Part I and II, ${ }^{42}$ the Concept Shifting Test Part A and B, ${ }^{43}$ and the Letter-Digit Substitution Test, ${ }^{44}$ as this cognitive domain has been associated with albuminuria in the present cohort. ${ }^{36}$

\section{Statistical analyses}

All analyses were performed with IBM SPSS Statistics Version 22.0 (IBM Corp., Armonk, NY, USA) unless stated otherwise. Population characteristics were presented stratified by the presence of clinically relevant depressive symptoms and by the presence of a major depressive episode. Associations of albuminuria and eGFR $_{\text {crcys }}$ with depressive symptoms were evaluated with negative binomial regression analyses because of the extremely skewed distribution of PHQ-9 scores ${ }^{45}$ (Stata Statistical Software: Release 11.2SE, StataCorp LP, College Station, TX, USA). Albuminuria was entered as categorical variable $(<15 \mathrm{mg} / 24 \mathrm{~h}$ [reference category], $15-<30 \mathrm{mg} / 24 \mathrm{~h}$ and $\geq 30 \mathrm{mg} / 24 \mathrm{~h}^{46}$ ) since the associations appeared to be non-linear. eGFR $_{\text {crcys }}$ was entered as continuous variable and expressed per $10 \mathrm{ml} / \mathrm{min} / 1.73 \mathrm{~m}^{2}$ lower eGFR $_{\text {crys }}$. The regression coefficients were exponentiated to obtain the ratio of the depressive symptom score per $10 \mathrm{ml} / \mathrm{min} / 1.73 \mathrm{~m}^{2}$ lower eGFR crcys $_{\text {or }}$ or compared with UAE $<15 \mathrm{mg} / 24 \mathrm{~h}$, respectively.

Associations of albuminuria and eGFR $_{\text {crcys }}$ with clinically relevant depressive symptoms, major depressive episode, and minor or major depressive episode were evaluated with multivariable logistic regression analyses.

All regression analyses were adjusted for potential confounders as follows: model 1) unadjusted model; model 2) age, sex, educational level, marital status, comorbid disease, glucose metabolism status; model 3) model 2 + waist circumference, total-to-HDL cholesterol, triglycerides, use of lipid-modifying medication, smoking behavior, alcohol consumption; model 4): model $3+$ eGFR $_{\text {crcys }}$ or UAE; model 5a) model $4+$ office systolic pressure, use of 
antihypertensive medication, prevalent CVD; model 5b) as model 5a but with replacement of office systolic pressure by $24 \mathrm{~h}$ average ambulatory systolic pressure. Blood pressure and prevalent CVD were added separately as these variables may be confounders and/or intermediates in the above associations.

Several additional analyses were performed to explore the robustness of our results. First, we restricted the analyses to participants with UAE $\leq 300 \mathrm{mg} / 24 \mathrm{~h}$ and to the subpopulation with two valid urine collections. Second, we additionally adjusted for total or moderate to vigorous physical activity. Third, we additionally adjusted for cognitive performance, expressed as either the MMSE score or information processing speed. Fourth, we assessed associations of albuminuria and eGFR $_{\text {crcys }}$ with affective and somatic subscores of the PHQ-9 to explore whether any associations with the total PHQ-9 score were driven by somatic complaints in individuals with higher UAE or lower GFR $_{\text {crys }}$. Fifth, we included antidepressant use in our definitions of major depressive episode, and minor or major depressive episode.

\section{RESULTS}

\section{Characteristics of the study population}

Figure 6.1 presents a flow diagram delineating the derivation of the final study populations. The analyses on the PHQ-9 were based on 2872 participants (PHQ-9 subpopulation) and the analyses on the MINI on 3083 participants (MINI subpopulation).

Table 6.1 shows the characteristics of the MINI subpopulation. Due to oversampling, 846 (27.4\%) participants had T2DM. In total, 122 (4.3\%) participants had clinically relevant depressive symptoms, 112 (3.6\%) had a major depressive episode and 54 (1.8\%) had a minor depressive episode. Of those with a major or minor depressive episode, 33 (29.5\%) and 4 $(7.4 \%)$ used an antidepressant, respectively. Characteristics of the PHQ-9 subpopulation (Table 6.1) were similar.

In general, participants with a major depressive episode were slightly younger, slightly more often women, less educated; more often lived alone, more often had T2DM and other comorbid disease; had a worse CVD risk profile and had a lower information processing speed. 


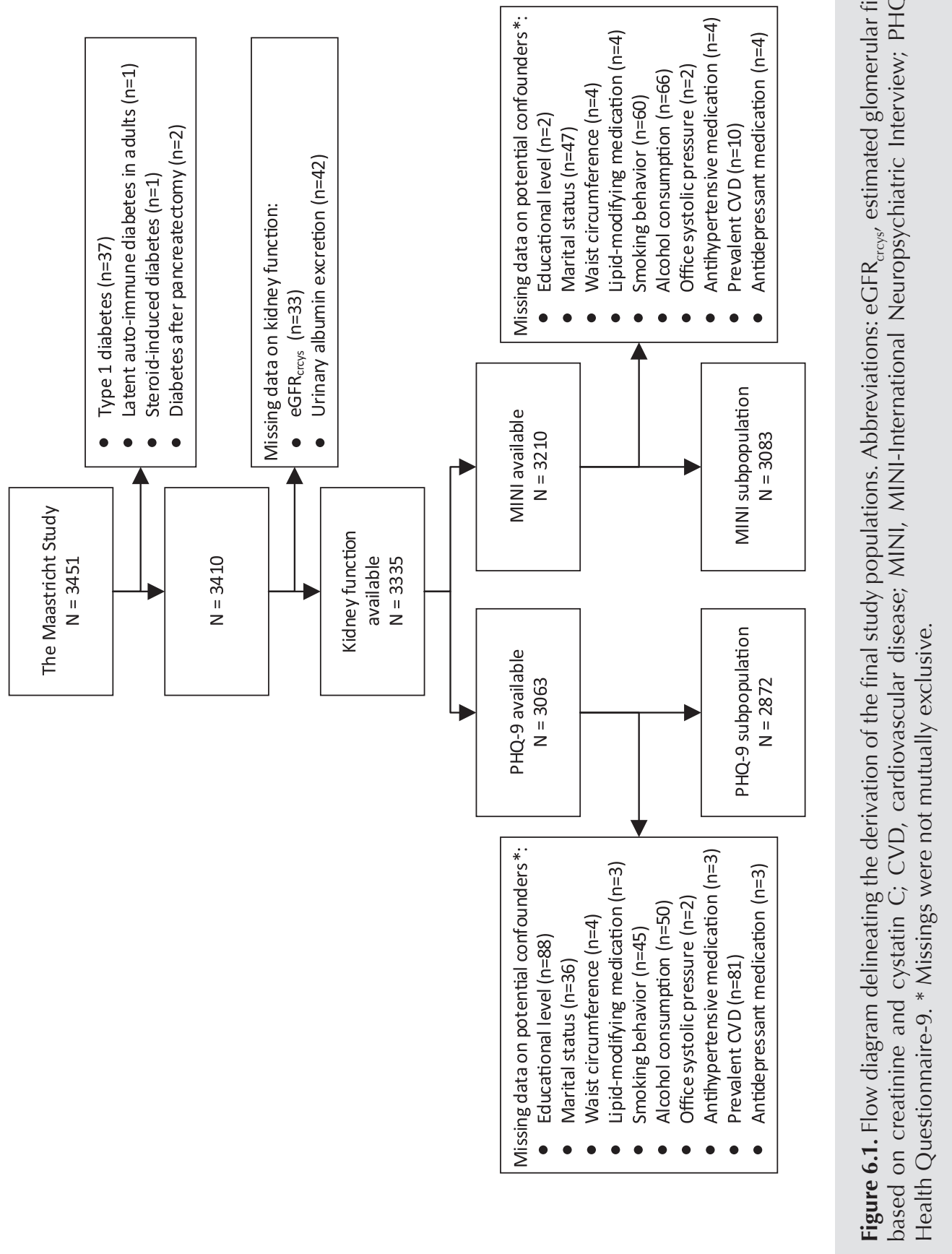




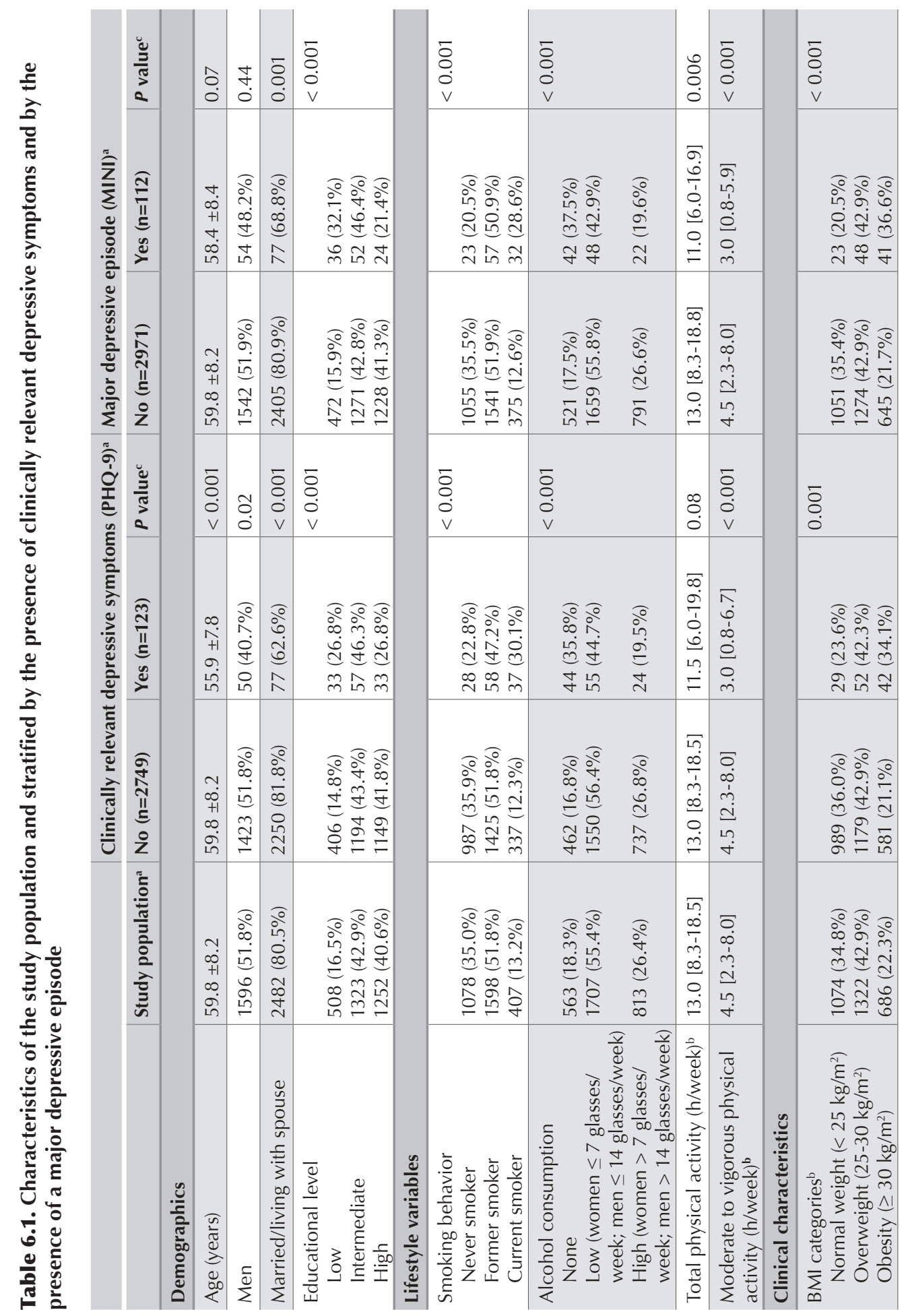




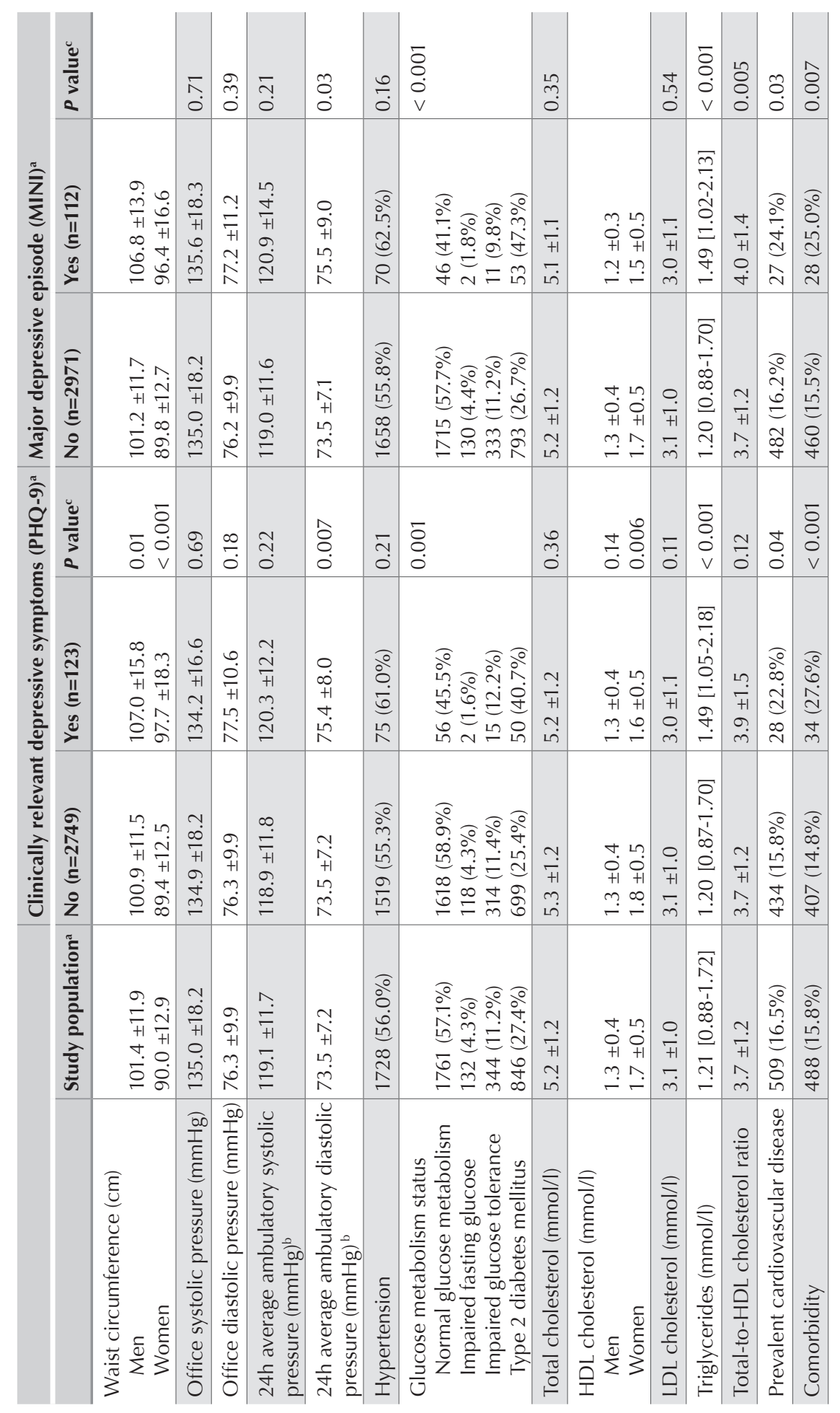




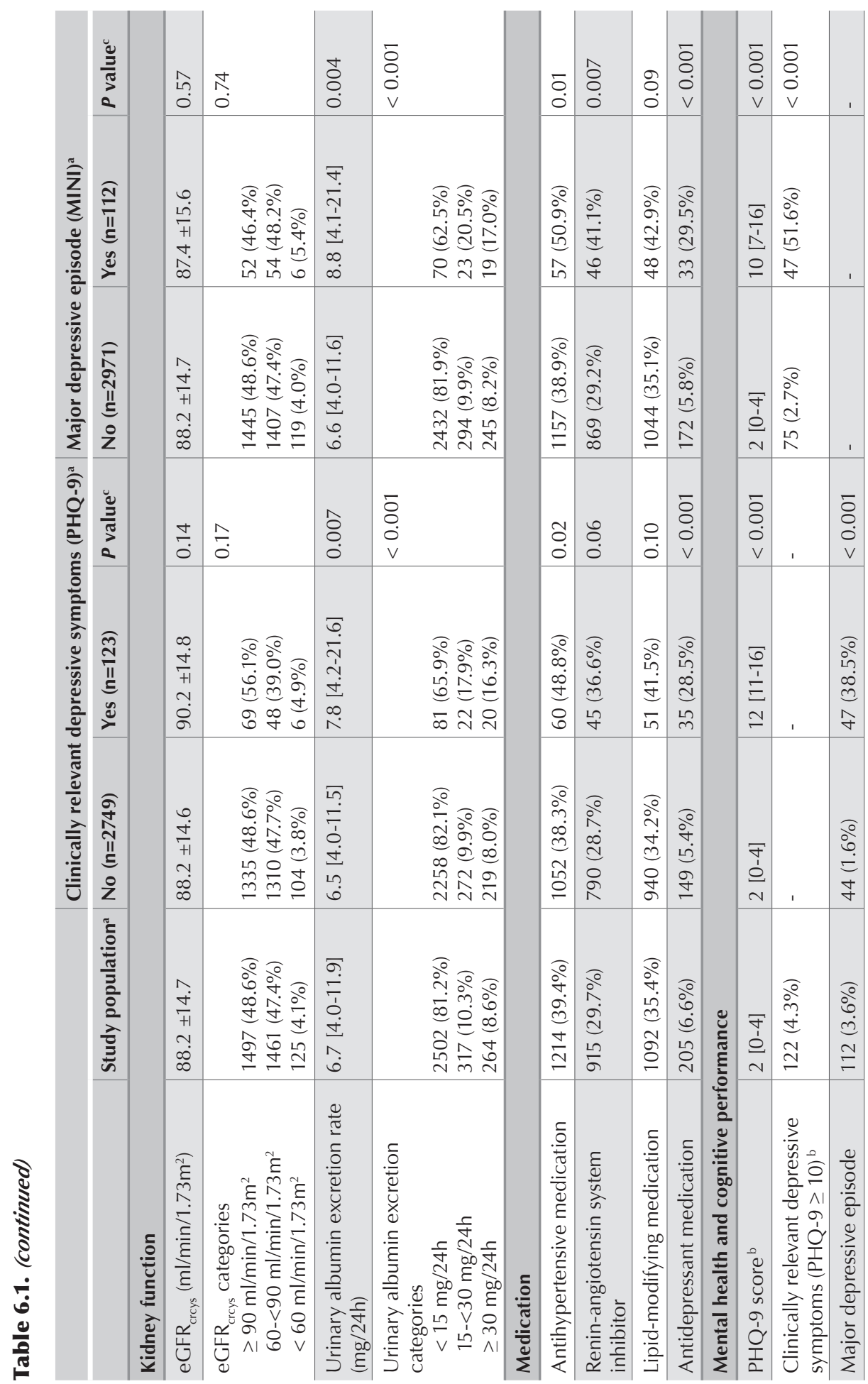




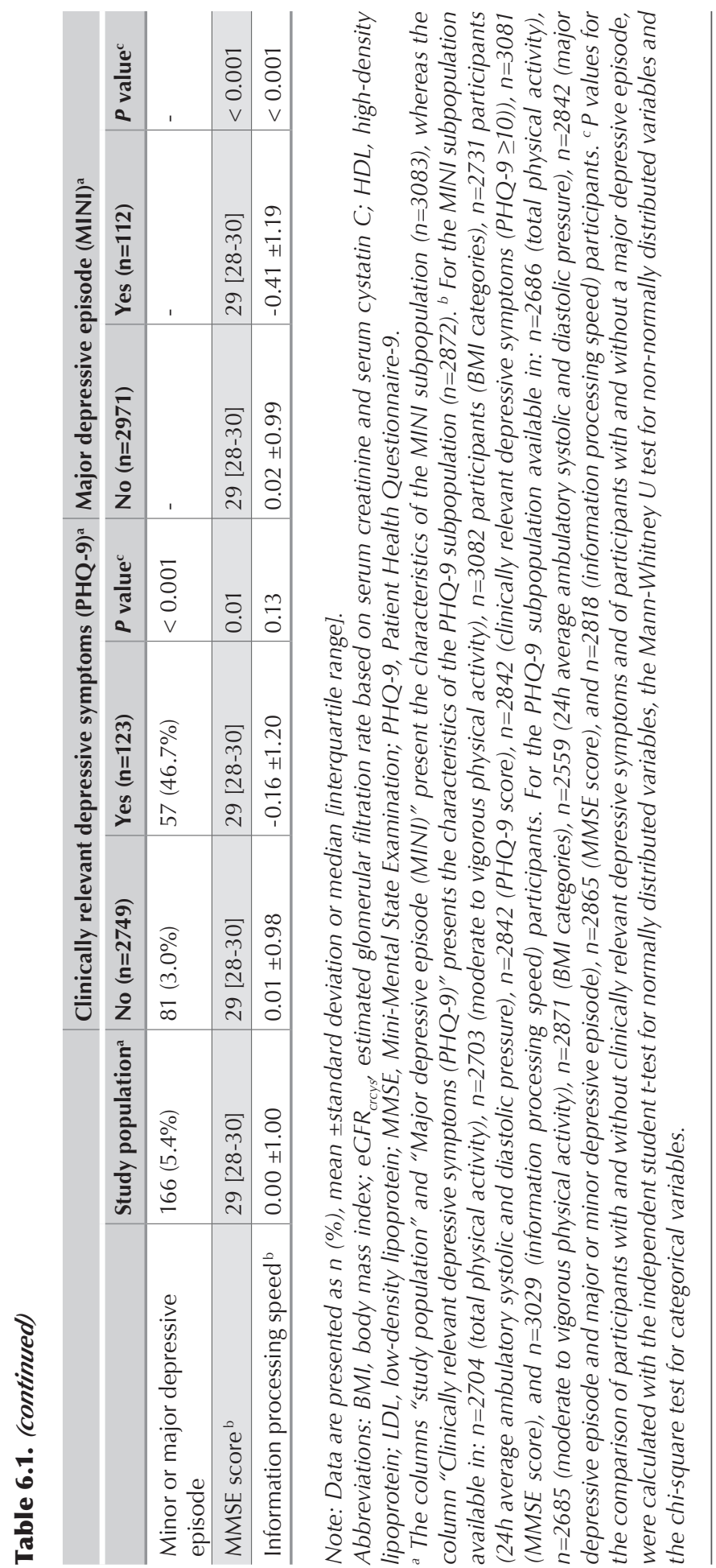




\section{Albuminuria, depressive symptoms and depressive episodes}

Median UAE was 6.7 [IQR 4.0-11.9] mg/24h. UAE was <15 mg/24h in 2502 (81.2\%) participants, $15-<30 \mathrm{mg} / 24 \mathrm{~h}$ in 317 (10.3\%) participants, and $\geq 30 \mathrm{mg} / 24 \mathrm{~h}$ in 264 (8.6\%) participants (Table 6.1).

The depressive symptom score was (median [IQR]) 2 [0-4], 2 [0-5] and 2 [1-5] in individuals with UAE $<15 \mathrm{mg} / 24 \mathrm{~h}, 15-<30 \mathrm{mg} / 24 \mathrm{~h}$ and $\geq 30 \mathrm{mg} / 24 \mathrm{~h}$, respectively.

After adjustment, and as compared with participants with UAE $<15 \mathrm{mg} / 24 \mathrm{~h}$, participants with UAE $15-<30 \mathrm{mg} / 24 \mathrm{~h}$ and $\geq 30 \mathrm{mg} / 24 \mathrm{~h}$ had a higher depressive symptom score, and more often had a depressive episode, regardless of their definitions (Table 6.2, model 5a). That is, the odds ratio (OR) and 95\% confidence interval $(95 \% \mathrm{Cl})$ for clinically relevant depressive symptoms was 2.28 (1.34 to 3.89) for UAE $15-<30 \mathrm{mg} / 24 \mathrm{~h}$ and 1.84 (1.00 to 3.35) for $\mathrm{UAE} \geq 30 \mathrm{mg} / 24 \mathrm{~h}$ (Table 6.2 , model $5 \mathrm{a}$ ). Similarly, the OR $(95 \% \mathrm{Cl})$ for a major depressive episode was 2.49 (1.48 to 4.21) for UAE $15-<30 \mathrm{mg} / 24 \mathrm{~h}$ and 1.76 (0.97 to 3.21) for UAE $\geq 30$ $\mathrm{mg} / 24 \mathrm{~h}$ (Table 6.2, model 5a). In addition, the OR $(95 \% \mathrm{Cl})$ for minor or major depressive episode was 2.13 (1.36 to 3.36) for UAE $15-<30 \mathrm{mg} / 24 \mathrm{~h}$ and 1.81 (1.10 to 2.98) for UAE $\geq 30$ $\mathrm{mg} / 24 \mathrm{~h}$ (Table 6.2, model 5a).

When the above associations were adjusted for $24 \mathrm{~h}$ average ambulatory systolic pressure instead of office systolic pressure, results were similar (Table 6.2, model 5b).

\section{eGFR, depressive symptoms and depressive episodes}

Average eGFR crcys $_{\text {was }} 88.2 \pm 14.7 \mathrm{ml} / \mathrm{min} / 1.73 \mathrm{~m}^{2}$ (Table 6.1 ). eGFR ${ }_{\text {crys }}$ was $\geq 90 \mathrm{ml} / \mathrm{min} / 1.73 \mathrm{~m}^{2}$ in 1497 (48.6\%) participants, $60-<90 \mathrm{ml} / \mathrm{min} / 1.73 \mathrm{~m}^{2}$ in 1461 (47.4\%) participants, and <60 $\mathrm{ml} / \mathrm{min} / 1.73 \mathrm{~m}^{2}$ in 125 (4.1\%) participants.

The depressive symptom score was (median [IQR]) 2 [0-5], 1.5 [0-4] and 2 [0-4] for individuals with eGFR ${ }_{\text {crcys }}<60 \mathrm{ml} / \mathrm{min} / 1.73 \mathrm{~m}^{2}, 60-<90 \mathrm{ml} / \mathrm{min} / 1.73 \mathrm{~m}^{2}$ and $\geq 90 \mathrm{ml} / \mathrm{min} / 1.73 \mathrm{~m}^{2}$, respectively.

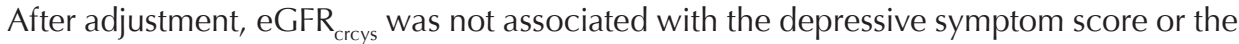
presence of a depressive episode, regardless of their definitions (Table 6.3, models 5a and 5b).

\section{Additional analyses}

Results were not materially altered: when the analyses were restricted to individuals with UAE $\leq 300 \mathrm{mg} / 24 \mathrm{~h}$ or to individuals with two valid urine collections (Table 6.4); and when results were additionally adjusted for total or moderate to vigorous physical activity, the MMSE score or information processing speed (Tables 6.4 and 6.5). Analyses of the associations

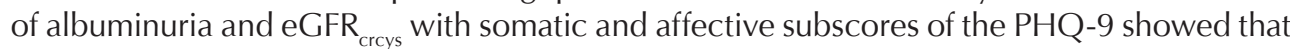
albuminuria was associated with both a higher affective and somatic symptom score, although the association of $U A E \geq 30 \mathrm{mg} / 24 \mathrm{~h}$ with affective symptoms was not statistically significant after adjustment for lifestyle factors and CVD risk factors. EFR $_{\text {crcys }}$ was associated with neither subscore (data not shown). When we included antidepressant use in our definition of major depressive episode, and minor or major depressive episode, UAE $15-<30 \mathrm{mg} / 24 \mathrm{~h}$ and $\geq 30 \mathrm{mg} / 24 \mathrm{~h}$ remained associated with both major depressive episode, and minor or major depressive episode, although the strength of the associations was attenuated and the association of $U A E \geq 30 \mathrm{mg} / 24 \mathrm{~h}$ with major depressive episode was no longer statistically significant after adjustment for lifestyle factors and CVD risk factors. eGFR crys $_{\text {was }}$ wot associated with the alternative definitions of depressive episode (data not shown). 


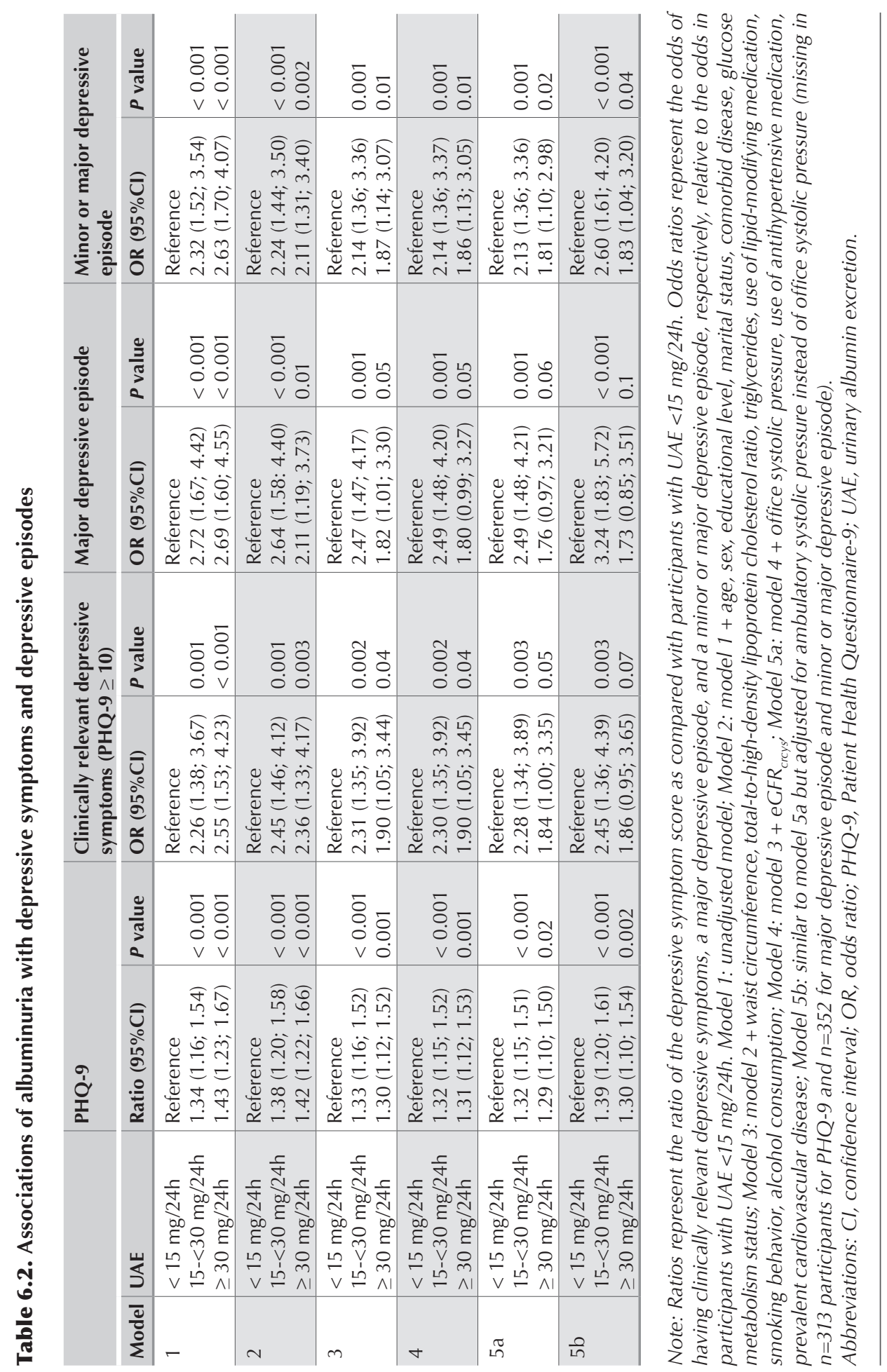




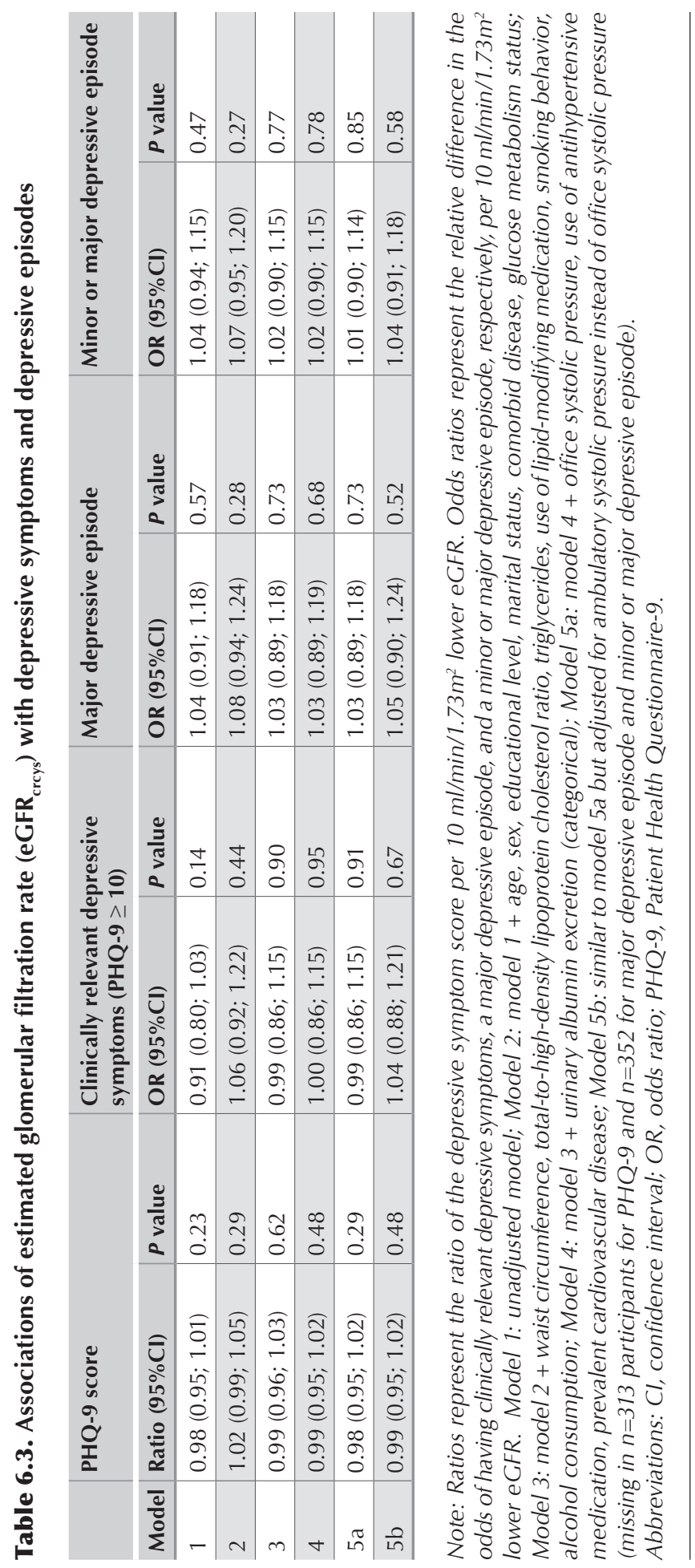




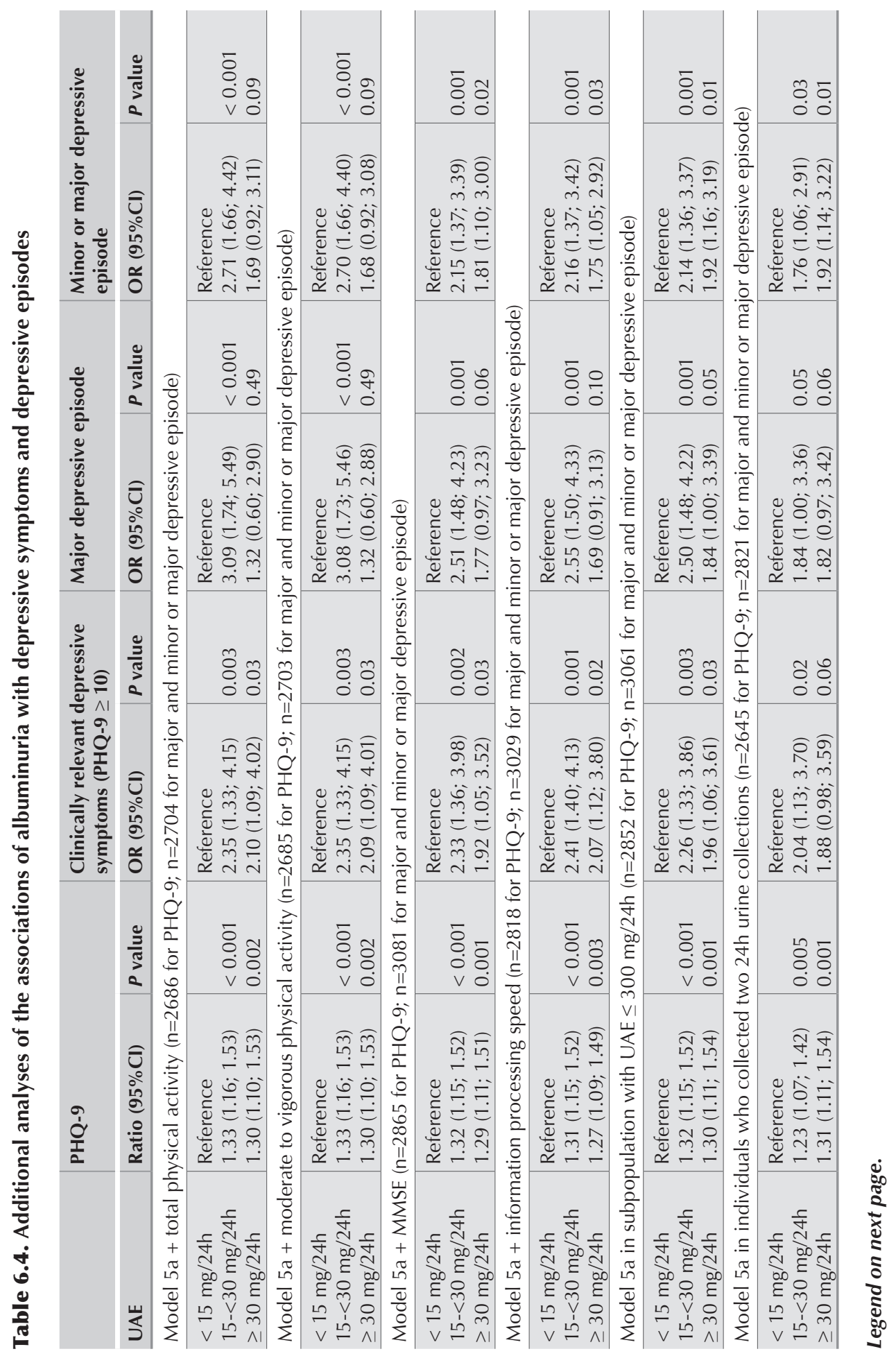




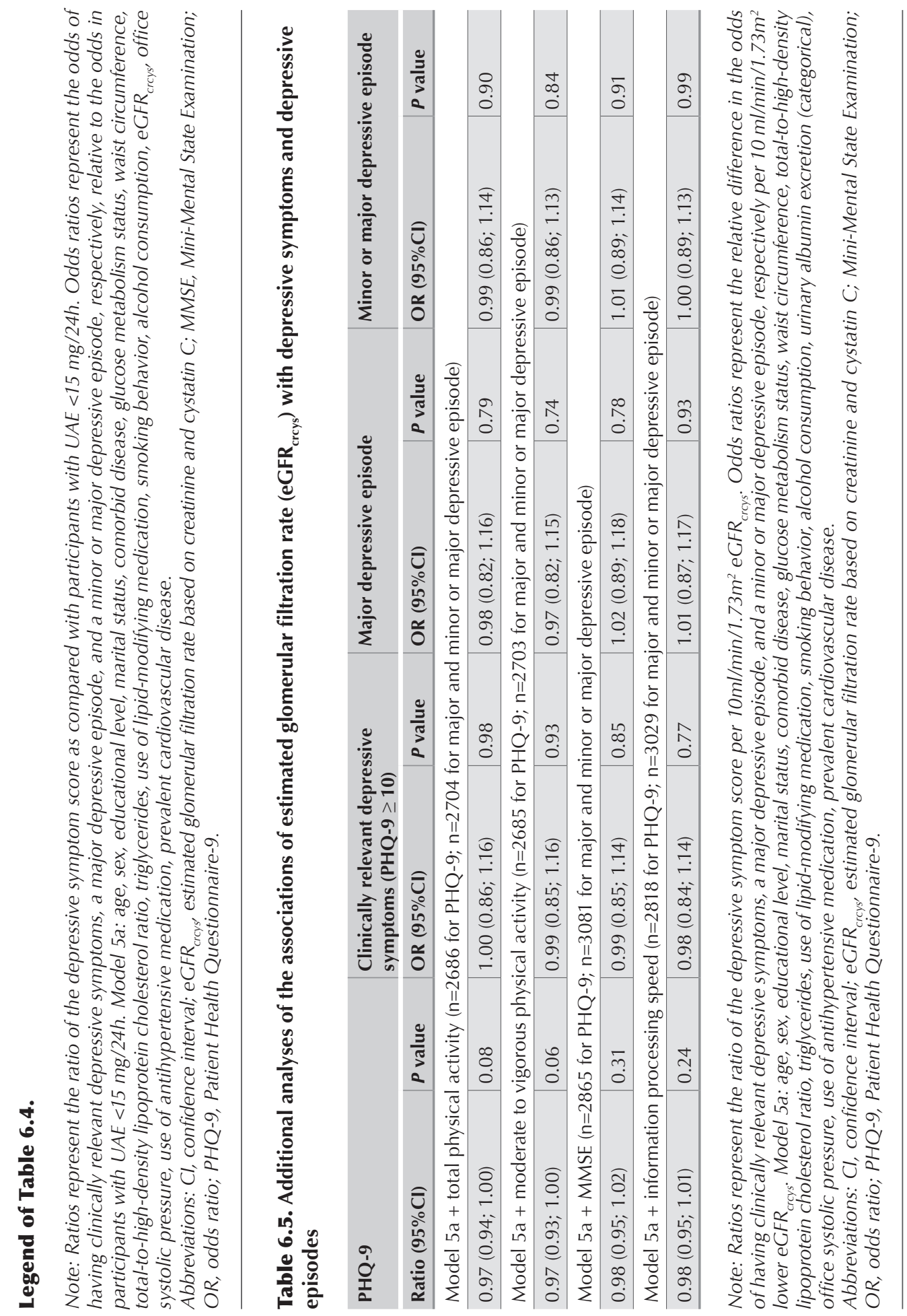




\section{DISCUSSION}

To our knowledge, this study is the first to examine whether albuminuria and eGFR are, independently of each other, associated with depression in a population-based setting. It had two main findings. First, albuminuria was associated with both self-reported depressive symptoms and minor or major depressive episode after adjustment for demographic variables, comorbidity, lifestyle factors and CVD risk factors (including eGFR), and even at levels of UAE that do not fulfill the CKD criteria. Second, eGFR was neither associated with depressive symptoms, nor with minor or major depressive episode in this cohort without substantial CKD.

The results of this study contrast with a study in individuals with CKD, ${ }^{11}$ which showed no independent association between albuminuria and depressive symptoms. However, its participants were selected for the presence of CKD based on eGFR values, ${ }^{11}$ whereas most participants in the present population-based study had normal or mildly reduced eGFR. The higher burden of symptoms of CKD and comorbid disease ${ }^{11}$ may have reduced the contrast between participants with higher and lower albuminuria levels. In another study, albuminuria was only borderline statistically significantly associated with depressive symptoms in individuals with diabetes without CVD but not with CVD..$^{10}$ However, a large proportion had poor glycemic control and its complications may have been classified erroneously as depressive symptoms.

Generalized endothelial dysfunction may explain the association between albuminuria and depression. According to this concept, microvascular endothelial dysfunction in the kidney causes albuminuria ${ }^{12,13}$ whereas in the brain it causes cSVD. ${ }^{14}$ According to the vascular depression hypothesis, ${ }^{5,6}$ the latter may lead to depression through disruption of neuronal circuits involved in mood regulation in fronto-limbic brain areas..$^{5,6}$ Indeed, albuminuria has been associated with magnetic resonance imaging findings of $\mathrm{CSVD}^{47}$ and SCVD has been associated with incident depressive symptoms. ${ }^{48,49}$ In addition, studies showing an association of (plasma) biomarkers of endothelial dysfunction with depressive symptoms ${ }^{50}$ and minor or major depressive episode ${ }^{51}$ indirectly support this view. However, we cannot rule out reverse causation. Indeed, depressive symptoms ${ }^{52}$ and major depressive episode ${ }^{2,53}$ have been associated with a higher risk of end-stage renal disease. ${ }^{2,52,53}$ This may also be true for albuminuria, for example through the adoption of an unhealthy lifestyle and poor treatment adherence. ${ }^{54,55}$ However, adiposity, smoking behavior, alcohol consumption and physical activity did not explain the reported associations.

The non-linear association of albuminuria with depression contrasts with the reported linear associations of (plasma) biomarkers of endothelial dysfunction with depressive symptoms $\mathrm{s}^{50}$ and minor or major depressive episode. ${ }^{51}$ Selective non-participation of individuals with depression and $U A E \geq 30 \mathrm{mg} / 24 \mathrm{~h}$ due to a higher comorbid disease burden in these individuals ${ }^{46,56}$ (i.e., incidence-prevalence bias ${ }^{57}$ ) could account for the non-linearity. Further, the low number of cases with depression limited power and the $95 \% \mathrm{Cls}$ do not exclude a linear association.

Importantly, the association of albuminuria with depression is not likely due to misclassification of somatic symptoms of comorbid disease as albuminuria was associated with both self-reported depressive symptoms and an interview-based diagnosis of minor or major depressive episode. Further, we adjusted for comorbid disease and albuminuria was related to affective as well as somatic depressive symptoms.

A lack of power probably explains why the association of UAE $\geq 30 \mathrm{mg} / 24 \mathrm{~h}$ with major depressive episode was borderline statistically significant whereas it was statistically significant for minor and major depressive episode combined. Minor and major depressive episode are 
part of a continuum of mood disorders, differing only in the number of depressive symptoms. ${ }^{58}$ Indeed, lower quality of life, more disability, higher healthcare consumption, and, although not consistently, increased mortality in individuals with a minor depressive episode, ${ }^{58}$ subscribe its clinical importance.

In contrast, the inclusion of individuals who only had had an early-onset major depressive episode may have attenuated the association between albuminuria and depression when antidepressant use was included in our definition of depression. Early- and late-onset depression may have different causes ${ }^{59}$ and cerebrovascular disease is more likely involved in late-onset depression. ${ }^{60}$ In addition, antidepressants may have been prescribed for other indications than depression, for example neuropathic pain, leading to misclassification of depression status.

In this study without substantial CKD, eGFR was not associated with depression. However, this study was underpowered to comment on the association of eGFR $<60 \mathrm{ml} / \mathrm{min} / 1.73 \mathrm{~m}^{2}$ with depression. Nevertheless, when combined with the results of other studies on the association of eGFR with depression, ${ }^{11,17-29}$ eGFR seems not to be associated with depression until it is moderately to severely reduced.

An important strength of this study was the assessment of albuminuria with $24 \mathrm{~h}$ urine collections and the assessment of eGFR based on creatinine and cystatin C. Another strength was the evaluation of an interview-based diagnosis of DSM-IV minor or major depressive episode, which reduced the risk of misclassification of symptoms of somatic diseases as depressive symptoms. ${ }^{1}$ In addition, the elaborate clinical characterization of the study participants allowed for extensive adjustment for potential confounders, including $24 \mathrm{~h}$ average ambulatory blood pressure. However, some limitations of this study should be considered. First, the cross-sectional design limited causal inferences. Second, even though we adjusted for an extensive series of potential confounders, we cannot fully exclude residual confounding. For example, we had no data on polymorphisms of the renin-angiotensin system ${ }^{60,61}$ or activity of the hypothalamic-pituitary-adrenal axis. ${ }^{62,63}$ Third, the exclusion of participants with missing data may have led to an underestimation of the examined associations if those with a higher UAE or reduced eGFR, and concomitant (severe) depression were selectively excluded. Fourth, we had no data on the use of non-pharmacological treatments of depression which may have been applied successfully in some participants and could have led to an underestimation of the association of eGFR and albuminuria with depression. Fifth, the study population was recruited from a single region in the Netherlands and primarily consisted of Caucasian individuals from European descent (98.6\%), which may limit generalizability to other ethnic and racial groups.

In conclusion, albuminuria was associated with depressive symptoms and minor or major depressive episode, even at levels of UAE that do not fulfill the CKD criteria. Future longitudinal studies should examine the direction of this association and whether albuminuria could serve as a biomarker to identify individuals at risk of depression. 


\section{REFERENCES}

1. Palmer S, Vecchio M, Craig JC, Tonelli M, Johnson DW, Nicolucci A, et al. Prevalence of depression in chronic kidney disease: systematic review and meta-analysis of observational studies. Kidney Int. 2013 Jul;84(1):179-91.

2. Hedayati SS, Minhajuddin AT, Afshar M, Toto RD, Trivedi MH, Rush AJ. Association between major depressive episodes in patients with chronic kidney disease and initiation of dialysis, hospitalization, or death. Jama. 2010 May 19;303(19):1946-53.

3. Palmer SC, Vecchio M, Craig JC, Tonelli M, Johnson DW, Nicolucci A, et al. Association between depression and death in people with CKD: a meta-analysis of cohort studies. Am J Kidney Dis. 2013 Sep;62(3):493-505.

4. Makin SD, Cook FA, Dennis MS, Wardlaw JM. Cerebral small vessel disease and renal function: systematic review and meta-analysis. Cerebrovasc Dis. 2015;39(1):39-52.

5. Alexopoulos GS, Meyers BS, Young RC, Campbell S, Silbersweig D, Charlson M. 'Vascular depression' hypothesis. Arch Gen Psychiatry. 1997 Oct;54(10):915-22.

6. Krishnan KR, Hays JC, Blazer DG. MRI-defined vascular depression. Am J Psychiatry. 1997 Apr;154(4):497-501.

7. De Deyn PP, Vanholder R, Eloot S, Glorieux G. Guanidino compounds as uremic (neuro)toxins. Semin Dial. 2009 Jul-Aug;22(4):340-5.

8. Kimmel PL. Depression in patients with chronic renal disease: what we know and what we need to know. J Psychosom Res. 2002 Oct;53(4):951-6.

9. Kidney Disease: Improving Global Outcomes (KDIGO). KDIGO 2012 Clinical practice guideline for the evaluation and management of chronic kidney disease. Kidney Int Suppl. 2013;3(1):1-150.

10. Katon WJ, Lin EH, Russo J, Von Korff M, Ciechanowski P, Simon G, et al. Cardiac risk factors in patients with diabetes mellitus and major depression. J Gen Intern Med. 2004 Dec;19(12):1192-9.

11. Fischer MJ, Xie D, Jordan N, Kop WJ, Krousel-Wood M, Kurella Tamura M, et al. Factors associated with depressive symptoms and use of antidepressant medications among participants in the Chronic Renal Insufficiency Cohort (CRIC) and Hispanic-CRIC Studies. Am J Kidney Dis. 2012 Jul;60(1):27-38.

12. Deckert T, Feldt-Rasmussen B, Borch-Johnsen K, Jensen T, Kofoed-Enevoldsen A. Albuminuria reflects widespread vascular damage. The Steno hypothesis. Diabetologia. 1989 Apr;32(4):219-26.

13. Stehouwer CD, Smulders YM. Microalbuminuria and risk for cardiovascular disease: Analysis of potential mechanisms. J Am Soc Nephrol. 2006 Aug;17(8):2106-11.

14. Wardlaw JM, Sandercock PA, Dennis MS, Starr J. Is breakdown of the blood-brain barrier responsible for lacunar stroke, leukoaraiosis, and dementia? Stroke. 2003 Mar;34(3):806-12.

15. Chronic Kidney Disease Prognosis Consortium, Matsushita K, van der Velde M, Astor BC, Woodward M, Levey AS, et al. Association of estimated glomerular filtration rate and albuminuria with all-cause and cardiovascular mortality in general population cohorts: a collaborative meta-analysis. Lancet. 2010 Jun 12;375(9731):2073-81.

16. Stam F, van Guldener C, Becker A, Dekker JM, Heine RJ, Bouter LM, et al. Endothelial dysfunction contributes to renal function-associated cardiovascular mortality in a population with mild renal insufficiency: the Hoorn study. J Am Soc Nephrol. 2006 Feb;17(2):537-45.

17. Shidler NR, Peterson RA, Kimmel PL. Quality of life and psychosocial relationships in patients with chronic renal insufficiency. Am J Kidney Dis. 1998 Oct;32(4):557-66.

18. Hedayati SS, Jiang W, O'Connor CM, Kuchibhatla M, Krishnan KR, Cuffe MS, et al. The association between depression and chronic kidney disease and mortality among patients hospitalized with congestive heart failure. Am J Kidney Dis. 2004 Aug;44(2):207-15.

19. Odden MC, Whooley MA, Shlipak MG. Depression, stress, and quality of life in persons with chronic kidney disease: the Heart and Soul Study. Nephron Clin Pract. 2006;103(1):c1-7.

20. Cohen SD, Patel SS, Khetpal P, Peterson RA, Kimmel PL. Pain, sleep disturbance, and quality of life in patients with chronic kidney disease. Clin J Am Soc Nephrol. 2007 Sep;2(5):919-25.

21. Abdel-Kader K, Unruh ML, Weisbord SD. Symptom burden, depression, and quality of life in chronic and end-stage kidney disease. Clin J Am Soc Nephrol. 2009 Jun;4(6):1057-64.

22. Fischer MJ, Kimmel PL, Greene T, Gassman JJ, Wang X, Brooks DH, et al. Sociodemographic factors contribute to the depressive affect among African Americans with chronic kidney disease. Kidney Int. 2010 Jun;77(11):1010-9.

23. Ricardo AC, Fischer MJ, Peck A, Turyk M, Lash JP. Depressive symptoms and chronic kidney disease: results from the National Health and Nutrition Examination Survey (NHANES) 2005-2006. Int Urol Nephrol. 2010 Dec;42(4):1063-8.

24. Minev E, Unruh M, Shlipak MG, Simsonick E, Yaffe K, Leak TS, et al. Association of cystatin C and depression in healthy elders: the health, aging and body composition study. Nephron Clin Pract. 2010;116(3):c241-6.

25. McClellan WM, Abramson J, Newsome B, Temple E, Wadley VG, Audhya P, et al. Physical and psychological burden of chronic kidney disease among older adults. Am J Nephrol. 2010;31(4):309-17.

26. Kop WJ, Seliger SL, Fink JC, Katz R, Odden MC, Fried LF, et al. Longitudinal association of depressive symptoms with rapid kidney function decline and adverse clinical renal disease outcomes. Clin J Am Soc Nephrol. 2011 Apr;6(4):834-44.

27. Campbell KH, Huang ES, Dale W, Parker MM, John PM, Young BA, et al. Association between estimated GFR, healthrelated quality of life, and depression among older adults with diabetes: the Diabetes and Aging Study. Am J Kidney Dis. 2013 Sep;62(3):541-8.

28. Hedayati SS, Minhajuddin AT, Toto RD, Morris DW, Rush AJ. Prevalence of major depressive episode in CKD. Am J Kidney Dis. 2009 Sep;54(3):424-32.

29. Kalender B, Ozdemir AC, Koroglu G. Association of depression with markers of nutrition and inflammation in chronic kidney disease and end-stage renal disease. Nephron Clin Pract. 2006;102(3-4):c115-21. 
30. Schram MT, Sep SJ, van der Kallen CJ, Dagnelie PC, Koster A, Schaper N, et al. The Maastricht Study: an extensive phenotyping study on determinants of type 2 diabetes, its complications and its comorbidities. Eur J Epidemiol. 2014 Jun;29(6):439-51.

31. Inker LA, Schmid CH, Tighiouart H, Eckfeldt JH, Feldman HI, Greene T, et al. Estimating glomerular filtration rate from serum creatinine and cystatin C. N Engl J Med. 2012 Jul 5;367(1):20-9.

32. Kroenke K, Spitzer RL, Williams JB. The PHQ-9: validity of a brief depression severity measure. J Gen Intern Med. 2001 Sep;16(9):606-13.

33. Smolderen KG, Spertus JA, Reid KJ, Buchanan DM, Krumholz HM, Denollet J, et al. The association of cognitive and somatic depressive symptoms with depression recognition and outcomes after myocardial infarction. Circ Cardiovasc Qual Outcomes. 2009 Jul;2(4):328-37.

34. Janssen EP, Köhler S, Stehouwer CD. The PHQ-9 as a screening tool for depression in type 2 diabetes mellitus: The Maastricht Study. J Am Geriatr Soc. 2016;Accepted for publication.

35. Sheehan DV, Lecrubier Y, Sheehan KH, Amorim P, Janavs J, Weiller E, et al. The Mini-International Neuropsychiatric Interview (M.I.N.I.): the development and validation of a structured diagnostic psychiatric interview for DSM-IV and ICD-10. J Clin Psychiatry. 1998;59 Suppl 20:22-33; quiz 4-57.

36. Martens RJ, Kooman JP, Stehouwer CD, Dagnelie PC, van der Kallen CJ, Koster A, et al. Estimated GFR, Albuminuria, and Cognitive Performance: The Maastricht Study. Am J Kidney Dis. 2016 Jun 10.

37. World Health Organization. Definition and diagnosis of diabetes mellitus and intermediate hyperglycemia: report of a WHO/IDF consultation2006: Available from: http://www.who.int/diabetes/publications/Definition\%20and\%20 diagnosis\%20of\%20diabetes_new.pdf.

38. De Bie SE. Standaardvragen 1987: Voorstellen voor uniformering van vraagstellingen naar achtergrondkenmerken en interviews [Standard questions 1987: Proposal for uniformization of questions regarding background variables and interviews]. Leiden, The Netherlands: Leiden University Press.; 1987.

39. Spauwen PJ, van Eupen MG, Kohler S, Stehouwer CD, Verhey FR, van der Kallen CJ, et al. Associations of advanced glycation end-products with cognitive functions in individuals with and without type 2 diabetes: the maastricht study. J Clin Endocrinol Metab. 2015 Mar;100(3):951-60.

40. Stewart AL, Mills KM, King AC, Haskell WL, Gillis D, Ritter PL. CHAMPS physical activity questionnaire for older adults: outcomes for interventions. Med Sci Sports Exerc. 2001 Jul;33(7):1126-41.

41. Folstein MF, Folstein SE, McHugh PR. "Mini-mental state". A practical method for grading the cognitive state of patients for the clinician. J Psychiatr Res. 1975 Nov;12(3):189-98.

42. Van der Elst W, van Boxtel MP, van Breukelen GJ, Jolles J. The Stroop color-word test: influence of age, sex, and education; and normative data for a large sample across the adult age range. Assessment. 2006 Mar;13(1):62-79.

43. Van der Elst W, van Boxtel MP, van Breukelen GJ, Jolles J. The Concept Shifting Test: adult normative data. Psychol Assess. 2006 Dec;18(4):424-32.

44. Van der Elst W, van Boxtel MP, van Breukelen GJ, Jolles J. The Letter Digit Substitution Test: normative data for 1,858 healthy participants aged 24-81 from the Maastricht Aging Study (MAAS): influence of age, education, and sex. J Clin Exp Neuropsychol. 2006 Aug;28(6):998-1009.

45. Sachdev PS, Parslow RA, Lux O, Salonikas C, Wen W, Naidoo D, et al. Relationship of homocysteine, folic acid and vitamin B12 with depression in a middle-aged community sample. Psychol Med. 2005 Apr;35(4):529-38.

46. Hillege HL, Janssen WM, Bak AA, Diercks GF, Grobbee DE, Crijns HJ, et al. Microalbuminuria is common, also in a nondiabetic, nonhypertensive population, and an independent indicator of cardiovascular risk factors and cardiovascular morbidity. J Intern Med. 2001 Jun;249(6):519-26.

47. Wada M, Nagasawa H, Kurita K, Koyama S, Arawaka S, Kawanami T, et al. Microalbuminuria is a risk factor for cerebral small vessel disease in community-based elderly subjects. J Neurol Sci. 2007 Apr 15;255(1-2):27-34.

48. Godin O, Dufouil C, Maillard P, Delcroix N, Mazoyer B, Crivello F, et al. White matter lesions as a predictor of depression in the elderly: the 3C-Dijon study. Biol Psychiatry. 2008 Apr 1;63(7):663-9.

49. Van Sloten TT, Sigurdsson S, van Buchem MA, Phillips CL, Jonsson PV, Ding J, et al. Cerebral Small Vessel Disease and Association With Higher Incidence of Depressive Symptoms in a General Elderly Population: The AGES-Reykjavik Study. Am J Psychiatry. 2015 Jun;172(6):570-8.

50. Van Sloten TT, Schram MT, Adriaanse MC, Dekker JM, Nijpels G, Teerlink T, et al. Endothelial dysfunction is associated with a greater depressive symptom score in a general elderly population: the Hoorn Study. Psychol Med. 2014 May;44(7):1403-16.

51. Lesperance F, Frasure-Smith N, Theroux P, Irwin M. The association between major depression and levels of soluble intercellular adhesion molecule 1, interleukin-6, and C-reactive protein in patients with recent acute coronary syndromes. Am J Psychiatry. 2004 Feb;161(2):271-7.

52. Tsai YC, Chiu YW, Hung CC, Hwang SJ, Tsai JC, Wang SL, et al. Association of symptoms of depression with progression of CKD. Am J Kidney Dis. 2012 Jul;60(1):54-61.

53. Yu MK, Weiss NS, Ding X, Katon WJ, Zhou XH, Young BA. Associations between depressive symptoms and incident ESRD in a diabetic cohort. Clin J Am Soc Nephrol. 2014 May;9(5):920-8.

54. Ziegelstein RC, Fauerbach JA, Stevens SS, Romanelli J, Richter DP, Bush DE. Patients with depression are less likely to follow recommendations to reduce cardiac risk during recovery from a myocardial infarction. Arch Intern Med. 2000 Jun 26;160(12):1818-23.

55. Ciechanowski PS, Katon WJ, Russo JE. Depression and diabetes: impact of depressive symptoms on adherence, function, and costs. Arch Intern Med. 2000 Nov 27;160(21):3278-85.

56. Bello AK, Hemmelgarn B, Lloyd A, James MT, Manns BJ, Klarenbach S, et al. Associations among estimated glomerular filtration rate, proteinuria, and adverse cardiovascular outcomes. Clin J Am Soc Nephrol. 2011 Jun;6(6):1418-26. 
57. Delgado-Rodriguez M, Llorca J. Bias. J Epidemiol Community Health. 2004 Aug;58(8):635-41.

58. Meeks TW, Vahia IV, Lavretsky H, Kulkarni G, Jeste DV. A tune in "a minor" can "b major": a review of epidemiology, illness course, and public health implications of subthreshold depression in older adults. J Affect Disord. 2011 Mar;129(1-3):126-42.

59. Pedersen CB, Mors O, Bertelsen A, Waltoft BL, Agerbo E, McGrath JJ, et al. A comprehensive nationwide study of the incidence rate and lifetime risk for treated mental disorders. JAMA Psychiatry. 2014 May;71(5):573-81.

60. Taylor WD, Aizenstein HJ, Alexopoulos GS. The vascular depression hypothesis: mechanisms linking vascular disease with depression. Mol Psychiatry. 2013 Sep;18(9):963-74.

61. Ruggenenti P, Bettinaglio P, Pinares F, Remuzzi G. Angiotensin converting enzyme insertion/deletion polymorphism and renoprotection in diabetic and nondiabetic nephropathies. Clin J Am Soc Nephrol. 2008 Sep;3(5):1511-25.

62. Broadley AJ, Korszun A, Abdelaal E, Moskvina V, Deanfield J, Jones CJ, et al. Metyrapone improves endothelial dysfunction in patients with treated depression. J Am Coll Cardiol. 2006 Jul 4;48(1):170-5.

63. Belmaker RH, Agam G. Major depressive disorder. N Engl J Med. 2008 Jan 3;358(1):55-68. 
Supplemental Material 


\section{SUPPLEMENTAL METHODS}

\section{Kidney function}

To assess urinary albumin excretion (UAE), participants were requested to collect two $24 \mathrm{~h}$ urine collections. Urinary albumin concentration was measured with a standard immunoturbidimetric assay by an automatic analyzer (due to a change of supplier by the Beckman Synchron LX20, Beckman Coulter Inc., Brea, USA and the Roche Cobas 6000, F. Hoffmann-La Roche Ltd, Basel, Switzerland) and multiplied by collection volume to obtain the $24 \mathrm{~h}$ UAE. A urinary albumin concentration below the detection limit of the assay $(2 \mathrm{mg} / \mathrm{l}$ for the Beckman Synchron LX20 and $3 \mathrm{mg} / \mathrm{l}$ for the Roche Cobas 6000) was set at $1.5 \mathrm{mg} / \mathrm{l}$ before multiplying by collection volume. Only urine collections with a collection time between $20 \mathrm{~h}$ and $28 \mathrm{~h}$ were considered valid. If needed, UAE was extrapolated to a $24 \mathrm{~h}$ excretion. UAE was preferably based on the average of two (available in $91.5 \%$ of the participants) $24 \mathrm{~h}$ urine collections, and categorized into: $<15 \mathrm{mg} / 24 \mathrm{~h}, 15-<30 \mathrm{mg} / 24 \mathrm{~h}$ and $\geq 30 \mathrm{mg} / 24 \mathrm{~h}{ }^{1}$

The glomerular filtration rate (GFR) was estimated with the Chronic Kidney Disease Epidemiology Collaboration (CKD-EPI) equation based on the combination of serum creatinine and serum cystatin $\mathrm{C}\left(\mathrm{eGFR}_{\text {crcys }}\right)^{2}{ }^{2}$ Serum creatinine was measured with a Jaffé method traceable to isotope dilution mass spectrometry (due to a change of supplier by the Beckman Synchron LX20, Beckman Coulter Inc., Brea, USA and the Roche Cobas 6000, F. Hoffmann-La Roche Ltd, Basel, Switzerland). Serum cystatin C was measured with a particle enhanced immunoturbidimetric assay standardized against ERM-DA471/IFCC reference material (Roche Cobas 8000, F. Hoffman-La Roche Ltd, Basel, Switzerland). 


\section{REFERENCES}

1. Hillege HL, Janssen WM, Bak AA, Diercks GF, Grobbee DE, Crijns HJ, et al. Microalbuminuria is common, also in a nondiabetic, nonhypertensive population, and an independent indicator of cardiovascular risk factors and cardiovascular morbidity. J Intern Med. 2001 Jun;249(6):519-26.

2. Inker LA, Schmid CH, Tighiouart H, Eckfeldt JH, Feldman HI, Greene T, et al. Estimating glomerular filtration rate from serum creatinine and cystatin C. N Engl J Med. 2012 Jul 5;367(1):20-9. 


\section{Chapter 7}

Remy J.H. Martens*

Julianne D. van der Berg*

Coen D.A. Stehouwer

Ronald M.A. Henry

Hans Bosma

Pieter C. Dagnelie

Martien C.J.M. van Dongen

Simone J.P.M. Eussen

Miranda T. Schram

Simone J.S. Sep

Carla J.H. van der Kallen

Nicolaas C. Schaper

Hans H.C.M. Savelberg

Frank M. van der Sande

Abraham A. Kroon

Jeroen P. Kooman ${ }^{+}$

Annemarie Koster ${ }^{\dagger}$

* contributed equally, + contributed equally

Submitted for publication 


\section{Daily activity is associated}

with estimated GFR and albuminuria:

The Maastricht Study 


\section{ABSTRACT \\ Objective: To examine cross-sectional associations of objectively measured}

amounts and patterns of physical activity and sedentary behavior with estimated glomerular filtration rate (eGFR) and albuminuria.

Methods: We included 2258 participants of the population-based Maastricht Study (average age $60.1 \pm 8.1$ years, $51.3 \%$ men), who were requested to wear an accelerometer $24 \mathrm{~h} /$ day on 8 consecutive days. Associations with continuous eGFR and categories of urinary albumin excretion (UAE; $<15$ [reference category], $15-<30, \geq 30 \mathrm{mg} / 24 \mathrm{~h}$ ) were evaluated with linear regression analyses and multinomial logistic regression analyses, respectively.

Results: After adjustment for potential confounders, each extra hour of total physical activity was associated with a higher eGFR (beta 2.30,95\% confidence interval $(95 \% \mathrm{Cl}) 1.46$ to 3.14$)$, whereas each extra hour of sedentary time was associated with a lower eGFR (beta $-0.71,-1.08$ to -0.35 ). Having more daily prolonged sedentary bouts and having longer average sedentary bout duration were associated with lower eGFR. Further, an extra hour of total physical activity was associated with lower odds for albuminuria $\left(\mathrm{OR}_{15-<30 \mathrm{mg} / 24 \mathrm{~h}} 0.63,0.41\right.$ to 0.96 ; $\mathrm{OR}_{\geq 30 \mathrm{mg} / 24 \mathrm{~h}} 0.84,0.53$ to 1.35 (highest vs. lowest quartile of total physical activity)). An extra hour of sedentary time was associated with higher odds for albuminuria $\left(\mathrm{OR}_{15-30 \mathrm{mg} / 24 \mathrm{~h}} 1.11,1.01\right.$ to $1.22 ; \mathrm{OR}_{\geq 30 \mathrm{mg} / 24 \mathrm{~h}} 1.10,0.99$ to 1.22$)$. No associations were observed between patterns of sedentary behavior and albuminuria.

Conclusion: Physical activity and sedentary time were, independently of each other, associated with eGFR and albuminuria. Additionally, sedentary behavior patterns were associated with eGFR. This suggests that prevention strategies should focus not only on increasing physical activity levels, but on reducing sedentary time as well. 


\section{INTRODUCTION}

Reduced estimated glomerular filtration rate (eGFR) and albuminuria, which together define chronic kidney disease (CKD), have become highly prevalent in modern Western society. ${ }^{1}$ Both reduced eGFR and albuminuria have been associated with end-stage renal disease, ${ }^{2}$ acute kidney injury, ${ }^{3}$ and cardiovascular disease (CVD) risk. ${ }^{2}$ Therefore, it is important to identify factors that contribute to the development of reduced eGFR and albuminuria, which are amenable for intervention.

A possibly important modifiable factor is the level of physical activity, which includes not only moderate to vigorous physical activity (MVPA) like brisk walking or running, but also light intensity physical activity such as casual walking and household work. ${ }^{4}$ Further, adults spend most time of the day in sedentary behaviors, ${ }^{5}$ such as watching TV, using the computer or driving. Sedentary behavior has been associated with metabolic and CVD risk factors, independent of physical activity. ${ }^{6}$ Therefore, sedentary behavior should be examined next to the different levels of physical activity. Several studies have reported on associations of physical activity ${ }^{7-12}$ and sedentary behavior ${ }^{9,13}$ with eGFR, $, 9,11,12$ albuminuria, ${ }^{8-10,13}$ or both combined as CKD. ${ }^{9}$ However, these studies have used self-reported measures, which may be biased and the reported results have been inconsistent.

Since several years the complete daily activity spectrum, from sedentary behavior to high intensity physical activity, can be objectively measured with an accelerometer. To date only a few studies have described associations between accelerometry data and kidney function. . $^{14,15}$ Additionally, these studies have not reported on the pattern of sedentary time (i.e., the manner in which sedentary time was accumulated). Since not all sedentary time is bad (certain amounts are needed for rest and recovery) and particularly prolonged sedentary time may be harmful, sedentary patterns should be examined. These patterns can be expressed by sedentary breaks, which refers to the frequency with which sedentary time was interrupted (for example, transitions from sitting to standing) and sedentary bouts, which refers to uninterrupted periods of sedentary time of a certain duration (for example, $30 \mathrm{~min}$ ). Previous studies have demonstrated that sedentary patterns were associated with detrimental health outcomes, including a larger waist circumference and a higher body mass index, higher levels of triglycerides and glucose, and the metabolic syndrome. . $^{16,17}$

In view of the above, we measured both total amount and patterns of physical activity and sedentary behavior in a large sample of adults aged 40-75 years who participated in the population-based Maastricht Study. We used the activalPAL3 accelerometer (PAL Technologies, Glasgow, UK), which assesses (patterns of) sedentary behavior using posture data, since this has shown to be a highly accurate method. ${ }^{18,19}$ The aim of this study was to examine associations of physical activity, sedentary behavior and its patterns with eGFR and albuminuria.

\section{METHODS}

\section{Study population and design}

We used data of The Maastricht Study, an observational prospective population-based cohort study. The rationale and methodology have been described previously. ${ }^{20}$ In brief, the study focuses on the etiology, pathophysiology, complications and comorbidities of type 2 diabetes (T2DM) and is characterized by an extensive phenotyping approach. Eligible participants were individuals aged between 40 and 75 years and living in the southern part of the Netherlands. Participants were recruited through mass media campaigns and from the municipal registries 
and the regional Diabetes Patient Registry via mailings. Recruitment was stratified according to known T2DM status, with an oversampling of individuals with T2DM, for reasons of efficiency. The present report includes cross-sectional data from the first 3451 participants, who completed the baseline survey between November 2010 and September 2013. Participants with type 1 diabetes, latent auto-immune diabetes in adults, steroid-induced diabetes or diabetes after pancreatectomy $(n=41)$ were excluded. After further successively excluding participants who did not receive an accelerometer due to logistics $(n=668)$ or whose accelerometer measurement failed ( $n=135)$, whose eGFR was missing $(n=20)$, whose $24 \mathrm{~h}$ urine collections were either collected erroneously $(<20 \mathrm{~h}$ or $>28 \mathrm{~h})$ or were not handed in at all $(n=23)$, or who had other missing data $(n=306)$, a total of 2258 participants were included in the present study.

The study has been approved by the institutional medical ethical committee (NL31329.068.10) and the Minister of Health, Welfare and Sports of the Netherlands (Permit 131088-105234-PG), and was conducted in accordance with the Declaration of Helsinki. All participants gave written informed consent.

\section{Accelerometry data}

Daily activity levels were measured using the activPAL3 ${ }^{\text {TM }}$ physical activity monitor (PAL Technologies, Glasgow, UK), as described elsewhere. ${ }^{17}$ Participants were asked to wear the accelerometer for 8 consecutive days, without removing it at any time. Participants were included if they provided at least 1 valid day ( $\geq 10 \mathrm{~h}$ of waking data).

The total amount of physical activity was based on the stepping posture and calculated as the mean time spent in stepping during waking time per day. The method used to determine waking time has been described elsewhere. ${ }^{21}$ Physical activity (stepping time) was further classified into higher intensity physical activity (HPA; minutes with a step frequency $>110$ steps/min during waking time) and lower intensity physical activity (LPA; minutes with a step frequency $\leq 110$ steps/min during waking time; standing time was not included). The total amount of sedentary time was based on the sedentary posture (sitting or lying), and calculated as the mean time spent in a sedentary position during waking time per day. The number of sedentary breaks during waking time was determined as each transition from a sitting or lying position to standing or stepping with a duration of at least $1 \mathrm{~min}$, and the mean number of breaks per day was calculated. Sedentary time accumulated in a consecutive period $\geq 30 \mathrm{~min}$ was defined as a prolonged sedentary bout, and the mean number of prolonged sedentary bouts during waking time per day was calculated. Average bout duration was calculated by dividing total sedentary time by total number of sedentary bouts of any duration.

\section{Kidney function}

GFR was estimated with the Chronic Kidney Disease Epidemiology Collaboration (CKD-EPI) equation based on the combination of serum creatinine and serum cystatin $\mathrm{C}(\mathrm{eGFR} \text { crcys })^{22}$ Serum creatinine and serum cystatin $C$ were assessed as described elsewhere. ${ }^{23}$ To assess urinary albumin excretion (UAE), participants were requested to collect two $24 \mathrm{~h}$ urine collections, as described elsewhere. ${ }^{23}$ Only urine collections with a collection time between $20 \mathrm{~h}$ and $28 \mathrm{~h}$ were considered valid. If needed, UAE was extrapolated to a $24 \mathrm{~h}$ excretion. These analyses were preferably based on the average of two (available in $92.6 \%$ of the participants) $24 \mathrm{~h}$ urine collections. 


\section{Potential confounders or mediators}

Potential confounders or mediators were extracted from questionnaires and included sex, age, smoking behavior, alcohol consumption, daily energy intake, mobility limitation (having any difficulties with walking in the previous week), comorbidity (the presence of (a history of) non-skin cancer, inflammatory respiratory disease or Parkinson's disease), and history of CVD. Level of education and use of antihypertensive and lipid-modifying medication were assessed by interview.

Other potential confounders or mediators were obtained from physical examination and laboratory assessment as described elsewhere, ${ }^{20}$ and included waist circumference, total cholesterol, high-density lipoprotein (HDL) cholesterol, triglycerides, office blood pressure, $24 \mathrm{~h}$ average ambulatory blood pressure, and glucose metabolism status.

\section{Statistical analyses}

Characteristics of the total study population and according to sex-specific quartiles of sedentary time (to obtain equal distributions of men and women) were summarized as means with standard deviations (SD) or as numbers and percentages. Non-normally distributed variables were described using the median and the interquartile range. General linear models were used to obtain adjusted levels of physical activity and sedentary behavior variables according to categories of eGFR crcys $_{\text {and }}$ and albuminuria. eGFR crcys was categorized into: $\geq 90 \mathrm{ml} / \mathrm{min} / 1.73 \mathrm{~m}^{2}$, $60-<90 \mathrm{ml} / \mathrm{min} / 1.73 \mathrm{~m}^{2}$, and $<60 \mathrm{ml} / \mathrm{min} / 1.73 \mathrm{~m}^{2}{ }^{2.3}$ Albuminuria was categorized into: $<15 \mathrm{mg} / 24 \mathrm{~h}$, $15-<30 \mathrm{mg} / 24 \mathrm{~h}$, and $\geq 30 \mathrm{mg} / 24 \mathrm{~h} .{ }^{23}$

Associations of total physical activity (h/day), HPA (10 min/day), LPA (h/day), sedentary time (h/day), sedentary breaks (10/day), prolonged sedentary bouts (\#/day), and average sedentary bout duration $(\mathrm{min})$ with $\mathrm{GGFR}_{\text {crcys }}$ as dependent variable were evaluated with multivariable linear regression analyses. The regression coefficients (betas) represent the difference in eGFR $_{\text {crys }}$ per one unit increase in the independent variable. The associations of the physical activity and sedentary behavior variables with albuminuria were evaluated with categories of albuminuria using multinomial logistic regression analyses, because UAE was highly positively skewed and could not be transformed adequately using common transformations. ${ }^{24}$ Total physical activity and LPA were categorized into quartiles as the association with categorical albuminuria was non-linear. The odds ratios (ORs) represent the odds of having a UAE of $15-<30 \mathrm{mg} / 24 \mathrm{~h}$ or a UAE of $\geq 30 \mathrm{mg} / 24 \mathrm{~h}$ (with a UAE of $<15 \mathrm{mg} / 24 \mathrm{~h}$ as reference category), respectively, relative to the odds in the first quartile for total physical activity and LPA, or per one unit increase in HPA or the sedentary behavior variables.

The associations in model 1 were adjusted for age, sex, glucose metabolism status, educational level, smoking status, alcohol consumption, energy intake, comorbid disease, mobility limitation, and waking time (to exclude the possibility that estimated effects were biased due to differences in waking hours). In model 2 the associations with the sedentary behavior variables were additionally adjusted for HPA, to examine whether the associations were independent of the amount of HPA since HPA has been identified as an important health factor. ${ }^{25}$ In model 3 the associations with HPA and the sedentary behavior pattern variables were additionally adjusted for sedentary time, to examine whether the associations were independent of the amount of sedentary time. In model 4 all associations were additionally adjusted for potential mediators (or confounders) which included office systolic blood pressure, use of antihypertensive medication, waist circumference, total-to-HDL cholesterol ratio, triglycerides, use of lipid-modifying medication, and prevalent CVD.

All analyses were performed with IBM SPSS Statistics Version 22.0 (IBM Corp., Armonk, NY, USA). 


\section{RESULTS}

Table 7.1 presents descriptive characteristics of the total study population and according to sex-specific quartiles of sedentary hours per day. Of the total study population, $51.3 \%$ were men and the average age was $60.1 \pm 8.1$ years. GGFR $_{\text {crys }}$ was on average $87.9 \pm 14.6 \mathrm{ml} /$ $\mathrm{min} / 1.73 \mathrm{~m}^{2}$ in the total study population, and $4.3 \%$ had an $\mathrm{eGFR}_{\text {crcys }}$ of $<60 \mathrm{ml} / \mathrm{min} / 1.73 \mathrm{~m}^{2}$. The median UAE was $6.6 \mathrm{mg} / 24 \mathrm{~h}$, and $8.8 \%$ of the total study population had a UAE of $\geq 30$ $\mathrm{mg} / 24 \mathrm{~h}$. The accelerometer was worn on average $6.3 \pm 1.2$ days $(57.5 \%$ of the participants provided 7 valid days of data). Average waking time was $15.7 \pm 0.9 \mathrm{~h} /$ day, of which most time was spent sedentary $(9.4 \pm 1.7 \mathrm{~h})$, and only $4.3 \pm 1.3 \mathrm{~h}$ and $2.0 \pm 0.7 \mathrm{~h}$ were spent standing and being physically active (stepping), respectively. The amount of LPA was on average $1.6 \pm 0.6 \mathrm{~h} /$ day, and the median HPA was 18.4 [9.0 - 31.4] min/day. Figure 7.1 shows the daily percentages of sedentary time, standing time and time spent physically active (stepping) according to eGFR $_{\text {crys }}$ and albuminuria categories. Participants with a lower eGFR crcys $_{\text {and }}$ and those with a higher UAE spent more time sedentary, so consequently less time standing and physically active in comparison with those with a higher GFR $_{\text {crys }}$ and those with a lower UAE. Sedentary time was interrupted on average $37.4 \pm 8.5$ times per day (sedentary breaks). The daily number of prolonged sedentary bouts (accumulated in a consecutive period $\geq 30 \mathrm{~min}$ ) was on average $4.9 \pm 1.6$, and the median average sedentary bout duration was 10.7 [8.7-13.2] min (Table 7.1).

Table 7.1. Characteristics of the total study population and stratified according to quartiles of total amount of sedentary time

\begin{tabular}{|c|c|c|c|c|c|}
\hline & \multirow[b]{2}{*}{\begin{tabular}{|l} 
Total \\
$(n=2258)$
\end{tabular}} & \multicolumn{4}{|c|}{ Sex-specific quartiles of total amount of sedentary time } \\
\hline & & $\begin{array}{l}Q 1 \\
(n=563)\end{array}$ & $\begin{array}{l}\text { Q2 } \\
(n=565)\end{array}$ & $\begin{array}{l}\text { Q3 } \\
(n=565)\end{array}$ & $\begin{array}{l}\mathrm{Q} 4 \\
(\mathrm{n}=565)\end{array}$ \\
\hline $\begin{array}{l}\text { Range of sedentary time } \\
\text { (h/day) in men }\end{array}$ & $4.3-15.9$ & $4.3-8.9$ & $8.9-10.0$ & $10.0-11.0$ & 11.0-15.9 \\
\hline $\begin{array}{l}\text { Range of sedentary time } \\
\text { (h/day) in women }\end{array}$ & $2.5-14.4$ & $2.5-7.8$ & 7.8-8.8 & 8.8-9.9 & 9.9-14.4 \\
\hline Age (years) & $60.1 \pm 8.1$ & $58.8 \pm 8.3$ & $61.0 \pm 7.7$ & $60.6 \pm 8.2$ & $60.2 \pm 8.0$ \\
\hline Men & $1159(51.3)$ & $289(51.3)$ & $290(51.3)$ & $290(51.3)$ & $290(51.3)$ \\
\hline $\begin{array}{l}\text { Educational level } \\
\text { Low } \\
\text { Intermediate } \\
\text { High }\end{array}$ & $\begin{array}{l}370(16.4) \\
971(43.0) \\
917(40.6)\end{array}$ & $\begin{array}{l}97(17.2) \\
264(46.9) \\
202(35.9) \\
\end{array}$ & $\begin{array}{l}96(17.0) \\
245(43.4) \\
224(39.6)\end{array}$ & $\begin{array}{l}77(13.6) \\
235(41.6) \\
253(44.8)\end{array}$ & $\begin{array}{l}100(17.7) \\
227(40.2) \\
238(42.1)\end{array}$ \\
\hline $\begin{array}{l}\text { Smoking behavior } \\
\text { (\% current) }\end{array}$ & $281(12.4)$ & $61(10.8)$ & $54(9.6)$ & $58(10.3)$ & $108(19.1)$ \\
\hline $\begin{array}{l}\text { Alcohol consumption } \\
\text { (\% high) }\end{array}$ & $581(25.7)$ & $135(24.0)$ & $151(26.7)$ & $159(28.1)$ & $136(24.1)$ \\
\hline Energy intake (kcal/day) & $2170 \pm 602$ & $2217 \pm 608$ & $2153 \pm 586$ & $2177 \pm 593$ & $2136 \pm 619$ \\
\hline Body mass index & $27.0 \pm 4.5$ & $26.1 \pm 4.3$ & $26.7 \pm 4.2$ & $26.9 \pm 4.1$ & $28.4 \pm 5.0$ \\
\hline $\begin{array}{l}\text { Waist circumference }(\mathrm{cm}) \\
\text { Men } \\
\text { Women }\end{array}$ & $\begin{array}{l}101.7 \pm 12.0 \\
89.5 \pm 12.6\end{array}$ & $\begin{array}{l}97.7 \pm 11.1 \\
86.3 \pm 11.6\end{array}$ & $\begin{array}{l}100.5 \pm 11.0 \\
87.8 \pm 11.0\end{array}$ & $\begin{array}{l}101.9 \pm 11.2 \\
89.3 \pm 11.2 \\
\end{array}$ & $\begin{array}{l}106.7 \pm 12.9 \\
94.4 \pm 14.8\end{array}$ \\
\hline $\begin{array}{l}\text { Office systolic blood } \\
\text { pressure }(\mathrm{mmHg})\end{array}$ & $135.2 \pm 18.2$ & $134.7 \pm 18.7$ & $135.3 \pm 18.3$ & $134.8 \pm 17.3$ & $136.3 \pm 18.7$ \\
\hline
\end{tabular}


Table 7.1. (continued)

\begin{tabular}{|c|c|c|c|c|c|}
\hline & & Sex-specific qu & vartiles of total & amount of sede & ntary time \\
\hline & $\begin{array}{l}\text { Total } \\
(\mathrm{n}=2258)\end{array}$ & $\begin{array}{l}\text { Q1 } \\
(n=563)\end{array}$ & $\begin{array}{l}\text { Q2 } \\
(n=565)\end{array}$ & $\begin{array}{l}\text { Q3 } \\
(n=565)\end{array}$ & $\begin{array}{l}\text { Q4 } \\
(n=565)\end{array}$ \\
\hline $\begin{array}{l}\text { Office diastolic blood } \\
\text { pressure }(\mathrm{mmHg})\end{array}$ & $76.2 \pm 9.9$ & $76.1 \pm 10.1$ & $75.9 \pm 10.0$ & $75.9 \pm 9.3$ & $77.1 \pm 10.2$ \\
\hline Hypertension & $1298(57.5)$ & $275(48.8)$ & $333(58.9)$ & $323(57.2)$ & $367(65.0)$ \\
\hline $\begin{array}{l}\text { Antihypertensive } \\
\text { medication }\end{array}$ & $920(40.7)$ & $175(31.1)$ & $211(37.3)$ & $235(41.6)$ & $299(52.9)$ \\
\hline $\begin{array}{l}\text { Glucose metabolism status } \\
\text { Normal glucose } \\
\text { metabolism } \\
\text { Prediabetes } \\
\text { Type } 2 \text { diabetes }\end{array}$ & $\begin{array}{l}1268(56.2) \\
351(15.5) \\
639(28.3)\end{array}$ & $\begin{array}{l}363(64.5) \\
91(16.2) \\
109(19.4)\end{array}$ & $\begin{array}{l}345(61.1) \\
81(14.3) \\
139(24.6)\end{array}$ & $\begin{array}{l}320(56.6) \\
87(15.4) \\
158(28.0)\end{array}$ & $\begin{array}{l}240(42.5) \\
92(16.3) \\
233(41.2)\end{array}$ \\
\hline Total cholesterol (mmol/l) & $5.2 \pm 1.2$ & $5.4 \pm 1.1$ & $5.3 \pm 1.2$ & $5.3 \pm 1.2$ & $5.1 \pm 1.2$ \\
\hline $\begin{array}{l}\text { HDL cholesterol }(\mathrm{mmol} / \mathrm{l}) \\
\text { Men } \\
\text { Women }\end{array}$ & $\begin{array}{l}1.4 \pm 0.4 \\
1.8 \pm 0.5\end{array}$ & $\begin{array}{l}1.5 \pm 0.4 \\
1.9 \pm 0.5\end{array}$ & $\begin{array}{l}1.4 \pm 0.4 \\
1.9 \pm 0.5\end{array}$ & $\begin{array}{l}1.3 \pm 0.4 \\
1.7 \pm 0.5\end{array}$ & $\begin{array}{l}1.2 \pm 0.3 \\
1.6 \pm 0.5\end{array}$ \\
\hline LDL cholesterol (mmol/l) & $3.0 \pm 1.0$ & $3.1 \pm 1.0$ & $3.1 \pm 1.0$ & $3.1 \pm 1.1$ & $2.9 \pm 1.1$ \\
\hline Triglycerides (mmol/l) & 1.23 [0.89-1.73] & $1.09[0.83-1.51]$ & $1.19[0.87-1.58]$ & $1.26[0.91-1.75]$ & 1.40 [1.01-1.97] \\
\hline $\begin{array}{l}\text { Total-to-HDL cholesterol } \\
\text { ratio }\end{array}$ & $3.6 \pm 1.1$ & $3.5 \pm 1.1$ & $3.5 \pm 1.1$ & $3.6 \pm 1.1$ & $3.8 \pm 1.2$ \\
\hline $\begin{array}{l}\text { HbA1c }(\%)^{b} \\
\text { No type } 2 \text { diabetes } \\
\text { Type } 2 \text { diabetes }\end{array}$ & $\begin{array}{l}5.5 \pm 0.4 \\
6.9 \pm 1.0\end{array}$ & $\begin{array}{l}5.5 \pm 0.4 \\
6.8 \pm 1.0\end{array}$ & $\begin{array}{l}5.5 \pm 0.4 \\
7.0 \pm 1.0 \\
\end{array}$ & $\begin{array}{l}5.5 \pm 0.4 \\
6.8 \pm 0.9\end{array}$ & $\begin{array}{l}5.5 \pm 0.4 \\
7.0 \pm 1.1\end{array}$ \\
\hline $\begin{array}{l}\text { Lipid-modifying } \\
\text { medication }\end{array}$ & $837(37.1)$ & $169(30.0)$ & $192(34.0)$ & $214(37.9)$ & $262(46.4)$ \\
\hline $\begin{array}{l}\text { Prevalent cardiovascular } \\
\text { disease }\end{array}$ & $378(16.7)$ & $79(14.0)$ & $93(16.5)$ & $94(16.6)$ & $112(19.8)$ \\
\hline $\begin{array}{l}\text { Comorbidity } \\
\text { (\% with comorbidity) }\end{array}$ & $292(12.9)$ & $65(11.5)$ & $65(11.5)$ & $64(11.3)$ & $98(17.3)$ \\
\hline $\begin{array}{l}\text { Limited mobility } \\
(\% \text { limited })\end{array}$ & 367 (16.3) & 67 (11.9) & $73(12.9)$ & $82(14.5)$ & $145(25.7)$ \\
\hline $\mathrm{eGFR}_{\text {crcys }}\left(\mathrm{ml} / \mathrm{min} / 1.73 \mathrm{~m}^{2}\right)$ & $87.9 \pm 14.6$ & $90.8 \pm 13.8$ & $87.8 \pm 13.7$ & $87.0 \pm 15.0$ & $86.1 \pm 15.7$ \\
\hline $\begin{array}{l}\text { eGFR }{ }_{\text {crcys }} \text { categories } \\
\geq 90 \mathrm{ml} / \mathrm{min} / 1.73 \mathrm{~m}^{2} \\
60-<90 \mathrm{ml} / \mathrm{min} / 1.73 \mathrm{~m}^{2} \\
<60 \mathrm{ml} / \mathrm{min} / 1.73 \mathrm{~m}^{2}\end{array}$ & $\begin{array}{l}1078(47.7) \\
1082(47.9) \\
98(4.3)\end{array}$ & $\begin{array}{l}308(54.7) \\
243(43.2) \\
12(2.1) \\
\end{array}$ & $\begin{array}{l}265(46.9) \\
281(49.7) \\
19(3.4)\end{array}$ & $\begin{array}{l}256(45.3) \\
279(49.4) \\
30(5.3) \\
\end{array}$ & $\begin{array}{l}249(44.1) \\
279(49.4) \\
37(6.5) \\
\end{array}$ \\
\hline $\begin{array}{l}\text { Urinary albumin excretion } \\
\text { rate }(\mathrm{mg} / 24 \mathrm{~h})\end{array}$ & $6.6[3.9-12.3]$ & $6.0[3.8-11.0]$ & $6.3[3.7-11.2]$ & $6.6[3.9-12.6]$ & 7.9 [4.2-15.8] \\
\hline $\begin{array}{l}\text { Urinary albumin excretion } \\
\text { categories } \\
\quad<15 \mathrm{mg} / 24 \mathrm{~h} \\
15-<30 \mathrm{mg} / 24 \mathrm{~h} \\
\geq 30 \mathrm{mg} / 24 \mathrm{~h} \\
\end{array}$ & $\begin{array}{l}1812(80.2) \\
247(10.9) \\
199(8.8) \\
\end{array}$ & $\begin{array}{l}479(85.1) \\
50(8.9) \\
34(6.0)\end{array}$ & $\begin{array}{l}465(82.3) \\
55(9.7) \\
45(8.0) \\
\end{array}$ & $\begin{array}{l}458(81.1) \\
62(11.0) \\
45(8.0) \\
\end{array}$ & $\begin{array}{l}410(72.6) \\
80(14.2) \\
75(13.3)\end{array}$ \\
\hline Valid days (\#) & $6.3 \pm 1.2$ & $6.2 \pm 1.3$ & $6.4 \pm 1.0$ & $6.4 \pm 1.0$ & $6.1 \pm 1.2$ \\
\hline
\end{tabular}


Table 7.1. (continued)

\begin{tabular}{|c|c|c|c|c|c|}
\hline & \multirow[b]{2}{*}{\begin{tabular}{|l} 
Total \\
$(n=2258)$
\end{tabular}} & \multicolumn{4}{|c|}{ Sex-specific quartiles of total amount of sedentary time } \\
\hline & & $\begin{array}{l}\text { Q1 } \\
(n=563)\end{array}$ & $\begin{array}{l}\text { Q2 } \\
(n=565)\end{array}$ & $\begin{array}{l}\text { Q3 } \\
(n=565)\end{array}$ & $\begin{array}{l}\text { Q4 } \\
(n=565)\end{array}$ \\
\hline Waking time (h/day) & $15.7 \pm 0.9$ & $15.6 \pm 0.9$ & $15.6 \pm 0.9$ & $15.7 \pm 0.9$ & $16.1 \pm 0.9$ \\
\hline Sedentary time (h/day) & $9.4 \pm 1.7$ & $7.4 \pm 0.9$ & $8.9 \pm 0.6$ & $9.9 \pm 0.6$ & $11.4 \pm 0.9$ \\
\hline Standing time (h/day) & $4.3 \pm 1.3$ & $5.6 \pm 1.2$ & $4.5 \pm 1.0$ & $3.9 \pm 0.9$ & $3.2 \pm 0.8$ \\
\hline $\begin{array}{l}\text { Total physical activity } \\
\text { (h/day) }\end{array}$ & $2.0 \pm 0.7$ & $2.5 \pm 0.6$ & $2.1 \pm 0.6$ & $1.8 \pm 0.5$ & $1.5 \pm 0.5$ \\
\hline $\begin{array}{l}\text { Lower intensity physical } \\
\text { activity (h/day) }\end{array}$ & $1.6 \pm 0.6$ & $2.0 \pm 0.5$ & $1.7 \pm 0.5$ & $1.5 \pm 0.4$ & $1.2 \pm 0.4$ \\
\hline $\begin{array}{l}\text { Higher intensity physical } \\
\text { activity (min/day) }\end{array}$ & $18.4[9.0-31.4]$ & $25.3[14.3-39.6]$ & 19.9 [11.0-31.8] & $16.8[8.1-29.0]$ & $12.4[5.3-23.0]$ \\
\hline Sedentary breaks (\#/day) & $37.4 \pm 8.5$ & $38.3 \pm 9.6$ & $38.1 \pm 8.3$ & $37.4 \pm 7.7$ & $35.8 \pm 8.2$ \\
\hline $\begin{array}{l}\text { Prolonged sedentary bouts } \\
(\# / \text { day })\end{array}$ & $4.9 \pm 1.6$ & $3.4 \pm 1.0$ & $4.5 \pm 1.0$ & $5.2 \pm 1.1$ & $6.4 \pm 1.3$ \\
\hline $\begin{array}{l}\text { Average sedentary bout } \\
\text { duration (min) }\end{array}$ & $10.7[8.7-13.2]$ & $8.7[7.2-10.3]$ & $10.1[8.5-12.1]$ & $11.2[9.6-13.4]$ & 13.2 [11.0-15.7] \\
\hline
\end{tabular}

Note: Data are presented as $n(\%)$, mean \pm standard deviation, median [interquartile range] or range (only for range of sedentary time).

Abbreviations: $e G F R_{\text {crys' }}$ estimated glomerular filtration rate based on serum creatinine and serum cystatin C; HbA1c, hemoglobin A1c (glycated hemoglobin); HDL cholesterol, high-density lipoprotein cholesterol; LDL cholesterol, low-density lipoprotein cholesterol.

${ }^{a}$ Body mass index was available in $n=2257 .{ }^{b} \mathrm{HbA1}$ c was available in $n=2254$. 


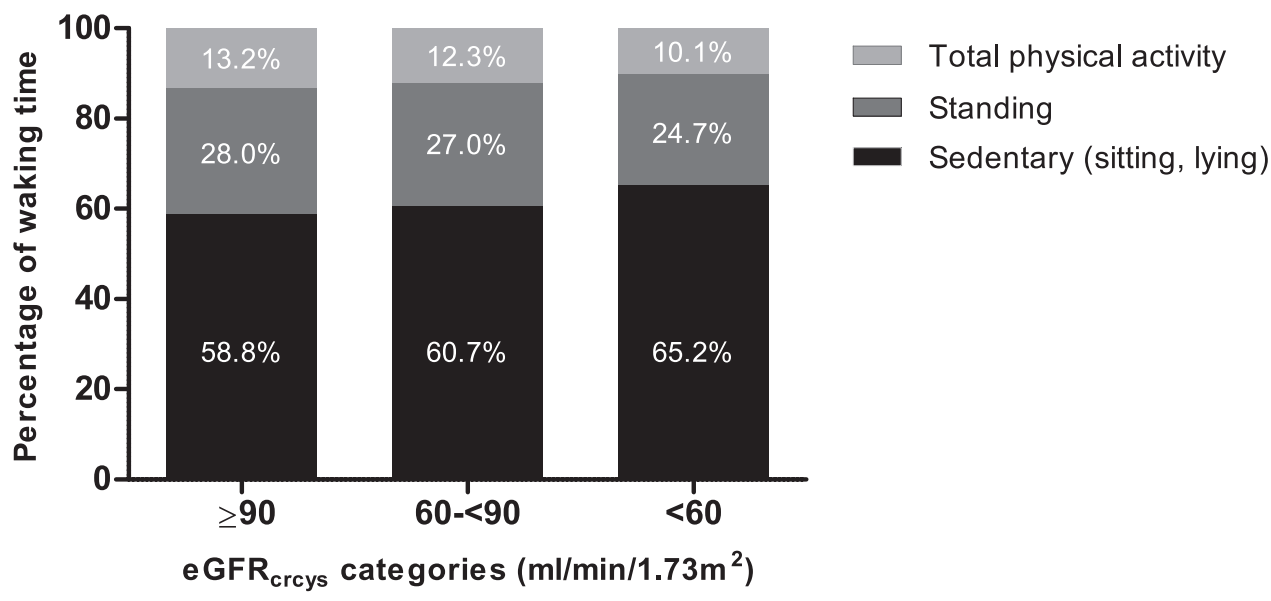

B

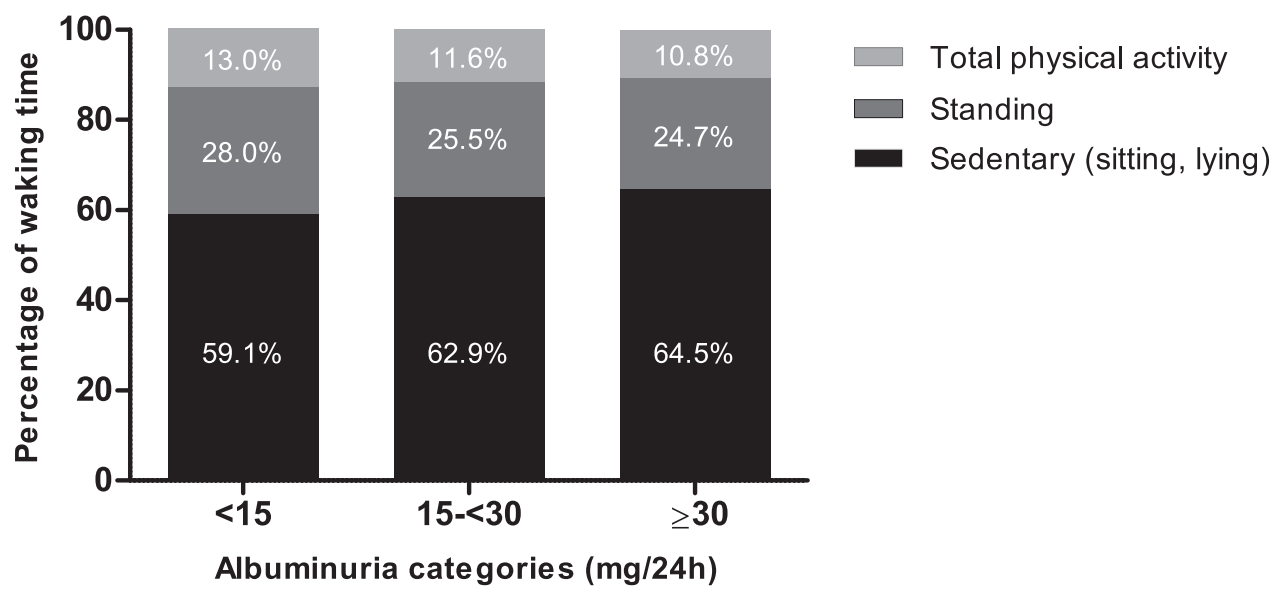

Figure 7.1. Percentage of waking time spent sedentary, standing, and physically active according to categories of eGFR crys (panel A) and albuminuria (panel B). Distribution of participants in the $e^{-G F R}$ crys categories: $\geq 90 \mathrm{ml} / \mathrm{min} / 1.73 \mathrm{~m} 2 \mathrm{n}=1073,60-<90 \mathrm{ml} / \mathrm{min} / 1.73 \mathrm{~m} 2 \mathrm{n}=1077$, $<60 \mathrm{ml} / \mathrm{min} / 1.73 \mathrm{~m} 2 \mathrm{n}=97$. Distribution of participants in the albuminuria categories: $<15 \mathrm{mg} / 24 \mathrm{~h} \mathrm{n}=1804,15-<30 \mathrm{mg} / 24 \mathrm{~h} \mathrm{n}=246, \geq 30 \mathrm{mg} / 24 \mathrm{~h} \mathrm{n}=197$. 


\section{Daily activity and eGFR}

Table 7.2 presents the adjusted means of the physical activity and sedentary behavior variables

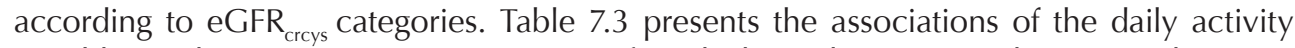
variables with eGFR crys. Larger amounts of total physical activity and LPA per day were statistically significantly associated with a higher EGFR $_{\text {crcys }}$ after adjustment for confounders (beta total physical activity $2.30,95 \%$ confidence interval $(95 \% \mathrm{Cl}) 1.46$ to 3.14 ; beta LPA 2.10, 1.08 to 3.12; model 1). After additional adjustment for potential mediators (model 4), the associations were attenuated, but remained statistically significant. The amount of daily HPA was also statistically significantly associated with eGFR crys $_{\text {after adjustment for confounders }}$ and sedentary time (beta 0.53, 0.21 to 0.85 ), but after further adjustment for potential mediators in model 4, the association was attenuated and no longer statistically significant. Larger amounts of daily sedentary time were statistically significantly associated with a lower eGFR $_{\text {crys }}$ (beta -0.71, -1.08 to -0.35), after adjustment for confounders including HPA (model 2).

After additional adjustment for potential mediators (model 4), the association was attenuated, but remained statistically significant. A larger number of sedentary breaks per day was associated with a higher eGFR $_{\text {crcys }}$ in model 2 (beta 0.80, 0.12 to 1.47), but after additional adjustment for sedentary time in model 3, the association became statistically nonsignificant. Having more daily prolonged sedentary bouts and having a longer average sedentary bout duration were both statistically significantly associated with a lower eGFR crys' $^{\prime}$ even after adjustment for relevant confounders in model 3 and potential mediators in model 4 (beta prolonged bouts -0.57, -1.14 to -0.01; beta bout duration-0.23, -0.41 to -0.04).

\section{Daily activity and albuminuria}

Table 7.4 presents the adjusted means of the physical activity and sedentary behavior variables according to albuminuria categories. Table 7.5 presents the associations of the daily activity variables with albuminuria. The associations between total physical activity and LPA were non-linear and described using quartiles. Larger amounts of total physical activity were associated with lower ORs for higher UAE, although not all quartiles were statistically significant. After adjustment for potential mediators in model 4, most ORs became statistically nonsignificant, although the ORs for a UAE of $15-<30 \mathrm{mg} / 24 \mathrm{~h}$ were similar to those in model 1 . The associations of LPA and HPA with albuminuria were, after adjustment for confounders (models 1 and 3), not statistically significant. In contrast, larger amounts of daily sedentary time were associated with a statistically significantly higher odds for a UAE of $15-<30 \mathrm{mg} / 24 \mathrm{~h}\left(\mathrm{OR}_{15-<30 \mathrm{mg} / 24 \mathrm{~h}}-1.11\right.$, 1.01 to 1.22$)$ and with a borderline significantly higher odds for a UAE of $\geq 30 \mathrm{mg} / 24 \mathrm{~h}\left(\mathrm{OR}_{\geq 30 \mathrm{mg} / 24 \mathrm{~h}}\right.$ -1.10, 0.99 to 1.22) in model 2. After adjustment for potential mediators in model 4 , the association with a UAE of $15-<30 \mathrm{mg} / 24 \mathrm{~h}$ was similar to the association in model 2 . The daily number of sedentary breaks was not statistically significantly associated with albuminuria in any model. Having more daily prolonged sedentary bouts and having a longer average sedentary bout duration were associated with a higher odds for a UAE of $15-<30 \mathrm{mg} / 24 \mathrm{~h}$ and $\geq 30 \mathrm{mg} / 24 \mathrm{~h}$ in model 1 . These associations were no longer statistically significant after adjustment for HPA and sedentary time (models 2 and 3). 
Table 7.2. Adjusted means of physical activity and sedentary behavior variables according to GFR $_{\text {crcys }}$ categories

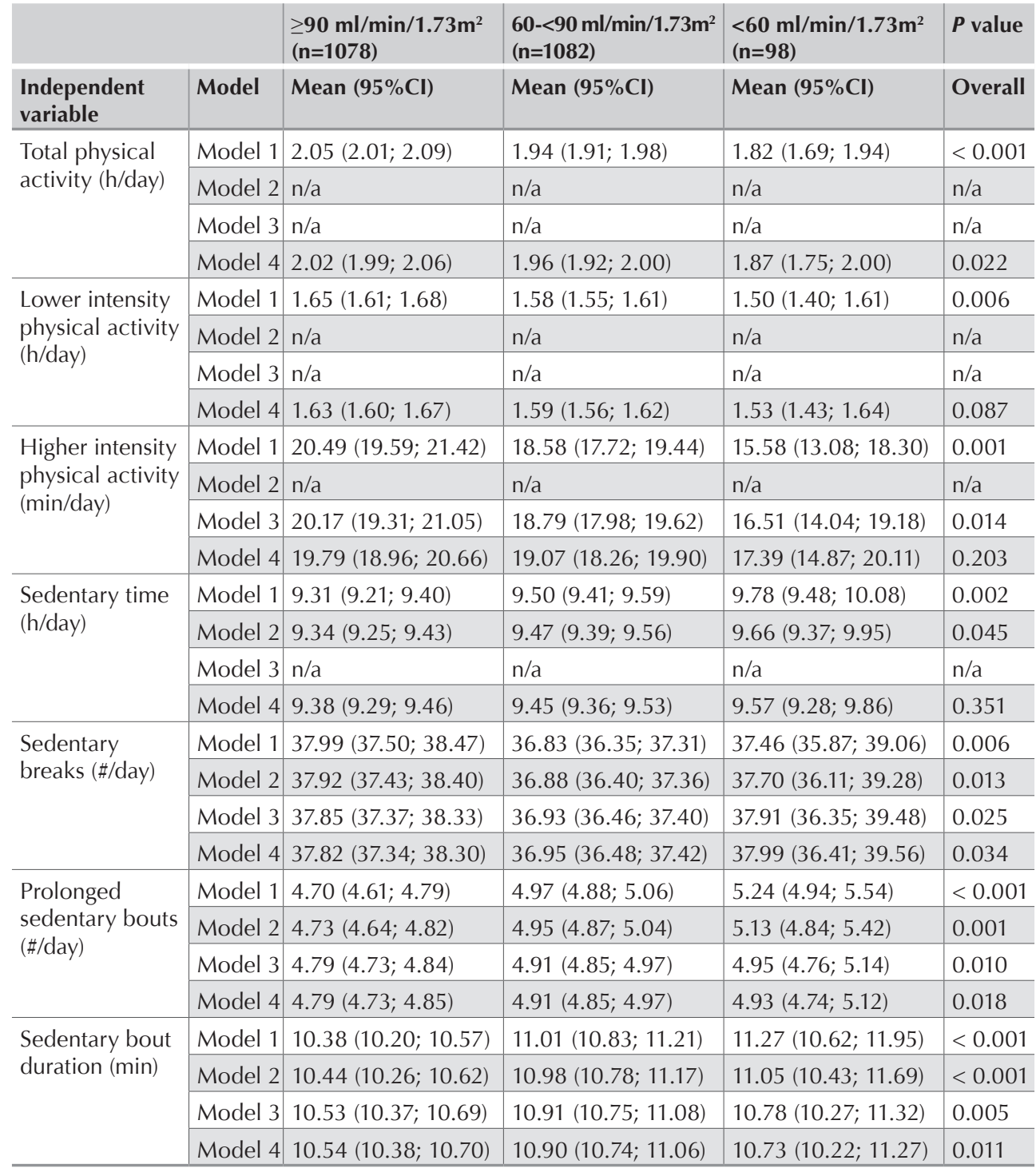

Note: Means represent adjusted means of the dependent variables in each eGFR ${ }_{\text {crcys }}$ category. The means in model 1 were adjusted for age, sex, glucose metabolism status, waking time, educational level, smoking behavior, alcohol consumption, energy intake, comorbid disease, mobility limitation, waking time; in model 2 the means of the sedentary behavior variables were additionally adjusted for higher intensity physical activity; in model 3 the means of higher intensity physical activity and the sedentary behavior pattern variables were additionally adjusted for sedentary time; in model 4 all means were additionally adjusted for office systolic blood pressure, use of antihypertensive medication, waist circumference, total-to-high-density lipoprotein cholesterol ratio, triglycerides, use of lipid-modifying medication, prevalent cardiovascular disease.

Abbreviations: $\mathrm{Cl}$, confidence interval; eGFR crys' estimated glomerular filtration rate based on serum creatinine and serum cystatin C; n/a, not applicable. 


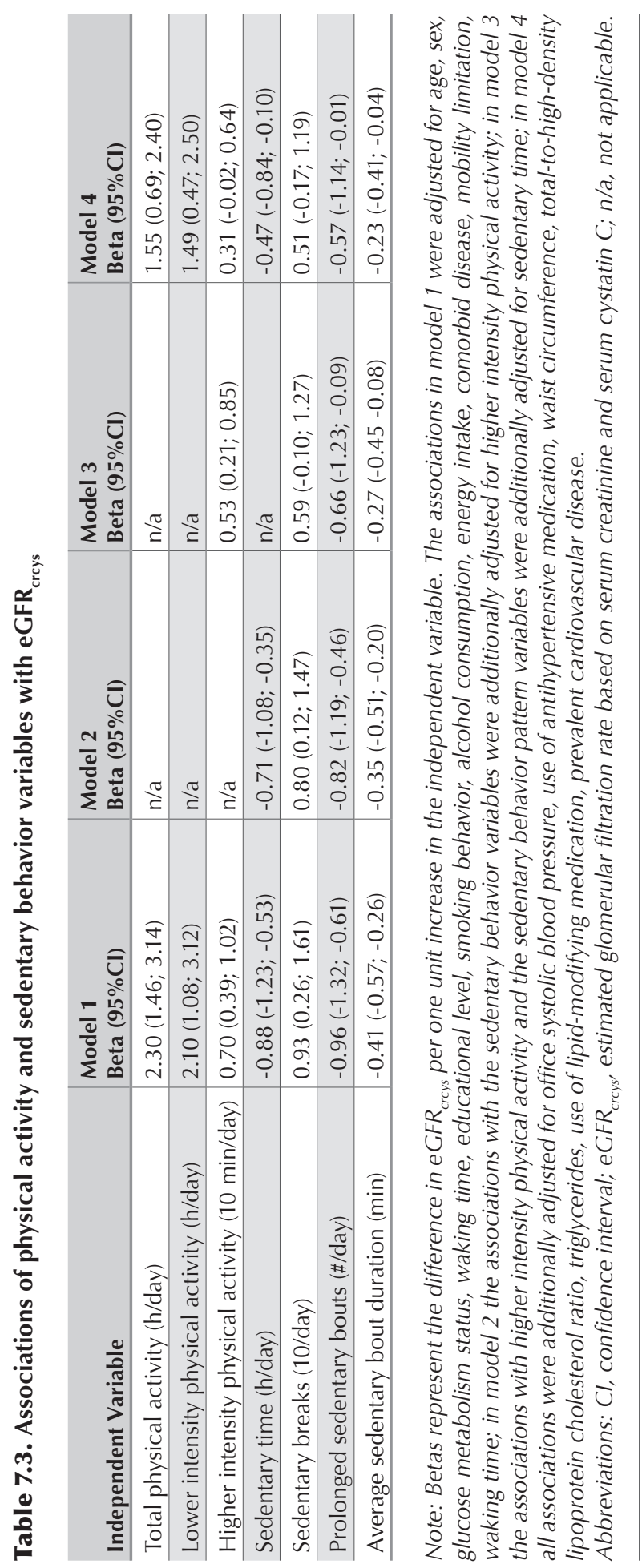


Table 7.4. Adjusted means of physical activity and sedentary behavior variables according to albuminuria categories

\begin{tabular}{|c|c|c|c|c|c|}
\hline & & $\begin{array}{l}<15 \mathrm{mg} / 24 h \\
(\mathrm{n}=1812)\end{array}$ & $\begin{array}{l}15-<30 \mathrm{mg} / 24 h \\
(\mathrm{n}=247)\end{array}$ & $\begin{array}{l}\geq 30 \mathrm{mg} / 24 \mathrm{~h} \\
(\mathrm{n}=199)\end{array}$ & $P$ value \\
\hline $\begin{array}{l}\text { Independent } \\
\text { variable }\end{array}$ & Model & Mean $(95 \% \mathrm{CI})$ & Mean $(95 \% \mathrm{CI})$ & Mean $(95 \% \mathrm{CI})$ & Overall \\
\hline \multirow{4}{*}{$\begin{array}{l}\text { Total physical } \\
\text { activity (h/day) }\end{array}$} & Model 1 & $2.00(1.98 ; 2.03)$ & $1.94(1.87 ; 2.02)$ & $1.89(1.80 ; 1.98)$ & 0.033 \\
\hline & Model 2 & $\mathrm{n} / \mathrm{a}$ & $\mathrm{n} / \mathrm{a}$ & $\mathrm{n} / \mathrm{a}$ & $\mathrm{n} / \mathrm{a}$ \\
\hline & Model 3 & $\mathrm{n} / \mathrm{a}$ & $\mathrm{n} / \mathrm{a}$ & $\mathrm{n} / \mathrm{a}$ & $\mathrm{n} / \mathrm{a}$ \\
\hline & Model 4 & $2.00(1.97 ; 2.03)$ & $1.95(1.87 ; 2.03)$ & $1.92(1.83 ; 2.01)$ & 0.177 \\
\hline \multirow{4}{*}{$\begin{array}{l}\text { Lower intensity } \\
\text { physical activity } \\
\text { (h/day) }\end{array}$} & Model 1 & $1.62(1.60 ; 1.65)$ & $1.57(1.51 ; 1.64)$ & $1.54(1.46 ; 1.61)$ & 0.062 \\
\hline & Model 2 & $\mathrm{n} / \mathrm{a}$ & $\mathrm{n} / \mathrm{a}$ & $\mathrm{n} / \mathrm{a}$ & $\mathrm{n} / \mathrm{a}$ \\
\hline & Model 3 & $\mathrm{n} / \mathrm{a}$ & $\mathrm{n} / \mathrm{a}$ & $\mathrm{n} / \mathrm{a}$ & $\mathrm{n} / \mathrm{a}$ \\
\hline & Model 4 & $1.62(1.60 ; 1.64)$ & $1.58(1.51 ; 1.64)$ & $1.55(1.48 ; 1.63)$ & 0.173 \\
\hline \multirow{4}{*}{$\begin{array}{l}\text { Higher intensity } \\
\text { physical activity } \\
\text { (min/day) }\end{array}$} & Model 1 & $19.64(18.97 ; 20.31)$ & $18.85(17.11 ; 20.68)$ & $17.29(15.41 ; 19.28)$ & 0.087 \\
\hline & Model 2 & $\mathrm{n} / \mathrm{a}$ & $\mathrm{n} / \mathrm{a}$ & $\mathrm{n} / \mathrm{a}$ & $\mathrm{n} / \mathrm{a}$ \\
\hline & Model 3 & & & $17.89(16.06 ; 19.83)$ & 0.306 \\
\hline & Model 4 & $18.47(18.81 ; 20.05)$ & $19.41(17.75 ; 21.15)$ & $18.47(16.62 ; 20.42)$ & 0.653 \\
\hline \multirow{4}{*}{$\begin{array}{l}\text { Sedentary time } \\
\text { (h/day) }\end{array}$} & Model 1 & $9.37(9.30 ; 9.44)$ & $9.60(9.41 ; 9.79)$ & $9.64(9.43 ; 9.85)$ & 0.012 \\
\hline & Model 2 & $9.38(9.31 ; 9.45)$ & $9.58(9.40 ; 9.76)$ & $9.57(9.37 ; 9.78)$ & 0.041 \\
\hline & Model 3 & $\mathrm{n} / \mathrm{a}$ & $\mathrm{n} / \mathrm{a}$ & $\mathrm{n} / \mathrm{a}$ & $\mathrm{n} / \mathrm{a}$ \\
\hline & Model 4 & $9.39(9.32 ; 9.45)$ & $9.58(9.40 ; 9.75)$ & $9.53(9.33 ; 9.73)$ & 0.090 \\
\hline \multirow{4}{*}{$\begin{array}{l}\text { Sedentary breaks } \\
(\# / \text { day) }\end{array}$} & Model 1 & $37.56(37.20 ; 37.93)$ & $37.06(36.08 ; 38.05)$ & $36.45(35.33 ; 37.58)$ & 0.156 \\
\hline & Model 2 & $37.54(37.18 ; 37.91)$ & $37.09(36.11 ; 38.08)$ & $36.58(35.46 ; 37.70)$ & 0.238 \\
\hline & Model 3 & $37.51(37.15 ; 37.86)$ & $37.24(36.27 ; 38.21)$ & $36.72(35.62 ; 37.83)$ & 0.405 \\
\hline & Model 4 & $37.48(37.12 ; 37.83)$ & $37.31(36.35 ; 38.28)$ & $36.91(35.80 ; 38.02)$ & 0.637 \\
\hline \multirow{4}{*}{$\begin{array}{l}\text { Prolonged } \\
\text { sedentary bouts } \\
\text { (\#/day) }\end{array}$} & Model 1 & $4.81(4.74 ; 4.88)$ & $5.01(4.82 ; 5.20)$ & $5.08(4.87 ; 5.29)$ & 0.015 \\
\hline & Model 2 & $4.82(4.75 ; 4.88)$ & $5.00(4.82 ; 5.18)$ & $5.03(4.82 ; 5.23)$ & 0.047 \\
\hline & Model 3 & $4.85(4.80 ; 4.89)$ & $4.87(4.76 ; 4.99)$ & $4.91(4.78 ; 5.04)$ & 0.652 \\
\hline & Model 4 & $4.85(4.81 ; 4.89)$ & $4.87(4.75 ; 4.99)$ & $4.89(4.75 ; 5.02)$ & 0.835 \\
\hline \multirow{4}{*}{$\begin{array}{l}\text { Sedentary bout } \\
\text { duration (min) }\end{array}$} & Model 1 & $10.61(10.48 ; 10.76)$ & $11.06(10.65 ; 11.46)$ & $11.27(10.82 ; 11.75)$ & 0.008 \\
\hline & Model 2 & $10.63(10.50 ; 10.77)$ & $11.02(10.64 ; 11.43)$ & $11.16(10.71 ; 11.61)$ & 0.029 \\
\hline & Model 3 & $10.68(10.56 ; 10.79)$ & $10.84(10.52 ; 11.18)$ & $10.98(10.60 ; 11.36)$ & 0.263 \\
\hline & Model 4 & $10.69(10.60 ; 10.82)$ & $10.80(10.49 ; 11.13)$ & $10.87(10.50 ; 11.26)$ & 0.604 \\
\hline
\end{tabular}

Note: Means represent adjusted means of the dependent variables in each albuminuria category. The means in model 1 were adjusted for age, sex, glucose metabolism status, waking time, educational level, smoking behavior, alcohol consumption, energy intake, comorbid disease, mobility limitation, waking time; in model 2 the means of the sedentary behavior variables were additionally adjusted for higher intensity physical activity; in model 3, the means of higher intensity physical activity and the sedentary behavior pattern variables were additionally adjusted for sedentary time; in model 4 all means were additionally adjusted for office systolic blood pressure, use of antihypertensive medication, waist circumference, total-to-higher-intensity physical activity cholesterol ratio, triglycerides, use of lipidmodifying medication, prevalent cardiovascular disease.

Abbreviations: $\mathrm{Cl}$, confidence interval; eGFR crcys' estimated glomerular filtration rate based on serum creatinine and serum cystatin C; n/a, not applicable. 


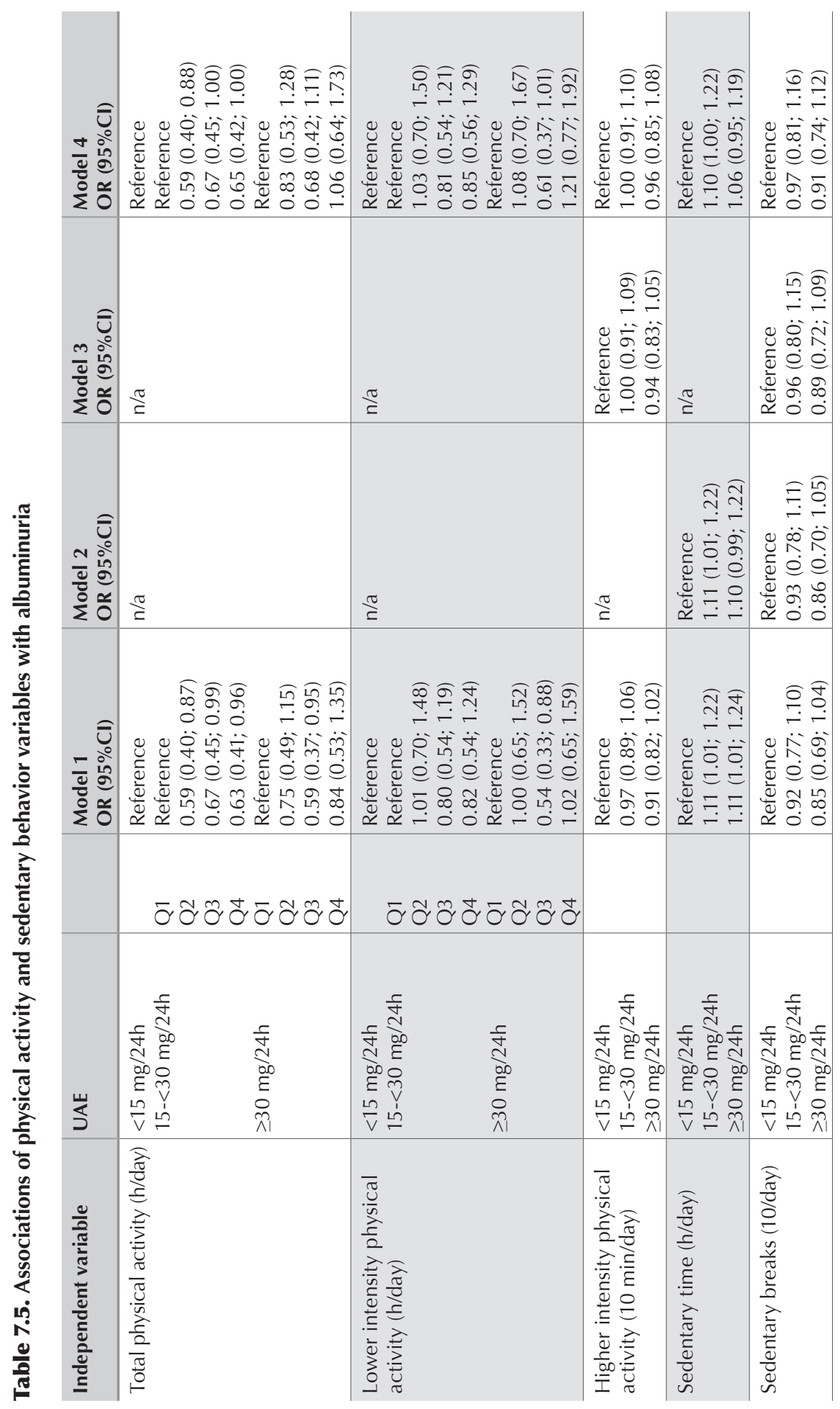




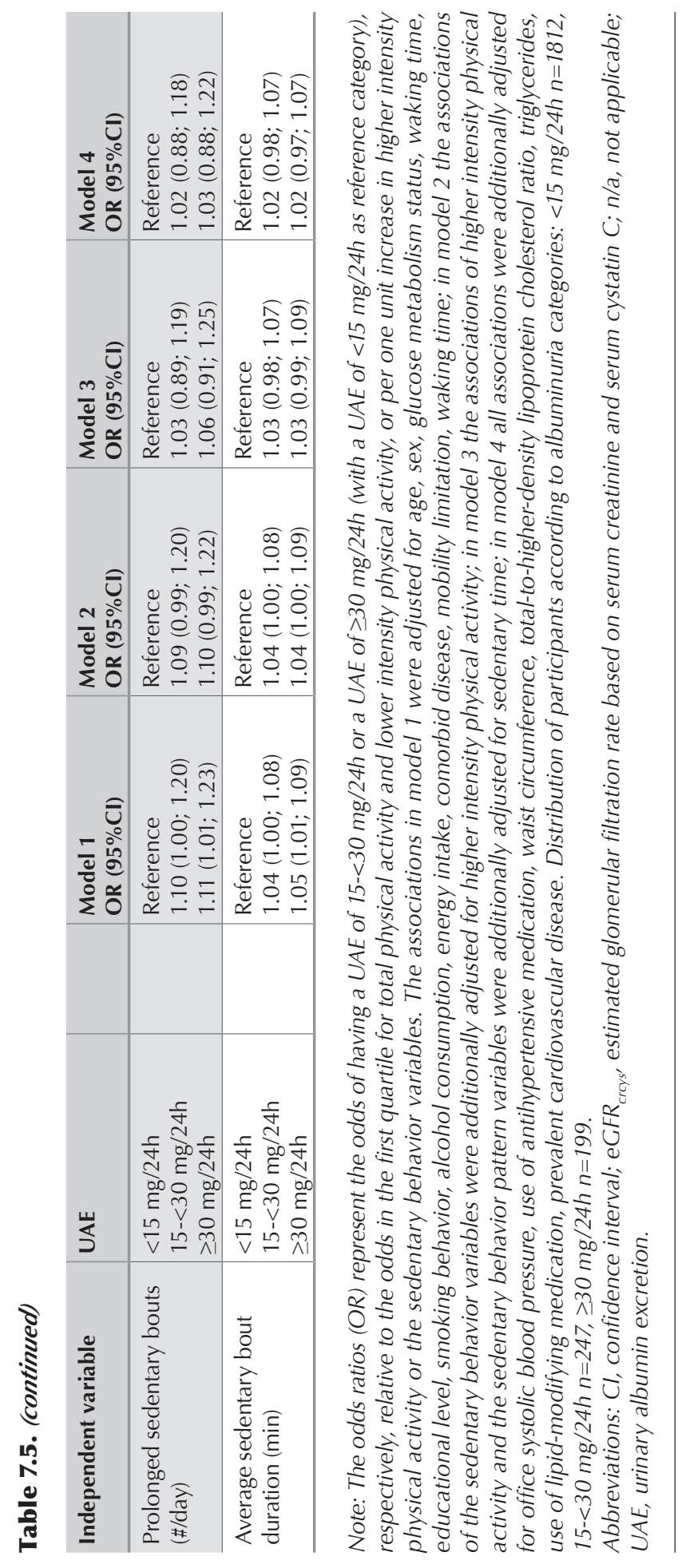




\section{Additional analyses}

In additional analyses, office systolic blood pressure was replaced with 24h average ambulatory systolic blood pressure $(n=1996)$. The effect sizes of the associations of all variables with eGFR $_{\text {crys }}$ were smaller in model 4 and the associations of sedentary time, prolonged sedentary bouts and average sedentary bout duration with eGFR $_{\text {crys }}$ became statistically nonsignificant in model 4 (data not tabulated). However, these analyses were hampered by a loss of statistical power. The effect sizes of the associations of all physical activity and sedentary behavior variables with albuminuria were also attenuated, but the associations of total physical activity and sedentary time remained statistically significant. Further, results were similar when the analyses were repeated with replacement of antihypertensive medication with renin-angiotensinaldosterone system inhibitors or when participants with a UAE of $>300 \mathrm{mg} / 24 \mathrm{~h}$ were excluded or when participants with $<4$ valid days ( $\geq 10 \mathrm{~h}$ of waking data) were excluded (data for the above not tabulated).

\section{DISCUSSION}

To our knowledge, this is the first study in which posture-based accelerometry data were used to measure total amount and patterns of physical activity and sedentary behavior in order to examine associations of daily activity with kidney function. The results demonstrated that an extra hour of total physical activity (stepping time) or LPA was associated with an up to $2.30 \mathrm{ml} / \mathrm{min} / 1.73 \mathrm{~m}^{2}$ higher $\mathrm{eGFR}_{\text {crcys }}$ after adjustment for confounders. Also, larger amounts of daily HPA (10 min/day) were associated with a higher eGFR crcys of $0.53 \mathrm{ml} / \mathrm{min} / 1.73 \mathrm{~m}^{2}$. Further, each extra hour of sedentary time was associated with a lower eGFR crcys $_{\text {of }} 0.71 \mathrm{ml} /$ $\mathrm{min} / 1.73 \mathrm{~m}^{2}$ and also the pattern in which sedentary time was accumulated was associated with a lower eGFR ${ }_{\text {crcys }}$ independent of the amount of HPA and sedentary time.

The total amount of physical activity per day was also associated with albuminuria. Being more physically active resulted in lower odds of having higher UAE. The separate associations of LPA and HPA with albuminuria were not statistically significant. The small numbers of participants in the quartiles of LPA may have contributed to the nonsignificant associations. Alternatively, the amounts of LPA and HPA may have been insufficient to detect a significant association with albuminuria. Each extra hour of sedentary time was associated with statistically significantly higher odds of having a higher UAE, whereas sedentary behavior patterns were not statistically significantly associated with albuminuria after adjustment for confounders. From a pathophysiological perspective, albuminuria is hypothesized to be a biomarker of generalized endothelial dysfunction (i.e., endothelial dysfunction in the micro- and macrocirculation ${ }^{26}$ and capillary rarefaction. ${ }^{27}$ Hence, our results suggest that a sedentary lifestyle may contribute to the development of generalized endothelial dysfunction and/or capillary rarefaction. This notion may be supported by previous studies which have shown effects of sedentariness on the endothelium..$^{28,29}$

The associations of physical activity and sedentary behavior with eGFR and albuminuria may be (partly) mediated by traditional risk factors such as T2DM, ${ }^{17,30,31}$ higher blood pressure, ${ }^{32}$ adiposity, ${ }^{33-35}$ and dyslipidemia. 6,33-35 Therefore, the adjustment for glucose metabolism status (to take into account the oversampling of participants with T2DM in The Maastricht Study) could have resulted in overadjustment bias. ${ }^{36}$ Analyses without adjustment for glucose metabolism status suggested that the associations with albuminuria may indeed have been underestimated (data not shown). Further, the small changes of the regression coefficients of

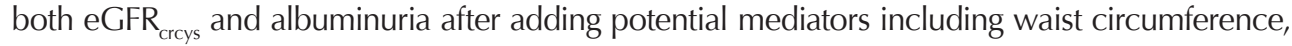


blood pressure, lipid profile and prior CVD in model 4 suggested that these risk factors did not fully explain the associations reported. Therefore, physical activity and sedentary behavior may be associated with eGFR crcys $_{\text {and }}$ albuminuria via other mechanisms such as low-grade inflammation, ${ }^{37}$ endothelial dysfunction, ${ }^{28,29,38}$ reduced activity of the renin-angiotensin system, ${ }^{39}$ reduced renal sympathetic nerve activity, ${ }^{38}$ and/or currently unknown effects. In addition, some factors in model 4 , such as adiposity, may have been confounding factors as well. So, true effect sizes of the associations of physical activity and sedentary behavior with eGFR crcys $_{\text {s }}$ and albuminuria were probably smaller than those reported in the partly adjusted models but larger than those in the fully adjusted model.

Taken together, our study provides new insights into the risk factors for reduced eGFR and albuminuria. This is important given the increasing number of people with a reduced eGFR or albuminuria ${ }^{1}$ and their associated burden of end-stage renal disease, ${ }^{2}$ acute kidney injury, ${ }^{3}$ and CVD. ${ }^{2}$ Our results suggest that prevention strategies should not only focus on increasing physical activity levels, but on reducing sedentary time as well. In addition, with regard to eGFR, further benefits may be obtained by altering the pattern of sedentary behavior.

Previously, studies have reported on associations of physical activity or sedentary behavior with kidney function. Some studies did show associations of physical activity with eGFR ${ }^{7,9,11}$ or albuminuria, ${ }^{8,9}$ while others did not. ${ }^{10,12}$ Similar inconsistent results have been reported in studies on sedentary behavior and eGFR ${ }^{9,13}$ or albuminuria. ${ }^{9,13}$ This inconsistency could have been due to the use of self-reported measures for physical activity and sedentary behavior, which easily could have been subject to recall and reporting bias. ${ }^{40}$ Only a few studies have used accelerometry data to examine associations of physical activity and sedentary behavior with kidney function. In line with our results, it has been reported that in individuals with reduced eGFR and/or albuminuria, smaller amounts of LPA and larger amounts of sedentary time were associated with a lower eGFR. ${ }^{14}$ In contrast, a longitudinal study conducted among individuals with T2DM has reported that changes in MVPA and sedentary time were associated with changes in serum creatinine, but not with eGFR and UAE. ${ }^{15}$ These inconsistencies with our results may have been caused by differences in study design (cross-sectional vs. longitudinal) and study population, but may also be due to differences in the determination of physical activity and sedentary behavior. We used the activPAL accelerometer, which was worn on the thigh for $24 \mathrm{~h}$ per day. This device classifies activity using data on posture in combination with acceleration, so our estimates of sedentary time were more accurate than those in other studies which were based solely on acceleration. ${ }^{18,19}$

Thus, the use of $24 \mathrm{~h}$ posture-based accelerometry data and the measurement of total daily activity were major strengths of our study. In addition, we were the first to examine associations of different constructs of sedentary behavior patterns with eGFR and albuminuria. Another strength was the adjustment for an extensive series of potential confounders, including mutual adjustment for HPA and sedentary time, although residual confounding cannot be excluded. Some limitations should also be mentioned, of which the most important is the cross-sectional nature of our analyses. Therefore, we cannot make strong causal inferences, and reverse causality cannot be excluded. However, the previously reported association between changes of daily activity levels with changes in serum creatinine ${ }^{15}$ suggests that the direction of the association is from daily activity levels to kidney function in individuals with a mildly to moderately reduced eGFR. Nevertheless, longitudinal studies are needed to confirm this assumption. In addition, due to missing data, we had to exclude almost 1200 participants. However, the excluded participants did not differ from our study sample with regard to demographic factors, accelerometry variables and kidney function (data not 
shown). Further, LPA and HPA were based on step frequency, which is less precise than using acceleration to determine intensity levels. However, it has been demonstrated that a step frequency $>\sim 100$ steps/minute equals a metabolic equivalent of task (MET) score of $\geq 3.0^{41}$ and we used a cut-off point $>110$ steps/minute for HPA. Finally, our study population consisted of a relatively healthy population of primarily Caucasians from European descent with wellcontrolled individuals with T2DM. Therefore, the results might not be representative for the general population of adults aged 40-75 years or other ethnicities.

To conclude, this large posture-based accelerometry study showed that both total physical activity and sedentary behavior were associated with eGFR crcys $_{\text {and }}$ albuminuria. Additionally, the pattern in which sedentary time was accumulated may be of importance for eGFR Therefore, not only increasing physical activity levels, but also decreasing amount of sedentary time may be relevant targets in strategies aiming to prevent a reduced eGFR crcys $_{\text {and }}$ and albuminuria. However, future (longitudinal) accelerometry studies are needed to confirm our results and to further disentangle the associations of (patterns of) daily activity with kidney function. 


\section{REFERENCES}

1. Coresh J, Selvin E, Stevens LA, Manzi J, Kusek JW, Eggers P, et al. Prevalence of chronic kidney disease in the United States. Jama. 2007 Nov 7;298(17):2038-47.

2. Fox CS, Matsushita K, Woodward M, Bilo HJ, Chalmers J, Heerspink HJ, et al. Associations of kidney disease measures with mortality and end-stage renal disease in individuals with and without diabetes: a meta-analysis. Lancet. 2012 Nov 10;380(9854):1662-73.

3. James MT, Hemmelgarn BR, Wiebe N, Pannu N, Manns BJ, Klarenbach SW, et al. Glomerular filtration rate, proteinuria, and the incidence and consequences of acute kidney injury: a cohort study. Lancet. 2010 Dec 18;376(9758):2096-103.

4. Ainsworth BE, Haskell WL, Whitt MC, Irwin ML, Swartz AM, Strath SJ, et al. Compendium of physical activities: an update of activity codes and MET intensities. Med Sci Sports Exerc. 2000 Sep;32(9 Suppl):S498-504.

5. Matthews CE, Chen KY, Freedson PS, Buchowski MS, Beech BM, Pate RR, et al. Amount of time spent in sedentary behaviors in the United States, 2003-2004. Am J Epidemiol. 2008 Apr 1;167(7):875-81.

6. Brocklebank LA, Falconer CL, Page AS, Perry R, Cooper AR. Accelerometer-measured sedentary time and cardiometabolic biomarkers: A systematic review. Prev Med. 2015 Jul;76:92-102.

7. Finkelstein J, Joshi A, Hise MK. Association of physical activity and renal function in subjects with and without metabolic syndrome: a review of the Third National Health and Nutrition Examination Survey (NHANES III). Am J Kidney Dis. 2006 Sep;48(3):372-82.

8. Robinson ES, Fisher ND, Forman JP, Curhan GC. Physical activity and albuminuria. Am J Epidemiol. 2010 Mar 1;171(5):515-21.

9. Bharakhada N, Yates T, Davies MJ, Wilmot EG, Edwardson C, Henson J, et al. Association of sitting time and physical activity with CKD: a cross-sectional study in family practices. Am J Kidney Dis. 2012 Oct;60(4):583-90.

10. Chang A, Van Horn L, Jacobs DR, Jr., Liu K, Muntner P, Newsome B, et al. Lifestyle-related factors, obesity, and incident microalbuminuria: the CARDIA (Coronary Artery Risk Development in Young Adults) study. Am J Kidney Dis. 2013 Aug;62(2):267-75.

11. Robinson-Cohen C, Littman AJ, Duncan GE, Weiss NS, Sachs MC, Ruzinski J, et al. Physical activity and change in estimated GFR among persons with CKD. J Am Soc Nephrol. 2014 Feb;25(2):399-406.

12. Herber-Gast GC, Hulsegge G, Hartman L, Verschuren WM, Stehouwer CD, Gansevoort RT, et al. Physical Activity Is not Associated with Estimated Glomerular Filtration Rate among Young and Middle-Aged Adults: Results from the Population-Based Longitudinal Doetinchem Study. PloS one. 2015;10(10):e0133864.

13. White SL, Dunstan DW, Polkinghorne KR, Atkins RC, Cass A, Chadban SJ. Physical inactivity and chronic kidney disease in Australian adults: the AusDiab study. Nutr Metab Cardiovasc Dis. 2011 Feb;21(2):104-12.

14. Hawkins MS, Sevick MA, Richardson CR, Fried LF, Arena VC, Kriska AM. Association between physical activity and kidney function: National Health and Nutrition Examination Survey. Med Sci Sports Exerc. 2011 Aug;43(8):1457-64.

15. Guo VY, Brage S, Ekelund U, Griffin SJ, Simmons RK. Objectively measured sedentary time, physical activity and kidney function in people with recently diagnosed Type 2 diabetes: a prospective cohort analysis. Diabet Med. 2015 Aug 18.

16. Benatti FB, Ried-Larsen M. The Effects of Breaking up Prolonged Sitting Time: A Review of Experimental Studies. Med Sci Sports Exerc. 2015 Oct;47(10):2053-61.

17. Van der Berg JD, Stehouwer CD, Bosma H, van der Velde JH, Willems PJ, Savelberg HH, et al. Associations of total amount and patterns of sedentary behaviour with type 2 diabetes and the metabolic syndrome: The Maastricht Study. Diabetologia. 2016 Apr;59(4):709-18.

18. Kozey-Keadle S, Libertine A, Lyden K, Staudenmayer J, Freedson PS. Validation of wearable monitors for assessing sedentary behavior. Med Sci Sports Exerc. 2011 Aug;43(8):1561-7.

19. Edwardson CL, Rowlands AV, Bunnewell S, Sanders J, Esliger DW, Gorely T, et al. Accuracy of Posture Allocation Algorithms for Thigh- and Waist-Worn Accelerometers. Med Sci Sports Exerc. 2016 Jan 7.

20. Schram MT, Sep SJ, van der Kallen CJ, Dagnelie PC, Koster A, Schaper N, et al. The Maastricht Study: an extensive phenotyping study on determinants of type 2 diabetes, its complications and its comorbidities. Eur J Epidemiol. 2014 Jun;29(6):439-51.

21. Van der Berg JD, Willems PJ, van der Velde JH, Savelberg HH, Schaper NC, Schram MT, et al. Identifying waking time in 24-h accelerometry data in adults using an automated algorithm. J Sports Sci. 2016 Feb 2:1-7.

22. Inker LA, Schmid CH, Tighiouart H, Eckfeldt JH, Feldman HI, Greene T, et al. Estimating glomerular filtration rate from serum creatinine and cystatin C. N Engl J Med. 2012 Jul 5;367(1):20-9.

23. Martens RJ, Kooman JP, Stehouwer CD, Dagnelie PC, van der Kallen CJ, Koster A, et al. Estimated GFR, Albuminuria, and Cognitive Performance: The Maastricht Study. Am J Kidney Dis. 2016 Jun 10.

24. Altman DG. Practical statistics for medical research. London: Chapman and Hall/CRC; 1990. p. 143-5.

25. Lee IM, Shiroma EJ, Lobelo F, Puska P, Blair SN, Katzmarzyk PT. Effect of physical inactivity on major non-communicable diseases worldwide: an analysis of burden of disease and life expectancy. Lancet. 2012 Jul 21;380(9838):219-29.

26. Stehouwer CD, Smulders YM. Microalbuminuria and risk for cardiovascular disease: Analysis of potential mechanisms. J Am Soc Nephrol. 2006 Aug;17(8):2106-11.

27. Martens RJ, Henry RM, Houben AJ, Van der Kallen CJ, Kroon AA, Schalkwijk CG, et al. Capillary rarefaction associates with albuminuria: the Maastricht Study. J Am Soc Nephrol. 2016.

28. Thosar SS, Bielko SL, Mather KJ, Johnston JD, Wallace JP. Effect of prolonged sitting and breaks in sitting time on endothelial function. Med Sci Sports Exerc. 2015 Apr;47(4):843-9.

29. Restaino RM, Holwerda SW, Credeur DP, Fadel PJ, Padilla J. Impact of prolonged sitting on lower and upper limb micro- and macrovascular dilator function. Exp Physiol. 2015 Jul 1;100(7):829-38. 
30. Wilmot EG, Edwardson CL, Achana FA, Davies MJ, Gorely T, Gray LJ, et al. Sedentary time in adults and the association with diabetes, cardiovascular disease and death: systematic review and meta-analysis. Diabetologia. 2012 Nov;55(11):2895-905.

31. Aune D, Norat T, Leitzmann M, Tonstad S, Vatten LJ. Physical activity and the risk of type 2 diabetes: a systematic review and dose-response meta-analysis. Eur J Epidemiol. 2015 Jul;30(7):529-42.

32. Huai P, Xun H, Reilly KH, Wang Y, Ma W, Xi B. Physical activity and risk of hypertension: a meta-analysis of prospective cohort studies. Hypertension. 2013 Dec;62(6):1021-6.

33. Kelley GA, Kelley KS. Aerobic exercise and lipids and lipoproteins in men: a meta-analysis of randomized controlled trials. J Mens Health Gend. 2006;3(1):61-70.

34. Kelley GA, Kelley KS, Tran ZV. Aerobic exercise and lipids and lipoproteins in women: a meta-analysis of randomized controlled trials. J Womens Health (Larchmt). 2004 Dec;13(10):1148-64.

35. Cooper AR, Sebire S, Montgomery AA, Peters TJ, Sharp DJ, Jackson N, et al. Sedentary time, breaks in sedentary time and metabolic variables in people with newly diagnosed type 2 diabetes. Diabetologia. 2012 Mar;55(3):589-99.

36. Schisterman EF, Cole SR, Platt RW. Overadjustment bias and unnecessary adjustment in epidemiologic studies. Epidemiology. 2009 Jul;20(4):488-95.

37. Henson J, Yates T, Edwardson CL, Khunti K, Talbot D, Gray LJ, et al. Sedentary time and markers of chronic low-grade inflammation in a high risk population. PloS one. 2013;8(10):e78350.

38. Padilla J, Simmons GH, Bender SB, Arce-Esquivel AA, Whyte JJ, Laughlin MH. Vascular effects of exercise: endothelial adaptations beyond active muscle beds. Physiology (Bethesda). 2011 Jun;26(3):132-45.

39. Goessler K, Polito M, Cornelissen VA. Effect of exercise training on the renin-angiotensin-aldosterone system in healthy individuals: a systematic review and meta-analysis. Hypertens Res. 2015 Sep 24.

40. Atkin AJ, Gorely T, Clemes SA, Yates T, Edwardson C, Brage S, et al. Methods of Measurement in epidemiology: sedentary Behaviour. Int J Epidemiol. 2012 Oct;41(5):1460-71.

41. Tudor-Locke C, Craig CL, Brown WJ, Clemes SA, De Cocker K, Giles-Corti B, et al. How many steps/day are enough? For adults. Int J Behav Nutr Phys Act. 2011;8:79. 
Daily activity and kidney function | 213 


\section{Chapter 8}


Summary and

general discussion 

Chronic kidney disease (CKD), which is currently defined as the presence of a urinary albumin excretion (UAE) $\geq 30 \mathrm{mg} / 24 \mathrm{~h}$ and/or an estimated glomerular filtration rate $(\mathrm{eGFR})<60 \mathrm{ml} /$ $\min / 1.73 \mathrm{~m}^{2}, 1,2$ affects $8-16 \%$ of the population worldwide. ${ }^{3}$

Given its large public health impact, ${ }^{4}$ the aims of this dissertation were threefold: first, to gain more insight into the mechanisms that link albuminuria with cardiovascular disease (CVD) and other adverse health conditions; second, to study the associations of eGFR and albuminuria with CVD, cognitive performance and depression, and, in particular, to study at what point in the course from normal kidney function to CKD these associations appear; and third, to evaluate the associations of physical activity and sedentary behavior, as potentially modifiable risk factors, with eGFR and albuminuria.

In this chapter the main findings of this dissertation are summarized, and discussed in light of the current scientific literature and methodological considerations. In addition, their scientific, clinical and public health implications are addressed.

\section{SUMMARY OF THE MAIN FINDINGS}

In chapters 2 and 3, we aimed to gain more insight into the mechanisms that could explain the strong link of albuminuria with CVD and other adverse health conditions.

For this purpose, we examined in chapter 2 the association of capillary rarefaction in the microcirculation of the finger skin with albuminuria. Lower capillary density (i.e., capillary rarefaction) was associated with the presence of albuminuria, regardless of the presence of type 2 diabetes (T2DM). Importantly, this association was independent of CVD risk factors, including $24 \mathrm{~h}$ average ambulatory blood pressure and biomarkers of low-grade inflammation.

In chapter 3, we examined the association of microvascular endothelial dysfunction, which was assessed by flicker light-induced retinal arteriolar dilation and heat-induced skin hyperemia, with albuminuria. In addition, we examined whether any association of microvascular endothelial dysfunction with albuminuria is stronger in individuals with T2DM. Lower flicker light-induced retinal arteriolar dilation was associated with higher albuminuria and this association was stronger in individuals with than in those without T2DM. In addition, lower heat-induced skin hyperemia was associated with albuminuria in participants with T2DM but not in non-diabetic participants. Again, these associations were independent of CVD risk factors. Further analyses of the mechanism(s) underlying the statistical interaction of microvascular endothelial dysfunction with T2DM showed that both measures of microvascular endothelial dysfunction were more strongly associated with albuminuria at higher $\mathrm{HbA1c}$ levels, but not at higher eGFR.

In chapters 4-6, we aimed to gain more insight into the associations of eGFR and albuminuria with cardiac injury, lower cognitive performance and depression. In particular, we studied whether any associations of eGFR and albuminuria were mutually independent, and whether such associations were already evident at levels of eGFR and albuminuria which do not fulfill the current CKD criteria.

For this purpose, we examined in chapter 4 the associations of eGFR and albuminuria with the high-sensitivity cardiac troponins T (hs-cTnT) and I (hs-cTnl), and N-terminal pro-brain natriuretic peptide (NT-proBNP), which are biomarkers of (subclinical) cardiac injury. ${ }^{5,6}$ Lower eGFR and higher albuminuria were, independently of each other and CVD risk factors, associated with higher levels of these biomarkers, and these associations already appeared at levels of eGFR and albuminuria which do not fulfill the current CKD criteria. Interestingly, eGFR was more strongly associated with hs-cTnT than with hs-cTnl, whereas the association of albuminuria with both cardiac troponins was similar. 
In chapter 5, we examined the associations of eGFR and albuminuria with three domains of cognitive performance (i.e., memory function, information processing speed, and executive function) as well as a summary score. In the entire study population, a UAE $\geq 30 \mathrm{mg} / 24 \mathrm{~h}$ was associated with lower cognitive performance, in particular with lower information processing speed. Importantly, this association was independent of CVD risk factors and eGFR. In contrast, in the entire study population, eGFR was not independently associated with cognitive performance. However, the associations of eGFR and albuminuria with cognitive performance could differ by age due to decrements in brain reserve capacity ${ }^{7,8}$ with aging. Indeed, further analyses showed that both eGFR and albuminuria were more strongly and extensively associated with cognitive performance at higher age.

In chapter 6, we examined the associations of eGFR and albuminuria with depression. To avoid misclassification of the somatic symptoms of (comorbid) diseases as depressive symptoms we assessed the presence of an interview-based diagnosis of minor or major depressive episode as well as the presence of self-reported clinically relevant depressive symptoms, which had been used in the previous studies on this topic..$^{910}$ With both methods, a UAE $15-<30 \mathrm{mg} / 24 \mathrm{~h}$ and a UAE $\geq 30 \mathrm{mg} / 24 \mathrm{~h}$ were associated with depression, whereas eGFR was not. These associations were independent of comorbid diseases, CVD risk factors and eGFR. Further, in additional analyses, albuminuria was associated with both somatic and affective depressive symptoms, albeit, for a UAE $\geq 30 \mathrm{mg} / 24 \mathrm{~h}$, not statistically significantly with the latter. Taken together, these results strongly suggested an independent association of albuminuria with depression.

The public health impact of reduced eGFR and albuminuria warrants a search for modifiable risk factors that are common in the general population. In chapter 7 , we, therefore, examined the associations of the lifestyle factors physical activity and sedentary behavior with eGFR and albuminuria. Lower amounts of physical activity and higher amounts of sedentary time were, independently of each other, associated with lower eGFR and higher albuminuria. In addition, the pattern in which sedentary time was accumulated (i.e., longer sedentary bout duration and more prolonged sedentary bouts) was associated with eGFR, but not albuminuria. These associations were not only independent of lifestyle factors which may confound the associations examined, but also of CVD risk factors which could mediate these associations, for example T2DM and higher blood pressure.

\section{METHODOLOGICAL CONSIDERATIONS}

The limitations of the methodology applied should be considered when interpreting the results presented in this dissertation. In this regard, all results were based on cross-sectional analyses of a prospective population-based cohort study. In the following paragraphs, the internal and external validity of this approach are addressed. In addition, limitations to the drawing of causal inferences are discussed.

\section{Internal validity}

Internal validity refers to the validity of inferences about the source population. ${ }^{11}$ Potential threats to the internal validity of cohort studies can be broadly divided into selection bias, information bias and confounding. ${ }^{11}$ 


\section{Selection bias}

The associations observed in a study may differ from those in the source population if the inclusion of participants across levels of the central determinant depends on the study outcome (i.e., selection bias). This may be due to the procedures applied to select the study population and factors associated with study participation.11,12 In this regard, the selection of the Maastricht Study population and the selection of the analysis populations are considered.

Lower eGFR and higher UAE are often accompanied by comorbid disease $\mathrm{i}^{13,14}$ and it is conceivable that individuals with the greatest comorbid disease burden, which may include diseases that were the topic of this dissertation, participated less often in the Maastricht Study. This selective non-response may have led to an underestimation of the associations reported and may, in particular, explain the apparent non-linearity of the association of flicker light-induced retinal arteriolar dilation with albuminuria (chapter 3) and of the association of albuminuria with depression (chapter 6).

For all primary analyses presented in this dissertation, participants with missing data were excluded (i.e., complete cases analysis). This approach provides unbiased results if the data are missing completely at random. ${ }^{15,16}$ However, bias may occur if missingness depends on observed (i.e., missing at random) or unobserved (i.e., missing not at random) variables. ${ }^{15,16}$ In chapter 5, characteristics of participants with missing data differed from included participants. Therefore, we additionally conducted multiple imputation analyses, which reduce bias if the data are missing at random. ${ }^{15,16}$ These analyses confirmed the complete cases analyses, except that lower eGFR was also borderline statistically significantly associated with lower memory function. This suggests that selection bias had indeed occurred and that the results of the primary analyses were conservative.

\section{Information bias}

Errors in the measurement (i.e., misclassification) of variables included in the analyses bias the associations examined (i.e., information bias)..$^{11}$ Misclassification can be non-differential and differential. Non-differential misclassification, for example due to biological and analytical variability, will generally result in bias toward the null. Conversely, differential misclassification may either augment or attenuate the associations examined. ${ }^{11}$ In this section, the validity of the central determinants and outcome variables evaluated in this dissertation is considered.

For all primary analyses, we calculated eGFR with the Chronic Kidney Disease-Epidemiology Collaboration (CKD-EPI) equation based on creatinine and cystatin C (eGFR $\left.{ }_{\text {crcys }}\right){ }_{1}^{17}$ which has the best precision and accuracy of the currently available equations across the range of GFRs. ${ }^{17}$ Nevertheless, its performance is still lower at higher GFR, ${ }^{17}$ because both the biological variability in the non-GFR determinants of creatinine and cystatin $C$ relative to GFR and the analytical variability in both filtration markers are greater at higher GFR. ${ }^{18}$ Muscle mass is the most important non-GFR determinant of serum creatinine..$^{19}$ In contrast, the non-GFR determinants of cystatin $\mathrm{C}$ are less clear. These include alterations in thyroid and steroid hormones, ${ }^{19}$ and possibly visceral adiposity, diabetes and inflammation. ${ }^{20}$ The misclassification resulting from the non-GFR determinants of creatinine and cystatin $C$ is expected to have to led to an underand overestimation of the associations examined, respectively. For example, in chapter 5, the association of eGFR based on cystatin $C$ only $\left(\mathrm{eGFR}_{\text {cys }}\right)$ with memory function was stronger than that of $\mathrm{eGFR}_{\text {crcys }}$. This may be because cystatin $\mathrm{C}$ is a more reliable biomarker of GFR than creatinine in individuals with more extensive comorbid disease ${ }^{21}$ or, alternatively, because associations of cystatin $\mathrm{C}$ with visceral adiposity and inflammation have exaggerated the association of eGFR $_{\text {cys }}$ with memory function. ${ }^{21-24}$ 
In all studies, we measured 24h UAE to quantify albuminuria, which is considered the gold standard because of the diurnal variation in UAE. ${ }^{25}$ However, the high biological variability in UAE and inaccurate urine collections (i.e., incorrect timing and/or incomplete collections) may still cause non-differential misclassification of UAE. ${ }^{18}$ To reduce the effects of biological variability, participants were requested to collect two 24h urine collections (available in approximately $90 \%$ ), and to reduce the effects of incorrect timing, UAE was extrapolated to a $24 \mathrm{~h}$ excretion if needed. In addition, we repeated all analyses in the subpopulation with two 24h urine collections and, in chapters 2 and 3, also in the subpopulation with a measured creatinine excretion rate within $30 \%$ of expected values. ${ }^{26}$ These analyses did not indicate that non-differential misclassification due to biological variability and inaccurate collection, respectively, had biased the associations reported, possibly except for a slight underestimation of the association of heat-induced skin hyperemia with albuminuria. The use of renin-angiotensin system inhibitors may also lead to misclassification of UAE, because these medications may reduce UAE by lowering intraglomerular pressure, ${ }^{27,28}$ without necessarily affecting the mechanisms that had increased UAE. A UAE $\geq 30 \mathrm{mg} / 24 \mathrm{~h}$ is used as an indication for their use. ${ }^{29}$ Thus, the associations of UAE $\geq 30 \mathrm{mg} / 24 \mathrm{~h}$ may have been attenuated whilst those of UAE $15-<30 \mathrm{mg} / 24 \mathrm{~h}$ may have been augmented. This may particularly pertain to participants with T2DM, who more frequently used renin-angiotensin system inhibitors.

In chapter 2, we used skin capillary density after arterial occlusion and during venous congestion as reproducible ${ }^{30,31}$ estimates of maximal skin capillary density. ${ }^{32}$ In addition, in chapter 3, we used flicker light-induced retinal arteriolar dilation and heat-induced skin hyperemia as reproducible ${ }^{33,34}$ estimates of endothelial dysfunction in the microcirculation of the retina ${ }^{35}$ and skin, ${ }^{36}$ respectively. Flicker light-induced retinal arteriolar dilation and heat-induced skin hyperemia both depend on the endothelial release of nitric oxide (NO), ${ }^{35,36}$ which is a key endothelial function. ${ }^{37,38}$ However, endothelial dysfunction is a heterogeneous concept ${ }^{39}$ and a single method may not capture all endothelial functions relevant to albuminuria. In addition, for logistic reasons, participants were not asked to come in fasting, which may introduce information bias because of the effects of dietary intake on the microcirculation..$^{40-42}$ However, to minimize these effects, participants were instructed to have a standardized meal and to refrain from caffeine-containing beverages and smoking.

In chapter 4, we used hs-cTnT, hs-cTnl and/or NT-proBNP to identify (subclinical) cardiac injury. The hs assays used to quantify cTnT and cTnl show less analytical variability than the conventional assays. ${ }^{43}$ However, most participants still had concentrations of hs-cTnT, hs-cTnl and NT-proBNP in the ranges with a coefficient of variation higher than 10\% (chapter 4 provides a description of assay characteristics), which may have resulted in non-differential misclassification. In addition, the substantial number of participants with hs-cTnT and hs-cTnl concentrations below the LoB, for whom concentrations were imputed, could bias results. ${ }^{44}$ However, additional analyses with concentrations below the LoB set at the LoB instead of LoB/2, suggested that this effect was limited (data not shown). To avoid biological variability from diurnal variation, as has been demonstrated for $\mathrm{CTnT}^{45}$ all measurements were performed in morning blood samples. In contrast, the use of frozen instead of fresh samples may have led to analytical errors. However, the limited available data suggest that $\mathrm{CTnT}^{46}, \mathrm{CTnl}^{47}$ and NT-proBNP ${ }^{48}$ are relatively stable during long-term ( $\geq 1$ year) frozen storage.

In chapter 4, we also defined cardiac injury by the presence of ischemic ECG abnormalities. The ECG findings included in this definition ${ }^{49}$ have been shown to be associated with CVD mortality. ${ }^{50}$ However, the cardiac biomarkers may detect cardiac injury that is not evident on an ECG. ${ }^{51}$

In chapter 5, we examined the performance in the cognitive domains of memory function, 
information processing speed, and executive function. These domains have been shown to be sensitive to the cognitive decline associated with CKD. ${ }^{52-73}$ For conceptual clarity, we summarized scores on individual tests into domain scores. This approach also increases statistical efficiency and reduces the influence of variability. ${ }^{11,74}$ However, an important assumption is that the tests included in a given domain measure the same construct. In this regard, cognitive tasks often appeal to multiple cognitive functions and their classification is, therefore, somewhat arbitrary. ${ }^{75}$ Nevertheless, the classification scheme applied in this dissertation has been established in the literature. ${ }^{76}$

In chapter 6, we used both the presence of self-reported clinically relevant depressive symptoms and an interview-based diagnosis of a minor or major depressive episode to assess depression. A clinical interview is considered the 'gold standard' for the diagnosis of depression as it is less prone to misclassification of somatic symptoms of (comorbid) diseases than self-report questionnaires. ${ }^{77}$ Nevertheless, both methods gave similar results, suggesting that misclassification, if any, has not substantially biased the associations with clinically relevant depressive symptoms.

In chapter 7, the amounts of physical activity and sedentary time were assessed with the activPAL3 ${ }^{\mathrm{TM}}$ physical activity monitor. In contrast to self-report questionnaires, this method is not subject to recall and reporting bias. ${ }^{78}$ In addition, this device combines posture and acceleration data to classify activities, which provides more valid estimates of sedentary time than devices which base their classification solely on acceleration. ${ }^{79-81}$ Importantly, the average wearing time in this study $(6.3 \pm 1.2$ days) was higher than the minimum of 4 days of monitoring which may be required to obtain reliable estimates of sedentary time and close to the minimum of 7 days for the assessment of physical activity. ${ }^{82}$ In chapter 7 , we also evaluated sedentary breaks, prolonged sedentary bouts and sedentary bout duration to characterize patterns of sedentary behavior. These constructs have previously been associated with other metabolic health outcomes. ${ }^{83-87}$ However, this is a relatively new field of research, and the most relevant constructs and their definitions are not yet clear. ${ }^{87}$

\section{Confounding}

The observed association between an independent and dependent variable may be biased if it is mixed with those of one or more extraneous risk factors of the dependent variable which are associated with the independent variable (i.e., confounding). ${ }^{11}$ To limit confounding, we utilized the in-depth phenotyping approach of the Maastricht Study and adjusted the associations under study for an extensive series of potential confounders. However, despite these efforts, we cannot fully exclude residual confounding due to unmeasured confounders, errors in the measurement of confounders and/or variable handling. ${ }^{11}$ For example, data on biomarkers of low-grade inflammation, which may (partly) explain the associations of albuminuria with adverse health conditions, ${ }^{37}$ were not yet available in all participants. In addition, current levels of potential confounders may not fully reflect cumulative lifetime exposure. Further, the independent variables and confounders had to be categorized in some analyses due to non-linearity of their associations with the outcome, which may, however, have led to a loss of information. ${ }^{11}$

Theoretically, adjustment for variables that are intermediates in the associations examined, or descending proxies of such intermediates, should be avoided as this may lead to an underestimation of these associations (i.e., overadjustment bias). ${ }^{88}$ Similarly, associations may be underestimated if these are adjusted for variables that are proximal to, and measured with greater precision than the central determinant. ${ }^{89}$ However, the relations between variables 
in the associations examined in this dissertation are often complex. For example, variables may simultaneously act as confounders and intermediates. This may particularly apply to blood pressure and prior CVD. To evaluate the extent of possible overadjustment, variables were grouped according to their putative roles and these groups were added sequentially to the regression analyses. Therefore, the associations reported in the final models, which contain potential intermediate variables, may be conservative.

\section{External validity}

External validity refers to the generalizability of inferences about the source population to other populations. ${ }^{11}$ Because of the population-based design of The Maastricht Study our results may at least be generalized to middle-aged and older Caucasian individuals who have eGFR and albuminuria levels in the range observed in the general population. However, associations may be different in populations with a different distribution of effect modifiers. ${ }^{11}$ Most importantly, associations may be different in individuals with advanced CKD, in whom, for example, albuminuria may be caused by a primary renal disease. In addition, the results may not necessarily be extrapolated to other ethnic and racial groups.

\section{Causal inferences}

All analyses were based on cross-sectional, observational data. Therefore, we cannot make strong causal inferences. In particular, we cannot determine the temporality of the associations reported. In fact, some associations may even be bidirectional in nature, for example, the association of kidney function with depression. To address this point, longitudinal studies are required.

\section{OVERALL INTERPRETATION OF THE RESULTS}

\section{Pathophysiology albuminuria}

The associations of capillary rarefaction in skin and the direct measures of microvascular endothelial dysfunction in the retina and skin with albuminuria fit the hypothesis that albuminuria is a biomarker of generalized (i.e., microvascular and macrovascular) endothelial dysfunction (Figure 9.1). . $^{37,90}$

Endothelial dysfunction of the renal arterioles and capillaries (i.e., the renal microcirculation) may cause albuminuria by increasing intraglomerular pressure and by increasing glomerular capillary wall permeability, ${ }^{37}$ the former eventually leading to the loss of glomerular capillaries (rarefaction) and further increases in intraglomerular pressure. ${ }^{91}$ Concomitantly, endothelial dysfunction of the extrarenal microcirculation may contribute to, for example, retinopathy, ${ }^{92,93}$ cognitive decline, ${ }^{94}$ depression ${ }^{95}$ and heart failure with preserved ejection fraction, ${ }^{96}$ whilst endothelial dysfunction in coronary and carotid arteries (i.e., the macrocirculation) may lead to atherothrombotic CVD. ${ }^{97}$ In addition, besides endothelial dysfunction, genetic influences and impaired (intrauterine) growth and development could affect both glomerular and systemic capillary density 98,99 and may, therefore, connect albuminuria to systemic microvascular disease.

In view of the above, there is indeed ample direct evidence for macrovascular endothelial dysfunction in individuals with albuminuria, ${ }^{100-106}$ whereas the evidence for microvascular involvement had hitherto been primarily indirect. ${ }^{107-119}$ In addition, thus far, there had been only limited evidence for an association of capillary rarefaction with albuminuria. ${ }^{120}$ 


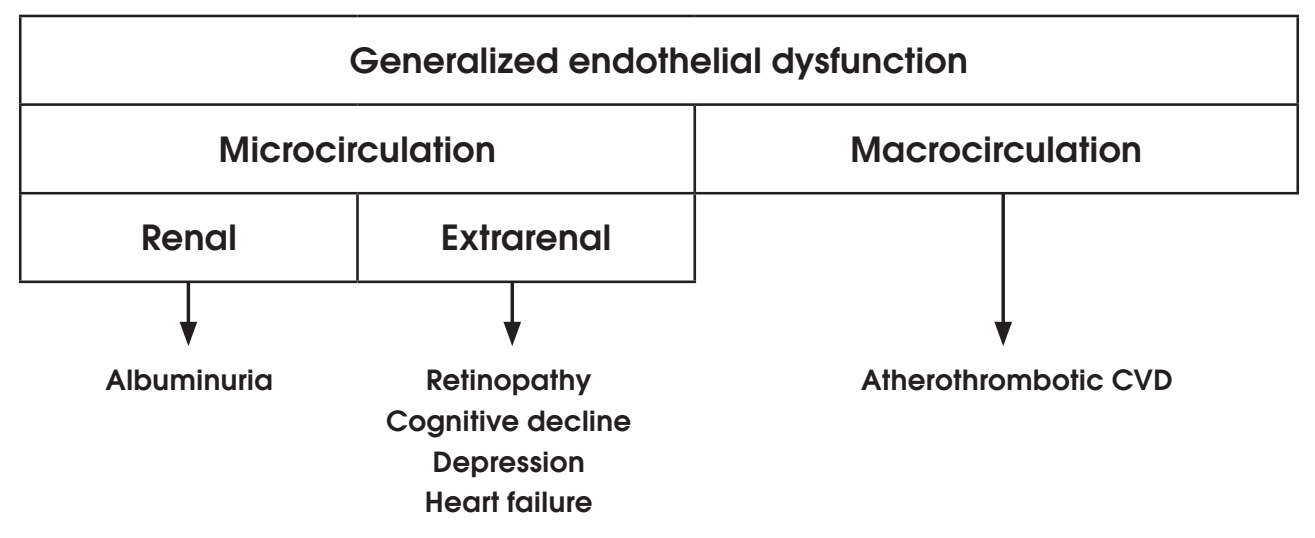

Figure 9.1. Pathophysiological model for the associations of albuminuria with extrarenal adverse health conditions.

The association of microvascular endothelial dysfunction was stronger in individuals with than in those without T2DM, which seemed to be due to hyperglycemia. Hyperglycemia may augment the association of microvascular endothelial dysfunction with albuminuria through dysregulation of the vascular endothelial growth factor (VEGF)-NO axis, which may exacerbate vascular injury. ${ }^{121}$ Alternatively, (hyperglycemia-induced) glomerular hyperfiltration ${ }^{122-125}$ may increase permeation of albumin through the injured glomerular capillary wall. Although the absence of a positive interaction between microvascular endothelial dysfunction and eGFR argues against the latter, eGFR equations may still be too imprecise at higher GFR ${ }^{17}$ to detect this interaction.

The associations with endothelial dysfunction in microvascular beds distant from the kidney also support the notion that endothelial dysfunction related to albuminuria is not only generalized with regard to the vessel types affected, but with regard to the vascular beds involved as well. ${ }^{37}$ In addition, our results fit with the concept that multiple endothelial functions are affected in individuals with albuminuria. ${ }^{37}$ In this regard, lower flicker light-induced retinal arteriolar dilation and lower heat-induced skin hyperemia may reflect reduced microvascular NO availability. ${ }^{35,36}$ The latter may indicate microvascular endothelial dysfunction in general, but $\mathrm{NO}$ is also a key mediator of the vasoregulatory, antithrombotic, anti-inflammatory and barrier properties of the endothelium. ${ }^{37,38}$

While the above discussion focuses on the endothelium, others have pointed to podocytes as culprits in the pathophysiology of albuminuria. ${ }^{126}$ However, it is less likely that podocyte injury explains the association of albuminuria with CVD, given the absence of podocytes outside the renal circulation. Recently, endothelial-podocyte cross-talk has been proposed to connect the involvement of both endothelial dysfunction and podocyte injury in the pathophysiology of albuminuria. ${ }^{127}$

In addition, it is important to note that in some individuals, albuminuria may be a manifestation of renal disease per se instead of systemic endothelial dysfunction. Indeed, it has been proposed previously that albuminuria may occur without and with concomitant generalized endothelial dysfunction, and that the latter form is accompanied by the highest risk of adverse outcomes. ${ }^{128,129}$ 


\section{Adverse health conditions related to reduced eGFR and albuminuria}

The associations of lower eGFR and higher albuminuria with cardiac injury and lower cognitive performance, and of higher albuminuria with depression, are in agreement with studies which have shown associations of CKD with (chronic) health problems other than the classic CVD manifestations. ${ }^{52-73,77}$ In addition, our finding that the associations of lower eGFR and higher albuminuria were mutually independent supports the concept that both represent, to some extent, different pathophysiological mechanisms. The latter is in line with the results of meta-analyses which have shown that lower eGFR and higher albuminuria were, independently of each other, associated with CVD mortality, irrespective of the presence or absence of diabetes ${ }^{130}$ and hypertension. ${ }^{131}$

Importantly, the associations of eGFR and albuminuria reported in this dissertation already appeared at levels which do not fulfill the current CKD criteria. For albuminuria, this agrees with the reported continuous association with CVD mortality. ${ }^{132}$ In contrast, results of studies which have examined associations of eGFR at levels $\geq 60 \mathrm{ml} / \mathrm{min} / 1.73 \mathrm{~m}^{2}$ with hard clinical outcomes are conflicting. ${ }^{132-140}$ Several reasons may explain this controversy. First, the precision of the various equations used to estimate GFR is lower at GFR levels $\geq 60 \mathrm{ml} / \mathrm{min} / 1.73 \mathrm{~m}^{2}{ }^{217}$ which may obscure any associations of eGFR in this range. Indeed, the high biological variability in the non-GFR determinants of creatinine relative to GFR at levels $\geq 60 \mathrm{ml} / \mathrm{min} / 1.73 \mathrm{~m}^{2}$ may even have led to reverse J-shaped associations in some studies which have estimated GFR from serum creatinine only. ${ }^{132,139}$ Second, a large sample size and long follow-up duration may be required to detect any associations of eGFR with hard clinical outcomes, such as acute myocardial infarction and dementia, in the general population, where their incidence is relatively low. Studying high-risk groups, for example individuals with T2DM or older individuals, and using intermediate or surrogate outcomes may increase study power. Both approaches were applied in this dissertation, and studies which have observed associations of eGFR at levels $\geq 60 \mathrm{ml} / \mathrm{min} / 1.73 \mathrm{~m}^{2}$ with hard clinical outcomes have studied high-risk groups. ${ }^{133-136}$ Importantly, lower performance on neuropsychological tests of memory function, information processing speed, and executive function have been associated with a higher risk of dementia. ${ }^{141,142}$ In addition, higher hs-cTnT, hs-cTnl, and NT-proBNP have been associated with a higher risk of CVD events and all-cause mortality. ${ }^{143-145}$ These data support the relevance of the outcome variables studied in this dissertation.

Current knowledge on the pathophysiology of lower cognitive performance, depression, and the release of the cardiac troponins and NT-proBNP points to a role for (micro)vascular dysfunction in the associations reported. In this regard, the results presented in chapters 2 and 3 support the hypothesis that capillary rarefaction and/or microvascular endothelial dysfunction underlie the associations of albuminuria with cardiac injury, lower cognitive performance and depression. The microvascular endothelial dysfunction observed in the retina of individuals with albuminuria may be particularly relevant to the latter two associations, given the embryological, anatomical and physiological similarities between the retinal and cerebral microcirculation. ${ }^{146}$

Interestingly, the results of chapter 3 suggested that albuminuria may be a better biomarker of microvascular endothelial dysfunction in individuals with than in those without T2DM. This may lead to stronger associations of albuminuria with microvascular disease in individuals with T2DM. Indeed, the observation, in chapter 4, that the association of albuminuria with NT-proBNP was statistically significantly stronger in individuals with T2DM supports this hypothesis. However, we did not observe a similar phenomenon for the associations of albuminuria with cognitive performance (chapter 5) and depression 
(data not shown), and, to the best of our knowledge, no other studies have examined this issue.

Studies on the associations of albuminuria with CVD morbidity (i.e., coronary heart disease, heart failure and stroke $)^{147}$ and mortality, ${ }^{130}$ which may be related principally to macrovascular disease, have found no positive statistical interaction with diabetes. If our results are confirmed, this may suggest that diabetes specifically augments the association of albuminuria with microvascular disease. Alternatively, more intensive clinical intervention in individuals with diabetes may have attenuated the associations of albuminuria with hard clinical outcomes in that group and may, thereby, have obscured such interaction.

A reduction in eGFR may reflect systemic vascular damage as well, ${ }^{148}$ but may also itself lead to higher blood pressure, accumulation of toxic solutes, chronic low-grade inflammation and endothelial dysfunction, ${ }^{148,149}$ and is accompanied by a decline in metabolic and endocrine functions of the kidney. ${ }^{4}$ However, the relative contributions of these processes to the associations of eGFR are unknown.

\section{Search for new risk factors for reduced eGFR and albuminuria}

The results presented in this dissertation suggest that physical activity and sedentary behavior may be independent targets in the prevention of reduced eGFR and albuminuria. In this regard, our results expand evidence from the few other studies that have used accelerometers to assess daily activity, ${ }^{150,151}$ because of the more valid estimate of sedentary behavior and the evaluation of patterns of sedentary behavior. Interestingly, our results suggested that conventional risk factors for reduced eGFR and albuminuria did not (fully) explain these associations, although we did not perform a formal mediation analysis. This suggests that physical activity and sedentary behavior may have direct effects on biological processes involved in the pathophysiology of reduced eGFR and albuminuria. The nature of these effects was not examined in this dissertation. However, results from other studies suggest that these may include effects on low-grade inflammation, ${ }^{152}$ endothelial function, ${ }^{153-155}$ the renin-angiotensin system, ${ }^{156}$ and renal sympathetic nerve activity. ${ }^{153}$

\section{CONCLUSIONS AND IMPLICATIONS}

Taken together, this dissertation showed that lower eGFR and higher albuminuria were, independently of each other, associated with several adverse health conditions, and that these associations already appeared at levels of eGFR and albuminuria which do not fulfill the current CKD criteria. In addition, it provided further evidence for the hypothesis that generalized endothelial dysfunction underlies the associations of albuminuria with extrarenal health problems. Further, the results presented in this dissertation suggested that physical activity and sedentary time could be valuable targets in the prevention of reduced eGFR and albuminuria. These findings have scientific, clinical and public health implications.

From a scientific perspective, this dissertation underlines the notion that albuminuria and eGFR represent, to some extent, different pathophysiological mechanisms, which should be examined as separate entities and across their entire range. In addition, the epidemiological approach expanded direct evidence for an association of microvascular endothelial dysfunction with albuminuria, which was derived from animal studies ${ }^{157,158}$ and studies in selected patient groups, ${ }^{117-119}$ to the general population. However, all analyses were based on cross-sectional data and longitudinal studies are required to examine the temporality of events. In addition, longitudinal studies should examine whether associations of lower eGFR and higher albuminuria 
with intermediate or surrogate outcomes translate into a higher risk of hard clinical outcomes, and which pathophysiological mechanisms are involved.

From a clinical perspective, our results stress that physicians who take care of individuals with known CKD should not only pay attention to their increased CVD risk, but should also inquire about cognitive complaints and depression. In addition, individuals with albuminuria may not only benefit from reducing albuminuria by improving renal endothelial function and hemodynamics, but from improving systemic endothelial function as well. Further, it may be clinically relevant to study whether albuminuria is indeed a better biomarker of microvascular disease in individuals with than in those without T2DM.

From a public health perspective, however, a large part of individuals with CKD may not come to clinical attention as it is generally asymptomatic until its more advanced stages. ${ }^{4}$ For this reason, screening for albuminuria is recommended in guidelines for the clinical management of diabetes and hypertension..$^{159-161}$ In addition, a combined screening and early treatment program for albuminuria has been proposed for the general population. ${ }^{162}$ This may be a cost-effective approach to prevent end-stage renal disease and, in particular, CVD, ${ }^{163}$ although this is controversial. ${ }^{164}$ Future studies should, therefore, evaluate whether testing for albuminuria improves the prediction, prevention and/or treatment of other adverse health conditions as well.

Importantly, eGFR and albuminuria were already associated with adverse health conditions at levels which do not fulfill the current CKD criteria. Should we, therefore, change the definition of CKD or add a category of individuals who have 'pre-CKD'? 165 Preferably, the definitions of CKD stages are based on, among other things, their prognostic value and therapeutic implications, cost-effectiveness when applied in clinical practice and/or screening programs, and consequences of unnecessary disease labelling. ${ }^{166}$ In this regard, only a part of the large group of individuals with levels of eGFR and albuminuria which do not fulfill the current CKD criteria will likely develop their associated adverse outcomes. Thus, future studies should first improve risk stratification. For example, it may be worthwhile to distinguish between albuminuria without and with evidence of concomitant generalized endothelial dysfunction. ${ }^{128,129}$

Nevertheless, the public health impact of albuminuria and reduced eGFR warrants a search for efficacious preventive strategies. In this regard, sedentary behavior in particular is a promising target for at least two reasons. First, in modern Western society, individuals spend most of their waking time in sedentary behavior, ${ }^{167-169}$ which suggests that the health benefits may be large at a population level. Second, limiting the amount of time spent sedentary during working hours ${ }^{170}$ and at home ${ }^{171}$ seems feasible. However, the quality of current evidence is suboptimal ${ }^{170,171}$ and the effects of interventions to reduce sedentary time on eGFR and albuminuria are unknown. Therefore, future studies should estimate the effect of reducing sedentary time on eGFR and albuminuria, and on their associated adverse outcomes as well. 


\section{REFERENCES}

1. National Kidney Foundation. K/DOQI clinical practice guidelines for chronic kidney disease: evaluation, classification, and stratification. Am J Kidney Dis. 2002 Feb;39(2 Suppl 1):S1-266.

2. Kidney Disease: Improving Global Outcomes (KDIGO). KDIGO 2012 Clinical practice guideline for the evaluation and management of chronic kidney disease. Kidney Int Suppl. 2013;3(1):1-150.

3. Jha V, Garcia-Garcia G, Iseki K, Li Z, Naicker S, Plattner B, et al. Chronic kidney disease: global dimension and perspectives. Lancet. 2013 Jul 20;382(9888):260-72.

4. Levey AS, Coresh J. Chronic kidney disease. Lancet. 2012 Jan 14;379(9811):165-80.

5. Giannitsis E, Katus HA. Cardiac troponin level elevations not related to acute coronary syndromes. Nat Rev Cardiol. 2013 Nov;10(11):623-34.

6. Struthers A, Lang C. The potential to improve primary prevention in the future by using BNP/N-BNP as an indicator of silent 'pancardiac' target organ damage: BNP/N-BNP could become for the heart what microalbuminuria is for the kidney. Eur Heart J. 2007 Jul;28(14):1678-82.

7. Stern Y. What is cognitive reserve? Theory and research application of the reserve concept. J Int Neuropsychol Soc. 2002 Mar;8(3):448-60.

8. Stern Y. Cognitive reserve in ageing and Alzheimer's disease. Lancet Neurol. 2012 Nov;11(11):1006-12.

9. Fischer MJ, Xie D, Jordan N, Kop WJ, Krousel-Wood M, Kurella Tamura M, et al. Factors associated with depressive symptoms and use of antidepressant medications among participants in the Chronic Renal Insufficiency Cohort (CRIC) and Hispanic-CRIC Studies. Am J Kidney Dis. 2012 Jul;60(1):27-38.

10. Katon WJ, Lin EH, Russo J, Von Korff M, Ciechanowski P, Simon G, et al. Cardiac risk factors in patients with diabetes mellitus and major depression. J Gen Intern Med. 2004 Dec;19(12):1192-9.

11. Rothman KJ, Greenland S, Lash TL. Modern Epidemiology. 3rd ed. Philadelphia: Lippincott Williams \& Wilkins; 2008.

12. Bouter LM, Van Dongen MC, Zielhuis GA. Epidemiologisch onderzoek: opzet en interpretatie. 6th ed. Houten: Bohn Stafleu van Loghum; 2010.

13. Hillege HL, Janssen WM, Bak AA, Diercks GF, Grobbee DE, Crijns HJ, et al. Microalbuminuria is common, also in a nondiabetic, nonhypertensive population, and an independent indicator of cardiovascular risk factors and cardiovascular morbidity. J Intern Med. 2001 Jun;249(6):519-26.

14. Bello AK, Hemmelgarn B, Lloyd A, James MT, Manns BJ, Klarenbach S, et al. Associations among estimated glomerular filtration rate, proteinuria, and adverse cardiovascular outcomes. Clin J Am Soc Nephrol. 2011 Jun;6(6):1418-26.

15. Sterne JA, White IR, Carlin JB, Spratt M, Royston P, Kenward MG, et al. Multiple imputation for missing data in epidemiological and clinical research: potential and pitfalls. BMJ. 2009;338:b2393.

16. De Goeij MC, van Diepen M, Jager KJ, Tripepi G, Zoccali C, Dekker FW. Multiple imputation: dealing with missing data. Nephrol Dial Transplant. 2013 Oct;28(10):2415-20.

17. Inker LA, Schmid CH, Tighiouart $\mathrm{H}$, Eckfeldt JH, Feldman $\mathrm{HI}$, Greene T, et al. Estimating glomerular filtration rate from serum creatinine and cystatin C. N Engl J Med. 2012 Jul 5;367(1):20-9.

18. Levey AS, Becker C, Inker LA. Glomerular filtration rate and albuminuria for detection and staging of acute and chronic kidney disease in adults: a systematic review. Jama. 2015 Feb 24;313(8):837-46.

19. Levey AS, Inker LA, Coresh J. GFR estimation: from physiology to public health. Am J Kidney Dis. 2014 May;63(5):820-34.

20. Rule AD, Bailey KR, Lieske JC, Peyser PA, Turner ST. Estimating the glomerular filtration rate from serum creatinine is better than from cystatin C for evaluating risk factors associated with chronic kidney disease. Kidney Int. 2013 Jun;83(6):1169-76.

21. Shlipak MG, Mattes MD, Peralta CA. Update on cystatin C: incorporation into clinical practice. Am J Kidney Dis. 2013 Sep;62(3):595-603.

22. Kerwin DR, Gaussoin SA, Chlebowski RT, Kuller LH, Vitolins M, Coker LH, et al. Interaction between body mass index and central adiposity and risk of incident cognitive impairment and dementia: results from the Women's Health Initiative Memory Study. J Am Geriatr Soc. 2011 Jan;59(1):107-12.

23. Schram MT, Euser SM, de Craen AJ, Witteman JC, Frolich M, Hofman A, et al. Systemic markers of inflammation and cognitive decline in old age. J Am Geriatr Soc. 2007 May;55(5):708-16.

24. Noble JM, Manly JJ, Schupf N, Tang MX, Mayeux R, Luchsinger JA. Association of C-reactive protein with cognitive impairment. Arch Neurol. 2010 Jan;67(1):87-92.

25. Gansevoort RT, Lambers H, Witte EC. Methodology of screening for albuminuria. Nephrol Dial Transplant. 2007 Aug;22(8):2109-11.

26. Ix JH, Wassel CL, Stevens LA, Beck GJ, Froissart M, Navis G, et al. Equations to estimate creatinine excretion rate: the CKD epidemiology collaboration. Clin J Am Soc Nephrol. 2011 Jan;6(1):184-91.

27. Anderson S, Rennke HG, Garcia DL, Brenner BM. Short and long term effects of antihypertensive therapy in the diabetic rat. Kidney Int. 1989 Oct;36(4):526-36.

28. Pelayo JC, Quan AH, Shanley PF. Angiotensin II control of the renal microcirculation in rats with reduced renal mass. Am J Physiol. 1990 Feb;258(2 Pt 2):F414-22.

29. Kidney Disease: Improving Global Outcomes (KDIGO) Blood Pressure Work Group. KDIGO Clinical Practice Guideline for the Management of Blood Pressure in Chronic Kidney Disease. Kidney Int Suppl. 2012;2:337-414.

30. Serne EH, Gans RO, ter Maaten JC, Tangelder GJ, Donker AJ, Stehouwer CD. Impaired skin capillary recruitment in essential hypertension is caused by both functional and structural capillary rarefaction. Hypertension. 2001 Aug;38(2):238-42. 
31. Jonk AM, Houben AJ, Schaper NC, de Leeuw PW, Serne EH, Smulders YM, et al. Angiotensin II enhances insulin-stimulated whole-body glucose disposal but impairs insulin-induced capillary recruitment in healthy volunteers. J Clin Endocrinol Metab. 2010 Aug;95(8):3901-8.

32. Antonios TF, Rattray FE, Singer DR, Markandu ND, Mortimer PS, MacGregor GA. Maximization of skin capillaries during intravital video-microscopy in essential hypertension: comparison between venous congestion, reactive hyperaemia and core heat load tests. Clin Sci (Lond). 1999 Oct;97(4):523-8.

33. Nguyen TT, Kreis AJ, Kawasaki R, Wang JJ, Seifert BU, Vilser W, et al. Reproducibility of the retinal vascular response to flicker light in Asians. Curr Eye Res. 2009 Dec;34(12):1082-8.

34. Agarwal SC, Allen J, Murray A, Purcell IF. Comparative reproducibility of dermal microvascular blood flow changes in response to acetylcholine iontophoresis, hyperthermia and reactive hyperaemia. Physiological measurement. 2010 Jan;31(1):1-11.

35. Lim M, Sasongko MB, Ikram MK, Lamoureux E, Wang JJ, Wong TY, et al. Systemic associations of dynamic retinal vessel analysis: a review of current literature. Microcirculation. 2013 Apr;20(3):257-68.

36. Roustit M, Cracowski JL. Assessment of endothelial and neurovascular function in human skin microcirculation. Trends Pharmacol Sci. 2013 Jul;34(7):373-84.

37. Stehouwer CD, Smulders YM. Microalbuminuria and risk for cardiovascular disease: Analysis of potential mechanisms. J Am Soc Nephrol. 2006 Aug;17(8):2106-11.

38. Forstermann U, Sessa WC. Nitric oxide synthases: regulation and function. Eur Heart J. 2012 Apr;33(7):829-37, 37a-37d.

39. Deanfield J, Donald A, Ferri C, Giannattasio C, Halcox J, Halligan S, et al. Endothelial function and dysfunction. Part I: Methodological issues for assessment in the different vascular beds: a statement by the Working Group on Endothelin and Endothelial Factors of the European Society of Hypertension. J Hypertens. 2005 Jan;23(1):7-17.

40. Jonk AM, Houben AJ, Schaper NC, de Leeuw PW, Serne EH, Smulders YM, et al. Meal-related increases in microvascular vasomotion are impaired in obese individuals: a potential mechanism in the pathogenesis of obesity-related insulin resistance. Diabetes Care. 2011 May;34 Suppl 2:S342-8.

41. Keske MA, Clerk LH, Price WJ, Jahn LA, Barrett EJ. Obesity blunts microvascular recruitment in human forearm muscle after a mixed meal. Diabetes Care. 2009 Sep;32(9):1672-7.

42. Clerk LH, Vincent MA, Jahn LA, Liu Z, Lindner JR, Barrett EJ. Obesity blunts insulin-mediated microvascular recruitment in human forearm muscle. Diabetes. 2006 May; 55(5):1436-42.

43. Apple FS, Collinson PO. Analytical characteristics of high-sensitivity cardiac troponin assays. Clin Chem. 2012 Jan;58(1):54-61.

44. Whitcomb BW, Schisterman EF. Assays with lower detection limits: implications for epidemiological investigations. Paediatr Perinat Epidemiol. 2008 Nov;22(6):597-602.

45. Klinkenberg LJ, van Dijk JW, Tan FE, van Loon LJ, van Dieijen-Visser MP, Meex SJ. Circulating cardiac troponin T exhibits a diurnal rhythm. J Am Coll Cardiol. 2014 May 6;63(17):1788-95.

46. Agarwal SK, Avery CL, Ballantyne CM, Catellier D, Nambi V, Saunders J, et al. Sources of variability in measurements of cardiac troponin T in a community-based sample: the atherosclerosis risk in communities study. Clin Chem. 2011 Jun;57(6):891-7.

47. Kavsak PA, MacRae AR, Yerna MJ, Jaffe AS. Analytic and clinical utility of a next-generation, highly sensitive cardiac troponin I assay for early detection of myocardial injury. Clin Chem. 2009 Mar;55(3):573-7.

48. Nowatzke WL, Cole TG. Stability of N-terminal pro-brain natriuretic peptide after storage frozen for one year and after multiple freeze-thaw cycles. Clin Chem. 2003 Sep;49(9):1560-2.

49. Keen H, Morrish N, Lee ET. An analysis of serial Minnesota ECG code changes in the London cohort of the WHO Multinational Study of Vascular Disease in Diabetes. Diabetologia. 2001 Sep;44 Suppl 2:S72-7.

50. De Bacquer D, De Backer G, Kornitzer M, Myny K, Doyen Z, Blackburn H. Prognostic value of ischemic electrocardiographic findings for cardiovascular mortality in men and women. J Am Coll Cardiol. 1998 Sep;32(3):680-5.

51. Gori M, Gupta DK, Claggett B, Selvin E, Folsom AR, Matsushita K, et al. Natriuretic Peptide and High-Sensitivity Troponin for Cardiovascular Risk Prediction in Diabetes: The Atherosclerosis Risk in Communities (ARIC) Study. Diabetes Care. 2016 May;39(5):677-85.

52. Kurella M, Yaffe K, Shlipak MG, Wenger NK, Chertow GM. Chronic kidney disease and cognitive impairment in menopausal women. Am J Kidney Dis. 2005 Jan;45(1):66-76.

53. Kurella M, Chertow GM, Fried LF, Cummings SR, Harris T, Simonsick E, et al. Chronic kidney disease and cognitive impairment in the elderly: the health, aging, and body composition study. J Am Soc Nephrol. 2005 Jul;16(7):2127-33.

54. Kurella Tamura M, Wadley V, Yaffe K, McClure LA, Howard G, Go R, et al. Kidney function and cognitive impairment in US adults: the Reasons for Geographic and Racial Differences in Stroke (REGARDS) Study. Am J Kidney Dis. 2008 Aug;52(2):227-34.

55. Slinin Y, Paudel ML, Ishani A, Taylor BC, Yaffe K, Murray AM, et al. Kidney function and cognitive performance and decline in older men. J Am Geriatr Soc. 2008 Nov;56(11):2082-8.

56. Buchman AS, Tanne D, Boyle PA, Shah RC, Leurgans SE, Bennett DA. Kidney function is associated with the rate of cognitive decline in the elderly. Neurology. 2009 Sep 22;73(12):920-7.

57. Elias MF, Elias PK, Seliger SL, Narsipur SS, Dore GA, Robbins MA. Chronic kidney disease, creatinine and cognitive functioning. Nephrol Dial Transplant. 2009 Aug;24(8):2446-52.

58. Khatri M, Nickolas T, Moon YP, Paik MC, Rundek T, Elkind MS, et al. CKD associates with cognitive decline. J Am Soc Nephrol. 2009 Nov;20(11):2427-32.

59. Yaffe K, Ackerson L, Kurella Tamura M, Le Blanc P, Kusek JW, Sehgal AR, et al. Chronic kidney disease and cognitive function in older adults: findings from the chronic renal insufficiency cohort cognitive study. J Am Geriatr Soc. 2010 Feb;58(2):338-45. 
60. Feng L, Yap KB, Yeoh LY, Ng TP. Kidney function and cognitive and functional decline in elderly adults: findings from the Singapore longitudinal aging study. J Am Geriatr Soc. 2012 Jul;60(7):1208-14.

61. Darsie B, Shlipak MG, Sarnak MJ, Katz R, Fitzpatrick AL, Odden MC. Kidney function and cognitive health in older adults: the Cardiovascular Health Study. Am J Epidemiol. 2014 Jul 1;180(1):68-75.

62. Slinin Y, Peters KW, Ishani A, Yaffe K, Fink HA, Stone KL, et al. Cystatin C and cognitive impairment 10 years later in older women. J Gerontol A Biol Sci Med Sci. 2015 Jun;70(6):771-8.

63. Abbatecola AM, Barbieri M, Rizzo MR, Grella R, Laieta MT, Quaranta E, et al. Arterial stiffness and cognition in elderly persons with impaired glucose tolerance and microalbuminuria. J Gerontol A Biol Sci Med Sci. 2008 Sep;63(9):991-6.

64. Weiner DE, Bartolomei K, Scott T, Price LL, Griffith JL, Rosenberg I, et al. Albuminuria, cognitive functioning, and white matter hyperintensities in homebound elders. Am J Kidney Dis. 2009 Mar;53(3):438-47.

65. Jassal SK, Kritz-Silverstein D, Barrett-Connor E. A prospective study of albuminuria and cognitive function in older adults: the Rancho Bernardo study. Am J Epidemiol. 2010 Feb 1;171(3):277-86.

66. Barzilay JI, Gao P, O'Donnell M, Mann JF, Anderson C, Fagard R, et al. Albuminuria and decline in cognitive function: The ONTARGET/TRANSCEND studies. Arch Intern Med. 2011 Jan 24;171(2):142-50.

67. Helmer C, Stengel B, Metzger M, Froissart M, Massy ZA, Tzourio C, et al. Chronic kidney disease, cognitive decline, and incident dementia: the 3C Study. Neurology. 2011 Dec 6;77(23):2043-51.

68. Heringa SM, van den Berg E, Dekker JM, Nijpels G, Kessels RP, Kappelle LJ, et al. Albuminuria and cognitive functioning in an older population: the Hoorn study. Dement Geriatr Cogn Dis. 2011;32(3):182-7.

69. Hailpern SM, Melamed ML, Cohen HW, Hostetter TH. Moderate chronic kidney disease and cognitive function in adults 20 to 59 years of age: Third National Health and Nutrition Examination Survey (NHANES III). J Am Soc Nephrol. 2007 Jul;18(7):2205-13.

70. Joosten H, Izaks GJ, Slaets JP, de Jong PE, Visser ST, Bilo HJ, et al. Association of cognitive function with albuminuria and eGFR in the general population. Clin J Am Soc Nephrol. 2011 Jun;6(6):1400-9.

71. Kurella Tamura M, Xie D, Yaffe K, Cohen DL, Teal V, Kasner SE, et al. Vascular risk factors and cognitive impairment in chronic kidney disease: the Chronic Renal Insufficiency Cohort (CRIC) study. Clin J Am Soc Nephrol. 2011 Feb;6(2):248-56.

72. Tsai CF, Wang SJ, Fuh JL. Moderate chronic kidney disease is associated with reduced cognitive performance in midlife women. Kidney Int. 2010 Sep;78(6):605-10.

73. Barzilay JI, Lovato JF, Murray AM, Williamson J, Ismail-Beigi F, Karl D, et al. Albuminuria and cognitive decline in people with diabetes and normal renal function. Clin J Am Soc Nephrol. 2013 Nov;8(11):1907-14.

74. Yudkin JS, Stehouwer CD, Emeis JJ, Coppack SW. C-reactive protein in healthy subjects: associations with obesity, insulin resistance, and endothelial dysfunction: a potential role for cytokines originating from adipose tissue? Arterioscler Thromb Vasc Biol. 1999 Apr;19(4):972-8.

75. Lezak MD, Howieson DB, Bigler ED, Tranel D. Neuropsychological assessment. 5th ed. New York: Oxford University Press, Inc.; 2012.

76. Geijselaers SL, Sep SJ, Stehouwer CD, Biessels GJ. Glucose regulation, cognition, and brain MRI in type 2 diabetes: a systematic review. The lancet Diabetes \& endocrinology. 2015 Jan;3(1):75-89.

77. Palmer S, Vecchio M, Craig JC, Tonelli M, Johnson DW, Nicolucci A, et al. Prevalence of depression in chronic kidney disease: systematic review and meta-analysis of observational studies. Kidney Int. 2013 Jul;84(1):179-91.

78. Atkin AJ, Gorely T, Clemes SA, Yates T, Edwardson C, Brage S, et al. Methods of Measurement in epidemiology: sedentary Behaviour. Int J Epidemiol. 2012 Oct;41(5):1460-71.

79. Godfrey A, Culhane KM, Lyons GM. Comparison of the performance of the activPAL Professional physical activity logger to a discrete accelerometer-based activity monitor. Med Eng Phys. 2007 Oct;29(8):930-4.

80. Kozey-Keadle S, Libertine A, Lyden K, Staudenmayer J, Freedson PS. Validation of wearable monitors for assessing sedentary behavior. Med Sci Sports Exerc. 2011 Aug;43(8):1561-7.

81. Edwardson CL, Rowlands AV, Bunnewell S, Sanders J, Esliger DW, Gorely T, et al. Accuracy of Posture Allocation Algorithms for Thigh- and Waist-Worn Accelerometers. Med Sci Sports Exerc. 2016 Jan 7.

82. Barreira TV, Hamilton MT, Craft LL, Gapstur SM, Siddique J, Zderic TW. Intra-individual and inter-individual variability in daily sitting time and MVPA. J Sci Med Sport. 2016 Jun;19(6):476-81.

83. Healy GN, Dunstan DW, Salmon J, Cerin E, Shaw JE, Zimmet PZ, et al. Breaks in sedentary time: beneficial associations with metabolic risk. Diabetes Care. 2008 Apr;31(4):661-6.

84. Healy GN, Winkler EA, Brakenridge CL, Reeves MM, Eakin EG. Accelerometer-derived sedentary and physical activity time in overweight/obese adults with type 2 diabetes: cross-sectional associations with cardiometabolic biomarkers. PloS one. 2015;10(3):e0119140.

85. Bankoski A, Harris TB, McClain JJ, Brychta RJ, Caserotti P, Chen KY, et al. Sedentary activity associated with metabolic syndrome independent of physical activity. Diabetes Care. 2011 Feb;34(2):497-503.

86. Benatti FB, Ried-Larsen M. The Effects of Breaking up Prolonged Sitting Time: A Review of Experimental Studies. Med Sci Sports Exerc. 2015 Oct;47(10):2053-61.

87. Van der Berg JD, Stehouwer CD, Bosma H, van der Velde JH, Willems PJ, Savelberg HH, et al. Associations of total amount and patterns of sedentary behaviour with type 2 diabetes and the metabolic syndrome: The Maastricht Study. Diabetologia. 2016 Apr;59(4):709-18.

88. Schisterman EF, Cole SR, Platt RW. Overadjustment bias and unnecessary adjustment in epidemiologic studies. Epidemiology. 2009 Jul;20(4):488-95.

89. Wlazlo N, Van Bussel BC, Van Greevenbroek MM, Schalkwijk CG, Bravenboer B, Ferreira I, et al. Mediation analyses in aetiological biomedical research: the influence of random error. In: Wlazlo N, editor. Novel aspects of insulin resistance and type 2 diabetes mellitus: iron metabolism, the complement system, and liver cirrhosis. Maastricht: Maastricht University; 2014. 
90. Deckert T, Feldt-Rasmussen B, Borch-Johnsen K, Jensen T, Kofoed-Enevoldsen A. Albuminuria reflects widespread vascular damage. The Steno hypothesis. Diabetologia. 1989 Apr;32(4):219-26.

91. Brenner BM, Meyer TW, Hostetter TH. Dietary protein intake and the progressive nature of kidney disease: the role of hemodynamically mediated glomerular injury in the pathogenesis of progressive glomerular sclerosis in aging, renal ablation, and intrinsic renal disease. N Engl J Med. 1982 Sep 9;307(11):652-9.

92. Van Hecke MV, Dekker JM, Nijpels G, Moll AC, Heine RJ, Bouter LM, et al. Inflammation and endothelial dysfunction are associated with retinopathy: the Hoorn Study. Diabetologia. 2005 Jul;48(7):1300-6.

93. Spijkerman AM, Gall MA, Tarnow L, Twisk JW, Lauritzen E, Lund-Andersen H, et al. Endothelial dysfunction and low-grade inflammation and the progression of retinopathy in Type 2 diabetes. Diabet Med. 2007 Sep;24(9):969-76.

94. Heringa SM, van den Berg E, Reijmer YD, Nijpels G, Stehouwer CD, Schalkwijk CG, et al. Markers of low-grade inflammation and endothelial dysfunction are related to reduced information processing speed and executive functioning in an older population - the Hoorn Study. Psychoneuroendocrinology. 2014 Feb;40:108-18.

95. Van Sloten TT, Schram MT, Adriaanse MC, Dekker JM, Nijpels G, Teerlink T, et al. Endothelial dysfunction is associated with a greater depressive symptom score in a general elderly population: the Hoorn Study. Psychol Med. 2014 May;44(7):1403-16.

96. Ter Maaten JM, Damman K, Verhaar MC, Paulus WJ, Duncker DJ, Cheng C, et al. Connecting heart failure with preserved ejection fraction and renal dysfunction: the role of endothelial dysfunction and inflammation. Eur J Heart Fail. 2016 Jun;18(6):588-98.

97. Hansson GK. Inflammation, atherosclerosis, and coronary artery disease. N Engl J Med. 2005 Apr 21;352(16):1685-95.

98. Luyckx VA, Brenner BM. The clinical importance of nephron mass. J Am Soc Nephrol. 2010 Jun;21(6):898-910.

99. Clough GF, Norman M. The microcirculation: a target for developmental priming. Microcirculation. 2011 May;18(4):286-97.

100. Stehouwer CD, Henry RM, Dekker JM, Nijpels G, Heine RJ, Bouter LM. Microalbuminuria is associated with impaired brachial artery, flow-mediated vasodilation in elderly individuals without and with diabetes: further evidence for a link between microalbuminuria and endothelial dysfunction--the Hoorn Study. Kidney Int Suppl. 2004 Nov(92):S42-4.

101. Dogra G, Rich L, Stanton K, Watts GF. Endothelium-dependent and independent vasodilation studies at normoglycaemia in type I diabetes mellitus with and without microalbuminuria. Diabetologia. 2001 May;44(5):593-601.

102. Poredos P, Kek A. Relation of blunted dilation of the brachial artery in insulin-dependent diabetes mellitus to microalbuminuria. Am J Cardiol. 2000 Aug 1;86(3):364-7.

103. Clausen P, Jensen JS, Jensen G, Borch-Johnsen K, Feldt-Rasmussen B. Elevated urinary albumin excretion is associated with impaired arterial dilatory capacity in clinically healthy subjects. Circulation. 2001 Apr 10;103(14):1869-74.

104. Papaioannou GI, Seip RL, Grey NJ, Katten D, Taylor A, Inzucchi SE, et al. Brachial artery reactivity in asymptomatic patients with type 2 diabetes mellitus and microalbuminuria (from the Detection of Ischemia in Asymptomatic Diabetics-brachial artery reactivity study). Am J Cardiol. 2004 Aug 1;94(3):294-9.

105. Zenere BM, Arcaro G, Saggiani F, Rossi L, Muggeo M, Lechi A. Noninvasive detection of functional alterations of the arterial wall in IDDM patients with and without microalbuminuria. Diabetes Care. 1995 Jul;18(7):975-82.

106. Cosson E, Pham I, Valensi P, Paries J, Attali JR, Nitenberg A. Impaired coronary endothelium-dependent vasodilation is associated with microalbuminuria in patients with type 2 diabetes and angiographically normal coronary arteries. Diabetes Care. 2006 Jan;29(1):107-12.

107. Stehouwer CD, Nauta JJ, Zeldenrust GC, Hackeng WH, Donker AJ, den Ottolander GJ. Urinary albumin excretion, cardiovascular disease, and endothelial dysfunction in non-insulin-dependent diabetes mellitus. Lancet. 1992 Aug 8;340(8815):319-23.

108. Stehouwer CD, Gall MA, Twisk JW, Knudsen E, Emeis JJ, Parving HH. Increased urinary albumin excretion, endothelial dysfunction, and chronic low-grade inflammation in type 2 diabetes: progressive, interrelated, and independently associated with risk of death. Diabetes. 2002 Apr;51(4):1157-65.

109. Stehouwer CD, Fischer HR, van Kuijk AW, Polak BC, Donker AJ. Endothelial dysfunction precedes development of microalbuminuria in IDDM. Diabetes. 1995 May;44(5):561-4.

110. Jager A, van Hinsbergh VW, Kostense PJ, Emeis JJ, Nijpels G, Dekker JM, et al. C-reactive protein and soluble vascular cell adhesion molecule-1 are associated with elevated urinary albumin excretion but do not explain its link with cardiovascular risk. Arterioscler Thromb Vasc Biol. 2002 Apr 1;22(4):593-8.

111. Clausen P, Feldt-Rasmussen B, Jensen G, Jensen JS. Endothelial haemostatic factors are associated with progression of urinary albumin excretion in clinically healthy subjects: a 4-year prospective study. Clin Sci (Lond). 1999 Jul;97(1):37-43.

112. Persson F, Rossing P, Hovind P, Stehouwer CD, Schalkwijk CG, Tarnow L, et al. Endothelial dysfunction and inflammation predict development of diabetic nephropathy in the Irbesartan in Patients with Type 2 Diabetes and Microalbuminuria (IRMA 2) study. Scand J Clin Lab Invest. 2008;68(8):731-8.

113. Feldt-Rasmussen B. Increased transcapillary escape rate of albumin in type 1 (insulin-dependent) diabetic patients with microalbuminuria. Diabetologia. 1986 May;29(5):282-6.

114. Nannipieri M, Rizzo L, Rapuano A, Pilo A, Penno G, Navalesi R. Increased transcapillary escape rate of albumin in microalbuminuric type II diabetic patients. Diabetes Care. 1995 Jan;18(1):1-9.

115. Nannipieri M, Penno G, Rizzo L, Pucci L, Bandinelli S, Mattei P, et al. Transcapillary escape rate of albumin in type II diabetic patients. The relationship with microalbuminuria and hypertension. Diabetes Care. 1997 Jun;20(6):1019-26.

116. Jensen EW, Espersen K, Knudsen JH, Nielsen SL. Increased transcapillary escape rate of albumin in elderly subjects due to long-term smoking habits. Clin Physiol. 1995 Mar;15(2):159-67.

117. Guglielmi MD, Pierdomenico SD, Salvatore L, Romano F, Tascione E, Pupillo M, et al. Impaired left ventricular diastolic function and vascular postischemic vasodilation associated with microalbuminuria in IDDM patients. Diabetes Care. 1995 Mar;18(3):353-60. 
118. Schmiedel O, Schroeter ML, Harvey JN. Microalbuminuria in Type 2 diabetes indicates impaired microvascular vasomotion and perfusion. Am J Physiol Heart Circ Physiol. 2007 Dec;293(6):H3424-31.

119. Houben AJ, Schaper NC, Slaaf DW, Tangelder GJ, Nieuwenhuijzen Kruseman AC. Skin blood cell flux in insulindependent diabetic subjects in relation to retinopathy or incipient nephropathy. Eur J Clin Invest. 1992 Jan;22(1):67-72.

120. Triantafyllou A, Anyfanti P, Zabulis X, Gavriilaki E, Karamaounas P, Gkaliagkousi E, et al. Accumulation of microvascular target organ damage in newly diagnosed hypertensive patients. J Am Soc Hypertens. 2014 Aug;8(8):542-9.

121. Nakagawa T. Uncoupling of the VEGF-endothelial nitric oxide axis in diabetic nephropathy: an explanation for the paradoxical effects of VEGF in renal disease. Am J Physiol Renal Physiol. 2007 Jun;292(6):F1665-72.

122. Vora JP, Dolben J, Dean JD, Thomas D, Williams JD, Owens DR, et al. Renal hemodynamics in newly presenting non-insulin dependent diabetes mellitus. Kidney Int. 1992 Apr;41(4):829-35.

123. Nelson RG, Bennett PH, Beck GJ, Tan M, Knowler WC, Mitch WE, et al. Development and progression of renal disease in Pima Indians with non-insulin-dependent diabetes mellitus. Diabetic Renal Disease Study Group. N Engl J Med. 1996 Nov 28;335(22):1636-42.

124. Vedel P, Obel J, Nielsen FS, Bang LE, Svendsen TL, Pedersen OB, et al. Glomerular hyperfiltration in microalbuminuric NIDDM patients. Diabetologia. 1996 Dec;39(12):1584-9.

125. Melsom T, Mathisen UD, Ingebretsen OC, Jenssen TG, Njolstad I, Solbu MD, et al. Impaired fasting glucose is associated with renal hyperfiltration in the general population. Diabetes Care. 2011 Jul;34(7):1546-51.

126. Wolf G, Chen S, Ziyadeh FN. From the periphery of the glomerular capillary wall toward the center of disease: podocyte injury comes of age in diabetic nephropathy. Diabetes. 2005 Jun;54(6):1626-34.

127. Siddiqi FS, Advani A. Endothelial-podocyte crosstalk: the missing link between endothelial dysfunction and albuminuria in diabetes. Diabetes. 2013 Nov;62(11):3647-55.

128. Stehouwer CD, Yudkin JS, Fioretto P, Nosadini R. How heterogeneous is microalbuminuria in diabetes mellitus? The case for 'benign' and 'malignant' microalbuminuria. Nephrol Dial Transplant. 1998 Nov;13(11):2751-4.

129. Jager A, van Hinsbergh VW, Kostense PJ, Emeis JJ, Nijpels G, Dekker JM, et al. Prognostic implications of retinopathy and a high plasma von Willebrand factor concentration in type 2 diabetic subjects with microalbuminuria. Nephrol Dial Transplant. 2001 Mar;16(3):529-36.

130. Fox CS, Matsushita K, Woodward M, Bilo HJ, Chalmers J, Heerspink HJ, et al. Associations of kidney disease measures with mortality and end-stage renal disease in individuals with and without diabetes: a meta-analysis. Lancet. 2012 Nov 10;380(9854):1662-73.

131. Mahmoodi BK, Matsushita K, Woodward M, Blankestijn PJ, Cirillo M, Ohkubo T, et al. Associations of kidney disease measures with mortality and end-stage renal disease in individuals with and without hypertension: a meta-analysis. Lancet. 2012 Nov 10;380(9854):1649-61.

132. Chronic Kidney Disease Prognosis Consortium, Matsushita K, van der Velde M, Astor BC, Woodward M, Levey AS, et al. Association of estimated glomerular filtration rate and albuminuria with all-cause and cardiovascular mortality in general population cohorts: a collaborative meta-analysis. Lancet. 2010 Jun 12;375(9731):2073-81.

133. Stam F, van Guldener C, Becker A, Dekker JM, Heine RJ, Bouter LM, et al. Endothelial dysfunction contributes to renal function-associated cardiovascular mortality in a population with mild renal insufficiency: the Hoorn study. J Am Soc Nephrol. 2006 Feb;17(2):537-45.

134. Nag S, Bilous R, Kelly W, Jones S, Roper N, Connolly V. All-cause and cardiovascular mortality in diabetic subjects increases significantly with reduced estimated glomerular filtration rate (eGFR): 10 years' data from the South Tees Diabetes Mortality study. Diabet Med. 2007 Jan;24(1):10-7.

135. Berhane AM, Weil EJ, Knowler WC, Nelson RG, Hanson RL. Albuminuria and estimated glomerular filtration rate as predictors of diabetic end-stage renal disease and death. Clin J Am Soc Nephrol. 2011 Oct;6(10):2444-51.

136. Zhang R, Zheng L, Sun Z, Zhang X, Li J, Hu D, et al. Decreased glomerular filtration rate is associated with mortality and cardiovascular events in patients with hypertension: a prospective study. PloS one. 2011;6(11):e27359.

137. So WY, Kong AP, Ma RC, Ozaki R, Szeto CC, Chan NN, et al. Glomerular filtration rate, cardiorenal end points, and all-cause mortality in type 2 diabetic patients. Diabetes Care. 2006 Sep;29(9):2046-52.

138. Brantsma AH, Bakker SJ, Hillege HL, de Zeeuw D, de Jong PE, Gansevoort RT, et al. Cardiovascular and renal outcome in subjects with K/DOQI stage 1-3 chronic kidney disease: the importance of urinary albumin excretion. Nephrol Dial Transplant. 2008 Dec;23(12):3851-8.

139. Tonelli M, Klarenbach SW, Lloyd AM, James MT, Bello AK, Manns BJ, et al. Higher estimated glomerular filtration rates may be associated with increased risk of adverse outcomes, especially with concomitant proteinuria. Kidney Int. 2011 Dec;80(12):1306-14.

140. Smink PA, Lambers Heerspink HJ, Gansevoort RT, de Jong PE, Hillege HL, Bakker SJ, et al. Albuminuria, estimated GFR, traditional risk factors, and incident cardiovascular disease: the PREVEND (Prevention of Renal and Vascular Endstage Disease) study. Am J Kidney Dis. 2012 Nov;60(5):804-11.

141. Holtzer R, Verghese J, Wang C, Hall CB, Lipton RB. Within-person across-neuropsychological test variability and incident dementia. Jama. 2008 Aug 20;300(7):823-30.

142. Tierney MC, Moineddin R, McDowell I. Prediction of all-cause dementia using neuropsychological tests within 10 and 5 years of diagnosis in a community-based sample. J Alzheimers Dis. 2010;22(4):1231-40.

143. De Lemos JA, Drazner MH, Omland T, Ayers CR, Khera A, Rohatgi A, et al. Association of troponin T detected with a highly sensitive assay and cardiac structure and mortality risk in the general population. Jama. 2010 Dec 8;304(22):2503-12.

144. Thorsteinsdottir I, Aspelund T, Gudmundsson E, Eiriksdottir G, Harris TB, Launer LJ, et al. High-Sensitivity Cardiac Troponin I Is a Strong Predictor of Cardiovascular Events and Mortality in the AGES-Reykjavik Community-Based Cohort of Older Individuals. Clin Chem. 2016 Apr;62(4):623-30. 
145. Linssen GC, Bakker SJ, Voors AA, Gansevoort RT, Hillege HL, de Jong PE, et al. N-terminal pro-B-type natriuretic peptide is an independent predictor of cardiovascular morbidity and mortality in the general population. Eur Heart J. 2010 Jan;31(1):120-7.

146. Patton N, Aslam T, Macgillivray T, Pattie A, Deary IJ, Dhillon B. Retinal vascular image analysis as a potential screening tool for cerebrovascular disease: a rationale based on homology between cerebral and retinal microvasculatures. J Anat. 2005 Apr;206(4):319-48.

147. Alexander N, Matsushita K, Sang Y, Ballew S, Mahmoodi BK, Astor BC, et al. Kidney measures with diabetes and hypertension on cardiovascular disease: the Atherosclerosis Risk in Communities Study. Am J Nephrol. 2015;41(4-5):409-17.

148. Tonelli M, Pfeffer MA. Kidney disease and cardiovascular risk. Annual review of medicine. 2007;58:123-39.

149. Schiffrin EL, Lipman ML, Mann JF. Chronic kidney disease: effects on the cardiovascular system. Circulation. 2007 Jul 3;116(1):85-97.

150. Hawkins MS, Sevick MA, Richardson CR, Fried LF, Arena VC, Kriska AM. Association between physical activity and kidney function: National Health and Nutrition Examination Survey. Med Sci Sports Exerc. 2011 Aug;43(8):1457-64.

151. Guo VY, Brage S, Ekelund U, Griffin SJ, Simmons RK. Objectively measured sedentary time, physical activity and kidney function in people with recently diagnosed Type 2 diabetes: a prospective cohort analysis. Diabet Med. 2015 Aug 18.

152. Henson J, Yates T, Edwardson CL, Khunti K, Talbot D, Gray LJ, et al. Sedentary time and markers of chronic low-grade inflammation in a high risk population. PloS one. 2013;8(10):e78350.

153. Padilla J, Simmons GH, Bender SB, Arce-Esquivel AA, Whyte JJ, Laughlin MH. Vascular effects of exercise: endothelial adaptations beyond active muscle beds. Physiology (Bethesda). 2011 Jun;26(3):132-45.

154. Thosar SS, Bielko SL, Mather KJ, Johnston JD, Wallace JP. Effect of prolonged sitting and breaks in sitting time on endothelial function. Med Sci Sports Exerc. 2015 Apr;47(4):843-9.

155. Restaino RM, Holwerda SW, Credeur DP, Fadel PJ, Padilla J. Impact of prolonged sitting on lower and upper limb micro- and macrovascular dilator function. Exp Physiol. 2015 Jul 1;100(7):829-38.

156. Goessler K, Polito M, Cornelissen VA. Effect of exercise training on the renin-angiotensin-aldosterone system in healthy individuals: a systematic review and meta-analysis. Hypertens Res. 2015 Sep 24.

157. Zhao HJ, Wang S, Cheng H, Zhang MZ, Takahashi T, Fogo AB, et al. Endothelial nitric oxide synthase deficiency produces accelerated nephropathy in diabetic mice. J Am Soc Nephrol. 2006 Oct;17(10):2664-9.

158. Nakagawa T, Sato W, Glushakova O, Heinig M, Clarke T, Campbell-Thompson M, et al. Diabetic endothelial nitric oxide synthase knockout mice develop advanced diabetic nephropathy. J Am Soc Nephrol. 2007 Feb;18(2):539-50.

159. Genootschap NH. Multidisciplinaire richtlijn Cardiovasculair risicomanagement, herziening 2011. Houten: Bohn Stafleu van Loghum; 2011.

160. American Diabetes Association. Standards of Medical Care in Diabetes-2016. Diabetes Care. 2016 Jan;39 Suppl 1:S1-119.

161. Mancia G, Fagard R, Narkiewicz K, Redon J, Zanchetti A, Bohm M, et al. 2013 ESH/ESC guidelines for the management of arterial hypertension: the Task Force for the Management of Arterial Hypertension of the European Society of Hypertension (ESH) and of the European Society of Cardiology (ESC). Eur Heart J. 2013 Jul;34(28):2159-219.

162. de Jong PE, Curhan GC. Screening, monitoring, and treatment of albuminuria: Public health perspectives. J Am Soc Nephrol. 2006 Aug;17(8):2120-6.

163. Boersma C, Gansevoort RT, Pechlivanoglou P, Visser ST, van Toly FF, de Jong-van den Berg LT, et al. Screen-and-treat strategies for albuminuria to prevent cardiovascular and renal disease: cost-effectiveness of nationwide and targeted interventions based on analysis of cohort data from the Netherlands. Clin Ther. 2010 Jun;32(6):1103-21.

164. Komenda P, Ferguson TW, Macdonald K, Rigatto C, Koolage C, Sood MM, et al. Cost-effectiveness of primary screening for CKD: a systematic review. Am J Kidney Dis. 2014 May;63(5):789-97.

165. Curhan GC. Prediabetes, prehypertension ... is it time for pre-CKD? Clin J Am Soc Nephrol. 2010 Apr;5(4):557-9.

166. Moynihan R, Glassock R, Doust J. Chronic kidney disease controversy: how expanding definitions are unnecessarily labelling many people as diseased. BMJ. 2013;347:f4298.

167. Matthews CE, Chen KY, Freedson PS, Buchowski MS, Beech BM, Pate RR, et al. Amount of time spent in sedentary behaviors in the United States, 2003-2004. Am J Epidemiol. 2008 Apr 1;167(7):875-81.

168. Davis MG, Fox KR, Hillsdon M, Sharp DJ, Coulson JC, Thompson JL. Objectively measured physical activity in a diverse sample of older urban UK adults. Med Sci Sports Exerc. 2011 Apr;43(4):647-54.

169. Arnardottir NY, Koster A, Van Domelen DR, Brychta RJ, Caserotti P, Eiriksdottir G, et al. Objective measurements of daily physical activity patterns and sedentary behaviour in older adults: Age, Gene/Environment Susceptibility-Reykjavik Study. Age and ageing. 2013 Mar;42(2):222-9.

170. Shrestha N, Kukkonen-Harjula KT, Verbeek JH, ljaz S, Hermans V, Bhaumik S. Workplace interventions for reducing sitting at work. Cochrane Database Syst Rev. 2016;3:CD010912.

171. Martin A, Fitzsimons C, Jepson R, Saunders DH, van der Ploeg HP, Teixeira PJ, et al. Interventions with potential to reduce sedentary time in adults: systematic review and meta-analysis. Br J Sports Med. 2015 Aug;49(16):1056-63. 
Appendix 
- Nederlandstalige samenvatting

- Valorization addendum

- Dankwoord

- Curriculum vitae 


\section{Nederlandstalige samenvatting}


Chronische nierschade (CNS) treft wereldwijd 8-16\% van de bevolking. In oudere personen en in personen met diabetes mellitus type 2 (T2DM), hoge bloeddruk (hypertensie) en/of obesitas komt CNS zelfs vaker voor. In de klinische praktijk wordt CNS gedefinieerd als een dagelijkse uitscheiding (excretie) van het eiwit albumine in de urine (albuminurie) $\geq 30$ $\mathrm{mg}$ en/of een verminderde nierfunctie, d.w.z. een geschatte glomerulaire filtratiesnelheid $(\mathrm{eGFR})<60 \mathrm{ml} / \mathrm{min} / 1.73 \mathrm{~m}^{2}$, gedurende een periode van minimaal drie maanden.

De sterke relatie met hart- en vaatziekten (HVZ) maakt CNS een belangrijke bedreiging voor de volksgezondheid. Daarnaast zijn er aanwijzingen voor verbanden tussen CNS en andere (chronische) gezondheidsproblemen die gerelateerd zijn aan HVZ en die gepaard gaan met een lagere kwaliteit van leven. Voorbeelden hiervan zijn een lager cognitief functioneren en depressie. Sommige studies hebben zelfs gesuggereerd dat eGFR en albuminurie al gepaard gaan met extrarenale (buiten de nier gelegen) gezondheidsproblemen bij waarden die niet voldoen aan de diagnose CNS.

In het licht van bovenstaande had dit proefschrift drie doelstellingen: ten eerste, meer inzicht verkrijgen in mechanismen die de verbanden van albuminurie met HVZ en andere gezondheidsproblemen verklaren; ten tweede, meer inzicht verkrijgen in de relaties van eGFR en albuminurie met HVZ, cognitieve prestaties en depressie. Hierbij werd in het bijzonder gelet op het moment in het beloop van een normale nierfunctie naar CNS waarop dergelijke verbanden verschijnen; en ten derde, het bestuderen van de relaties van fysieke activiteit en sedentair gedrag, als mogelijk beïnvloedbare risicofactoren, met eGFR en albuminurie.

Alle vraagstellingen in dit proefschrift werden onderzocht met gegevens van De Maastricht Studie. De Maastricht Studie is een grootschalig onderzoek naar T2DM en andere chronische aandoeningen. Het onderzoek wordt uitgevoerd onder personen van 40-75 jaar die woonachtig zijn in de regio Maastricht-Heuvelland.

\section{BELANGRIJKSTE BEVINDINGEN EN HUN INTERPRETATIE}

\section{Mechanismen van albuminurie}

Albuminurie is sterk gerelateerd aan het optreden van HVZ en andere gezondheidsproblemen. Een mogelijke verklaring hiervoor is dat albuminurie een biomarker is voor gegeneraliseerde endotheeldisfunctie. Het endotheel vormt de binnenlaag van de bloedvatwand en speelt een belangrijke rol bij de regulatie van de vaatdiameter, de bloedstolling en ontstekingsreacties. Daarnaast vormt het een barrière tussen het bloed en het achterliggende weefsel. Met gegeneraliseerde endotheeldisfunctie wordt bedoeld dat er sprake is van disfunctie van het endotheel in zowel de kleine bloedvaten (microcirculatie) als de grote bloedvaten (macrocirculatie; Figuur appendix 1).

In dit verband kan endotheeldisfunctie van de arteriolen en capillairen van de nier (d.w.z. de renale microcirculatie) albuminurie veroorzaken door het verhogen van de druk in de glomeruli (kluwens capillairen die als nierfilters fungeren) en door het verhogen van de doorgankelijkheid van de wand van deze glomeruli. Dat eerste leidt uiteindelijk tot het verlies van glomerulaire capillairen (rarefactie) en een verdere toename van de druk in de resterende glomeruli. Tegelijkertijd kan endotheeldisfunctie van de extrerenale microcirculatie bijdragen aan bijvoorbeeld oogschade (retinopathie), cognitieve achteruitgang, depressie en hartfalen. Daarnaast kan endotheeldisfunctie in de kransslagaders en halsslagaders (d.w.z. de macrocirculatie) leiden tot respectievelijk een hartinfarct en een herseninfarct. 


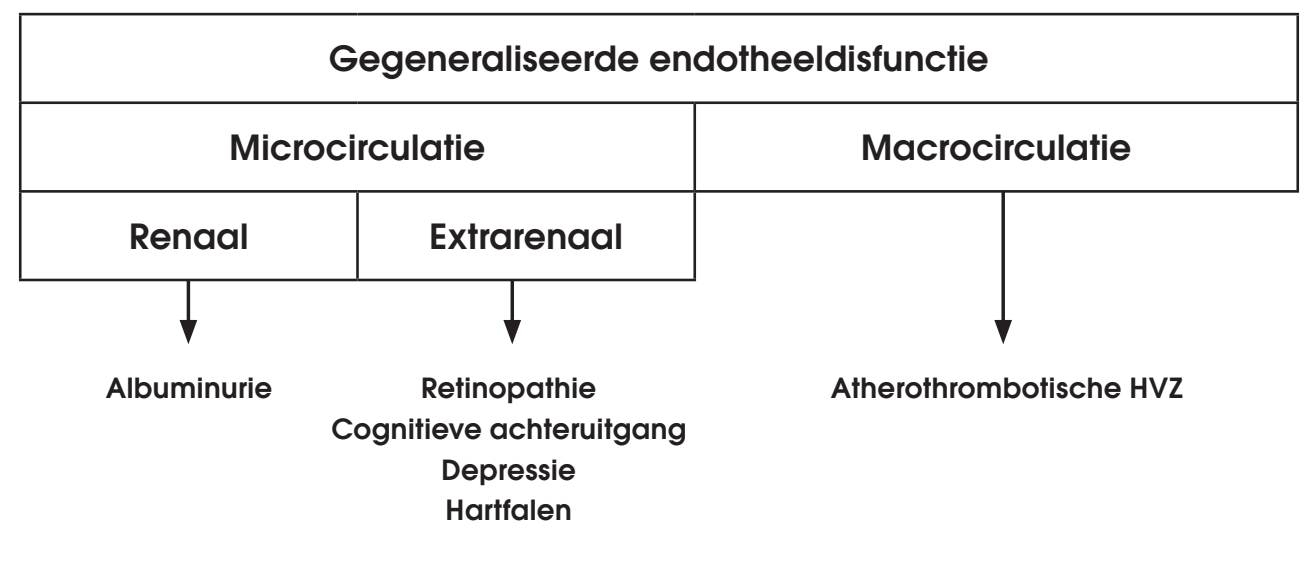

Figuur appendix 1. Pathofysiologisch model voor het verband tussen albuminurie en extrarenale gezondheidsproblemen.

Naast endotheeldisfunctie in de microcirculatie, zouden ook genetische variaties en een verstoorde (intra-uteriene) groei en ontwikkeling gepaard kunnen gaan met zowel een kleiner aantal glomerulaire capillairen als een kleiner aantal capillairen in de rest van het lichaam. Dit mechanisme zou albuminurie eveneens kunnen koppelen aan schade aan de extrarenale microcirculatie.

In het licht van bovenstaande is er inderdaad uitvoerig direct bewijs voor endotheeldisfunctie in de macrocirculatie van personen met albuminurie. Het bewijs voor endotheeldisfunctie in de microcirculatie was tot nog toe echter voornamelijk indirect. Daarnaast was er slechts beperkt bewijs voor een verband tussen een afname van capillairen (capillaire rarefactie) en albuminurie.

In hoofdstuk 2 onderzochten we daarom allereest het verband tussen capillaire rarefactie in de microcirculatie en albuminurie. In dit hoofdstuk werd de microcirculatie van de huid gebruikt om een indruk te krijgen van de microcirculatie in de rest van het lichaam, waaronder de nieren. In de huid werd het aantal capillairen gemeten met een videomicroscoop. Een kleiner aantal capillairen, d.w.z. capillaire rarefactie, was gerelateerd aan de aanwezigheid van albuminurie, ongeacht de aanwezigheid van T2DM. Het is belangrijk dat dit verband niet verklaard werd door risicofactoren voor HVZ, waaronder de gemiddelde 24-uurs ambulante bloeddruk en biomarkers voor laaggradige ontsteking. De resultaten van hoofdstuk 2 passen daarmee goed bij de gedachte dat albuminurie een uiting is van capillaire rarefactie.

In hoofdstuk 3 onderzochten we vervolgens het verband tussen endotheeldisfunctie in de microcirculatie (microvasculaire endotheeldisfunctie) en albuminurie. Daarnaast bekeken we of een dergelijk verband tussen microvasculaire endotheeldisfunctie en albuminurie sterker was in personen met T2DM, zoals was gesuggereerd in proefdieronderzoek. Microvasculaire endotheeldisfunctie was op twee manieren gemeten: als de vaatverwijdende respons van arteriolen in het netvlies na blootstelling aan stroboscopisch licht, en als de toename van de huiddoorbloeding na lokale verhitting van de huid. Een lagere vaatverwijdende respons van arteriolen in het netvlies na blootstelling aan stroboscopisch licht ging gepaard met een hogere albumine-excretie. Dit verband was sterker in personen met T2DM dan in personen zonder T2DM. Daarnaast ging een geringere toename van de huiddoorbloeding 
na lokale verhitting gepaard met een hogere albumine-excretie in personen met T2DM maar niet in personen zonder T2DM. Ook deze verbanden werden niet verklaard door risicofactoren voor HVZ. De resultaten van hoofdstuk 3 passen dus ook goed bij de gedachte dat albuminurie een uiting is van microvasculaire endotheeldisfunctie.

Overeenkomend met proefdieronderzoek, was het verband tussen microvasculaire endotheeldisfunctie en albuminurie sterker in personen met T2DM dan in personen zonder T2DM. Dit leek in een aanvullende analyse te worden verklaard door verhoogde bloedglucosespiegels (hyperglykemie) in personen met T2DM. Hyperglykemie zou het verband tussen microvasculaire endotheeldisfunctie en albuminurie kunnen versterken door ontregeling van de zogenaamde vasculaire endotheliale groeifactor (VEGF)-stikstofmonoxide (NO) as, hetgeen vaatschade kan verergeren. Een alternatieve verklaring is dat bij personen met T2DM sprake is van glomerulaire hyperfiltratie, al dan niet als gevolg van hyperglykemie. Hierbij werken de individuele glomeruli harder. Dit leidt tot een toegenomen passage van albumine door de beschadigde wand van deze glomeruli.

Het is belangrijk om op te merken dat albuminurie vermoedelijk niet bij iedereen een uiting is van gegeneraliseerde endotheeldisfunctie, maar ook het gevolg kan zijn van een primair nierprobleem. In overeenstemming hiermee is door anderen geopperd dat albuminurie kan voorkomen zonder en met gegeneraliseerde endotheeldisfunctie en dat de laatste vorm gepaard gaat met de slechtste prognose.

\section{Gezondheidsproblemen gerelateerd aan een lagere eGFR en albuminurie}

Het doel van hoofdstuk 4-6 was meer inzicht te verkrijgen in extrarenale gezondheidsproblemen gerelateerd aan een lagere eGFR en albuminurie. Daartoe bestudeerden we de relaties van eGFR en albuminurie met hartschade, cognitieve prestaties en depressie. Daarnaast bekeken we in het bijzonder of eGFR en albuminurie onafhankelijk van elkaar gerelateerd waren aan deze uitkomsten en of dergelijke verbanden al aantoonbaar waren bij waarden van eGFR en albuminurie die niet voldoen aan de huidige criteria voor CNS.

In hoofdstuk 4 onderzochten we de relaties van eGFR en albuminurie met biomarkers voor (subklinische, d.w.z. klinisch niet waarneembare) hartschade. Als biomarkers voor (subklinische) hartschade werden de hoogsensitieve cardiale troponines T (hs-cTnT) en I (hs-cTnl), en N-terminaal pro-brein natriuretisch peptide (NT-proBNP) gebruikt. Een lagere eGFR en een hogere albuminurie gingen, onafhankelijk van elkaar, gepaard met hogere concentraties van deze biomarkers. Deze verbanden werden niet verklaard door risicofactoren voor HVZ. Daarnaast waren deze verbanden al aanwezig bij waarden van eGFR en albuminurie die niet voldoen aan de huidige criteria voor CNS.

In hoofdstuk 5 onderzochten we de relaties van eGFR en albuminurie met cognitief functioneren. Er werd gekeken naar drie domeinen van cognitief functioneren (te weten: geheugenfunctie, informatieverwerkingssnelheid, en uitvoerende functies), alsook naar een samenvattende score. In de studiepopulatie als geheel ging een albumine-excretie $\geq 30 \mathrm{mg} / 24 \mathrm{~h}$ gepaard met lagere cognitieve prestaties, in het bijzonder met een lagere informatieverwerkingssnelheid. Daarentegen was er, in de studiepopulatie als geheel, geen verband tussen een lagere eGFR en cognitieve prestaties. De relaties van eGFR en albuminurie met cognitieve prestaties zouden echter kunnen verschillen naar gelang de leeftijd, doordat de reservecapaciteit van de hersenen afneemt bij veroudering. Inderdaad lieten verdere analyses zien dat zowel eGFR als albuminurie sterkere en uitgebreidere verbanden vertoonden met cognitieve prestaties op hogere leeftijd. 
In hoofdstuk 6 onderzochten we de relaties van eGFR en albuminurie met depressie. In dit hoofdstuk werd op twee manieren gekeken naar depressie. Allereerst werd hiervoor de aanwezigheid van een mineure of majeure depressieve episode, zoals vastgesteld aan de hand van een gestructureerd diagnostisch interview, gebruikt. Bij deze methode is de kans dat de resultaten worden vertekend door lichamelijke klachten van bijkomende ziekten het kleinst. Ten tweede werd gekeken naar de aanwezigheid van zelfgerapporteerde klinisch relevante depressieve symptomen. Deze methode was toegepast in eerder onderzoek naar het verband tussen albuminurie en depressie, maar gaat gepaard met een grotere kans op vertekening van de onderzoeksresultaten. In De Maastricht Studie waren een albumine-excretie $15-<30 \mathrm{mg} / 24 \mathrm{~h}$ en een albumine-excretie $\geq 30 \mathrm{mg} / 24 \mathrm{~h}$ met beide methoden gerelateerd aan de aanwezigheid van depressie. Er was echter geen verband tussen eGFR en depressie. De verbanden tussen albuminurie en depressie werden niet verklaard door bijkomende ziekten, risicofactoren voor HVZ en een lagere eGFR.

Samengevat zagen we in hoofdstuk 4-6 relaties van een lagere eGFR en een hogere albuminurie met hartschade en lagere cognitieve prestaties, en van een hogere albuminurie met depressie. Deze bevindingen zijn in overeenstemming met eerdere studies die verbanden hebben laten zien tussen CNS en extrarenale gezondheidsproblemen anders dan de klassieke manifestaties van HVZ. Daarnaast ondersteunt onze bevinding dat de relaties van een lagere eGFR en een hogere albuminurie onafhankelijk van elkaar waren de gedachte dat beiden, tot op zekere hoogte, verschillende pathofysiologische mechanismen weerspiegelen.

Een belangrijke bevinding van dit proefschrift is dat de verbanden van eGFR en albuminurie al aantoonbaar waren bij waarden die nog niet voldoen aan de huidige criteria voor CNS. Voor albuminurie komt dit overeen met het eerder gerapporteerde continue verband met sterfte door HVZ. Daarentegen zijn de resultaten van studies die de verbanden tussen eGFRwaarden $\geq 60 \mathrm{ml} / \mathrm{min} / 1.73 \mathrm{~m}^{2}$ en harde klinische eindpunten hebben onderzocht tegenstrijdig. Hiervoor bestaan verschillende verklaringen. Ten eerste is de precisie van de formules die worden gebruikt voor het schatten van de GFR lager bij GFR-waarden $\geq 60 \mathrm{ml} / \mathrm{min} / 1.73 \mathrm{~m}^{2}$. Dit leidt tot een onderschatting van de verbanden van eGFR in dit meetbereik. Ten tweede zijn een grote onderzoekspopulatie en een lange follow-upduur waarschijnlijk nodig voor het aantonen van verbanden tussen eGFR en harde klinische eindpunten, zoals het optreden van een hartinfarct en dementie, in de algemene bevolking. In de algemene bevolking is de incidentie van deze harde klinische eindpunten namelijk relatief laag. Het bestuderen van hoog-risico groepen, bijvoorbeeld personen met T2DM of oudere personen, en het gebruik van intermediaire of surrogaatuitkomsten kunnen hiervoor een oplossing zijn. Beide benaderingen werden toegepast in dit proefschrift, terwijl studies die verbanden hebben laten zien tussen eGFR-waarden $\geq 60 \mathrm{ml} / \mathrm{min} / 1.73 \mathrm{~m}^{2}$ en harde klinische eindpunten hoog-risico groepen hebben onderzocht. Voor de interpretatie van de resultaten van dit proefschrift is het belangrijk dat lagere prestaties op neuropsychologische tests voor geheugenfunctie, informatieverwerkingssnelheid en uitvoerende functies gepaard gaan met een hoger risico op dementie. Daarnaast gaan hogere concentraties hs-cTnT, hs-cTnl en NT-proBNP gepaard met een hoger risico op HVZ en een hoger risico op overlijden. Deze gegevens ondersteunen de relevantie van de bestudeerde uitkomstvariabelen.

De huidige kennis over de mechanismen achter cognitieve achteruitgang, depressie en het vrijkomen van de cardiale troponines en NT-proBNP suggereert een rol voor vaatdisfunctie in de gerapporteerde verbanden. In dit opzicht ondersteunen de resultaten van hoofdstuk 2 en 3 de hypothese dat capillaire rarefactie en/of microvasculaire endotheeldisfunctie ten grondslag liggen aan de relaties van albuminurie met hartschade, lagere cognitieve prestaties 
en depressie. Wat dat betreft is de microvasculaire endotheeldisfunctie in het netvlies van personen met albuminurie mogelijk bijzonder relevant voor de verbanden met cognitieve prestaties en depressie. De microcirculatie van het netvlies vertoont namelijk embryologische, anatomische en fysiologische overeenkomsten met die van de hersenen.

De resultaten van hoofdstuk 3 suggereren dat albuminurie een betere biomarker is voor microvasculaire endotheelschade in personen met T2DM dan in personen zonder T2DM. Dit zou ertoe kunnen leiden dat albuminurie in personen met T2DM ook sterker gerelateerd is aan microvasculaire aandoeningen. Het sterkere verband tussen albuminurie en NT-proBNP in personen met T2DM (hoofdstuk 4) ondersteunt deze gedachte inderdaad. Een vergelijkbaar fenomeen werd echter niet gezien voor de relaties van albuminurie met cognitieve prestaties (hoofdstuk 5) en depressie (data niet getoond). Voor zover bekend, zijn er geen andere studies die dit hebben onderzocht.

Studies naar het verband tussen albuminurie en zowel morbiditeit (d.w.z. coronaire hartziekten, hartfalen en herseninfarct) als mortaliteit gerelateerd aan HVZ vonden geen sterker verband in personen met T2DM. Deze uitkomsten zijn echter vooral uitingen van problemen in de macrocirculatie. Als onze resultaten in toekomstig onderzoek worden bevestigd, suggereert dit dus mogelijk dat T2DM specifiek het verband tussen albuminurie en microvasculaire aandoeningen versterkt. Een alternatieve verklaring voor het verschil met onze bevindingen is mogelijk dat intensievere klinische therapie in personen met T2DM de verbanden tussen albuminurie en harde klinische uitkomsten heeft verzwakt in die groep. Hierdoor zou het versterkende effect van T2DM onopgemerkt kunnen zijn gebleven.

Ook een lagere eGFR is mogelijk een uiting van systemische vaatschade. Een lagere eGFR zou op zichzelf echter ook kunnen leiden tot een hogere bloeddruk, stapeling van afvalstoffen, laaggradige ontsteking en endotheeldisfunctie. Daarnaast gaat een lagere eGFR gepaard met een afname van metabole en endocriene functies van de nier. De relatieve bijdrage van deze processen aan de verbanden van een lagere eGFR is echter onbekend.

\section{Nieuwe risicofactoren voor een verlaagde eGFR en albuminurie}

De impact van een verlaagde eGFR en albuminurie op de volksgezondheid vraagt om meer inzicht in risicofactoren die potentieel beïnvloedbaar zijn en vaak voorkomen in de algemene bevolking. In hoofdstuk 7 onderzochten we daarom de relaties van de leefstijlfactoren fysieke activiteit en sedentair gedrag met eGFR en albuminurie. Met sedentair gedrag worden activiteiten bedoeld waarbij het energieverbruik niet of nauwelijks hoger is dan dat in rust. Voorbeelden daarvan zijn bureauwerk en televisie kijken. Fysieke activiteit en sedentair gedrag waren in dit hoofdstuk gemeten met een accelerometer. De analyses lieten zien dat minder fysieke activiteit en meer sedentaire tijd, onafhankelijk van elkaar, gepaard gingen met een lagere eGFR en een hogere albuminurie. Deze verbanden werden niet verklaard door leefstijlfactoren die de onderzochte verbanden zouden kunnen vertekenen, maar ook niet door risicofactoren voor HVZ die deze zouden kunnen verklaren, bijvoorbeeld T2DM en een hogere bloeddruk. Vervolgens hebben we gekeken naar patronen van sedentair gedrag. Het hebben van (gemiddeld) langere aaneengesloten perioden met sedentair gedrag en het hebben van meer lange ( $\geq 30$ minuten) perioden met sedentair gedrag ging gepaard met een lagere eGFR, maar niet met een hogere albuminurie. Ook deze verbanden werden niet verklaard door leefstijlfactoren en risicofactoren voor HVZ.

Bovengenoemde resultaten suggereren dat fysieke activiteit en sedentair gedrag onafhankelijke aangrijpingspunten zijn voor de preventie van een verlaagde eGFR en albuminurie. Deze resultaten zijn een aanvulling op eerdere studies die het dagelijkse activiteitsniveau 
hebben gemeten met accelerometers, omdat met de accelerometer die is gebruikt in hoofdstuk 7 sedentair gedrag meer valide kan worden gemeten en omdat ook gekeken is naar sedentaire patronen. Interessant genoeg zagen we dat conventionele risicofactoren voor een verlaagde eGFR en albuminurie de onderzochte verbanden niet (volledig) verklaarden. Dit suggereert dat fysieke activiteit en sedentair gedrag een direct effect hebben op biologische processen die een rol spelen in de pathofysiologie van een verlaagde eGFR en albuminurie. De aard van deze effecten is niet onderzocht in dit proefschrift. Resultaten van eerdere studies suggereren echter dat het zou kunnen gaan om effecten op laaggradige ontsteking, endotheelfunctie, het renine-angiotensine systeem en de renale sympathicusactiviteit.

\section{CONCLUSIES}

Dit proefschrift laat zien dat een lagere eGFR en een hogere albuminurie, onafhankelijk van elkaar, gepaard gaan met verschillende extrarenale gezondheidsproblemen en dat deze verbanden deels al aantoonbaar zijn bij waarden van eGFR en albuminurie waarbij momenteel nog niet gesproken wordt van CNS. Wat dit betreft biedt dit proefschrift verder bewijs voor de hypothese dat gegeneraliseerde endotheeldisfunctie ten grondslag ligt aan de verbanden tussen albuminurie en extrarenale gezondheidsproblemen. Daarnaast suggereerden de resultaten van dit proefschrift dat fysieke activiteit en sedentair gedrag mogelijk onafhankelijke aangrijpingspunten zijn voor de preventie van een verlaagde eGFR en albuminurie. Toekomstig onderzoek zal moeten uitwijzen of strategieën gericht op deze leefstijlfactoren en op gegeneraliseerde endotheeldisfunctie de ziektelast gerelateerd aan een lagere eGFR en een hogere albuminurie inderdaad kunnen verminderen. 
Valorization addendum 
Apart from education and research, knowledge valorization is considered to be a core activity of universities. ${ }^{1}$ In this regard, knowledge valorization is defined as "the process of creating value from knowledge, by making knowledge suitable and/or available for societal (and/or economic) purposes, and suitable for translation into competitive products, services, processes and new entrepreneurship" (adapted definition based on the National Committee Valorization 2011:8). This addendum describes how society may benefit from the results presented in this dissertation.

Chronic kidney disease (CKD) affects $8-16 \%$ of the population worldwide. ${ }^{2}$ For the Netherlands, the prevalence has been estimated at $10.4 \%,{ }^{3}$ which means that about 1.8 million of its approximately 17 million citizens have CKD. CKD imposes a significant economic burden on society. This includes costs from dialysis treatment and transplantation in end-stage renal disease, and from the management of cardiovascular disease (CVD) and other adverse health conditions related to CKD in all CKD stages. At least as important are the consequences of CKD related adverse health conditions for quality of life.

This dissertation expands the evidence for associations of reduced estimated glomerular filtration rate (eGFR) and albuminuria, which define CKD, ${ }^{4}$ with (chronic) health problems other than the classic CVD manifestations. In addition, it provides further evidence for the hypotheses that generalized endothelial dysfunction explains the unfavorable associations of albuminuria, and that physical activity and sedentary behavior may be independent targets in the prevention of reduced eGFR and albuminuria. The associations reported already appeared at levels of eGFR and albuminuria which do not fulfill the current CKD criteria, thus at the levels which are commonly observed in the general population. Therefore, the results presented in this dissertation may not only be relevant to individuals with CKD and their health care providers, but for individuals in the general population and health care policy makers as well. In addition, the results may be relevant to the pharmaceutical industry.

In the short-term, the results presented in this dissertation may lead to at least three kinds of research initiatives, which may in the long-term contribute to a reduction in the adverse health conditions related to lower eGFR and higher albuminuria.

First, future longitudinal studies are required to confirm the results presented in this dissertation and to provide more insight into the underlying mechanisms. With regard to the latter, it is, for example, important to examine the relative contribution of cardiac production and (renal) elimination to the associations of eGFR with the biomarkers of cardiac injury. In addition, future studies may examine whether vascular dysfunction in the brain indeed explains the associations of albuminuria with lower cognitive performance and depression, as hypothesized in this dissertation.

Second, this dissertation may contribute to the discussion on the implementation of combined screening and early treatment programs for albuminuria. Such programs have been proposed for the general population to reduce the societal and health impact of CKD. ${ }^{5}$ Indeed, albuminuria screening may be a cost-effective approach to prevent end-stage renal disease and, in particular, CVD. ${ }^{6}$ However, its cost-efficacy is controversial and seems to depend on the assumptions made in the analyses. ${ }^{7}$ An important consideration is the outcomes that may be prevented by treating individuals with albuminuria. ${ }^{6}$ In this regard, the results presented in this dissertation, if confirmed, suggest that future studies on the cost-efficacy of albuminuria screening may not only consider the prevention of end-stage renal disease and CVD events, but the prevention of other adverse health conditions, for example dementia and depression, as well. Another important consideration is the efficacy of treatment with renin-angiotensin system inhibitors in individuals with albuminuria. ${ }^{7}$ Renin-angiotensin system 
inhibitors lower albuminuria and have been shown to reduce the risk of end-stage renal disease and nonfatal CVD events. However, their effects on mortality and fatal CVD events have been questioned. ${ }^{8}$ The results presented in this dissertation support the hypothesis that individuals with albuminuria benefit most from interventions which improve not only renal endothelial function and hemodynamics, but systemic endothelial function as well. In this regard, future studies could examine the effects of currently available medications with pleiotropic effects on the endothelium, such as 3-hydroxy-3-methyl coenzyme A (HMG-CoA) reductase inhibitors (i.e., statins), ${ }^{9}$ on CVD and other adverse health conditions in individuals with albuminuria. In addition, the effects of medications which directly target endothelial function may be examined, for example the endothelin antagonist atrasentan, which has already been shown to reduce albuminuria. ${ }^{10}$ Herein lies a role for the pharmaceutical industry.

Third, the efficacy of preventive strategies that target lifestyle factors at the general population level to prevent reduced eGFR, albuminuria and their associated adverse health conditions should be examined. The results presented in this dissertation suggest that reducing the time spent sedentary as well as increasing physical activity could be valuable targets for such preventive strategies. However, the amounts of physical activity and sedentary time that are required to achieve a clinically significant effect on eGFR and albuminuria as well as the 'ideal' pattern of sedentary behavior are unknown and deserve further study. This also pertains to the strategies to achieve the required behavioral alterations. Eventually, the results of future studies on this topic may be implemented in national guidelines on physical activity and sedentary behavior. In this regard, a national guideline on physical activity already exists for other outcomes. ${ }^{11}$ In addition, a national guideline on sedentary behavior has been recommended based on the unfavorable associations of sedentary behavior with several metabolic outcomes. ${ }^{12}$

The research initiatives described above may be translated into several PhD projects. A close collaboration between researchers from several disciplines is required to disentangle the associations of eGFR and albuminuria with extrarenal disease. In addition, combining data from multiple (existing) cohorts will increase the statistical power to study these associations in the general population and improve generalizability in a way that efficiently utilizes available resources. Importantly, in particular the first research initiative described above calls for studies with a detailed characterization of their participants. In this regard, follow-up data of The Maastricht Study are eagerly awaited. 


\section{REFERENCES}

1. VSNU vereniging van universiteiten. Een raamwerk valorisatie-indicatoren. 's-Gravenzande: van Deventer; 2013. Available from: http://www.vsnu.nl/files/documenten/Domeinen/Onderzoek/Valorisatie/130422\%20-\%20VSNU\%20 Raamwerk\%20Valorisatie-indicatoren_web.pdf.

2. Jha V, Garcia-Garcia G, Iseki K, Li Z, Naicker S, Plattner B, et al. Chronic kidney disease: global dimension and perspectives. Lancet. 2013 Jul 20;382(9888):260-72.

3. De Zeeuw D, Hillege HL, de Jong PE. The kidney, a cardiovascular risk marker, and a new target for therapy. Kidney Int Suppl. 2005 Sep(98):S25-9.

4. Kidney Disease: Improving Global Outcomes (KDIGO). KDIGO 2012 Clinical practice guideline for the evaluation and management of chronic kidney disease. Kidney Int Suppl. 2013;3(1):1-150.

5. De Jong PE, Curhan GC. Screening, monitoring, and treatment of albuminuria: Public health perspectives. J Am Soc Nephrol. 2006 Aug;17(8):2120-6.

6. Boersma C, Gansevoort RT, Pechlivanoglou P, Visser ST, van Toly FF, de Jong-van den Berg LT, et al. Screen-and-treat strategies for albuminuria to prevent cardiovascular and renal disease: cost-effectiveness of nationwide and targeted interventions based on analysis of cohort data from the Netherlands. Clin Ther. 2010 Jun;32(6):1103-21.

7. Komenda P, Ferguson TW, Macdonald K, Rigatto C, Koolage C, Sood MM, et al. Cost-effectiveness of primary screening for CKD: a systematic review. Am J Kidney Dis. 2014 May;63(5):789-97.

8. Maione A, Navaneethan SD, Graziano G, Mitchell R, Johnson D, Mann JF, et al. Angiotensin-converting enzyme inhibitors, angiotensin receptor blockers and combined therapy in patients with micro- and macroalbuminuria and other cardiovascular risk factors: a systematic review of randomized controlled trials. Nephrol Dial Transplant. 2011 Sep;26(9):2827-47.

9. Forstermann U, Sessa WC. Nitric oxide synthases: regulation and function. Eur Heart J. 2012 Apr;33(7):829-37, 37a-37d.

10. De Zeeuw D, Coll B, Andress D, Brennan JJ, Tang H, Houser M, et al. The endothelin antagonist atrasentan lowers residual albuminuria in patients with type 2 diabetic nephropathy. J Am Soc Nephrol. 2014 May;25(5):1083-93.

11. Kemper HC, Ooijendijk WT, Stiggelbout M. Consensus over de Nederlandse norm voor gezond bewegen. TSG. 2000;78(3):180-3.

12. Van der Berg JD. General discussion. In: Van der Berg JD, editor. Sedentary behavior and cardio-metabolic health. Maastricht: Maastricht University; 2016. 


\section{Dankwoord}


De sleutel tot succesvol onderzoek is samenwerking. Ook dit proefschrift was niet tot stand gekomen zonder de inzet van anderen. Ik wil dan ook iedereen die heeft bijgedragen aan mijn proefschrift hartelijk danken. Een aantal (groepen) personen wil ik in het bijzonder noemen:

Mijn promotieteam, bestaande uit prof. dr. Jeroen P. Kooman, prof. dr. Coen D.A. Stehouwer en dr. Ronald M.A. Henry. Ik ben er trots op dat jullie mijn begeleidingsteam vormden, en dankbaar voor de prettige samenwerking en de mogelijkheden die mij zijn geboden om me te ontwikkelen als wetenschapper.

Beste Jeroen, vanaf ons eerste gesprek over de mogelijkheden om promotieonderzoek te doen bij de afdeling nefrologie voelde ik mij erg welkom. Met je enthousiasme en interesse weet je anderen voortdurend te motiveren. Tegelijkertijd ben je niet te beroerd om alternatieve hypotheses te opperen (is er iets waarover jij geen ideeën hebt?) en daarmee je jongere collegae voortdurend te prikkelen hun eigen ideeën nog eens kritisch tegen het licht te houden. Hartelijk dank daarvoor.

Beste Coen, het klopt echt wat mijn voorgangers al schreven: de snelheid waarmee jij manuscripten bekijkt, jouw oog voor zowel de grote lijnen als de details en jouw accuratesse zijn ongekend. Ik wil je daarnaast bedanken voor de interessante discussies over pathofysiologie, logisch redeneren en retorica. Daar heb ik ontzettend veel van geleerd.

Beste Ronald, jij bent als geenander in staat enthousiasme en vertrouwen over te brengen (ja, dat vliegwiel is uiteindelijk toch echt gaan draaien). Je staat daarnaast niet alleen open voor het delen van je wetenschappelijke expertise maar hebt ook aandacht voor de ontwikkeling van andere belangrijke, niet strikt wetenschappelijke, competenties. Hartelijk dank daarvoor.

De leden van de beoordelingscommissie, prof. dr. Peter W. de Leeuw (voorzitter), prof. dr. Ron T. Gansevoort (Universitair Medisch Centrum Groningen, Groningen), prof. dr. Matthijs K.C. Hesselink, prof. dr. Kitty J. Jager (Academisch Medisch Centrum, Amsterdam) en prof. dr. Frans J.R. Verhey. Bedankt voor de kritische beoordeling van mijn proefschrift.

Mijn paranimfen, Natascha Broers en Pauline Linssen.

Natascha, jij was mijn collega promovendus bij de nefrologie en voor het grootste deel van mijn promotietraject ook mijn kamergenoot. Dank voor alle leuke wetenschappelijke en nietwetenschappelijke discussies, en bovenal voor alle gezelligheid. De gezamenlijke bezoeken aan congressen in binnen- en buitenland (en we hebben wat afgereisd) zal ik niet zo snel vergeten.

Pauline, jij was een van mijn eerste collega's bij De Maastricht Studie en daar ben ik heel blij mee. Je bent iemand die er altijd staat. Ik wil je bedanken voor je collegialiteit, vriendschap en goede gesprekken. Ook het congresbezoek in Venetië (inclusief 'acqua alta') zal me nog wel even bijblijven.

De collega's van De Maastricht Studie. De groep met wie ik de afgelopen jaren heb samengewerkt bij De Maastricht Studie is dusdanig groot, dat ik me er hier niet aan waag iedereen bij naam te noemen, om te voorkomen dat ik iemand vergeet. Daarom wil ik jullie allereerst als groep bedanken voor de fijne samenwerking. Zes personen wil ik er in het bijzonder uitlichten: Julianne van der Berg, Stefan Geijselaers, Thomas van Sloten, Jeroen Smets, Peggy Spauwen en Jeroen van der Velde. Met jullie heb ik het grootste deel van mijn tijd bij De Maastricht Studie gedeeld. Naast hard werken en pittige discussies over wetenschap 
en het besturen van een studie van dit formaat, was er zo nu en dan gelukkig ook tijd voor een lolletje. De gezellige terrasbezoeken en etentjes, een heus AIO-uitje en zeker ook het organiseren daarvan, waren een welkome afwisseling!

De collega's van de afdeling Interne Geneeskunde. Bedankt voor de gezelligheid tijdens o.a. journal club-besprekingen en congresbezoeken, en de fijne samenwerking.

De collega's van de onderafdeling Nefrologie, in het bijzonder de collega's van de onderzoeksgroep 'chronische nierschade', prof. dr. Karel M.L. Leunissen, dr. Frank M. van der Sande, Nanda Diederen, Marijke Dekker, dr. Jeroen B. van der Net; de medewerkers van het secretariaat, Lilian Dassen en Anke Hendriks; en Bryan Franssen en Thijs de Graaf. Doordat ik de eerste jaren van mijn promotietraject voornamelijk aanwezig was bij De Maastricht Studie, was ik enigszins een buitenbeentje binnen de afdeling. Toch heb ik mij altijd zeer welkom gevoeld. Dank daarvoor.

Alle overige co-auteurs, prof. dr. Otto Bekers, dr. Tos T.J.M. Berendschot, prof. dr. Hans Bosma, dr. Martin P.J. van Boxtel, prof. dr. Pieter C. Dagnelie, prof. dr. Marja P. van Dieijen-Visser, dr. Simone J.P.M. Eussen, dr. Martien C.J.M. van Dongen, dr. Ed H.B.M. Gronenschild, dr. Alfons (Boy) J.H.M. Houben, dr. Carla J.H. van der Kallen, Dorien M. Kimenai, dr. Sebastian Köhler, dr. Annemarie Koster, prof. dr. Abraham (Bram) A. Kroon, dr. Steven J.R. Meex, dr. Dennis M. Muris, prof. dr. Giel Nijpels, prof. dr. Hans H.C.M. Savelberg, prof. dr. Casper G. Schalkwijk, dr. Jan S.A.G. Schouten, dr. Miranda Schram, dr. Simone J.S. Sep, prof. dr. Nicolaas C. Schaper, Ben M. Sörensen, dr. Jeroen D. van Suijlen en dr. Frans E.S. Tan. Dank voor jullie constructieve commentaren op mijn manuscripten.

Alle deelnemers aan De Maastricht Studie. Het is misschien een cliché, maar dat maakt het niet minder waar: zonder jullie inzet was dit proefschrift er niet geweest.

Mijn vrienden. Bedankt voor de gezellige etentjes en andere uitjes, jullie interesse in mijn werk, de inspirerende verhalen uit de kliniek tussen al het onderzoek door en de momenten om gewoon even slap te ouwehoeren. Jullie zijn geweldig!

Mijn zus en broer. Lieve Anique en Rolin, wat is het heerlijk om samen te eten en weer even bij te praten, of te ontspannen met een bordspelletje. Hartelijk dank daarvoor. Ik kan mij geen betere zus en broer wensen!

Mijn ouders. Lieve papa en mama, ik weet dat jullie liever niet in de belangstelling staan maar een speciaal woord van dank is hier meer dan op zijn plaats. Van kinds af aan hebben jullie het beste met mij, Anique en Rolin voor, en steunen jullie ons onvoorwaardelijk. Dat klinkt misschien vanzelfsprekend, maar dat is het niet. Hartelijk dank voor alles. Ik kan mij geen betere ouders wensen!

Remy 
Curriculum vitae 
Remigius (Remy) Johannes Hendrikus Martens was born on December 29, 1987 in Maastricht, the Netherlands. After graduating from secondary school in 2006 (Gymnasium, Graaf Huyn College, Geleen, cum laude), he started studying medicine at Maastricht University. During his medical training, he was awarded the top 3\% student award in academic year 2010-2011. Remy obtained his medical degree in 2012 (cum laude). In the same year, he started his PhD research project at the Department of Internal Medicine, Division of Nephrology, and within NUTRIM School of Nutrition and Translational Research in Metabolism, of Maastricht University Medical Center+, Maastricht. The PhD research project, of which the results are descibed in the present dissertation, was performed under supervision of prof. dr. Jeroen P. Kooman, prof. dr. Coen D.A. Stehouwer and dr. Ronald M.A. Henry. During his PhD research project, Remy obtained a Master's degree in Epidemiology at the Department of Epidemiology and Biostatistics, VU Medical Center, Amsterdam. From 2016 onwards, Remy is working as a resident Internal Medicine under supervision of prof. dr. Coen D. A. Stehouwer and prof. dr. Richard P. Koopmans at Maastricht University Medical Center+, Maastricht. 
